\title{
REVISION OF THE GENUS ISCHYRUS LACORDAIRE (1842) (EROTYLIDAE : TRIPLACINAE) \\ OF NORTH AND CENTRAL AMERICA
}

By

PAUL EDWARD SKELLEY

A DISSERTATION PRESENTED TO THE GRADUATE SCHOOL OF THE UNIVERSITY OF FLORIDA IN PARTIAL FULFILLMENT OF THE REQUIREMENTS FOR THE DEGREE OE DOCTOR OE PHILOSOPHY

UNIVERSITY OF FLORIDA

1994 
Copyright 1994

by

Paul Edward Skelley 
ACKNOWLEDGMENTS

I thank my committee, R. E. Woodruff and M. C. Thomas, Elorida State Collection of Arthropods, and D. H. Habeck and J. W. Kimbrough, University of Florida, for their guidance, encouragement, assistance, and editorial comments for this and many other studies. Without them I would never have attained my goals. I thank M. A. Goodrich, Eastern Illinois University, for assistance during this study and for his continued support with other studies on the Erotylidae. For loans of specimens, including types, I thank the following people and their associated institutions: F. G. Andrews, California state Collection of Arthropods; R. S. Anderson, Canadian Museum of Nature; J. S. Ashe, R. W. Brooks, and R. A. B. Leschen, Snow Entomological Museum, University of Kansas; D. Azuma, Academy of Natural Sciences, Philadelphia; A. O. Bachmann, Museo Argentino de Ciencias Naturales; N. Berti, Museum National d'Histoire Naturelle, Paris; R. L. Blinn, University of Missouri; M. Brancucci, Naturhistorisches Museum Basel; R. L. Brown, Mississippi State University; C. Carlton, University of Arkansas; E. D. Cashatt, Illinois State Museum; R. D. Cave, Escuela Agricola Panamericana, Tegucigalpa, Honduras; D. S. Chandler, University of New Hampshire; F. A. Cholick, South Dakota State University; S. M. Clark, West Virginia Department of 
Agriculture; W. E. Clark, Auburn University; C. Covell, University of Louisville, Kentucky; D. P. Cowan, Western Michigan University; R. L. Davidson, Carnegie Museum of Natural History; $K$. Desender, Institute Royale des Sciences Naturalles de Belgique; M. A. Deyrup, Archbold Biological Station; M. E. Douglas, Arizona State University; O. V. Ferreira, Fundação Oswaldo Cruz; R. W. Flowers, Florida A. \& M. University; W. A. Foster, University of Cambridge, United Kingdom; P. H. Freytag, University of Kentucky; M. H. M. Galileo, Museu de Ciências Naturais, Porto Alegre, Brazil; M. A. Goodrich, Eastern Illinois University; I. Goreyeb and T. P. Chaves, Museu Paraense Emílio Goeldi; L. H. Herman, American Museum of Natural History; M. W. Heyn, Clemson University; F. Hieke, Museum für Naturkunde der HumboldtUniversität zu Berlin; G. N. House, United States National Museum; N. Johnson and P. W. Kovarik, Ohio State University; D. H. Kavanaugh and R. Brett, California Academy of Sciences; M. D. Kerley, Natural History Museum, London; B. C. Kondratieff, Colorado State University; M. Kosztarab, Virginia Polytechnic Institute and State University; S. Krauth, University of Wisconsin; W. E. LaBerge and K. C. McGriffen, Illinois Natural History Survey; P. K. Lago, University of Mississippi; J. F. Lawrence, CSIRo, Canberra, Australia; R. Lawson, Chadron State College; R. E. Lewis, Iowa State University; J. K. Liebherr, K. E. M. Galley, and J. V. McHugh, Cornell University; J. McNamara, Canadian National Collection of Insects; J. E. McPherson, Southern 
Illinois University; O. Merkl, Hungarian Natural History Museum; C. R. Nelson, Brigham Young University; A. E. Newton, Jr., and P. Parillo, Field Museum of Natural History; D. Núñez, Escuela Nacional de Ciencias Forestales, Honduras; M. F. O’Brien, University of Michigan Museum of Zoology; C. A. Olson, University of Arizona; G. Onore, Pontificia Universidad Católica de Ecuador; C. S. Parron, North Carolina State University; S. Pratt, Museum of Comparative Zoology, Harvard University; A. Provonsha, Purdue University; B. C. Ratcliffe, University of Nebraska State Museum; E. G. Riley, Texas A. \& M. University; R. A. Ronderos, Universidad Nacional de La Plata, Argentina; S. Santiago, Universidad Nacional Autónoma de México; G. Scherer, Zoologische Staatssammlung, München; Y. Sedman, Western Illinois University; D. Shpeley and D. A. Pollock, Strickland Museum, University of Alberta; C. L. Smith, University of Georgia, Athens; R. R. Snelling, Los Angeles County Museum; C. A. Springer, Hastings College, Nebraska; F. W. Stehr, Jr., Michigan State University; A. L. Terán, Fundación Miguel Lillo, Tucuman, Argentina; R. E. Woodruff and M. C. Thomas, Florida State Collection of Arthropods; R. S. Zack, Washington State University; L. Zerche, Deutsches Entomologisches Institut, Eberswalde-Finow.

I thank the following private collectors for allowing me to study their collections: A. Allen, R. J. Barney, J. L. Carr, J. M. Cicero, E. J. Eord, S. M. Eullerton, D. H. Habeck, M. A. Ivie, D. H. Kavanaugh, P. K. Lago, R. A. B. 
Leschen, R. W. Lundgren, S. McCleve, J. V. McHugh, R. F. Morris, G. H. Nelson, T. K. Philips, R. Prange, W. Suter, R. H. Turnbow, Jr., J. E. Wappes, and J. Watts.

For assistance in locating types, I thank W. A. Foster, Cambridge University, United Kingdom; F. Hieke, Museum für Naturkund der Humboldt-Universität zu Berlin;

D. S. Horning, University of Sydney; M. D. Kerley, Natural History Museum, London; G. C. McGavin, Oxford University.

For assistance with the scanning electron microscope and specimen preparation techniques, I thank H. Cromroy and W. Carpenter, University of Florida. For darkroom assistance and other photographic reproductions, I thank J. Lotz, Division of Plant Industry, Florida Department of Agriculture and Consumer Services.

I thank E. Mayr, J. McCarthy, and E. Langosy, Harvard University, for the support of an Ernst Mayr Grant, which allowed me to study specimens in both the Crotch Erotylidae Collection, Cambridge University, and the Natural History Museum, London. This study would not have been completed without their assistance.

I thank M. C. Thomas, Florida State collection of Arthropods, for assistance with computer graphic programs used in the illustrations. I thank all of the personnel (too numerous to mention) at the Florida Department of Agriculture and Consumer Services, Florida state collection of Arthropods, for their support and tolerance during my eight years of study. 
If I have unknowingly omitted anyone, I thank them here for their assistance.

Last, yet foremost, I thank my parents, Paul F. and Antoinette, and my wife, Lucy, for their encouragement and love over these many years. 
TABLE OF CONTENTS

ACKNOWLEDGMENTS

page

iii

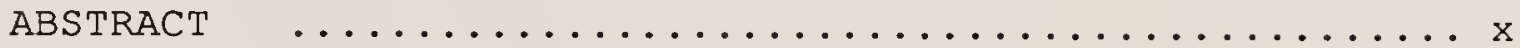

INTRODUCTION $\ldots \ldots \ldots \ldots \ldots \ldots \ldots \ldots \ldots \ldots \ldots \ldots \ldots \ldots \ldots \ldots \ldots \ldots$

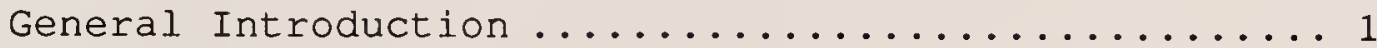

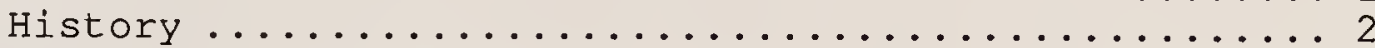

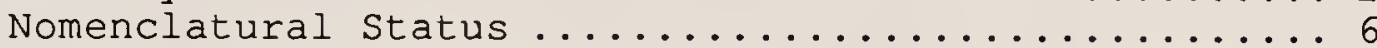

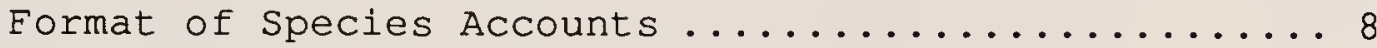

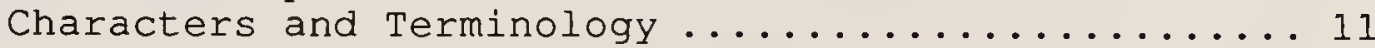

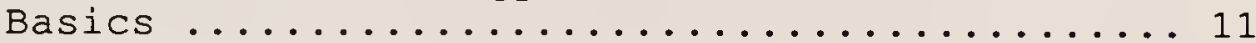

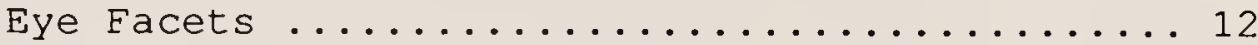

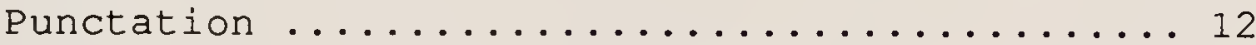

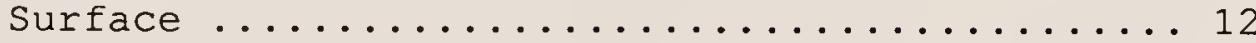

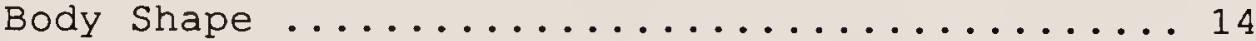

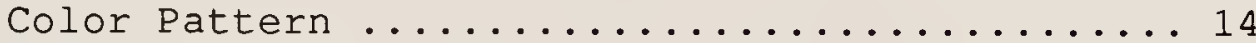

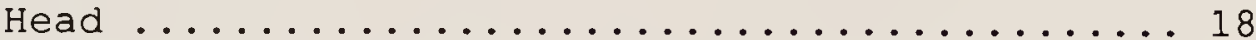

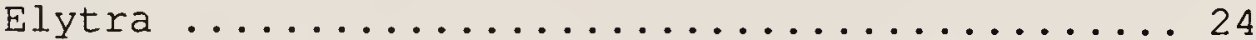

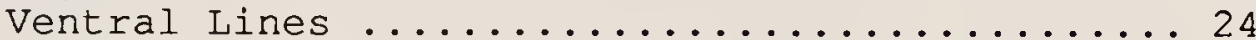

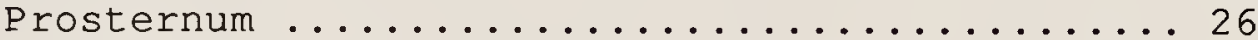

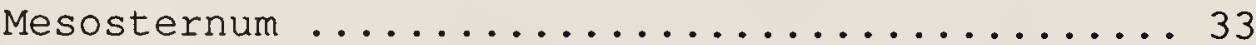

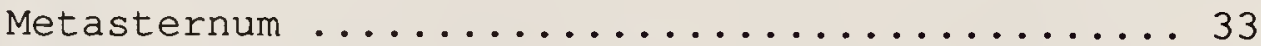

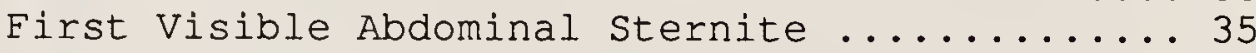

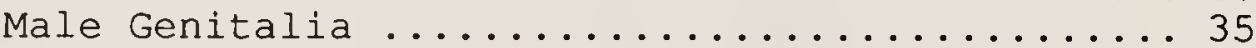

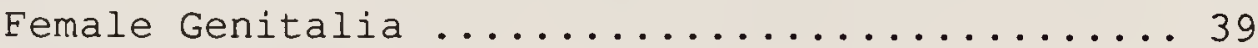

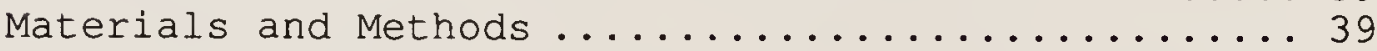

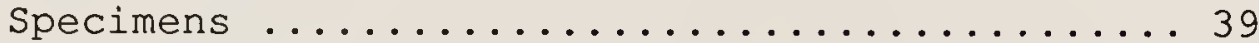

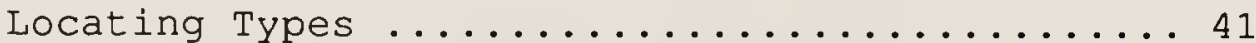

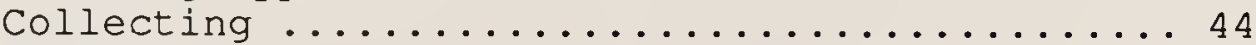

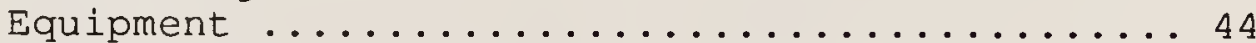

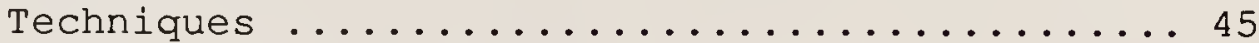

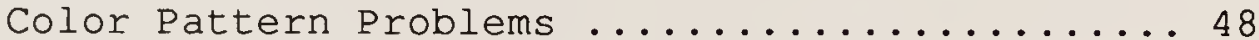

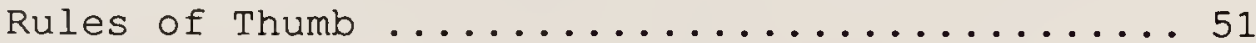

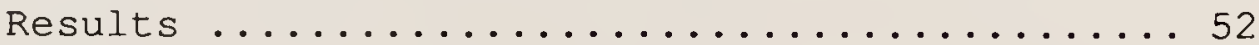

ISCHYRUS LACORDAIRE ...................... 53

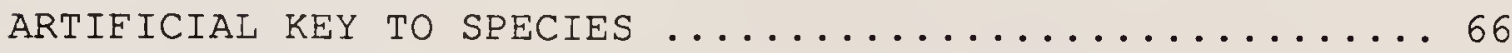

SPECIES ACCOUNTS ......................... 81

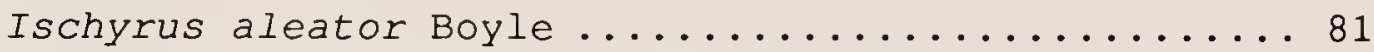

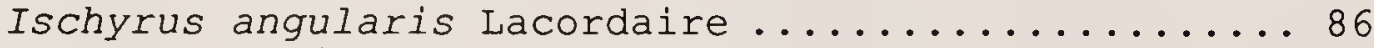

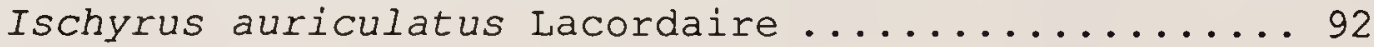




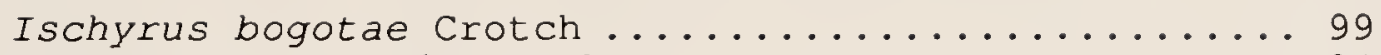

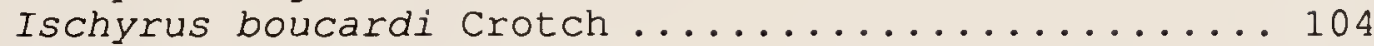

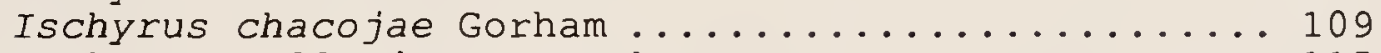

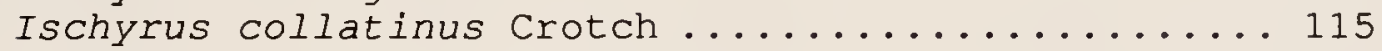

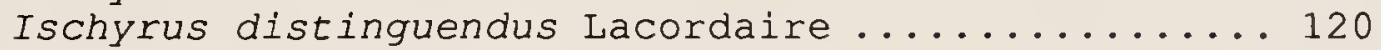

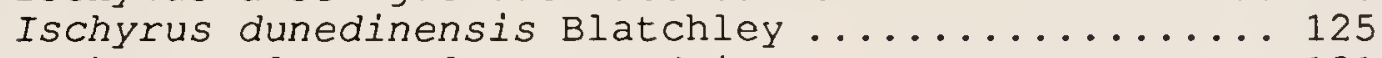

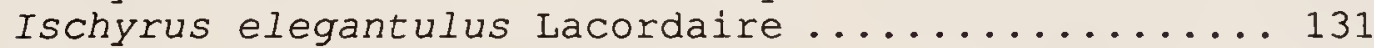

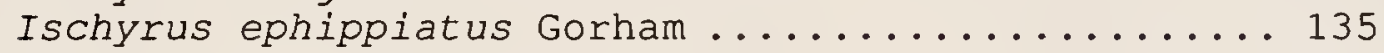

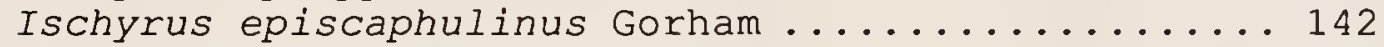

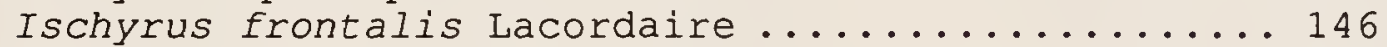

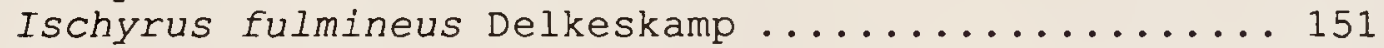

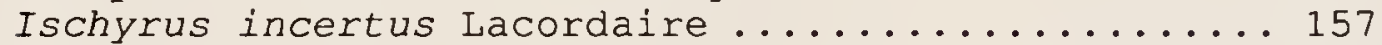

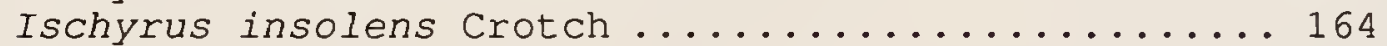

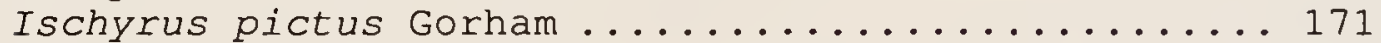

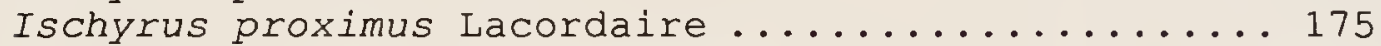

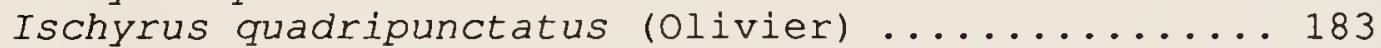

Ischyrus quadripunctatus quadripunctatus (Olivier) 191

Ischyrus quadripunctatus chiasticus Boyle, New Status

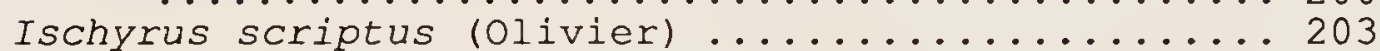

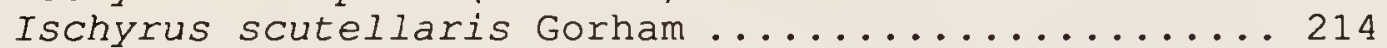

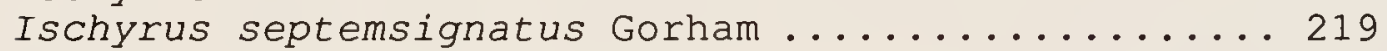

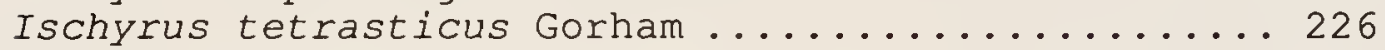

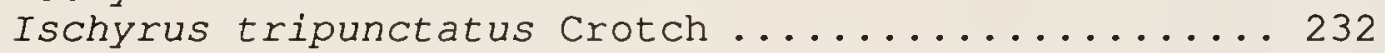

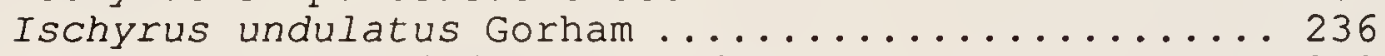

Ischyrus vespertilio Lacordaire .............. 240

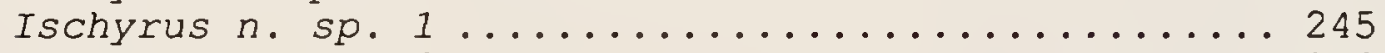

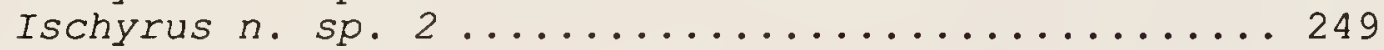

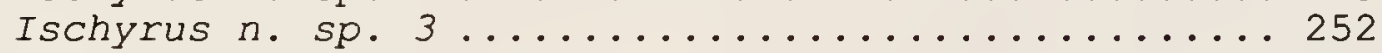

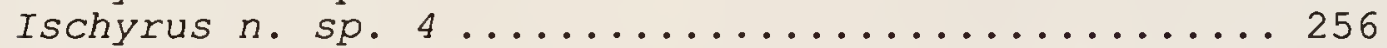

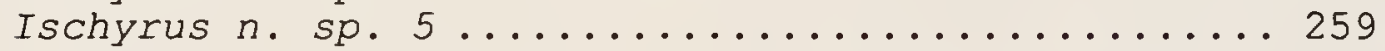

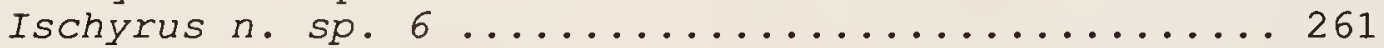

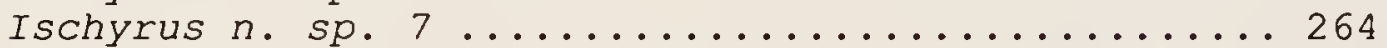

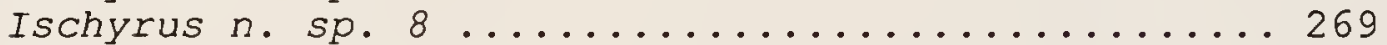

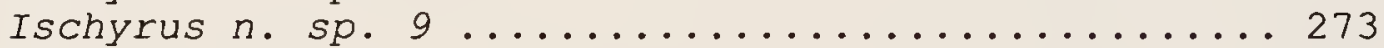

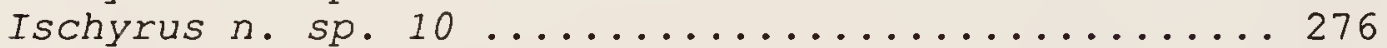

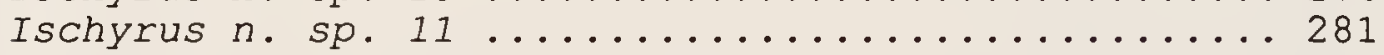

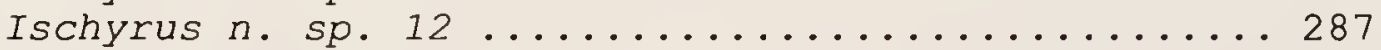

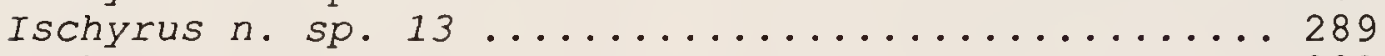

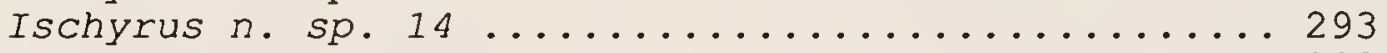

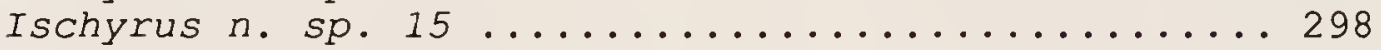

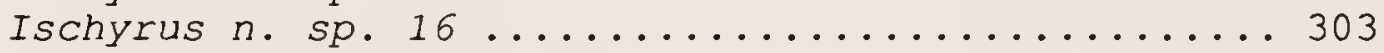

APPENDIX A: ISCHYRUS SPECIES NAMES ....................

APPENDIX B: COLLECTIONS STUDIED AND CODENS ......... 317

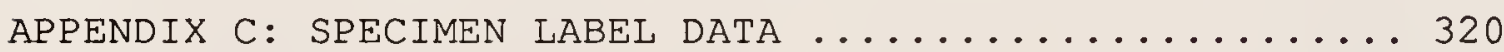

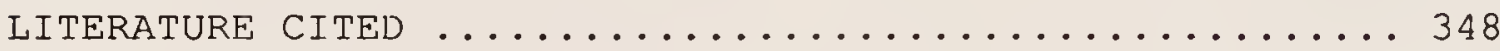

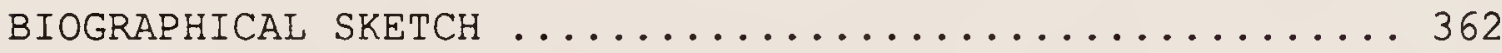


Abstract of Dissertation Presented to the Graduate School of the University of Florida in Partial Fulfillment of the Requirements for the Degree of Doctor of Philosophy

\title{
REVISION OF THE GENUS ISCHYRUS LACORDAIRE (1842) \\ (EROTYLIDAE: TRIPLACINAE) \\ OF NORTH AND CENTRAL AMERICA
}

\author{
By \\ Paul Edward Skelley
}

April 1994

Chairman: Robert E. Woodruff

Major Department: Entomology and Nematology

This revision treats all known species of the genus Ischyrus Lacordaire occurring from Panama north. A key to the species, descriptions and illustrations of terms used, habitus and genitalic illustrations for all species, distribution maps, detailed species descriptions, complete synonymies, label data from specimens studied, and comparisons with similar species are presented to aid in the identification of specimens. A list of all names used in combination with Ischyrus and their current status is presented to prevent future homonyms. A total of 26, valid previously described species is addressed, nine new synonymies made, and 16 new species described. 


\section{INTRODUCTION}

\section{General Introduction}

The family Erotylidae is composed of fungus-feeding beetles that vary in body size and color; many are elaborately patterned. Recently published catalogs detail the Old World species (Delkeskamp 1981; Chûjô \& Chûjô 1988, 1989, 1990). In contrast, Crotch's (1876) world revision of the Erotylidae was the last study to cover the entire New World fauna, but it provided no keys or illustrations and few descriptions. Since Crotch's time, the New World erotylid fauna has been studied intermittently, with scattered regional studies, catalogs, and species descriptions. Most New World erotylid genera have no modern revision.

The purpose of this study is to begin bringing the nomenclature of the New World Erotylidae into the 20th century and to publish the results in a manner that will enable entomological students to identify their specimens. "Progress in Natural History necessarily starts from a basis of species, and until these are accurately described so that others can arrive at a knowledge of them no great advance is possible" (Horn 1887:7).

Nomenclatural changes and lectotype designations made in this dissertation are not to be considered valid until 
they are published. Holotypes are not selected and names are not proposed for the new species to avoid potential nomenclatural problems.

\section{History}

The first described member of the genus Ischyrus Lacordaire is Erotylus quadripunctatus olivier (1792). The first use of the name Ischyrus was by Chevrolat in fascicle 5 of the second edition of Dejean's catalog (1836). Because most of the second edition was burned in a fire, the third edition of the Dejean catalog (1837) was immediately printed. (See Madge, 1988, for dates of publication and history of the Dejean catalogs.)

Dejean's (1836, 1837) catalogs were among the first works to split the genus Erotylus Fabricius (1775) into more manageable, related taxa. Species and generic concepts were in their infancy during the early 1800s. For the Erotylidae, Dejean's genera appear to be groups of species with similar body size and color. This is evident in the proposed genus Ischyrus chevrolat containing large dull-black species, Mycotretus Chevrolat containing smaller species with yellow and black color patterns, and Lybas Chevrolat containing species that were oval and solid red. Dejean's catalogs were simply checklists of his collection in which many generic and specific names were proposed. Because the Dejean names lacked descriptions, they were often ignored by early taxonomists. 
The next use of the name Ischyrus was by Falderman (1837) in describing Ischyrus lepidus, presently a member of Triplax Herbst (1793) (fide Chûjô \& Chûjô 1990). The name Ischyrus was then used as a subgroup of Erotylus Fabricius (1775) by Guérin-Méneville (1841) in describing E. (Ischyrus) nebulosus, presently a member of Brachysphaenus Lacordaire (1842) (fide Crotch 1876). These uses of "Ischyrus" illustrate early workers" attempts at placing new species into taxa based on superficial characters.

Lacordaire (1842) was the first person to provide a description of the genus Ischyrus, for which he gave credit to Chevrolat in Dejean (1836) as the author of the name. He moved many previously described species into Ischyrus and described 17 new species. Unfortunately, Lacordaire did not designate a type species for Ischyrus.

Lacordaire split the genus into two divisions. The first division contained species with larger body size and strongly keeled prosternum, mostly species listed in the Dejean catalogs as Ischyrus Chevrolat. The second division contained species with smaller body size and a weakly keeled prosternum, mostly species listed under Mycotretus Chevrolat in the Dejean catalogs, including Erotylus quadripunctatus Olivier. Lacordaire based his generic concepts on reasonably sound morphological features that are still in use. He also maintained many previously published species names that had not been described [nomina 
nuda]. With his descriptions, Lacordaire became the author of these names.

Subsequent authors, Guérin-Méneville (1844) and Erichson (1847), used Lacordaire's generic names and described seven additional species of Ischyrus.

Crotch (1873b) separated Lacordaire's divisions into distinct genera. The first division, containing species of larger size, he named Megischyrus. The second division, containing species of smaller size, he maintained as Ischyrus, crediting Lacordaire as the describer and noting the original use of the name by Chevrolat in Dejean (1836). At that time, it was common to give credit for a name to the first describer of the taxon and not to the author of that name. Following this trend, crotch cited it as Ischyrus Lacordaire.

In 1873 Crotch received a grant to visit tropical Australia and adjacent islands to collect natural history specimens. Before his departure from Cambridge, U.K., he placed his collection and manuscript in the care of $E$. $W$. Janson. Unfortunately, crotch became ill and died in 1874 while in the U.S.A. Edward W. Janson put Crotch's manuscript into final form and published it. Numerous notes within the revision are undoubtedly those of Janson. Without Crotch's input, many of the species problems alluded to within the text were left unresolved. This "revision" is simply an annotated catalog of the species previously described, with brief descriptions of the new 
species. Yet, it has been the basis for all subsequent studies of the family. The name Ischyrus Lacordaire, as cited and used in Crotch's revision, was accepted and used by all subsequent workers, with the exception of Alvarenga (1965, discussed below). Crotch (1876) listed 44 species of Ischyrus, 13 of which were new species.

Ischyrus Lacordaire (sensu Crotch) has been referenced in a multitude of papers and texts. Many of these are simply species descriptions, regional studies, catalogs, general entomological texts, or biological accounts. These are too numerous to list here, but they can be found in the species accounts of this revision.

Some of the more important references are worth noting. Gemminger and Harold's (1876) Catalogus Coleopterorum was published shortly after Crotch's revision and contains the names as used by Crotch. Gorham (18871899), in the Biologia Centrali-Americana, gave accounts for 22 species of Ischyrus that included 10 new species. Kuhnt (1909, 1911) provided two catalogs, the first of which contained a simple grouping of the species by various color pattern characters.

The most recent catalog of the genus Ischyrus Lacordaire is Blackwelder's (1945) Checklist of the Coleopterous Insects of Mexico, Central America, the West Indies, and South America, which lists 56 names. Boyle (1954, 1956) revised the family Erotylidae for America, 
north of Mexico, thoroughly describing the genus Ischyrus and one new species.

The most recent paper of importance to the genus Ischyrus Lacordaire is Alvarenga (1965). Following current nomenclatural rules, Alvarenga realized that Crotch (1873b) had incorrectly applied the name Ischyrus and selected an invalid type species. Alvarenga made some major changes in the standing of the names Ischyrus and Megischyrus, which are discussed in the following section.

Before the present study, there were 65 valid species placed in the genus Ischyrus Lacordaire. This study addresses 26 of these, synonymizes 9, and describes 16 new species. This brings the total to 72 species. (See Appendix A for a list of all specific names used in association with Ischyrus and their current status.)

\section{Nomenclatural Status}

The early nomenclature of this genus is typical for many taxa, with names being proposed and ignored. The name Ischyrus Chevrolat in Dejean (1836) is a nomen nudum (name without description) and was not valid in the opinion of some early workers. Thus, the first use of the name to be accompanied by a description was the valid name. Crotch (1873b) undoubtedly had this in mind when he raised Lacordaire's divisions to full generic status. Crotch proposed the name Megischyrus for Lacordaire's first division, designating Erotylus undatus olivier as the type species. Crotch retained the name Ischyrus for the second 
division, crediting Lacordaire as the first describer of the genus, and designated Erotylus quadripunctatus olivier as the type species. This was accepted and used by all subsequent workers until Alvarenga (1965) found some errors in the type designations and credits for these genera. According to the current International code of Zoological Nomenclature (1985) the first valid use of a name is to be followed--the Law of Priority. Before 1931, the first use of a generic name is valid if it is followed by a description or has a valid species name listed under it, an indication. Also, in designating a type species for a genus subsequent to its first use, the reviser designating the type must choose a species from those originally included within the genus (as indicated by Barber \& Bidwell 1940). This makes the Dejean catalogs (1836, 1837) the first valid uses of the generic name Ischyrus, and the type species should have been chosen from the species listed within it.

According to these rules, Crotch (1873b) had incorrectly chosen the type species of Ischyrus, because Erotylus quadripunctatus was not listed in Dejean (1836) as Ischyrus. Erotylus undatus olivier was listed under the name Ischyrus Chevrolat in Dejean (1836). Crotch chose Erotylus undatus as the type species of his genus Megischyrus. This makes Megischyrus Crotch an objective synonym of Ischyrus Chevrolat, leaving Ischyrus Lacordaire (sensu Crotch) without a valid name. 
Discovering these problems, Alvarenga (1965) corrected them by synonymizing Megischyrus Crotch under Ischyrus Chevrolat, designating Erotylus undatus olivier as the type species. For Ischyrus Lacordaire (sensu Crotch) he proposed the name Micrischyrus, designating Erotylus quadripunctatus olivier as the type species. In essence, he discarded one name, moved another, and proposed a third. In my opinion, Alvarenga's actions were not fully justifiable because they create unnecessary confusion. The main purpose of the International Code of Zoological Nomenclature is to stabilize nomenclature, as stated in its preamble. The code has provisions (Article 79) to conserve long-standing, widely accepted names like Megischyrus Crotch and Ischyrus Lacordaire (sensu Crotch). Therefore, a proposal has been submitted to the International Commission of Zoological Nomenclature (Skelley \& Goodrich, in press) to conserve these names by suppressing all uses and indications of the name Ischyrus prior to Ischyrus Lacordaire (1842). Pending the ruling of the Commission, I am using the name Ischyrus Lacordaire (sensu crotch), in preference to Micrischyrus Alvarenga, as the name for the genus studied in this revision.

\section{Format of species Accounts}

Title. This heading is the valid name for the species to be discussed.

Synenymy. This section lists all combinations of the specific name and any synonyms of the valid name. These 
are organized in the following manner: Genus species describer date:page [comments], author of the synonymy or combination date:page. Example: Engis variegata Dejean 1821:45 [nomen nudum], Gemminger \& Harold 1876:3691.

Diagnosis. This section lists the set of characters separating the species under consideration from all known species in the genus.

Description. This section is a detailed description of the species being discussed. It is organized in the following manner: body measurements, overall appearance, color pattern, head and antenna, visible mouthparts, pronotum, scutellum, elytra, prosternum, mesosternum, metasternum, first visible abdominal sternite, male genitalia, female genitalia, stridulatory files, sexual dimorphisms. Legs are not described because no characters of use at the species level were found.

Variation. This section is a discussion of the color pattern or morphological features that vary from specimen to specimen in the species.

Type. Here I list the type specimens for all species names appearing in the synonymy, their label data, type locality (if not on their labels), current location, sex, and if they were studied.

Label data for type specimens are given in the following manner: "/ label data/ [my comments] label data/" $[\mathrm{XXXX}]$. The quotation marks, " ", indicate the beginning and ending of the data. The slash marks, /, indicate the 
beginning and ending of an individual label. My comments are placed in brackets, [ ], and usually indicate paper color or label shape. When no comment is made, the paper is white. After the label data are presented, a coden is given in brackets, $[\mathrm{XXXX]}]$, for the institution (see Appendix B) where the specimen it is currently located.

Many species needed lectotypes designated. A red "lectotype" label was placed on these specimens and dated when they were designated as the "type."

Type specimens of previously described species were dissected only if it was absolutely necessary to solve a species problem. Since this was such a rare occurrence, determining the sex of the types was accomplished using external characters. In some cases, where sexual dimorphism is distinct, the determination was easy. In most cases, when the sex was unclear, it is listed as "not determined."

Specimens examined. Here I list the label data for all specimens studied, if there were fewer than ten records. Species with more than ten collection records have their data presented in tabular form in Appendix $C$ to help keep the text uncluttered and to present it in a more usable format.

Distribution. A brief account of the known geographic distribution of the species is presented. A map is provided for each species to illustrate the distribution. 
Etymology. An attempt is made to present what the species epithet means and possibly why the original author chose it. This is included more for historical purposes and may help the reader remember the name. Brown's (1985) Composition of Scientific Words was an indispensable reference in this research.

Taxonomic notes. This section includes nomenclatural aspects that need clarification. I present some unsolved problems of taxonomic importance indicating that this revision is just a beginning.

Biology. This section is included only for the few species where some biological or life history data are known.

Remarks. This section contains statements on similar species and how to separate them from other species being covered.

References. This section lists the references where the species name occurs. Each species name appearing in the synonymy is listed separately to aid in future literature searches for specific names other than the valid name.

\section{Characters and Terminology}

\section{Basics}

Most general terms follow the meaning presented in The Torre-Bueno Glossary of Entomology (Nichols \& Schuh 1989). Terms for the genitalia follow Sharp and Muir (1912), 
Tanner (1927), and Boyle (1956). Some characters and terms need further explanation, as follows.

\section{Eye Facets}

Eye facet size, coarse vs. fine, is used to separate many genera in the Triplacinae. This character is based on the relative size and distinctiveness of the eye facets in relation to the head. Coarse facets (Fig. 1a) are larger and more prominent, often bulging from the surface. Fine facets (Fig. 1b) are smaller and less prominent, with a smoother eye surface. There are many species that are intermediate in facet development, making this character difficult to interpret.

\section{Punctation}

The puncture size is compared with the eye facet: facet diameter to puncture diameter. Most Ischyrus species have coarse punctation where the punctures are as large or larger in diameter than a facet.

Punctures can be normal, impressed, or foveate. A normal puncture appears like a simple pinprick. Impressed punctures are deep punctures, usually with a rounded edge and bottom. Foveate punctures are large, shallow, flatbottomed punctures, usually with a distinct edge. Surface

The body is generally covered with a hexagonal microsculpturing. Variations in the strength of this microreticulation change the surface from shiny to dull and are visible to the naked eye. 

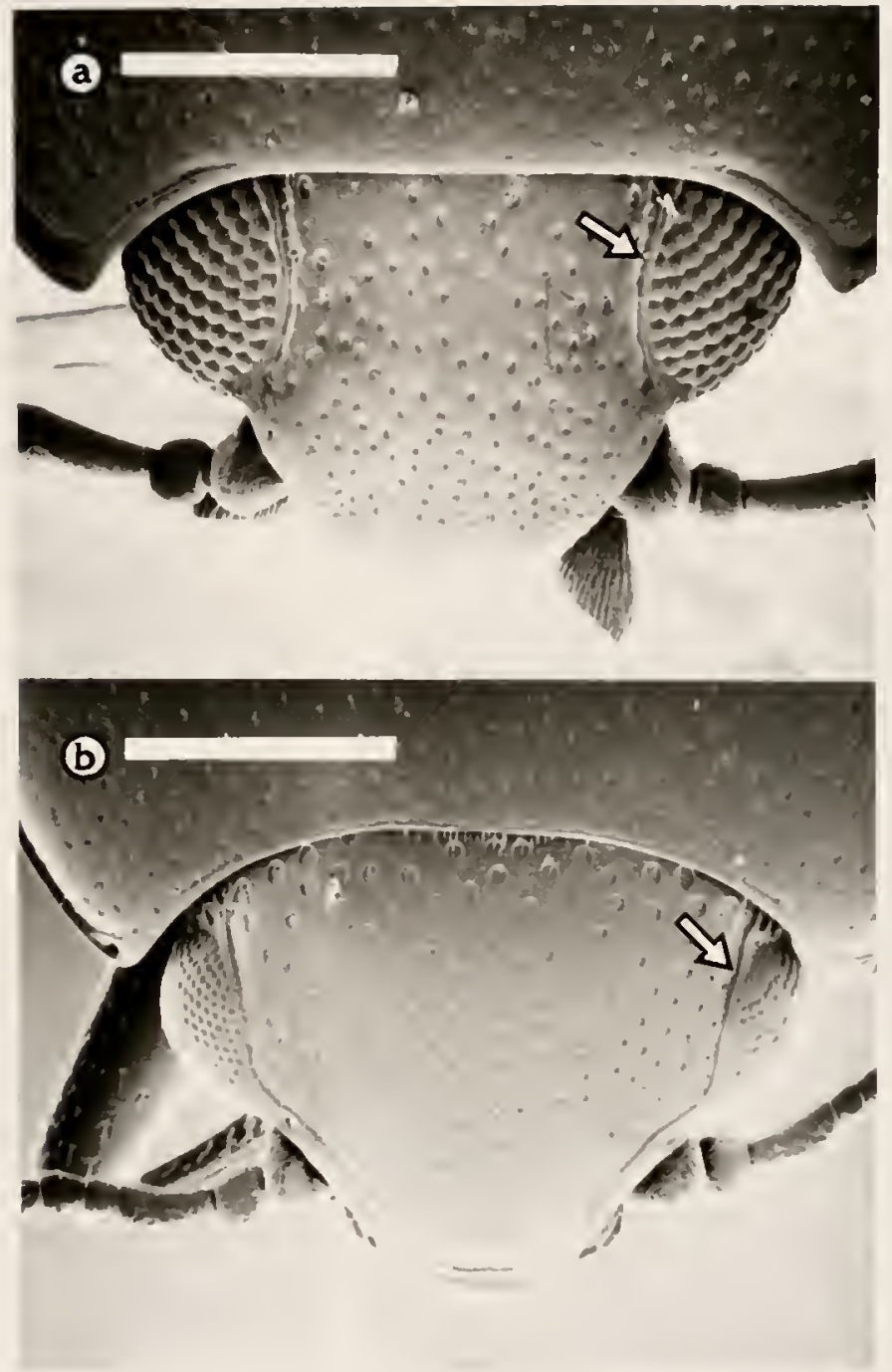

Figure 1. Dorsal view of heads showing eyes: a.) Ischyrus q. quadripunctatus (Olivier) with coarsely faceted eyes, line $=0.5 \mathrm{~mm}$; b.) Tritoma atriventris LeConte with finely faceted eyes, line $=0.38 \mathrm{~mm}$. The arrow points to the ocular stria. 
Body Shape

Most of the species are flattened to slightly convex dorsally; vespertilio Lacordaire and duponti Lacordiare are convex dorsally (Fig. 2a, 2b). Most parallel-sided bodies (Fig. 2c) are flattened dorsally. Most elongate bodies have the sides parabolically rounded (Fig. $2 d$ ) and are slightly convex above. Oval bodies (Fig. 2e) are rounded on the sides and can be flattened or convex dorsally. Ovoid bodies are egg-shaped (Fig. 2f) and wider anteriorly and can be flattened or convex dorsally.

\section{Color Pattern}

Color patterns are the most useful characters in the recognition of species. Understanding the terms for various aspects of the color pattern is essential in using the key (Fig. 3).

A band is a wide transverse marking, wider than long. A stripe is a longitudinal marking, longer than wide. A spot is a small marking, usually circular or elongate. I use the term "fascia" to mean a band that may be broken by additional markings. A free spot is not connected to any margin. A tooth-like spot is a triangular spot connected to a margin.

The color patterns of most species are variations of a basic pattern. I have named the components of the pattern in reference to its position on the body (Fig. 4): anterior pronotal, free pronotal, basal pronotal, pronotal hind angle, humeral, subhumeral, scutellar, elytral suture, 


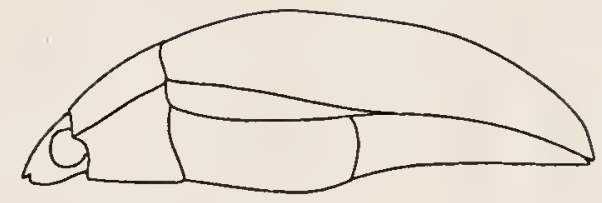

a

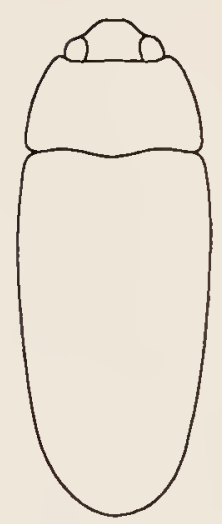

C

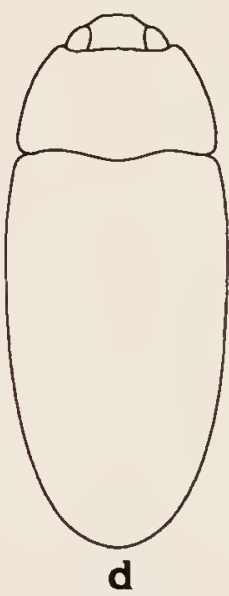

d
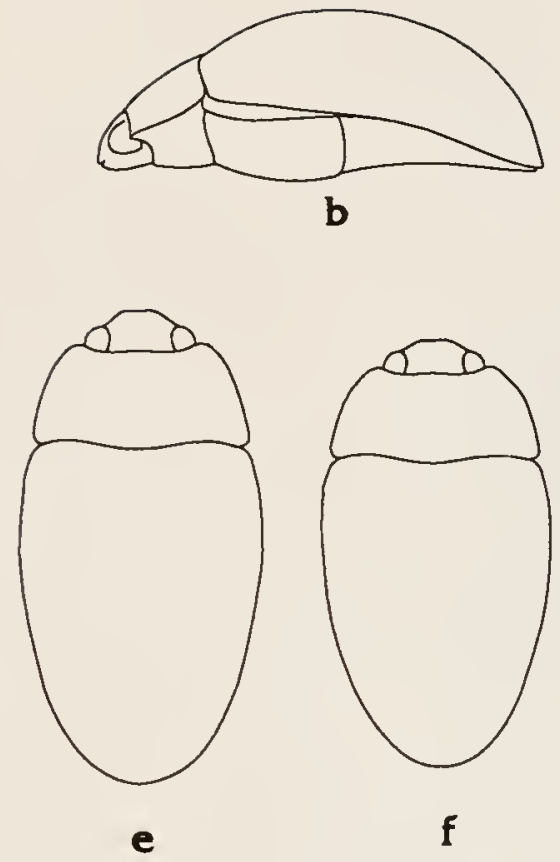

Figure 2. Ischyrus body shapes: a.) flattened; b.) convex; c.) parallel-sided; d.) elongate; e.) oval; f.l ovoid. 

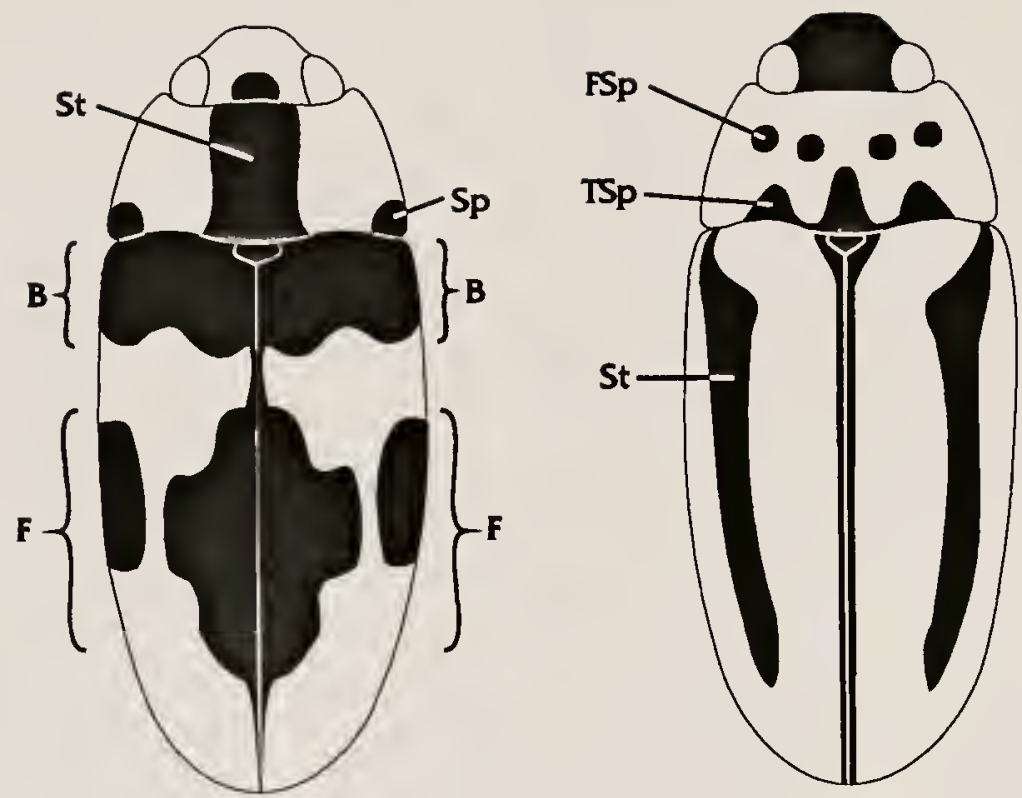

Figure 3. Diagrammatic representation of color pattern terms: $\mathrm{B}=$ band, $E=$ fascia, $\mathrm{ESp}=$ free spot, $\mathrm{Sp}=$ spot, $S t=$ stripe, $\mathrm{TSp}=$ toothlike spot. 


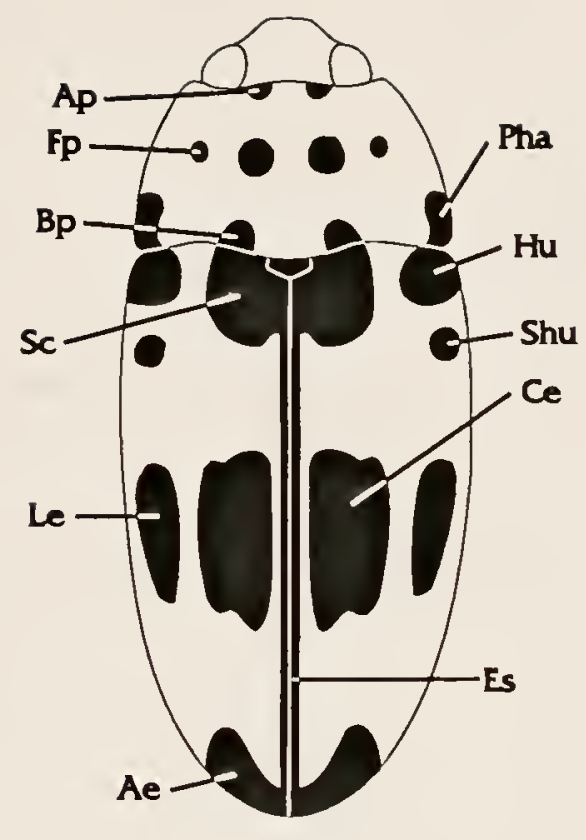

Figure 4. Diagrammatic representation of a generalized color pattern indicating spot names: $\mathrm{Ae}=$ apical elytral, $\mathrm{Ap}=$ anterior pronotal, $\mathrm{BP}=$ basal pronotal, $\mathrm{Ce}=$ central elytral, Es = elytral suture, $\mathrm{FP}=$ free pronotal, $\mathrm{Hu}=$ humeral, Le = lateral elytral, Pha = pronotal hind angle, shu = subhumeral, $\mathrm{SC}=$ scutellar, $\mathrm{Sc}+\mathrm{Hu}=$ basal elytral band, $\mathrm{Ce}+\mathrm{Le}=$ central elytral band. 
central elytral, lateral elytral, and apical elytral. When the scutellar and humeral spots are connected, they make up the basal elytral band. When the central and lateral elytral spots are connected, they make up the central elytral band.

Head

The dorsal surface of the head has relatively few useful characters. On each side of the vertex following the margin of the eye is a line or shallow groove, the ocular stria (Fig. 1). Its length appears to be useful at generic levels and is commented upon for future reference. Since this line is shorter than the eye length in the vast majority of Ischyrus, its length is given as a decimal that indicates how far forward the line reaches on the eye. For example, it could reach " 0.75 distance to the anterior angle of the eye," which means the line stops $3 / 4$ of the distance from the base to the anterior angle of the eye. In Figure 1a, the ocular stria stops at the anterior angle. The head size vs. eye size is given as a proportion: head width between eyes $=$ " $N$ " eye widths (Fig. 5). The smaller the eyes or the wider the head, the larger the number " $\mathrm{N}$ ".

The base of the head often has structures which have been called stridulatory files (Alexander et al. 1963; Arrow 1924, 1925, 1942; Delkeskamp 1959). These structures appear as iridescent spots under a dissecting microscope. Study with the scanning electron microscope shows them to 


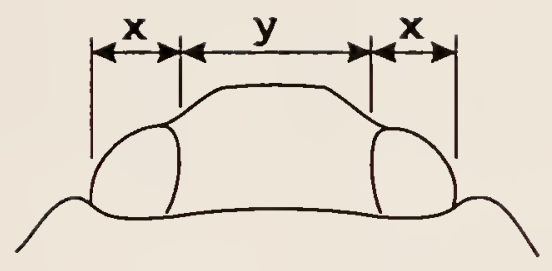

Figure 5. Diagrammatic dorsal view of a head showing the measurements used for determining the ratio of head to eye width; dorsal head width between eyes $=y / x$ times eye width. 
be patches of parallel ridges. Even though these have been called stridulatory, I have found no statement about the sound produced. They appear only on males in some species and on both sexes in others. The exact function of these structures is unknown.

Representative species' antennae are illustrated on a single plate for ease in comparison (Fig. 6). If a species antenna is not illustrated, a reference is given to the antenna that is most similar: "(similar to Fig. X)", where " $x$ " is the figure number.

The shape and proportions of the maxillary and labial palp terminal segments are important for species distinctions. These are illustrated on a single plate (Fig. 7) for ease in comparing shapes and proportions. This plate illustrates the palpi of representative species to show the basic forms. The descriptions of species with similar palpi have the statement "(similar to Fig. X)," which refers to the figure " $x$ " that is most similar to that seen in the species being discussed.

The "triangular mentum" is a characteristic of Ischyrus. The "triangle" is a sunken area of the mentum surrounded by a ridge (Fig. 8). The triangular sunken area is the mental plate. The ridge surrounding the plate is the mental ridge; it is often extended forward at the middle as a sharp divider between the labial palps. This projection is called the medial ridge extension. As with palp terminal segments, representative menta are 


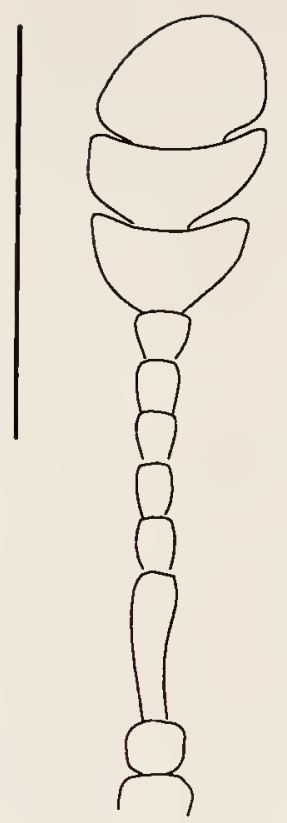

a

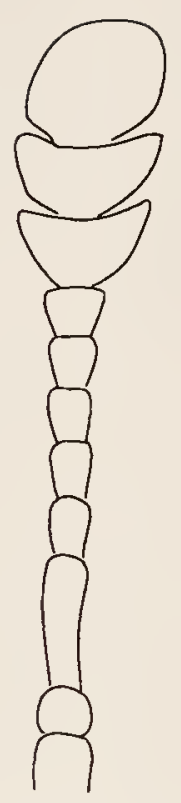

b

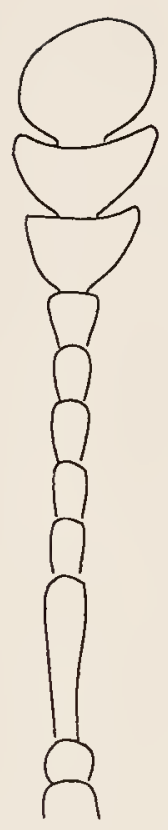

C
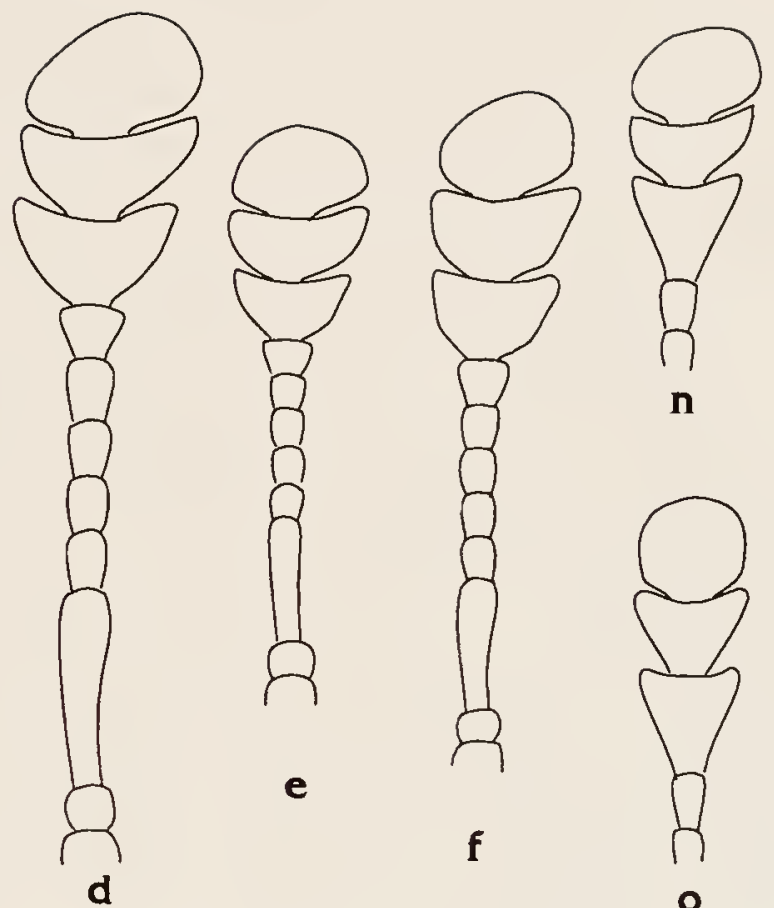

n

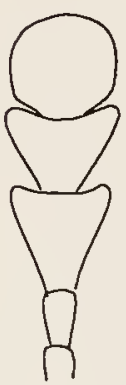

○

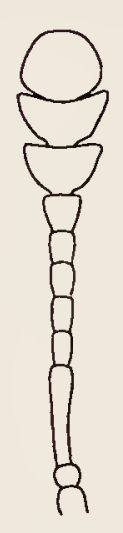

$\mathbf{g}$

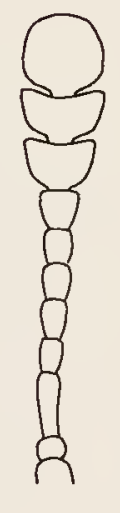

h

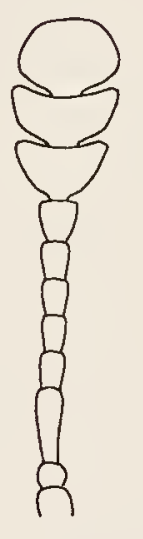

I

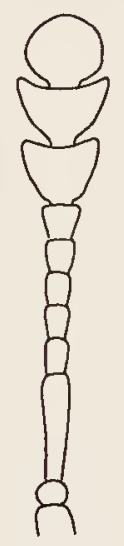

J
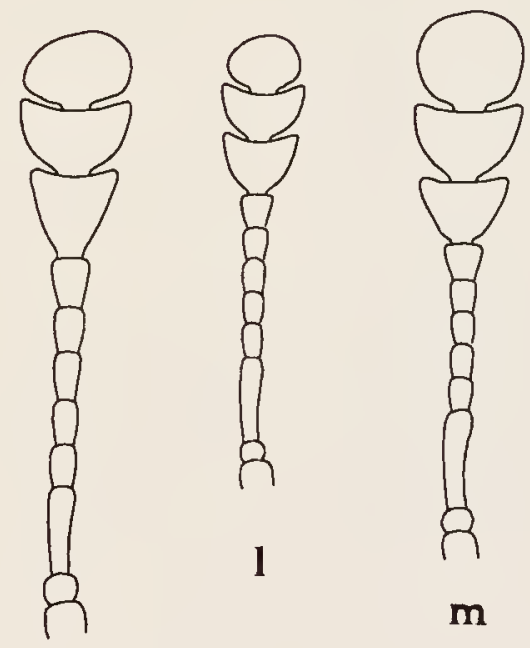

m

Figure 6. Antennae, line $=1.0 \mathrm{~mm}:$ a.) Ischyrus distinguendus Lacordaire; b.) I. n. sp. 2; c.) I. insolens Crotch; d.) I. bogotae Crotch; e.) I. angularis Lacordaire; f.) I. q. quadripunctatus (Olivier); g.) I. n. sp. 3; h.) I. n. sp. 4; i.) I. n. sp. 6; j.) I. n. sp. 5; k.) I. n. sp. 1; 1.j I. n. sp. 9; m.) I. n. sp. 14; n.) Megischyrus zonalis (Lacordaire); o.) Megischyrus sp. 


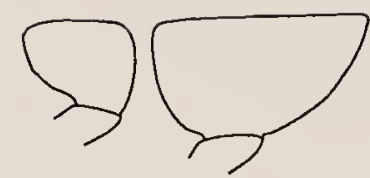

a
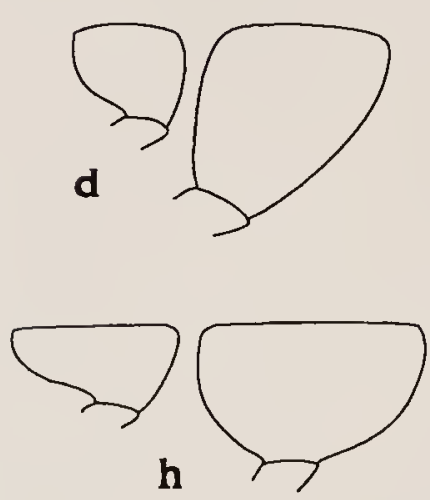

h
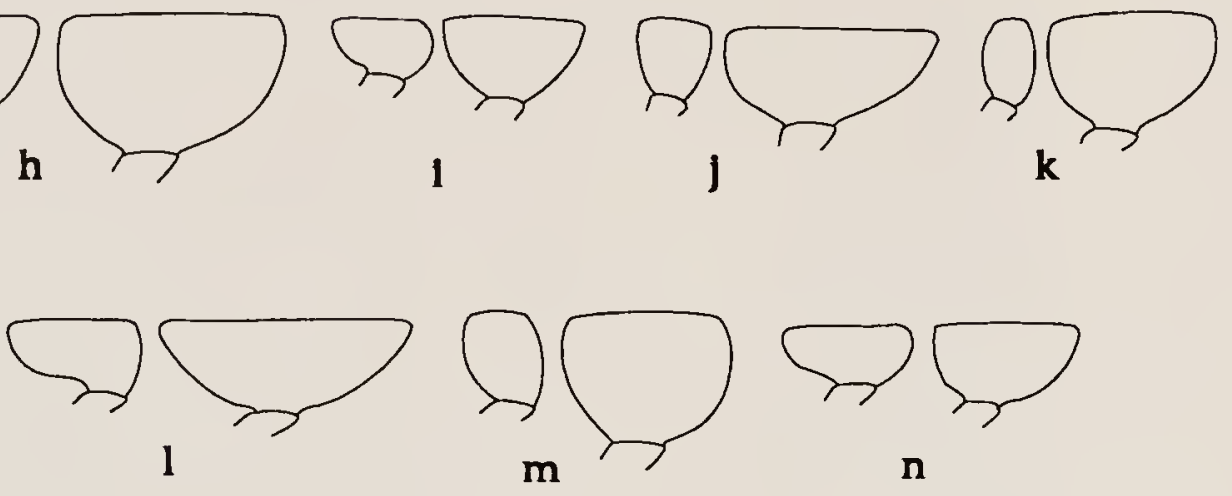

n
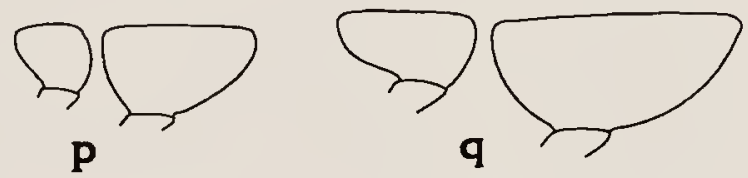

Figure 7. Terminal segments of labial palp (left) and maxillary palp (right), line $=0.33 \mathrm{~mm}: \mathrm{a}_{.}$) Ischyrus distinguendus Lacordaire; b.) I. n. sp. 2 ; c.) I. insolens Crotch; d.) I. bogotae Crotch; e.) I. septemsignatus Gorham; f.) I. q. quadripunctatus (Olivier); g.) I. n. sp. 3; h.) I. undulatus Gorham; i.) I. n. sp. 4; j.) I. n. sp. 6; k.) I. n. sp. 7; l.) I. n. sp. 5; m.) I. aleator Boyle; n.) I. n. sp. 1; o.) I. n. sp. 9; p.) I. ephippiatus Gorham; q.) I. tripunctatus Crotch. 


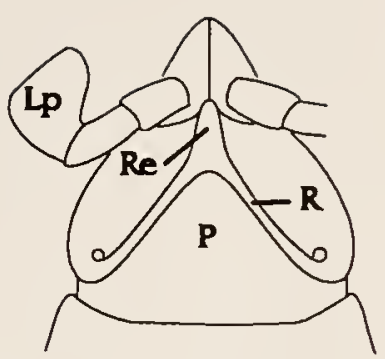

a

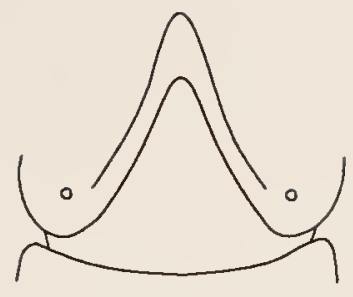

b
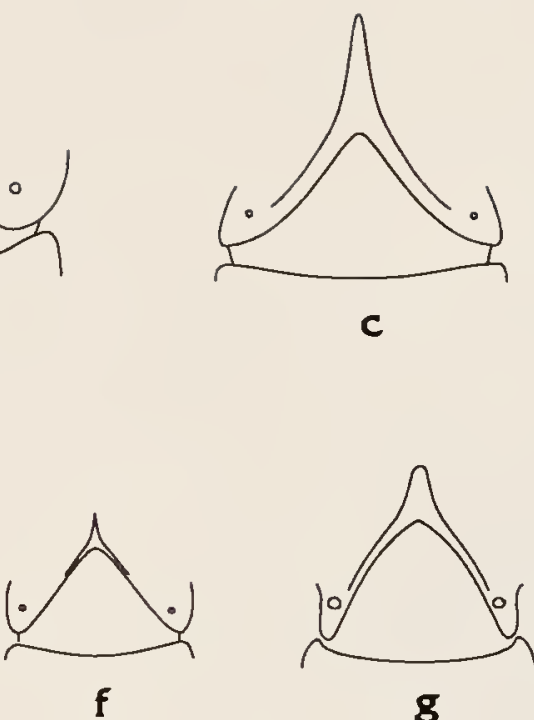

g
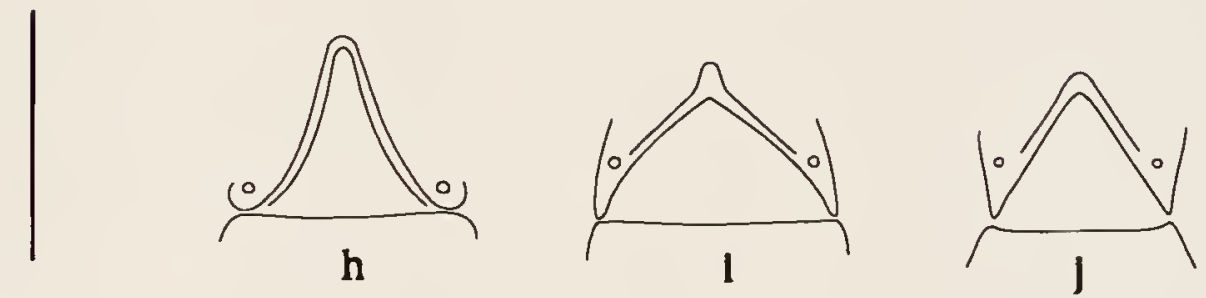

Eigure 8. Menta, line $=0.33 \mathrm{~mm}$ : a.) Ischyrus distinguendus Lacordaire; b.) I. n. sp. 2; c.) I. insolens Crotch; d.) I. bogotae Crotch; e.) I. n. sp. 3; f.) I. n. sp. 4; g.) I. n. sp. 6; h.) I. n. sp. 5; i.) I. aleator Boyle; j.) I. ephippiatus Gorham; Lp = labial palp, $\mathrm{P}=$ mental plate, $\mathrm{R}=$ mental ridge, $\mathrm{Re}=$ mental ridge medial extension. 
illustrated on a single plate (Fig. 8) and are often referred to in the text as "(similar to Fig. X)."

\section{Elytra}

Except for color patterns mentioned above, the elytra have few useful characters. One is the number of elytral striae and the strength of the strial punctures. Most species have seven complete striae; stria I next to the elytral suture, striae V and VI originating at the humerus. Stria VIII on most species is reduced to a short row of punctures visible at the basal quarter under the humerus and/or the apical quarter near the lateral edge of each elytron. Two species (I. n. sp. $6 \& I . n \cdot s p \cdot 7$ ) have stria VIII complete, one species (I. n. sp. 1) has parts of stria IX visible.

The size of the strial interval punctures is variable from species to species. In the majority of species the punctures are small and obscured in the microsculpturing. In a few other species they are large and distinct, occasionally obscuring the strial punctures.

\section{Ventral Lines}

A "line" refers to a ridge or fine groove on a sclerite that is not a suture, but probably has some supportive function. These lines surround the coxae and often extend onto the sclerite (Fig. 9). The term "coxal line" is used in reference to the line on the median side of the coxa. The lines anterior or posterior to the coxae are referred to by the structure they are on or near; e.g., 


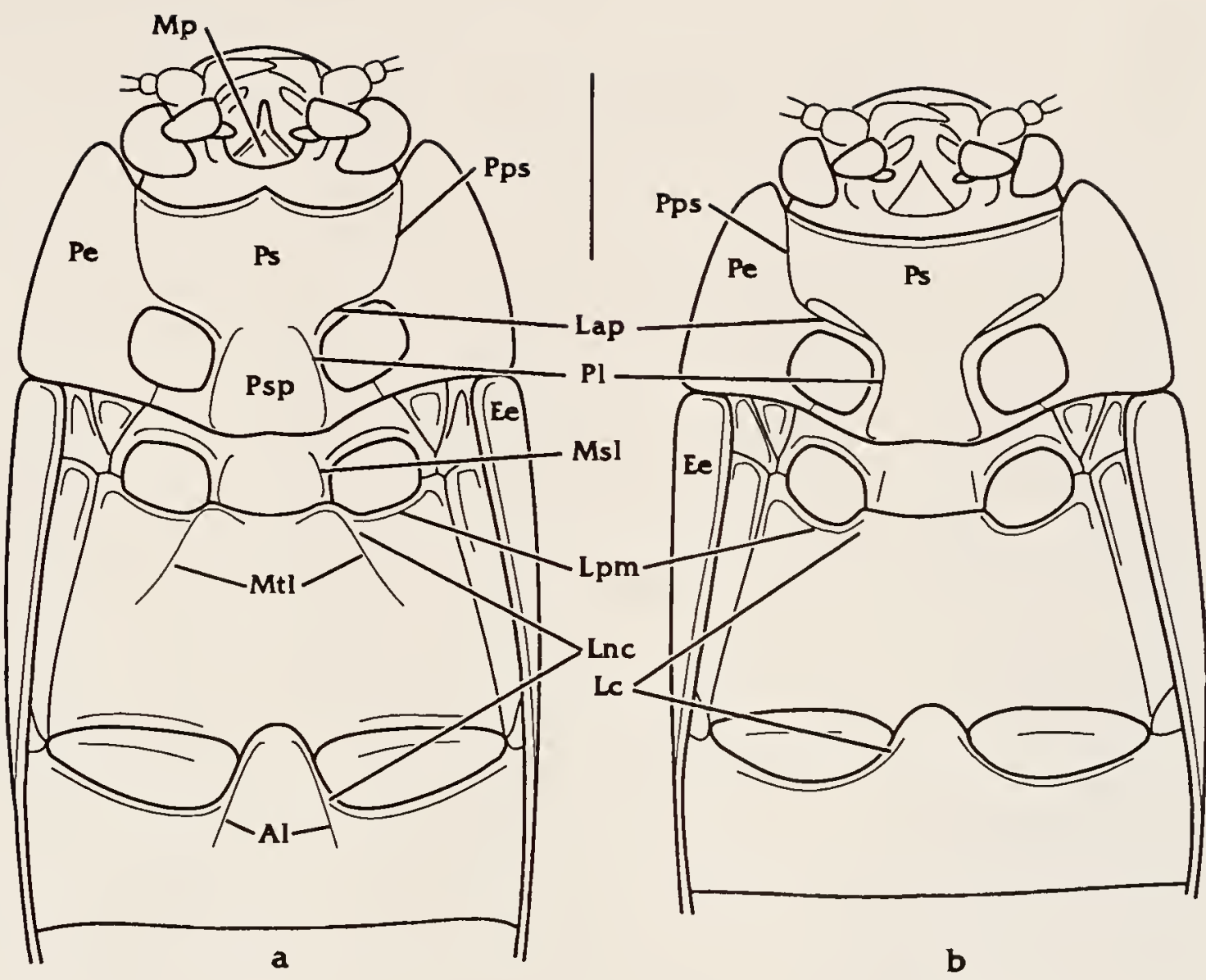

Figure 9. Ventral view of a.) Ischyrus proximus Lacordaire and b.) I. n. sp. 1, line $=1.0 \mathrm{~mm}$ : Al = abdominal coxal line, $\mathrm{Ee}=$ epipleural fold of elytron, Lap = prosternal line anterior to procoxa, Lc = coxal line continuous around coxa, Lnc = coxal line not continuous around coxa, Lpm = metasternal line posterior to mesocoxa, $\mathrm{Mp}=$ mental plate, $\mathrm{Msl}=$ mesocoxal line, $\mathrm{Mtl}=$ metacoxal line, $\mathrm{Pe}=$ pronotal epipleuron, $\mathrm{Pl}=$ procoxal line, $\mathrm{Pps}=$ prosternalpronotal epipleuron suture, $\mathrm{Ps}=$ prosternum, $\mathrm{Psp}=$ prosternal plate. 
the prosternal line in front of the procoxa or the metasternal line behind the mesocoxa.

In the majority of Ischyrus species the coxal Iines are not connected to other lines and extend onto the sclerite (Fig. 9a). If the coxal line is connected to the anterior or posterior line, it is "continuous around the coxae," because there is no break in the line surrounding the coxae (Fig. 9), and the line does not extend onto the sclerite.

\section{Prosternum}

The prosternum is a T-shaped sclerite with the base between the procoxae and the cap anterior to the procoxae. The anteromedial section of the prosternum is often keellike and elevated above the sides to the level between the procoxae (Fig. 10), straight in profile. This elevation makes the anterior margin project at the middle, appearing as a "pitcher-like lip" (according to Boyle 1956). When the prosternum is keeled and has this "pitcher-like lip," I refer to it as being "pinched," because it appears laterally pinched. The strength of this pinch, also the amount it projects, is variable throughout Ischyrus and can be absent (Fig. 10a, 10b), weak (Fig. 10c, 10d), or strong (Fig. 10e, 10f).

In a few species (for example, I. n. sp. 5, I. n. sp. 6, and I. n. sp. 7) the prosternal keel appears anteriorly swollen just behind the margin (Fig. log, 10h). I call this "swollen above the pinch." 


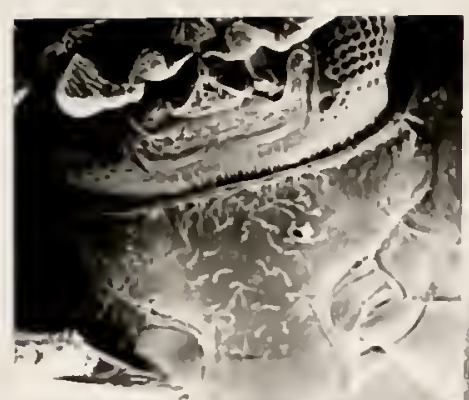

(a)

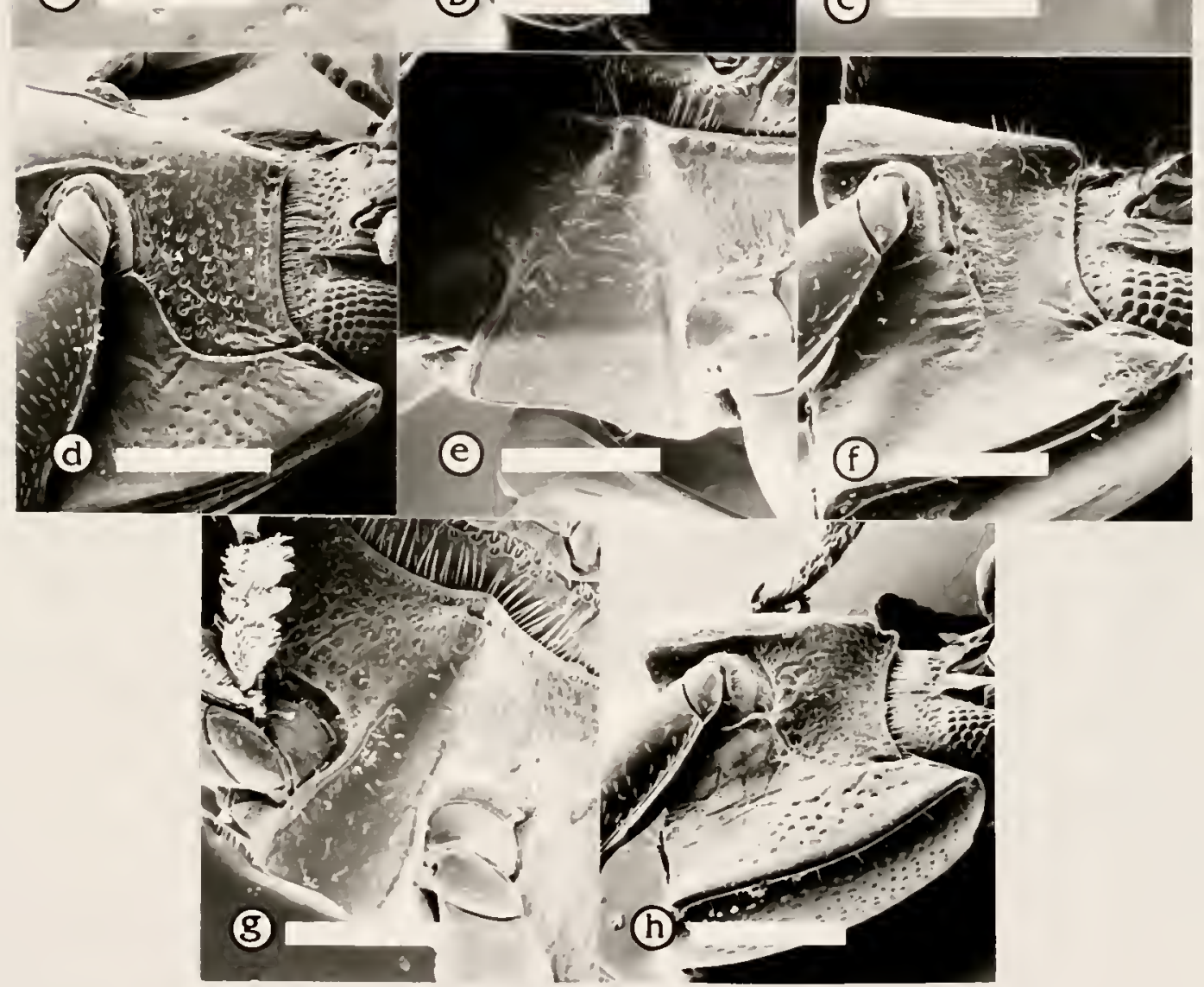

Figure 10. Prosternal development: a.) ventral and b.) lateral view of Ischyrus aleator Boyle [Mexico, Sonora] prothorax lacking anterior pinch, line $=0.60$ $\mathrm{mm}$; c.) ventral and d.) lateral view of Ischyrus $q$. quadripunctatus (Olivier) [USA, Florida] prothorax with weakly developed prosternal keel and pinch, line $=0.60 \mathrm{~mm}$; e.) ventral and $\left.\mathrm{f}_{.}\right)$lateral view of Ischyrus scutellaris Gorham [Mexico, Yucatan] prothorax with strong keel and pinch, line $=0.40 \mathrm{~mm}$; g.) ventral and $h$. .) lateral view of Ischyrus $n . s p .7$ [Panama] prothorax with prosternal keel swollen above pinch, line $=0.44 \mathrm{~mm}$. 
I use the term "prosternal plate" in reference to the surface of the prosternum between the coxal lines (Fig. 9). This "plate" is most often flat, but can be slightly convex. The plate shape varies throughout the genus (Fig. 11), from semicircular (wider than long) to elongate, parallel-sided (longer than wide).

The length of the procoxal lines varies from species to species. I use three phrases to describe the length of these lines in relation to the procoxae: surpassing coxae, barely surpassing coxae, not surpassing coxae. The phrase "surpassing coxa" (Fig. IIb) indicates the line passes beyond an imaginary line drawn between the anterior edge of the procoxae. The phrase "barely surpassing coxa" (Fig. 11a, 11c) indicates the line passes beyond the point where the line in front of coxa begins, but does not pass beyond an imaginary line drawn between the anterior edge of the procoxae. The phrase "not surpassing coxa" (Fig. 11d) indicates where the line stops where the line in front of procoxae begins, well before the imaginary line.

Many species have sexual dimorphism on the prosternum in one or two forms. The majority of the species studied have a differing number, or varying development, of foveate punctures in front of the procoxa. In these species, females have more numerous or distinct foveate punctures than the males (Figs. 12-14), the opposite of Delkeskamp's (1959) observations of certain African Dacninae. 


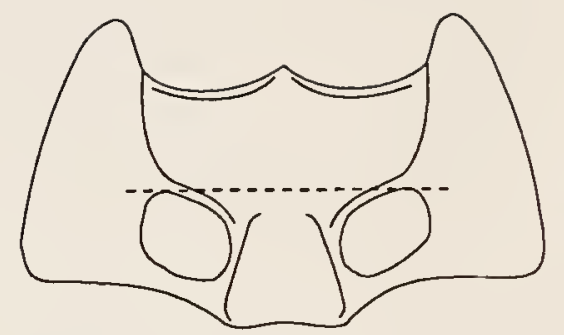

a

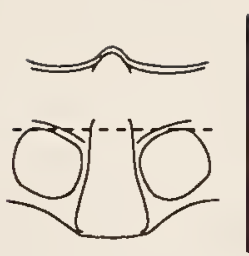

b

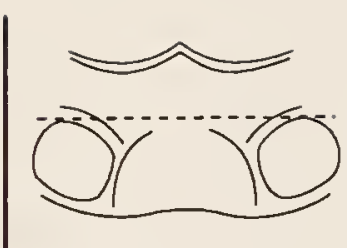

c

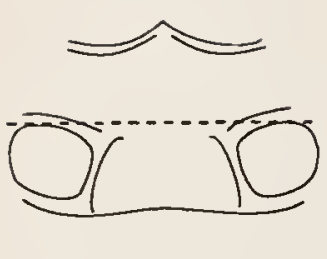

d

Figure 11. Prosternal plates showing procoxal line shapes and anterior development, line $=1.0 \mathrm{~mm}$; a.) Ischyrus proximus Lacordaire, barely suprassing coxa; b.) I. n. sp. 7, parallel-sided and surpassing coxa; c.) I. n. sp. 5, semicircular and barely surpassing coxa; d.) I. duponti Lacordaire, not surpassing coxa. Imaginary line (dashed) included for referencing anterior edge of procoxae in determining procoxal line development. 


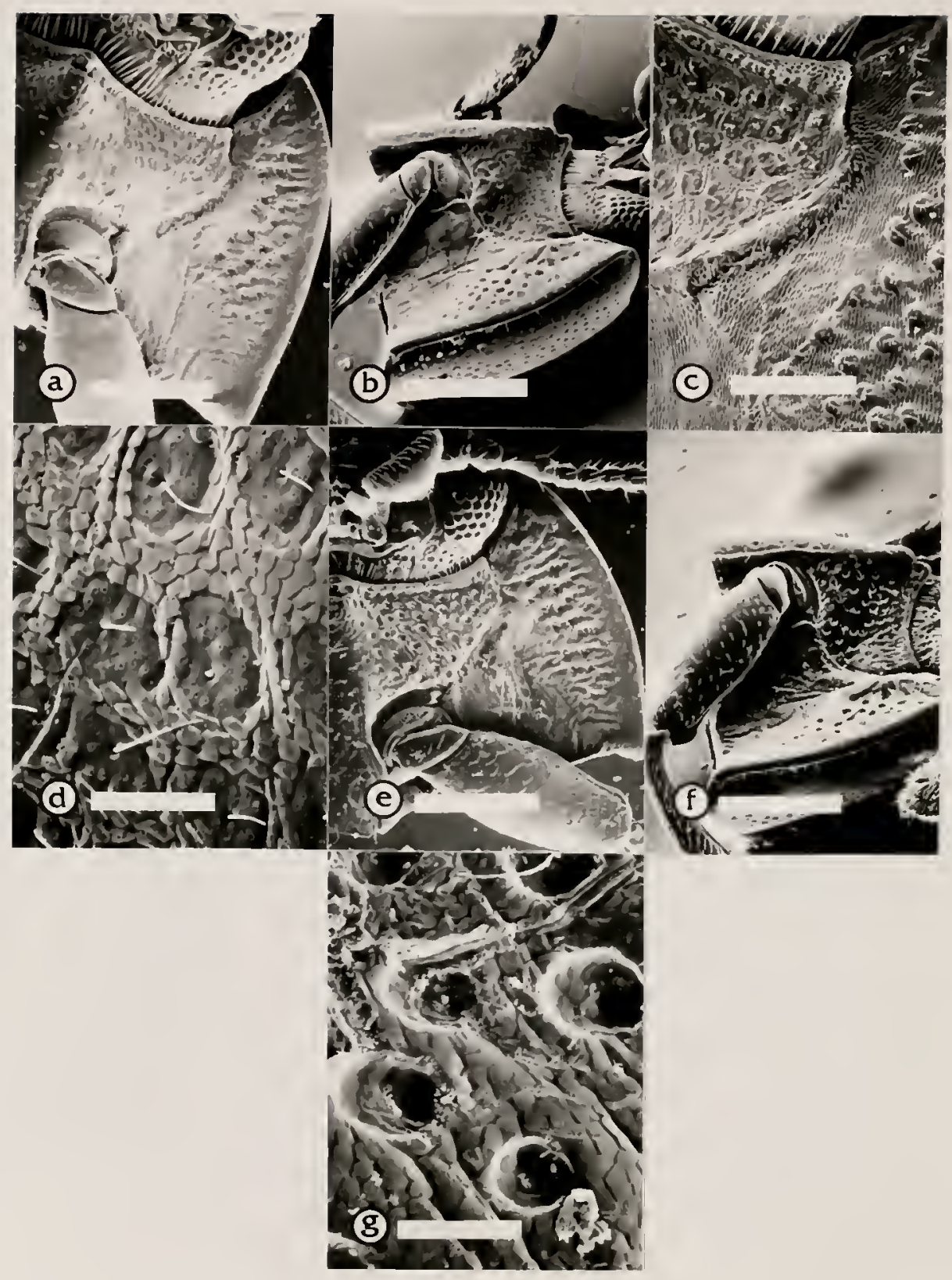

Figure 12. Prosternal sexual dimorphism in puncture development. Male Ischyrus n. sp. 7 [Panama] prosternum: a.) ventral view, line $=0.38 \mathrm{~mm}$; b.) lateral view, line $=0.50 \mathrm{~mm}$; c.) ventral view of prosternal-pronotal epipleural suture, line $=0.17 \mathrm{~mm}$; d.) prosternal punctures in front of procoxa, line $=$ $0.04 \mathrm{~mm}$. Female Ischyrus n. sp. 7 [Panama] prosternum; e.) ventral view, line $=0.43 \mathrm{~mm}$; f.) lateral view, line $=0.50 \mathrm{~mm} ; \mathrm{g.l}$ prosternal punctures in front of procosa, line $=0.04 \mathrm{~mm}$. 

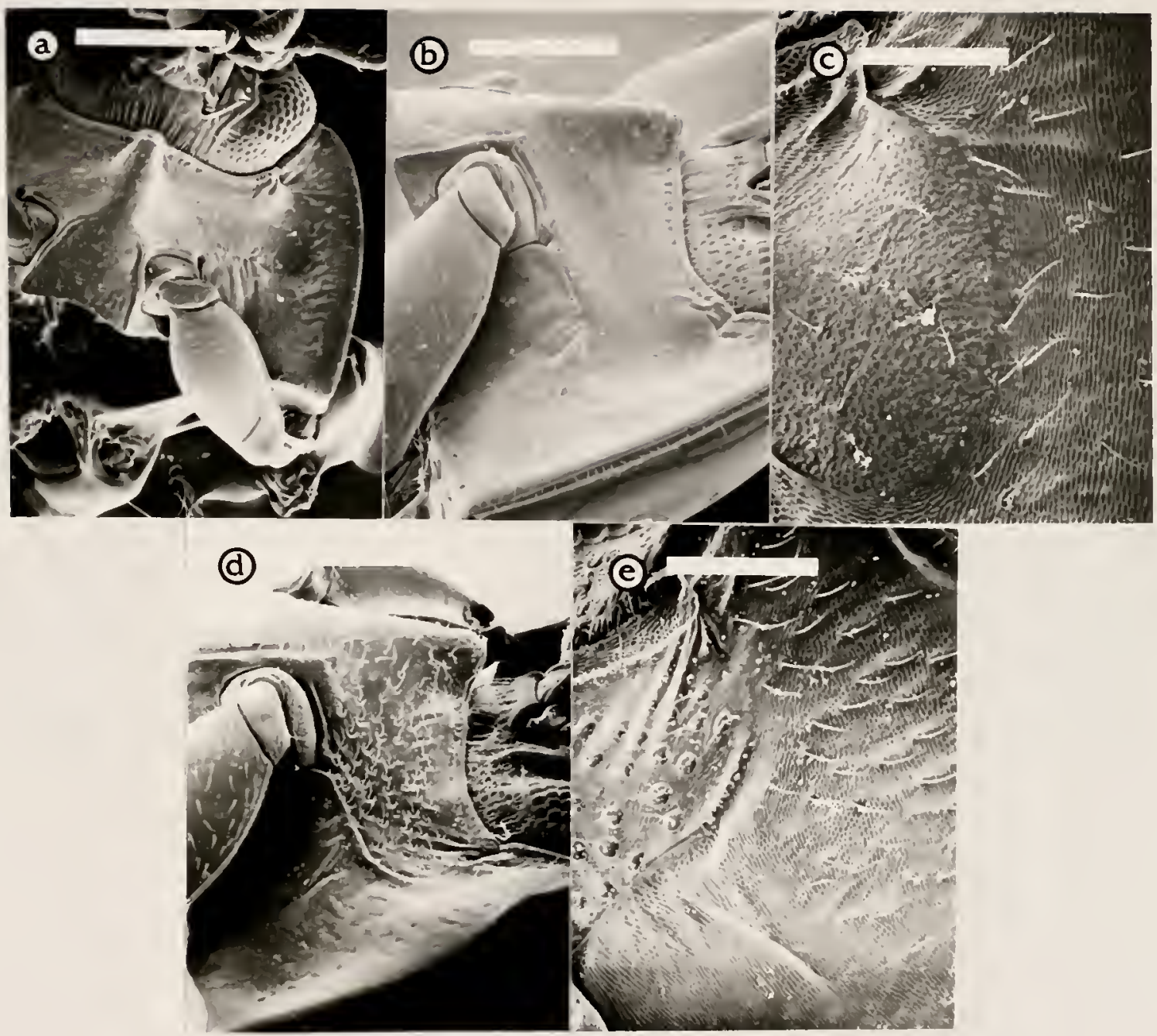

Figure 13. Prosternal sexual dimorphism in puncture development and lateral expansion. Male Ischyrus incertus Lacordaire [Mexico, Chiapas] prosternum: a.) ventral view, line $=0.75 \mathrm{~mm}$; b.) lateral view, line = $0.50 \mathrm{~mm}$; c.) ventral view of laterally expanded prosternal-pronotal epipleural suture, line $=0.17 \mathrm{~mm}$. Female Ischyrus incertus Lacordaire [Panama] prosternum; d.) lateral view, line $=0.50 \mathrm{~mm}$; e.) ventral view of prosternal-pronotal epipleural suture, line $=0.25 \mathrm{~mm}$. 


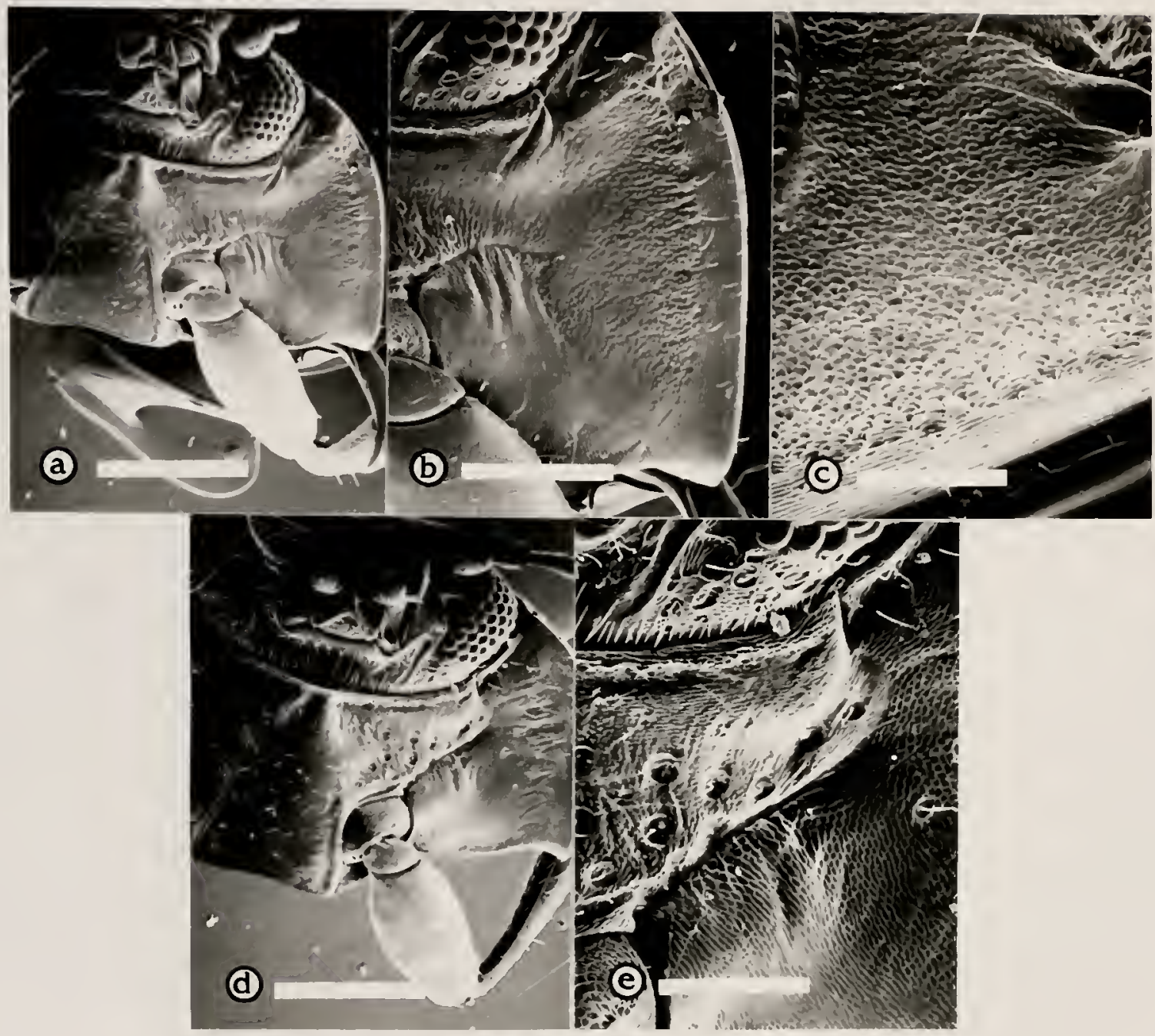

Figure 14. Prosternal sexual dimorphism in puncture development and lateral expansion. Male Ischyrus scutellaris Gorham [Mexico, Yucatan] prosternum: a.) ventral view, line $=0.60 \mathrm{~mm}$; b.) ventral view, line = $0.30 \mathrm{~mm}$; c.) lateral view of prosternal expansion, line $=0.12 \mathrm{~mm}$. Female Ischyrus scutellaris Gorham [Mexico, Yucatan] prosternum; d.) ventral view, line = $0.50 \mathrm{~mm}$; e.) ventral view of prosternal-pronotal epipleural suture, line $=0.17 \mathrm{~mm}$. 
In a few species, males have the prosternum expanded laterally, obscuring the prosternal-pronotal epipleural suture (Figs. 13-14). The extent of the expansion appears consistent in all specimens of a species, but is variable among species. It can be a small expansion (Fig. 13), or it can nearly cover the entire pronotal epipleuron (Fig. 14).

\section{Mesosternum}

The mesosternum has few useful characters. The length of the mesosternal lines in relation to the distance between them, along with the meso-metasternal suture shape, is useful in grouping related species. This suture can be truncate (Fig. 15a), sinuate (Fig. 15f), or broadly sinuate (Fig. 15c).

\section{Metasternum}

The metacoxal lines usually extend posteriorly away from the medial side of the mesocoxa towards the hind angle of the metasternum (Fig. 9, 15). These lines are variable in shape and length.

Anteriorly, the metacoxal lines can stop near the mesocoxa or continue along the meso-metasternal suture, often meeting at the middle. The shape of the line between the coxae varies from species to species and is useful in grouping related species. The term "recurved" is used to describe a line that curves away from the meso-metasternal suture (Fig. 15C-f). Medially, these lines can take several forms: absent, not recurved nor meeting medially 

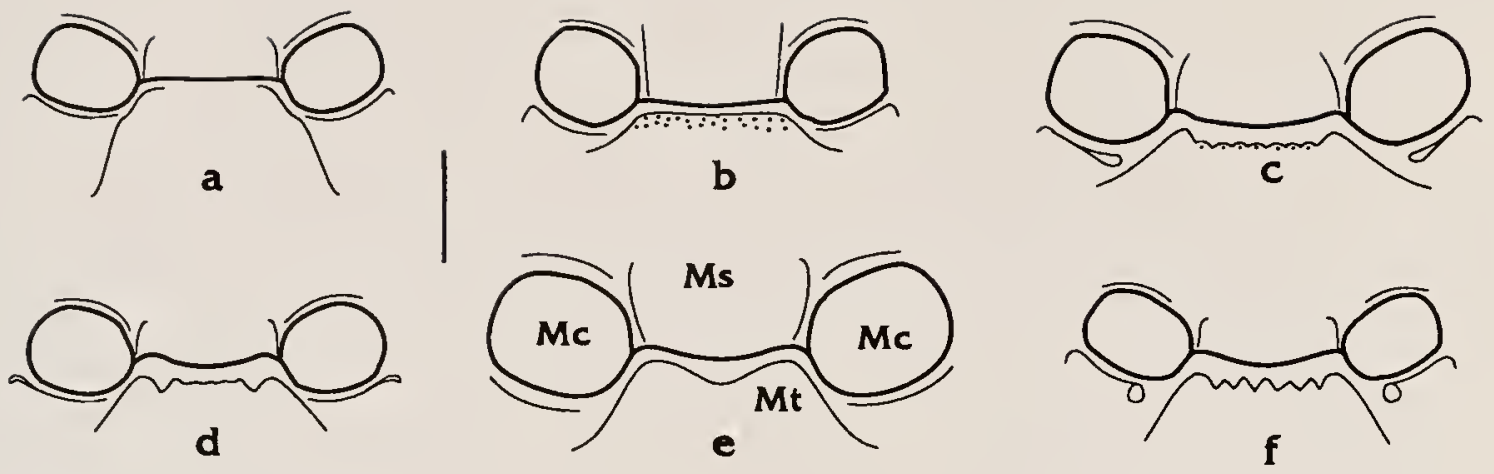

Figure 15. Meso- and metasternum showing coxal line development, line $=0.5 \mathrm{~mm}$ : a.) Ischyrus auriculatus Lacordaire, not recurved or meeting at middle; b.) I. aleator Boyle, not recurved and meeting at middle; c.) I. undulatus Gorham, recurved and meeting at middle; d.) I. n. sp. 13; e.) I. distinguendus Lacordaire, Mc = mesocoxa, Ms = mesosternum, $M t=$ metasternum; f.) $I . n . s p \cdot 3$. 
(Fig. 15a); not recurved meeting in a straight line (Fig. 15b); meeting with a series of punctures or undulations (Fig. 15c); meeting as a single tooth (Fig. 15e); meeting with two widespread teeth (Fig. 15d); or meeting with many teeth (Fig. 15f).

The mesosternal line behind the mesocoxa is variable in its structure from species to species. It can be a simple line (Fig. 16a) which is single-sided, a groove (Fig. 16b) which is double-sided, or a groove which is notably deeper on one end and leads into a large pit (Eig. 16c). This pit is most often present at the medial end of this line, but the groove can be deepened at the lateral end (for example, I. n. sp. 13).

Eirst Visible Abdominal sternite

The coxal lines on the first visible abdominal sternite extend posteriorly from the medial side of the metacoxa. They are variable in length from specimen to specimen and are of little use in determining species.

This first visible abdominal sternite can be rounded, broadly rounded or truncate between the metacoxa at the junction with the metasternum.

Male Genitalia

The internal sac of the male genitalia is held inverted within the median lobe (Eig. 17a). During copulation, the internal sac is everted, exposing any microstructure and extending the flagellum (Eig. 17b). The median lobe, internal sac, and flagellum are the true 

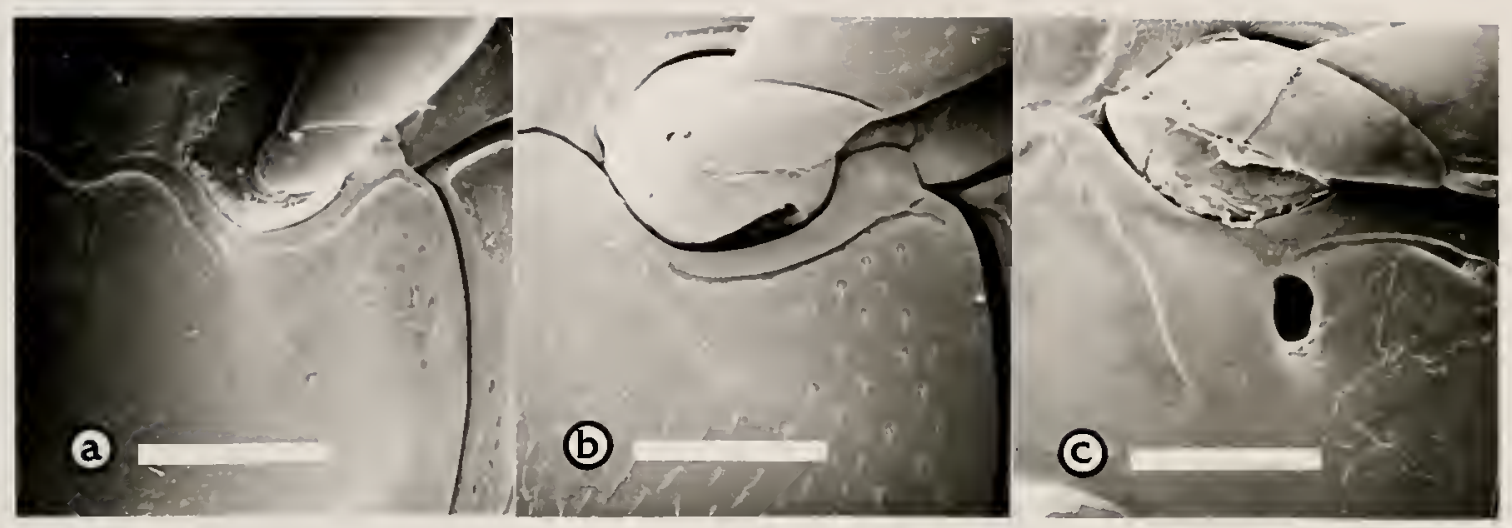

Figure 16. Metasternal line posterior to mesocoxa: a.) simple line on Ischyrus proximus Lacordaire [Mexico, Chiapas], line $=0.75 \mathrm{~mm} ; \mathrm{b}_{\text {.) }}$ groove on Ischyrus $q$. quadripunctatus (Olivier) [USA, Florida] line $=0.38$ $\mathrm{mm}$; c.) groove with pit at medial end on Ischyrus $n$. sp. 3 [Panama], line $=0.28 \mathrm{~mm}$. 


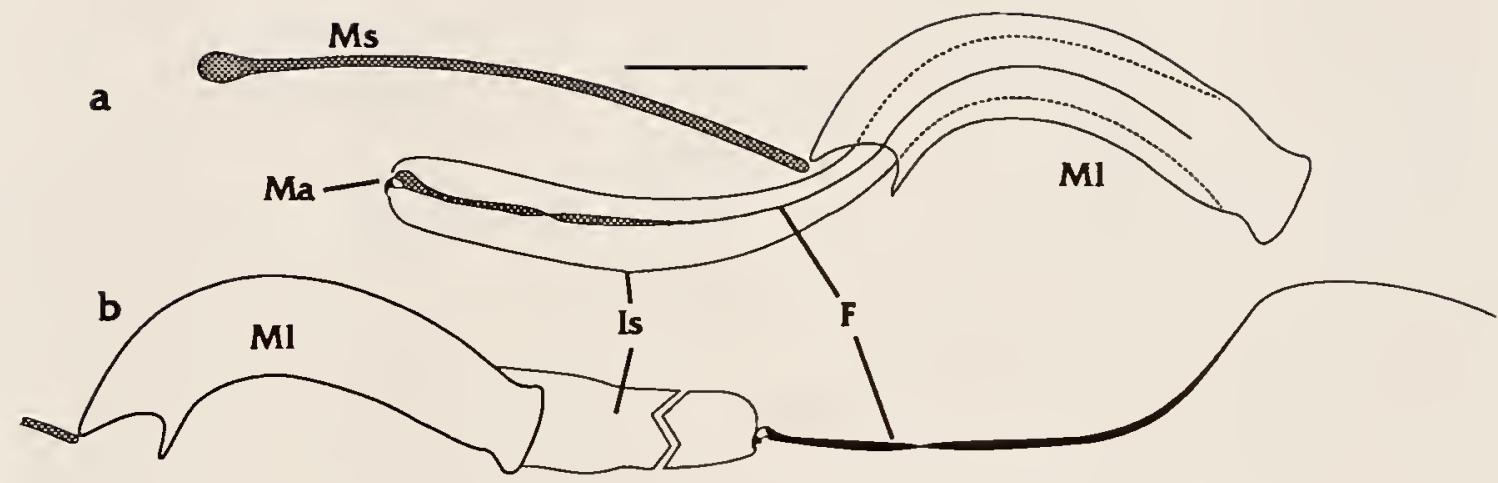

Figure 17. Male genitalia of Ischyrus q. quadripunctatus (Olivier), line $=0.66 \mathrm{~mm}$; a.) internal sac inverted as held within the body; b.) internal sac and flagellum everted as during copulation; $\mathrm{F}=$ flagellum, Is = internal sac, Ma = sclerite for muscle attachment at anterior end of flagellum, MI = medial lobe, $M s$ = median strut. 
intromittent organs and show the majority of species specific characters. For additional insight into the genitalia of Coleoptera, I recommend the following: Lindroth 1957; Sharp and Muir 1912; Skelley 1993; Snodgrass 1957; Tuxen 1970; Verhoeff 1895; Williams 1945; and Wood 1952.

The median lobe is a simple tubular structure that is curved and laterally flattened. The degree of curvature varies from species to species and can be slightly curved to arched. The shape of the median lobe's posterior end varies, and can be truncate, rounded, or narrowed and then rounded.

The internal sac occasionally has pigmented areas, which are patches of microspinules. These can be large lightly pigmented patches of widely scattered microspinules, or small dark paired patches. These patches are known in only a few species.

I found the shape of the sclerite for muscle attachment at the flagellum's base to be important in species recognition. The sclerites are all basically Ushaped, but with many variations. Just posterior to this sclerite is a pigmented section. This section of the flagellum is often variable in shape and curvature. A close study showed it to be flexible, like cartilage. The shape of this structure was not used to distinguish species because it can vary from specimen to specimen. The flagellum is variable throughout the genus: long, 
cylindrical, and hair-like; flattened and ribbon-like; or straight and rigid. The tip of the flagellum can be pointed or flared.

\section{Female Genitalia}

Female genitalia (Fig. 18) varied little from species to species. Structures had proportions which varied, but species recognition based on female genitalia was not possible with any degree of confidence. The sclerotized spermatheca showed some variation in shape which could be useful in studies of higher categories.

The spermatheca consisted of two parts; the head and tail. The head is the large bulbous, terminal structure, which varies in shape from circular to kidney-shape. Many species have spermathecae with a top-knot (bump on the head), variable in size and occasionally in position. The spermatheca tail is a sclerotized section of the duct extending from the spermatheca's head to the genitalia. The shape and thickness of the tail is variable, but similar in related species.

\section{Materials and Methods}

Specimens

Dry preserved specimens were borrowed from many sources (institutions and individuals) during this revision. Appendix $B$ lists these sources with their coden (mostly from Arnett et al., 1993) used throughout this study . 


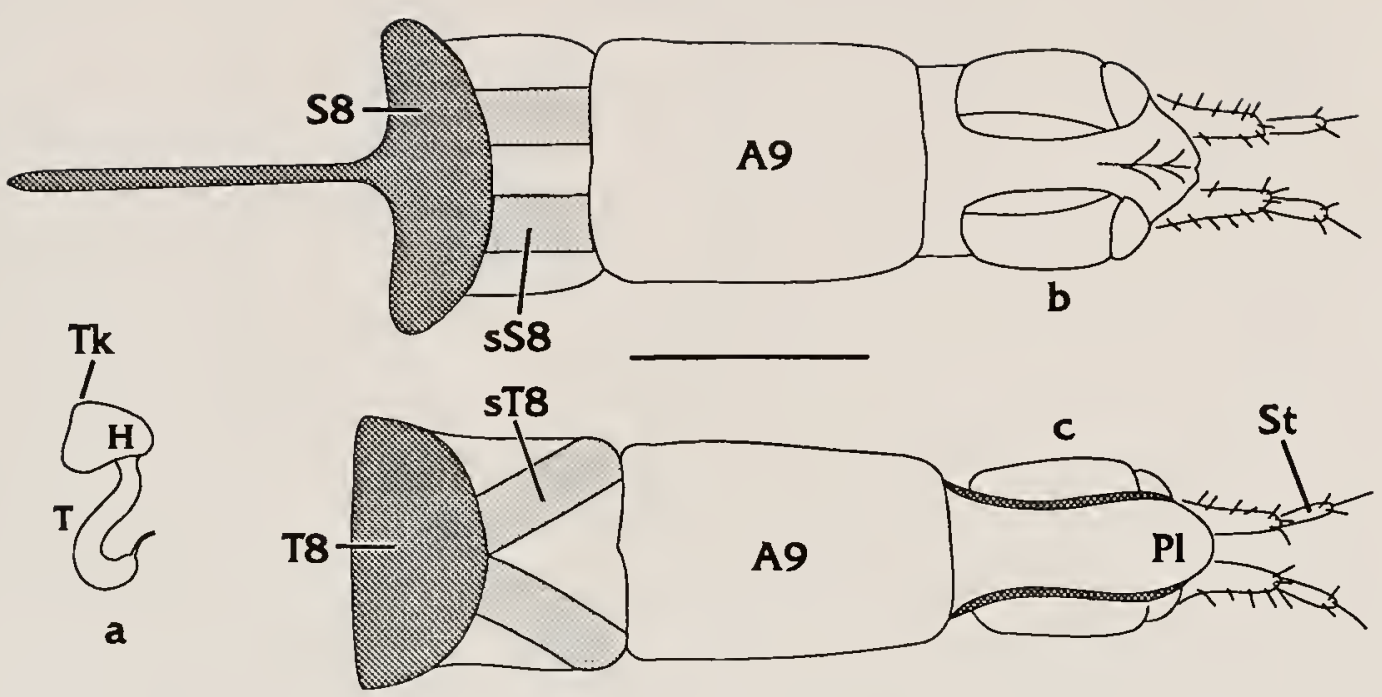

Figure 18. Female genitalia of Ischyrus q. quadripunctatus (Olivier), line $=1.0 \mathrm{~mm}$ : a.) spermatheca; b.) ventral view; c.) dorsal view; $A 9$ = abdominal segment IX, $H=$ head of spermatheca, $\mathrm{Pl}=$ proctigeral lobe, $\mathrm{S} 8=$ abdominal sternum VIII, $s S 8$ = straps appendant to abdominal sternum VIII, $\mathrm{sT} 8$ = straps appendant to abdominal tergum VIII, St $=$ styli, $\mathrm{T} 8=$ abdominal tergum VIII, $\mathrm{T}=$ tail of spermatheca, $\mathrm{Tk}=$ top-knot on spermathecal head. 


\section{Locating Types}

In most taxonomic research the investigators must study material seen by the describer of a species in creating the description. These specimens are the reference point for the name. Many descriptions were poorly done, or lack specific details needed to identify additional specimens. The history of each "type" specimen becomes important in locating it or discovering if it still exists. Modern researchers must record the depository of specimens studied. Early researchers did not always do this. Horn and Kahle (1935-1937) and Sachtleben (1961) stated the location or fate of many collections and can be helpful in locating a specific specimen.

For New World Erotylidae the majority of early type material can be found in three places: the Museum National d'Histoire Naturelle, Paris (MNHN); the Crotch Erotylidae Collection, University of Cambridge, U.K. (CUMZ); and the Natural History Museum, London (NHML).

Many of the nomina nuda in Dejean's catalogs (1836, 1837) and collection, were validated by Lacordaire because he acquired Dejean's Erotylidae (Horn \& Kahle 1935-1937) and used Dejean's names in his descriptions. Horn \& Kahle indicate that Lacordaire's collection was divided and deposited in various European museums. I have been unable to find all of Lacordaire's Erotylidae, but he studied specimens of several other collectors whose material can be 
found in two places: the crotch collection (CUMZ); or the Oberthür collection (MNHN).

Many of Lacordaire's species were described from the Dupont collection. Horn \& Kahle indicate that the Dupont collection was divided with some of the material being deposited in the collections of G. V. Mniszech and R. Oberthür. Nicole Berti at the Museum National d'Histoire Naturelle, Paris (in litt.), stated that the oberthür collection, including the Mniszech collection, is at the MNHN, and that Oberthür indicated on the back of a box that specimens studied by Lacordaire are in the collection of Mniszech. For Ischyrus, the specimens labeled "Type" from this collection matched the original descriptions in both morphology and label data. Most specimens in this collection do not have "Type" labels, but they are potentially type material and should be considered in subsequent type designations for Lacordaire species.

Lacordaire also studied specimens from the collections of L. A. A. Chevrolat and L. J. Rieche. These erotylid collections, and others, were acquired by G. R. Crotch. Crotch's Erotylidae collection, at the Cambridge University Museum of Zoology, is rich in types. In this collection, label data indicate which specimens are types, and often from whose collection they came. The Ischyrus specimens labeled "Type" fit the original descriptions, label data, and collection of origin. 
The Natural History Museum, London, (formerly known as the British Museum of Natural History) houses the specimens studied in the Biologia Centrali-Americana (Gorham 18871899).

Tracking one specimen illustrates that it is not always a simple matter. The type specimen of Ischyrus quadripunctatus (Olivier), the generotype of Ischyrus, was not studied by Boyle (1956) in his family revision of America north of Mexico. Olivier (1791) stated that the specimen was in the collection of M. Francillon. Horn and Kahle (1935-1937) state that the Francillon collection was divided and deposited in the Natural History Museum, London, and the Hope Entomological collections, University of Oxford, U.K. I visited the Natural History Museum and found no specimen which could be the type. The curator of the Hope Entomological Collections, G. C. McGavin, wrote that the majority of their part of the Francilion collection was sent to the (Alexander) MacLeay Museum, Sydney, Australia, in 1818. The curator of the Macleay Museum, D. S. Horning, Jr., wrote that they do have specimens from the Francillon collection, including some from the locality stated in Olivier's description. But, he would be unable to look for the specimen until his recent injury had healed. Thus, I still do not know if the specimen studied by Olivier exists. 


\section{collecting}

Specimens of the genus Ischyrus can be found feeding on their host fungus. Based on the number of specimens known for most species, we still do not know where to look. Most specimens appear to have been haphazardly collected, even those collected in light traps.

No definitive statement can be made about where to look for, or how to collect, members of this genus. I have collected various species of Ischyrus and related genera by using a beating square on dead sticks at night. Sticks, limbs, branches, etc., which produced the most specimens were either still on the tree, or on the ground, but suspended above the surface. The only known hosts are prostrate white fungi which seem to prefer dead suspended branches.

Much work remains to be done in understanding the biology of this genus and the family. (See the Biology section under the Generic Account for additional comments.)

\section{Equipment}

Specimens were studied under a binocular dissection microscope, Unitron ZSB, with a zoom-magnification of $0.7 x^{-}$ $4.5 x$ and $20 x$ ocular lenses. A Hitachi s-570 scanning electron microscope was used. Although useful in seeing and understanding many of the minute characters, it was not an essential part of this study. I made an effort to base species descriptions and key characters on those visible at low magnifications. 
Techniques

Adult specimens often needed to be cleaned before surface structures could be studied. This was accomplished by brushing the specimen with a small soft-bristle brush dipped in ethyl acetate or alcohol. Ethyl acetate was also used to degrease badly soiled specimens. If the mouthparts were badly soiled, the specimen was dipped in warm water to loosen the dirt, and to relax the specimen before brushing the dirt away. On rare occasions specimens were so badly soiled that they were totally relaxed, cleaned, and remounted.

European-style card mounting made it impossible to study the ventral surfaces without removing the specimen from the card. The solvent used to soften the glue depended on what glue was used. The following series of chemicals was used until one dissolved the glue: water, $70 \%$ isopropanol, 80\% ethanol; ethyl acetate. Rarely did the specimen require treatment with all of these, but occasionally a specimen needed to have the glue manually removed.

I dissected many genitalia for further study. Specimens were chosen from across the distributional range of the species and from those showing variation in external characters. Each specimen was put into a weak solution of hot detergent water and allowed to sit from one hour to overnight. Once relaxed, the specimen was carefully held between the thumb and forefinger under the dissecting 
microscope. With a pair of jewelers forceps, the elytra were lifted just enough to slip one side of the forceps underneath and the abdomen was grasped on a side. In this way, the specimen was held and the remainder of the body was not effected by the dissection to follow.

The abdominal tergites (membranous) and underlying muscle masses were separated from the visible sternites on the side not held by the forceps. This was done with a bent-tipped minuten attached to a small wooden toothpick. Once loosened, the forceps were moved to hold only the sternites of the side just separated, and the same operation performed on the second side. After these separations were complete the tergites and underlying muscle masses were removed with a second pair of forceps. This technique allows the visible abdominal sternites to remain attached; the specimen appears intact.

The removed muscle masses containing the genitalia, and terminal segments of the abdomen, were cleaned and cleared in a warm 10\% potassium hydroxide (KOH) solution, and the remaining unwanted tissues were removed manually with forceps. The genitalia were rinsed in $70 \%$ isopropanol or water and stored in glycerin in genitalia vials associated with the appropriate specimen. Genitalia vials are small plastic or glass vials that can be placed under the pinned specimen, with the pin piercing the stopper.

Detailed study of these genitalia rarely required more magnification than the dissecting microscope allowed. The 
genitalia were studied in glycerin, and moved into various positions to see the shape of the muscle attachment at the anterior end of the internal sac. The shapes of this structure and the flagellum were important in solving many of the species problems. When finished, the genitalia were returned to the genitalia vial and pinned under the appropriate specimen.

The "stridulatory files" were not studied for many species since this required removing the head from the body. This type of dissection destroyed the specimen, and I was not willing to sacrifice the few specimens available for most species.

Illustrations were made with the use of a glass-grid insert placed in an ocular of the dissecting microscope. The imposed grid on the specimen was used as reference and the drawing was made on a piece of grid paper. It was necessary to make various adjustment to each of the drawings, because the curvature of the lenses produced distortions. This was most apparent when comparing the finished pencil drawing and the specimen without the aid of the microscope. The drawings were then traced in India ink onto tracing paper with a 000 Koh-i-nor Rapidograph technical pen, scanned into electronic form using a Hewlett Packard Scanjet IIP, finished using CorelDRAW 2.01 (a computer graphics program) on a Unisys 486 personal computer, and printed with an Apple LaserWriter ${ }^{\otimes}$ I. 
Habitus drawings lack legs and antennae for several reasons. First, the legs are of little use in determining species. The antennae need to be illustrated side-by-side for close comparisons. Adding these structures doubles or triples the time to do an illustration. Lastly, by omitting these structures, the habitus drawings can be placed closer together, requiring less space and fewer pages

In plotting distribution maps, many specific localities were not found because of poor label data. If the information was adequate enough find the general area, an open symbol was placed on the map in the general area. Specific localities are shown with solid symbols. If label data were vague and there was already a plotted locality in the general area, an additional symbol was not added. Questionable records are plotted with a question mark "?". Color Pattern Problems

Species level decisions have historically been based simply on color and color patterns. Museum specimens vary in the shades of orange because of age, killing agent, and preservation technique. Because of this, the exact color is of little use in species determination.

The color pattern is most important in determining species, but care must be taken in analyzing differences. The specimen(s) in question must first be placed within the proper section of the genus. This was done by using morphological and genitalic characters. Many recently 
described species were compared to an unrelated species in the original description. This made determinations based on the literature impossible, and the type specimens had to be studied.

A different appearing color pattern did not necessarily mean the specimen was a different species. For example, a species may have two spots on each elytron. When these spots are enlarged, they blend together and form a band. Differences based on changes in pattern due to the spot size generally were not specific.

In other cases, a spot which varied in its location, generally indicated a specific difference. For example, in two closely related species the only color pattern difference is that one species has a humeral spot touching the base and the other has a subhumeral spot well removed from the base. In I. scriptus, I. proximus, I. palliatus, and $I$. incertus, the relative position of the pronotal spots and the shape of the circle they form is useful in determining species.

Written descriptions cannot convey the exact details of these patterns the way an illustration does. Every species and many variations are here illustrated. In some cases the differences are subtle, but they are constant and correlate with other morphological differences. Care should be taken when comparing any specimen to these illustrations because of color pattern variations mentioned above, and ones not yet known. 
Studying series of specimens from a large geographic range has allowed me to observe geographic variations in color patterns that were once considered specific. One such character is the color of the head, which can be red, black, or with some variation of both. In only a few cases has this variation been more than a clinal or subspecific difference.

The term "pattern" was used for variations of a color pattern in situations where previously described species were found to be part of a cline. These "patterns" were maintained because they still had some relation to a geographic range. The "pattern" name is the specific name that once applied to that pattern, or a name was applied if that "pattern" was not previously described. New "pattern" names were applied only if specific names already existed for other patterns (see $I$. quadripunctatus and $I$. scriptus). These named "patterns" have no nomenclatural status.

Another general trend is the change of elytral patterns from north to south. Many species have solid bands with smooth edges in the north; moving south, these edges become more and more sinuate. Some even develop into stripes as the sinuate edges on both sides of the band meet. Many species from mid-South America have striped patterns. In contrast, the majority of northern species have banded patterns. This is best illustrated with I. 
quadripunctatus, I. scriptus, and their variations. This trend may indicate mimetic relationships amoung species. Rules of Thumb

In determining the taxonomic status of various names, and in naming new taxa, several general rules were followed which require some explanation.

Many species are variable in color pattern over their geographic range. This is illustrated in several species where adequate series have been studied. Certain color patterns are known from only a few specimens, often from scattered localities. If two specimens have different, but basically similar color patterns and their morphology (including the genitalia) is similar, they are considered variations of a single species.

In other cases a radical color pattern difference is observed, but the genitalia are incomparable (i.e., male vs. female). These are considered variations of a single species, and are discussed under the most closely related described species, noting the variations and their taxonomic status.

If a previously described species was a member of several patterns in a cline, that name was synonymized under the senior name and discussed in the species account.

Consistent morphological differences correlated with color pattern differences are considered to be specific, and these taxa are described. New species are simply 
numbered, because of problems with nomeclatural priority, and names will be proposed when published.

The lack of series in many species indicates that there is much to be discovered in this genus. Several of the species discussed here may actually represent complexes. Because of inadequate material these problem taxa are left unresolved and are discussed under the appropriate species account.

\section{Results}

The genus Ischyrus is composed of 42 North and Central American species, including 16 previously undescribed; leaving 30 additional described species in South America. A total of 3741 North and Central American specimens was studied (2890 I. quadripunctatus) and 363 were dissected. The 148 figures, key, appendices, and descriptions are provided to complete this revision. 


\section{ISCHYRUS LACORDAIRE}

Ischyrus Lacordaire 1842:89-131.

Micrischyrus Alvarenga 1965:86.

Type species. Erotylus quadripunctatus Olivier 1791:431,437. Subsequent designation by Crotch $1873 \mathrm{a}: 353 ; 1873 \mathrm{~b}: 144$.

Diagnosis. Characterized by having coarsely faceted eyes, triangular mentum, short ocular stria not surpassing anterior angle of eye, undilated tibia, and semicircular or trapezoidal antennomere IX.

Description. Length $3.5-9.9 \mathrm{~mm}$. Body shape parallel-sided, to elongate, or ovoid, slightly flattened to convex dorsally; microreticulation, surface dull to shining; unicolorous brown to variously banded or spotted, yelloworange with black pattern.

Head with ocular striae generally ending at or before anterior angle of eye, rarely extending onto epistome at base of antenna; frons often with an impression at each side near base of antennae; epistome wedge-shaped, generally with truncate apex; epistome punctures generally denser than punctures on vertex. Eye large, bulging from side; facets coarse (Fig. 1a), varying in size throughout the genus, rarely fine. 
Antenna surpassing middle of pronotum, often reaching basal 0.25; antennomere I large, elongate; antennomere II circular, ball-like, length $=0.5 \mathrm{x}$ antennomere $\mathrm{I}$; antennomere III elongate, length equal to next 2 to 4 segments combined; antennomeres IV to VIII length subequal to width, length rarely more than $1.5 \mathrm{x}$ width; antennomeres IV to VII rounded at ends; antennomere VIII edged and angled apically; antennomeres IX to XI form a loose club; antennomeres IX to X 3 to $4 \times$ wider and 1.5 to $2 \times$ longer than antennomere VIII; antennomere IX semicircular to trapezoidal, rarely triangular (Fig. 6); antennomere $\mathrm{x}$ crescent-shaped to trapezoidal; antennomere XI transversely elongate-oval to circular; antennomeres X-XI often asymmetrical.

Mandibles each with two finger-like teeth and a large prostheca bearing many inwardly pointing setae. Maxilla with lacinia bearing an apical tooth, often bifid (Fig. 19b); terminal segment of palp triangular or securiform, width $=1$ to $3 \mathrm{x}$ length. Labial palpi vary from squared or circular to securiform, width $=1$ to $2 \times$ length (Fig. 7). Mentum with a pore on each side in front of basal corner; mental plate triangular, rarely longer than wide; ridge surrounding plate often raised laterally giving mentum a three prong crown-shape, medial prong (medial ridge extension) variously shaped, protruding or not (Figs. 8, 19a). Postmandibular lobes present, broadly rounded, 


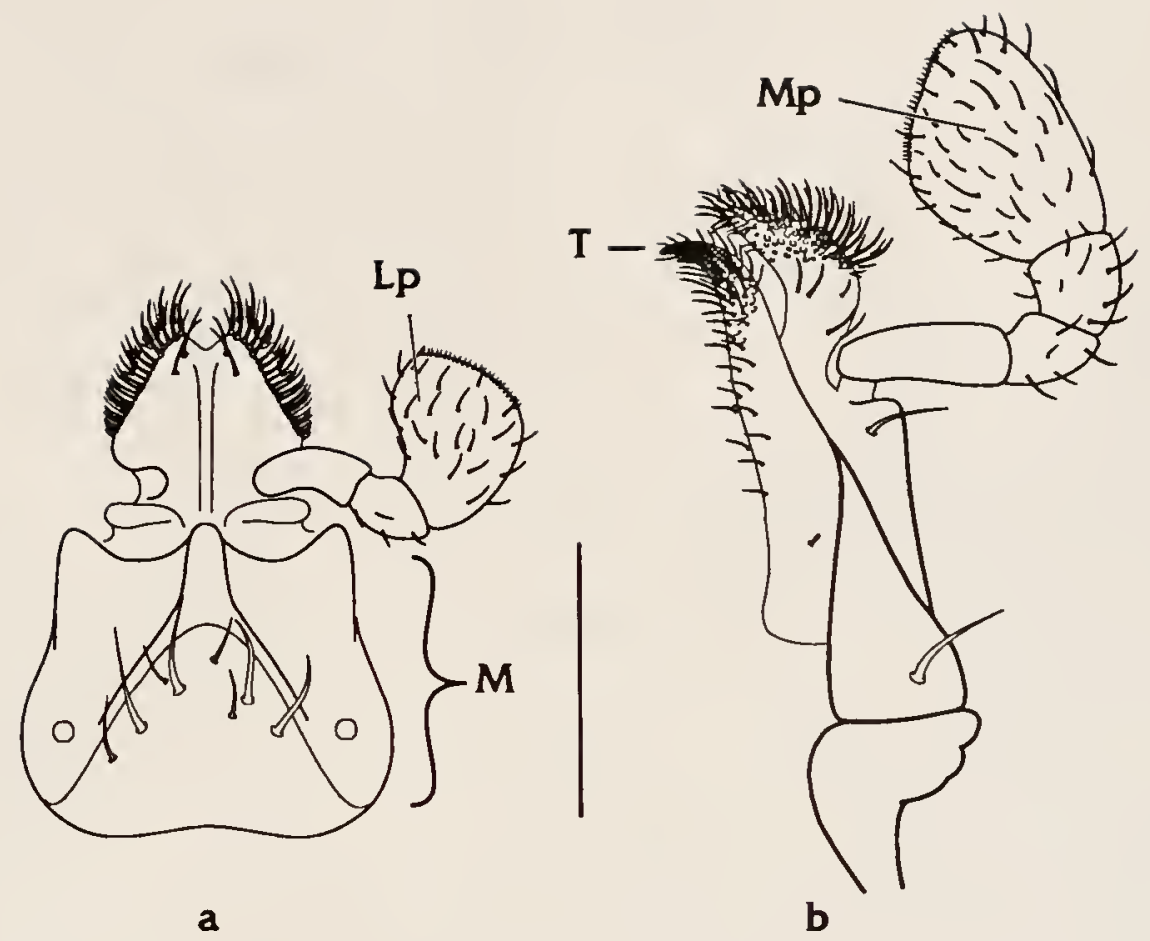

Figure 19. Ischyrus q. quadripunctatus (Olivier) a.) labium and b.) left maxilla ventral view, line $=0.25 \mathrm{~mm}: \mathrm{M}=$ mentum, $\mathrm{Lp}=$ labial palp, $\mathrm{Mp}=$ maxillary palp, $\mathrm{T}=$ bifid tooth of lacinia. 


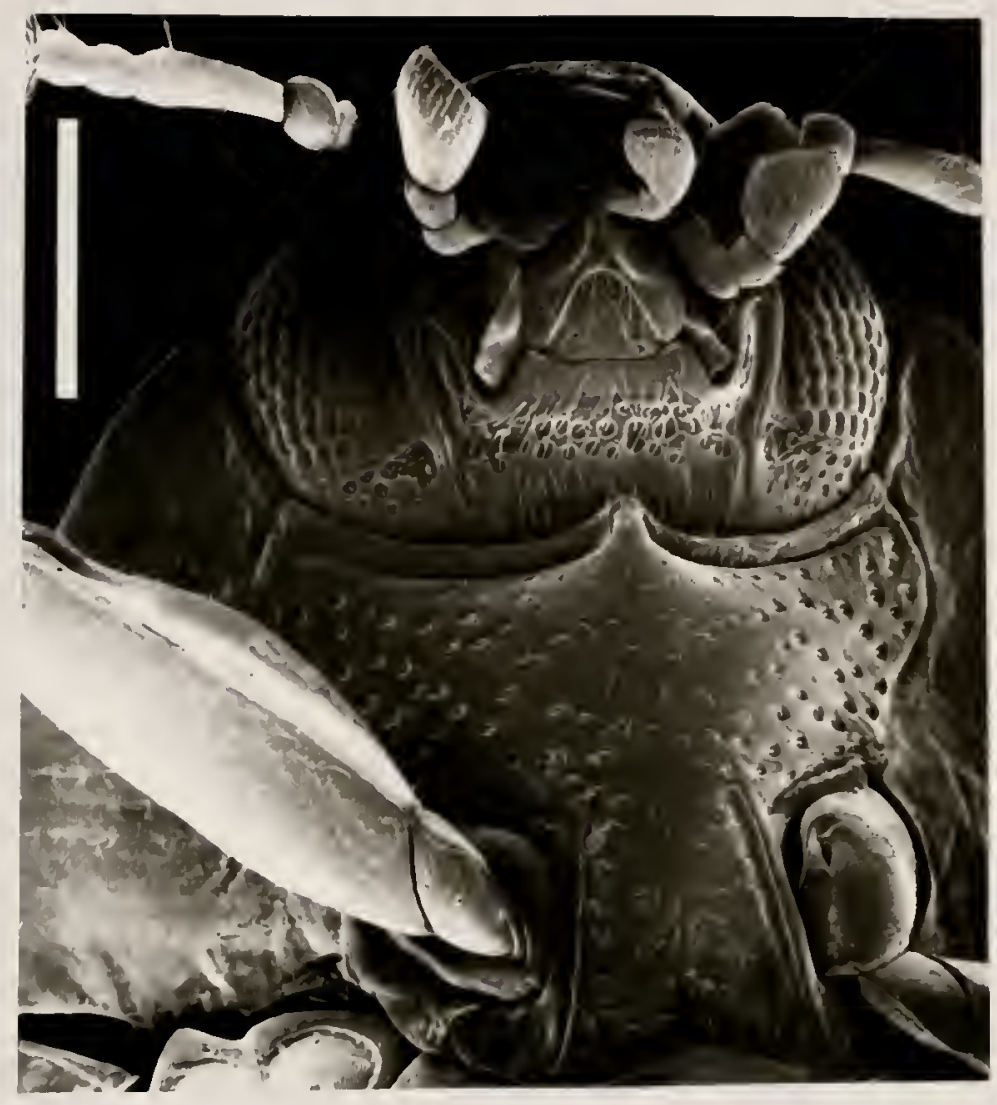

Figure 20. Ventral view Ischyrus q. quadripunctatus (Olivier) [USA, Elorida] head and prosternum, line= $0.50 \mathrm{~mm}$. 
forming inner side of groove next to the eye for reception of antennomeres II to III (Fig. 20).

Pronotal disc evenly rounded; sides variably arched inwardly toward eyes; anterior angles closer together than posterior angles; anterior edge not margined between eyes; anterior angles forwardly produced, making anterior edge concave; base sinuate, not margined, lobed at middle, with group of large punctures at each side. Scutellum pentagonal, wider than long.

Elytra with sides parabolically rounded to apex; 7 to 9 stria evident by rows of punctures, lacking at humerus and extreme apex, rarely impressed or missing; intervals flattened, often with minute punctures; base rarely margined; elytral epipleuron widest at base, strongly narrowed at hind coxae, gradually folding under to apex (Fig. 9); some elytral punctures each with a small protruding seta, visible in profile.

Prosternum usually keeled, margined and constricted (pinched) at front (Figs. 10, 20); sternal plate shape and proportions variable (Fig. 11); lines anteriorly converging or parallel, rarely surpassing front of procoxa, lines not continuous around coxae (except n. sp. 1); posteriorly prosternum truncate or slightly concave, not margined.

Mesosternal lines parallel or anteriorly divergent, straight or arched; plate square or transversely rectangular; posteriorly sinuate or truncate. 
Metasternal lines extending onto disc from inside of mesocoxa toward posterior angle of metasternum, rarely continuous around mesocoxae; variable in length, up to 0.5 distance to posterior angle; line behind mesocoxae variably impressed or grooved, occasionally with pit (Fig. 16).

Legs with femora slightly swollen, complete margin on inner surface (Fig. 21); tibia straight, almost parallelsided, slightly widened toward apex; tarsi pseudotetramerous.

Abdominal coxal lines present, short; rarely continuous around metacoxae.

Male genitalia with median strut length variable, equal to or larger than median lobe; internal sac can bear patches of spinules; flagellum varying in length and thickness, with sclerotized muscle attachment at base, non-slerotized section at base flexible; lateral lobes of tegmen generally flattened.

Female genitalia with straps appendant to abdominal segment VIII; abdominal segment IX elastic, length variable; flattened plate-like proctigeral lobe; apical segment of coxite with slender styli (Eig. 18). Proportions of these stuctures vary little throughout the genus. Spermatheca sclerotized, shape of head and tail variable, occasionally with a top-knot (Fig. 18).

Stridulatory files often present at the base of the head (Fig. 22) 


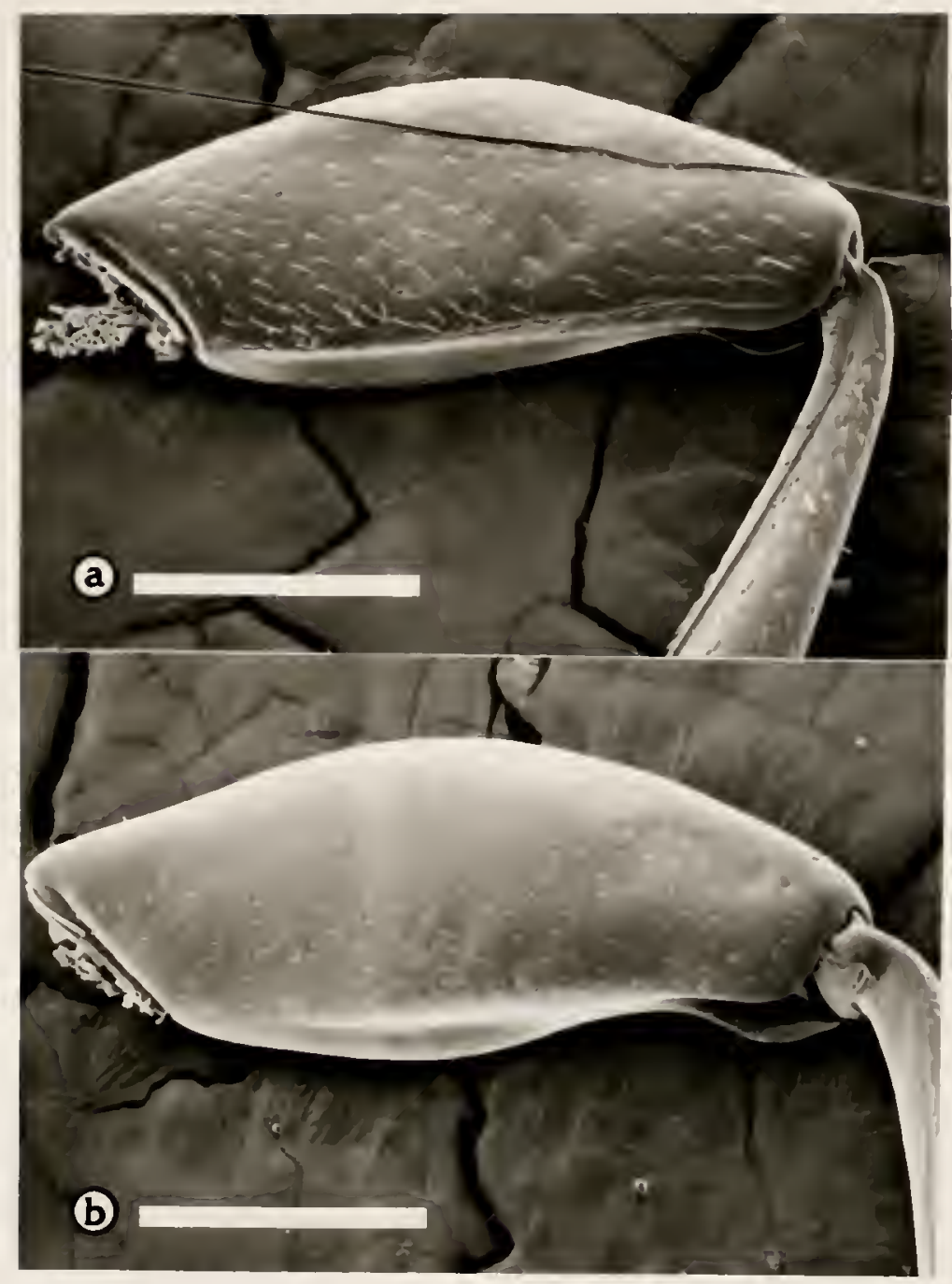

Figure 21. Ventral view of meso-femur: a.) Ischyrus $q$. quadripunctatus (Olivier) [USA, Florida] with posterior margin, line $=0.50 \mathrm{~mm}$; b.) Oocyanus flavitarsis

(Lacordaire) [Cuba] lacking posterior margin, line = $0.60 \mathrm{~mm}$. 


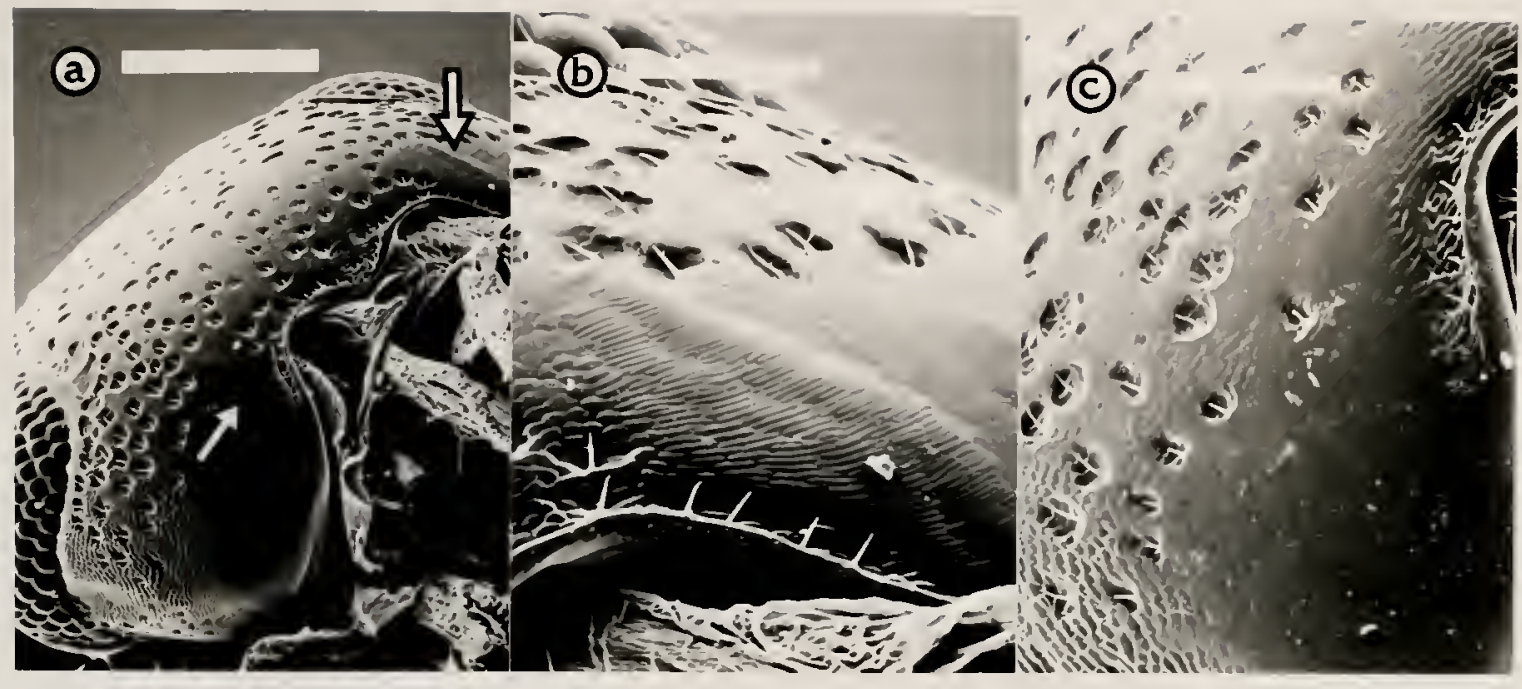

Figure 22. Ischyrus q. quadripunctatus (Olivier) [USA, Florida] occipital region of head showing stridulatory file (arrow): male with stridulatory file, a.) line = $0.38 \mathrm{~mm}, \mathrm{~b}$.$) line =0.08 \mathrm{~mm} ; \mathrm{c}$. ) female lacking stridulatory file, line $=0.15 \mathrm{~mm}$. 
Sexual dimorphism often present. Males of some species have the prosternum laterally expanded onto the pronotal epipleuron; not expanded in females (Figs. 13-14). Males of many species have fewer, or less distinct, punctures on the prosternum in front of the procoxae (Eigs. 12-14).

Distribution. This genus is restricted to the New World, where it is widespread, occurring from southeastern Canada near the St. Lawrence Seaway and southeastern North Dakota through the eastern U.S. and southern Arizona, Mexico, Central America, the West Indies, into South America to northern Argentina.

Biology. The life history of this genus is basically unknown. Only one species has its larva described; the type species I. q. quadripunctatus (Olivier) (see Weiss 1920, Skelley 1988b, Chapuis \& Candeze 1855, Chapuis 1876). The following is based on published accounts of this species, a few bits of information taken from label data, and personal communications and observations.

The larva of I. q. quadripunctatus has well developed dorsal sclerotization with short spines. It is unusual in that the pronotal sclerotized area is broken into parts appearing like false eyes (Fig. 23). Members of a related genus, Oocyanus Hope, have a similar set of "eye-spots". This peculiarity could be of adaptive significance in warding off predators. Both of these larvae have been found feeding exposed on prostrate white fungus growing on dead wood (personal observations). Other larvae of the 

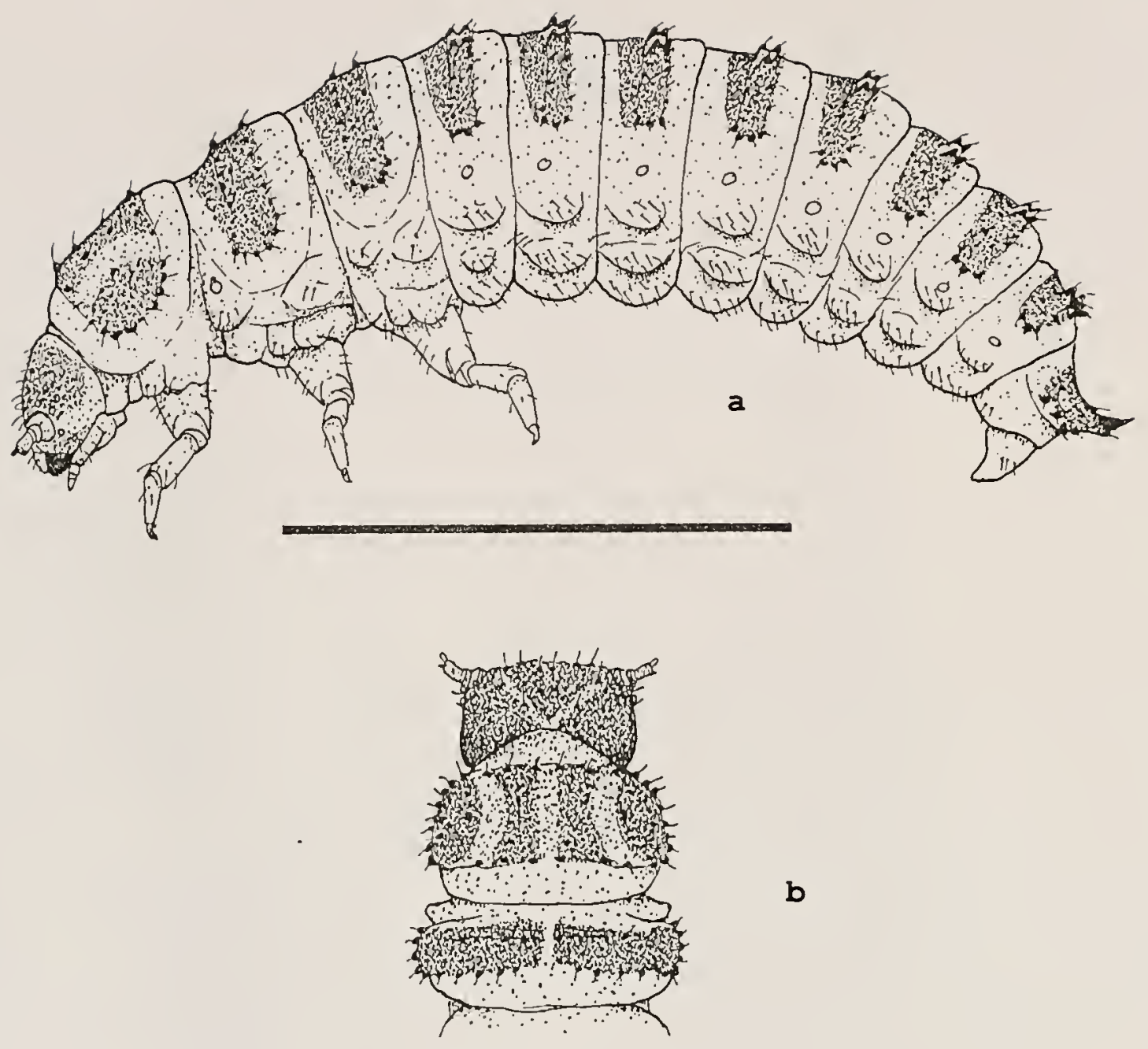

Figure 23. Ischyrus q. quadripunctatus (Olivier) larva [USA, Florida], line $=4.0 \mathrm{~mm}$; a.) lateral view; b.) dorsal view of head and thorax. 
Erotylidae are burrowers in fungi (some Triplacinae, Dacninae) or are surface feeders (some Erotylinae). The surface feeding Erotylinae are often protected by a covering of large spines and often have color patterns; whereas burrowing species lack these spines and patterns (see Roberts 1958; Costa, et al. 1988; and Lawrence 1991, for illustrations of various erotylid larvae).

Ischyrus q. quadripunctatus has been collected on a white resupinate polypore fungus, oxyporus latemarginatus (Dur. \& Mont. ex. Mont.) Donk, also known as Poria ambigua Bres. (Skelley, et al. 1991). Richard Leschen (pers. comm.) collected I. proximus on Schizopora paradoxa (Er.) Donk in Costa Rica, also a white resupinate polypore. Both of these fungi are white rot fungi of wood.

Adults have been taken by general collecting methods; in leaf litter, under bark, sweeping vegetation, etc. Many specimens have been taken at light, suggesting nocturnal activity. This is also indicated by the large eye facets present in members of this genus. Using a beating square at night, I collected several species of Ischyrus and other related genera on small dead limbs both on the ground and hanging from the trees.

Several species have pits on one of the thoracic sternites, for example; I. undulatus and I. n. sp. 3 on the metasternum behind the mesocoxa, and $I . n . s p .1$ on the prosternum. These pits occur on both sexes of the species and show no sexual dimorphism in their development. Their 
function is not known, but they could be used for structural support, muscle attachment, areas for glandular secretion, or mycangia (Crowson 1981).

Etymology. Ischyros: Greek for strong, mighty, excessive (Brown 1985). Possibly named in reference to the strongly clubbed antennae or pronounced color patterns. Gemminger and Harold (1876) indicated that the name Ischyrus means "validus".

Remarks. Although Boyle (1956:110) stated that Ischyrus lacks teeth on the lacinia; this is incorrect. The tooth illustrated (Fig. 19) is located in a dense patch of setae and is difficult to see.

Ischyrus Lacordaire appears most closely related to Megischyrus Crotch, Callischyrus Crotch, and Oocyanus Hope in having a triangular mentum, loose antennal club, strongly microreticulate body surface, and in basic color patterns.

Ischyrus differs from oocyanus in having the femora margined along the inner side where the tibiae meet the femora (Fig. 2la); this margin is lacking in Oocyanus (Fig. 21b). Callischyrus differs from Ischyrus in having the eyes finely faceted and the ocular stria surpassing the antennal base; in Ischyrus the eyes are coarsely faceted and the ocular stria at most touch the antennal base. Megischyrus differs from Ischyrus in having a larger body size (greater than $11 \mathrm{~mm}$ ) and in having antennomere IX triangular (Figs. 6n-0); in Ischyrus the body size is smaller (less than 10 
mm) and antennomere IX is semicircular or trapezoidal, rarely triangular.

References. Alvarenga 1965:85; Arnett 1963:817-821;

1985:341-342; Blackwelder 1945:465; Boyle 1956:132-137,128;

Chapuis 1876:35-38; Crotch 1873a:353-354; 1873b:144;

1876:426-433(50-57); Curran 1944:1-5; Edwards 1949:94;

Gemminger \& Harold 1876:3690-3691; Germar 1843:133; Girard 1873:820; Gorham 1887:39-45; Kuhnt 1909:55,57,61-64;

1911:42-44; Lacordaire 1842:89-131; LeConte \& Horn 1883:124; Leschen 1991:180, 192; Mader 1942:171,195-196; 1951:209-210; Neave 1939-1940:790; Pallister 1955a:4; 1955b:6-7; Seidlitz 1891:288; Skelley 1988b:60. 


\section{ARTIFICIAL KEY TO SPECIES}

This key was built using characters visible under low magnification, without dissection. Several species appear in the key more than once, beacuse some characters are variable or have an intermediate state on some species. Couplet 3 is the best example of a character that can be difficult to interpret. If a specimens does not adequately key, or does not match what it does key to, then try the other choice in the couplet.

1. Antennomere IX triangular, sides straight, as long or longer than wide (Figs. $6 \mathrm{k}, 6 \mathrm{n}-0$ ); body convex dorsally

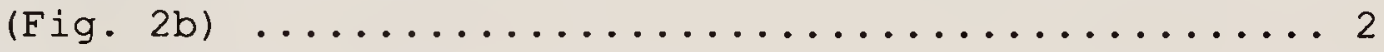

1'. Antennomere IX trapezoidal to semicircular, sides angled or rounded, generally wider than long (Eigs. 6a-j, 61m); body parallel-sided, elongate or ovoid; flattened above $($ Eig. 2) $\ldots \ldots \ldots \ldots \ldots \ldots \ldots \ldots \ldots \ldots \ldots \ldots \ldots \ldots \ldots \ldots$

2. (1) Pronotum with 2 free spots (Eig. 24). . . . . . . . ....................... vespertilio Lacordaire 2'. Pronotum with central stripe (Fig. 25). ......n. sp. 1

3. (1') Antennal club segments distinctly asymmetrical; antennomere XI larger (wider or longer) than antennomere $\mathrm{x}(\mathrm{Fig} \cdot 6 \mathrm{a}-\mathrm{f}) \ldots \ldots \ldots \ldots \ldots \ldots \ldots \ldots$ 3'. Antennal club segments symmetrical; antennomere XI size variable; if appearing asymmetrical, antennomere XI 

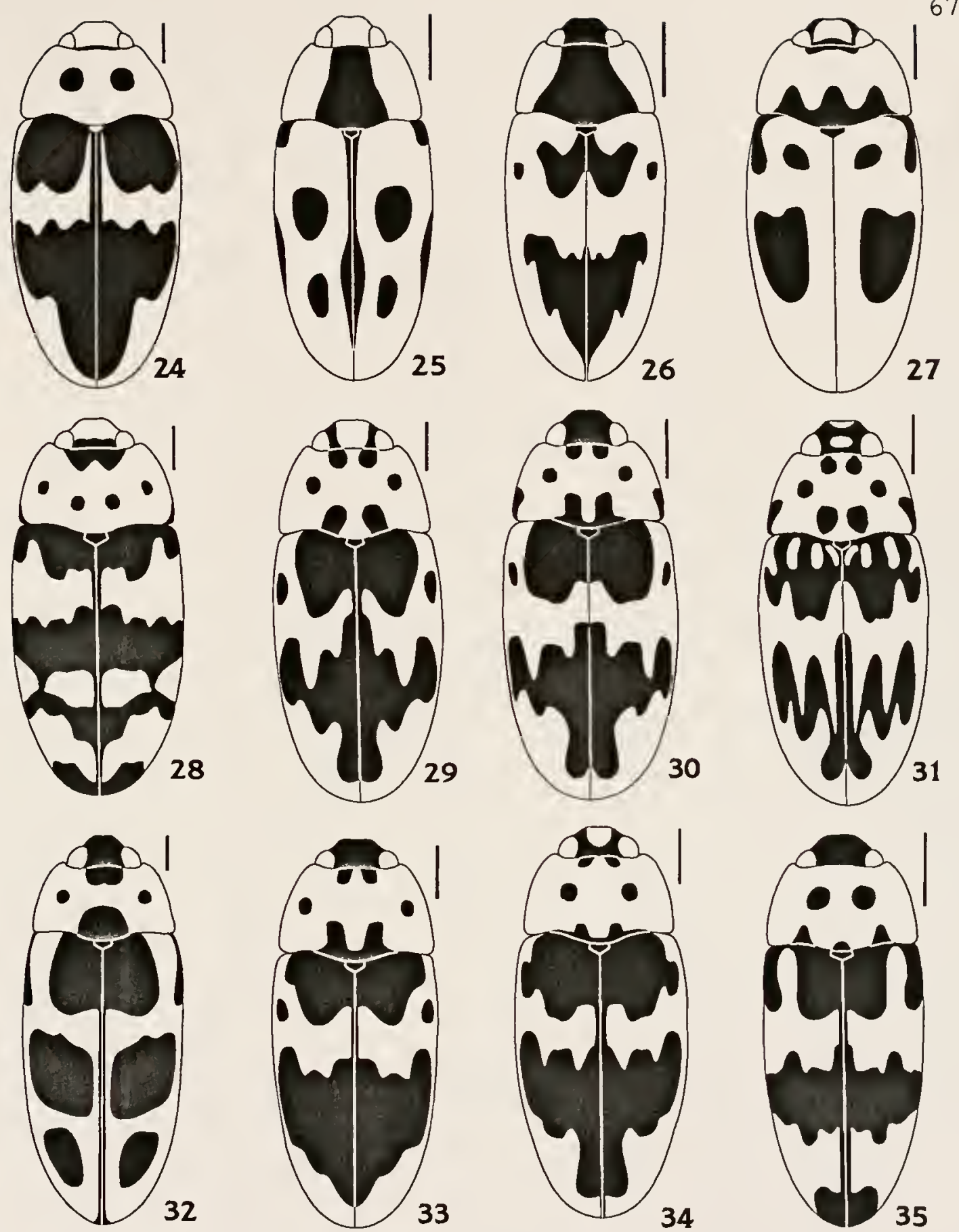

Figures 24-35. Dorsal habitus, line $=1.0 \mathrm{~mm}: 24$.

Ischyrus vespertilio Lacordaire; 25.) I. n. sp. 1; 26.) I. n. sp. 2; 27.) I. distinguendus Lacordaire; 28.) I. insolens Crotch; 29.) I. scriptus (Olivier) "northern"; 30-31.) I. scriptus "southern"; 32.) I. bogotae Crotch; 33.) I. incertus Lacordaire; 34.) I. proximus Lacordaire; 35.) I. angularis Lacordaire. 
equal in size or smaller than antennomere $x$ (Fig. 6g-

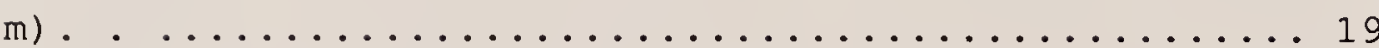

4. (3) Pronotum without free spots ............... 5 4'. Pronotum with free spots $\ldots \ldots \ldots \ldots \ldots \ldots \ldots \ldots$

5. (4) Pronotum with a central black stripe and red sides, no basal spots (Eig. 26). . ............... sp. 2 5'. Pronotum red with three basal spots only (Fig. 27). . . .................. distinguendus Lacordaire

6. (4') Pronotal hind angles with a dark marking, black of lateral margin encroaches upon the side $\ldots \ldots \ldots \ldots .7$ 6'. Pronotal hind angles without distinct dark markings .. 8

7. (6) Pronotum with 4 free spots in a transverse arc; 2 central spots well separated from the base (Fig. 28). . insolens Crotch

7'. Pronotum with 2 basal, 2 central, and 2 anterior spots forming a circle; 2 central spots close to or connected with the base (Figs. 29-31) ...... scriptus (Olivier)

8. (6') Pronotum with 2 free spots; 2 basal spots rarely free or weakly touching margin; if appearing free, then spots separated from base by less than their diameter

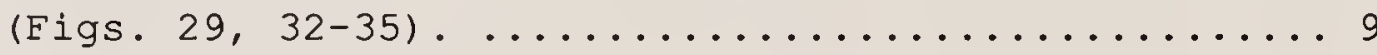

8'. Pronotum with 3-4 free spots; if 4, then central spots separated from base by more than their diameter (Figs. $37-47)$. . . . . . . . . . . . . . . 14

9. (8) Pronotum with spots on anterior margin. . ....... 10 9'. Pronotum without spots on anterior margin ........ 13 

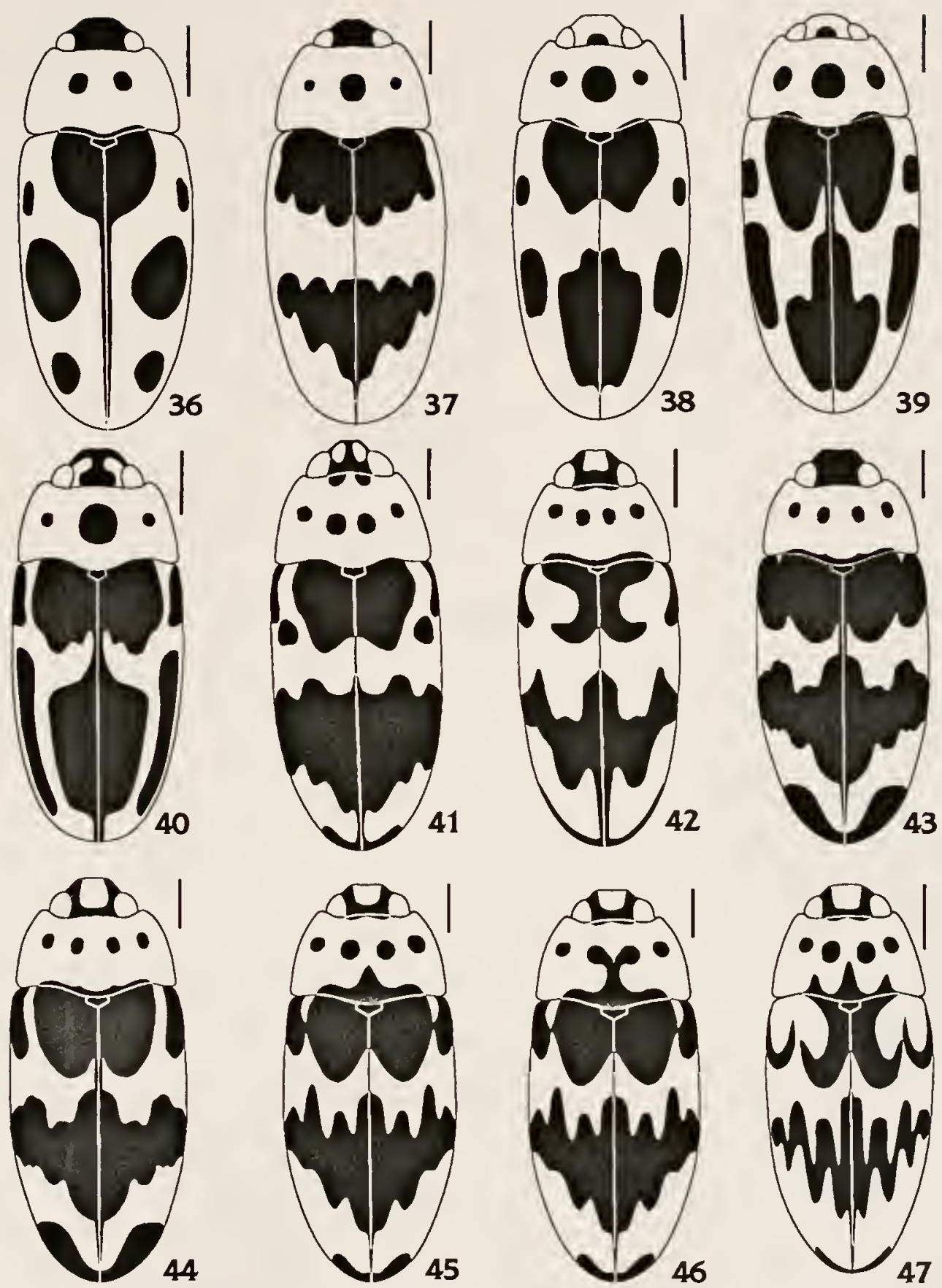

Eigures 36-47. Dorsal habitus, line $=1.0 \mathrm{~mm}: 36$.$) Ischyrus$ septemsignatus Gorham; 37.) I. tripunctatus Crotch; 38.) I. frontalis Lacordaire; 39.) I. frontalis var.; 40.) I. dunedinensis Blatchley; 41.) I. boucardi Crotch; 42.) I. quadripunctatus chiasticus Boyle; 4347.) I. quadripunctatus quadripunctatus (Olivier); 43.) I. q. q. "quadripunctatus"; 44.) I. q. q. "graphicus"; 45.) I. q. q. "subcyindricus"; 46.) I. q. q. "Antillean"; 47.) I. q. q. "banded-leg". 
10. (9) Pronotum with 1 large basal spot (Fig. 32).

bogotae Crotch

$10^{\prime}$. Pronotum with 2 basal spots .................. 11

11. (10') Antennomere XI equal in size to antennomere X (Fig. 61); femur black; elytra with weak microreticulation, strongly shining; pronotal spots forming a transversely elongate ellipse (Fig. 33) ....... incertus Lacordaire

11'. Antennomere XI larger than antennomere X (Fig. 6C); femur red or black; elytra with dulling microreticulations; pronotal spots forming a circle, longitudinally elongate circle, or rarely a weak transverse ellipse (Figs. 29-31, 34) ......... 12

12. (11') Femur red with dark knee; humeral spot free from scutellar spot; elytral epipleural fold black, occasionally pale in teneral specimens; pronotal spots form a circle or weakly transversely elongate ellipse

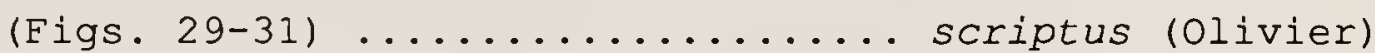

12'. Femur and scutellum black; humeral spot connected to scutellar spot; elytral epipleural fold red, at least at base, rarely dark; pronotal spots forming a longitudinally elongate ellipse (Fig. 34)..........

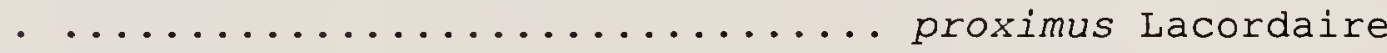

13. (9') Elytra with central band and apical spots connected to suture (Fig. 35) ........... angularis Lacordaire 13'. Elytra with central band and apical spots not reaching the edge (Fig. 36) ........... septemsignatus Gorham

14. (8') Pronotum with 3 free spots ............... 15 
14'. Pronotum with 4 free spots ................ 17

15. (14) Central elytral band broken into spots ........ 16 15'. Central elytral band complete (Fig. 37).

. . .................... tripunctatus Crotch

16. (15) Lateral spot of elytra small, circular; Central America (Figs. 38-39). ........ frontalis Lacordaire

16'. Lateral spot of elytra elongate, stripe-like; USA, Florida (Fig. 40). . . . . dunedinensis Blatchley

17. (14') Maxillary palps narrow (Fig. 7f), longer than wide. quadripunctatus (Olivier). .18

17'. Maxillary palps wide (Fig. 7c), wider than long; (Fig. 41) boucardi crotch

18. (17) Scutellar spots form an X-shaped mark; narrow band of black at base of pronotum (Fig. 42). . .............. quadripunctatus chiasticus Boyle 18'. Scutellar spots not $X$-shaped, or if $X$-shaped then base of pronotum with prominent tooth-like spots (Figs. 4347) . ..... quadripunctatus quadripunctatus (Olivier)

19. (3') Metasternal line behind mesocoxa impressed with a distinct pit near middle (Figs. 15c, 15f, 16c); epistome angled at side, flat and sharp in profile; face flat, usually lacking impressions; body

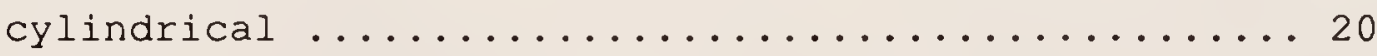

19'. Metasternal line behind mesocoxa without pit, often impressed (Figs. 15a-b, 15d-e, 16a-b); epistome angled or not, often thickened at apex and rounded in profile; face often with impressions; body often flattened .. 21 
20. (19) Pronotum with 2 basal spots and a central stripe connecting the base and anterior margin (Fig. 48). . .

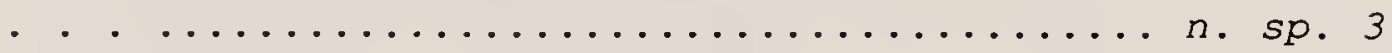

20'. Pronotum without a central stripe, 4 free spots (Fig. $49)$. $\ldots \ldots \ldots \ldots \ldots \ldots \ldots \ldots$ undulatus Gorham

21.(19') Color pattern lacking, uniformly colored, often paler at lateral margins. . .............. 22

$21^{\prime}$. With distinct color pattern ................ 25

22. (21) Body with metallic blue sheen; strial punctures present only at base and along sutural margin; Cuba

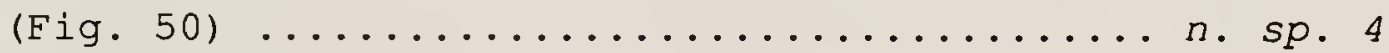

22'. Body without metallic sheen; strial punctures present over entire elytral disc ................. 23

23. (22') Prosternum 2-3 times longer than the distance between the procoxae (Fig. 11b); labial palps not expanded, squared or rounded (Fig. $7 \mathrm{k}$ ) $\ldots \ldots \ldots 24$

$23^{\prime}$. Prosternum at most 1.5 times longer than the distance between the procoxae; labial palps expanded, securiform (Eig. 7j); (Fig. 51) .................... sp. 5

24. (23) Pronotal punctures distinctly larger laterally; shiny black; parabolically rounded at sides (Fig. 52) . . ............................. sp. 6

24'. Pronotal punctures same size throughout; dull brown; parallel-sided (Fig. 53) . ................ sp. 7 25. (21') Pronotum without free spots ............. 26 25'. Pronotum with free spots $\ldots \ldots \ldots \ldots \ldots \ldots \ldots \ldots \ldots \ldots \ldots \ldots \ldots$ 

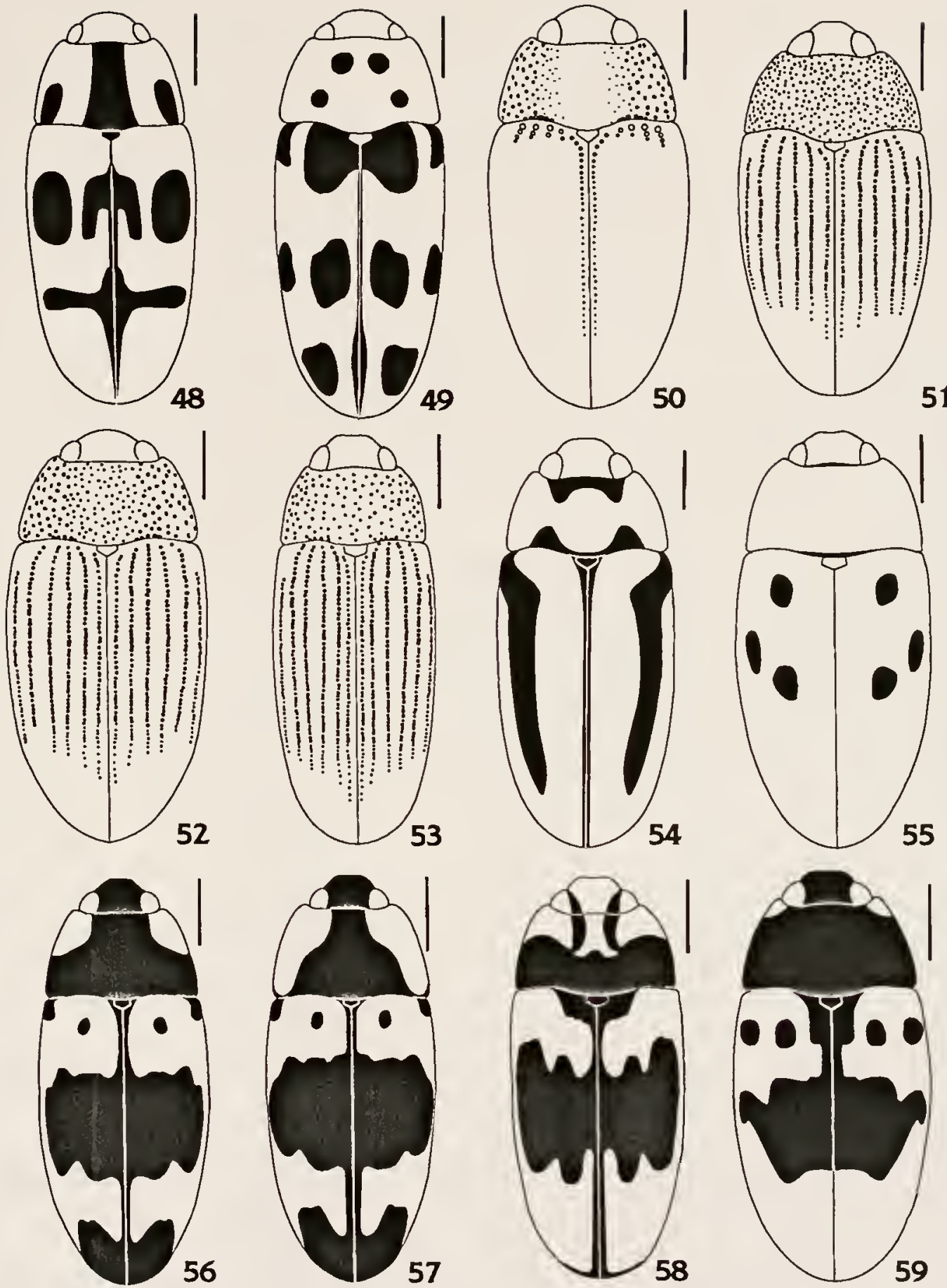

Eigures 48-59. Dorsal habitus, line $=1.0 \mathrm{~mm}: 48$.

Ischyrus n. sp. 3; 49.) I. undulatus Gorham; 50.) I. n. sp. 4; 51.) I. n. sp. 5; 52.) I. n. sp. 6; 53.) I. n. sp. 7; 54.) I. aleator Boyle; 55.) I. n. sp. 8;

56.) I. auriculatus Lacordaire; 57.) I. auriculatus var.; 58.) I. ephippiatus Gorham; 59.) I. n. sp. 9. 
26. (25) Prosternum not strongly constricted at anterior margin, not produced in profile, not pinched (Fig. 10a)

26'. Prosternum strongly constricted at anterior margin, produced in profile, pinched (Fig. 10c-f). ......30

27. (26) Each elytron with 1 central stripe-like spot (Fig.

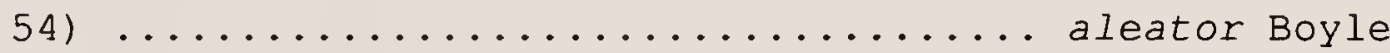

$27^{\prime}$. Elytra banded or spotted ................... 28

28. (27') Pronotum entirely pale, elytra with small spots

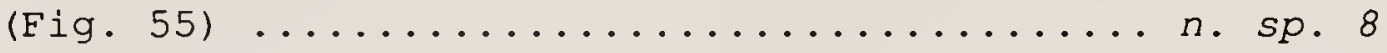

28'. Pronotum black or with black markings, elytral marking

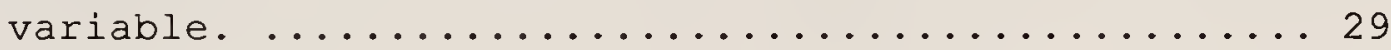

29. (28') Elytra with distinct free spots, not banded (Fig. 25); metasternal coxal lines continuous behind mesocoxae; line behind mesocoxa not impressed; prosternal line in front of coxa a pit-like groove (Fig. $9 b) \ldots \ldots \ldots \ldots \ldots \ldots \ldots \ldots \ldots \ldots \ldots \ldots \ldots \ldots \ldots \ldots \ldots$

29'. Elytra distinctly banded (Figs. 56-57); metasternal coxal lines not continuous behind mesocoxae, long; line behind mesocoxa impressed, groove-like; prosternal line in front of coxa simply impressed.

\section{auriculatus Lacordaire}

30. (26') Body stout, rounded laterally; pronotum entirely black, or with anterior angles pale; each elytron with a free basal spot $\ldots \ldots \ldots \ldots \ldots \ldots \ldots \ldots \ldots \ldots \ldots \ldots \ldots \ldots \ldots$

30'. Body parallel-sided, elongate; pronotum with pale anterior angles and often with central red markings; 
elytra lacking free basal spots (Fig. 58)

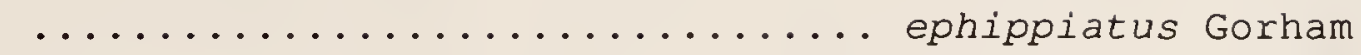
31. (30) Free scutellar and humeral spots in transverse line, central elytral fascia not extended to apical quarter (Fig. 59) . . ....................... sp. 9

31'. Free humeral spot located behind free scutellar spot; central elytral fascia reaching apical quarter (Fig.

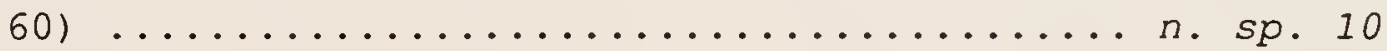

32. (25') Pronotum with 2 free spots and three basal spots (1 band-like free spot in collatinus), 3 basal spots not including possible posterior angle spots ........33

32'. Pronotum with 2 or more free spots, possibly with three basal spots, but not with the above combination ... 37

33. (32) Pronotal hind angle with a spot or widening in the black margin; often with 2 weak black spots at anterior margin of pronotum (Eig. 61) .............. sp. 11

33'. Pronotal hind angle without spot, lacking spots at pronotal anterior margin .............. 34

34.(33') Two free pronotal spots circular; scutellar spot often broadly connected to elytral base ......... 35

34'. Free pronotal spot(s) transversely elongate, rectangular; scutellar spot not connected to elytral

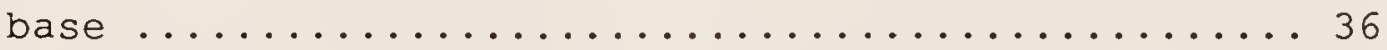

35. (34) Apical elytral spot free; central band not reaching lateral margin (Figs. 62-63) ........ pictus Gorham 35'. Apical elytral spot broadly connected to suture and apex; central band complete, reaching lateral margin (Fig. 35) . . ............. angularis Lacordaire 

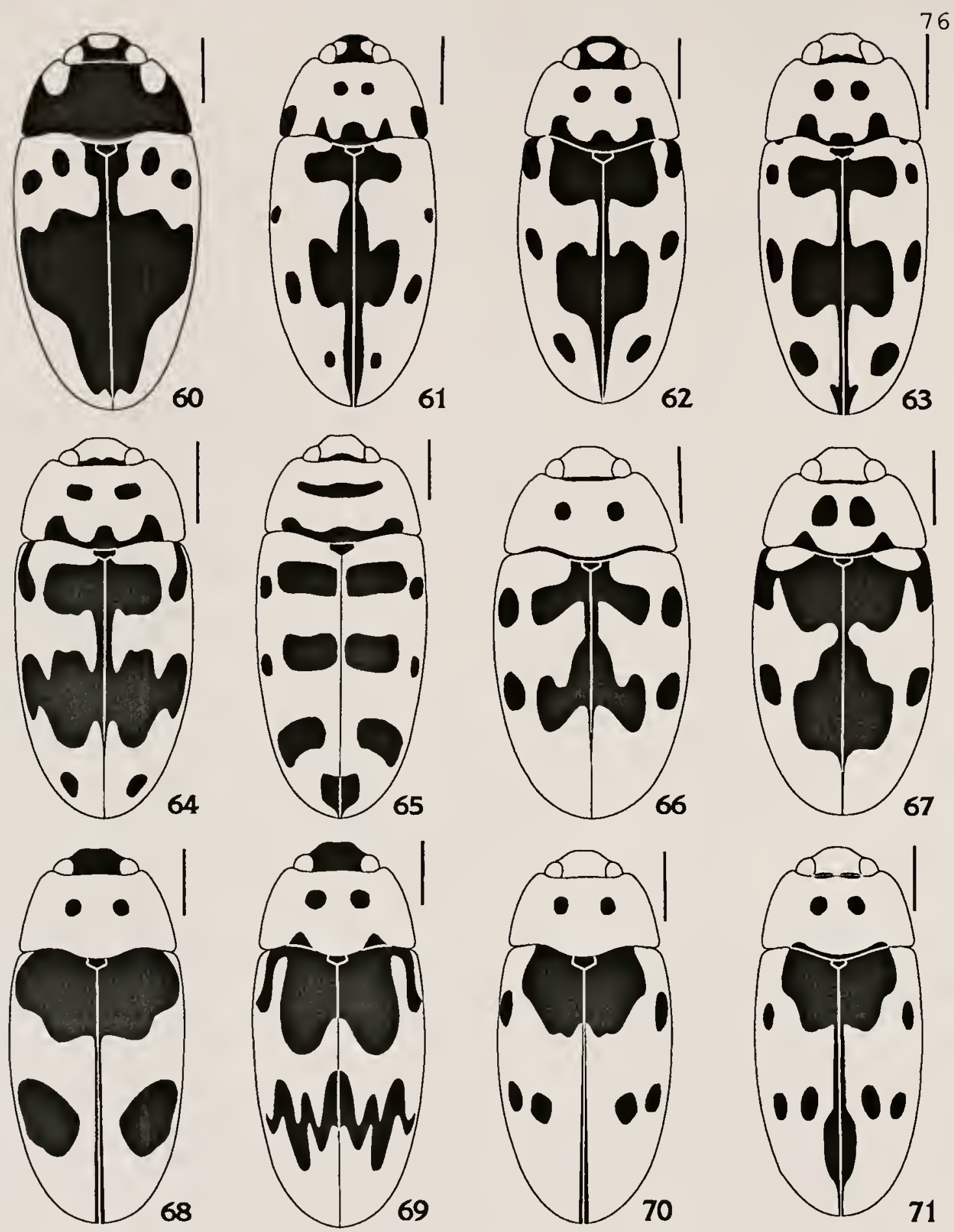

Figures 60-71. Dorsal habitus, line $=1.0 \mathrm{~mm}: 60$.$) Ischyrus$ n. sp. 10; 61.) I. n. sp. 11; 62.) I. pictus Gorham; 63.) I. pictus var.; 64.) I. episcaphulinus Gorham; 65.) I. collatinus Crotch; 66.) I. elegantulus Lacordaire; 67.) I. elegantulus var.; 68.) I. chacojae Gorham; 69.) I. chacojae var.; 70.) I. scutellaris Gorham; 71.) I. scutellaris var. 
36. (34') Pronotum with 2 free rectangular spots; lacking sutural spot near elytral apex (Fig. 64). . . . . . .

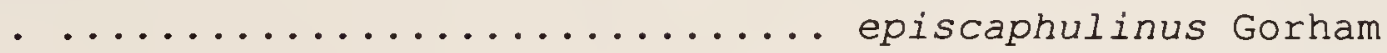

36'. Pronotum with 1 transverse spot; with a sutural spot near the elytral apex (Eig. 65) .... collatinus Crotch

37. (32') Pronotum with 2 free spots, base at most with thin black margin, rarely with anterior spots ........ 38

37'. Pronotum variously marked with 2-4 discal spots, other markings variously connected to margins ......... 42

38. (37) Scutellar spot narrowly connected to elytral base at scutellum, connection narrower than the spots' width (Figs. 66-67)...............egantulus Lacordaire

38'. Scutellar spot broadly connected to elytral base, connection same width as spot $\ldots \ldots \ldots \ldots \ldots \ldots \ldots$

39. (38') Humeral and scutellar spots usually separated; scutellar spot broadly connected to suture; antennomere IX rounded or angled at base, not triangular .....4 40

39'. Humeral and scutellar spots connected, appearing as one, separated from suture; antennomere IX triangular (Fig. 24)................ vespertilio Lacordaire 40. (39) Head entirely red; humeral spot not connected to

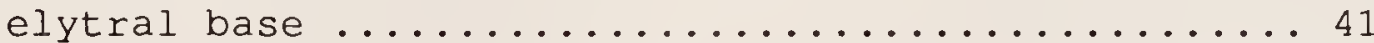

40'. Head with at least base black; humeral spot connected to elytral base, often connected to scutellar spot

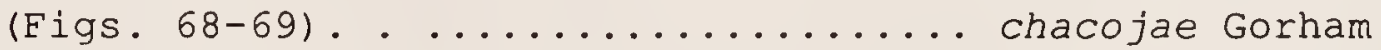

41. (40) Central elytral band broken into round spots (Figs.

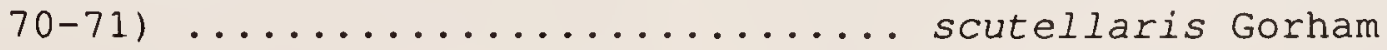


41 ' Central elytral band broken into longitudinally

elongate spots (Eig. 72) ........................ 12

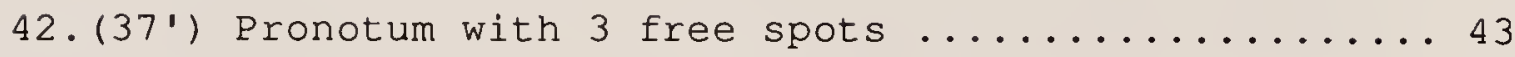

$42^{\prime}$. Pronotum with 2 or 4 free spots ................... 45

43. (42) Central elytral fascia complete (Fig. 37). . . . . .

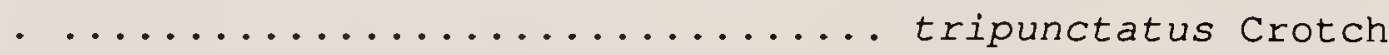

43'. Central elytral fascia broken into spots. . ......44

44. (43') Lateral spot of elytra small, circular; Central America (Figs. 38-39) .......... frontalis Lacordaire

44'. Lateral spot of elytra elongate, stripe-like; USA,

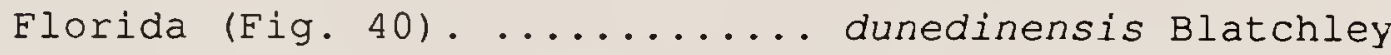

45. (42') Pronotum with 2 free, 2 basal, and 2 anterior spots

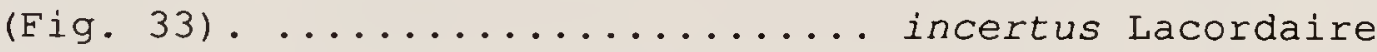

45'. Pronotum with 4 free spots; or with pronotal disc markings based on 4 spots in a transverse line; 2 central spots occasionally connected to the anterior margin, giving it the appearance of 2 free spots ... 46 46. (45') Pronotum with 4 free spots only; occasionally with dark base, but no distinct basal spots .........4 47

46'. Pronotum with 4 free spots and additional markings

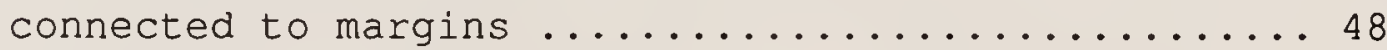

47. (46) Elytral central spot not connected to suture (Fig.

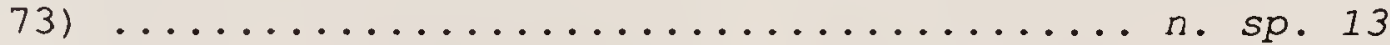

47'. Elytral central band complete, one continuous marking connected to suture, possibly reaching lateral margin

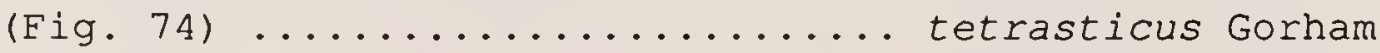



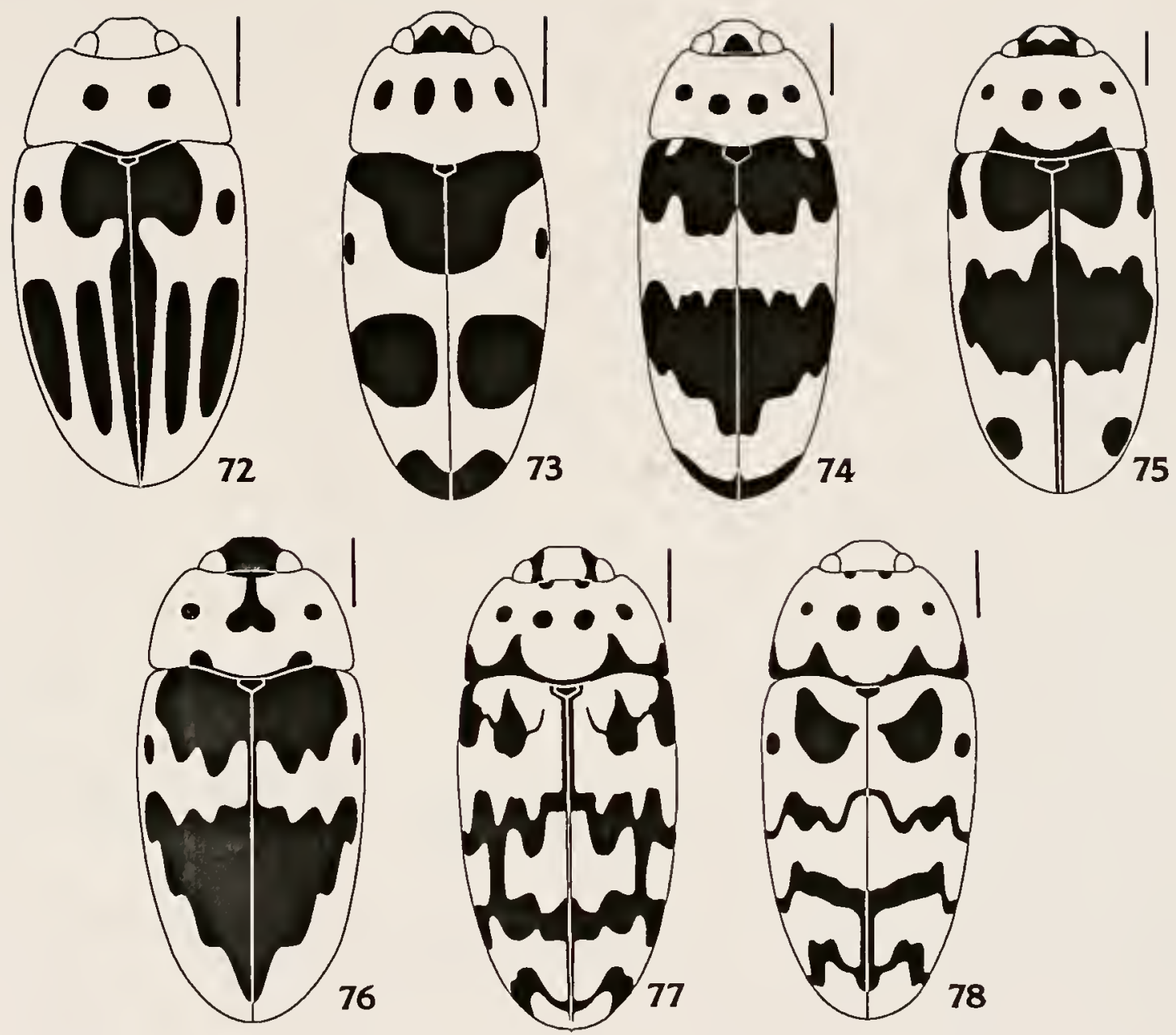

Figures 72-78. Dorsal habitus, line $=1.0 \mathrm{~mm}: 72$. Ischyrus n. sp. 12; 73.) I. n. sp. 13; 74.) I. tetrasticus Gorham; 75.) I. n. sp. 14; 76.) I. n. sp. 15; 77.) I. fulmineus Delkeskamp; 78.) I. n. sp. 16. 
48. (46') With distinct anterior pronotal markings, or markings connecting discal spots to anterior margin 49 48'. Without distinct anterior pronotal marks, discal spots

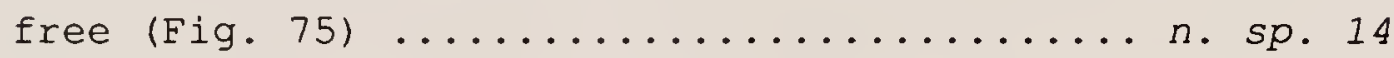

49. (48) Each pronotal hind angle with a spot, occasionally reduced and appearing as dark swelling at margin of

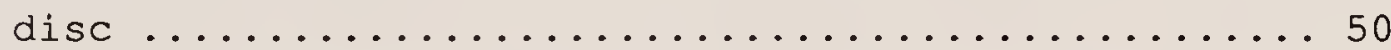

49'. Pronotal hind angles without spots, lateral margin dark but not extending onto disc (Fig. 76) ...... n. sp. 15

50. (49) Humeral spot connected to elytral base; central elytral band divided by orange except at stria $V \& V I$ (Fig. 77). . .............. fulmineus Delkeskamp $50^{\prime}$. Subhumeral spot not connected to elytral base; central elytral band completely divided by orange (Fig. 78). .

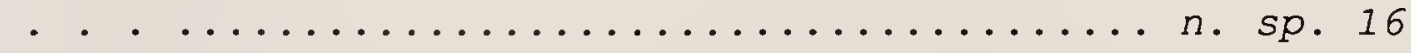


SPECIES ACCOUNTS

\section{Ischyrus aleator Boyle}

Ischyrus aleator Boyle 1954:46-48.

Diagnosis. Unique in Ischyrus by its linear elytral spots (from base at humerus to apical third), pronotum lacking free spots, and weakly pinched prosternum.

Description. Length: $5.6-7.4 \mathrm{~mm}$; width: $2.5-3.4 \mathrm{~mm}$. Body elongate, parallel-sided, widest at basal third elytra; strongly microreticulate, dull; pale orange with black pattern (Fig. 54).

Head orange, often with black epistome. Pronotum entirely edged in black; anterior edge with 2 spots; basal edge with 2 spots farther apart than anterior spots; spots occasionally touching on disc. Scutellum black. Each elytron with black epipleural fold, often with pale base; suture finely edged in black; disc with elongate triangular stripe, widest anteriorly, narrowly connected at base near humerus, reaching apical quarter of elytra. Ventral color variable from mostly black to orange with black sclerite edges. Legs black, femur occasionally banded with pale orange.

Head dorsal distance between eyes $=2.3 \mathrm{x}$ eye width; ocular striae reaching antennal base; vertex and epistome 
puncture size $=1 \times$ facet, separated on vertex by 2 diameters, separated on epistome by 1 diameter. Antenna reaching base of pronotum; antennomere III as long as next 3 antennomeres combined; antennomeres IX-XI symmetrical; antennomere XI oval, circular to transverse (similar to Fig. 6i).

Maxillary palp terminal segment semicircular; medial edge straight at base, angle $90^{\circ}$; lateral side rounded, angle obtuse; width = length. Labial palp terminal segment triangular, extended on medial side, narrow, sides rounded, width $=0.8 \times$ length. Labial palp width $=0.5 \times$ maxillary palp width (Fig. 7m). Mentum with plate broadly triangular, length $=0.5 \times$ width, sides slightly convex, ridge medial extension acutely pointed (Fig. 8i)

Pronotal disc puncture size = 1 x facet, separated by 2 to 3 diameters; lateral punctures slightly larger and denser, separated by 1 to 2 diameters. Scutellum pentagonal, length $=0.6 \times$ width. Each elytron with 7 visible striae; strial puncture size $=0.5 \times 1$ ateral pronotal puncture size, becoming finer toward apex; intervals finely punctate, obscured by strong microreticulation.

Prosternum not keeled, convex; anterior pinch weak, if present (Eig. 10a-b); with (female) or without (male) foveate punctures in front of procoxa; coxal lines nearly straight, length $=0.5 \mathrm{x}$ sternal length, lines not surpassing coxae, length $=0.6 \mathrm{x}$ basal width; prosternal 
plate flat, apical width $=0.75 \times$ basal width; base shallowly concave.

Mesosternum basal width $=2 \mathrm{x}$ mesocoxal line length; coxal lines straight, parallel to anteriorly divergent; base sinuate. Metasternum coxal lines meeting at middle in straight line with a row of punctures, often weak (Fig. 15b); coxal line length variable, continuous around coxae or reaching a maximum of 0.33 distance to posterior angle of metasternum; line behind mesocoxa deep, groove-like; sternum medial punctures fine, few coarse lateral punctures.

First visible abdominal sternite with coxal lines reaching 0.25 to 0.5 distance to posterior margin; rounded between metacoxae.

Male genitalia with median lobe weakly arched, narrowed and apically rounded; internal sac without noticeable sclerotized structures; flagellum long and narrow, straight and apparently rigid at basal 0.5 , length $=2 \times$ median lobe length (Fig. 79a); base of flagellum straight, sclerite at base elongate claw-shaped (Fig. 79b-d) ( 9 northern Mexican, 1 Central American dissected).

Female genitalia with spermathecal head cone-shaped; tail swollen and recurved onto itself at middle (Fig. 79e) ( 6 northern Mexican dissected).

Stridulatory files present on occipital region of males' heads; absent on females. Males with few or no foveate punctures on prosternum in front of procoxae; females with few to many punctures on prosternum in front of 

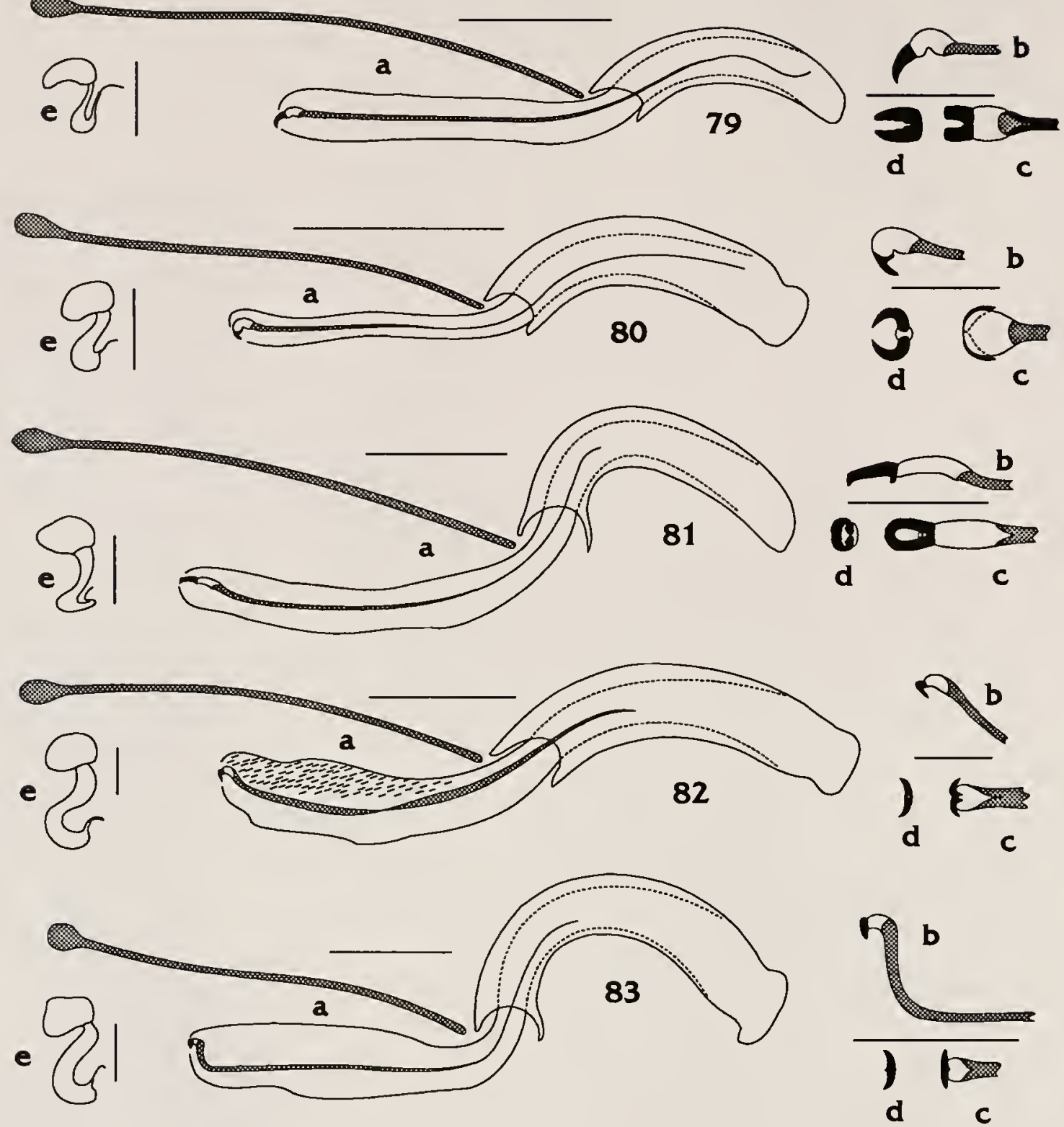

Figures 79-83. Genitalia: 79.) Ischyrus aleator Boyle [male, Mexico, Chihuahua; female, Mexico, Sonora]; 80.) I. angularis Lacordaire [male \& female, Panama]; 81.) I. auriculatus Lacordaire [male, Mexico, Chiapas; female, Mexico, Veracruz]; 82.) I. bogotae Crotch [male, Costa Rica, Puntarenas; female, Ecuador, Pichincha]; 83.) I. boucardi Crotch [male, Panama; female Peru, Madre de Dios]; a.) male genitalia, line $=0.66 \mathrm{~mm}$; b.) lateral view, c.) dorsal view, and d.) anterior view of the sclerotized muscle attachment at anterior end of male flagellum, line $=0.22 \mathrm{~mm}$; e.) female spermatheca, line $=0.33 \mathrm{~mm}$. 
procoxae. There is some overlap in the numbers of visible punctures between males and females.

Variation. Markings vary dramatically in the width on specimens from north to south. Pronotal markings often touch in the middle, becoming stripe-like, leaving 3 pale circles. The width of the elytral stripe varies from 1 to 3 strial intervals. Central American specimens have banded legs, an orange elytral epipleural fold, and black epistome. Specimens from Northern Mexico and Arizona have entirely black legs, black epipleural fold, and an orange epistome. The type specimen, which appears to be slightly teneral, has brown legs.

Variation in mesocoxal line, from parallel to anteriorly divergent, did not correlate with geographic range. Specimens from Arizona and northern Mexico have the metacoxal line short, reaching a quarter of the distance to the posterior angle, or continuous around the coxae. Specimens from southern Mexico and Central America have the metacoxal lines longer, nearly reaching a third of the distance to the posterior angle.

The prosternal pinch is not present on the holotype. On other specimens this pinch varies from absent to weak but distinct.

Type. The holotype (original designation) of Ischyrus aleator Boyle label data: "/ Cave Creek, Cochise Co./ Chiricahua Mts., Az., $7000 \mathrm{ft}$, June 24, 1927/ J.A.Kusche 
Collector/ Van Dyke Collection/ [red] Holotype Ischyrus aleator Boyle/" [CASC, Type \#8369, studied]. Sex male.

Specimens examined. The holotype and 44 specimens, representing 20 collection records, were studied (see Appendix C for specific data).

Distributien. Southeastern Arizona, Mexico, El Salvador, and Guatemala (Eig. 84).

Etymology. aleator: Latin = dice layer, gambler. Name alludes to the resemblence of the trifoliate tawny spot on the pronotum to the emblem of the club suit in a deck of cards (Boyle 1954).

Taxonomic notes. The variation in leg color, size of elytral stripe, and development of metacoxal lines, appear to be correlated with geographic range. Few specimens with banded legs were studied from central Mexico and Central America. The importance of this color variety is uncertain. References. Boyle 1956:133,136-137,169 f.131-132; Skelley et al. 1991:65.

\section{Ischyrus angularis Lacordaire}

Ischyrus angularis Lacordaire 1842:126

Ischyrus quinquepunctatus Gorham 1887:43-44, t.3 f.6, new synonymy.

Diagnosis. Characterized by its elongate body, complete central elytral band, apical elytral spots touching margins, and 2 free and 3 basal pronotal spots.

Description. Length: $5.0-5.8 \mathrm{~mm}$; Width: $2.4-2.9 \mathrm{~mm}$. Body elongate, parallel-sided, widest at basal third of 


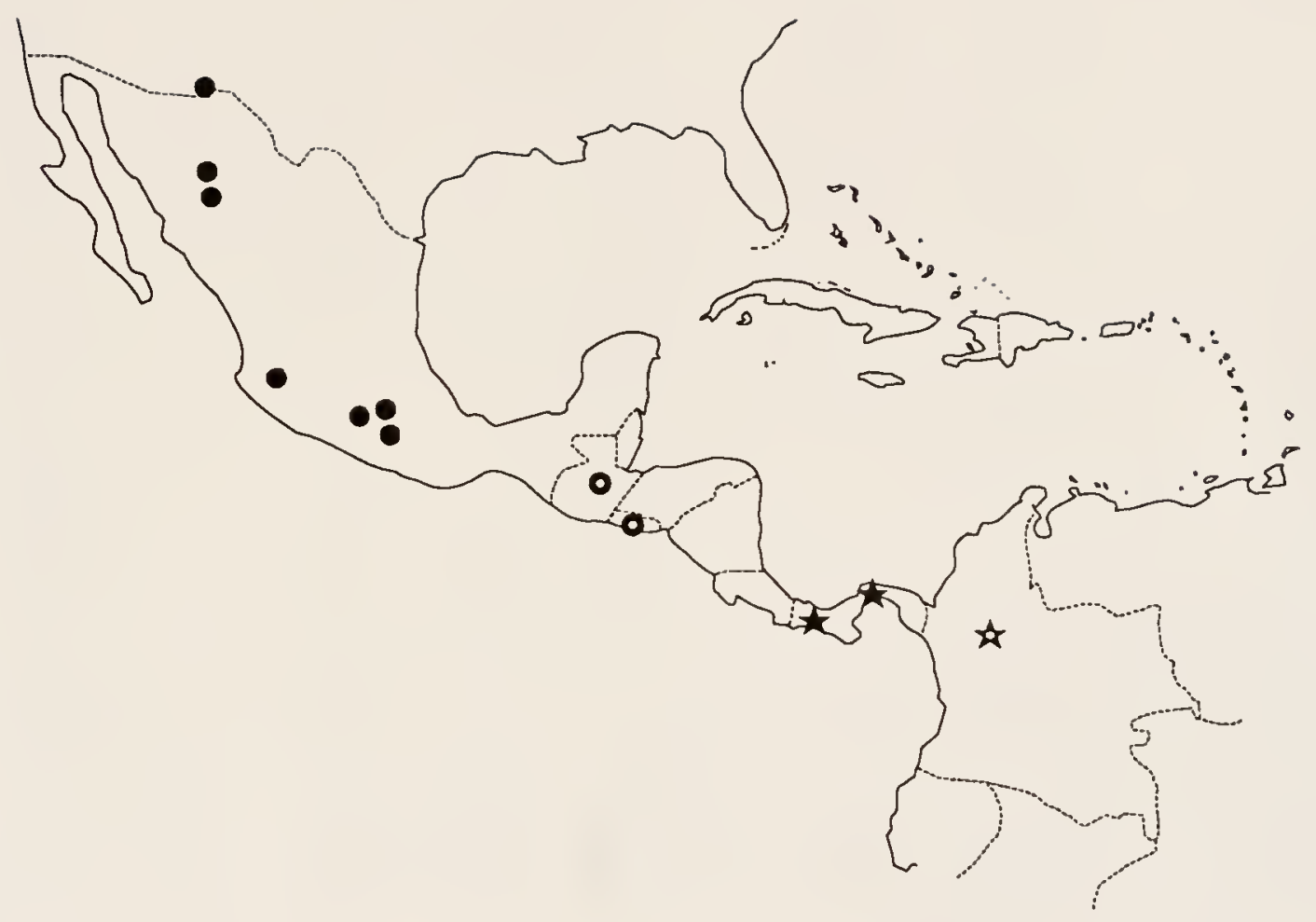

Figure 84. Ischyrus aleator Boyle [circle] and $I$. angularis Lacordaire [star] distribution map. 
elytra; weakly microreticulate, shining; yellow-orange with black pattern (Fig. 35).

Head entirely black, or with orange epistome and frons. Pronotum with 2 free spots and 3 basal spots; medial basal spot small; lateral basal spots larger, tooth-like. Scutellum black. Each elytron with orange epipleural fold; elongate subhumeral spot connected to base, often narrowly connected to large scutellar spot at base; scutellar spot broadly connected to base and suture; suture finely edged black; central band connected to lateral margin and suture; apical spot broadly connected to suture and apical margin; lateral margin black from central band to apex. Venter black, except for the orange lateral abdominal sternites and pronotal epipleuron. Legs black, tarsi brown.

Head dorsal distance between eyes $=2.2 \mathrm{x}$ eye width; ocular striae reaching 0.8 to 1.0 distance to anterior angle of eye; vertex puncture size $=1 \mathrm{x}$ facet, separated by 1 to 2 diameters; epistome puncture size $=0.5 \mathrm{x}$ facet, separated by 1 diameter. Antenna reaching basal 0.25 of pronotum; antennomere III as long as next 3 antennomere combined; antennomeres X to XI asymmetrical; antennomere XI transverse (Fig. 6e).

Maxillary palp terminal segment triangular, securiform, basally rounded, apical angles nearly $90^{\circ}$, length $=0.75 \times$ width. Labial palp terminal segment triangular, extended on medial side, rounded basally, length $=0.66 \mathrm{x}$ width. Labial palp width $=0.75 \times$ maxillary palp width (similar to Fig. 
7b). Mentum with plate broadly triangular, length $=0.6 \mathrm{x}$ width, sides straight, ridge medial extension acutely pointed (similar to Fig. 8d).

Pronotal puncture size $=1$ x facet, separated by 1 to 2 diameters; punctures smaller and denser at extreme lateral edge. Scutellum pentagonal, length $=0.75 \times$ width. Each elytron with 7 complete striae; stria VIII weak, visible on apical half; strial puncture size $=2 \mathrm{x}$ pronotal disc punctures, gradually decreasing in size posteriorly; intervals finely punctate.

Prosternum keeled and pinched anteriorly; with (female) or without (male) foveate punctures in front of procoxa; coxal lines straight, length $=0.5 \times$ sternal length, lines surpassing coxae, length = basal width; prosternal plate flat, apical width $=0.6 \times$ basal width; base shallowly concave.

Mesosternum basal width $=2.5 \mathrm{x}$ mesocoxal line length; coxal lines straight; base sinuate, lobed medially. Metasternum coxal lines not meeting at middle; coxal lines extend 0.5 distance to posterior lateral angle; sternum with medial punctures fine, few coarse lateral punctures separated by 2 to 3 diameters.

First visible abdominal sternite with coxal lines reaching 0.5 distance to posterior edge; rounded between metacoxae; coarse punctures laterally, fine punctures medially. 
Male genitalia with median lobe weakly arched, apically truncate with constriction just before tip; internal sac with end near median lobe roughened; flagellum long and narrow, length $=1.6 \times$ median lobe length (Fig. 80a); base of flagellum straight, sclerite at base claw-shaped (Fig. $80 b-d)$ (2 dissected).

Female genitalia with spermathecal head kidney-shaped, often with top-knot; tail swollen, weakly curved (Fig. 80e) (3 dissected).

Presence of stridulatory files on occipital region of head unknown (heads retracted). Females have foveate punctures on prosternum in front of procoxae; males lack these punctures.

Variation. One specimen with a red head, probably teneral, has the same collection data as a black headed specimen.

Types. The lectotype (here designated) of Ischyrus angularis Lacordaire label data: "/ Colombie/ Angularis Lac./ Type/ Ex-Musaeo Mniszech/ [red] TYPE/ [pale blue] Muséum Paris ex Coll. R. Oberthür 1952/ [red] LECTOTYPE Ischyrus angularis Lacordaire des.P.E.Skelley 1993/" [MNHN, studied]. Sex apparently female, abdomen missing.

The holotype (by monotypy) of Ischyrus quinquepunctatus Gorham label data: "/ [red circle on white paper] Type/ Type sp. figured/ Bugaba, Panama, Champion/ Ischyrus 5-punctatus Gorham/ B.C.A., Col.,VII, Ischyrus/" [NHML, studied]. Sex not determined. 
Specimens examined. The 2 types and 5 specimens, representing 5 collection records, were studied. Label data: Panama, Canal Zone, Barro Colorado Island, 15-27-V-

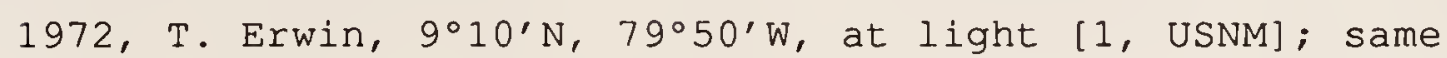
data, 10-VII-1973 [1, USNM]; same locality, 18-28-IV-1964, W. D. Duckworth [1, USNM]; same data, 10-17-V-1964 [1, USNM]; Panama Prov., Las Cumbres, 26-VI-1975, H. Wolda [1, OSUC] .

Distribution. Known only from Panama and Colombia (Fig. 84).

Etymology. angularis: Latin = having angles. Possibly named for the oblique angled apical spot on the elytra, commented on by Lacordaire in the original description.

Taxonomic Note. No differences were found between the types of $I$. angularis Lacordaire, from Colombia, and $I$. quinquepunctatus Gorham, from Panama. Ischyrus quinquepunctatus Gorham is here synonymized under $I$. angularis Lacordaire.

A lectotype was chosen for $I$. angularis because Lacordaire made no indication that only one specimen was seen. The specimen chosen is from the oberthür collection, which contains specimens reported to have been studied by Lacordaire. This specimen fits the original description both in label data and morphological characteristics. Remarks. The color pattern of 2 free and 3 basal pronotal spots is much like the patterns of $I$. pictus and $I$. episcaphulinus. These species have free apical elytral 
spots, I. angularis has the apical elytral spot connected to the margins.

References. Ischyrus angularis Lacordaire: Blackwelder 1945:465; Crotch 1876:430(54); Gemminger \& Harold 1876:3690; Kuhnt 1909:62; 1911:42.

Ischyrus quinquepunctatus Gorham: Blackwelder 1945:465; Kuhnt 1909:63; 1911:43; Pallister 1955b:7.

\section{Ischyrus auriculatus Lacordaire}

Ischyrus auriculatus Lacordaire 1842:123. Episcaphula bellopicta Kuhnt 1910:222, new synonymy. Amblyopus bellopictus (Kuhnt) 1910, Delkeskamp $1943: 42$. Ischyrus bellopictus (Kuhnt) 1910, Delkeskamp 1957:109

Ischyrus auriculatus var. "hamatus" Kuhnt [1914] [unpublished name].

Diagnosis. Characterized by its wide central elytral band, reduced basal elytral markings, black pronotum with orange sides or anterior angles, apical elytral spots, and weakly pinched prosternum.

Description. Length: $5.3-7.1 \mathrm{~mm} ;$ Width: $2.7-3.7 \mathrm{~mm}$. Body elongate, widest at basal third of elytra; weakly microreticulate, shining; orange-red with black pattern (Figs. 56-57).

Head black. Pronotum black except for lateral orange spot at anterior angle; spot variable in size and shape, often attaining base. Scutellum black. Each elytron with orange-red epipleural fold; small humeral spot connected to base; small free scutellar spot; suture with black margin; central band wide, can touch lateral edge; apical spot 
broadly connected to suture and apex. Venter black except for the orange lateral prothorax and lateral abdominal sternites. Legs and antennae black; palpi and tarsi brown. Head dorsal distance between eyes $=3 \mathrm{x}$ eye width; ocular striae reaching 0.75 distance to anterior angle of eye; vertex puncture size $=0.75 \mathrm{x}$ facet, separated by 2 to 3 diameters; epistome puncture size $=0.75 \mathrm{x}$ facet, separated by 0.5 to 1.0 diameter. Antenna reaching basal 0.25 to 0.5 of pronotum; antennomere III as long as next 2 antennomere combined; antennomeres IX to XI symmetrical; antennomere XI oval, transverse (similar to Fig. 6i). Maxillary palp terminal segment triangular, sides rounded, lateral angle acute, medial angle nearly $90^{\circ}$, width $=2 \times$ length (similar to Fig. 7j). Labial palp terminal segment triangular, angles nearly $90^{\circ}$, length $=$ width (similar to Fig. 7g). Labial palp width $=0.33 \mathrm{x}$ maxillary palp width. Mentum with plate triangular, length $=0.8 \mathrm{x}$ width, all sides nearly equal in length, sides convex, ridge medial extension pointed (similar to Fig. 8g).

Pronotal disc puncture size $=0.75 \mathrm{x}$ facet, separated by 2 to 3 diameters; lateral puncture size $=1 \mathrm{x}$ facet, separated by 1 to 2 diameters. Scutellum pentagonal, length $=0.5 \mathrm{x}$ width. Each elytron with 7 complete striae; stria VIII weak, nearly complete; strial puncture size at base = pronotal disc puncture, impressed, gradually becoming finer posteriorly; intervals finely punctate, often obscured by microreticulations. 
Prosternum keeled and weakly pinched anteriorly; without punctures or with few weakly impressed foveate punctures in front of procoxa; line in front of procoxa deep, groove-like; procoxal lines sinuate, slightly concave at middle, length $=0.5 \times$ sternal length, lines barely (if at all) surpassing coxae, length $=1.1 \times$ basal width; prosternal plate narrowed anteriorly, flat, apical width = $0.6 \times$ basal width; base shallowly concave.

Mesosternum basal width $=3 \mathrm{x}$ mesocoxal line length; coxal lines straight, parallel; base truncate. Metasternum coxal lines not meeting at middle, not recurved (Eig. 15a); coxal lines fine, extend 0.33 distance to posterior lateral angle; sternum with medial punctures fine, few coarse lateral puncture.

Eirst visible abdominal sternite with coxal lines reaching 0.33 to 0.5 distance to posterior edge; rounded between metacoxae; with coarse punctures laterally, finer punctures medially.

Male genitalia with median lobe strongly arched, narrowed with apically rounded; internal sac without noticeable sclerotized structures; flagellum long and narrow, length $=1.7 \times$ median lobe length (Fig. 81a); base of flagellum straight, sclerite at base elongate ring-shaped (Eig. $81 \mathrm{~b}-\mathrm{d})(8 \mathrm{dissected})$.

Female genitalia with spermathecal head oval; tail thick, weakly curved, angled at end (Eig. 8le) (9 dissected). 
Presence of stridulatory files on occipital region of head unknown (heads retracted). Prosternal sexual dimorphism present but not constant. Males lack punctures in front of procoxae. Some females have foveate punctures on prosternum in front of procoxae, others apparently lack punctures.

Variation. Ischyrus auriculatus (Panama, Trinidad, Ecuador, Venezuela, Brazil) has lateral orange mark of pronotum restricted to anterior angle (Fig. 56). Ischyrus bellopictus (Mexico, Peru, Bolivia) has the lateral orange mark of the pronotum broadly connected with the base and connected to the lateral margin from the anterior angle nearly to the posterior angle (Fig. 57). Ischyrus auriculatus var. "hamatus" (Argentina, Bolivia) is identical to $I$. auriculatus and I. bellopictus, except it is intermediate in the size of the orange lateral pronotal marking .

Iype. The lectotype (here designated) of Ischyrus auriculatus Lacordaire label data: "/ [blue paper] Type / Type auriculatus Ch./ [red] LECTOTYPE Ischyrus auriculatus Lacordaire des.P.E.Skelley 1993/" [CUMZ, studied]. Sex not determined. Lacordaire stated the type locality is "Cayenne".

The lectotype (here designated) of Ischyrus bellopictus (Kuhnt) label data: "/ [hand written] Motzoro./ 104629/ [orange] Typus/ [pale green with black border, folded] Episcaphula bellopicta Kuhnt/ Zool.Mus.Berlin/ [red] 
LECTOTYPE Episcaphula bellopicta Kuhnt des.P.E.Skelley 1993" [ZMHB, studied]. Two specimens are on the pin, the bottom specimen is the lectotype. Sex not determined. Delkeskamp (1957:109) stated that "Motzor." = Motzorongo, Veracruz, Mexico.

Kuhnt's undescribed type of Ischyrus auriculatus var. "hamatus" label data: "/[purple paper] Coll.R.I.SC.N.B. Argentina/ [green paper, glued to purple label] Entre-Rios./ [glued to purple label] Coll.Camille Van Voixem./ [white with black border] Typus/ [red with black border] TYPE/ [hand written, once folded] Ischyrus auriculatus var. hamatus Kuhnt/ P.KUHNT det., 1914: Ischyrus auriculatus Lac. var.: hamatus Kuhnt/" [ISNB, studied]. Sex not determined. Specimens examined. The 3 "types" and 51 specimens, representing 32 collection records, were studied (see Appendix $C$ for specific data).

Distribution. Widespread throughout Mexico, Central, and South America (Fig. 85).

Etymology. auricula: Latin = lobe of ear, little ear. Possibly the name refers to the pale pronotal marking behind the eyes, appearing like an ear.

Iaxonomic notes. A lectotype was chosen for $I$. auriculatus Lacordaire because there was no indication that only one specimen was studied in the original description. The specimen chosen has the label data, "auriculatus Ch.", indicating it came from the Chevrolat collection, as stated in the original description. 


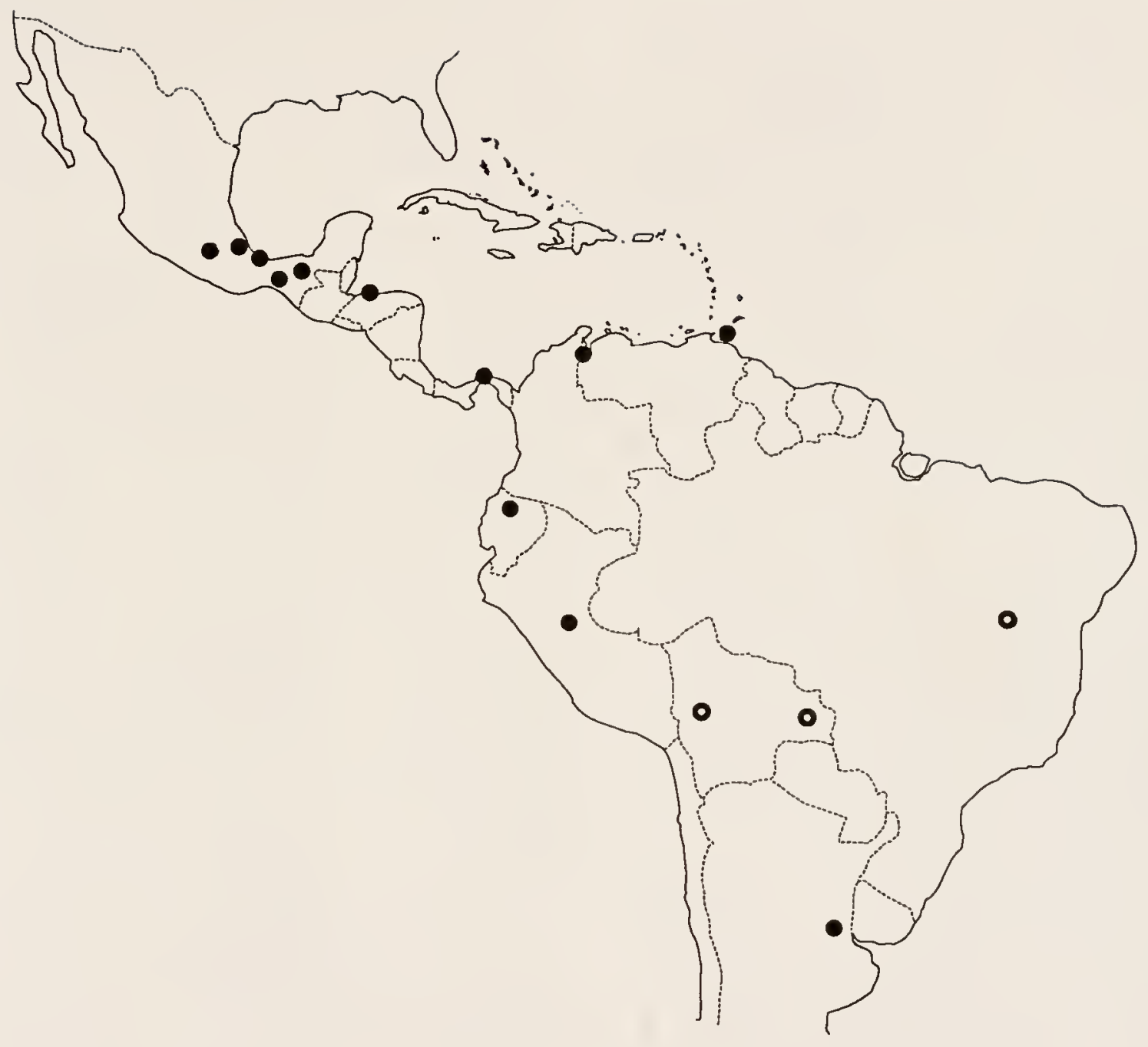

Figure 85. Ischyrus auriculatus Lacordaire distribution map. 
A lectotype was chosen for Episcaphula bellopictus Kuhnt from the "Typus" specimens because Kuhnt made no mention that only one specimen was studied, and 2 specimens are present on the pin. The lower specimen was chosen as the lectotype because it was the more intact. The upper specimen and 3 separate additional specimens with identical locality labels are designated as paralectotypes. With these specimens are 6 others bearing similar locality labels, but with different ink and speling. They could have been studied by Kuhnt, but this is not certain. They are not designated as paralectotypes.

The variety "hamatus" was recognized by Kuhnt who had a series of specimens (all in the ISNB), selected a type, but apparently never published the name. The date on one of the labels, "1914", indicated that Kunnt's work was done at the beginning of World War I. His paper may have been lost in the war, never published, or simply never referenced. No publication or citation to the description of this variety has been located. The "type" label data are stated in case its publication was overlooked.

The "hamatus" variety is slightly different in color pattern, but no additional characters were found to separate it from the other varieties. All 3 color patterns (auriculatus, bellopictus, and "hamatus") are from scattered, intermixed localities. At present, they are considered varieties of the same species. 
Remarks. Ischyrus auriculatus superficially resembles I. ephippiatus in body shape and color pattern. Ischyrus auriculatus has an apical elytral spot, I. ephippiatus lacks this spot.

References. Ischyrus auriculatus Lacordaire: Blackwelder 1945:465; Crotch 1876:(57) 433; Delkeskamp 1957:109; Gemminger \& Harold 1876:3690; Gorham 1887:43; Kuhnt 1909:63; 1911:42; Mader 1942:195; 1952:182-183.

Episcaphula bellopictus Kuhnt: Delkeskamp 1943:42; 1957:109; Kuhnt 1911:77.

\section{Ischyrus bogotae crotch}

Ischyrus bogotae Crotch 1876:430(54).

Diagnosis. Recognized by its single large basal spot and 2 free pronotal spots, and asymmetrical antennal club segments.

Description. Length: $7.2-9.5 \mathrm{~mm} ;$ width: $3.4-4.4 \mathrm{~mm}$. Body elongate widest at elytral third; microreticulate, feebly shining; orange-red patterned with black (Fig. 32). Head black. Pronotum with 2 anterior spots, occasionally connected to each other; 2 free spots, one on each side near middle; one large basal spot at middle. Scutellum black. Each elytron with black epipleural fold; subhumeral spot elongate, connected to base; large scutellar spot broadly connected to suture and base; suture black; central spot large, often free, may touch suture; apical spot free. Venter orange except around coxae; episterna and epimera 
black; abdomen orange with black sutures. Legs black; palpi and tarsi brown.

Head dorsal distance between eyes $=2 \mathrm{x}$ eye width; ocular striae reaching 0.8 distance to anterior angle of eye; vertex puncture size $=1$ x facet, separated by 1 to 2 diameters; epistome puncture size $=0.5 \times$ facet, separated by 1 diameter. Antenna reaching basal 0.25 of pronotum; antennomere III as long as next 3 antennomere combined; club broad, 3 to 4 times wider than antennomere VIII; antennomeres X to XI asymmetrical; antennomere XI triangular, transverse (Fig. 6d).

Maxillary palp terminal segment triangular, narrowed, apical angles $90^{\circ}$ or more, width $=$ length. Labial palp terminal segment triangular, extended on medial side, length = width. Labial palp width $=0.5 \times$ maxillary palp width (Eig. 7d). Mentum with plate broadly triangular, length = $0.6 \mathrm{x}$ width, sides straight, ridge medial extension acutely pointed (Eig. 8d).

Pronotum puncture size $=1$ x facet, separated by 2 to 3 diameters. Scutellum pentagonal, length $=0.5 \times$ width. Each elytron with 7 complete striae; strial puncture size = $1.5 \mathrm{x}$ pronotal disc puncture; intervals finely punctate. Prosternum weakly keeled and pinched anteriorly; with foveate punctures in front of procoxa, weakly impressed and obscure if present; coxal lines straight, length $=0.5 \mathrm{x}$ sternal length, lines barely surpassing coxae, length = 
basal width; prosternal plate flat, apical width $=0.6 \mathrm{x}$ basal width; base shallowly concave.

Mesosternum basal width $=2 \times$ mesocoxal line length; coxal lines straight to weakly curved; base sinuate, lobed medially. Metasternum coxal lines recurved, not meeting medially, ridge at suture with mesosternum gives appearance of lines meeting; coxal lines extend 0.33 to 0.5 distance to posterior lateral angle; sternum with medial punctures fine, few coarse lateral punctures weakly impressed.

First visible abdominal sternite with coxal lines short, reaching 0.25 distance to posterior edge; broadly rounded between metacoxae; coarse punctures laterally, fine punctures medially.

Male genitalia with median lobe weakly arched, apically truncate, slightly constricted just before tip; internal sac with patch of setal-like structures at end near base of flagellum; flagellum long and narrow, flattened and ribbonlike for most of length, length = median lobe length (Fig. 82a); base of flagellum straight, sclerite at base clawshaped (Fig. 82b-d) (2 dissected).

Female genitalia with spermathecal head oval; tail swollen, curved like an inverted question mark, "i" (Fig. 82e) (8 dissected).

Stridulatory files on occipital region of head weakly developed on males; not present on females. No other sexual dimorphism observed. 
Variation. The anterior pronotal spots often connected with each other forming a single bilobed spot. The basal pronotal spot often has a small anterior notch, indicating it could be a fusion of 2 spots. The central elytral spot touches the suture in specimens from Guatemala, but is free on the other specimens.

Type. The lectotype (here designated) of Ischyrus bogotae Crotch label data: "/ [blue paper] Type/ Bog. [underside] Jans. / Type Bogotae/ [red] LECTOTYPE Ischyrus bogotae Crotch des.P.E.Skelley 1993/" [CUMZ, studied]. Sex not determined.

Specimens examined. The lectotype and 47 specimens, representing 29 collection records, were studied (see Appendix $C$ for specific data).

Distribution. Mexico and Central America to Colombia and Ecuador (Fig. 86).

Etymology. Named after the type locality; Bogota, Colombia.

Taxonomic notes. A lectotype was chosen because crotch made no mention in the original description that only one specimen was studied.

Remarks. Ischyrus bogotae is similar to I. septemsignatus in color pattern. Ischyrus septemsignatus can be separated by the absence of the large basal pronotal spot, present in I. bogotae.

References. Blackwelder 1945:465; Gemminger \& Harold 1876:3690; Gorham 1887:40; Kuhnt 1909:63; 1911:42. 


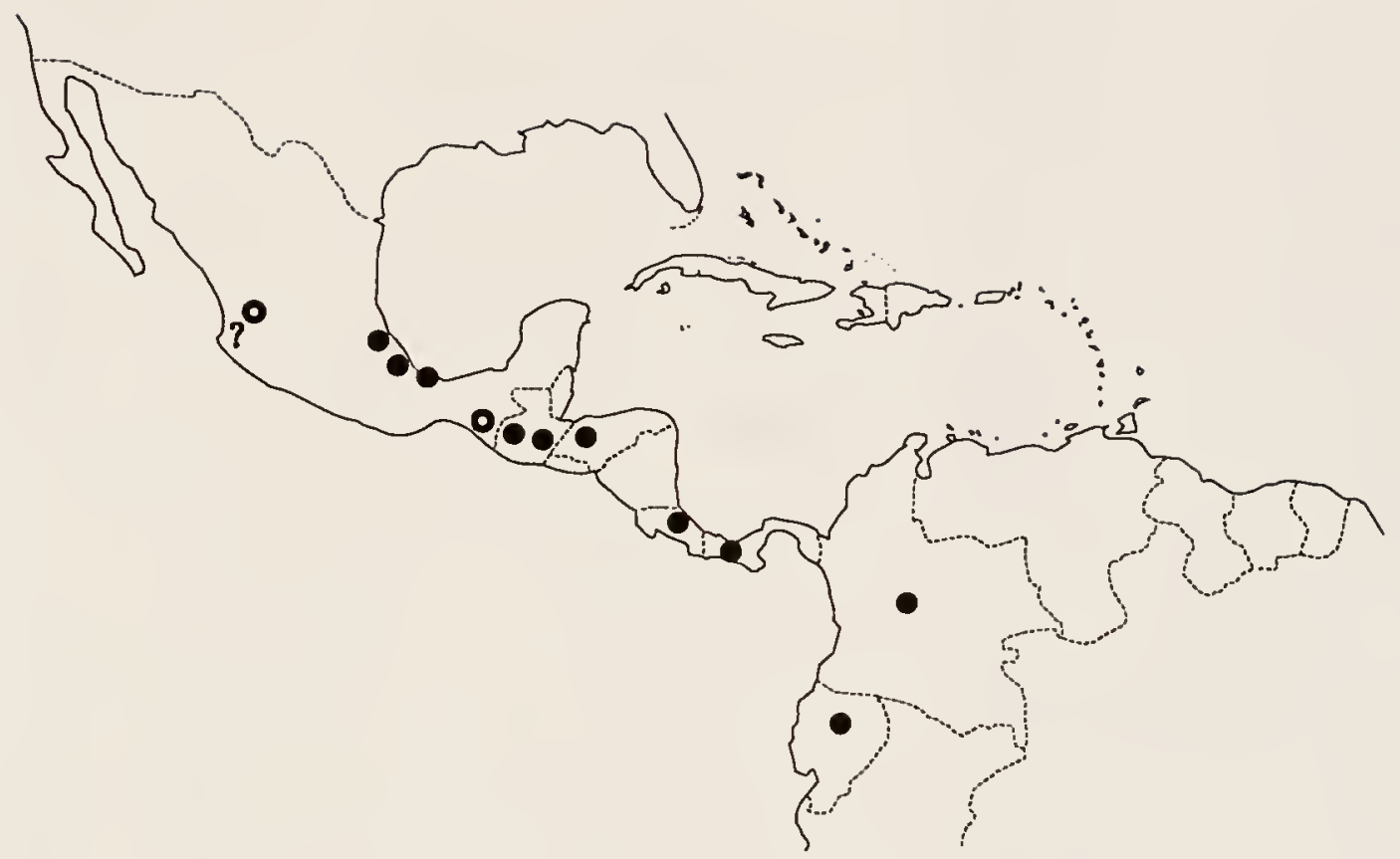

Figure 86. Ischyrus bogotae Crotch distribution map. 


\section{Ischyrus boucardi Crotch}

Ischyrus boucardi Crotch 1876: (53) 429 .

Ischyrus peruvianus Gorham 1883:85-86, new synonymy.

Diagnosis. Characterized by its broad terminal

maxillary palp segment, 4 free pronotal spots in a transverse row, anterior pronotal spots, absence of basal and hind angle pronotal spots, complete band-like central elytral marking, and orange-yellow legs with black knees.

Description. Length: 5.8-8.1 mm; Width: $2.7-3.8 \mathrm{~mm}$. Body elongate, parallel-sided; widest at basal third of elytra; microreticulate; yellow-orange with black pattern (Fig. 41).

Head black; often with lateral orange mark at each eye. Pronotum with 2 anterior spots connected to margin; 4 free spots in transverse, anteriorly concave arch; occasionally with black basal margin. Scutellum black. Each elytron with black epipleural fold; elongate humeral spot, connected to base; subhumeral spot often free, may touch scutellar spot and/or humeral spot; scutellar spot broadly connected to base and suture; suture black; central band wide, often reaching lateral margin, widest at suture; apical spot small, broadly connected to apical margin. Ventral color variable, sclerites solid black to orange with black margins. Legs orange with black knee and coxa; palpi and tarsi brown.

Head dorsal distance between eyes $=2.0$ to $2.2 \times$ eye width; ocular striae reaching 0.5 distance to anterior angle of eye; vertex puncture size $=1$ x facet, separated by 2 to 
3 diameters; epistome puncture size $=1 \mathrm{x}$ facet, separated by 0.5 to 1.0 diameter. Antenna reaching basal 0.25 pronotum; antennomere III as long as next 3 antennomere combined; club broad, segments transverse; antennomere IX narrower than $X$; antennomeres $X$ to $X I$ asymmetrical; antennomere XI transverse to subcircular (similar to Fig. $6 e)$.

Maxillary palp terminal segment triangular, securiform, basally rounded, angles $90^{\circ}$, length $=0.5 \mathrm{x}$ width. Labial palp terminal segment elongate, extended on medial side, rounded basally, length $=0.5 \times$ width. Labial palp width $=$ $0.5 \times$ maxillary palp width (similar to Fig. 7c). Mentum with plate broadly triangular, length $=0.6$ width, sides straight, ridge medial extension pointed (similar to Fig. $8 d)$.

Pronotal disc puncture size $=0.75 \mathrm{x}$ facet, separated 2 to 4 diameters; lateral punctures same size, slightly denser, separated 1 to 2 diameters. Scutellum pentagonal, length $=0.5 \times$ width. Each elytron with 7 complete striae; stria VIII weak, visible on apical half; strial puncture size $=1 \mathrm{x}$ facet; intervals finely punctate.

Prosternum weakly keeled and pinched anteriorly; with (female) or without (male) foveate punctures in front of procoxa; coxal lines straight, length $=0.5 \times$ sternal length, lines barely surpassing coxae, length = basal width; prosternal plate flat, apical width $=0.6 \times$ basal width; base shallowly concave. 
Mesosternum basal width $=1.5 \mathrm{x}$ mesocoxal line length; coxal lines straight; base sinuate. Metasternum coxal lines often recurved, not meeting at middle; coxal lines short, barely surpassing coxa; line behind mesocoxa deep, groovelike; sternum with medial punctures fine, lacking lateral punctures.

First visible abdominal sternite with coxal lines barely surpassing coxa or reaching up to 0.5 distance to posterior margin; rounded between metacoxae; coarse punctures laterally, fine punctures medially.

Male genitalia with median lobe strongly arched, apically truncate, constricted just before tip; internal sac without noticeable sclerotized structures; flagellum long and narrow, length $=1.5 \mathrm{x}$ median lobe length (Fig. 83a); base of flagellum angled, sclerite at base claw-shaped (Fig. $83 b-d)(8$ dissected).

Female genitalia with spermathecal head kidney-shaped, often with top-knot; tail swollen, curved like an inverted question mark, " $i "$ (Fig. 83e) (7 dissected).

Stridulatory files on occipital region of head not visible, presence unknown (heads retracted). Females have foveate punctures on prosternum in front of procoxae; males lack these punctures.

Variation. Gorham's I. peruvianus differs from I. boucardi Crotch only in the head being entirely black and the subhumeral spot not connected to the scutellar spot. Both of these characters are variable and several 
intermediate specimens have been studied. The specimen illustrated (Fig. 41) is one of these intermediates.

Types. The lectotype (here designated) of Ischyrus boucardi Crotch label data: "/ [blue paper] TYPE/ S.Cat. [underside] Bouc./ Type Boucardi/ [red] LECTOTYPE Ischyrus boucardi Crotch des.P.E.Skelley 1993/" [CUMZ, studied]. Sex not determined.

The lectotype (here designated) of Ischyrus peruvianus Gorham label data: "/ [red circle on white paper] Type/ Peru Buckley/ Gorham Coll. BM. 1927-143/ [red] LECTOTYPE Ischyrus peruvianus Gorham des.P.E.Skelley 1993/" [NHML, studied]. Sex not determined.

specimens examined. The lectotype plus 22 specimens, representing 14 collection records, were studied (see Appendix C for specific data).

Distribution. Widespread in South America from Panama to Argentina (Fig. 87).

Etymology. Ischyrus boucardi is named after A. Boucard, collector of the type specimen.

Taxonomic notes. A lectotype was chosen for $I$. boucardi Crotch because specimens from Santa Catarina and Amazonas were stated to have been studied in the original description.

The lectotype of $I$. peruvianus was chosen because Gorham made no indication that only one specimen was studied. The specimen chosen is from his collection, fits 


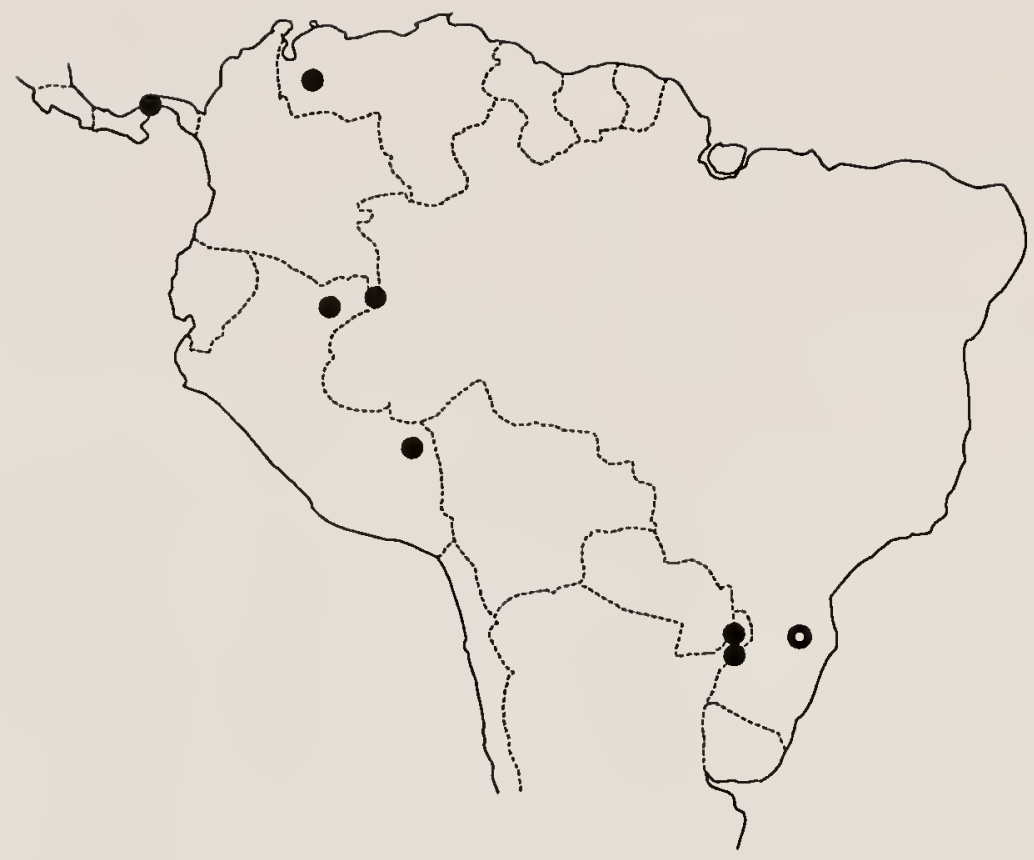

Figure 87. Ischyrus boucardi Crotch distribution map. 
the description, and had previously been labeled as the type.

No difference, except for color pattern, was found between I. boucardi and I. peruvianus, with several specimens exhibiting intermediate color patterns. Based on this, I. peruvianus Gorham is placed in synonymy under I. boucardi Crotch.

References. Ischyrus boucardi Crotch: Blackwelder 1945:465; Gemminger \& Harold 1876:3690; Guérin 1948:19; Kuhnt 1909:64; 1911:42; Mader 1942:171; 1951:209-210; $1952: 159-160$.

Ischyrus peruvianus Gorham: Blackwelder 1945:465; Fleutiaux 1886:222; Kuhnt 1909:63; 1911:43; Mader 1942:171; $1951: 209-210 ; 1952: 159-160$.

\section{Ischyrus chacejae Gorham}

Ischyrus chacojae Gorham 1887:43, t.3 f.5. Ischyrus chalcojae Gorham, in Kuhnt 1909:63 [misspelling].

Diagnosis. Characterized by the black head base, scutellar spot broadly connected to elytral base, central elytral marking a single spot or band, 2 free pronotal spots, and lacking anterior pronotal spots.

Description. Length 4.8-5.7 mm; Width: $2.6-3.2 \mathrm{~mm}$. Body elongate-oval, widest at basal third of elytra; weakly microreticulate, shining; orange with black color pattern (Figs. 68-69) .

Head black, often with orange epistome and frons. Pronotum with 2 free spots, base can have 2 small spots. 
Scutellum orange, often with black edges. Each elytron with orange epipleural fold; subhumeral spot connected to base, broadly or narrowly connected to large scutellar spot, occasionally reaching lateral edge; scutellar spot broadly connected to base and suture; suture can have black margin; central markings vary in shape and size, from free spot to complete band connected to medial and lateral edges (see Variation below). Venter orange with black sutural margins. Appendages black; palpi and tarsi brown.

Head dorsal distance between eyes $=2.5 \mathrm{x}$ eye width; ocular striae reaching anterior angle of eye; vertex puncture size $=1$ x facet, separated by 2 diameters; epistome puncture size $=0.75 \mathrm{x}$ facet, nearly coalescing. Antenna reaching base of pronotum; antennomere III as long as next 3 antennomere combined; antennomeres IX to XI symmetrical; antennomere XI subcircular, narrower than antennomere $\mathrm{X}$ (similar to Fig. 6l).

Maxillary palp terminal segment triangular, sides rounded, angles nearly $90^{\circ}$, length $=0.5 \times$ width. Labial palp terminal segment triangular, extended medially, sides rounded, angles nearly $90^{\circ}$, length $=0.8$ width. Labial palp width $=0.5 \times$ maxillary palp width (similar to Fig. 7o). Mentum with plate broadly triangular, length $=0.5 \mathrm{x}$ width, sides concave (similar to Fig. 8h); medial extension short, rounded, projecting.

Pronotal disc puncture size $=1$ x facet, separated by 2 to 3 diameters; laterally separated by 1 to 2 diameters. 
Scutellum pentagonal, length $=0.5 \times$ width. Each elytron with 7 complete striae; stria VIII present at base and apical half, often obscured by interval punctation; strial puncture size at base $=2 \times$ pronotal disc punctures, gradually becoming finer posteriorly; interval punctures fine, impressed, distinct.

Prosternum keeled and strongly pinched anteriorly; with (female) or without (male) foveate punctures in front of procoxa; coxal lines curved at ends, length $=0.6 \mathrm{x}$ sternal length, lines barely surpassing coxae, length = basal width; prosternal plate flat, apical width $=0.6$ to $0.8 \mathrm{x}$ basal width; base concave.

Mesosternum basal width $=3 \times$ mesocoxal line length; coxal lines straight; base broadly sinuate. Metasternum coxal lines meet at middle, often crenate, recurved; coxal Iines extend 0.5 distance to posterior lateral angle; sternum shining, medial punctures fine, coarse lateral punctures often obscured by strong microreticulation.

First visible abdominal sternite with coxal lines reaching 0.25 to 0.33 distance to posterior edge; broadly rounded between metacoxae; coarse punctures laterally, fine punctures medially.

Male genitalia with median lobe weakly arched, apically rounded; internal sac with pair of darkened patches near median lobe; flagellum thickened for most of its length, length $=1.2 \times$ median lobe length (Fig. 88a); base of 

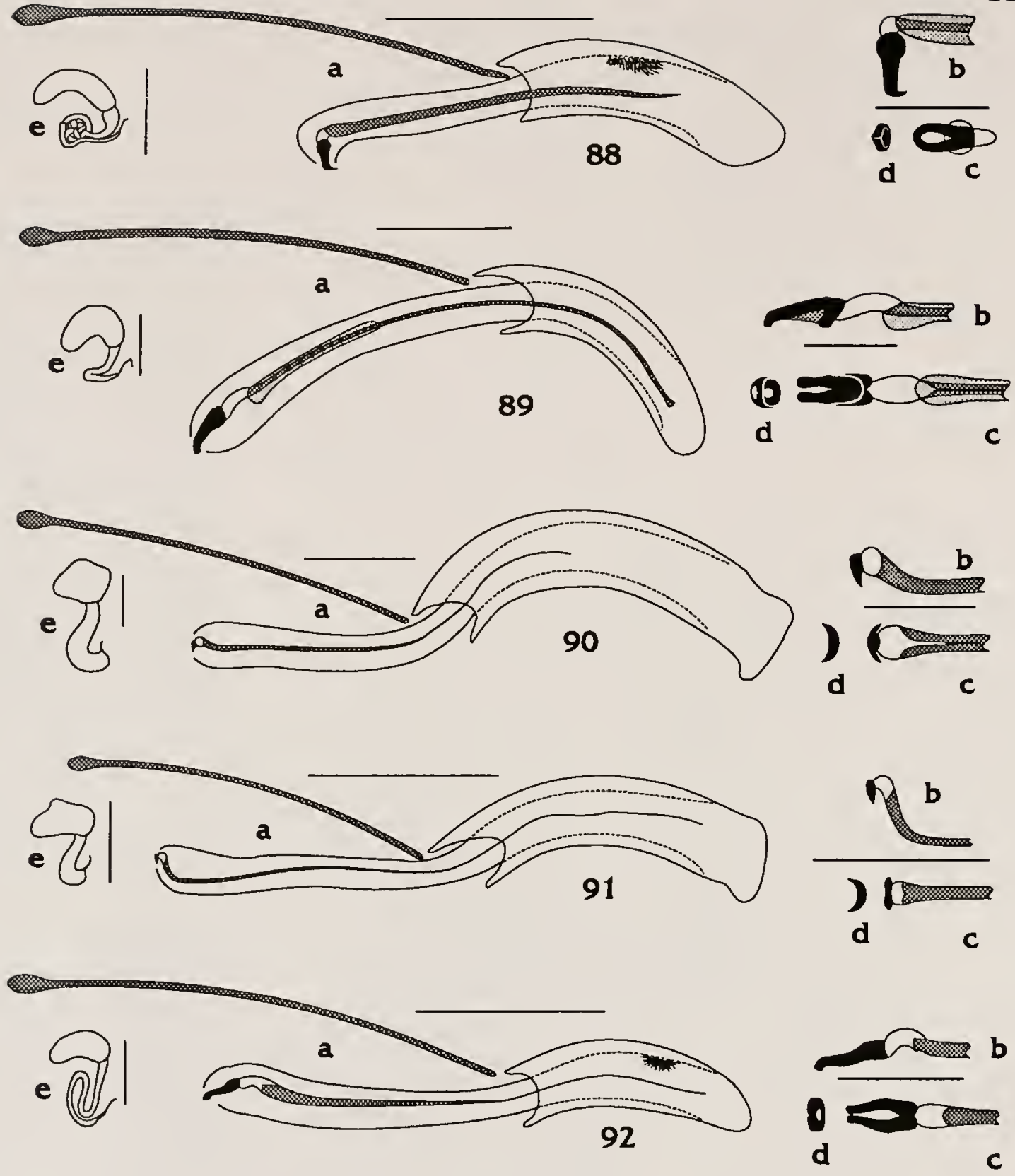

Eigures 88-92. Genitalia: 88.) Ischyrus chacojae Gorham [male \& female, Panama]; 89.) I. collatinus Crotch [male \& female, Panama]; 90.) I. distinguendus Lacordaire [male \& female, Mexico, Veracruz]; 91.) I. dunedinensis Blatchley [male \& female, USA, Florida]; 92.) I. elegantulus Lacordaire [male \& female, Panama]; a.) male genitalia, line $=0.66 \mathrm{~mm}$; b.) lateral view, c.) dorsal view, and d.) anterior view of the sclerotized muscle attachment at anterior end of male flagellum, line $=0.22 \mathrm{~mm}$; e.) female spermatheca, line $=0.33 \mathrm{~mm}$. 
flagellum straight, sclerite at base elongate, claw-shaped, almost ring-like (Fig. 88b-d) ( 3 dissected).

Female genitalia with spermathecal head elongate kidney-shaped; tail narrow, looped or coiled on itself (Fig. 88e) (4 dissected).

Presence of stridulatory files on occipital region of head unknown (heads retracted). Females with foveate punctures on prosternum in front of procoxae; males lacking these punctures, or at most, with a few punctures near procoxae.

Variation. Ischyrus chacojae color pattern is variable, and the specimens studied may encompass several taxa. No differences, outside of color pattern, were found that would support their separation. More specimens are needed to make any confident conclusion, especially with the South American varieties where only female specimens were studied.

Mexican specimens and the Guatemalan holotype (Fig. 68) have black heads, often with an orange spot on frons; base of pronotum lacking black spots; subhumeral and scutellar spots broadly connected, not reaching lateral margin; central elytral spot free; suture finely margined black. Panamanian specimens have black head with orange epistome; base of pronotum without spots; subhumeral and scutellar spots narrowly connected at base, nearly free from each other, not reaching lateral margin; central elytral spot free; suture finely margined with black. 
The female Peruvian specimen (Eig. 69) has a black

head; base of pronotum with 2 weak spots; subhumeral and scutellar spot narrowly connected at base, nearly free from each other, not reaching lateral margin; central elytral mark reduced to jagged line connected to suture, not connected to lateral margin; suture black.

The female Brazilian specimen has a black head with a large pale spot on frons; base of pronotum with 2 indistinct spots; subhumeral and scutellar spots broadly connected, reaching lateral margin; central elytral marking band-like, connected to both suture and lateral margin.

Type. The holotype (by monotypy) of Ischyrus chacojae Gorham label data: "/ [red circle on white paper] Type/ Type, sp. figured/ Chacoj, Vera Paz., Champion/ Ischyrus chacojae, Gorh/ B.C.A., Col., VII, Ischyrus/" [NHML, studied]. The type locality is a settlement in Guatemala, on the Rio Polochic, just west of La Tinta, about $15^{\circ} 19^{\prime} \mathrm{N}$, 89.56'W (Selander \& Vaurie 1962). Sex undetermined.

Specimens examined. The holotype and 7 specimens, representing 5 collection records, were studied. Label data: Brazil, Amazonas, $20 \mathrm{~km}$ S. Manaus, 13-XI-1966, Bologh, Soil Zoological Exp. no.539 [1, HNHM]; Mexico, Veracruz, Lake Catemaco, 8-16-VIII-1960, H. F. Howden [1, CNCI]; Veracruz, 6 mi.N Sontecomapan, 24-VIII-1982, C. W. \& L. O'Brien, 100' elev. [1, PESC]; Panama, Panama Prov., Cerro Campana, 10-VIII-1961, J. M. Campbell, 3000' elev. [3, 
CNCI]; Peru, Junin, Satipo, 10-VII-1940, P. Paprzycki [1, CASC ] .

Distribution. Mexico, Guatemala, Panama, Peru, and Brazil (Fig. 93).

Etymology. The name chacojae is based on the type locality, Chacoj.

Remarks. Ischyrus chacojae is similar in color pattern to I. scutellaris, I. n. sp. 12, and I. elegantulus. Each differs from I. chacojae in color pattern characters: $I . n$. sp. 12 and $I$. septemsignatus have 2 free central spots on each elytron; I. elegantulus has the scutellar spot not touching the elytral base.

References. Blackwelder 1945:465; Gorham 1887:44; Kuhnt 1909:63; 1911:42.

\section{Ischyrus collatinus crotch}

Ischyrus collatinus Crotch 1876:(57) 433.

Diagnosis. Unique in Ischyrus by its single transversely linear free pronotal spot.

Description. Length: $5.4-6.8 \mathrm{~mm}$; width: $2.8-3.8 \mathrm{~mm}$. Body elongate-oval, widest at basal third of elytra; microreticulate, feebly shining; orange-yellow with black pattern (Fig. 65).

Head orange-yellow with black base. Pronotum with one free, transversely linear spot; base with medial 0.75 margin black, ends and middle with spot-like swelling. Scutellum black. Each elytron with orange epipleural fold; free subhumeral spot; transverse scutellar spot, not connected to 


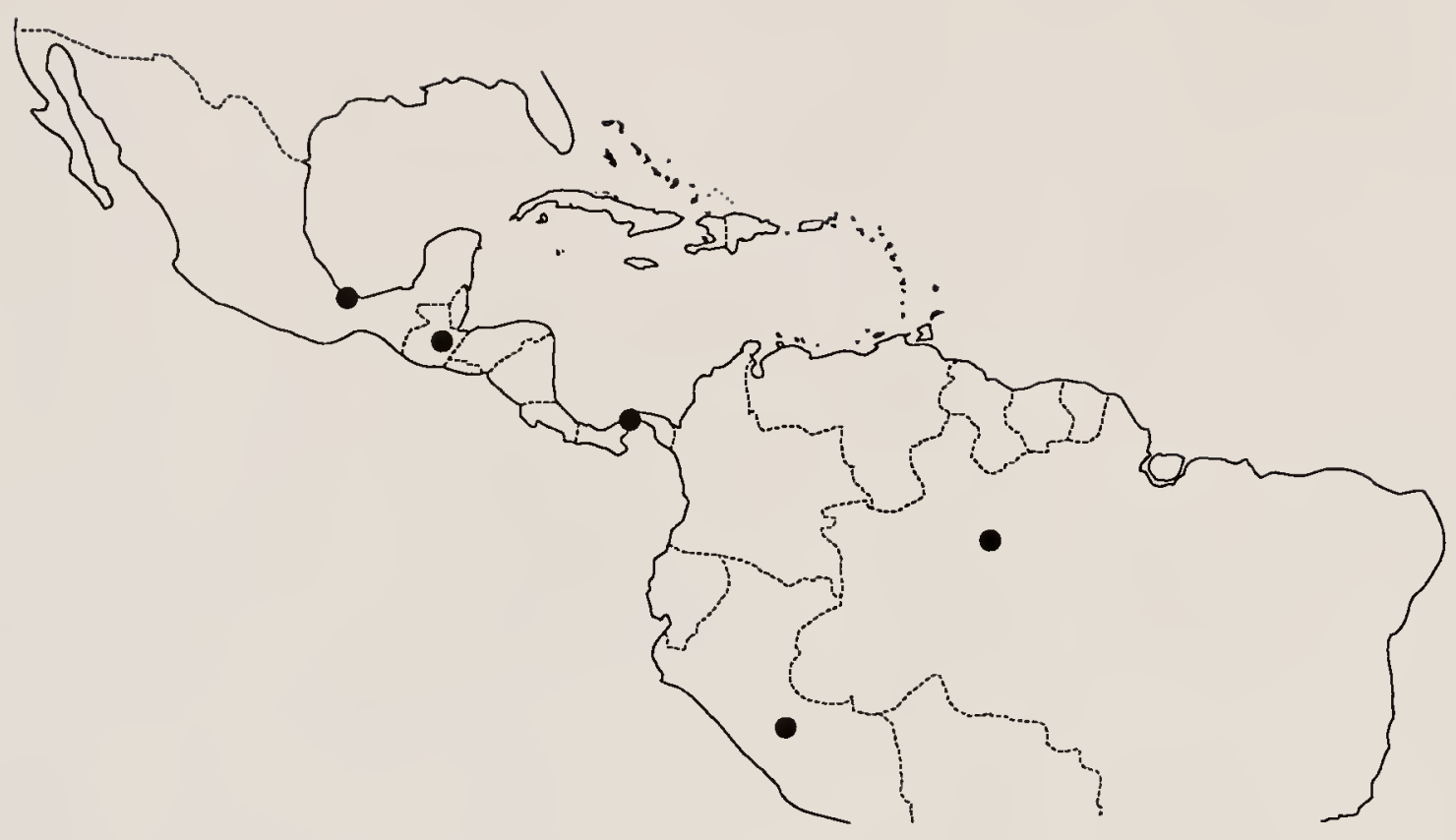

Figure 93. Ischyrus chacojae Gorham distribution map. 
base, sometimes connected to suture; subhumeral and scutellar spot occasionally connected forming band; central and lateral spots similar shape and pattern as subhumeral and scutellar spots; apical spot free, at apical third of elytra, arched anteriorly toward suture; suture with apical mark. Venter black, lateral prosternum and pronotal epipleuron orange. Appendages black; palpi, tarsi, and base of antennae brown.

Head dorsal distance between eyes $=2.5 \mathrm{x}$ eye width; ocular striae reaching 0.5 distance to anterior angle of eye, weakly continued forward; vertex puncture size $=0.75 \mathrm{x}$ facet, separated by 2 to 3 diameters; epistome puncture size $=0.5 \mathrm{x}$ facet, nearly coalescing. Antenna reaching base of pronotum; antennomere III as long as next 3 antennomere combined; antennomeres IX to XI symmetrical; antennomere XI subcircular, narrower than antennomere $X$ (similar to Fig. 61).

Maxillary palp terminal segment triangular, sides rounded, lateral angle acute, medial angle nearly 90\%, width $=2.5 \mathrm{x}$ length. Labial palp terminal segment triangular, extended medially, sides rounded, angles nearly $90^{\circ}$, length $=0.6 \times$ width. Labial palp width $=0.5 \times$ maxillary palp width (similar to Fig. 70). Mentum with plate broadly triangular, length $=0.5 \times$ width, sides concave (similar to Fig. 8h); ridge medial extension short, blunt, projecting. Pronotal disc puncture size $=0.75 \times$ facet, separated by 1 to 2 diameters; laterally puncture size $=1 \mathrm{x}$ facet, 
separated by 1 to 2 diameters. Scutellum pentagonal, length $=0.5 \times$ width. Each elytron with 7 complete striae; stria VIII present at base and apical half, often obscured by microreticulation and interval punctation; strial puncture size at base $=$ pronotal disc puncture, gradually becoming finer posteriorly; interval punctures fine, often obscured by microreticulation.

Prosternum strongly keeled and pinched anteriorly; with (female) or without (male) foveate punctures in front of procoxa; coxal lines slightly arched, length $=0.5 \times$ sternal length, lines barely surpassing coxae, length = basal width; prosternal plate flat, apical width $=0.8$ to $1.0 \mathrm{x}$ basal width; base concave.

Mesosternum basal width $=3 \times$ mesocoxal line length; coxal lines straight; base broadly sinuate. Metasternum coxal lines meet at middle, often crenate or punctate, recurved; coxal lines extend 0.5 distance to posterior lateral angle; sternum shining, medial punctures fine, coarse lateral punctures obscured by strong microreticulation.

First visible abdominal sternite with coxal lines reaching 0.33 to 0.5 distance to posterior edge; broadly rounded between metacoxae; coarse punctures laterally, fine punctures medially.

Male genitalia with median lobe weakly arched, apically rounded; internal sac without noticeable sclerotized structures; flagellum swollen at basal half, narrow on 
apical half, tip flared, length $=2 \times$ median lobe length (Fig. 89a); base of flagellum straight and swollen, sclerite at base elongate, parallel-sided (Fig. 89b-d) (4 dissected). Female genitalia with spermathecal head arched, kidneyshaped; tail narrowed, angled onto itself (Fig. 89e) (2 dissected) .

Stridulatory files not present on occipital region of female head; males heads retracted, file presence unknown. Females with foveate punctures on prosternum in front of procoxae; males lack these punctures.

Variation. The size and amount of connection between the elytral spots vary. On some specimens the elytra are banded, others are spotted. The free pronotal spot remained consistent throughout the specimens studied. There was no indication that this spot is a fusion of 2 spots as seen on I. episcaphulinus Gorham. It is always one elongate spot.

On specimens from Guatemala and Panama, the elytral spots are in a straight transverse line. On specimens from Colombia and one from Panama, the elytral spots are transverse, anteriorly convex arch.

Iype. The lectotype (here designated) Ischyrus collatinus Crotch label data: "/ [blue paper] TYPE/ [green paper] Nova Gran/ Type collatinus/ [red] LECTOTYPE Ischyrus collatinus Crotch des.P.E.Skelley 1993/" [CUMZ, studied]. Sex not determined. 
Specimens examined. The lectotype and 14 specimens, representing 12 collection records, were studied (see Appendix C for specific data).

Distribution. Guatemala, Nicaragua (Kuhnt 1909), Panama, and Colombia (Fig. 94).

Etymology. collatus: Latin = gathered together, collected. Possibly, this species was named for the single, transversely linear, free pronotal spot, unique to this species.

Taxonomic notes. The Lectotype, from the Crotch Collection, was chosen because Crotch made no indication that he saw only one specimen.

Remarks. Ischyrus collatinus is similar to I. episcaphulinus and $I$. pictus in body shape and basic color pattern. The number and shape of the free pronotal spots will separate these species. Ischyrus episcaphulinus has 2 rectangular free pronotal spots. In Ischyrus pictus the 2 free pronotal spots are circular.

References. Blackwelder 1945:465; Gemminger \& Harold 1876:3690; Gorham 1887:45; Kuhnt 1909:63; 1911:42.

\section{Ischyrus distinguendus Lacordaire}

Ischyrus distinguendus Lacordaire 1842:111.

Episcaphula distinguenda Dupont, in Lacordaire 1842:111 [nomen nudum].

Diagnosis. Unique in Ischyrus by the pronotum having only 3 basal spots, and a single large free spot on each elytron. 


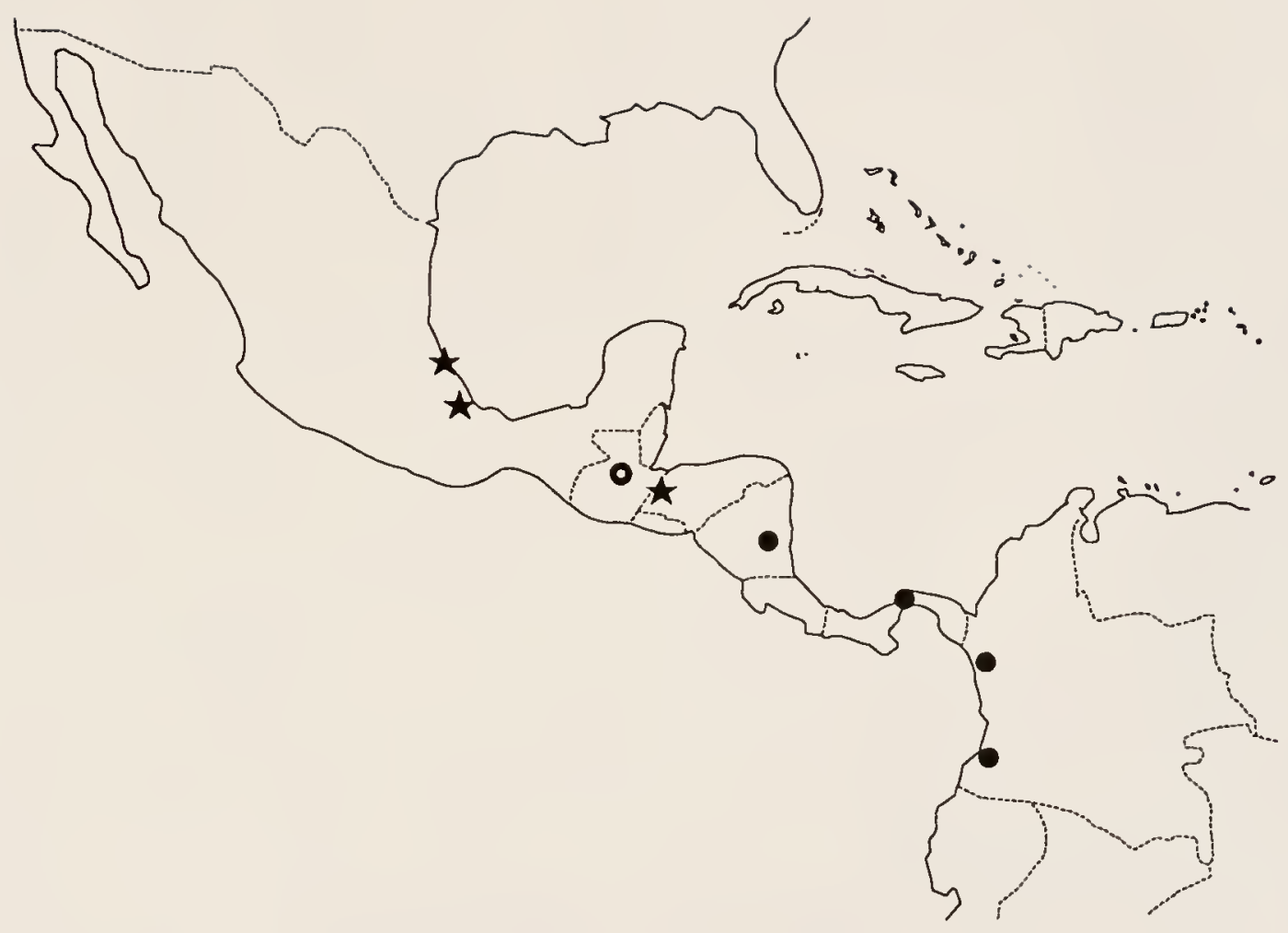

Figure 94. Ischyrus collatinus Crotch [circle] and $I$. distinguendus Lacordaire [star] distribution map. 
Description. Length: $7.2-9.3 \mathrm{~mm}$; Width $4.2-5.1 \mathrm{~mm}$. Body elongate, dorsally rounded, widest at basal third of elytra; shiny with weak microreticulations; yellow-tan to orange-red with black color pattern (Eig. 27).

Head edged in black, frons and vertex paler. Pronotum edged in black, with 3 large basal spots connected to each other at base; narrow black anterior margin between eyes. Scutellum black. Each elytron with fine black suture and lateral edge; epipleural fold basally orange and edged in black; small free scutellar spot well separated from base and suture; elongate subhumeral spot connected to base; large, free, anteriorly bilobed central spot. Venter pale except for black margins of sclerites; episterna and epimera of meso- and metathorax black. Appendages black; tarsi and palpi paler.

Head shining, width between eyes $=2.3$ x eye width; ocular striae reaching anterior angle of eye; vertex puncture size $=0.5$ to $0.75 \times$ facet, separated by 1 to 3 diameters; epistome puncture size $=0.5$ to $0.75 \mathrm{x}$ facet, separated 0.5 to 1.0 diameter. Antenna reaching middle of pronotum; antennomere III as long as next 3 antennomere combined; antennomeres X to XI asymmetrical; antennomere XI transversely circular, subtriangular (Fig. 6a).

Maxillary palp terminal segment triangular, securiform, basally rounded, apical angles nearly $90^{\circ}$, length $=0.66 \mathrm{x}$ width. Labial palp terminal segment elongate, extended on medial side, rounded basally, length $=0.75 \times$ width. Labial 
palp width $=0.5 \times$ maxillary palp width (Fig. 7a). Mentum with plate triangular, length $=0.75 \times$ width, apical sides straight or outwardly curved, ridge medial extension blunt (Fig. 8a) .

Pronotal disc puncture size $=0.5$ to $0.75 \times$ facet, separated by 1 to 3 diameters; lateral punctures smaller and denser, separated by 1 to 2 diameters. Scutellum pentagonal, length $=0.5 \times$ width. Each elytron with 7 complete striae; stria VIII weak or absent, indicated by few fine punctures at base; strial puncture size = pronotal disc punctures; intervals finely punctate.

Prosternum weakly keeled and pinched anteriorly; with few obscure foveate punctures in front of procoxa; coxal lines straight, length $=0.5 \mathrm{x}$ sternal length, barely surpassing coxae, line length $=0.8 \times$ basal width; prosternal plate flat, apical width $=0.5 \times$ basal width; base shallowly concave.

Mesosternum basal width $=2 \mathrm{x}$ mesocoxal line length; coxal lines divergent anteriorly; base sinuate, lobed medially. Metasternum coxal lines recurved, meeting medially in a tooth (Fig. 15e); coxal line extends 0.5 distance to posterior lateral angle; sternum with medial punctures fine, few scattered coarse lateral punctures.

First visible abdominal sternite with coxal lines reaching 0.5 to posterior edge; broadly rounded between metacoxae, almost truncate; coarse lateral punctures, fine medially. 
Male genitalia with median lobe moderately arched, apically truncate, slightly constricted just before tip; internal sac without noticeable sclerotized structures; flagellum long and narrow, flattened and ribbon-like at basal 0.5, length = median lobe length (Fig. 90a); base of flagellum straight, sclerite at base claw-shaped (Fig. 90bd) (4 dissected).

Female genitalia with spermathecal head oval, often with top-knot; tail swollen, weakly curved like an inverted question mark, " $\dot{c}$ " (Fig. 90e) (4 dissected).

Presence of stridulatory files on occipital region of head unknown (heads retracted). Females have few weak foveate punctures on prosternum in front of procoxa; males, at most, with a couple of punctures near the procoxae.

Variation. The color pattern was constant in all specimens studied.

Type. The lectotype (here designated) of Ischyrus distinguendus Lacordaire label data: "/ Mexique/ Distinguendus Lac./ Type/ Ex-Musaeo Mniszech/ [red] TYPE/ [pale blue] Muséum Paris ex Coll. R. Oberthür 1952/ [red] LECTOTYPE Ischyrus distinguendus Lacordaire des.P.E.Skelley 1993/" [MNHN, studied]. Sex not determined.

Specimens examined. The lectotype and 14 specimens, representing 12 collection records, were studied (see Appendix C for specific data).

Distribution. Known only from Veracruz, Mexico, and Honduras (Fig. 94). 
Etymology. distinguo: Latin = separate, discriminate. This species was probably named because of its unique, easily distinguished color pattern.

Taxonomic notes. A lectotype was designated because Lacordaire gave no indication that he studied only one specimen. In the description, Lacordaire stated that Dupont sent a specimen to him under the name "Episcaphula distinguenda." He placed it in Ischyrus, retaining the species name. The combination, "Episcaphula distinguenda", does not occur elsewhere in the literature, and is considered to be a nomen nudum.

Remarks. One specimen labeled as Biologia CentraliAmericana material [NHML], was determined as "Mycotretus ornatus var." but was not mentioned in the Biologia Centrali-America (Gorham 1887).

References. Blackwelder 1945:465; Crotch 1876:(57)433; Gemminger \& Harold 1876:3690; Gorham 1887:45, t.2 f.23; Kuhnt 1909:63; 1911:42.

\section{Ischyrus dunedinensis Blatchley}

Ischyrus tripunctatus Blatchley 1917:238, not I. tripunctatus Crotch 1873b:144.

Ischyrus dunedinensis Blatchley 1917:279, new name for I. tripunctatus Blatchley 1917:238.

Diagnosis. Recognized by 3 free pronotal spots in a transverse row, and linear free lateral elytral spot, longer than the central elytral spot.

Description. Length: 4.9-7.0 mm; Width: $2.4-3.1 \mathrm{~mm}$. Body elongate, widest at basal third of elytra; dull, 
strongly microreticulate; punctures coarse to foveate and distinctly impressed; orange with black pattern (Eig. 40).

Head black with an orange spot at each eye; spot often enlarged making black central mark hourglass-shaped. Pronotum with 3 free spots in a transverse row; lateral spots 0.25 to 0.5 size of central spot; central spot large, diameter $=0.5 \times$ or more pronotal length; base with narrow black margin on medial half. Scutellum dark orange to black. Each elytron with orange basal half of epipleural fold; subhumeral spot elongate, touching or nearly touching base; scutellar spot large, rounded, broadly attached to base and suture; sutural margin black; longitudinally elongate central spot connected to suture throughout length, widest anteriorly, truncate posteriorly; lateral spot longitudinally elongate, linear, as long or longer than central spot. Venter black with orange anterior half of prothorax and lateral abdominal sternites. Legs black; palpi and tarsi brown.

Head dorsal distance between eyes $=2.5 \mathrm{x}$ eye width; ocular striae reaching 0.75 distance to anterior angle of eye, extended forward to apical angle as row of coarse punctures; vertex puncture size $=1.5 \mathrm{x}$ facet, separated by 1 diameter; epistome puncture size $=0.75$ to $1.0 \mathrm{x}$ facet, separated by 1 diameter. Antenna reaching middle of pronotum; antennomere III as long as next 3 antennomere combined; antennomere IX can be narrower than $\mathrm{X}$; antennomeres $\mathrm{x}$ to XI asymmetrical, often appearing 
symmetrical; antennomere XI elongate transversely (similar to Fig. 6e).

Maxillary palp terminal segment triangular to semicircular, securiform, basally rounded, apical angles $90^{\circ}$, length $=0.75 \times$ width (similar to Fig. 7e). Labial palp terminal segment elongate, extended on medial side, rounded basally, length $=$ width (similar to Fig. 7a). Labial palp width $=0.5 \times$ maxillary palp. Mentum with plate broadly triangular, all sides straight and equal in length, ridge medial extension acutely pointed (similar to Fig. 8g). Pronotal disc puncture size $=1$ x facet, separated by 2 to 3 diameters; lateral punctures denser, separated by 1 diameter. Scutellum pentagonal, length $=0.5 \times$ width. Each elytron with 7 complete striae; stria VIII weak, visible on apical half; strial puncture size = pronotal disc puncture; intervals finely punctate.

Prosternum not keeled and weakly pinched anteriorly; with (female) or without (male) foveate punctures in front of procoxa; coxal lines straight, length $=0.5 \times$ sternal length, lines barely surpassing coxae, length $=0.75 \mathrm{x}$ basal width; prosternal plate flat, apical width $=0.6$ to $0.75 \mathrm{x}$ basal width; base shallowly concave.

Mesosternum basal width $=2 \times$ mesocoxal line length; coxal lines straight; base shallowly sinuate. Metasternum coxal lines not or barely meeting at middle, weakly recurved; coxal lines extend 0.13 to 0.35 distance to posterior lateral angle; line behind mesocoxa deep, groove- 
like; sternum with medial punctures fine, few coarse lateral punctures weakly impressed.

First visible abdominal sternite with coxal lines reaching 0.25 distance to posterior edge; broadly rounded between metacoxae; coarse punctures laterally, finely punctate medially.

Male genitalia with median lobe weakly arched, apically truncate, slightly constricted just before tip; internal sac without noticeable sclerotized structures; flagellum long and narrow, length $=1.5 \times$ median lobe length (Fig. 91a); base of flagellum angled, sclerite at base claw-shaped (Fig. $91 \mathrm{~b}-\mathrm{d})$ (4 dissected).

Female genitalia with spermathecal head kidney-shaped, with top-knot; tail swollen, weakly curved (Fig. 9le) (3 dissected) .

Stridulatory files present on occipital region of male head; absent on females. Females have foveate punctures on the prosternum in front of procoxae; males lack these punctures.

Variation. The pronotal free central spot is variable in shape; circular, hexagonal, quadrate, or triangular. The size of this spot varies from 0.5 to 0.9 pronotal length.

The central and lateral spots of the elytra occasionally touch at their ends. In one specimen the lateral elytral spot and humeral spot are connected forming a single linear spot. 
Type. The holotype (by monotypy) of Ischyrus dunedinensis Blatchley label data: "/ $92 /$ Type/ Dunedin, Fla, W.S.B. Coll. 2-V-16/ Ischyrus dunedinensis sp.nov./" [PURC, studied]. Sex not determined.

Specimens examined. The holotype and 72 specimens, representing 49 collection records, were studied (see Appendix C for specific data).

Distribution. Known only from extreme southeastern Georgia and the Florida peninsula (Fig. 95).

Etymology. This species was originally described as I. tripunctatus for the 3 pronotal spots. A few pages following the description, Blatchley renamed the species $I$. dunedinensis meaning "from Dunedin", the type locality.

Taxonomic Note. The name I. tripunctatus was preoccupied by Crotch $(1873 b: 144)$. Blatchley was informed of his mistake soon after his description, so he renamed it I. dunedinensis.

The Leng Catalog (1920:201) listed I. dunedinensis as occurring in Indiana, Texas, and Florida. The origin of the records for Indiana and Texas is unknown. They are most likely in error since no specimens have been studied from outside the extreme southeastern U.S.

Biology. The type specimen was collected from a bromeliad, Tillandsia utriculata L. Most of the known specimens have been collected in light traps at various localities in Florida, from the central ridge to the beach dunes. All known localities have scrub vegetation, which 


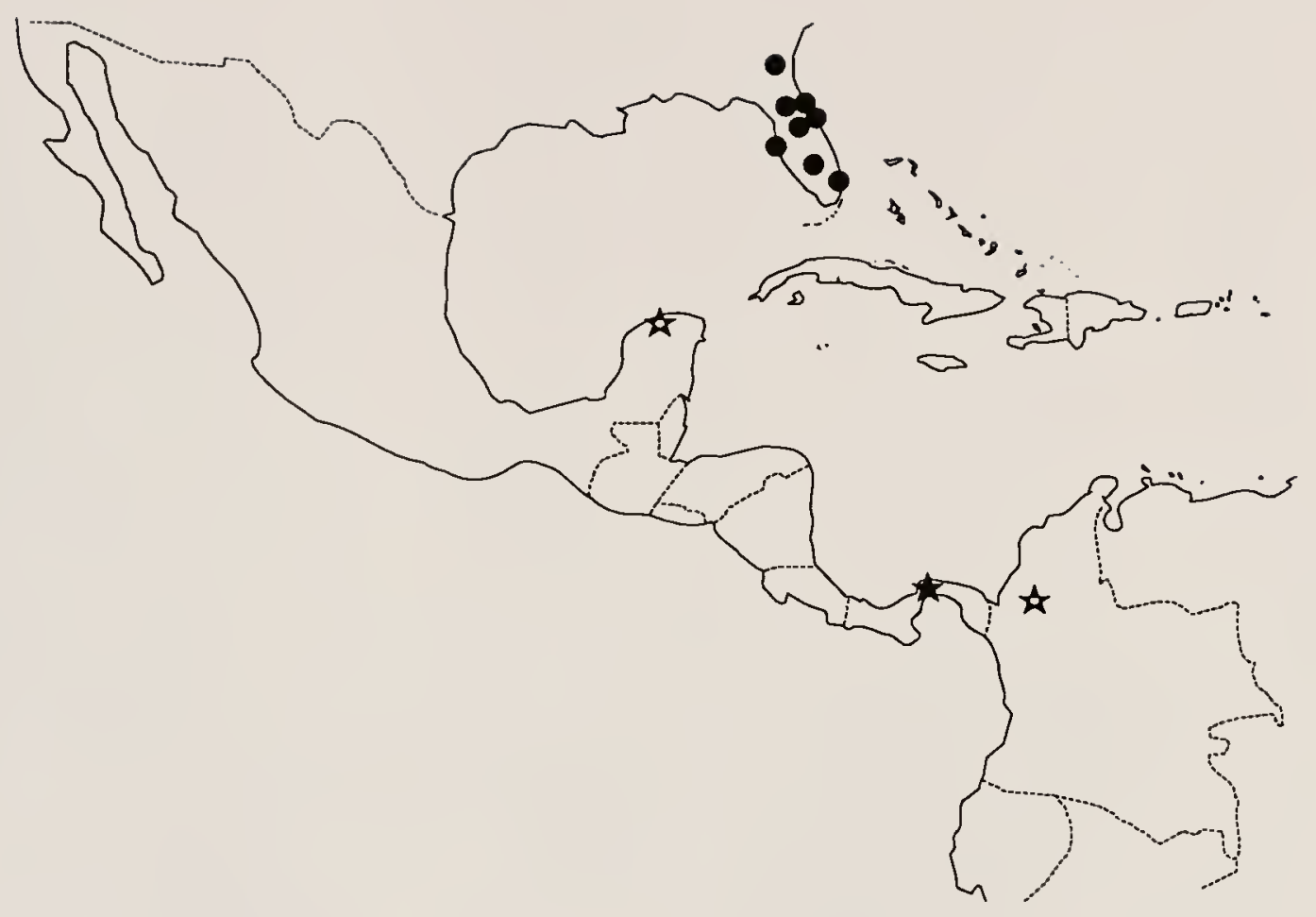

Figure 95. Ischyrus dunedinensis Blatchley [circle] and $I$. elegantulus Lacordaire [star] distribution map. 
grows in sandy soils. This type of vegetation is generally characterized as xeric. The fungal host of this species is unknown.

Remarks. Ischyrus dunedinensis is most similar to I. frontalis, and can be separate by the size of the lateral elytral spots: I. frontalis has the spot small and elongate, length less than half the central elytral spot length; I. dunedinensis has a linear lateral spot, longer than the central spot.

References. Boyle 1956:133,136; Leng 1920:201; Skelley 1988b:61-63; 1990:illustration; Skelley \& Goodrich 1989:349354; Skelley et al. 1991:65.

\section{Ischyrus elegantulus Lacordaire}

Ischyrus elegantulus Lacordaire 1842:121-122.

Diagnesis. Characterized by having 2 free pronotal spots, no basal pronotal spots, and scutellar spot narrowly connected to the elytral base, connection less than half spots' width.

Description. Length 4.2-4.9 mm; width: $2.4-2.8 \mathrm{~mm}$. Body elongate-oval, widest at basal third of elytra; microreticulate; orange-yellow with black pattern (Fig. 66).

Head orange with epistome edge black. Pronotum completely edged with black, width at base; 2 free spots on disc. Scutellum black. Each elytron with orange epipleural fold; scutellar and central spot elongate, obliquely angled forward to connect with suture; sutural margin black; subhumeral and lateral spots free, or connected with 
scutellar and central spots, respectively. Venter black, lateral prothorax occasionally orange. Appendages black; tarsi, palpi, and antennal base brown.

Head dorsal distance between eyes $=2.5 \times$ eye width; ocular striae reaching 0.5 distance to anterior angle of eye, continue weakly forward as a row of punctures; vertex puncture size $=1$ x facet, separated by 1 to 2 diameters; epistome puncture size $=0.5 \mathrm{x}$ facet, nearly coalescing. Antenna reaching base of pronotum; antennomere III as long as next 3 antennomere combined; antennomeres IX to XI symmetrical; antennomere XI subcircular, narrower than antennomere X (similar to Fig. 61).

Maxillary palp terminal segment triangular, sides rounded, lateral angle acute, medial angle nearly $90^{\circ}$, length $=0.5 \times$ width. Labial palp terminal segment triangular, extended medially, sides rounded, angles nearly $90^{\circ}$, length $=0.8 \times$ width. Labial palp width $=0.5 \mathrm{x}$ maxillary palp width (similar to Fig. 7o). Mentum with plate broadly triangular, length $=0.5 \times$ width, sides concave (similar to Fig. 8e); ridge medial extension short, acutely rounded.

Pronotal disc puncture size $=1$ x facet, separated by 1 to 2 diameters. Scutellum pentagonal, length $=0.5 \mathrm{x}$ width. Each elytron with 7 complete striae; stria VIII present at base and apical half, often obscured by interval punctation; strial puncture size at base $=2 \mathrm{x}$ pronotal disc punctures, 
gradually becoming finer posteriorly; intervals finely punctate, well defined laterally.

Prosternum strongly keeled and pinched anteriorly; with (female) or without (male) foveate punctures in front of procoxa, punctures often weakly impressed; coxal lines nearly straight, length $=0.6$ to $0.75 \mathrm{x}$ sternal length, lines barely surpassing coxae, length = basal width; prosternal plate flat, apical width $=0.8$ to $1.0 \mathrm{x}$ basal width; base concave.

Mesosternum basal width $=3 \mathrm{x}$ mesocoxal line length; coxal lines straight; base broadly sinuate. Metasternum coxal lines meeting at middle, often crenate, recurved; coxal lines extend 0.5 distance to posterior lateral angle; sternum shining, medial punctures fine, few coarse lateral punctures obscured by strong microreticulation, dulled.

First visible abdominal sternite with coxal lines reaching 0.5 distance to posterior edge; broadly rounded between metacoxae; coarse punctures laterally, fine punctures medially.

Male genitalia with median lobe short and straight, apically rounded; internal sac with paired dark patches near median lobe; flagellum weakly swollen at basal half, narrowed and thin apically, length $=2 \mathrm{x}$ median lobe length (Fig. 92a); base of flagellum straight, sclerite at base elongate, nearly parallel-sided (Fig. 92b-d) (4 dissected).

Female genitalia with spermathecal head kidney-shaped; tail narrow, looped (Fig. 92e) (5 dissected). 
Presence of stridulatory files on occipital region of head unknown (heads retracted). Males lacking prosternal foveate punctures in front of procoxae; females with few punctures, often weakly impressed.

Variation. Little variation was observed in size, shape, and color pattern. Elytral spots are occasionally connected to form bands.

A female from Yucatan, Mexico, has coarser punctation, 2 basal pronotal spots, scutellar and central spots broadly connected to the suture, and the subhumeral spot elongate, connected to base laterally (Fig. 67). This specimen may represent a distinct taxon. More specimens and study of male genitalia are needed before any separation can be made. At present, it is considered a variety of $I$. elegantulus.

Type. The lectotype (here designated) of Ischyrus elegantulus Lacordaire label data: "/ Colombie/ Elegantulus Lac./ Type/ Ex-Musaeo Mniszech/ [red] TYPE/ [pale blue] Muséum Paris ex Coll. R. Oberthür $1952 /$ [red] LECTOTYPE Ischyrus elegantulus Lacordaire des.P.E.Skelley 1993/" [MNHN, studied]. Sex apparently male, not dissected.

Specimens examined. The lectotype and 16 specimens, representing 17 collection records, were studied (see Appendix $C$ for specific data).

Distribution. Colombia and Panama to Nicaragua (Crotch 1873b) and Mexico (Fig. 95). 
Etymology. elegantulus: Latin = very fine, elegant, having grace, beauty. This name refers to the beautiful color pattern of this species.

Taxonomic notes. A lectotype was chosen because Lacordaire made no indication that only one specimen was studied. The specimen chosen is in the Oberthür Collection, fits the description, and is reported to have been studied by Lacordaire.

Remarks. Crotch (1873b) reported this species from Nicaragua. I have not been able to substantiate this record.

Ischyrus elegantulus is similar to $I$. chacojae and $I$. n. sp. 12. They can be distinguished from I. elegantulus by their large scutellar spot, broadly connected to the elytral base.

References. Blackwelder 1945:465; Crotch 1873b:144; 1876:(50)426; Gemminger \& Harold 1876:3690; Gorham 1887:40; Guérin-Méneville 1829-1838[1844]:310; Kuhnt 1909:63; $1911: 42$.

\section{Ischyrus ephippiatus Gorham}

Ischyrus ephippiatus Gorham 1887:43.

Diagnosis. Recognized by having the basal half of pronotum black, anterior pronotal markings often connecting with black base, wide central eltyral band, no apical elytral spot, and strongly constricted prosternal pinch. Description. Length: 4.4-5.5 mm; width: $2.3-2.7 \mathrm{~mm}$. Body elongate, parallel-sided, widest at basal third of 
elytra; weakly microreticulate, shining; body red to orange with black pattern; elytra yellow with black pattern (Fig. $58)$.

Head dark red to orange. Pronotum dark red with black basal half and 2 elongate, parallel spots connected to anterior margin; anterior spots may connect with the black basal half (spots fused to each other and basal half on the Lectotype). Scutellum dark red. Each elytron with yelloworange epipleural fold; scutellar spot small (lacking on the lectotype), broadly connected to base and suture; suture with wide black margin; central band appearing as 2 fused longitudinally elongate spots, not connected to lateral margin, occasionally free from suture. Venter black to dark red. Legs black, tarsi and palpi red-brown.

Head dorsal distance between eyes $=4.0 \times$ eye width; ocular striae reaching anterior angle of eye; vertex medial puncture size $=0.5 \times$ facet, separated by 1 to 2 diameters; vertex lateral puncture size $=0.75$ to $1.0 \mathrm{x}$ facet, separated by 1 to 2 diameters; epistome puncture size $=0.75$ $\mathrm{x}$ facet, separated by 0.5 to 1.0 diameter. Antenna reaching base of pronotum; antennomere III as long as next 2 antennomere combined; antennomeres IX to XI symmetrical; antennomere XI oval, transverse (similar to Fig. 6i). Maxillary palp terminal segment triangular, sides rounded, lateral angle acute, medial angle nearly $90^{\circ}$, width $=2 \times$ length. Labial palp terminal segment narrowed, rounded laterally and obtusely angled, acutely angled 
medially, length $=$ width. Labial palp width $=0.5 \mathrm{x}$ maxillary palp width (Fig. 7p). Mentum with plate triangular, length = width, all sides nearly equal in length, sides straight; ridge rounded anteriorly, without medial extension; lateral pores well removed from base (Fig. $8 j)$.

Pronotal disc puncture size $=0.5 \mathrm{x}$ facet, separated by 2 to 3 diameters; lateral puncture size $=1 \mathrm{x}$ facet, separated 1 to 2 diameters. Scutellum pentagonal, length = $0.5 \mathrm{x}$ width. Each elytron with 7 complete striae; stria VIII nearly complete but indistinct at ends, visible at middle; strial puncture size at base = lateral pronotal disc puncture, impressed, gradually becoming finer posteriorly; intervals finely punctate.

Prosternum keeled and strongly pinched anteriorly, swollen above pinch; lateral prosternum-pronotum epipleural suture deep, groove-like; with (female) or without (male) foveate punctures in front of procoxa; coxal lines sinuate, slightly concave at middle, length $=0.6 \mathrm{x}$ sternal length, lines surpassing coxae, length greater than or equal to basal width; prosternal plate narrowed anteriorly, slightly convex, apical width $=0.6 \times$ basal width; base shallowly concave.

Mesosternum basal width $=3 \mathrm{x}$ mesocoxal line length; coxal lines straight, parallel; base truncate to weakly sinuate. Metasternum coxal lines meeting at middle, often indistinct, not recurved; coxal lines extend 0.5 distance to 
posterior lateral angle; sternum shining, medial punctures fine, lateral microreticulation with few coarse punctures. First visible abdominal sternite with coxal lines reaching 0.5 distance to posterior edge; broadly rounded between metacoxae, nearly truncate; with coarse punctures laterally, fine punctures medially.

Male genitalia with median lobe short, moderately arched, apically truncate, slightly constricted just before tip; internal sac without noticeable sclerotized structures; flagellum long and hair-like, length $=3.5 \times$ median lobe length (Fig. 96a); base of flagellum straight, sclerite at base ring-shaped (Fig. 96b-d) (6 dissected).

Female genitalia with spermathecal head oval to coneshaped; tail weakly swollen and curved (Fig. 96e) (5 dissected).

Presence of stridulatory files on occipital region of head unknown (heads retracted). Males lack, or have a few, foveate punctures on prosternum in front of procoxae; females with many foveate punctures covering the surface of prosternum in front of procoxae.

Variation. The lectotype of $I$. ephippiatus differs from other specimens studied in lacking the scutellar spot and having a black pronotum with pale anterior angles.

The Bolivian specimen has the head dark red with an orange basal spot and the central elytral spots free from the sutural margin. In the other specimens the head is one 

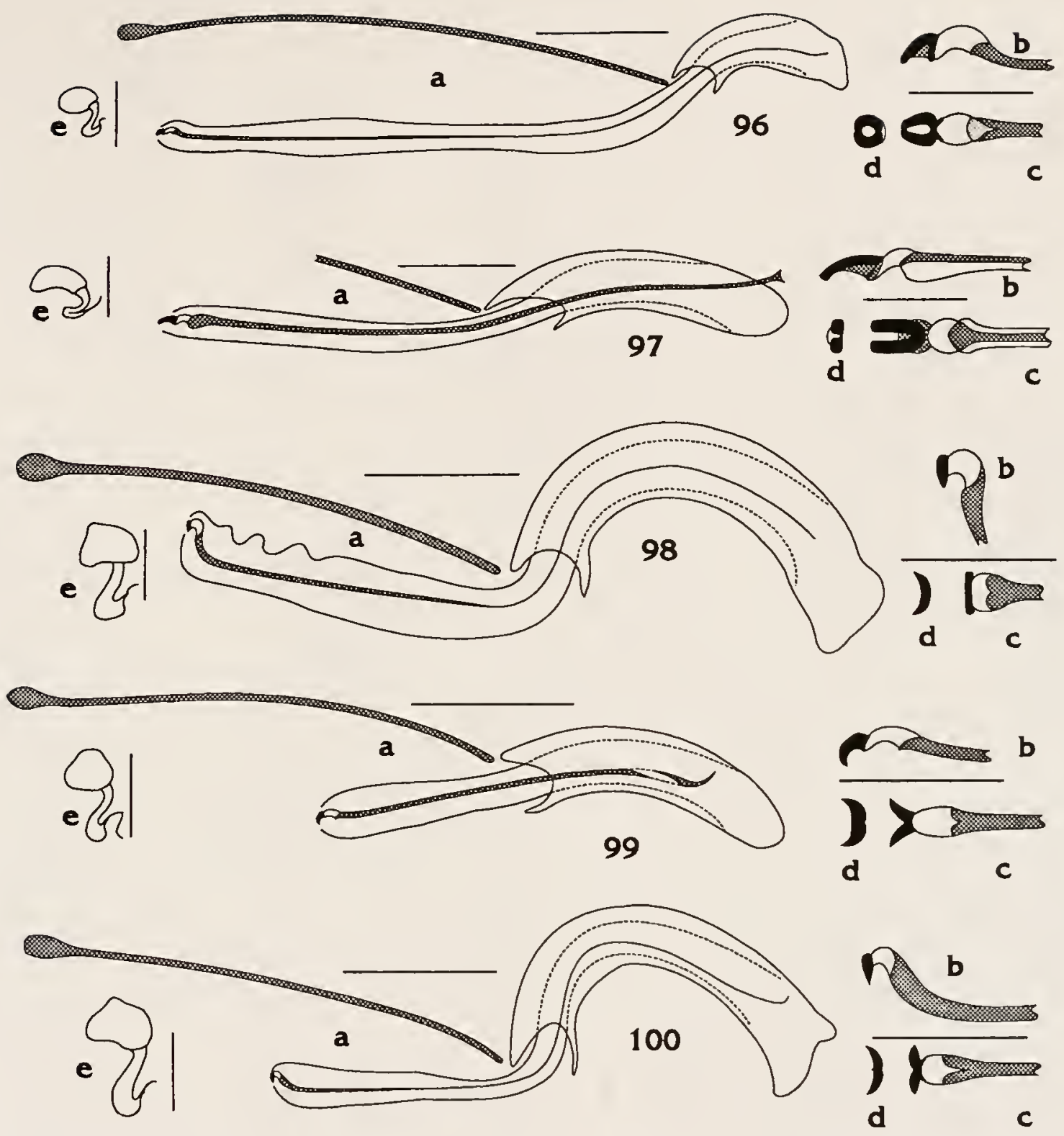

Figures 96-100. Genitalia: 96.) Ischyrus ephippiatus Gorham [male \& female, Panama]; 97.) I. episcaphulinus Gorham [male, Guatemala; female, Mexico, Chiapas]; 98.) I. frontalis Lacordaire [male, Mexico, Guerrero; female, Mexico]; 99.) I. fulmineus Delkeskamp [male \& female, Brazil, Rio Grande do Sul]; 100.) I. incertus Lacordaire [male, Mexico, Chiapas; female, Mexico, Campache]; a.) male genitalia, line $=0.66 \mathrm{~mm}$; b.) lateral view, c.) dorsal view, and d.) anterior view of the sclerotized muscle attachment at anterior end of male flagellum, line $=0.22 \mathrm{~mm}$; e.) female spermatheca, line $=0.33 \mathrm{~mm}$. 
color and the central elytral spots touch the sutural margin.

The series of specimens from Panama vary in the size and extent that the anterior pronotal spots connect with the black basal half. The majority of specimens have the spots touching the basal half, leaving a pale elongate mark between them. One specimen has the anterior spots free from the basal half.

Type. The lectotype (here designated) of Ischyrus ephippiatus Gorham label data: "/ [red circle on white paper] Type/ Bugaba, Panama, Champion./ Ischyrus ephippiatus/ B.C.A., Col., VII, Ischyrus/ [red] LECTOTYPE Ischyrus ephippiatus Gorham des.P.E.Skelley 1993/" [NHML, studied]. Sex apparently male, not dissected.

Specimens examined. The lectotype and 11 specimens, representing 10 collection records, were studied (see Appendix C for specific data).

Distribution. Panama and Bolivia (Fig. 101).

Etymology. ephippium: Latin = saddle. This species was named for the saddle-shaped central elytral spot.

Taxonomic notes. The lectotype of Ischyrus ephippiatus Gorham was chosen because Gorham stated he saw 2 specimens. Only one of these, the Lectotype, was located and studied. This group of specimens may represent separate taxa (see Variation). More material is needed to substantiate the differences observed. At present, they are considered varieties of the same species. 


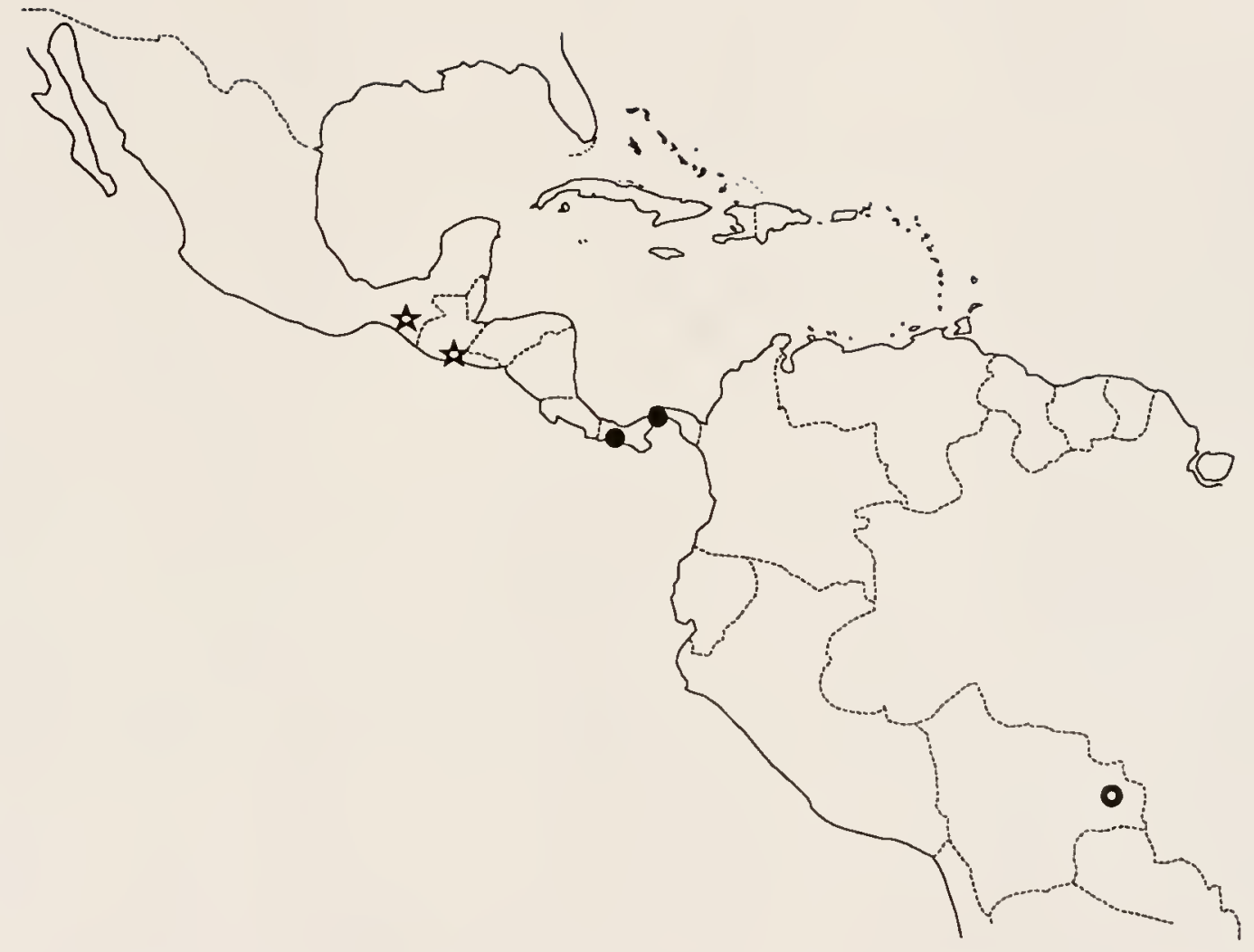

Figure 101. Ischyrus ephippiatus Gorham [circle] and I. episcaphulinus Gorham [star] distribution map. 
Remarks. Ischyrus ephippiatus is most similar to I. auriculatus in color pattern. Ischyrus auriculatus differs in having an apical elytral spot and lacks the strongly pinched prosternum.

References. Blackwelder 1945:465; Kuhnt 1909:63; $1911: 42$

\section{Ischyrus episcaphulinus Gorham}

Ischyrus episcaphulinus Gorham 1887:44, t.3 f.7.

Diagnesis. Characterized by having 2 free pronotal spots transverse and rectangular, 3 basal pronotal spots, lateral elytral spots connected to central spot, and scutellar spot not connected to elytral base.

Description. Length: $5.3-6.1 \mathrm{~mm}$; Width: $3.0-3.4 \mathrm{~mm}$. Body elongate-oval, widest at basal third of elytra; microreticulate, feebly shining; orange-yellow with black pattern (Fig. 64).

Head orange with black base and epistome margin. Pronotum with 2 Eree rectangular, transverse spots; 3 basal spots. Scutellum black. Each elytron with yellow epipleural fold yellow; elongate subhumeral spot connected to base; large scutellar spot broadly connected to suture, not connected to base; sutural margin black; central and lateral spots fused, band-like, sometimes connected to suture; apical spot free. Venter mostly orange with black sclerite margins, amount of black variable. Appendages black; palpi, tarsi, and base of antenna brown. 
Head dorsal distance between eyes $=2.5 \times$ eye width; ocular striae reaching 0.7 to 0.8 distance to anterior angle of eye; vertex puncture size = 1 x facet, separated by 1 diameter; epistome puncture size $=0.5$ to $0.75 \mathrm{x}$ facet, nearly coalescing. Antenna reaching base of pronotum; antennomere III as long as next 3 antennomere combined; antennomeres IX to XI symmetrical; antennomere XI subcircular narrower than antennomere $\mathrm{X}$ (similar to Fig. 61).

Maxillary palp terminal segment triangular, sides rounded, lateral angle acute, medial angle nearly $90^{\circ}$, width $=2 \times$ length. Labial palp terminal segment triangular, extended medially, sides rounded, angles nearly $90^{\circ}$, length $=0.8 \times$ width. Labial palp width $=0.5 \times$ maxillary palp width (similar to Eig. 70). Mentum with plate broadly triangular, length $=0.5 \mathrm{x}$ width, sides concave (similar to Fig. 8h); medial extension short, blunt, projecting. Pronotal disc puncture size $=1 \mathrm{x}$ facet, separated by 0.5 to 1 diameter. Scutellum pentagonal, length $=0.5 \mathrm{x}$ width. Each elytron with 7 complete striae; stria VIII present at base, obscured by interval punctation; strial punctures at base $=2 \times$ pronotal disc punctures, gradually becoming finer posteriorly; interval punctures fine, impressed, distinct.

Prosternum strongly keeled and pinched anteriorly; with (female) or without (male) foveate punctures in front of procoxa; coxal lines weakly arched, length $=0.5 \times$ sternal 
length, lines barely surpassing coxae, length = basal width; prosternal plate weakly convex, apical width $=0.75 \times$ basal width; base concave.

Mesosternum basal width $=3 \mathrm{x}$ mesocoxal line length; coxal lines straight; base broadly sinuate. Metasternum coxal lines meet at middle, weakly crenate, recurved; coxal lines extend 0.5 distance to posterior lateral angle; sternum shining medially, punctures finely impressed; few coarse lateral punctures obscured by strong microreticulation.

First visible abdominal sternite with coxal lines short, weak, barely surpassing coxa; broadly rounded between metacoxae; coarse punctures laterally, fine punctures medially.

Male genitalia with median lobe weakly arched, apically rounded; internal sac without noticeable sclerotized structures; flagellum long and narrow, apex flared, length $=$ $2 \times$ median lobe length (Fig. 97a); base of flagellum straight, sclerite at base elongate claw-shaped, parallelsided (Fig. 97b-d) (1 dissected).

Female genitalia with spermathecal head kidney-shaped; tail narrow, angled onto itself (Fig. 97e) (1 dissected). Presence of stridulatory files on occipital region of head unknown (heads retracted). Female with weakly impressed foveate punctures on prosternum in front of procoxae; male lacked these punctures. 
Variation. The holotype, illustrated by Gorham (1887), has the central elytral band broad, the other 2 specimens studied have the band much narrowed. This band is almost separated into 2 spots on the Mexican specimen.

Type. The holotype (by monotypy) of Ischyrus episcaphulinus Gorham label data: "/ [red circle on white paper] Type/ Zapote, Guatemala, G.C.Champion/ Ischyrus episcaphulinus/ B.C.A., Col., VII, Ischyrus/" [NHML, studied]. Sex not determined.

specimens examined. The holotype and 2 specimens, representing 2 collections, were studied. Label data: Guatemala [1, NHML]; Mexico, Chiapas, Mpio. Mapastepec, 11.5 mi. N. Mapastepec, 12-VIII-1991, P. W. Kovarik [1, PESC]. Distribution. Guatemala and Mexico (Fig. 101). Etymology. epi: Greek = upon, on; scaphion: Greek = cup-shaped like a boat. The name refers to the body shape of this species. As Gorham stated, it is "distinguished by the very convex oval form".

Remarks. Pronotal markings are intermediate between $I$. collatinus and the remainder of the species with the " 2 free-3 basal" pronotal spot pattern. The shape of the free pronotal spots is consistently different between the species. In I. pictus, the free pronotal spots are circular, and in I. collatinus the single free pronotal spot is transversely linear.

References. Blackwelder 1945:465; Kuhnt 1909:63;

$1911: 42$. 


\section{Ischyrus frontalis Lacordaire}

Ischyrus frontalis Lacordaire 1842:127.

Ischyrus agnatus Crotch 1876:426-427(50-51), Gorham $1887: 39$.

Ischyrus agnathus Crotch 1876, in Kuhnt:1909:63 [misspelling].

Diagnosis. Recognized by having 3 free pronotal spots in transverse row, central elytral fascia broken into spots, and elongate lateral elytral spots less than half the length of the central spot.

Description. Length: $5.8-7.6 \mathrm{~mm}$. Width: $2.8-3.7 \mathrm{~mm}$. Body elongate, widest at basal third of elytra; microreticulate, dull; orange with black color pattern (Fig. $38-39)$

Head orange with black basal spot. Pronotum with 3 free spots in transverse row; central spot larger than lateral spots, less than 0.5 total length of pronotum; often with fine black basal margin at medial half. Scutellum dark orange or black. Each elytron with orange epipleural fold; free subhumeral spot; large scutellar spot, broadly attached to base and suture; sutural margin black; longitudinally elongate central spot connected to suture throughout its length; longitudinally elongate lateral spot free, length = $0.5 \mathrm{x}$ or less central spot length. Venter mostly orange with black margins, amount of black variable. Legs black, paler in teneral specimens; palpi and tarsi brown.

Head dorsal distance between eyes $=2.2 \times$ eye width; ocular striae reaching 0.5 to 0.75 distance to anterior angle of eye, often finely extended forward to apical angle; 
vertex puncture size $=1 \mathrm{x}$ facet, separated 1 to 3

diameters; epistome puncture size $=0.5 \mathrm{x}$ facet, separated by 1 diameter. Antenna reaching middle of pronotum;

antennomere III as long as next 3 antennomere combined; antennomere IX can be narrower than $\mathrm{X}$; antennomeres $\mathrm{X}$ to XI asymmetrical, often weakly so and appearing symmetrical; antennomere XI transverse (similar to Fig. 6c).

Maxillary palp terminal segment triangular, securiform, basally rounded, angles nearly $90^{\circ}$, length $=0.66 \mathrm{x}$ width. Labial palp terminal segment elongate, extended on medial side, rounded basally, length $=0.75 \times$ width. Labial palp width $=0.5 \times$ maxillary palp width (similar to Fig. 7a). Mentum with plate triangular, length $=0.9 \times$ basal width, sides convex, ridge medial extension acutely pointed (similar to Fig. 8g).

Pronotal disc puncture size $=1 \mathrm{x}$ facet, separated by 1 to 2 diameters; lateral punctures separated by 0.5 diameter. Scutellum pentagonal, length $=0.5 \mathrm{x}$ width. Each elytron with 7 complete striae; stria VIII weak, visible on apical half; strial puncture size = pronotal disc puncture; intervals finely punctate.

Prosternum keeled and pinched anteriorly; with (female) or without (male) foveate punctures in front of procoxa; coxal lines straight, length $=0.5 \mathrm{x}$ sternal length, lines barely surpassing coxae, basal width $=0.8$ to $1.0 \mathrm{x}$ length; prosternal plate flat, apical width $=0.75$ to $0.9 \mathrm{x}$ basal width; base shallowly concave. 
Mesosternum basal width $=2 \mathrm{x}$ mesocoxal line length;

coxal lines straight; base shallowly sinuate. Metasternum coxal lines meet weakly at middle, if at all; coxal lines weakly recurved; line behind mesocoxa deep, groove-like; lines extend 0.33 distance to posterior lateral angle; sternum with medial punctures fine, few coarse lateral punctures.

First visible abdominal sternite with coxal lines reaching 0.33 to 0.5 distance to posterior edge; rounded between metacoxae; coarse punctures laterally, fine punctures medially.

Male genitalia with median lobe moderately arched, apically truncate, slightly constricted just before tip; internal sac without noticeable sclerotized structures; flagellum long and narrow, length $=2 \mathrm{x}$ median lobe length (Fig. 98a); base of flagellum gradually curved, sclerite at base claw-shaped (Fig. 98b-d) (4 dissected).

Female genitalia with spermathecal head kidney-shaped, often with top-knot; tail swollen, weakly curved (Fig. 98e) (4 dissected).

Presence of stridulatory files on occipital region of head unknown (heads retracted). Females have foveate punctures on prosternum in front of procoxae; males lack these punctures.

Variation. There are 2 variations in the color pattern that are difficult to separate further. The first, including the Lectotype, has the central elytral spot widest 
at the anterior end, and the lateral spot 2 times longer than wide (Fig. 38). The second has the central spot widest at the middle or posteriorly, and the lateral spot 3 times longer than wide (Fig. 39).

Some specimens have orange femora, others have black femora. Specimens with these variations are from scattered localities; some are from the same locality. This variation in color may simply be due to the specimen's age, some being teneral.

Type. The lectotype (here designated) of Ischyrus frontalis Lacordaire label data: "/ [blue paper] TYPE/ TYPE frontalis ch/ [red] LECTOTYPE Ischyrus frontalis Lacordaire des.P.E.Skelley 1993/" [CUMz, studied]. The type locality is stated by Lacordaire to be Mexico. Sex not determined.

The lectotype (here designated) of Ischyrus agnatus Crotch label data: "/ [blue paper] TYPE/ Nova Gr/TYPE agnatus/ [red] LECTOTYPE Ischyrus agnatus Crotch des.P.E.Skelley 1993/" [CUMZ, studied]. Sex not determined. specimens examined. The 2 lectotypes and 13 specimens, representing 13 collection records, were studied (see Appendix C for specific data).

Distribution. Mexico through Central America to Colombia (Nova Granada) (Fig. 102).

Etymology. frontalis: Latin= frons, front, forehead. This species may have been named for the black basal spot on the forehead. 


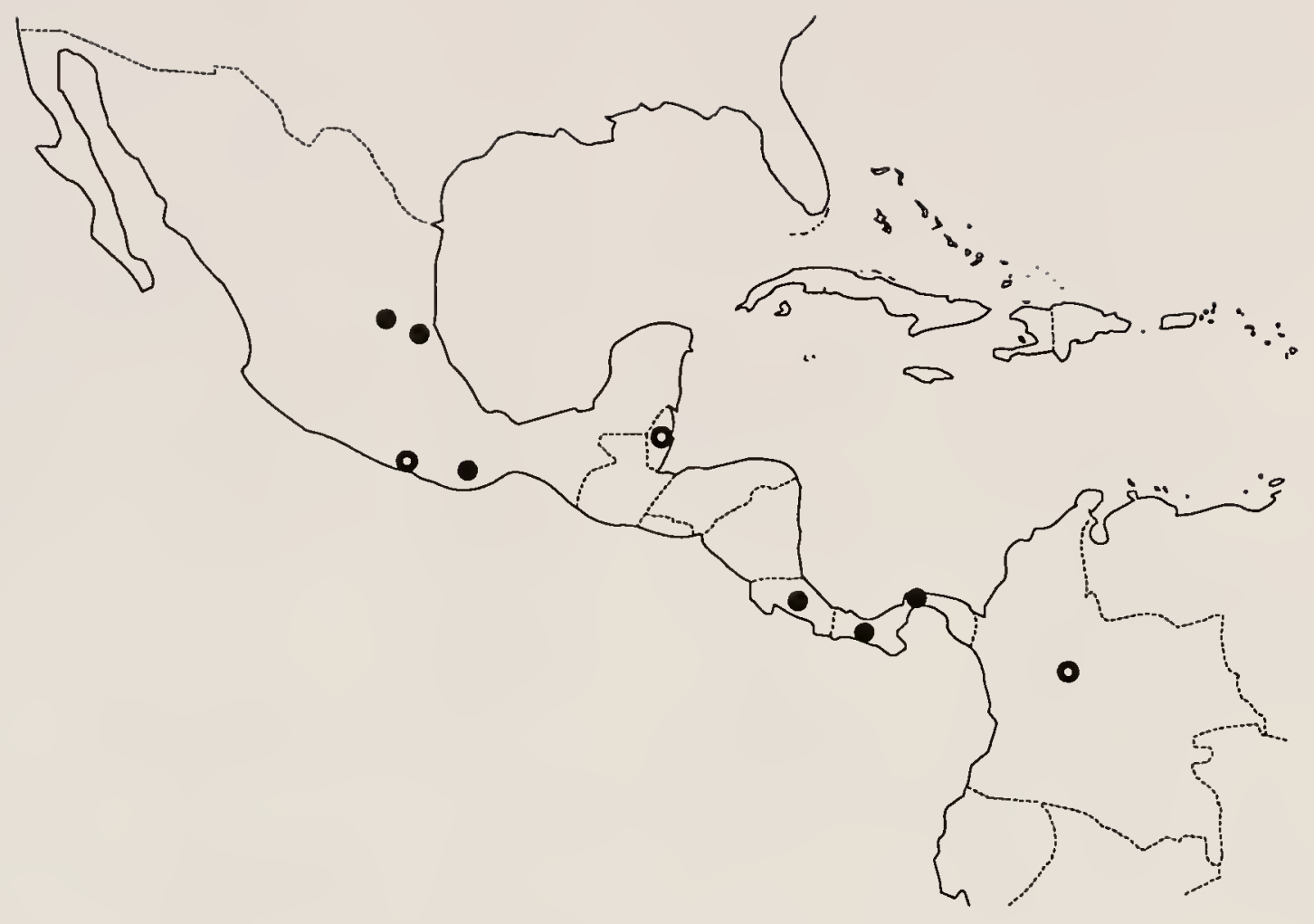

Figure 102. Ischyrus frontalis Lacordaire distribution map. 
Taxonomic notes. A lectotype was chosen for both I. frontalis Lacordaire and I. agnatus Crotch because no indication was made in the original descriptions that only one specimen was seen.

Gorham (1887:39) stated he could not find any important differences between I. frontalis and I. agnatus. After studying the types of both species, I concur with his synonymy

Remarks. Ischyrus frontalis is most similar to I. dunedinensis in color pattern. Ischyrus dunedinensis is distinguished by having the lateral elytral spots linear, and longer than the central spot.

References. Ischyrus frontalis Lacordaire: Blackwelder 1945:465; Crotch 1876:(50) 426; Gemminger \& Harold 1876:3690; Gorham 1887:39; Kuhnt 1909:63; 1911:42; Skelley \& Goodrich $1989: 349-354$.

Ischyrus agnatus Crotch: Blackwelder 1945:465; Gemminger \& Harold 1876:3690; Gorham 1887:39; Kuhnt 1909:63; $1911: 42$.

\section{Ischyrus fulmineus Delkeskamp}

Ischyrus fulmineus Delkeskamp 1957:98, 107-108.

Diagnosis. Recognized by having 4 free pronotal spots in a transverse row, a spot at each pronotal hind angle, 2 basal elytral spots set farther apart than the 2 central free pronotal spots, and a central band transversely divided by pale markings, except between stria $V$ \& VI. 
Description. Length: $5.6-6.7 \mathrm{~mm}$; width: $2.9-3.4 \mathrm{~mm}$. Body elongate, widest at basal third of elytra; weakly microreticulate, shining; pale yellow and orange-red with black pattern (Eig. 77).

Head orange-red with black lateral edge and base. Pronotum edged with black, black edge widest at base; 2 rounded anterior spots; 2 triangular basal spots, widely separated; one spot at each posterior angle as large as basal spot, connected at basal margin to basal spot; 4 free pronotal spots in anteriorly concave arch, 2 central spots often connected to anterior margin spots. Scutellum orangered with black margin. Each elytron with orange-red epipleural fold, edged in black; dorsally with pale sections near suture orange-red, laterally fading into pale yellow (except as noted); subhumeral spot reaching lateral and basal margins, connected to scutellar spot, both divided by 2 to 3 orange-red basal spots; scutellar spot shape variable, sometimes connected to base and sutural margin; suture edged in black; central band divided in middle by transverse orange-red band, except at stria V to VI where black extension connects anterior and posterior part of black central band; apical spot connected to apical and sutural margin, separated from apical angle by orange-red spot. Venter orange-red; sclerites with black margins. Legs orange-red, except for black tibial base; antennal club black, base orange-red. 
Head dorsal distance between eyes $=2.5 \times$ eye width; ocular striae reaching anterior angle of eye; vertex puncture size = 1 x facet, separated by 1 to 2 diameters; epistome puncture size $=0.5 \times$ facets, separated by 1 diameter. Antenna reaches middle of pronotum; antennomere III as long as next 3 antennomere combined; antennomeres IX to XI symmetrical; antennomere $\mathrm{X}$ wider than antennomere IX, wider than antennomere XI; similar to Fig. $6 \mathrm{~m}$ except antennomere XI wider than long.

Maxillary palp terminal segment triangular, securiform, basally rounded, apical angles acute, length $=0.5 \mathrm{x}$ width. Labial palp terminal segment elongate, extended on medial side, rounded basally, length $=0.75 \times$ width. Labial palp width $=0.5 \times$ maxillary palp width (similar to Fig. 7a). Mentum with plate triangular, length $=0.75 \times$ width, apical sides straight, ridge medial extension acute, projecting (similar to Fig. 8a).

Pronotal disc puncture size $=1$ x facet, separated by 2 to 3 diameters. Scutellum pentagonal, length $=0.6 \mathrm{x}$ width. Each elytron with 7 complete striae; stria VIII present at base and apical half; strial puncture size at base $=2 \times$ pronotal disc punctures, gradually becoming finer posteriorly; intervals finely punctate, laterally impressed and distinct.

Prosternum weakly keeled and pinched anteriorly; lacking punctures in front of procoxa; coxal lines straight, length $=0.5$ to $0.66 \times$ sternal length, lines barely 
surpassing coxae, length = basal width; prosternal plate flat, apical width $=0.5$ to $0.7 \mathrm{x}$ basal width; base concave. Mesosternum basal width $=2 \times$ mesocoxal line length; coxal lines straight; base sinuate. Metasternum coxal lines meeting at middle, weakly undulate, recurved; coxal lines extend 0.33 to 0.5 distance to posterior lateral angle; sternum shining, medial punctures fine; laterally with few coarse punctures, weakly impressed, obscured by microreticulations.

Eirst visible abdominal sternite with coxal lines reaching 0.33 distance to posterior edge; broadly rounded between metacoxae; coarse punctures laterally, fine punctures medially.

Male genitalia with median lobe weakly arched, narrowed and apically rounded; internal sac without noticeable sclerotized structures; flagellum thick with widened spearhead-like apex, widened part not sclerotized, length = $1.2 \times$ median lobe length (Fig. 99a); base of flagellum straight, sclerite at base claw-like, sclerite V-shaped in dorsal view (Fig. 99b-d) (6 dissected).

Female genitalia with spermathecal head ball-shaped with flattened face; tail swollen, weakly curved (Fig. 99e) (1 dissected).

Presence of stridulatory files on occipital region of head unknown (heads retracted). Prosternal punctation is similar in all specimens studied. 
Variation. This species is widespread in South America, yet it has a uniform color pattern throughout, varying only in the size of the orange-red markings on the elytral bands.

The specimens from Bolivia, Brazil (Santarem), and Panama have the central pronotal spots free from the anterior margin spots, although they are close to each other. These spots are connected in the specimens from Rio Grande do Sul and Mato Grosso, Brazil.

Type. The holotype (original designation) of Ischyrus fulmineus Delkeskamp label data: "/ Sarampiuni, San Carlos, 1000m, 6.9/ BOLIVIA 1950, leg.W.Foster/ [orange] Type/ Ischyrus fulmineus n.sp.det.Delkeskamp $1952 /$ Ischyrus fulmineus Delkeskamp HOLOTYPUS ["Holotypus" highlighted in pink]/" [ZSMC, studied]. Sex undetermined.

specimens examined. The holotype and 7 specimens, representing 7 collections, were studied. Label data: Bolivia, R.Japacani, e.Bolivia [1, ICCM]; Brazil, Mato Grosso, $12^{\circ} 50^{\prime} \mathrm{S}, 51^{\circ} 47^{\prime} \mathrm{W}, 5-\mathrm{X}-1968$, O. W. Richards [1, NHML]; Mato Grosso, $12^{\circ} 49^{\prime} \mathrm{S}, 51^{\circ} 45^{\prime} \mathrm{W}, 22-X I-1968$, W. J. Knight, gallery forest [1, NHML]; Para, Santarem, VI-1919, S. M. Klages [1. ICCM]; Rio Grande do Sul, S.Jerónimo, 8-X1982, T. Arignot, Col. MCN. 599964 [1, MCNZ]; same locality, 2-XI-1982, C. J. Becker, Col. MCN. 60513 [1, MCNZ]; Panama, Canal Zone, Fort Gulick, Qtrs.40.A, 1-9-XII-1979, H. J. Harlan, at lights [1, OSUC].

Distribution. Panama, Brazil, and Bolivia (Fig. 103). 


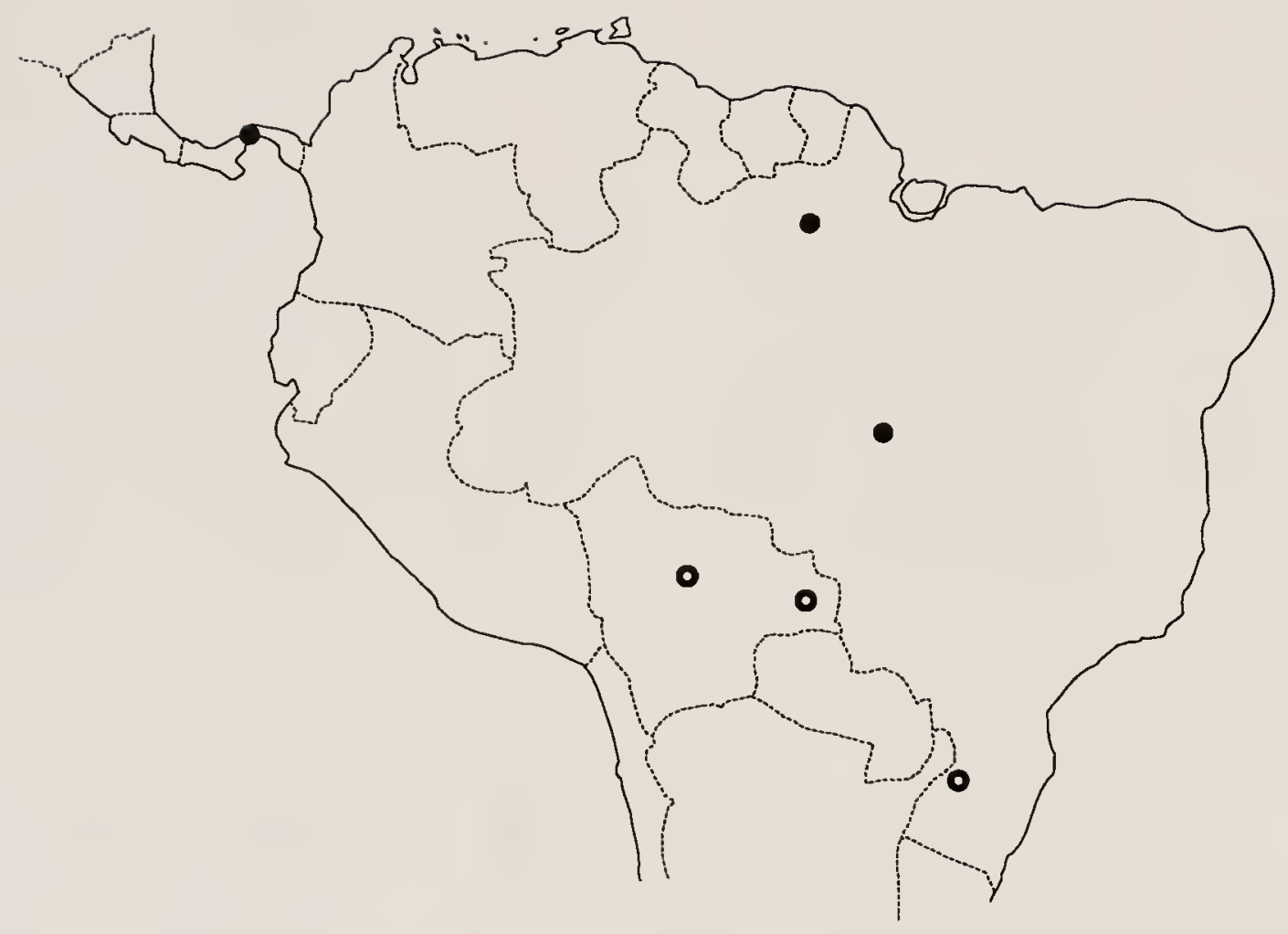

Figure 103. Ischyrus fulmineus Delkeskamp distribution map. 
Etymelegy. fulmineus: Latin = of lightning. This specific name was probably chosen because of the resemblance of the jagged elytral markings to a lightning bolt.

Remarks. Ischyrus fulmineus is most similar to I. insolens and I. n. sp. 16; I. insolens lacks basal pronotal spots, I. n. sp. 16 lacks the black connection between stria $\mathrm{V}$ and VI on the central elytral band.

\section{Ischyrus incertus Lacordaire}

Ischyrus incertus Lacordaire 1842:118-119. Mycotretus incertus Dejean 1836:429, 1837:453, [nomen nudum].

Ischyrus gratiosus Guérin-Méneville 1829$1838[1844]: 310$, new synonymy.

Diagnosis. Characterized by having 2 anterior, 2 basal, and 2 free pronotal spots, 2 free spots set farther apart than the head width (including the eyes), subhumeral spot free, legs entirely black, central elytral spot solid and triangular, and antennomeres X \& XI same size.

Description. Length: $5.1-7.2 \mathrm{~mm}$; Width: $2.8-3.8 \mathrm{~mm}$. Body elongate, widest at basal third of elytra; microreticulate, shining; yellow-orange with black pattern (Fig. 33)

Head solid black. Pronotum with 2 anterior spots connected to margin, often connected to each other along anterior margin, often squared; 2 basal spots connected to margin and to each other at base, often squared; 2 free spots widely separated, distance between centers wider than width of head including eyes. Scutellum black. Each elytron with black epipleural fold; small subhumeral spot, 
free or connected to scutellar spot; scutellar spot large, broadly connected to base and suture; suture finely margined in black; central spot large, triangular, broadly connected to suture, widest anteriorly, pointed posteriorly. Venter black, with lateral prothorax and lateral abdominal sternites orange. Legs black; palpi and tarsi brown. Head dorsal distance between eyes $=2.2 \times$ eye width; ocular striae reaching 0.75 to 1.0 distance to anterior angle of eye; vertex puncture size = 1 x facet, separated 1 to 2 diameters; epistome puncture size $=0.5 \mathrm{x}$ facet, separated by 1 diameter. Antenna reaching middle of pronotum; antennomere III as long as next 3 antennomere combined; antennomeres X to XI symmetrical; antennomere XI transverse, narrower than antennomere $\mathrm{X}$ (similar to $\mathrm{Fig}$. 61).

Maxillary palp terminal segment triangular, securiform, basally rounded, apical angles less than $90^{\circ}$, length $=0.5 \times$ width. Labial palp terminal segment elongate, extended on medial side, rounded basally, length = $0.5 \times$ width. Labial palp width $=0.5 \times$ maxillary palp width (similar to Fig. 7c). Mentum with plate triangular, length $=0.75 \times$ width, apical sides straight or outwardly curved, ridge medial extension acute (similar to Fig. 8a).

Pronotum puncture size $=1 \times$ facet, separated 1 to 2 diameters; denser laterally, separated by 0.5 to 1.0 diameter. Scutellum pentagonal, length $=0.6 \times$ width. Each elytron with 7 complete striae; stria VIII weak, visible on 
apical half; strial puncture size at base $=1.5 \mathrm{x}$ pronotal disc puncture; intervals finely punctate.

Prosternum strongly keeled and pinched anteriorly; with (female) or without (male) foveate punctures in front of procoxa; coxal lines straight, length $=0.5 \times$ sternal length, lines barely surpassing coxae, length = basal width; prosternal plate flat, apical width $=0.7$ to $0.8 \mathrm{x}$ basal width; base shallowly concave.

Mesosternum basal width $=2 \mathrm{x}$ mesocoxal line length; coxal lines straight to weakly curved; base sinuate, lobed medially. Metasternum coxal lines recurved, not meeting at middle; lines extend 0.33 to 0.5 distance to posterior lateral angle; sternum shining, with medial punctures fine; few coarse lateral punctures, twice the size of medial punctures.

First visible abdominal sternite with coxal lines reaching 0.33 to 0.5 distance to posterior edge; rounded between metacoxae; coarse punctures laterally, fine punctures medially.

Male genitalia with median lobe strongly arched, apically concave with slight constriction just before tip; internal sac without noticeable sclerotized structures; flagellum long and narrow, length $=2 \mathrm{x}$ median lobe length (Fig. 100a); base of flagellum gradually curved, sclerite at base claw-shaped (Fig. 100b-d) (3 dissected). 
Female genitalia with spermathecal head kidney-shaped, often with top-knot; tail swollen, weakly curved (Fig. 100e) ( 7 dissected).

Stridulatory files present on occipital region of male heads; absent on females. Males have a slight lateral extension of prosternum; extending 0.33 distance from sutural notch at anterior prosternal margin to lateral edge of prothorax (Fig. 13). Females have foveate punctures on prosternum in front of procoxae; males lack these punctures. Variation. The basal and anterior pronotal spots are often squared and connected at the margin. The majority of specimens has the connection less than half the spot's length. In a specimen from Panama these spots appear as single large spots.

Most specimens have the subhumeral spot free, and the scutellar and central spots well separated. In a few, the subhumeral spot touches the scutellar spot. One specimen, from Tobago, has the subhumeral spot fused with the scutellar spot. This specimen also has the scutellar and central spot connected from the suture to stria III (Lacordaire's "variété $A$ "). The other specimens studied have this connection narrowed to stria I or lacking.

Type. No specimen could be identified as a "type" of Ischyrus incertus. Lacordaire gave no indication where the "type" specimens were deposited, and their current location is unknown. Lacordaire stated in the original description 
that the species is from Cayenne (French Guiana) and Colombia.

The "type" of Ischyrus gratiosus Guérin-Méneville was not studied; its current location is unknown. GuérinMéneville stated in the original description that the species came from Colombia.

Specimens examined. A total of 40 specimens, representing 36 collection records, was studied (see Appendix C for specific data).

Distribution. Southern Mexico through Central America to Venezuela, Colombia, Trinidad, and Tobago (Fig. 104). Dejean (1836) indicated it was from "Brasilia". Lacordaire recorded it from Cayenne (French Guiana).

Etymology. incertus: Latin = doubtful. Perhaps Lacordaire used this name to indicate an uncertainty about its validity. Its color pattern is nearly identical to I. proximus Lacordaire and I. scriptus (Olivier).

Iaxonomic notes. The identity of this species is based on a female specimen in the crotch collection, label data: "/ [green] Cay./ TYPE [crossed out] incertus C.Reiche/" [CUMZ]. This specimen fits Lacordaire's description, except that the subhumeral spot touches the scuteliar spot. Lacordaire stated that these spots are separated; a character found to be variable in this species.

The second label on this specimen indicates it came from Reiche's collection, which Lacordaire studied. Whether this specimen was actually studied by Lacordaire is not 


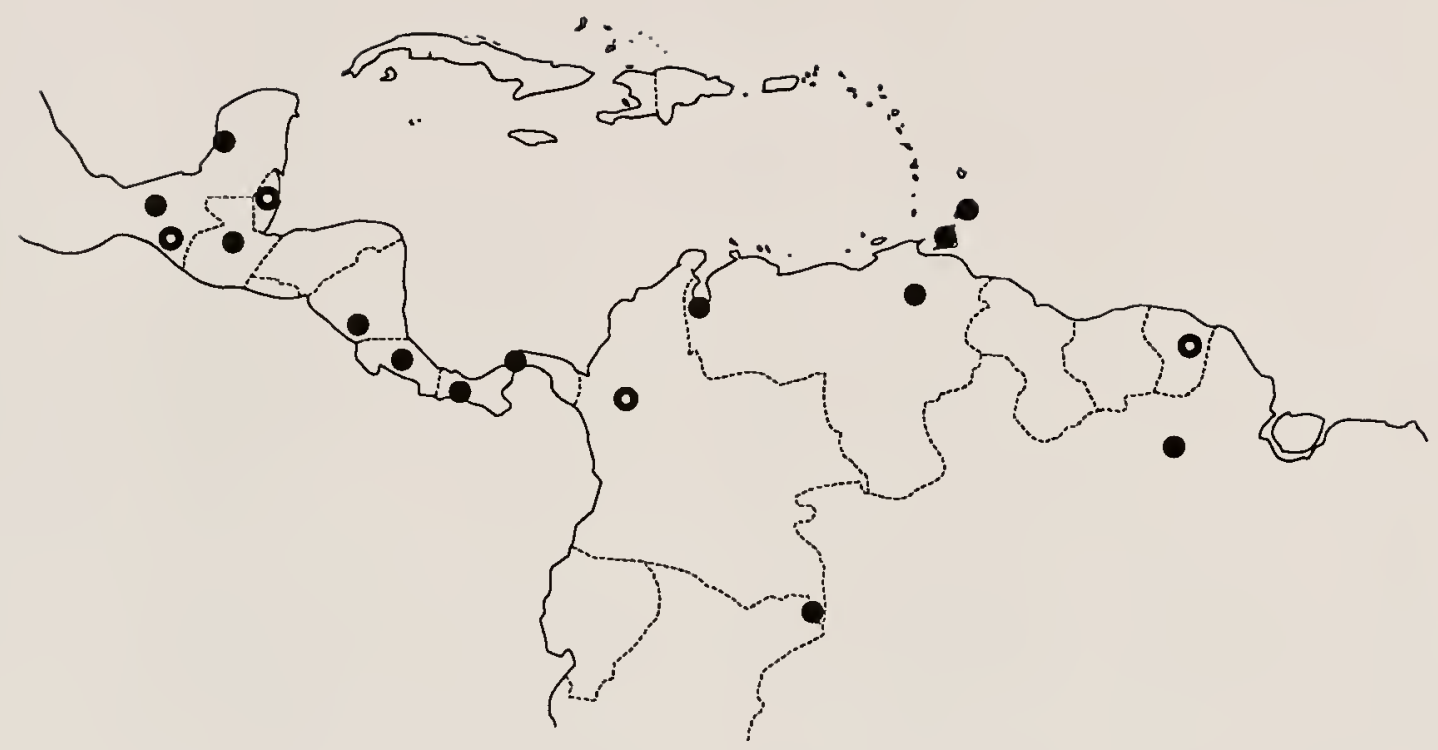

Figure 104. Ischyrus incertus Lacordaire distribution map. 
known. Since Lacordaire stated that he collected a specimen from Cayenne, the specimen from Cayenne was probably in his collection, not Reiche's. If it can be adequately shown that the specimens studied by Lacordaire are lost, or that Crotch's specimen was studied by Lacordaire, I recommend the specimen in the Crotch collection be chosen as the "type".

No "type" nor any specimens determined as Ischyrus gratiosus Guérin-Méneville were studied. The description clearly indicated that I. gratiosus is a member of the $I$. proximus, I. scriptus, and I. palliatus color pattern complex. The description fits I. incertus and matches specimens studied from Colombia and Venezuela. Based on this information I. gratiosus Guérin-Méneville is synonymized under $I$. incertus Lacordaire.

Remarks. Ischyrus incertus Lacordaire is similar to I. palliatus Lacordaire, I. scriptus (olivier), and I. proximus Lacordaire in color pattern. Despite the similarities and variability of color patterns, the 4 can be separated by the combination of characters listed in the Remarks section of I. scriptus (Olivier).

Ischyrus incertus is most similar to I. conductus Kuhnt in morphological characters and basic color pattern. Ischyrus incertus has the central elytral spot complete and triangular; I. conductus has the central elytral marking broken into linear spots.

References. Ischyrus incertus Lacordaire: Blackwelder 1945:465; Crotch 1876:(55) 431; Dejean 1836:429; 1837:453; 
Gemminger \& Harold 1876:3690; Guérin-Méneville 1829$1838[1844]: 310 ;$ Kuhnt 1909:62; 1911:42.

Ischyrus gratiosus Guérin-Méneville: Blackwelder 1945:465; Crotch 1876:(55)431; Gemminger \& Harold 1876:3690; Kuhnt 1909:62; 1911:42.

\section{Ischyrus insolens crotch}

Ischyrus insolens Crotch 1876:53(429).

Diagnosis. Characterized by having 4 free pronotal spots in a transverse row, large anterior pronotal spots, a spot at each pronotal hind angle (often reduced), no basal pronotal spots, and central elytral band transversely divided by orange marking.

Description. Length: $7.3-8.5 \mathrm{~mm}$; Width: $3.7-4.4 \mathrm{~mm}$. Body elongate, widest at basal third of elytra; weakly microreticulate, shiny; yellow and red with black markings (Fig. 28) .

Head solid black or red with basal black spot. Pronotum with 2 anterior spots, connected to each other and anterior margin; 4 free spots forming transverse arch, anteriorly concave, 2 central spots located at basal third (rarely touching base), 2 lateral spots at pronotal half; hind angle with spot, reduced in Central American specimens. Scutellum dark red with black edge. Each elytron pale yellow becoming red near suture; epipleural fold basally black or pale brown; scutellar and humeral spot connected basally (disrupted by pale marking on specimen from Paraguay); central band transversely divided by red marking; 
apical spot can connect with margin. Venter red and black, variable. Legs black or femur and tibia banded with red; tarsi and palpi brown; antenna brown, club black.

Head dorsal distance between eyes $=2.4 \mathrm{x}$ eye width; ocular striae reaching anterior angle of eye; vertex puncture size $=1$ x facet, impressed, separated by 1 to 3 diameters; epistome puncture size $=0.5$ to $0.75 \mathrm{x}$ facet, separated by 1 diameter. Antenna reaching middle of pronotum; antennomere III as long as next 3 antennomere combined; antennomere IX can be narrower than $\mathrm{X}$; antennomeres X to XI asymmetrical; antennomere XI subcircular (Fig. 6c).

Maxillary palp terminal segment triangular, securiform, basally rounded, apical angles less than $90^{\circ}$, length $=0.5 \mathrm{x}$ width. Labial palp terminal segment elongate, extended on medial side, rounded basally, length $=0.5 \times$ width. Labial palp width $=0.5 \times$ maxillary palp width (Eig. 7c). Mentum with plate broadly triangular, length $=0.5 \mathrm{x}$ width, sides weakly concave, ridge medial extension acutely pointed (Fig. 8 c).

Pronotum puncture size $=1 \mathrm{x}$ facet, separated by 1 to 2 diameters. Scutellum pentagonal, length $=0.5 \mathrm{x}$ width. Each elytron with 7 complete striae; stria VIII weak, indicated by a few punctures on apical half; strial puncture size $=2 \times$ pronotal disc punctures; intervals finely punctate. 
Prosternum keeled and pinched anteriorly; slightly expanded laterally in males; without foveate punctures in front of procoxa; coxal lines straight, length $=0.5 \mathrm{x}$ sternal length, not surpassing coxae, length $=1.5 \times$ basal width; prosternal plate flat, apical width $=0.6 \times$ basal width; base shallow V-shaped concavity.

Mesosternum basal width $=2 \times$ mesocoxal line length; coxal lines straight; base sinuate, lobed medially. Metasternum coxal lines recurved, arched as if to form a tooth, not or barely meeting medially; coxal lines faint, extend 0.33 to 0.5 distance to posterior lateral angle; sternum with medial punctures fine, few coarse lateral punctures weakly impressed.

First visible abdominal sternite with coxal lines faint, reaching 0.33 distance to posterior edge; rounded between metacoxae; coarse lateral punctures encroaching upon middle, fine punctures medially.

Male genitalia with median lobe moderately arched, apically truncate, slightly constricted just before tip; internal sac without noticeable sclerotized structures; flagellum thickened at middle, gradually narrowing to apex, length = median lobe length (Fig. 105a); base of flagellum angled, sclerite at base claw-shaped (Fig. 105b-d) (3 dissected).

Female genitalia with spermathecal head kidney-shaped, with weak top-knot; tail swollen, weakly curved (Fig. 105e) (1 dissected). 

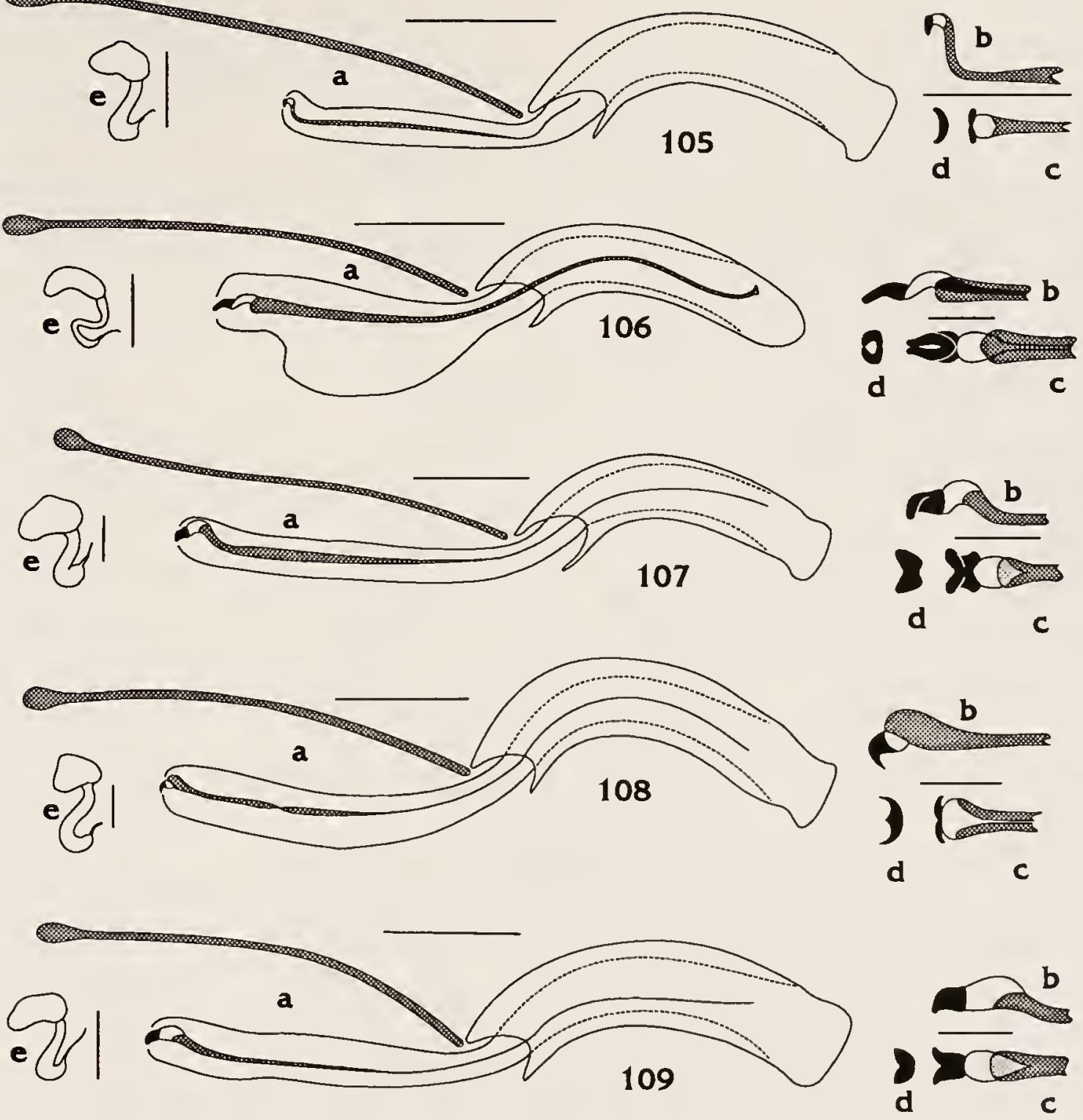

Figures 105-109. Genitalia: 105.) Ischyrus insolens Crotch [male, Mexico, Veracruz; female, Paraguay]; 106.) I. pictus Gorham [male, Mexico, Chiapas; female, Mexico, Tabasco]; 107.) I. proximus Lacordaire [male \& female, Costa Rica, Puntarenas]; 108.) I. q. quadripunctatus (Olivier) [male, USA, Florida; female, USA, Illinois]; 109.) I. scriptus (Olivier) [male, Venezuela, Bolivar; female, Argentina, Salta]; a.) male genitalia, line = $0.66 \mathrm{~mm}$; b.) lateral view, c.) dorsal view, and d.) anterior view of the sclerotized muscle attachment at anterior end of male flagellum, line $=0.22 \mathrm{~mm}$; e.) female spermatheca, line $=0.33 \mathrm{~mm}$. 
Presence of stridulatory files on occipital region of head unknown (heads retracted). Males with prosternum slightly expanded laterally, extend 0.5 distance from apical notch of suture to lateral margin of pronotum.

Variation. The specimens studied show a surprising amount of color pattern variation.

Mexican (Veracruz) specimens have black legs, red head with black base, small posterior pronotal angle spot, completely black elytral base, central elytral band smooth, apical elytral spot connected to margin, and black elytral epipleural fold. This pattern was illustrated by Gorham (1887).

Bolivian specimens have black legs, black head, large posterior pronotal angle spot, solid black elytral base, central elytral black band deeply cut (zig-zag), apical elytral spot connected to margin, and black elytral epipleural fold.

The Paraguay specimen has banded femora, red head with black central basal spot, large posterior pronotal angle spot, black basal elytral band broken by pale spots, central elytral band deeply cut almost into stripes, apical elytral spot free, and red elytral epipleural fold. Similar pattern differences indicate separate entities in other taxa and may indicate that this is distinct. The only specimen studied of this color pattern is a female, while dissected specimens of the other color patterns are males, making genitalic comparisons impossible. 
Type. The lectotype (here designated) of Ischyrus insolens Crotch label data: "/ Toxpam, Mexico, Sallé Coll./ [green] 2393/ sp. figured/ Ischyrus insolens, Crotch, apud Sallé/ B.C.A., Col. VII Ischyrus/ [red] LECTOTYPE Ischyrus insolens Crotch des.P.E.Skelley 1993/" [NHML, studied]. Sex not determined. Selander \& Vaurie (1962) did not locate "Toxpam", and stated that it is possibly a misspelling of Tuxpan, Veracruz, Mexico.

specimens examined. With the lectotype, one paralectotype was studied, label data: "/ Toxpam/ Mexico, Sallé Coll./ Ischyrus insolens, Crotch, apud Sallé/ B.C.A., Col., VII, Ischyrus/ [yellow] PARALECTOTYPE Ischyrus insolens Crotch des.P.E.Skelley 1993/" [1, NHML].

In addition to the types 1 isted above, 6 specimens, representing 6 collection records, were studied. Label data: Bolivia, Beni, Huachi, Rio Beni, IX, W. M. Mann [1, USNM]; La Paz, San Lorenzo, 12 km Caranavi, 1-2-I-1991, J. V. McHugh, JVM lot B91-11 [1, JVMC]; La Paz, Yungas La Paz, Puente Mururrata to Suapi, 24-28-XI-1984, L. Peña, 1200$1600 \mathrm{~m}$ elev. [1, HNHM]; Mexico, B.C.A.,Col.,VII [1, NHML]; Veracruz, Fortin de las Flores, Sumidero, 22-23-V-1965, H. V. Weems, Jr., 2500-3000' elev., blacklight [1, FSCA]; Paraguay, P.Cantera, C. Schrottky [1, MACN] .

Distribution. Mexico, Bolivia, and Paraguay (Fig. 110). 


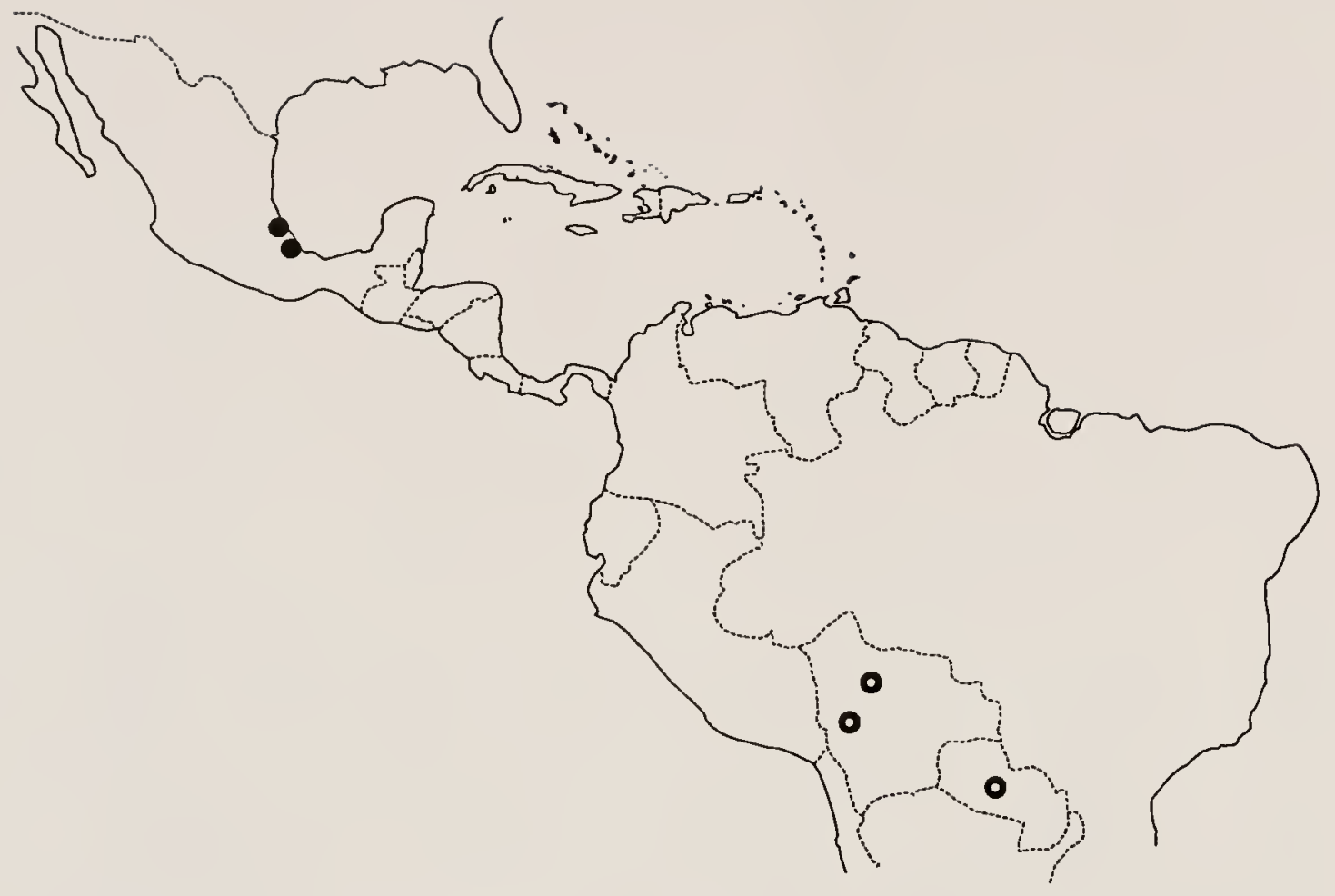

Eigure 110. Ischyrus insolens crotch distribution map. 
Etymology. insolens: Latin = proud, haughty. Crotch probably named this species because of the brilliant colors it bears.

Taxonomic notes. A lectotype was chosen because crotch made no indication that only one specimen was seen. The specimen chosen matched the label data, origin (ex Sallé collection), and characters given in the original description. In addition, the specimen chosen was illustrated by Gorham (1887) in the Biologia CentraliAmericana.

Remarks. Ischyrus insolens is most similar to $I$. fulmineus and I. n. Sp. 16 in color pattern. They differ from $I$. insolens in having 2 basal pronotal spots.

References. Blackwelder 1945:465; Delkeskamp 1957:107108; Gemminger \& Harold 1876:3690; Gorham 1887:43, t.2 f.20; Kuhnt 1909:64, t.3 f.6; 1911:43.

\section{Ischyrus pictus Gorham}

Ischyrus pictus Gorham 1887:42, t.3 f.4.

Diagnosis. Characterized by the pronotum having only 2 circular free spots with 3 basal spots, and the free lateral and apical elytral spots.

Description. Length: 4.7-7.2 mm; Width: $2.6-3.9 \mathrm{~mm}$. Body elongate-oval, widest at basal third of elytra; microreticulate, shining; orange-yellow with black pattern (Fig. 62) .

Head black with orange spot at each eye, orange spots often large and connected at middle forming one large 
central spot. Pronotum with 2 free spots; 3 basal spots connected to black basal margin. Scutellum black. Each elytron with epipleural fold entirely black or orange with black margins; humeral spot connected to base, rarely free; large scutellar spot broady connected to base and suture, rarely free from base (see Variation); suture with black margin; central spot rarely free; free lateral spot located at elytral half; apical spot free. Venter mostly orange with black sclerite margins. Appendages black, palpi and tarsi brown.

Head dorsal distance between eyes $=2.5 \times$ eye width; ocular striae reaching 0.75 distance to anterior angle of eye, often continued forward as a row of punctures; vertex puncture size $=1$ x facet, separated by 1 to 2 diameters; epistome puncture size $=0.75 \mathrm{x}$ facet, nearly coalescing. Antenna reaching basal 0.25 of pronotum; antennomere III as long as next 3 antennomere combined; antennomeres IX to XI symmetrical; antennomere XI subcircular, narrower than antennomere $\mathrm{X}$ (similar to Fig. 61).

Maxillary palp terminal segment triangular, sides rounded, lateral angle acute, medial angle nearly $90^{\circ}$, width $=2 \times$ length. Labial palp terminal segment triangular, extended medially, sides rounded, angles nearly $90^{\circ}$, length $=0.8 \times$ width. Labial palp width $=0.5 \times$ maxillary palp width (similar to Fig. 7o). Mentum with plate broadly triangular, length $=0.5 \times$ width, sides concave (similar to Fig. 8h); ridge medial extension short, blunt, projecting. 
Pronotal disc puncture size $=1 \times$ facet, separated by 1 to 2 diameters. Scutellum pentagonal, length $=0.5 \mathrm{x}$ width. Each elytron with 7 complete striae; stria VIII faint, present at base and apical half; strial punctures at base = 2 pronotal disc punctures, gradually becoming finer posteriorly; intervals finely punctate, impressed and distinct.

Prosternum strongly keeled and pinched anteriorly; with or without foveate punctures in front of procoxa, weakly impressed and obscure when present; coxal lines slightly arched or straight, length $=0.6 \mathrm{x}$ sternal length, lines barely surpassing coxae, length $=0.75 \times$ basal width; prosternal plate weakly convex, apical width = basal width; base concave.

Mesosternum basal width $=3 \mathrm{x}$ mesocoxal line length; coxal lines straight, parallel to divergent anteriorly; base sinuate. Metasternum coxal lines meeting at middle, strongly crenulate or punctured, recurved; coxal lines extend 0.33 to 0.5 distance to posterior lateral angle; sternum with medial punctures fine, impressed; few coarse lateral punctures often obscured by strong microreticulation.

First visible abdominal sternite with coxal lines short, extending 0.33 to 0.5 distance to posterior margin; broadly rounded between metacoxae; coarse punctures laterally, fine punctures medially. 
Male genitalia with median lobe weakly arched, apically rounded; internal sac without noticeable sclerotized structures; flagellum long and thick, apex flared, length = $1.6 \times$ median lobe length (Fig. 106a); base of flagellum straight and swollen, sclerite at base elongate, claw-shaped (Fig. 106b-d) (3 dissected).

Female genitalia with spermathecal head elongate, kidney-shaped; tail narrow, looped (Fig. 106e) (3 dissected).

Presence of stridulatory files on occipital region of head unknown (heads retracted). No consistent sexual difference was observed in the presence or absence of prosternal punctures.

Variation. A specimen (Fig. 63) from Oaxaca, Mexico, is similar to the description above, even in the genitalic characters. It differs in having the head mostly orange, elytral suture with small subapical spot, free subhumeral spot, minute humeral spot, scutellar spot not connected to the base, and prosternum slightly longer than wide.

Type. The holotype (by monotypy) of Ischyrus pictus Gorham label data: "/ [red circle on white paper] Type/ Type, sp. figured/ San Juan, Vera Paz., Champion/ Ischyrus pictus Gorh/ B.C.A., Col., VII, Ischyrus/" [NHML, studied]. Sex not determined. Gorham (1887) stated that the type locality is in Guatemala. 
Specimens examined. The holotype and 16 specimens, representing 13 collection records, were studied (see Appendix C for specific data).

Distribution. Honduras, Guatemala, and southern Mexico (Eig. 111)

Etymology. pictus: Latin = painted, colored. Undoubtedly named for the distinctive color pattern. Taxonomic notes. The variation mentioned above may represent a west Mexican variety or a distinct taxon. No conclusions can be made based on the single specimen studied.

Remarks. Ischyrus pictus is most similar to I. episcaphulinus and I. collatinus in color pattern. The circular free pronotal spots will separate I. pictus from these species which have transverse, rectangular, free pronotal spots.

References. Blackwelder 1945:465; Kuhnt 1909:63; 1911:43; Pal1ister 1955b:7.

\section{Ischyrus proximus Lacordaire}

Ischyrus proximus Lacordaire 1842:113.

Ischyrus sexpunctatus Chevrolat, in Lacordaire 1842:113 [nomen nudum].

Diagnesis. Recognized by the pronotum having 2 anterior, 2 free, and 2 basal spots, 2 free pronotal spots set closer together than head width (including eyes), hind pronotal angles without spots, legs entirely black, subhumeral spot connected to scuteliar spot, and orange elytral epipleural fold. 


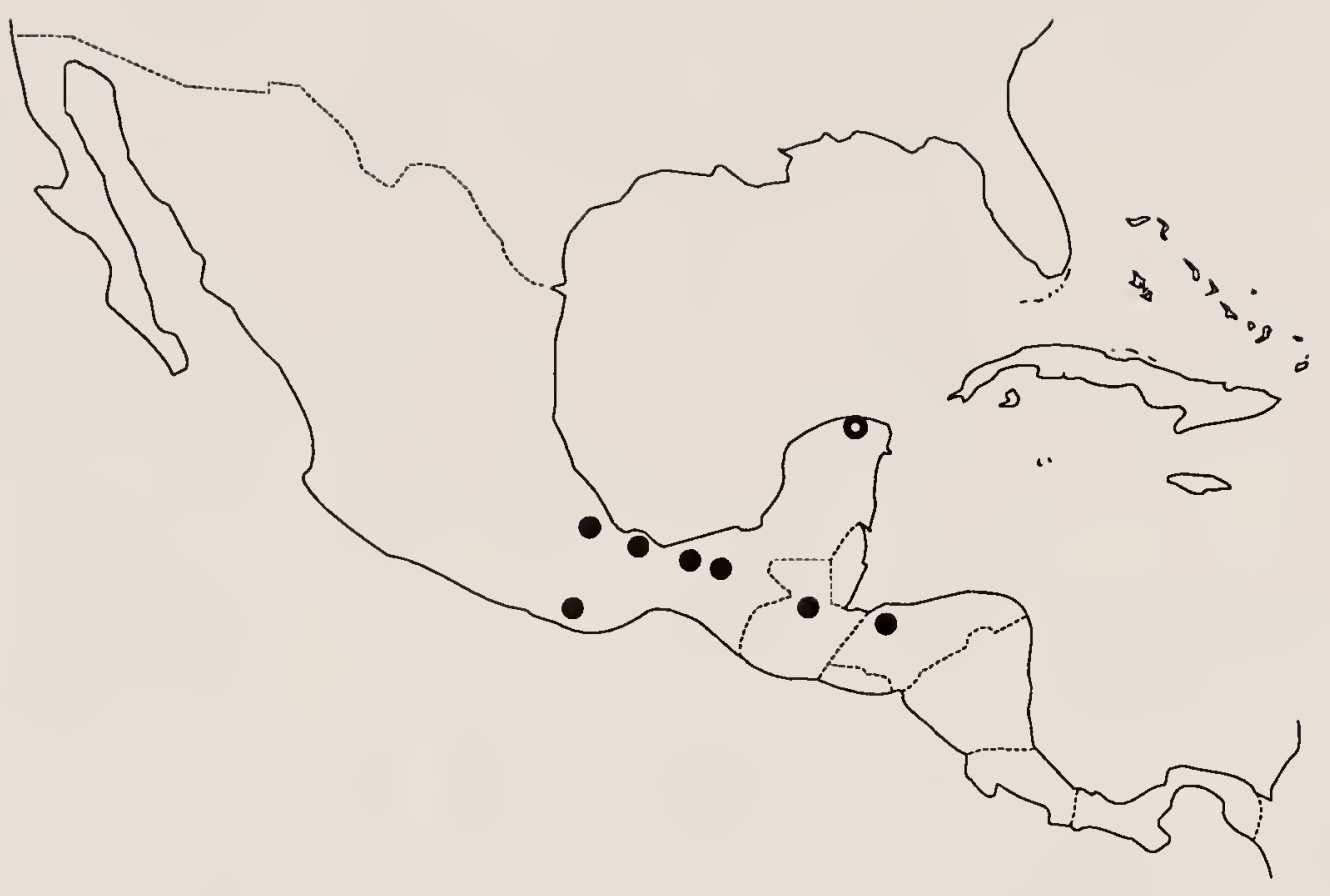

Figure 111. Ischyrus pictus Gorham distribution map. 
Description. Length: $6.0-8.2 \mathrm{~mm}$; width: $3.1-4.4 \mathrm{~mm}$. Body elongate, widest at basal third of elytra; dull, microreticulate; yellow to orange with black color pattern (Fig. 34)

Head solid black or with varying amounts of orange on the epistome and vertex. Pronotum with 2 anterior spots and 2 basal spots connected to margin; 2 free spots set so distance between centers is less than head width including eyes; all pronotal spots together form longitudinally elongate circle; base with thin black margin on central half. Scutellum black. Each elytron with orange epipleural fold, rarely dark and appearing black; subhumeral spot connected to large scutellar spot, rarely free; scutellar spot broadly connected to base and suture; suture black; central spot roughly triangular, broadly connected to suture from elytral half nearly to apex, anteriorly widened, posteriorly blunt, rarely swollen apically, with 2 indentations on anterior and posterior edges giving the spot the appearance of being formed from the fusion of 3 spots. Venter black with orange lateral margins of sclerites. Appendages black; palpi and tarsi brown.

Head dorsal distance between eyes $=2 \times$ eye width; ocular striae reaching 0.5 distance to anterior angle of eye, continued forward as row of punctures; vertex puncture size = 1 x facet, separated by 1 to 3 diameters; epistome puncture size $=0.75 \times$ facet, separated by 1 diameter. Antenna reaching basal 0.25 of pronotum; antennomere III as 
long as next 3 antennomere combined; antennomere IX narrow, nearly triangular; antennomeres $\mathrm{X}$ to XI asymmetrical (similar to Fig. 6c).

Maxillary palp terminal segment triangular, securiform, sides nearly straight, apical angles nearly $90^{\circ}$, length $=0.66 \times$ width. Labial palp terminal segment elongate, extended on medial side, rounded basally, length = $0.75 \times$ width. Labial palp width $=0.5 \times$ maxillary palp width (similar to Fig. 7a). Mentum with plate triangular, all sides of equal length, length $=0.6 \times$ width, sides straight, ridge medial extension acutely pointed (similar to Eig. 8d).

Pronotum puncture size $=1$ x facet, separated by 2 to 3 diameters. Scutellum pentagonal, length $=0.5 \times$ width. Each elytron with 7 complete striae; some specimens with stria VIII weak on apical half of elytra; strial puncture size at base $=$ pronotal disc puncture; intervals finely punctate.

Prosternum keeled and pinched anteriorly; with few weakly impressed foveate punctures in front of procoxa; coxal lines straight, length $=0.5 \times$ sternal length, lines barely surpassing coxae (Fig. 11a), length = basal width; prosternal plate flat, apical width $=0.5 \times$ basal width; base shallowly concave.

Mesosternum basal width $=2 \times$ mesocoxal line length; coxal lines straight to weakly curved; base sinuate, lobed medially. Metasternum coxal lines weakly recurved, meeting 
medially (Eig. 16a); coxal lines extend 0.5 distance to posterior lateral angle (Fig. 9a); sternum with medial punctures fine, few coarse lateral punctures $3 \mathrm{x}$ larger than medial punctures.

First visible abdominal sternite with coxal lines reaching 0.5 distance to posterior edge; broadly rounded between metacoxae; coarse punctures laterally, fine medial punctures dense.

Male genitalia with median lobe moderately arched, apically truncate, slightly constricted just before tip; internal sac without noticeable sclerotized structures; flagellum long and narrow, length $=1.9 \mathrm{x}$ median lobe length (Eig. 107a); base of flagellum curved, sclerite at base blunt claw-shaped and thickened at connection with flagellum (Fig. 107b-d) (5 dissected).

Eemale genitalia with spermathecal head kidney-shaped, often with top-knot; tail swollen, tightly curved like an inverted question mark, "i" (Eig. 107e) (13 dissected).

Stridulatory files on occipital region of head present in males; female specimens had heads retracted, presence unknown. Females with lateral patch of foveate punctures on prosternum in front of procoxae; males have, at most, 5 to 6 punctures immediately in front of procoxae.

Variation. Gorham (1887:40) comments on the differences in head color in this species, solid black or with orange epistome and vertex, and illustrated each form. In all of the specimens examined, the proportion of black 
heads to red heads is nearly $2: 1$. Most series of specimens show one or the other color; some bear both colors. The difference in color does not appear to correlate with geographic range or any other characteristics which would allow separation of the two.

Occasionally a specimen was studied in which the elytral epipleural fold appeared black. These could be confused with other species (I. scriptus and I. palliatus). Characters used in the key will allow adequate separation of these species (see Remarks section under I. scriptus).

The subhumeral spot is rarely separated from the scutellar spot. In these specimens, the other color characteristics will serve to distinguish them (see Remarks section under I. scriptus).

Type. The lectotype (here designated) of Ischyrus proximus Lacordaire label data: "/ Mexico/ Type proximus Ch./ [blue paper] TYPE/ [red] LECTOTYPE Ischyrus proximus Lacordaire des.P.E.Skelley/" [CUMz, studied]. Sex apparently male, not dissected.

Specimens examined. The lectotype and 78 specimens, representing 46 collection records, were studied (see Appendix C for specific data).

Distribution. Widespread from Mexico to Panama and Bolivia (Fig. 112).

Etymology. proximus: Latin = nearest. Maybe Lacordaire named it "proximus" because of its similarity to other species. 


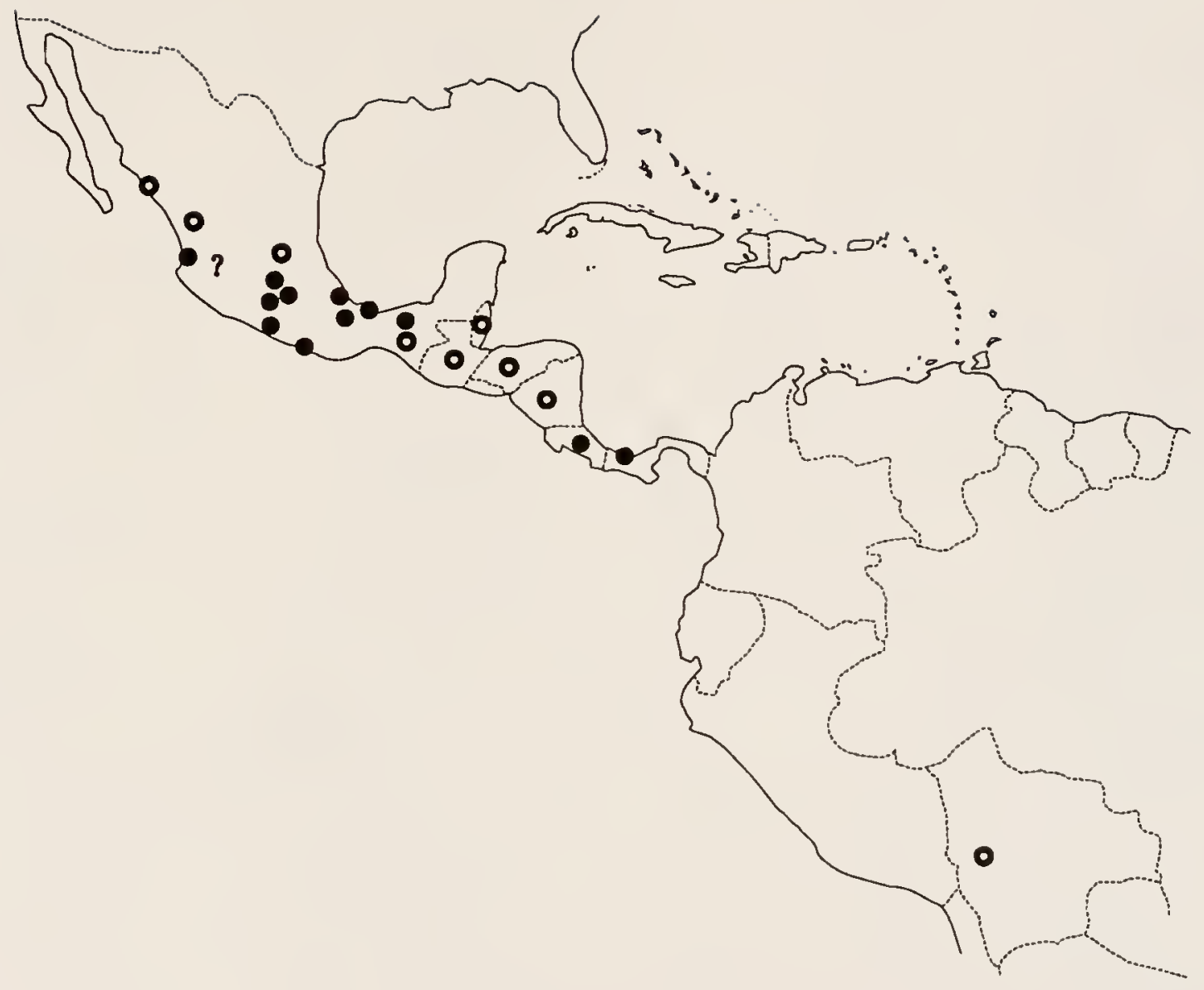

Figure 112. Ischyrus proximus Lacordaire distribution map. 
Taxonomic notes. Lacordaire stated that he received the specimen from Chevrolat under the name "6-punctatus". He proposed a different name because "6-punctatus" was already in use for another species in the "family".

The lectotype was designated because there is no indication that Lacordaire saw only one specimen. The specimen in Crotch's collection fits Lacordaire's description and is labeled "Ch.", indicating it came from Chevrolat's collection. This specimen, from Mexico, has the head entirely black.

Biology. A series of 4 specimens from Costa Rica is labeled "an Pilzbelag und trocknem Holz", which basically means "on fungus covering dry wood". Other biological label data: "at night on plants", "rain forest", and "lights, broad leaf forest".

One small series was collected on the fungus Schizopora paradoxa (Fr.)Donk in Costa Rica. This white rot fungus of wood is a white resupinate polypore when in fruit.

Remarks. Ischyrus proximus Lacordaire is similar to $I$. palliatus Lacordaire, I. scriptus (Olivier), and I. incertus Lacordaire in color pattern. Despite the similarities and variability of color patterns, they can be separated by the combination of characters listed in the Remarks section of I. scriptus (Olivier).

References. Blackwelder 1945:465; Crotch 1876:430(54); Gemminger \& Harold 1876:3691; Gorham 1887:40, t.2 f.21-22; Kuhnt 1909:62; 1911:43; Pittier \& Biolley 1895:37. 
Ischyrus quadripunctatus (olivier)

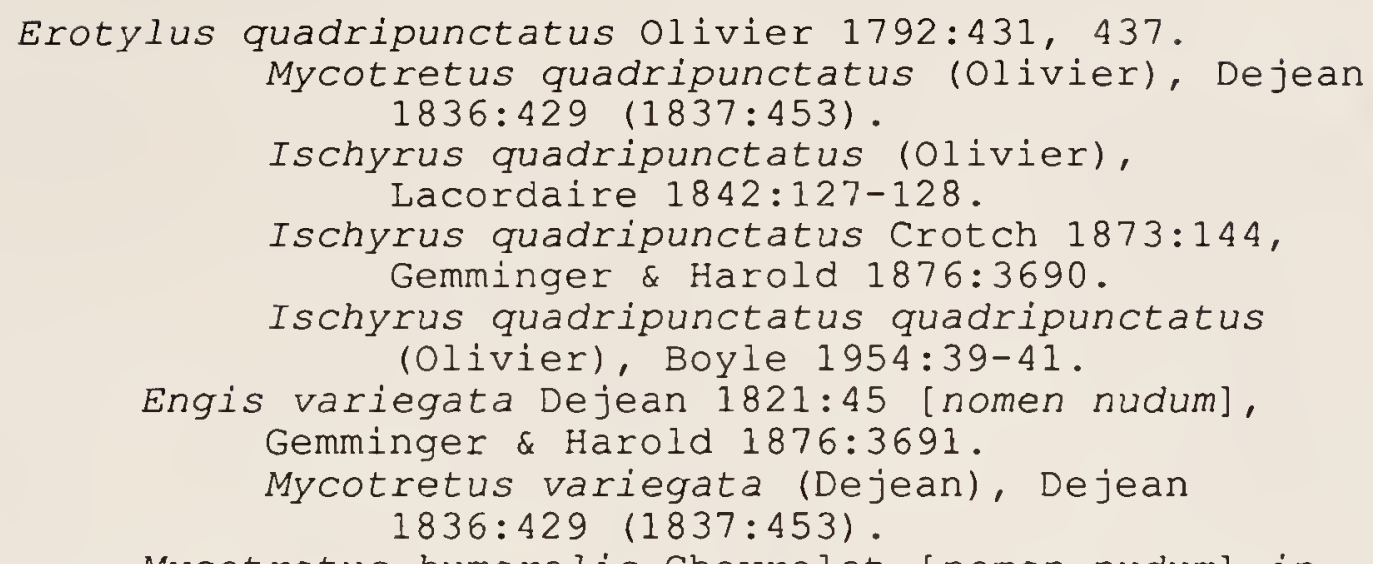

Mycotretus humeralis Chevrolat [nomen nudum] in Dejean 1836:429 (1837:453), Sturm 1843:305. Ischyrus subcylindricus Lacordaire 1842:117-118; new synonymy.

Mycotretus subcylindricus Chevrolat [nomen nudum] in Dejean 1836:429 (1837:453), Lacordaire 1842:117-118.

Ischyrus graphicus Lacordaire 1842:125-126.

Ischyrus quadripunctatus graphicus Lacordaire, Boyle 1954:41-43; new synonymy.

Ischyrus quadripunctatus var. alabamae schaeffer 1931:175, Mader 1938:19.

Ischyrus quadripunctatus var. antedivisa Mader 1938:19, Boyle 1954:39-41.

Ischyrus quadripunctatus var. A Lacordaire $1842: 127-128$.

Ischyrus puncticollis Gorham 1887:44-45; new synonymy.

Ischyrus chiasticus Boyle 1954:43-46.

Ischyrus quadripunctatus chiasticus Boyle, new status.

Diagnosis. Characterized by 4 free pronotal spots in transverse arch (rarely connecting with other markings), club antennomeres asymmetrical, and maxillary palp terminal segment narrowed (Figs. 7f, 20).

Description. Length: $4.8-8.8 \mathrm{~mm}$; Width: $2.3-3.7 \mathrm{~mm}$. Body elongate, widest at basal third of elytra; variably microreticulate, dull to shining; yellow-orange with black pattern (Figs. 42-47). 
Head black; often with central orange spot. Pronotum with 4 free spots in transverse arch, anteriorly concave; base with black marking on median half, marking variously widened from narrow margin to 3 tooth-like spots, central tooth occasionally connected to free central spots; anterior margin narrowly black between eyes, rarely with 2 weak spots. Scutellum black. Each elytron with orange epipleural fold; subhumeral spot shape variable, sometimes connected to scutellar spot and base; scutellar spot large, shape variable, broadly connected to base and suture; central black band with margin toothed or smoothly rounded, wide or narrow, sometimes connected to lateral edge, broadly connected to suture; apical spot present, size variable from large spot to widened black margin. Venter mainly black, variable orange markings on lateral abdomen and prothorax. Legs entirely black or banded with orange; tarsi dark brown to black; palpi pale brown to black; antenna brown, club black .

Head dorsal distance between eyes $=2.0$ to $2.5 \times$ eye width; ocular striae reaching apical angle of eye; vertex puncture size $=1$ x facet, separated 1 to 3 diameters; epistome puncture size $=0.5$ to $0.75 \times$ facet, separated by 1 diameter. Antenna reaching basal 0.25 of pronotum; antennomere II as long as next 3 antennomere combined; antennomeres X to XI asymmetrical; antennomere X angled at base; antennomere XI transverse (Fig. 6f). 
Maxillary palp terminal segment triangular, narrow; inner angle $90^{\circ}$, rounded; outer angle acute; longer than wide, width $=0.8 \times$ length. Labial palp terminal segment triangular, extended on medial side, narrow, width $=0.8 \mathrm{x}$ length. Labial palp width $=0.75 \times$ maxillary palp width (Fig. 7f). Mentum with plate broadly triangular, length = $0.7 \mathrm{x}$ basal width, sides straight, ridge medial extension acutely pointed (Figs. 8d, 20).

Pronotal disc puncture size $=1 \mathrm{x}$ facet, separated by 1 to 3 diameters. Scutellum pentagonal, length $=0.5 \mathrm{x}$ width. Each elytron with 7 complete striae; stria VIII weak, visible near humerus and apex; strial puncture size = pronotal disc puncture; interval puncture size $=0.20$ to 0.25 strial puncture.

Prosternum weakly keeled and pinched anteriorly (Fig. $10 \mathrm{c}-\mathrm{d})$; with foveate punctures in front of procoxa; coxal lines straight, length $=0.5 \times$ sternal length, lines barely surpassing coxae, basal width $=0.8 \times$ length; prosternal plate flat, apical width $=0.6$ x basal width; base shallowly concave.

Mesosternum basal width $=1.5 \times$ mesocoxal line length; coxal lines straight to slightly arched; base sinuate, medially lobed. Metasternal coxal lines not meeting at middle, weakly recurved; lines short, reaching less than 0.25 distance to posterior lateral angle; line behind mesocoxa deep, groove-like (Fig. 16b); sternum finely punctate medially, few shallow coarse lateral punctures. 
First visible abdominal sternite with coxal line not surpassing coxa, often continuous around coxa, at most reaching 0.5 distance to posterior edge; abdominal segment broadly rounded between metacoxae; coarse punctures laterally, fine punctures medially.

Male genitalia (Fig. 17) with median lobe moderately arched, apically truncate, slightly constricted just before tip; internal sac without noticeable sclerotized structures; flagellum long and narrow, flattened and ribbon-like at basal 0.5 , length $=1.6 \mathrm{x}$ median lobe length (Fig. 108a); base of flagellum straight and swollen, sclerite at base claw-shaped (Fig. 108b-d) (30 dissected).

Female genitalia (Fig. 18) with spermathecal head kidney-shaped, often with a top-knot; tail swollen, curved like an inverted question mark, "i" (Fig. 108e) (21 dissected).

Stridulatory files on occipital region of head visible on males; not found on females (Fig. 22). Compared to females, males have fewer, less impressed punctures on prosternum in front of procoxae.

Variation. This species shows variation in many of the characters as indicated above. The prosternal plate is variable in shape, from almost parallel-sided to nearly triangular. The palpi vary in general shape, but are always narrowed (Eigs. 7f, 20); a character appearing in only a few species of Ischyrus. 
The presence and number of prosternal punctures varies with no correlation to geographic range. The maximum number of punctures in males overlaps broadly with the minimum number seen in females. In this species, determination of the sexes based on this character is not reliable.

The distinctiveness of the prosternal anterior pinch varies as much from specimen to specimen as from population to population. Boyle (1954) discussed some of these, and other variations in detail.

The elytral color pattern varies from smoothly banded in North America to jagged, zig-zag edged bands (nearly striped in some specimens) in South America. The pattern changes are clinal from north to south.

Iypes. See under subspecies accounts.

Specimens examined. See under subspecies accounts.

Distribution. Widespread throughout the Americas: from southeast Canada and North Dakota in the north; south through Arizona, Mexico, Central America, and the Lesser Antilles, into South America to northern Argentina (Fig. 113) .

Etymology. quadripunctatus: Latin = 4-punctures; referring to the 4 pronotal spots.

Taxonomic notes. Despite the variation in morphological characters stated above, the amount of variation within any one population is similar and overlaps the variation seen in any other population. No consistent 


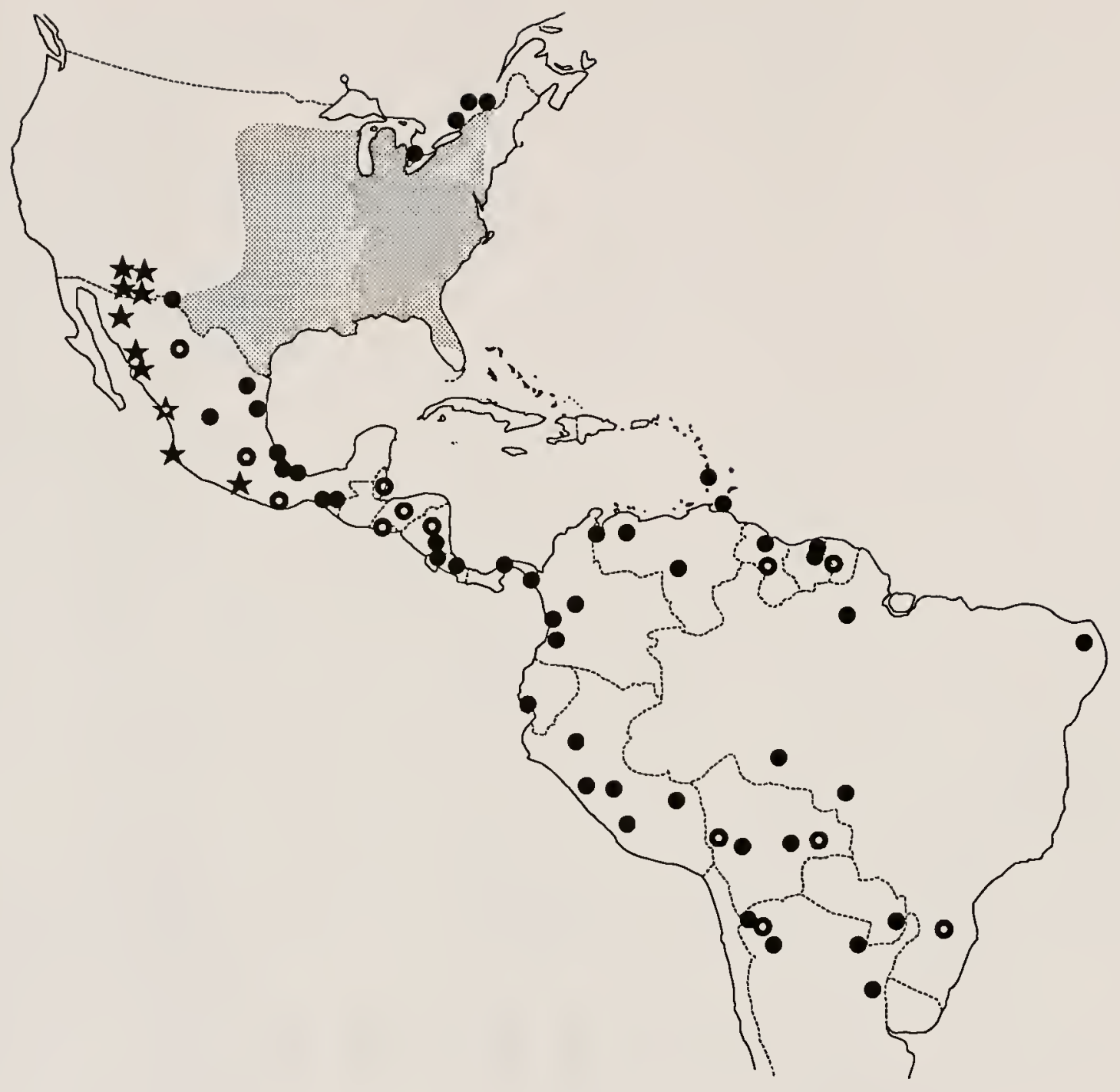

Figure 113. Ischyrus q. quadripunctatus (Olivier) [circle and shading] and I. quadripunctatus chiasticus Boyle [star] distribution map. 
morphological differences were found, including genitalia, between any taxa listed in the above synonymy.

Color patterns seem to correlate with specific geographic ranges and led to the description of various taxa: I. subcylindricus Lacordaire, I. graphicus Lacordaire, I. chiasticus Boyle, I. quadripunctatus var. alabamae Schaeffer, I. quadripunctatus var. antedivisa Mader. A study of specimens from localities at the edges of their distribution uncovered many intermediates; occasionally with several forms from the same population. All but one of the color pattern differences proved to be clinal in nature, therefore not deserving nomenclatural status. Based on this information (see also the subspecies accounts), all but $I$. chiasticus Boyle, which is lowered to subspecific rank, are synonymized under $I$. quadripunctatus (Olivier).

The year Olivier published the description of Erotylus quadripunctatus has usually been cited as 1791. Blackwelder (1949, 1957) stated that part 2 of Olivier's Encyclopédie Méthodique was printed in 1792, which I follow.

Biology. Many authors have published bits of information on the biology of this species, but little is actually known. The biological notes presented here are based on information published on material from eastern United States and will probably apply to all populations.

Data from published catalogs or faunal studies give little insight into the beetle's habits: in summer on fungi (Blatchley 1910), winter beneath rubbish (Dillon \& Dillon 
1961), at lights, and feeds on fungi on logs and dead tree trunk (Kirk 1969), under bark (Loding 1945), etc. Boyle (1956) consolidated much of this information in his account for I. quadripunctatus quadripunctatus.

Large eye facets of this species suggest nocturnal activity. The majority of specimens with any collection data were collected at lights, substantiating the nocturnal hypothesis.

Skelley, et al. (1991) compiled fungal host data on the erotylids north of Mexico. They listed 5 fungi as hosts: Irpex lacteus (Er.:Fr.)Fr., Oxyporus latemarginatus (Dur.\& Mont. ex Mont.)Donk, Phellinus gilvus (Schw.)Pat., Polyporus gilvus (Schw.)Fr., and Poria sp. Only oxyporus latemarginatus (= Poria ambigua Bres.) had more than one recorded collection for $I$. q. quadripunctatus, including rearings. This fungus is a white prostrate polypore which grows on the underside of dead wood suspended above the ground. Deciduous trees with dead limbs, stumps, or dead wood not touching the ground for some of its length, are suitable substrates for this fungus. I have found large numbers of Ischyrus $q$. quadripunctatus in these situations, occasionally associated with larvae.

The larva of I. q. quadripunctatus was first described by Chapuis \& Candeze (1853), later by Weiss (1920), and Skelley (1988b). Lawrence (1991) illustrated this species' larva, but provided no description. It has the dorsal shields darkened, nearly black, and the pronotum with false 
eye spots (Fig. 23). These characters are similar in

Oocyanus flavitarsis (Lacordaire) (see Candeze 1861). They differ in the shape of the urogomphi: 0. flavitarsis urogomphi are set on a single pedicel-like base; $I$. quadripunctatus urogomphi lack the pedicel base and are set separately on abdominal segment IX. These represent the only larvae described for species of Ischyrus and Oocyanus. Much work needs to be done on larval morphology and biology of this family.

Remarks. Ischyrus quadripunctatus is similar to I. patruelis Lacordaire in the narrowed maxillary palp terminal segment and the asymmetrical antennal club segments. They can be separated by the pronotal color pattern: I. quadripunctatus has 4 free spots in an arch; $I$. patruelis has 2 anterior, 2 basal, and 2 free pronotal spots forming a circle.

Ischyrus quadripunctatus is most similar to $I$. tetrasticus Gorham in color pattern, but the latter species has a red head with a basal black spot, and widened maxillary palp terminal segment (similar to Fig. 7e).

References. See under subspecies accounts.

Ischyrus quadripunctatus quadripunctatus (Olivier)

Diagnosis. Distinguished from I.quadripunctatus chiasticus by the apical elytral spot, pronotal basal spots present or absent, elytral scutellar spot rounded, or if $\mathrm{x}$ shaped then with distinct pronotal basal spots, and in geographic range; eastern U.S.A. and Mexico least of the 
Sierra Madre Occidental), the Lesser Antilles, Central, and South America.

Description. Length: $4.8-8.8 \mathrm{~mm}$; width: $2.3-3.7 \mathrm{~mm}$. Similar to the description under I. quadripunctatus, except in the following color pattern specifics (Figs. 43-47).

Head black; often with orange spot. Pronotum with basal black margin of variable width, often bearing 1 to 3 tooth-like spots; central tooth can connect with 2 free central spots on disc. Each elytron has a subhumeral spot variable in shape, touching or nearly touching base, connected or not to scutellar spot; central band wide or narrow, with edges smoothly rounded or jagged; apical spot present, variable in size. Legs entirely black, or femora banded orange. Genitalia dissected: 24 males, 20 females.

Variation. Most populations in the U.S., and some in northern Mexico, have the head and legs entirely black, and the pronotal base narrowly margined in black. More northern and central U.S. populations have the scutellar and subhumeral spots separated ("Var. A" Lacordaire 1842; var. antedivisa Mader 1938). Populations from southeastern U.S. have these spots connected (quadripunctatus olivier 1792; var. alabamae schaeffer 1931). This difference is clinal, with the amount of spot separation variable within some populations (detailed by Boyle 1954), and not deserving of taxonomic rank. I refer to the U.S. color pattern, with a solid black head, as "quadripunctatus" (Fig. 43). 
Populations from Mexico and Central America, and some individuals from extreme southern Texas, have the head black with an orange central spot, legs entirely black, and pronotum lacking spots on the anterior and posterior margins (graphicus Lacordaire 1842). The orange spot on the head is variable in size, almost absent to nearly covering the head. I refer to this color pattern as "graphicus" (Fig. 44).

Populations from most of South America and some individuais from southern Central America have a black head with an orange central spot, legs entirely black, and pronotal base with 1 to 3 spots (subcylindricus Lacordaire 1842). The size of the basal pronotal spots varies from small and indistinct to large and tooth-like. I refer to this color pattern as "subcylindricus" (Fig. 45).

Populations from the Lesser Antilles have the head with an orange central spot, legs entirely black, and base of the pronotum with 3 large tooth-like spots. The central toothlike spot connects with the 2 "free" central spots on the pronotal disc. I refer to this color pattern as "Antillean" (Fig. 46).

Specimens from southeastern Peru, southwestern Brazil, and Bolivia have a black head with an orange central spot, pronotal base with 3 tooth-like spots, and legs banded red with black knees. I refer to this color pattern as "bandedleg" (Fig. 47).

Types. The "type" of Erotylus quadripunctatus Olivier was not located. Olivier stated that the specimen is in the 
"cabinet de M. Erancillon." Its current location is unknown, possibly in the MacLeay Museum, University of Sydney, Australia (see Locating Types). The type locality was stated as "Amérique septentrionale, la Géorgie."

The lectotype (here designated) of Ischyrus subcylindricus Lacordaire label data: "/ Cayenne/ subcylindricus Lac./ Type/ Ex-Musaeo Mniszech/ [red] TYPE/ [pale blue] Muséum Paris ex Coll. R. Oberthür 1952/ LECTOTYPE Ischyrus subcylindricus Lacordaire des.P.E.Skelley 1993/" [MNHN, studied]. Sex not determined.

The lectotype (here designated) of Ischyrus graphicus Lacordaire label data: "/ [blue paper] TYPE/ TYPE graphicus Ch/ LECTOTyPE Ischyrus graphicus Lacordaire des.P.E.Skelley 1993/" [CUMZ, studied]. Sex not determined.

The holotype (by monotypy) of Ischyrus puncticollis Gorham label data: "/ [red circle on white paper] Type/ Paso del Norte, Chihuahua, Höge/ Ischyrus puncticollis/ B.C.A., Col., VII. Ischyrus/" [NHMI, studied]. The type locality is near Ciudad Juárez (Selander \& Vaurie 1962), a city on the border just south of El Paso, Texas. Sex male.

The holotype (original designation) of Ischyrus quadripunctatus var. alabamae schaeffer was not located. Schaeffer stated the type was deposited in his collection and Paratypes in the Loding collection. Specimens determined as alabamae, collected by Loding, were studied [CASC]. There is no indication that these are paratypes. 
Specimens examined. In addition to the types listed above, 2618 specimens, representing 1306 collection records, were studied (see Appendix C for specific data).

Distribution. The various color patterns have separate ranges with a large amount of overlap between their ranges. Color pattern "quadripunctatus": eastern U.S. from western Texas and northern Mexico (Pallister 1955a) east to Florida; north to southeastern North Dakota and Canada. Within this range it is common and often collected in deciduous woodland habitats. Gorham's (1887) record from Guatemala is undoubtedly in error, and probably represents a misidentified "graphicus" (Pallister 1955a).

Color pattern "graphicus": southern and western Texas south through Mexico and Central America to Panama.

Color pattern "subcylindricus": southern Central America south through South America to Argentina and Peru.

"Antillean" color pattern: known only from St. Vincent, St. Lucia, and Trinidad.

Color pattern "banded-leg": Bolivia, southeastern Peru, and southwestern Brazil.

Taxonomic notes. Engis variegata Dejean (1821:45) is Ischyrus subcylindricus Lacordaire, according to Gemminger \& Harold (1876:3691). Dejean (1836:429) placed these names together within the same bracket, possibly indicating synonymy. Since no description or citation to a description of this name was found, it should be considered a nomen nudum. 
Mycotretus humeralis Chevrolat (in Dejean 1836:429) is I. quadripunctatus (Olivier) according to Sturm (1843:305) and Gemminger \& Harold (1876:3691). Dejean (1836:429) placed these names together within the same bracket, possibly indicating synonymy. Since no description or citation to a description of this name was found, it should be considered a nomen nudum.

Lectotypes of both $I$. subcylindricus Lacordaire and $I$. graphicus Lacordaire were chosen because there was no indication that only one specimen was studied in either of the original descriptions. Both designated specimens came from collections apparently studied by Lacordaire (see Locating Types).

Various authors have commented on the similarities between I. quadripunctatus (Olivier), I. graphicus Lacordaire, and I. subcylindricus Lacordaire: Boyle (1954:39-43), Crotch (1873b:144; 1876:(51) 427), Gorham (1887:39-40; 1898:335), and Pallister (1955a:4-5). The only differences observed were in the color patterns. These differences proved to be clinal, as numerous intermediates were found in the overlapping parts of their ranges.

Based on the testimony of previous authors, a lack of distinguishing morphological characters, the clinal nature of the color patterns, and previous studies on this complex, I. graphicus Lacordaire and I. subcylindricus Lacordaire are synonymized under $I$. quadripunctatus (Olivier). I refer to these 3 as color patterns of I. q. quadripunctatus simply 
for record-keeping purposes. They have no nomenclatural status

The type of Ischyrus puncticollis Gorham is a malformed specimen. The name "puncticollis" refers to the indentations on the pronotum mentioned by Gorham in the original description. Specimens from nearby localities in Texas are externally identical to $I$. puncticollis, except for these malformations. A genitalic study of Gorham's type proved my suspicions to be correct. Ischyrus puncticollis Gorham is here synonymized under I. q. quadripunctatus (Olivier).

Gemminger \& Harold (1876:3690) indicated that "Ischyrus quadripunctatus var. Crotch (1873b:144)" is a synonym of I. graphicus Lacordaire (1842:125-126). They seemed to have misinterpreted Crotch, as no such variety was proposed. Crotch stated that I. graphicus from Nicaragua and "the Mexican exponents of this species, appear to be a southern form of $I$. quadripunctatus with the head more or less rufous."

Ischyrus quadripunctatus var. alabamae Schaeffer (1931:175) has the venter mostly red. Boyle (1954) stated "it is an aberrant specimen of the nominal form" which varies only in the ventral coloration. Boyle's statement implies that he studied the type, or type specimens.

Mader (1938:19) realized that Schaeffer's var. alabamae was actually the nominal pattern of $I$. quadripunctatus with the basal elytral band entire. He proposed the name "var. 
antedivisa" for Lacordaire's Var. A which has the basal elytral band separated into spots.

Boyle (1954) recognized that both Schaeffer's and Mader's varieties were part of a clinal change in the color pattern from north to south. He synonymized both under $I$. q. quadripunctatus (Olivier).

Specimens from Bolivia and southwestern Brazil have the legs banded with orange. All other color patterns have the legs entirely black. The geographic range of this "bandedleg" pattern appears to be isolated from those with solid black legs. No morphological differences, including genitalic characters, were found which correlated with leg color. Until more series of specimens are studied from additional localities, its distinctiveness is questionable. I cannot justify giving it subspecific status based on the available information.

Biology. This common subspecies appears in many regional checklists and occasionally in general texts. Additional references may be found in Hatch's (1928, 1929, 1941) indices to keys and local lists of Neartic Coleoptera. Its biology is discussed in the Biology section of the species account above.

References. Ischyrus quadripunctatus (Olivier): Beutenmuller 1891:11; Blackwelder 1939:46; 1945:465; Blatchley 1910:546, fig.205; Borror \& White 1970:177; Boyle $1954: 39-43 ; 1956: 133-136,152-153,169$, fig.126-130; Brimley 1938:180; Chagnon 1917:200; Chagnon \& Roberts 1962:156,397; 
Chantal 1979:19; Chapuis 1876:7,36; Chapuis \& Candeze 1853 [1855]:622, t.9 f.8 [in separate p.282-284]; Crotch 1873a:353; 1873c:43; 1876:(50)426; Deelder 1942:82; Dejean 1836:429; 1837:453; Dillon \& Dillon 1961:409 pl.XL no.10, 410; Duponchel 1825:175-176; Fattig 1937:253; Froeschner \& Meiner 1953:21,23; Frost 1964:141; Gemminger \& Harold 1876:3691; Gorham 1887:39; 1898:335; Haldeman \& LeConte 1853:46; Henshaw 1885:50; Horn 1886:140; Hubbard \& Schwarz 1878:652; Khalaf 1980:331; Kirk 1969:79; 1970:74; Kirk \& Balsbaugh 1975:95; Kuhnt 1909:62; 1911:43; Lacordaire 1842:127-128; Lawrence 1991:474, fig.34.551; LeConte 1854:158; Leng 1920:201; 1928:383; Loding 1945:79; Mader 1938:19; Montgomery \& Amos 1941:255; Olivier 1807:484, t.3 f.37; Pallister 1955a:4-5; Popenoe 1877:27; Roberts 1958:283; Say 1835:201; Schaeffer 1931:175; Schwarz 1878:445; Skelley 1988a:fig.3; 1988b:63-74,136-138 (figs.7, 18a, 19b, 19c, 29d, 31, 32); Skelley \& Goodrich 1989:349354, fig. 3; Skelley et al. 1991:65; Smith 1899:224; 1910:260; Sturm 1826:139; 1843:305; Summers 1874:99; Ulke 1902:16,44; Wade 1935:59; Weiss 1920a:14-15; Weiss \& West 1920:6,14,15; Wickham 1894:341, fig 61; Zesche \& Reinecke $1883: 6$.

Engis variegata Dejean: Dejean 1836:429; 1837:453; Gemminger \& Harold 1876:3691.

Mycotretus humeralis Chevrolat: Dejean 1836:429; 1837:453; Gemminger \& Harold 1876:3691; Kuhnt 1909:62; Sturm $1843: 305$. 
Ischyrus subcylindricus Lacordaire: Blackwelder 1945:465; Crotch 1876:428(52); Deelder 1942:82; Dejean 1836:429; 1837:453; Delkeskamp 1957:98; Gemminger \& Harold 1876:3691; Gorham 1887:40; 1898:335; Guérin 1949:234; Kuhnt 1909:64; 1911:43; Pallister 1955a:4-5.

Ischyrus graphicus Lacordaire: Blackwelder 1945:465; Boyle 1954:41-43; 1956:133,135,153; Crotch 1873b:144; 1876:(51) 427; Gemminger \& Harold 1876:3690; Gorham 1887:3940 t.2 f.17; 1898:335; Kuhnt 1909:63; 1911:42; Leng \& Mutchler 1914:412; Pallister 1955a:4-5; Skelley et al. $1991: 65$.

Ischyrus puncticollis Gorham: Blackwelder 1945:465; Kuhnt 1909:63; 1911:43.

Ischyrus quadripunctatus var. alabamae Schaeffer:

Blackwelder 1939:46; Boyle 1954:39; Leng \& Mutchler 1933:86; Loding 1933:146; 1945:79; Mader 1938:19.

Ischyrus quadripunctatus var. antedivisa Mader: Blackwelder 1939:46; Boyle 1954:39; Deelder 1942:82.

Ischyrus quadripunctatus chiasticus Boyle, New status

Diagnosis. Characterized by the combination of reduced apical elytral spots, absent basal pronotal spots, $x$-shaped scutellar spot, and geographic distribution.

Description. Length: 5.5-8.2 mm; Width: $2.5-3.7 \mathrm{~mm}$. Similar to the description under I. quadripunctatus, except in the following color pattern specifics (Fig. 42).

Head black with orange epistome and frons. Pronotum with narrow black basal margin, lacking teeth. Each elytron 
with elongate subhumeral spot, connected to base, not connected to scutellar spot; scutellar spot large, laterally concave, both scutellar spots combined to form an $\mathrm{X}$-shaped mark; central band with smooth rounded edges, extending along suture to apical angle; apical spot reduced to narrow margin at apex. Legs entirely black. Antenna club broad, antennomere $\mathrm{x}$ often with width $=2 \mathrm{x}$ length. Genitalia dissected: 6 males, 1 female.

Variation. Ischyrus quadripunctatus chiasticus shows some variation in the overall width of the markings, but not enough to change the appearance of the color pattern. The apical elytral spot can be a smooth black marking or a thin, sharply angled spot.

Type. The holotype (original designation) of Ischyrus chiasticus Boyle label data: "/ Patagonia Ariz. 7-36, E.S.Ross/ [red paper, black border] HOLOTYPE Ischyrus chiasticus Boyle/" [CASC, type \# 8370, studied]. Sex male.

specimens examined. The holotype and 372 specimens, representing 186 collection records, were studied (see Appendix C for specific data).

Distribution. This subspecies is found from the state of Morelos, Mexico, north and west of the Sierra Madre Occidental mountain range to southern Arizona (Fig. 113).

Etymology. Chiastos: Greek = cross-wise, X-shape; referring to the $x$-shaped scutellar spot on the elytra. 
Taxonomic notes. In the first paragraph of his description for Ischyrus chiasticus Boyle (1954:43-46) stated:

This form appears to be a possible subspecies of Ischyrus quadripunctatus (Olivier), yet both in color pattern and in geographical range, so far as is known, it constitutes a distinct population. It is known from the mountains of southern Arizona and from the Mexican State of Sinaloa (one specimen); thus it apparently ranges from southern Arizona into Mexico along the Sierra Madre occidental for an unknown distance. Its closest relative, I. quadripunctatus graphicus Lacordaire, is found from extreme southern Texas south into Mexico (presumably along the Sierra Madre oriental) and on into Central America. If intergrading populations of these two forms are eventually found, they will almost certainly occur in southern Mexico where the two cordilleras become confluent. The prairies and deserts of northern Mexico, western Texas, and southern New Mexico support few trees upon which grow the fungous food of these beetles.

Little information can be added to this, although specimens from further south into Mexico (state of Morelos) have been studied, with little or no notable variation in color pattern from the Arizona specimens.

No specimens were studied with intermediate color pattern. The ranges of these forms still appear to be distinct and isolated. Distinguishing morphological characters are apparently lacking, including the genitalia. Boyle (1956:135-136) mentioned a slight difference in the male median lobe between $I$. chiasticus and $I . q$. quadripunctatus, but stated "...the two must be placed side by side to see such differences, and even then positive identification would be hazardous." 
Since I. chiasticus is apparently isolated from I. q. quadripunctatus, has a distinctive color pattern, and no distinguishing morphological characters, including genitalia, it is reduced in rank to a subspecies of $I$. quadripunctatus (Olivier). If future studies produce intermediate populations, then I. chiasticus should be considered another of the I. quadripunctatus color patterns. Biology. Suspected biology as discussed under the species account.

Remarks. Ischyrus quadripunctatus chiasticus differs from "graphicus" in having a free comma-shaped subhumeral spot, scutellar spots laterally concave together looking (as Boyle stated) like "a fat " $x$ " enclosed in single quotation marks", and the apical elytral spot greatly reduced or absent .

References. Boyle 1956:133,135-136, 153-154; Hoebeke 1978:11; Ruette 1970:53; Skelley et al. 1991:65.

\section{Ischyrus scriptus (Olivier)}

Erotylus scriptus Olivier 1807:484-485, t.3 f.38. Mycotretus scriptus (Olivier), Dejean 1836:429, $1837: 453$.

Ischyrus scriptus (01ivier), Lacordaire 1842:119120 .

Erotylus affinis Duponchel 1825:47, t.1 f.26, Lacordaire 1842:119-120.

Mycotretus affinis (Duponchel), Dejean 1836:429, $1837: 453$.

Dacne femoralis Chevrolat 1841:63-64, new synonymy. Ischyrus femoralis (Chevrolat), Lacordaire

$1842: 114-115$.

Ischyrus velatus Lacordaire 1842:115-116, new synonymy. Ischyrus maculiventris Lacordaire 1842:120-121, Crotch $1876:$ (55) 431 . 
Diagnosis. Recognized by the pronotum having 2 anterior, 2 free, and 2 basal spots, 2 free spots set as far apart as head width (including eyes), each pronotal hind angle with or without a spot, legs orange with black knees, black elytral epipleural fold, free subhumeral spot, and central elytral band posterior extension swollen at end.

Description. Length: $6.0-8.4 \mathrm{~mm} ;$ Width: $3.9-4.1 \mathrm{~mm}$. Body elongate, widest at basal third of elytra; microreticulate; yellow-tan to red-orange with black markings (Figs. 29-31).

Head color solid black to black with orange central spot. Pronotum with 2 anterior, 2 free and 2 basal spots forming a circle; anterior and posterior spots occasionally free; 2 free central spots' distance between centers $=$ width of head including eyes; each posterior angle with a variable sized spot, narrowly connected to base, broadly connected to lateral margin. Scutellum dark red to black. Each elytron with black epipleural fold, paler in teneral specimens; subhumeral spot can touch scutellar spot; scutellar spot large, broadly connected to base and suture, occasionally broken by pale spots at base; suture finely margined in black; central band extends from basal third nearly to apex, laterally narrowed, reduced to zig-zag line in some specimens, can touch lateral margin, apically swollen at suture. Venter black; laterally pronotum and abdomen orange. Legs black with orange central femoral band, knee 
black; tibia often apically red; tarsi brownish or black; rarely legs entirely black.

Head dorsal distance between eyes $=2.0-2.3 \times$ eye width; ocular striae reaching 0.5-0.75 distance to anterior angle of eye, continued forward as row of punctures; vertex puncture size $=0.75-1.0 \times$ facet, separated by $1-2$ diameters; epistome puncture size $=0.5 \mathrm{x}$ facet, separated by $0.5-1$ diameter. Antenna reaching basal 0.25 of pronotum; antennomere III as long as next 3 antennomere combined; antennomere IX narrowed and angled at base, almost triangular; antennomeres X-XI asymmetrical; antennomere XI rounded, transverse (similar to Eig. 6c).

Maxillary palp terminal segment triangular, securiform, basally rounded, angles less than $90^{\circ}$, width $=2 x$ length. Labial palp terminal segment elongate, extended on medial side, rounded basally, width $=2 \times$ length. Labial palp width $=0.5 \times$ maxillary palp width (as in Fig. 7c). Mentum with plate triangular, all sides equal in length, ridge medial extension acutely pointed (similar to Fig. 8d). Pronotum puncture size $=0.75-1.0 \times$ facet, separated by 1 to 2 diameters. Scutellum pentagonal, length $=0.5 \mathrm{x}$ width. Each elytron with 7 complete striae; stria VIII weak, indicated at base and apical half by few punctures; strial punctures at base slightly larger in size than pronotal disc punctures, gradually becoming smaller apically; intervals finely punctate, often obscured by microreticulations. 
Prosternum keeled and pinched anteriorly; with foveate punctures in front of procoxa, often weak and obscured by microreticulations; coxal lines straight to weakly sinuate, length $=0.5 \times$ sternal length, barely surpassing coxae, length = basal width; prosternal plate flat, apical width = $0.5 \times$ basal width; base shallowly concave.

Mesosternum basal width $=2 \times$ mesocoxal line length; coxal lines arched inwardly; base sinuate, lobed medially. Metasternum coxal lines sometimes recurved, not meeting medially; coxal line faint, extend 0.33 distance to posterior lateral angle; sternum medial punctures fine, coarse lateral punctures, both separated by 1 to 2 diameters.

First visible abdominal sternite with coxal lines faint, reaching 0.33 distance to posterior edge; rounded between metacoxae; with coarse lateral punctures, fine medial punctures.

Male genitalia with median lobe moderately arched, apically truncate, slightly constricted just before tip; internal sac without noticeable sclerotized structures; flagellum long and narrow, length $=1.6 \times$ median lobe length (Fig. 109a); base of flagellum weakly curved, sclerite at base blunt claw-shaped and sometimes thickened at connection with flagellum (Eig. 109b-d) ( 8 dissected).

Female genitalia with spermathecal head kidney-shaped, often with top-knot; tail swollen, tightly curved like an inverted question mark, " $i "$ (Fig. 109e) (6 dissected). 
Stridulatory files on occipital region of head present in male; weak or absent in female. No easily visible sexual dimorphism was found.

Variation. A few specimens from northern South America appear to have entirely black legs. These could be soiled.

The majority of specimens studied have orange marks on the head. The orange spots are variable in size and can be absent, leaving the head entirely black. The size variation does not correlate with any other observed character. Some populations are variable, with both black and spotted heads. The elytral markings are variable in the degree of jaggedness. Some specimens have the markings smoothly rounded; some have the markings jaggedly cut, tooth-like; and others have the markings narrowed to a zig-zag line. This variability appears clinal, with the smoothly banded populations in the northern part of the range and the jaggedly edged populations in the southern parts of the range. Populations in the southern part of the range also have the basal elytral marking broken by a number of pale spots.

The size of the pronotal spots varied greatly through the geographic range. On occasion, the anterior and basal spots are broadly joined to the margins. Most specimens have these spots constricted at the margin and, at most, simply touch the margin. A few specimens have the spots free. 
The variation seen in the size of the posterior pronotal angle spot is clinal. Specimens from Mexico and Central America ("northern") have the spot reduced to a narrow black widening on the posterior lateral margin near the angle, or it is absent (Fig. 29). Specimens from South America ("southern") have the spot large and distinct (Figs. 30-31). Material from Panama and most specimens from northern South America are intermediate in spot development.

Types. The type of Erotylus scriptus olivier was not studied. Olivier stated that it was in the collection of $M$. Richard, and came from French Guiana. Its current location is unknown.

The type of Erotylus affinis olivier was not studied. Olivier stated that it was in the collection of Dejean, "M. le compte Dejean lui a donné dans sa collection", and was found in Brazil. Its current location is unknown.

The lectotype (here designated) of Ischyrus velatus Lacordaire label data: "/ Colombie/ Velatus Lac./ Type/ Ex. Musaeo Mniszech/ [red] Type/ [pale blue] Muséum Paris ex. Coll. R. Oberthür $1952 /$ [red] LECTOTYPE Ischyrus velatus Lacordaire des.P.E.Skelley 1993/" [MNHN, studied]. Sex not determined, not dissected.

The lectotype (here designated) of Dacne femoralis Chevrolat label data: "/ [blue paper] TYPE/ TYpe femoralis Ch./ [redj LECTOTYPE Dacne femoralis Chevrolat des.P.E.Skelley 1993/" [CUMZ, studied]. Chevrolat stated in 
the original description that the species came from Mexico. Sex not determined, not dissected.

The lectotype (here designated) of Ischyrus maculiventris Lacordaire label data: "/ blue paper] TYPE/ Type maculivent-ris Ch./ [red] LECTOTYPE Ischyrus maculiventris Lacordaire des.P.E.Skelley 1993/" [CUMZ, studied]. Lacordaire stated in the original description that the species came from Brazil. Sex not determined, not dissected.

Specimens examined. The lectotype and 177 specimens, representing 106 collection records, were studied (see Appendix C for specific data).

Distribution. Widespread from Mexico to northern Argentina (Fig. 114).

Etymology. scriptus: Latin = writing. Undoubtedly this name refers to the writing-like elytral markings.

Taxonomic notes. Lectotypes were chosen for I. velatus Lacordaire, D. femoralis Chevrolat, and I. maculiventris Lacordaire because the authors made no mention that they saw only one specimen. The specimens chosen for each have label and historical data indicating that they were studied by the describer.

Ischyrus femoralis (Chevrolat) is stated by Chevrolat to be from Mexico. Gorham (1887) stated that the specimen in Crotch's collection (the "type") was the only specimen he saw of the species. Specimens from Mexico and Central America lack the spot at the pronotal posterior angle; 


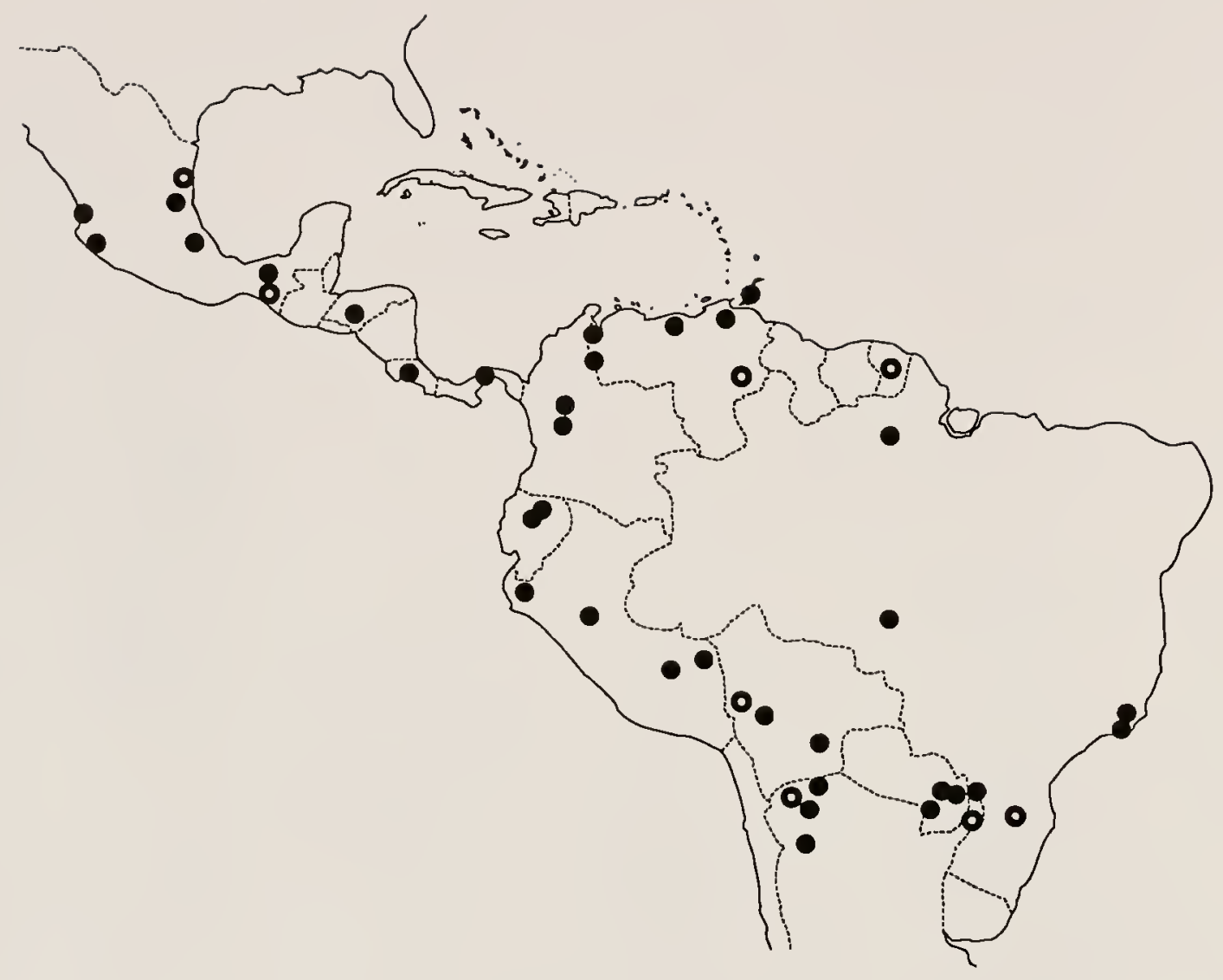

Figure 114. Ischyrus scriptus (Olivier) distribution map. 
whereas the lectotype of $D$. femoralis has a prominent spot. It is possible that this specimen is mislabeled. Because of the difference between the lectotype and specimens from Mexico and Central America, the name "femoralis" cannot be used in reference to them. Dacne femoralis Chevrolat is placed in full synonymy under I. scriptus (Olivier).

Specimens from Mexico and Central America, lacking the posterior pronotal angle spot, are referred to as "northern". Specimens from South America with the posterior pronotal angle spot are referred to as "southern". These color pattern differences have no nomenclatural status.

The lectotype of Ischyrus velatus Lacordaire was found to differ from the description of I. scriptus Lacordaire only in head color, and in the type locality; I. scriptus with orange epistome and frons is from Brazil, I. velatus with black head is from Colombia. Head color was found to be variable even within the same population. Based on this, I. velatus Lacordaire is placed in synonymy under $I$. scriptus (Olivier).

The type of Ischyrus maculiventris Lacordaire was found to be a malformed specimen. The dimples alluded to by Lacordaire in the original description were found to be depressions in the pronotum caused by outside forces. Lacordaire even stated that they may be accidental. Crotch must have realized this when he synonymized $I$. maculiventris Lacordaire under I. scriptus (Olivier). 
The type was not studied, nor any other specimen determined as Erotylus affinis Duponchel. The synonymy of E. affinis Olivier under I. scriptus (Olivier) is maintained.

Remarks. Ischyrus scriptus (Olivier) is similar to I. palliatus Lacordaire, I. proximus Lacordaire, and I. incertus Lacordaire in color pattern. Despite the similarities and variability of color patterns, the 4 can be separated by the combination of characters listed below.

Ischyrus palliatus Lacordaire has the femora entirely orange; free pronotal spots set farther apart than eyes; black lateral markings of the head generally widest at anterior half of eye, base orange; scutellum orange; elytral epipleural fold generally black, base paler in teneral specimens; and male with prosternum slightly expanded laterally.

Ischyrus scriptus (Olivier) has orange femora with a dark knee; free pronotal spots set as far apart as eyes; when head with orange, the black lateral markings are widest at base of eye; scutellum orange; elytral epipleural fold generally black, base paler in teneral specimens; and no external sexual dimorphism.

Ischyrus proximus Lacordaire has the femora entirely black; the free pronotal spots closer together than eyes; when head with orange, the black lateral markings widest at base of eye; scutellum black; elytral epipleural fold 
generally orange, darker on soiled specimens; and no external sexual dimorphism.

Ischyrus incertus Lacordaire has the femora entirely black; the free pronotal spots farther apart than eyes; head entirely black; scutellum black; black elytral epipleural fold; and male with the prosternum expanded laterally.

References. Ischyrus scriptus (Olivier): Blackwelder 1945:465; Crotch 1876:(55) 431; Dejean 1836:429; 1837:453; Duponchel 1825:47,175; Gemminger \& Harold 1876:3691; Guérin 1948:19; 1949:235; 1953:77; Kuhnt 1909:64; 1911:43; Lacordaire 1842:119-120; Sturm 1826:139; 1843:305.

Erotylus affinis Duponchel: Blackwelder 1945:465; Dejean 1836:429; 1837:453; Gemminger \& Harold 1876:3691; Kuhnt 1909:64; 1911:43; Lacordaire 1842:119.

Dacne femoralis Chevrolat: Blackwelder 1945:465; Crotch 1876:430(54); Gemminger \& Harold 1876:3690; Girard 1873:820; Gorham 1887:40-41; Kuhnt 1909:64; 1911:42; Lacordaire $1842: 114-115$

Ischyrus velatus Lacordaire: Blackwelder 1945:465; Crotch 1876:(55); Gemminger \& Harold 1876:3691; Kuhnt 1909:63; 1911:44; Mader 1942:171, 195, 196; 1951:209; $1952: 159,183$.

Ischyrus maculiventris Lacordaire: Blackwelder 1945:465; Crotch 1876:(55)431; Gemminger \& Harold 1876:3691; Kuhnt 1909:64; 1911:43. 


\section{Ischyrus scutellaris Gorham}

Ischyrus scutellaris Gorham 1887:41-42, t.3 f.2.

Diagnosis. Recognized by the pronotum with 2 free spots only, and small free central and lateral elytral spots.

Description. Length 4.5-6.4 mm; Width: $2.4-3.2 \mathrm{~mm}$. Body elongate, widest at basal third of elytra; microreticulate, feebly shining; orange-yellow with black pattern (Fig. 70-71).

Head orange with blackened epistome margin. Pronotum with 2 free spots; base weakly margined in black on medial half, with or without 2 black spots each on base and anterior margin. Scutellum black or dark orange. Each elytron with black epipleural fold, often with orange (see Variation); free subhumeral spot; large scutellar spot, broadly connected to base and suture; sutural margin black, often with subapical swelling; central and lateral spots' size = subhumeral spot, can touch each other, rarely touching suture (see Variation). Venter color variable, sclerites orange with black margins to entirely black with anterior prothorax and lateral abdominal edges orange. Legs black; palpi and tarsi brown.

Head dorsal distance between eyes $=2.5 \times$ eye width; ocular striae reaching anterior angle of eye; vertex puncture size $=1$ x facet, separated by 1 to 2 diameters; epistome puncture size $=0.75 \mathrm{x}$ facet, nearly coalescing. Antenna reaching base of pronotum; antennomere III as long 
as next 3 antennomere combined; antennomeres IX to XI symmetrical; antennomere XI transverse narrower than antennomere X (similar to Fig. 6g).

Maxillary palp terminal segment triangular, sides rounded, lateral angle acute, medial angle nearly $90^{\circ}$, width $=2 \times$ length. Labial palp terminal segment triangular, extended medially, sides rounded, angles nearly $90^{\circ}$, length $=0.8 \times$ width. Labial palp width $=0.5 \times$ maxillary palp width (similar to Fig. 70). Mentum with plate broadly triangular, length $=0.5 \times$ width, sides straight; ridge medial extension short, acutely pointed (similar to Fig. 8d).

Pronotal disc puncture size $=1 \mathrm{x}$ facet, separated by 1 to 2 diameters; laterally separated by 1 diameter. Scutellum pentagonal, length $=0.5 \mathrm{x}$ width. Each elytron with 7 complete striae; stria VIII faint, present at base and apical half, often obscured by interval punctation; strial punctures at base $=2 \times$ pronotal disc punctures, gradually becoming finer posteriorly; intervals finely punctate, punctures impressed laterally.

Prosternum strongly keeled and pinched anteriorly (Eig. 10e-f); expanded laterally in male; with (female) or without (male) foveate punctures in front of procoxa; coxal lines straight, converging anteriorly, length $=0.5 \times$ sternal length, lines barely surpassing coxae, length = basal width; prosternal plate slightly convex, apical width $=0.8 \mathrm{x}$ basal width; base concave. 
Mesosternum basal width $=2.5 \times$ mesocoxal line length; coxal lines straight; base broadly sinuate. Metasternum coxal lines meet at middle, recurved; coxal lines extend 0.33 to 0.5 distance to posterior lateral angle; line behind mesocoxa laterally deep, groove-like; sternum feebly shining, inedial punctures fine, few coarse lateral punctures obscured by strong microreticulation.

First visible abdominal sternite with coxal lines reaching 0.25 distance to posterior edge (Mexico), or barely surpassing coxa (Panama); broadly rounded between metacoxae; coarse punctures laterally, fine punctures medially.

Male genitalia with median lobe weakly arched, apically rounded; internal sac without noticeable sclerotized structures; flagellum straight and narrow, length $=2 \mathrm{x}$ median lobe length (Fig. 115a); base of flagellum straight, sclerite at base elongate claw-shaped (Fig. 115b-d) (3 dissected).

Female genitalia with spermathecal head elongate kidney-shaped, often with weak top-knot; tail narrow, weakly looped, recurved onto itself (Fig. 115e) (13 dissected).

Stridulatory files present on occipital region of males' head; absent on females. Male with lateral expansion of prosternum broad, covering most of pronotal epipleuron (Fig. 14). Females with foveate punctures on prosternum in front of procoxae; males lack these punctures.

Variation. Pronotal spots vary from small and obscure to large and prominent. Central and lateral elytral spots 

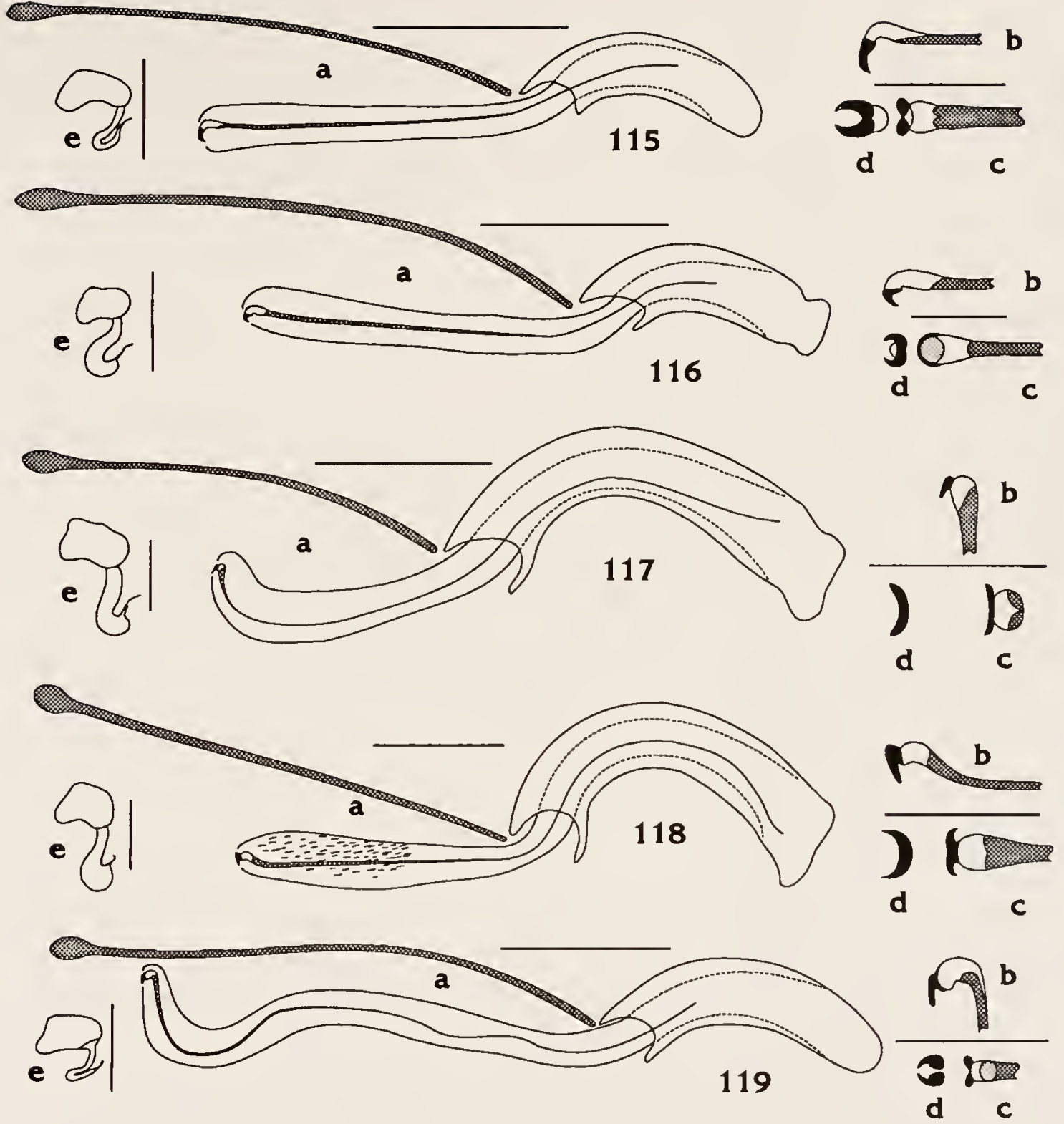

Figures 115-119. Genitalia: 115.) Ischyrus scutellaris Gorham [male \& female, Panama]; 116.) I. septemsignatus Gorham [male, Mexico, Veracruz; female, Guatemala, Baha Verapaz]; 117.) I. tetrasticus Gorham [male, Peru, Huanuco; female, Brasil, Espirito Santo]; 118.$)$ I. tripunctatus Crotch [male, Costa Rica; female, Mexico, Veracruz]; 119.) I. undulatus Gorham [male \& female, Panama]; a.) male genitalia, line $=0.66 \mathrm{~mm}$; b.)

lateral view, c.) dorsal view, and d.) anterior view of the sclerotized muscle attachment at anterior end of male flagellum, line $=0.22 \mathrm{~mm}$; e.) female spermatheca, line $=0.33 \mathrm{~mm}$. 
can touch, forming one spot. The variation discussed below appears to be clinal, with spot size and amount of connection varying over the known geographic range.

The Belize and Mexican specimens (Eig. 70) (2 males, 3 females dissected), including the type, lack the pronotal anterior and basal spots; lack the apical sutural swelling; have the lateral elytral spot anterior to the central spot; have the elytral epipleural fold orange basally; and the abdominal coxal lines surpass the coxae.

One specimen from Panama is similar to the Mexican specimens. Most Panamanian specimens (Fig. 71) (1 male, 10 females dissected) have pronotum with weak basal and anterior spots; sutural mark near apex, variable in size; central and lateral elytral spots at equal setting; epipleural fold of elytra solid black lorange in teneral specimens); and the abdominal coxal lines do not surpass the coxae.

The Colombian specimen (1 female dissected) has pronotum with weakly developed anterior and basal spots (2 each); apical sutural swelling large, connected to central spot; central and lateral elytral spots at equal setting; solid black epipleural fold of elytral; and the abdominal coxal lines surpass the coxa.

Type. The holotype (by monotypy) of Ischyrus scutellaris Gorham label data: "/ [red circle on white paper] Type/ Type, sp.figured/ Bugaba Panama, Champion/ 
Ischyrus scutellaris Type Gorham/ B.C.A., Col., VII, Ischyrus/" [NHML, studied]. Sex not determined.

specimens examined. The holotype and 34 specimens, representing 26 collection records, were studied (see Appendix $C$ for specific data).

Distribution. Southern Mexico, Belize, Panama, and Colombia (Fig. 120).

Etymelogy, Ischyrus scutellaris Gorham was probably named for the large scutellar spot.

Remarks. Ischyrus scutellaris is most similar to $I$. elegantulus, I. chacojae, I. septemsignatus, and I. n. sp. 12 in color pattern. Ischyrus chacojae and I. septemsignatus have only one free central elytral spot; I. scutellaris has 2 free central spots. Ischyrus elegantulus has the scutellar spot narrowly connected to the elytral base; I. scutellaris has this spot broadly connected. Ischyrus $n$. sp. 12 has the free spots of the central elytral marking longitudinally elongate, linear; I. scutellaris has these spots small and circular.

References. Blackwelder 1945:465; Kuhnt 1909:63; $1911: 43$.

\section{Ischyrus septemsignatus Gorham}

Ischyrus septemsignatus Gorham 1887:41, t.2 f.19. Ischyrus septemsignatus var. $\alpha$ Gorham 1887:41. Ischyrus septemsignatus var. $\beta$ Gorham 1887:41.

Diagnosis. Recognized by the pronotum having only 2 free spots, and the elytra with free central and apical spots. 


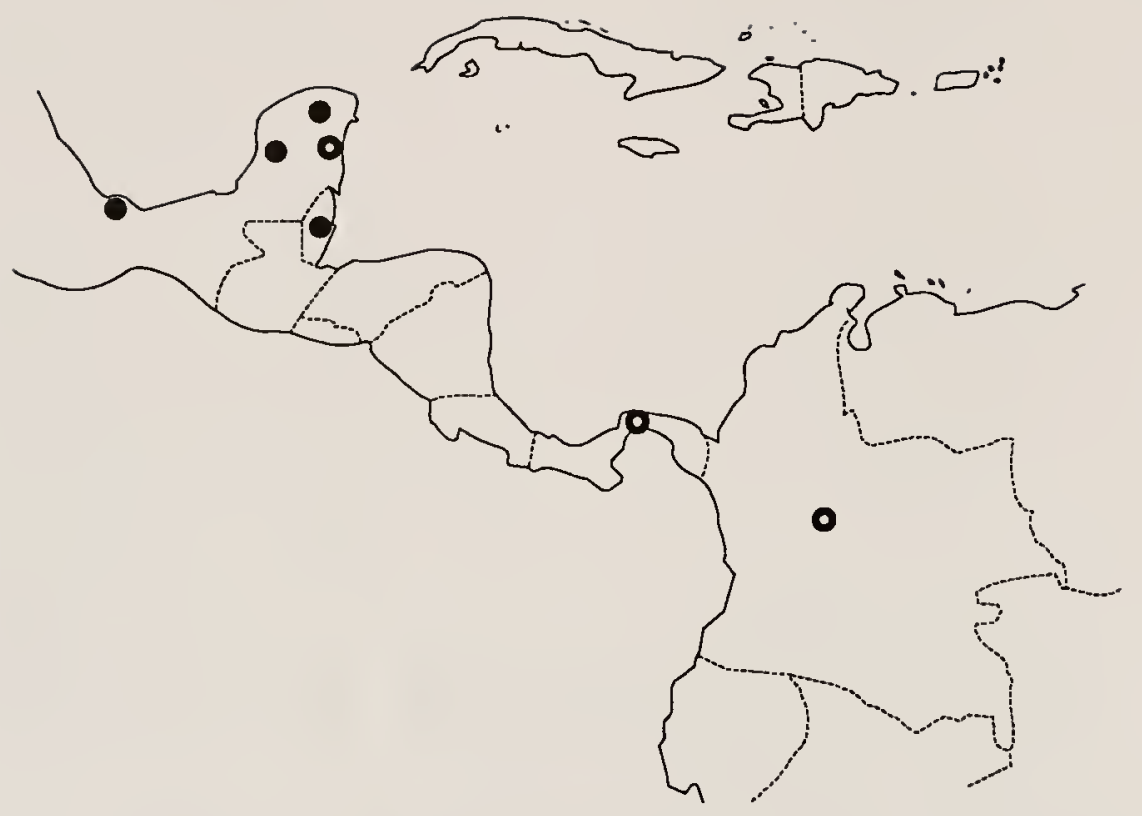

Eigure 120. Ischyrus scutellaris Gorham distribution map. 
Description. Length: $5.5-6.9 \mathrm{~mm}$ : Width: $2.6-3.1 \mathrm{~mm}$. Body elongate, widest at basal third of elytra; microreticulate; orange with black pattern (Fig. 36).

Head orange or black (see Variation). Pronotum with 2 free pronotal spots; medial half of base margined in black, occasionally with a black spot at ends of black margin. Scutellum black. Each elytron with orange epipleural fold; subhumeral spot free or touching base (see Variation); large scutellar spot, broadly connected to base and suture; suture margin black; free central spot, rarely touching black sutural edge; apical spot free. Venter black with orange lateral abdominal sternites and lateral prothorax. Legs black; tarsi and palpi brown.

Head dorsal distance between eyes $=2.5 \mathrm{x}$ eye width; ocular striae reaching 0.7 to 0.8 distance to anterior angle of eye; vertex puncture size $=1 \mathrm{x}$ facet, separated 1 to 3 diameters; epistome puncture size $=0.5 \mathrm{x}$ facet, separated by 1 diameter. Antenna reaching basal 0.25 of pronotum; antennomere III as long as next 3 antennomere combined; antennomeres $\mathrm{X}$ to XI asymmetrical; antennomere XI transverse (similar to Fig. 6e).

Maxillary palp terminal segment triangular, securiform, basally rounded, apical angles $90^{\circ}$ or more, length $=0.66 \mathrm{x}$ width. Labial palp terminal segment triangular, extended on medial side, length $=0.66 \times$ width. Labial palp width $=0.8$ $x$ maxillary palp width (Fig. 7e). Mentum with plate broadly 
triangular, length $=0.6 \mathrm{x}$ width, sides straight, ridge medial extension acutely pointed (similar to Fig. 8d). Pronotum puncture size $=1$ x facet, separated by 1 to 3 diameters. Scutellum pentagonal, length $=0.5 \mathrm{x}$ width. Each elytron with 7 complete striae; stria VIII weak, visible on apical half; strial puncture size $=2 \mathrm{x}$ pronotal disc punctures, gradually decreasing in size posteriorly; intervals finely punctate.

Prosternum keeled and pinched anteriorly; with (female) or without (male) foveate punctures in front of procoxa; coxal lines straight to weakly curved, length $=0.5 \mathrm{x}$ sternal length, lines barely surpassing coxae, length = basal width; prosternal plate slightly convex, apical width $=0.6 \times$ basal width; base shallowly concave.

Mesosternum basal width $=2 \mathrm{x}$ mesocoxal line length; coxal lines straight; base sinuate, lobed medially. Metasternum coxal lines almost meeting at middle, recurved; coxal lines extend 0.5 distance to posterior lateral angle; sternum medial punctures fine, few coarse lateral punctures.

First visible abdominal sternite with coxal lines reaching 0.5 distance to posterior edge; rounded between metacoxae; coarse punctures laterally, fine punctures medially.

Male genitalia with median lobe weakly arched, apically truncate, constricted just before tip; internal sac without noticeable sclerotized structures; flagellum long and narrow, length $=2 \times$ median lobe length (Fig. 116a); base of 
flagellum straight, sclerite at base claw-shaped (Fig. 116bd) (5 dissected).

Eemale genitalia with spermathecal head kidney-shaped, often with top-knot; tail swollen, curved like an inverted question mark, " $i "$ (Fig. 116e) (5 dissected).

Presence of stridulatory files on occipital region of head unknown (heads retracted). Females have foveate punctures on prosternum in front of procoxae; males lack these punctures.

Variation. Besides the typical specimens of $I$. septemsignatus with black heads, Gorham described varieties $\alpha$ and $\beta$ from Guatemala which have red heads: $\alpha$ is smaller and more finely punctate than $\beta$. The majority of specimens studied have the head entirely black. Some have the epistome and frons brown, others have the head almost entirely orange. These variations do not correlate with any other characteristic.

Specimens from Costa Rica, Guatemala, Belize, and southern Mexico (Chiapas and Yucatan) have the subhumeral spot small, free from the base. Specimens from the rest of Mexico (Veracruz, San Luis Potosi, and Hidalgo) have the subhumeral spot elongate, narrowly connected to the base. Type. The lectotype (here designated) of Ischyrus septemsignatus Gorham label data: "/ [red circle on white paper] Type/ sp. figured/ Toxpam / Mexico Salle Coll./ B.C.A., Col., VII, Ischyrus 7-signatus Gorham/ [red] LECTOTYPE Ischyrus septemsignatus Gorham des.P.E.Skelley 
1993/" [NHML, studied]. Sex not determined. Selander \& Vaurie (1962) did not locate "Toxpam", and stated that it is possibly a misspelling of Tuxpan, Veracruz, Mexico.

specimens examined. The lectotype, paralectotypes, and 17 specimens, representing 20 collection records, were studied (see Appendix C for specific data).

A paralectotype with data: "/ Toxpam/ Mexico Salle Coll./ Ischyrus 7-signatus/ B.C.A., Col., VII, Ischyrus/ [yellow] PARALECTOTYPE Ischyrus septemsignatus Gorham des.P.E.Skelley 1993/" [NHML, studied]. Sex not determined. The paralectotype of Ischyrus septemsignatus var. $\alpha$ Gorham label data: "/ Pantaleon, $1700 \mathrm{ft}$, Champion/ Ischyrus 7-signatus/ B.C.A., Col., VII, Ischyrus/ [yellow] PARALECTOTYPE Ischyrus septemsignatus Var. $\alpha$ Gorham des.P.E.Skelley 1993/" [NHML, studied]. Sex not determined. The paralectotype of Ischyrus septemsignatus Var. $\beta$ Gorham label data: "/ Capetillo Guatemala, C.Champion/ Ischyrus 7-signatus lg.var./ B.C.A., Col., VII, Ischyrus/ [yellow] PARALECTOTYPE Ischyrus septemsignatus Var. $\beta$ Gorham des.P.E.Skelley 1993/" [NHML, studied]. Sex not determined. Distribution. Mexico to Costa Rica (Fig. 121). Etymology. Ischyrus septemsignatus, or "7-signatus" was named for the 7 spots on the elytra.

Taxonomic notes. The lectotype was designated because Gorham made no indication that he saw only one specimen of the nominate variety. The specimen chosen was illustrated in the Biologia Centrali-Americana (Gorham 1887). 


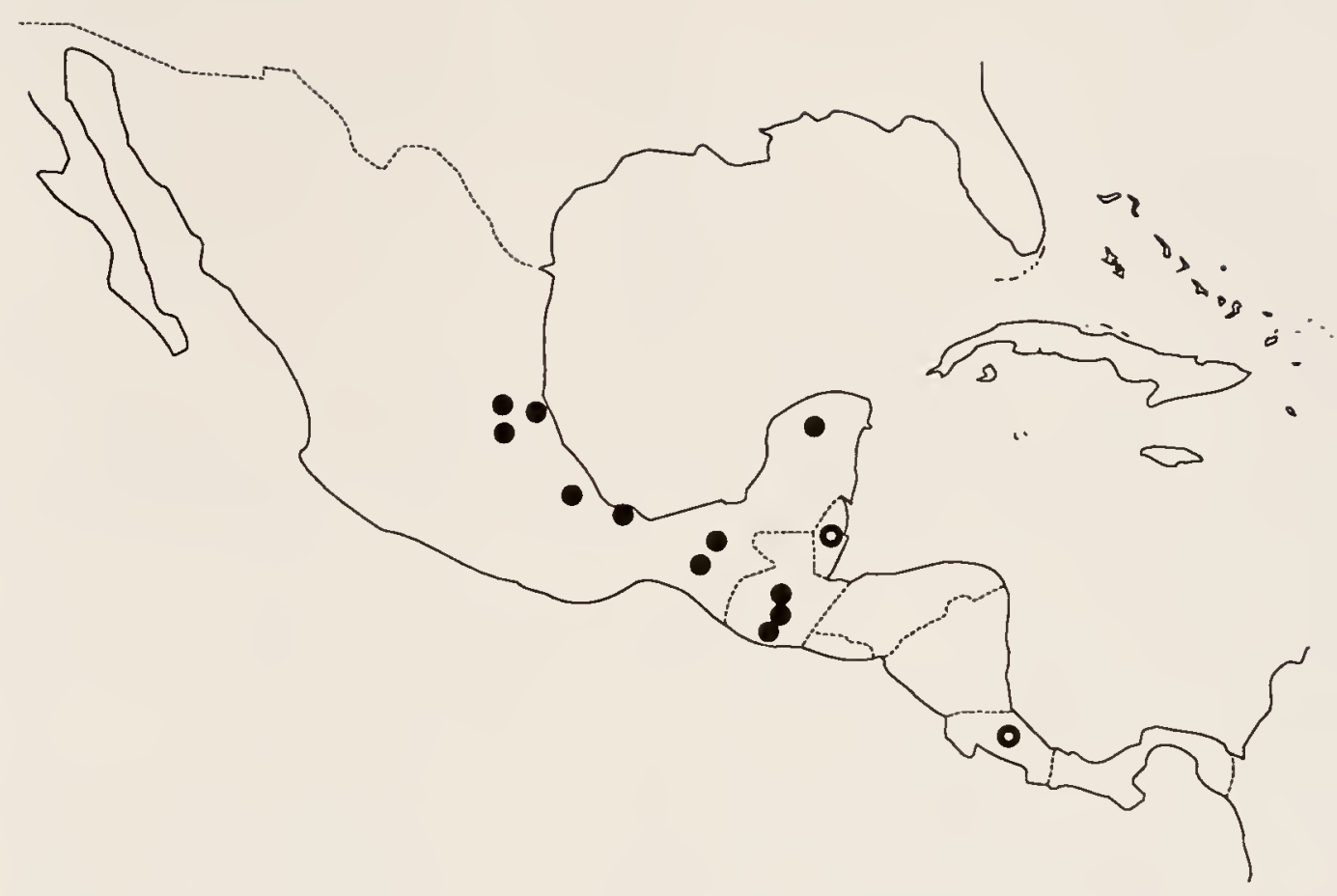

Eigure 121. Ischyrus septemsignatus Gorham distribution map. 
Gorham's varieties, $\alpha$ and $\beta$, differ from the black headed lectotype only in having a red head. As Gorham stated, "The variation in the colour of the head is not unusual in this genus." The differences between variety $\alpha$ and $\beta$ are even smaller: $\beta$ is larger and more coarsely punctate than $\alpha$. Both specimens of these varieties studied by Gorham are deposited in the Natural History Museum, London, and are designated as paralectotypes.

Remarks. Ischyrus septemsignatus is most similar to I. scutellaris and $I$. bogotae in color pattern. Ischyrus scutellaris has 2 free spots at the center of each elytron; I. septemsignatus has only one. Ischyrus bogotae has a larger body size and a single large basal pronotal spot; I. septemsignatus is smaller and lacks large basal elytral markings .

References. Blackwelder 1945:465; Kuhnt 1909:63; $1911: 43$.

\section{Ischyrus tetrasticus Gorham}

Ischyrus tetrasticus Gorham 1887:41, t.3 f.l.

Diagnosis. Recognized by pronotum having only 4 free pronotal spots in a transverse row, orange head with a black basal spot, broad maxillary palp terminal segment, and central elytral band broadly connected to the suture.

Description. Length $6.7-7.7 \mathrm{~mm}$; Width: $3.0-3.8 \mathrm{~mm}$. Body elongate, widest at basal third of elytra; microreticulate, feebly shining; orange with black pattern (Fig. 74) . 
Head orange with black epistome margin and spot on vertex. Pronotum with 4 free spots in anteriorly concave arch. Scutellum dark orange, often with blackened edges. Each elytron with orange epipleural fold; subhumeral spot elongate, connected to base, fused to scutellar spot or touching only at middle; scutellar spot large, broadly connected to base and suture; central band widest at suture, can touch lateral margin; apical spot large and well defined or small, broadly connected to suture and apex. Venter black; pronotal epipleuron and lateral abdominal sternites orange. Legs black; palpi pale brown.

Head dorsal distance between eyes $=2.2 \mathrm{x}$ eye width; ocular striae reaching 0.75 distance to anterior angle of eye; vertex puncture size $=1$ x facet, separated by 1 to 2 diameters; epistome puncture size $=0.5 \times$ facets, separated by 0.5 to 1 diameter. Antenna reaching base of pronotum; antennomere III as long as next 3 antennomere combined; antennomeres IX to XI symmetrical, sometimes appearing asymmetrical; antennomere XI oval, transverse (similar to Eig. 6i) .

Maxillary palp terminal segment triangular, swollen, securiform, basally rounded, apical angles $90^{\circ}$ or more, length $=0.66 \times$ width (see Variation). Labial palp terminal segment triangular, extended on medial side, length $=0.66$ width. Labial palp width $=0.8 \times$ maxillary palp width (similar to Fig. 7e). Mentum with plate triangular, length 
$=0.75 \mathrm{x}$ width, apical sides straight or outwardly curved, ridge medial extension acute (similar to Fig. 8a).

Pronotal disc puncture size $=1$ x facet, separated by 1 to 3 diameters; laterally separated by 0.5 to 1.0 diameter. Scutellum pentagonal, length $=0.5 \mathrm{x}$ width. Each elytron with 7 complete striae; stria VIII present on apical half; strial punctures at base $=2 \mathrm{x}$ pronotal disc punctures, gradually becoming finer posteriorly; intervals finely punctate, obscured by microreticulations.

Prosternum keeled and pinched anteriorly; with (female) or without (male) foveate punctures in front of procoxa; coxal lines straight, length $=0.5 \times$ sternal length, lines barely surpassing coxae, length = basal width; prosternal plate slightly convex, apical width $=0.5$ to $0.6 \times$ basal width; base concave.

Mesosternum basal width $=2 \mathrm{x}$ mesocoxal line length; coxal lines straight; base sinuate. Metasternum coxal lines not meeting at middle, recurved; coxal lines extend 0.33 distance to posterior lateral angle; line behind mesocoxa deep groove; sternum shining, medial punctures fine, few coarse lateral punctures.

Eirst visible abdominal sternite with coxal lines reaching 0.5 distance to posterior edge; rounded between metacoxae; coarse punctures laterally, fine punctures medially.

Male genitalia with median lobe moderately arched, apically truncate, slightly constricted just before tip; 
internal sac without noticeable sclerotized structures;

flagellum long and narrow, length $=1.4 \mathrm{x}$ median lobe length (Fig. 117a); base of flagellum gradually curved, sclerite at base claw-shaped (Fig. 117b-d) (2 dissected).

Female genitalia with spermathecal head kidney-shaped, with top-knot; tail swollen, tightly curved like an inverted

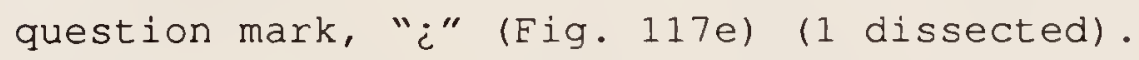

Presence of stridulatory files on occipital region of head unknown (heads retracted). Female with foveate punctures on prosternum in front of procoxae; males lack these punctures.

Variation. The amount of contact between the central elytral band and the lateral margin is variable: not touching in the Panama holotype and Brazil specimens; nearly touching in the Peru specimen; broadly connected in the Ecuador specimen.

The female from Brazil has the maxillary palp terminal segment wider (length $=0.5 \mathrm{x}$ width), angles acute (similar to Fig. 7j); central elytral marking extended posteriorly along suture; apical elytral spot smaller than the pronotal spots. The other specimens studied have maxillary palp terminal segment narrower (length $=0.66 \mathrm{x}$ width); angles nearly $90^{\circ}$ (similar to Fig. 7e); central elytral marking band-like, not extending along the suture; the apical spot larger than the pronotal spots. The Brazilian female may represent a distinct taxon, but without adequate material and a male, it is considered a variety of I. tetrasticus. 
Type. The holotype (by monotypy) of Ischyrus

tetrasticus Gorham label data: "/ [red circle on white paper] Type/ David, Panama, Champion/ Type, sp. figured/ Ischyrus tetrasticus Gorh./ B.C.A., Col., VII, Ischyrus/" [NHML, studied]. Sex apparently female, not dissected. specimens examined. The holotype and 3 specimens, representing 3 collection records, were studied. Label data: Brazil, Espirito Santo [1, HNHM]; Ecuador, Pichincha, Sn. Rafael, 5-I-1973, J. Avila [1, USNM] ; Peru, Huanuco, Tingo Maria, 26-X-1946, J. C. Pallister, 2200' elev. [1, AMNH ] .

Distribution. Panama, Ecuador, Peru, and Brazil (Eig. 122) .

Etymology. tetra: Greek = 4; sticus: Greek = punctured, spotted. This name refers to the 4 spots on the pronotum.

Remarks. Ischyrus tetrasticus is most similar to $I$. quadripunctatus and I. n. sp. 13. Ischyrus quadripunctatus has a black head often with red front and epistome, and narrow maxillary palp terminal segment; $I$. tetrasticus has a red head with a black basal spot, and a wide maxillary palp terminal segment. Ischyrus n. sp. 13 has the central elytral marking free from the suture; $I$. tetrasticus has the central elytral marking band-like, broadly connected to the suture.

References. Blackwelder 1945:465; Gorham 1887:44-45; Kuhnt 1909:64; 1911:43. 


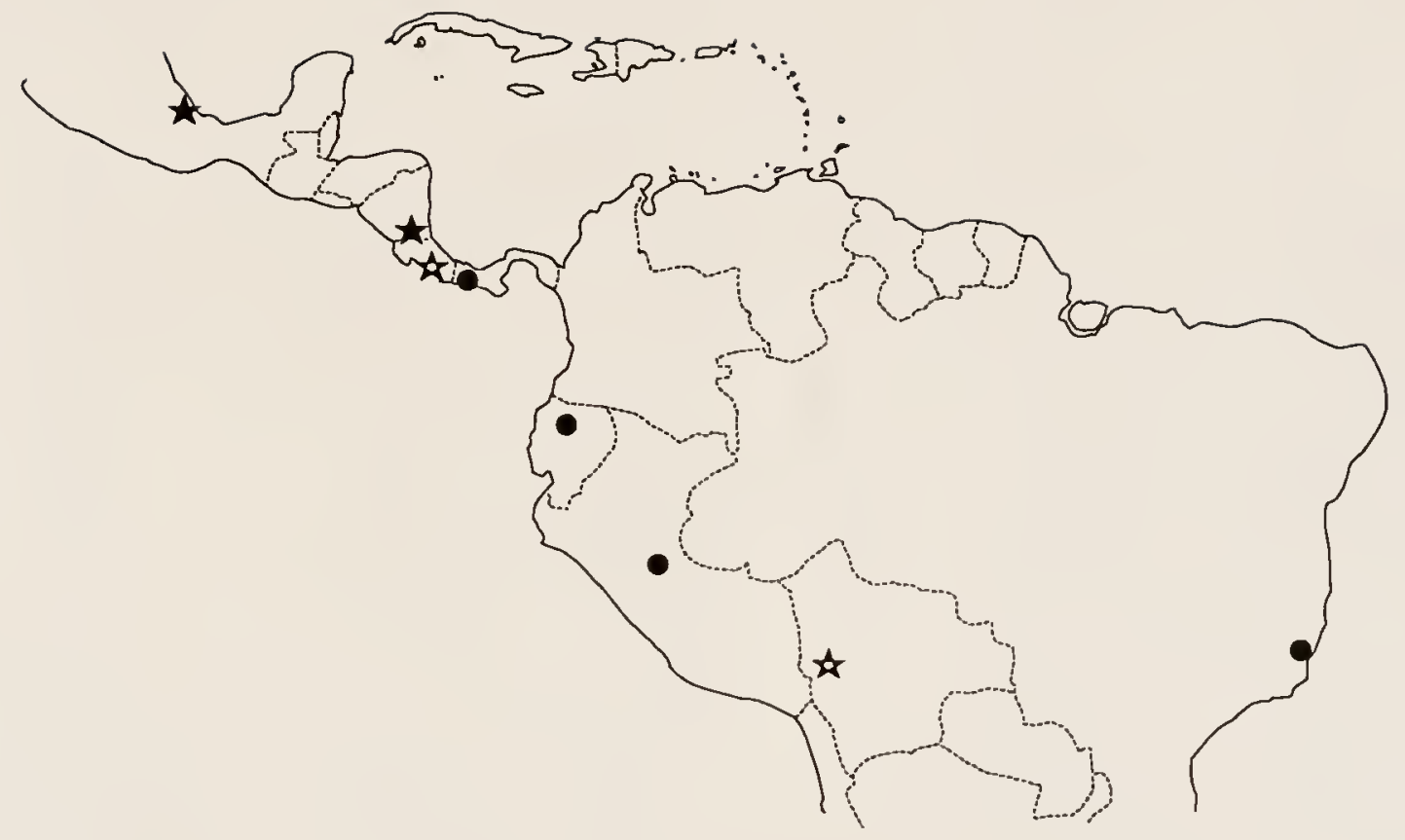

Figure 122. Ischyrus tetrasticus Gorham [circle] and $I$. tripunctatus Crotch [star] distribution map. 


\section{Ischyrus tripunctatus crotch}

Ischyrus tripunctatus Crotch 1873b:144.

Diagnosis. Characterized by having 3 free pronotal spots in transverse row, entirely black head and legs, scutellar and subhumeral spots fused, and central elytral marking broadly connected to suture.

Description. Length: $6.6-7.1 \mathrm{~mm} ;$ Width: $3.0-3.7 \mathrm{~mm}$. Body elongate, widest at basal third of elytra; finely microreticulate, shining; yellow-orange with black pattern (Fig. 37) .

Head black. Pronotum with 3 free spots in a transverse row, middle spot larger than lateral spots; basal margin with weak black edge at median half. Scutellum dark orange to black. Each elytron with black epipleural fold, occasionally orange at base; subhumeral and scutellar spots broadly connected to each other and base, appearing as one large posteriorly lobed spot; scutellar spot broadly connected to suture; central spot large, triangular, widest anteriorly, broadly connected to suture, edges lobed; suture finely black from central spot to apex. Venter orange with black meso- and metepisterna and epimera. Legs black; palpi and tarsi brown.

Head dorsal distance between eyes $=2 \mathrm{x}$ eye width; ocular striae reaching 0.8 distance to anterior angle of eye; vertex puncture size $=0.5$ to $0.75 \times$ facet, separated by 2 to 3 diameters; epistome puncture size $=0.5$ to $0.75 \mathrm{x}$ facet, separated by 1 diameter. Antenna reaching middle of 
pronotum; antennomere III as long as next 3 antennomere combined; antennomeres X to XI symmetrical; antennomere XI transverse, narrower than antennomere $\mathrm{x}$ (similar to Fig. 61).

Maxillary palp terminal segment triangular, securiform, basally rounded, medial angle nearly $90^{\circ}$, lateral angle acute, length $=0.4 \mathrm{x}$ width. Labial palp terminal segment elongate, almost triangular, extended on medial side, rounded basally, length $=0.4 \mathrm{x}$ width. Labial palp width $=$ $0.5 \times$ maxillary palp width (Fig. 7q). Mentum with plate broadly triangular, all sides straight and equal in length, ridge medial extension acutely pointed (similar to Fig. 8d). Pronotal disc puncture size $=1$ x facet, separated by 2 to 3 diameters. Scutellum pentagonal, length $=0.5 \times$ width. Each elytron with 7 complete striae; stria VIII weak, visible on apical half; strial puncture size $=1.5 \mathrm{x}$ pronotal disc puncture; intervals finely punctate.

Prosternum keeled and strongly pinched anteriorly; with (female) or without (male) foveate punctures in front of procoxa; coxal lines straight, length $=0.5 \times$ sternal length, lines barely surpassing coxae, length = basal width; prosternal plate flat, apical width $=0.75 \mathrm{x}$ basal width; base concave.

Mesosternum basal width $=2 \mathrm{x}$ mesocoxal line length; coxal lines straight; base sinuate. Metasternum coxal lines recurved, not meeting at middle; coxal lines extend 0.33 to 0.5 distance to posterior lateral angle; line behind 
mesocoxa deep, groove-like; sternum with medial punctures fine, coarse lateral punctures weakly impressed.

First visible abdominal sternite with coxal lines reaching 0.33 distance to posterior edge; broadly rounded between metacoxae; coarse punctures evenly distributed, often indistinct medially.

Male genitalia with median lobe strongly arched, apically truncate, slightly constricted just before tip; internal sac with rough darkened patch near flagellar base; flagellum hair-like, length $=1.7 \mathrm{x}$ median lobe length (Eig. $118 \mathrm{a})$; base of flagellum straight, sclerite at base clawshaped (Fig. $118 \mathrm{~b}-\mathrm{d})$ (1 dissected).

Female genitalia with spermathecal head kidney-shaped, with weak top-knot; tail greatly swollen, as large as head and kidney-shaped (Fig. 118e) (1 dissected).

Presence of stridulatory files on occipital region of head unknown (heads retracted). Females have few foveate punctures on prosternum immediately in front of procoxae; males lack these punctures.

Variation. No notable variation was observed in the specimens studied.

Type. The lectotype (here designated) of Ischyrus tripunctatus Crotch label data: "/ [red circle on white paper] Type/ Chontales, E.M.Janson [underside] 1929-289/ Ischyrus tripunctatus Type Crotch/ [red] LECTOTYPE Ischyrus tripunctatus Crotch des.P.E.Skelley 1993/" [NHML, studied]. Type locality was stated to be "the vicinity of santo 
Domingo, Chontales, Nicaragua" (Crotch 1873b). Sex not determined.

specimens examined. The lectotype and 3 specimens, representing 3 collection records, were studied. Label data: Bolivia, La Paz, Yolsa, montane forest, 6-I-1991, J. V. MCHugh, JVM lot B91-61 [1, JVMC]; Costa Rica, Hamburgfarm, Reventazon Ebene Limon, 25-V-1936, F. Nevermann, an trocknem holz nachte [1, USNM]; Mexico, Veracruz, Los Tuxtlas, nr. Balzapote, 1-6-V-1989, E. Giesbert [1, FSCA ] .

Distribution. Mexico, Nicaragua, Costa Rica, and Bolivia (Fig. 122).

Etymology. tri: Latin $=3$; punctatus: Latin $=$ punctures, spots. Undoubtedly this species was named for the 3 free spots on the pronotum.

Taxonomic notes. Some catalogers misinterpreted the type locality of "Santo Domingo" as meaning Santo Domingo, Dominican Republic, on the island of Hispaniola (Blackwelder 1945:465). Leng \& Mutchler (1914:412) even reported it from Haiti. This is in error, as the type is from Santo Domingo, Chontales, Nicaragua.

In the original description, Crotch did not state that only one specimen was studied, so a lectotype was designated. The lectotype chosen is from the Janson collection, from the type locality, and fits the original description. 
Remarks. Ischyrus tripunctatus is most similar to $I$. pardalinus Guérin and I. impressopunctatus Crotch in color pattern. Ischyrus pardalinus has a red head with black basal spot, and a free subhumeral spot; I. tripunctatus has an entirely black head, and fused subhumeral and scutellar spot. Ischyrus impressopunctatus has the basal and central elytral markings interrupted by orange, the central spot does not connect with the suture; I. tripunctatus has the basal and central elytral markings complete, broadly connected to the suture.

References. Blackwelder 1945:465; Crotch 1876:(51) 427; Gemminger \& Harold 1876:3691; Gorham 1887:39; Harold 1875:180; Kuhnt 1909:63; 1911:44; Leng \& Mutchler 1914:412.

\section{Ischyrus undulatus Gorham}

Ischyrus undulatus Gorham 1887:42, t.3. f.3.

Diagnosis. Recognized by having 4 free pronotal spots (2 anterior and 2 posterior), metasternum with a pit behind each mesocoxa, and free central, lateral and apical elytral spots.

Description. Length: $5.1-6.2 \mathrm{~mm}$; width: $3.2-3.5 \mathrm{~mm}$. Body elongate, subcylindrical, widest at basal third of elytra; weakly microreticulate, shining; orange with black pattern (Fig. 49).

Head orange. Pronotum with 2 free anterior spots, closer together than the eyes; 2 free posterior spots, as far apart as eyes, posterior spots occasionally reduced. scutellum orange. Each elytron with orange epipleural fold; 
humeral spot connected to base; scutellar spot broadly connected to base and suture; suture narrowly black, often swollen near apex; central spot usually free (see Variation), almost touching suture; lateral spot usually free (see Variation); apical spot free. Venter mostly black or dark orange with abdomen and prosternum orange. Antennal club and legs black or dark orange.

Head dorsal distance between eyes $=3 \mathrm{x}$ eye width; ocular striae reaching anterior angle of eye; vertex puncture size $=1 \times$ facet, separated by 2 to 3 diameters; epistome puncture size $=1$ x facet, separated by 1 diameter. Antenna reaching basal 0.25 of pronotum; antennomere III as long as next 3 antennomere combined; antennomeres $\mathrm{X}$ to XI symmetrical; antennomere XI subcircular (similar to Fig. $6 g)$.

Maxillary palp terminal segment semicircular, apical angles $90^{\circ}$, length $=0.7 \times$ width. Labial palp terminal segment triangular, extended on medial side, length $=0.5 \mathrm{x}$ width. Labial palp width $=0.75 \times$ maxillary palp width (Fig. 7h). Mentum with plate broadly triangular, length = $0.5 \times$ width, sides inwardly curved, ridge medial extension acutely pointed (similar to Fig. 8e).

Pronotal disc puncture size $=1 \mathrm{x}$ facet, separated 3 to 5 diameters; same size laterally, separated 2 to 3 diameters. Scutellum pentagonal, length $=0.5 \mathrm{x}$ width. Each elytron with 7 complete striae; basal strial puncture 
size = pronotal disc puncture, decreasing in size

posteriorly; intervals finely punctate.

Prosternum keeled and broadly pinched anteriorly; with (female) or without (male) foveate punctures in front of procoxa; coxal lines straight, length $=0.6 \times$ sternal length, lines barely surpassing coxae; length $=0.75 \times$ basal width; prosternal plate slightly convex, apical width $=0.6$ $x$ basal width; base shallowly concave.

Mesosternum lines $=0.5 \times$ basal width; lines straight, parallel to convergent anteriorly; base shallowly sinuate. Metasternum coxal lines meeting at middle in straight line often with shallow undulations or punctures (Fig. 15c), weakly recurved; coxal lines extend 0.25 to 0.33 distance to posterior lateral angle; line behind mesocoxa shallow externally, becoming deeper medially leading into a pit, not connected to coxa line; sternum with medial punctures fine, lacking coarse lateral punctures.

First visible abdominal sternite with coxal lines reaching 0.33 distance to posterior edge; broadly rounded between metacoxae, almost truncate; fine punctures medially; coarse lateral punctures weakly impressed.

Male genitalia with median lobe weakly arched, narrowed and apically rounded; internal sac without noticeable sclerotized structures; flagellum long and narrow, length = $2 \times$ median lobe length (Fig. 119a); base of flagellum gradually curved, sclerite at base claw-shaped (Fig. 119b-a) (4 dissected). 
Female genitalia with spermathecal head kidney-shaped, often with top-knot; tail small and narrow, looped (Fig. 119e) (3 dissected).

Presence of stridulatory files on occipital region of head unknown (heads retracted). Females have few foveate punctures on prosternum in front of procoxae; males lack these punctures.

Variation. Posterior free pronotal spots are small, almost lacking on one specimen from Panama. The others have the posterior pronotal spots nearly equal in size to the anterior spots.

The holotype has the central and lateral spot of the elytra fused, forming a wavy marking (illustrated in Gorham 1887). All other specimens studied have these spots separated. No additional differences were observed between the type and these specimens.

Type. The holotype (by monotypy) of Ischyrus undulatus Gorham label data: "/ [red circle on white paper] Type/ Bugaba Panama Champion/ Ischyrus undulatus Gorham/ B.C.A., Col.,VII, Ischyrus/" [NHML, studied]. Sex not determined. Specimens examined. The holotype and 8 specimens, representing 8 collection records, were studied. Label data: Panama, Canal Zone, Barro Colorado Island, 1-9-V-1964, W. D. Duckworth [1, USNM]; same data, 20-23-V-1964 [1, USNM]; same locality, 15-27-V-1972, T. Erwin, light at field station [1, USNM]; Canal Zone, Coco Solo Hospital, $9^{\circ} 21^{\prime} \mathrm{N}_{\text {, }}$ 79.51'W, 9-VI-1972, Engleman [1, CSUC] ; Canal Zone, 
Frijoles, 20-21-V-1981, B. Gill [1, CNCI]; Canal Zone, Paraiso, 1-V-1911, E. A. Schwarz [1, USNM]; Panama Prov., Howard Air Force Base, 21-V-1981, R. H. Turnbow [1, RHTC]; Panama Prov., Las Cumbres, 26-VI-1975, H. Wolda [1, OSUC]. Distribution. Known only from Panama (Fig. 123). Etymology. undulatus: Latin = wavy. Gorham's name probably refers to the wavy central elytral band, as illustrated in the original description.

Remarks. Ischyrus undulatus is most similar to $I$. bellus Guérin and I. nitidior Crotch in pronotal color pattern and body form. Both I. bellus and I. nitidior have the elytra completely banded; in I. undulatus the elytral markings are broken into spots.

References. Blackwelder 1945:465; Gorham 1887:44; Kuhnt 1909:63; 1911:44.

\section{Ischyrus vespertilio Lacordaire}

Ischyrus vespertilio Lacordaire 1842:112.

Diagnosis. Distinguished by the triangular-shaped antennomere IX, pronotum with 2 free spots, basal elytral marking not connected to suture, large triangular central elytral spot, and robust dorsally convex body.

Description. Length: $9.9 \mathrm{~mm}$; Width $5.3 \mathrm{~mm}$. Body oval, dorsally convex, widest at basal third of elytra; microreticulation strong, surface dulled; dark orange with black color pattern (Fig. 24).

Head orange. Pronotum entirely edged in black, black edge thickest on anterior and posterior margins near middle; 


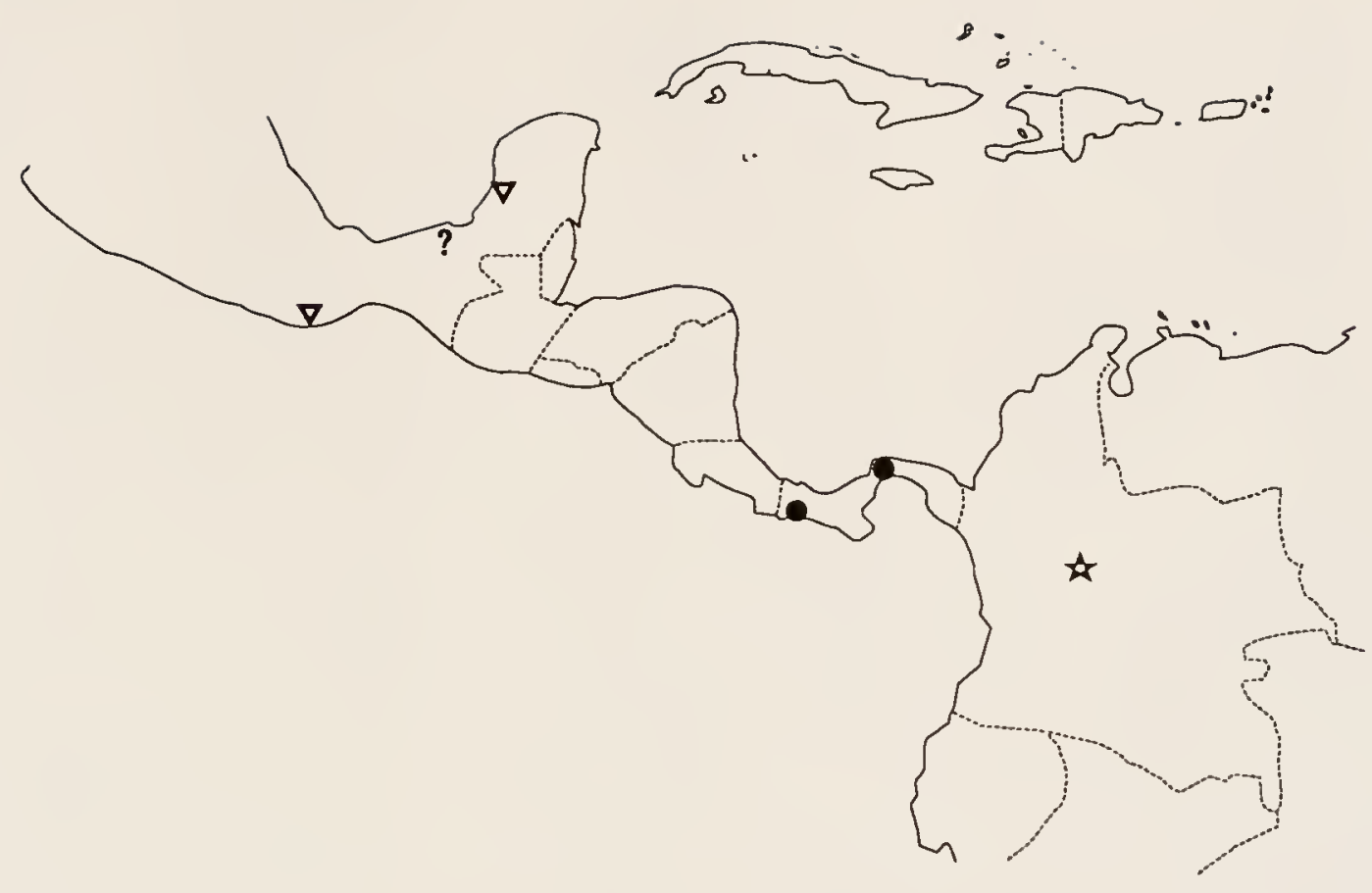

Figure 123. Ischyrus undulatus Gorham [circle], I. vespertilio Lacordaire [star and "?"], and I. n. sp. I [triangle] distribution map. 
2 large free spots. Scutellum orange with dark posterior edge. Each elytron with orange epipleural fold, edges black; scutellar and subhumeral spots fused forming one large bilobed spot; scutellar spot broadly connected to base, not connected to suture; suture with black margin; central marking large, triangular, connected to suture throughout its length, nearly reaching lateral margin and apical angle. Venter dark orange, edges of sclerites black. Femur orange with black apical quarter; tibia black; tarsi orange; palpi brown.

Head dorsal distance between eyes $=3 \mathrm{x}$ eye width; ocular striae reaching base of antenna; vertex puncture size $=0.5 \mathrm{x}$ facet, separated by 2 to 3 diameters; epistome puncture size $=0.5 \times$ facet, separated by 1 to 2 diameters. Antenna reaching basal 0.25 of pronotum; segments narrowed; antennomere III as long as next 3 antennomere combined; antennomeres IX to X triangular, narrowed, length = width; antennomeres IX to XI symmetrical (similar to Fig. 6k); antennomere XI squared, length $=$ width, sides flattened, parallel.

Maxillary palp terminal segment triangular, securiform, basally rounded, apical angles nearly $90^{\circ}$, length $=0.66 \mathrm{x}$ width. Labial palp terminal segment elongate, extended on medial side, rounded basally, length $=0.75$ width. Labial palp width $=0.5 \times$ maxillary palp width (similar to Fig. 7a). Mentum with plate triangular, length $=0.7 \times$ width, 
sides straight; ridge medial extension acute, projecting (similar to Fig. 8c).

Pronotum microreticulate; puncture size $=1 \mathrm{x}$ facet, separated by 2 to 3 diameters. Scutellum pentagonal, length $=0.4 \mathrm{x}$ width. Each elytron strongly microreticulate, dulled; strial punctures weak and obscure, distinct only at base of stria $\mathrm{V}$; interval punctures absent.

Prosternum strongly keeled and broadly pinched anteriorly, projecting, pinch blunt and truncate in ventral view, covering mentum when head turned ventrally; few foveate punctures in front of procoxa; coxal lines straight, length $=0.5 \mathrm{x}$ sternal length, lines barely surpassing coxae, line length = basal width; prosternal plate weakly convex, apical width $=0.5 \mathrm{x}$ basal width; base slightly concave.

Mesosternum basal width $=3 \mathrm{x}$ length 1 ines; lines straight; base sinuate. Metasternum coxal lines recurved, meeting medially; coxal line extends 0.33 distance to posterior lateral angle; sternum without medial punctures, coarse lateral punctures weakly impressed.

First visible abdominal sternite with coxal lines short, reaching 0.33 distance to posterior edge; rounded between metacoxae; finely punctate medially, coarsely punctate laterally.

Genitalia not studied, lectotype not dissected. Presence of stridulatory files on occipital region of head unknown (head retracted). 
Type. The lectotype (here designated) of Ischyrus vespertilio Lacordaire label data: "/ Colombie/ Vespertilio Lac./ Type/ Ex-Musaeo Mniszech/ [red] TYPE/ [pale blue] Muséum Paris ex Coll. R. Oberthür 1952/ [red] LECTOTYPE Ischyrus vespertilio Lacordaire des.P.E.Skelley 1993/" [MNHN, studied]. Sex not determined.

Specimens examined. Only the lectotype was studied. Distribution. Reported by Lacordaire to be from Colombia and Mexico (Tabasco) (Fig. 123). Gorham (1887:40) did not see any specimens of this species from Central America.

Etymology. vespertilio: Latin = bat. Perhaps some part of this specie's color pattern reminded Lacordaire of a bat.

Taxonomic notes. A lectotype was designated because Lacordaire stated that he saw specimens from 2 localities. The lectotype fits the original description and is reported to have been studied by Lacordaire (see Locating Types).

Remarks. Ischyrus vespertilio is most closely related to I. duponti Lacordaire, in body shape, antennal structure, and pronotal color pattern (2 large free spots). Ischyrus duponti has a large free central spot on each elytron; $I$. vespertilio has the central elytral spot large, triangular, and broadly connected to the suture. These species are provisionally left in Ischyrus because they possess most of 
the generic characters. They differ from other Ischyrus by their convex body and triangular antennomere IX.

References. Blackwelder 1945:465; Crotch 1876:426(50); Gemminger \& Harold 1876:3691; Gorham 1887:40; Kuhnt 1909:63; $1911: 44$.

\section{Ischyrus $n$. sp. 1}

Diagnesis. Unique by having a pit-like groove in front of the prosternum (Fig. 9b), antennomere Ix triangular, prosternal pinch lacking, metasternal coxal lines continuous around base of mesocoxa, 9 visible elytral striae, and color pattern (Fig. 25).

Description. Length: $5.8-6.4 \mathrm{~mm}$; Width: $2.8-3.9 \mathrm{~mm}$. Body elongate, widest at basal third of elytra; microreticulate, feebly shining; yellow with black pattern.

Head yellow. Pronotum with central stripe, widest basally; stripe can have a longitudinal elongate yellow spot. Scutellum black. Each elytron with yellow epipleural fold; humeral spot connected to base; sutural edge black; anteriorly placed free central and apical spots; lateral spot appearing as a marginal swelling; lateral margin edged in black from lateral spot to apex. Prosternum yellow except for black sternal plate. Meso- and metathorax black except for yellow mid-lateral area on metasternum. Abdomen yellow except for black medial spots on the posterior edge of sternites II to IV.

Head dorsal distance between eyes $=2.0$ to $2.2 \mathrm{x}$ eye width; ocular striae reaching 0.75 distance to anterior 
angle of eye; vertex and epistome puncture size $=1 \mathrm{x}$ facet, separated by 0.5 to 1.0 diameters. Antenna reaching base of pronotum; antennomere III as long as next 2 antennomere combined; antennomeres IX to XI symmetrical; antennomere VII elongate triangular, longer than wide; antennomere IX triangular, as long as wide; antennomere XI oval, transverse, as wide as antennomere $\mathrm{x}$ (Fig. 6k).

Maxillary palp terminal segment triangular, securiform, basally rounded, apical angles nearly $90^{\circ}$, length $=0.66 \mathrm{x}$ width. Labial palp terminal segment elongate, extended on medial side, rounded basally, length $=0.5 \times$ width. Labial palp width = maxillary palp width (Fig. 7n). Mentum with plate triangular, length $=0.75 \times$ width, sides concave, apical angle rounded; ridge with medial extension projecting, blunt (similar to Fig. 8h).

Pronotal disc puncture size $=1 \mathrm{x}$ facet, separated by 0.5 to 1.0 diameter. Scutellum pentagonal, length $=0.6 \mathrm{x}$ width. Each elytron with 8 striae, stria IX visible on apical half; strial puncture size = pronotal disc puncture; intervals finely punctate, obscured by microreticulations.

Prosternum convex, lacking pinched anterior margin; deep pit-like groove with few enclosed setae in front of procoxa (Eig. 9b), pit as long as procoxa; coxal lines straight, length $=0.4 \mathrm{x}$ sternal length, lines not surpassing coxae, length $=0.75 \times$ basal width; prosternal plate flat, apical width $=0.5 \mathrm{x}$ basal width; base shallowly concave. 
Mesosternum basal width $=2.5 \mathrm{x}$ mesocoxal line length; coxal lines straight; base evenly convex. Metasternum coxal lines not meeting at middle, continuous around coxa, not extending onto metasternum; sternum with medial punctures fine, few coarse lateral punctures.

First visible abdominal sternite with coxal lines continuous around coxa; broadly rounded between metacoxae; coarse punctures laterally, fine punctures medially.

Male genitalia with median lobe straight, short, apically truncate; internal sac without noticeable sclerotized structures; flagellum narrow, length $=1.8 \mathrm{x}$ median lobe length (Fig. 124a); base of flagellum straight and swollen, sclerite at base parallel-sided and fang-like (Fig. 124b-d) (1 dissected).

Female genitalia with spermathecal head ball-like; tail swollen, recurved on itself (Eig. 124e) (1 dissected).

Presence of stridulatory files on occipital region of head unknown (heads retracted). No external sexual dimorphism observed.

Variation. The specimens studied differ in the central pronotal stripe. The female, from Oaxaca, Mexico, has the stripe solid. The male, from Campeche, Mexico, has the stripe medially divided by an elongate yellow spot. This difference could be sexual, geographic, or simply normal variation within the population.

Specimens examined. Only 2 specimens, representing 2 collection records, were studied. Label data: Mexico, 

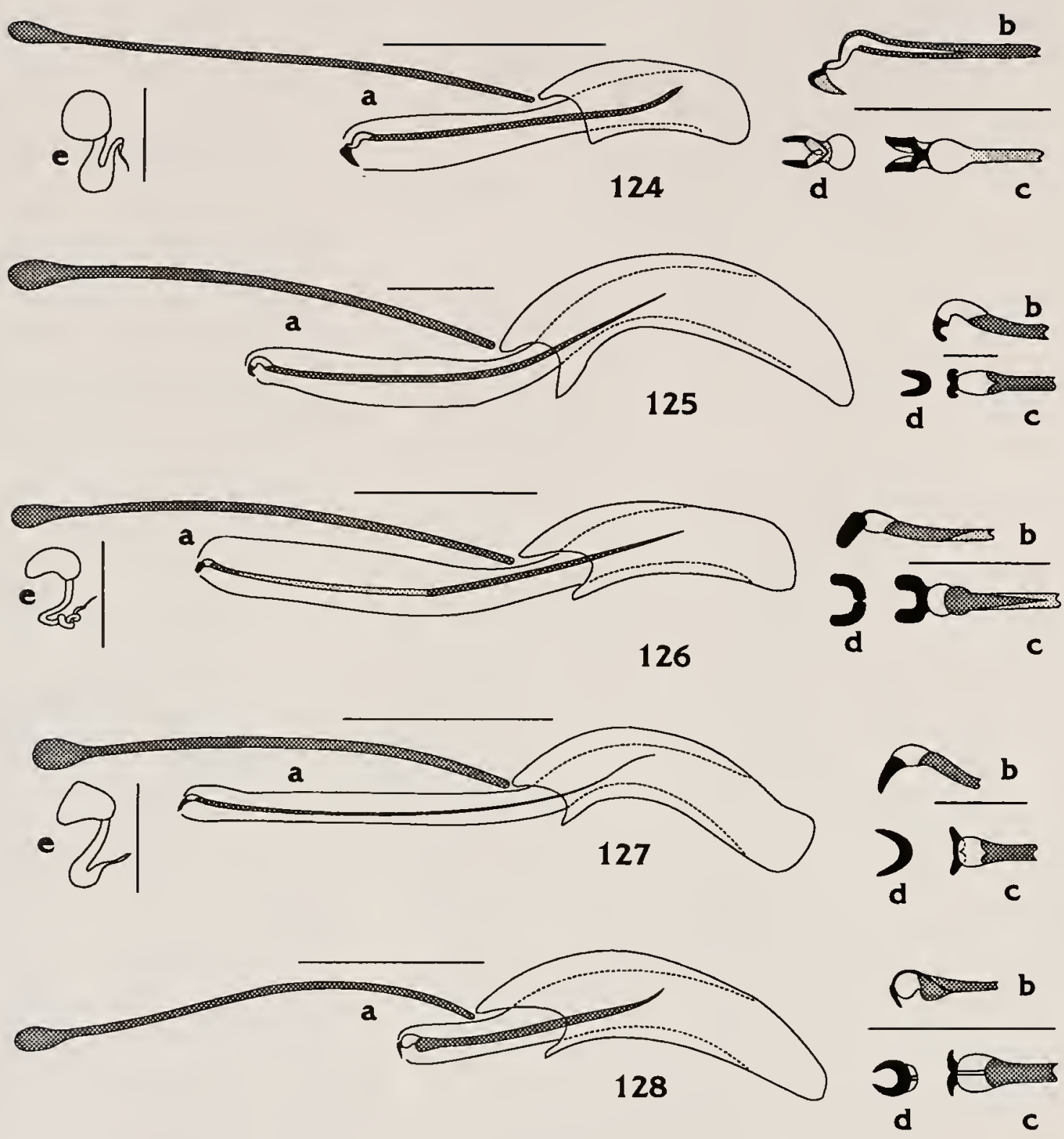

Eigures 124-128. Genitalia: 124.) Ischyrus n. sp. 1 [male, Mexico, Campache; female, Mexico, Oaxaca]; 125.) I. n. sp. 2 [male, Mexico, Chiapas; female unknown]; 126.) I. n. sp. 3 [male \& female, Panama]; 127.) I. n. sp. 4 [male \& female, Cuba]; 128.) I. n. sp. 5 [male,

Panama; female unknown]; a.) male genitalia, line = $0.66 \mathrm{~mm}$; b.) lateral view, c.) dorsal view, and d.) anterior view of the sclerotized muscle attachment at anterior end of male flagellum, line $=0.22 \mathrm{~mm}$; e.) female spermatheca, line $=0.33 \mathrm{~mm}$. 
Campeche, Chicana Ruins, 6mi. E. Xpujil, 13-14-VII-1983, 700' elev., R. M. Anderson, W. Maddison, trop. seas. for. [1, UASM] ; Oaxaca, Temascal, 29-VI-1964, A. G. Raske, at light $[1, \mathrm{CNCI}]$.

Distribution. Known only from Mexico (Fig. 123).

Iaxonomic notes. This unique species is provisionally placed in Ischyrus because it possesses most of the generic characters as stated in the Generic Account. It differs from other Ischyrus in its antennal club structure, prosternal pit, and genitalic characters.

\section{Ischyrus $n$. SD. 2}

Diagnosis. Unique in the black pronotum with orange sides, large triangular central elytral marking, and asymmetrical antennal club segments.

Description. Length: 8.6-9.1 mm; Width 4.5-4.7 mm. Body elongate, widest at basal third of elytra; weakly microreticulate, shining; yellow-orange with black color pattern (Eig. 26).

Head solid black with dark orange base (hidden when head retracted). Pronotum edged in black; black triangular central mark broadly connected to base and anterior margin, anteriorly narrowed. Scutellum black. Each elytron with small free subhumeral spot; V-shaped scutellar spot, connected to suture, not to base; central spot large and triangular, widest anteriorly and angled forward, nearly reaching apical edge along suture; central spots form a Vshaped mark with elytra together; suture with fine black 
edge; black epipleural fold, base reddish. Ventral prothorax black; mes- and metepisterna and epipleura black; remainder of venter dark orange with black sutural margins. Appendages entirely black, palpi pale.

Head dorsal distance between eyes $=2 \mathrm{x}$ eye width; ocular striae reaching 0.75 distance to anterior angle of eye, continued forward as row of coarse punctures; vertex puncture size $=1$ x facet, separated by 2 to 4 diameters; epistome puncture size $=0.9$ to $1.0 \mathrm{x}$ facet, separated 0.5 to 1.0 diameter. Antenna reaching pronotal base; antennomere III as long as next 3 antennomere combined; antennomeres $\mathrm{X}$ to XI asymmetrical; antennomere XI subcircular (Fig. 6b).

Maxillary palp terminal segment triangular, securiform, basally rounded, apical angles nearly $90^{\circ}$, length $=0.75 \times$ length. Labial palp terminal segment triangular, extended on medial side, rounded basally, length $=0.66 \times$ width. Labial palp width $=0.75 \times$ maxillary palp width (Fig. 7b). Mentum with plate triangular, length $=0.75 \mathrm{x}$ width, apical sides inwardly curved, ridge medial extension blunt (Fig. $8 b)$.

Pronotal puncture size $=1$ x facet, separated by 1 to 2 diameters. Scutellum pentagonal, length $=0.5 \mathrm{x}$ width. Each elytron with 7 complete striae; stria VIII weak, visible on apical half; strial puncture size = pronotal disc puncture; intervals finely punctate. 
Prosternum keeled and strongly pinched anteriorly; without foveate punctures in front of procoxa; coxal lines inwardly arched, length $=0.5 \mathrm{x}$ sternal length, lines barely surpassing coxae, line length $=0.75 \times$ basal width; prosternal plate flat, apical width $=0.6 \times$ basal width; base shallowly concave.

Mesosternum basal width $=2 \times$ mesocoxal line length; coxal lines arched inwardly; base sinuate, lobed medially. Metasternum coxal lines recurved, meet medially in a weak tooth; coxal line extends 0.5 distance to posterior lateral angle; sternum with medial punctures fine, coarse lateral punctures weakly impressed.

First visible abdominal sternite with coxal lines reaching 0.25 to posterior edge; rounded between metacoxae. Male genitalia with median lobe moderately arched, narrowed to a point; internal sac without noticeable sclerotized structures; flagellum gradually narrowing toward apex, length $=1.1 \times$ median lobe length (Fig. 125a); base of flagellum straight, sclerite at base claw-shaped (Fig. 125bd) (2 dissected).

Female unknown.

Presence of stridulatory files on occipital region of head unknown (heads retracted). Both males have the prosternum broadly expanded onto, and nearly covering, the pronotal epipleuron; possibly sexual dimorphism.

Variation. One specimen has a faint elongate marking at the center of the pronotal disc. This pale spot is 
hardly discernable from the black central mark and may simply indicate that it is still teneral.

Specimens examined. Only 2 specimens, representing 2 collection records, were studied. Label data: Mexico, Chiapas, $24 \mathrm{mi}$. NW Ocozocoautla, 24-VI-1965, H. R. Burke, et al. [1, USNM]; Veracruz, Omealca, 6-IV-1903, F. K. Knab [1, USNM] .

Distribution. Known from Mexico (Fig. 129).

Remarks. Several other Ischyrus species have males with the prosternum expanded but not to the extent seen in this species.

\section{Ischyrus n. sp. 3}

Diagnosis. Recognized by its elongate-subcylindrical body shape, pit in the metasternum behind each mesocoxa, Tshaped central elytral marking, and central pronotal stripe with a longitudinally elongate spot on each side at base.

Description. Length: 4.3-5.4 mm; Width: $2.1-2.6 \mathrm{~mm}$. Body elongate, subcylindrical, widest at basal third of elytra; weakly microreticulate, shining; orange-red with black pattern (Fig. 48).

Head orange. Pronotum with central stripe connecting base to apex, widest at base; one elongate spot connected to base near each posterior angle, converging anteriorly. Scutellum dark red. Each elytron with orange-red epipleural fold; large subhumeral spot well removed from base, as large or larger than, and occasionally touching scutellar spot; scutellar spot well removed from base, angled, only 


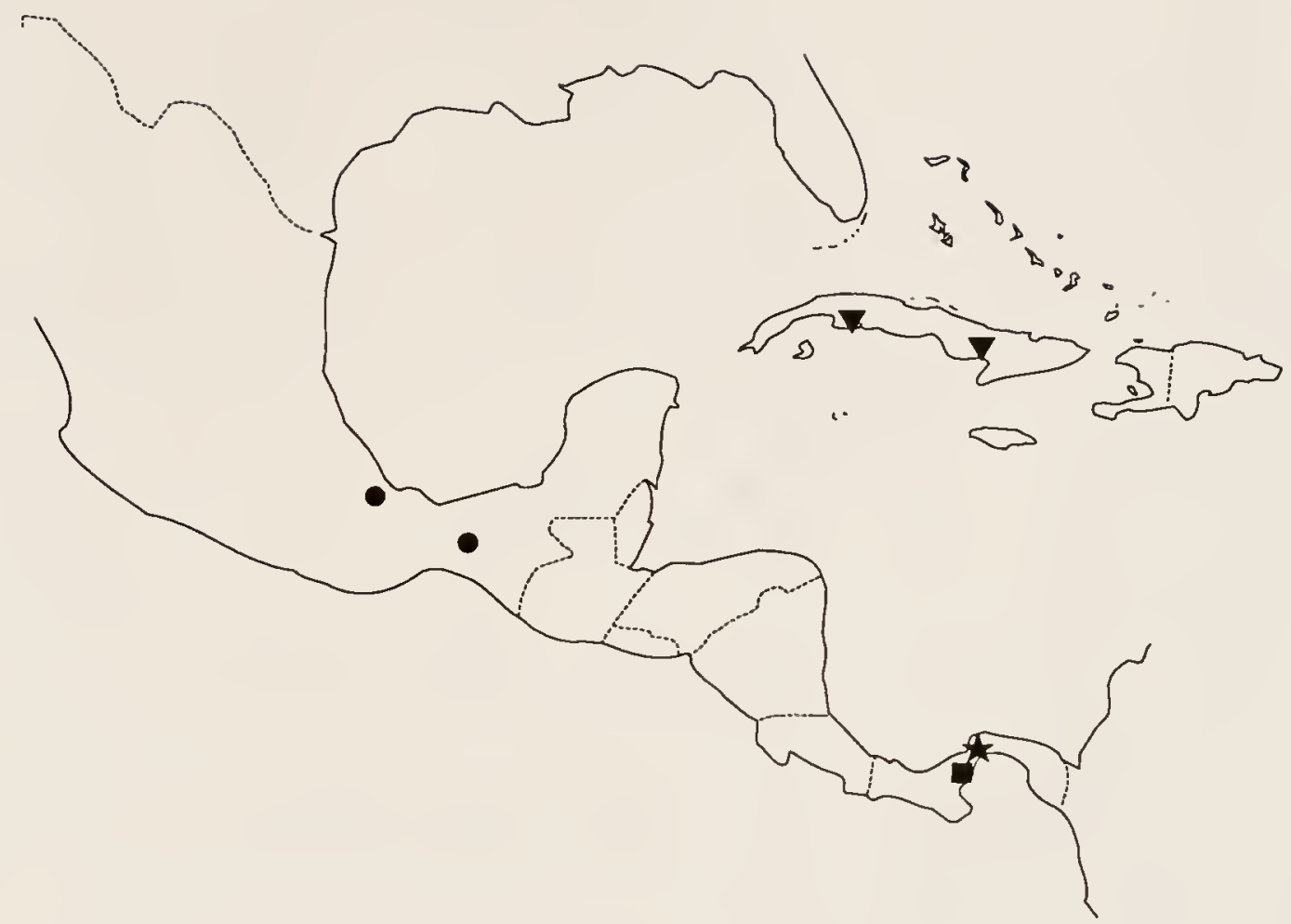

Figure 129. Ischyrus $n . s p .2$ [circle], I. n. sp. 3 [star), I. n. sp. 4 [triangle], and I. n. sp. 5 [square] distribution map. 
connected to suture at anterior half; central band narrow, edges straight, anterior extension short (if present) and rounded, posterior extension nearly reaching apical angle and acutely pointed; together elytral central bands form a T-shaped marking. Venter orange-red. Antennal base orangered, club black. Legs orange-red.

Head dorsal distance between eyes $=4 \mathrm{x}$ eye width; ocular striae reaching anterior angle of eye; vertex puncture size $=1$ x facet, separated by 2 to 3 diameters; epistome puncture size = 1 x facet, separated by 1 to 2 diameters, flat in profile. Antenna reaching base of pronotum; antennomere III as long as next 3 antennomere combined; antennomeres X to XI symmetrical; antennomere XI subcircular (Fig. $6 g)$.

Maxillary palp terminal segment triangular, almost circular, basally rounded, apical angles $90^{\circ}$, width $=$ length. Labial palp terminal segment triangular, extended on medial side, length $=$ width. Labial palp width $=0.5 \mathrm{x}$ maxillary palp width (Fig. 7g). Mentum with plate broadly triangular, length $=0.5 \mathrm{x}$ width, sides inwardly curved, ridge medial extension short and acutely pointed (Fig. 8e)

Pronotal disc puncture size $=1 \times$ facet, separated 3 to 4 diameters; laterally separated 2 to 4 diameters. Scutellum pentagonal, length $=0.5 \mathrm{x}$ width. Each elytron with 7 complete striae; stria VII often weak and obscure; basal strial puncture size $=2 \times$ pronotal disc punctures, 
rapidly decreasing in size posteriorly; intervals finely punctate.

Prosternum keeled and pinched anteriorly; with (female) or without (male) foveate punctures in front of procoxa; coxal lines straight, length $=0.5 \mathrm{x}$ sternal length, lines barely surpassing coxae, length $=0.75 \times$ basal width; prosternal plate slightly convex, apical width $=0.6 \mathrm{x}$ basal width; base shallowly concave.

Mesosternum basal width $=3 \mathrm{x}$ mesocoxal line length; coxal lines straight, parallel to converging anteriorly; base shallowly sinuate. Metasternum coxal lines often recurved, meet at middle in series of 2 to 6 tooth-like undulations (Fig. 15f), teeth occasionally weak, never with a single tooth; coxal lines extend 0.5 distance to posterior lateral angle; line behind mesocoxa deep, groove-like, deep pit in metasternum behind mesocoxa connected to middle of groove, not connected to coxa line (Fig. 16c); sternum finely punctate.

First visible abdominal sternite with fine coxal lines reaching 0.33 distance to posterior edge; broadly rounded between metacoxae, almost truncate; fine punctures medially; coarse lateral punctures weakly impressed.

Male genitalia with median lobe straight, apically truncate; internal sac without noticeable sclerotized structures; flagellum narrow, not sclerotized on basal 0.5 , length $=2 \times$ median lobe length (Eig. 126a); base of 
flagellum straight, sclerite at base horseshoe-shaped (Fig. $126 \mathrm{~b}-\mathrm{d})$ ( 6 dissected).

Female genitalia with spermathecal head kidney-shaped; tail narrow, angled and coiled (Fig. 126e) (4 dissected). Stridulatory files present, but weak, on occipital region of male heads; absent on females. Females have a few, weakly impressed and obscure foveate punctures on prosternum in front of procoxae; males lack these punctures.

Variation. The subhumeral and scutellar spots are occasionally connected posteriorly forming a band-like spot.

Specimens examined. A total of 39 specimens, representing 11 collection records, was studied (see Appendix $C$ for specific data).

Distribution. Known only from Panama (Fig. 129). Biology. The only biological data associated with specimens is "canopy fogging experiment in Luehea seemanni, Pyrethrin fog." The majority of specimens were collected in this manner on at least 10 occasions. This species may have arboreal habits.

\section{Ischyrus $n, s p, 4$}

Diagnosis. Unique in many characters including: pale white antennal club, elongate scutellum, foveate strial punctures at base of elytra, strial punctures lacking on elytral disc, metallic blue dorsal sheen, and short ovoid body shape. This is the only Ischyrus known to occur in the Greater Antilles, specifically Cuba. 
Description. Length: $3.5-4.6 \mathrm{~mm}$; width: $2.0-2.7 \mathrm{~mm}$. Body ovoid, widest at basal third of elytra; microreticulate, shining; black or dark brown, dorsally with metallic blue sheen; antenna black, terminal club segments pale white; legs black, palpi and tarsi brown (Fig. 50). Head dorsal distance between eyes $=2.2 \times$ eye width; eye raspberry-like, facets large; ocular striae strong, reaching base of antenna; vertex puncture size $=0.33 \mathrm{x}$ facet, separated by 3 to 4 diameters; epistome puncture size $=0.5$ to $0.75 \mathrm{x}$ facet, separated by 1 diameter. Antenna reaching base of pronotum; antennomere III as long as next 2 antennomere combined; antennomeres IX to XI symmetrical, all equal in width; antennomere XI subcircular (Fig. 6h).

Maxillary palp terminal segment semicircular, sides slightly flattened, apical angles $90^{\circ}$ or less, length $=0.8$ $\mathrm{x}$ width. Labial palp terminal segment triangular, extended on medial side, length $=0.75 \mathrm{x}$ width. Labial palp width $=$ $0.6 \times$ maxillary palp width (Fig. 7i). Mentum with plate triangular, length $=0.75 \mathrm{x}$ width, sides straight to convex, ridge medial extension acutely pointed (Fig. 8f).

Pronotal disc medial puncture size $=0.33 \mathrm{x}$ facet, separated by 3 to 4 diameters; lateral puncture size $=0.75$ $x$ facet, separated by 1 diameter. Scutellum elongate pentagonal, nearly triangular; length $=0.6 \times$ width. Each elytron with sutural striae complete; striae II to V indicated basally by 2 to 4 foveate punctures, size $=1$ to 2 
$x$ facets; disc lacking striae and strial punctures; surface with few fine interval punctures.

Prosternum convex, not pinched anteriorly; lacking foveate punctures in front of procoxa; coxal lines straight, almost parallel, length $=0.5 \mathrm{x}$ sternal length, lines not surpassing coxae, length $=0.9 \times$ basal width; prosternal plate flat or slightly convex, apical width $=0.9$ to $1 \mathrm{x}$ basal width; base shallowly concave.

Mesosternum basal width $=3 \mathrm{x}$ mesocoxal line length; coxal lines straight, lines parallel to diverging anteriorly; base sinuate. Metasternum coxal lines not meeting at middle, recurved; coxal lines extend 0.33 distance to posterior lateral angle; sternum with medial punctures fine; lacking lateral punctures, dulled.

First visible abdominal sternite with coxal lines reaching 0.25 to 0.33 distance to posterior edge; broadly rounded between metacoxae, almost truncate; lacking noticeable punctures.

Male genitalia with median lobe moderately arched, apically truncate slightly up-turned; internal sac without noticeable sclerotized structures; flagellum straight and narrow, length $=1.3 \times$ median lobe length (Fig. 127a); base of flagellum straight, sclerite at base claw-shaped (Fig. $127 b-d)$ (5 dissected).

Female genitalia with spermathecal head kidney-shaped, often with top-knot; tail weakly swollen, recurved onto itself (Fig. 127e) (2 dissected). 
Presence of stridulatory files on occipital region of head unknown (heads retracted). No sexual dimorphism was observed.

Variation. No notable variation was observed in the specimens studied.

Specimens examined. A total of 14 specimens, representing 11 collection records, was studied (see Appendix $C$ for specific data).

Distribution. Known only from Cuba, west Indies (Eig. 129).

Taxonomic notes. This species is different from all other Ischyrus in many characters (some listed in the Diagnosis), yet it possesses the generic characters listed in the Generic Account. Ischyrus n. sp. 4 is provisionally placed in Ischyrus pending a revision of the Triplacinae at the generic level.

\section{Ischyrus $n . s p .5$}

Diagnosis. Unique in having an ovoid body shape, uniform brown color (no color pattern), prosternal plate wider than long, labial palp terminal segment wider than long, and the epistome punctures 2 to 3 times larger than the vertex punctures.

Description. Length: $5.4 \mathrm{~mm}$; width: $3.2 \mathrm{~mm}$. Body ovoid, widest at basal third of elytra; microreticulate, weakly shining; body light brown (possibly teneral); apical half of antennae black, palpi pale (Eig. 51). 
Head dorsal distance between eyes $=3 \mathrm{x}$ eye width; ocular striae reaching antennal base; vertex shining, puncture size $=0.5 \times$ facet, separated by 2 to 3 diameters; epistome puncture size $=1 \mathrm{x}$ facet, coalescing at apex. Antenna reaching base of pronotum; antennomere III as long as next 3 antennomere combined; antennomeres IX to XI symmetrical; antennomere $\mathrm{X}$ crescent shaped; antennomere XI subcircular, narrower than antennomere $x$ (Fig. 6j).

Maxillary palp terminal segment triangular, transverse, basally rounded, apical angles acute, length $=0.4 \times$ width. Labial palp terminal segment triangular, expanded medially, length $=0.5 \times$ width. Labial palp width $=0.5 \times$ maxillary palp width (Fig. 71). Mentum with plate triangular, length = width, sides concave, apical angle rounded; apex projecting, ridge medial extension lacking (Fig. 8h). Pronotal disc puncture size $=0.75 \mathrm{x}$ facet, separated by 2 to 3 diameters; lateral puncture size $=1 \mathrm{x}$ facet, separated 1 to 2 diameters. Scutellum pentagonal, length = $0.5 \times$ width. Each elytron with 7 visible striae; strial puncture size at base $=1$ x facet, impressed, nearly uniform size to apex; intervals finely punctate.

Prosternum keeled anteriorly, projecting, slightly swollen above pinch; lacking foveate punctures in front of procoxa; coxal lines convex, curve inwardly toward head (Fig. 11C), length $=0.4 \times$ sternal length, lines not surpassing coxae, length $=0.5 \times$ basal width; prosternal 
plate semicircular, flat, apical width $=0.5 \times$ basal width; base shallowly concave.

Mesosternum basal width $=2 \times$ mesocoxal line length; coxal lines straight, divergent anteriorly; base sinuate, broadly lobed at middle. Metasternum coxal lines recurved, meet at middle with a shallow tooth; coxal lines extend 0.5 distance to posterior lateral angle; sternum with medial punctures fine, few coarse lateral punctures.

First visible abdominal sternite coxal lines reaching 0.33 distance to posterior edge; rounded between metacoxae; lateral punctures slightly larger than medial punctures.

Male genitalia with median lobe weakly arched, narrowed and apically pointed; internal sac without noticeable sclerotized structures; flagellum short and straight, length $=0.7 \times$ median lobe length (Fig. 128a); base of flagellum straight and swollen, sclerite at base claw-shaped (Fig. $128 \mathrm{~b}-\mathrm{d})$ ( 1 dissected).

Female unknown.

Presence of stridulatory file on occipital region of head unknown (head retracted).

specimens examined. The only known specimen has the following label data: Panama, Cocle Prov., El Valle, 14-VI67, D. M. DeLong \& C. A. Triplehorn [1, OSUC].

Distribution. Only known from Panama (Fig. 129).

$$
\text { Ischyrus n. sp. } 6
$$

Diagnosis. Characterized by having uniform dark brown color (no color pattern), elongate body, lateral pronotal 
punctures larger than on disc, labial palp terminal segment rounded or squared (length $=$ width), prosternal plate length $=2 \mathrm{x}$ width, and 8 complete elytral striae.

Description. Length: 4.1-6.0 mm; Width: $2.7-3.2 \mathrm{~mm}$. Body oval-elongate, coarsely punctate, widest at basal third of elytra; microreticulate, dull or shining; body dark brown to black; palpi, tarsi, apex of tibia, and antennae brown (Fig. 52).

Head dorsal distance between eyes $=3 \mathrm{x}$ eye width; ocular striae reaching anterior angle of eye; vertex puncture size $=0.25$ to 0.75 facet, separated by 1 to 3 diameters; epistome puncture size $=0.5$ to $0.75 \mathrm{x}$ facet, separated by 0.5 to 1.0 diameter. Antenna reaching base of pronotum; antennomere III as long as next 2 antennomere combined; antennomeres IX to XI symmetrical; antennomere XI oval, transverse (Fig. 6i).

Maxillary palp terminal segment triangular, sides rounded, lateral angle acute, medial angle nearly $90^{\circ}$, width $=2 \times$ length. Labial palp terminal segment semicircular, symmetrical, angles $90^{\circ}$, length $=$ width. Labial palp width $=0.33 \times$ maxillary palp width (Fig. $7 j$ ). Mentum with plate triangular, length $=0.8 \times$ width, sides nearly equal in length, sides convex, ridge medial extension bluntly pointed (Fig. 8g)

Pronotal disc punctures fine at base, becoming larger anteriorly, anterior puncture size $=0.5 \mathrm{x}$ facet, separated by 1 to 2 diameters; lateral puncture size $=1$ to $1.2 \mathrm{x}$ 
facet, separated 0.5 to 1.0 diameter. Scutellum pentagonal, length $=0.6 \mathrm{x}$ width. Each elytron with 8 complete striae; strial puncture size at base $=1$ x facet, impressed, gradually becoming smaller posteriorly; intervals finely punctate.

Prosternum strongly keeled and pinched anteriorly, swollen above pinch; with (female) or without (male) foveate punctures in front of procoxa; coxal lines sinuate, slightly concave at middle, length $=0.5$ to $0.6 \mathrm{x}$ sternal length, lines surpassing coxae, length = basal width; prosternal plate narrowed anteriorly, slightly convex, apical width = 0.5 x basal width; base shallowly concave.

Mesosternum basal width $=3 \mathrm{x}$ mesocoxal line length; coxal lines straight, parallel; base truncate or sinuate. Metasternum coxal lines not meeting at middle; coxal lines extend 0.5 distance to posterior lateral angle; sternum with medial punctures fine, few coarse lateral punctures size = pronotal punctures.

First visible abdominal sternite with coxal lines reaching 0.33 to 0.5 distance to posterior edge; broadly rounded between metacoxae; with coarse punctures laterally, fine punctures medially.

Male genitalia with median lobe moderately arched, apically truncate, slightly constricted just before tip; internal sac without noticeable sclerotized structures; flagellum hair-like, length $=2.3 \times$ median lobe length (Fig. 
130a); base of flagellum straight, sclerite at base elongate ring-shaped (Fig. $130 \mathrm{~b}-\mathrm{d}$ ) (12 dissected).

Female genitalia with spermathecal head kidney-shaped to cone-shaped; tail narrow, weakly curved with swollen end (Fig. 130e) (4 dissected).

Presence of stridulatory files on occipital region of head unknown (heads retracted). Females have foveate punctures in front of procoxae, covering the surface from coxae to anterior margin. Males lack these punctures or, at most, have a few punctures located near the procoxae.

Variation. Specimens from South America are more elongate (narrower) and duller (with stronger microreticulations) than the Central American specimens. The amount and strength of microreticulation varies tremendously across the geographic range of this species. specimens examined. A total of 21 specimens, representing 21 collection records, was studied (see Appendix $C$ for specific data).

Distribution. Bolivia, Brazil, and Central America (Fig. 135).

Remarks. See Remarks under Ischyrus n. sp. 7.

$$
\text { Ischyrus } n . \text { sp. } 7
$$

Diagnosis. Characterized by having uniform dark brown color (no color pattern), parallel-sided body, pronotal punctures uniform in size, labial palp terminal segment rounded or squared (length $=$ width), prosternal plate length $=3 \times$ width, and 8 complete elytral striae. 

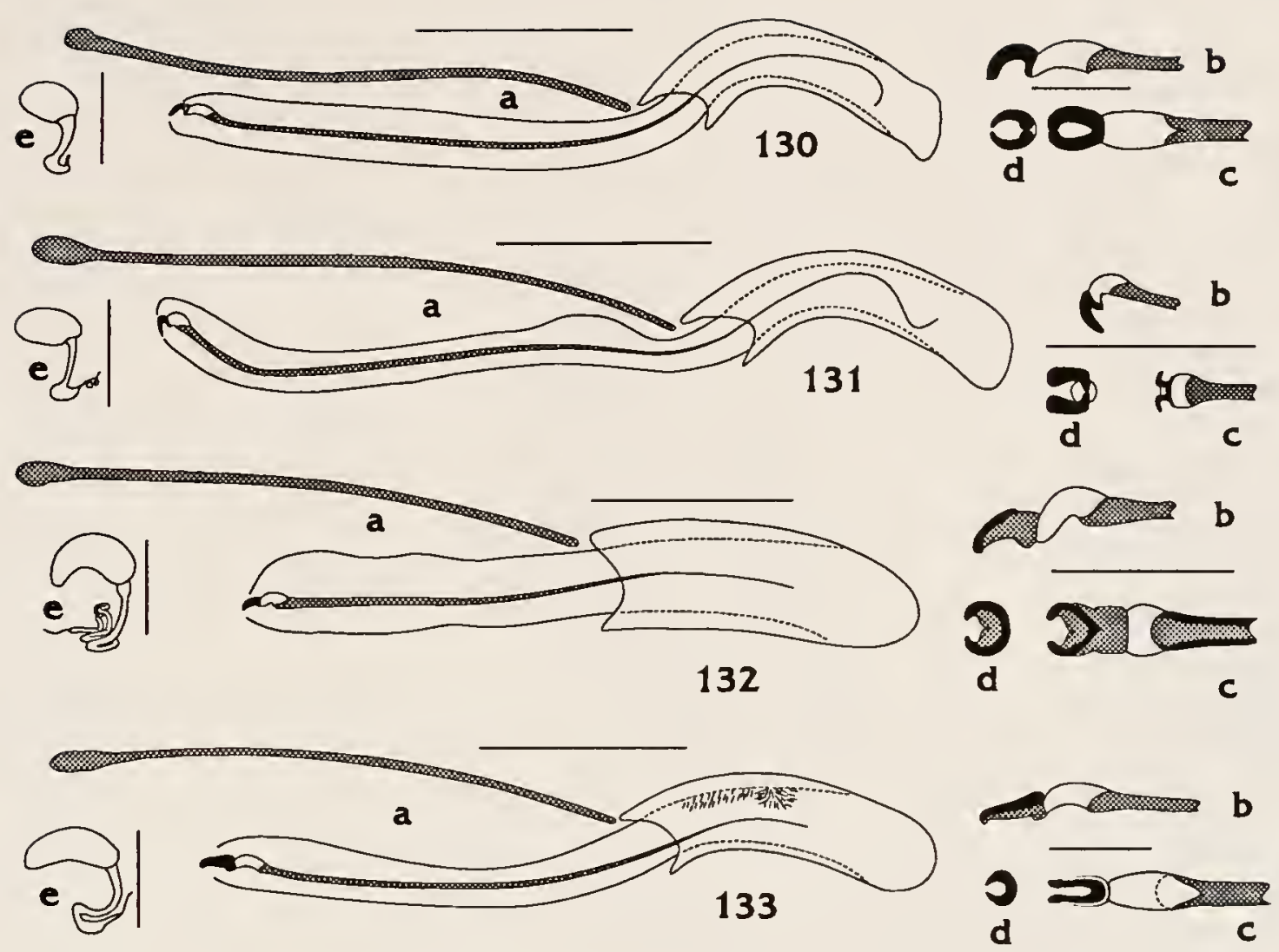

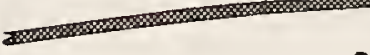

a
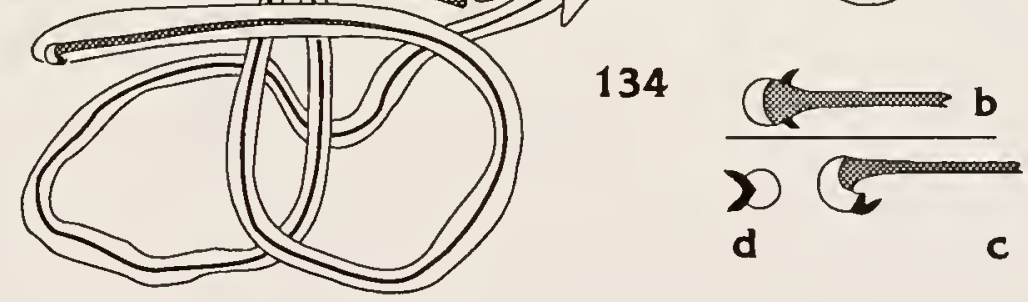

Figures 130-134. Genitalia: 130.) Ischyrus n. sp. 6 [male, Panama; female, San Salvador]; 131.) I. n. sp. 7 [male, Panama; female, Venezuela, Aragua]; 132.) I. n. sp. 9 [male \& female, Panama]; 133.) I. n. sp. 10 [male, Colombia; female, Panama]; 134.) I. n. sp. 11 [male, Panama; female spermatheca not found]; a.) male genitalia, line $=0.66 \mathrm{~mm}$; b.) lateral view, c.) dorsal view, and d.) anterior view of the sclerotized muscle attachment at anterior end of male flagellum, line = $0.22 \mathrm{~mm}$; e.) female spermatheca, line $=0.33 \mathrm{~mm}$. 
Figure 135. Map. n. sp. 6 


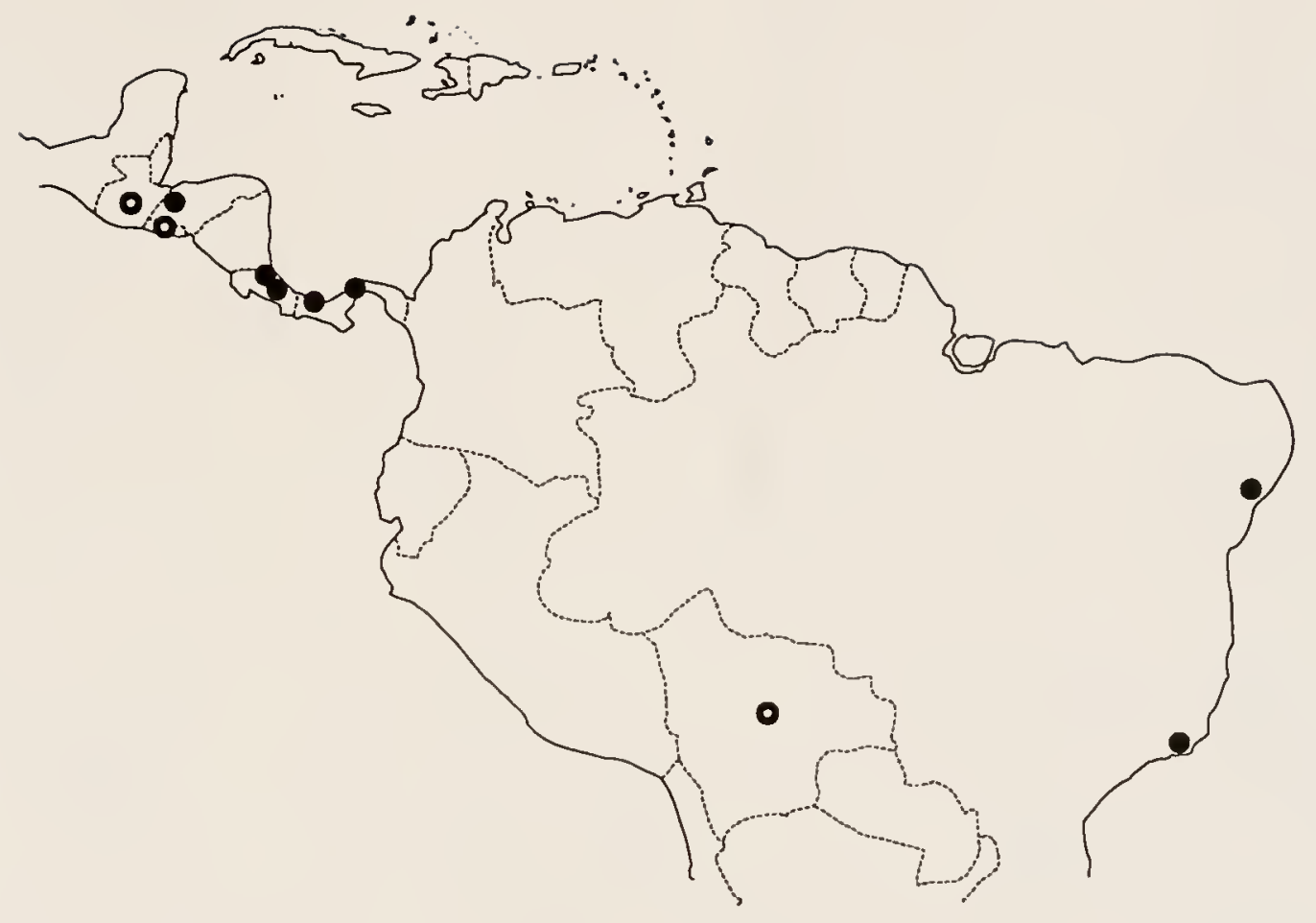

Eigure 135. Ischyrus n. sp. 6 distribution map. 
Description. Length: $4.1-5.2 \mathrm{~mm}$; width: $1.9-2.4 \mathrm{~mm}$. Body parallel-sided, coarsely punctate, widest at basal third of elytra; microreticulate, dull; body dark brown; mouthparts, antennal club and tarsi slightly pale brown (Eig. 53)

Head dorsal distance between eyes $=3 \times$ eye width; ocular striae reaching 0.7 to 0.8 apical angle of eye; vertex puncture size $=0.5$ to $0.75 \times$ facet, separated by 2 to 3 diameters; epistome puncture size $=0.5$ to $0.75 \mathrm{x}$ facet, separated by 0.5 to 1.0 diameter. Antenna reaching base of pronotum; antennomere III as long as next 2 antennomere combined; antennomeres IX to XI symmetrical; antennomere XI oval, transverse (similar to Fig. 6i).

Maxillary palp terminal segment semicircular, swollen, sides rounded, apical angles obtuse, length $=0.75 \times$ width. Labial palp terminal segment narrowed, elongate, symmetrical, sides rounded, angles obtuse, width $=0.75 \mathrm{x}$ length. Labial palp width $=0.33 \mathrm{x}$ maxillary palp width (Eig. 7k). Mentum with plate triangular, length $=0.8 \mathrm{x}$ width, sides nearly equal in length, sides convex, ridge medial extension bluntly pointed (similar to Fig. 8g).

Pronotal disc puncture size $=0.5$ to $0.75 \mathrm{x}$ facet, separated by 2 to 3 diameters; lateral puncture size $=1 \mathrm{x}$ facet, separated 0.5 to 1.0 diameter. Scutellum pentagonal, length $=0.6 \times$ width. Each elytron with 8 complete striae; strial puncture size $=1 \mathrm{x}$ facet, uniform in size almost to apical third; intervals finely punctate. 
Prosternum strongly keeled and pinched anteriorly, sternum swollen above pinch (Fig. $10 \mathrm{~g}-\mathrm{h}$ ); with (female) or without (male) foveate punctures in front of procoxa; coxal lines sinuate, nearly parallel, slightly concave at middle, length $=0.5$ to $0.6 \mathrm{x}$ sternal length, lines surpassing coxae (Eig. 1lb), basal width $=0.5 \times$ length; prosternal plate appearing swollen behind coxae, slightly convex, apical width $=0.9$ to $1.0 \times$ basal width; base shallowly concave.

Mesosternum basal width $=1.5 \mathrm{x}$ mesocoxal line length; coxal lines straight, parallel; base truncate. Metasternum coxal lines meet weakly at middle in straight line, often obscure; coxal lines extend 0.33 to 0.5 distance to posterior lateral angle; sternum with medial punctures fine, coarse lateral punctures similar to pronotal punctures.

First visible abdominal sternite with coxal lines reaching 0.33 to 0.5 distance to posterior edge; rounded between metacoxae; punctation similar to metasternum, coarse punctures laterally, fine punctures medially.

Male genitalia with median lobe weakly arched, apically rounded; internal sac without noticeable sclerotized structures; flagellum hair-like, length $=2.3 \mathrm{x}$ median lobe length (Fig. 13la); base of flagellum straight, sclerite at base claw-shaped to ring-shaped (Eig. 131b-d) (9 dissected). Female genitalia with spermathecal head elongate-oval; tail narrow, weakly curved with swollen end (Fig. 131e) (6 dissected). 
Stridulatory files present on occipital region of heads in both males and females. Females have foveate punctures in front of procoxae, covering the surface from coxae to anterior margin (Fig. 12); male prosternal punctures are obscure, not impressed.

Variation. The dorsal punctation varies in size and distinctiveness from specimen to specimen.

specimens examined. A total of 67 specimens, representing 16 collection records, was studied (see Appendix $C$ for specific data).

Distribution. Brazil, Venezuela, Panama, and Costa Rica (Fig. 136).

Remarks. Ischyrus n. sp. 7 is similar to Ischyrus $n$. sp. 6 in many characters. Ischyrus n. sp. 6 has an elongate body, lateral pronotal punctures larger than on the disc, and the prosternal plate length $=2 \mathrm{x}$ widths; I. n. sp. 7 has a parallel-sided body, pronotal punctures of equal size, and the prosternal plate length $=3 \mathrm{x}$ widths.

\section{Ischyrus $n, s p .8$}

Diagnosis. Characterized by its dull, uniformly orange-brown color with 3 small free spots on each elytron, and the weakly pinched prosternum.

Description. Length: $5.9-6.6 \mathrm{~mm}$; Width: $3.1-3.5 \mathrm{~mm}$. Body elongate, widest at basal third of elytra; strongly microreticulate, dull; orange-brown with black pattern (Fig. 55) . 
270

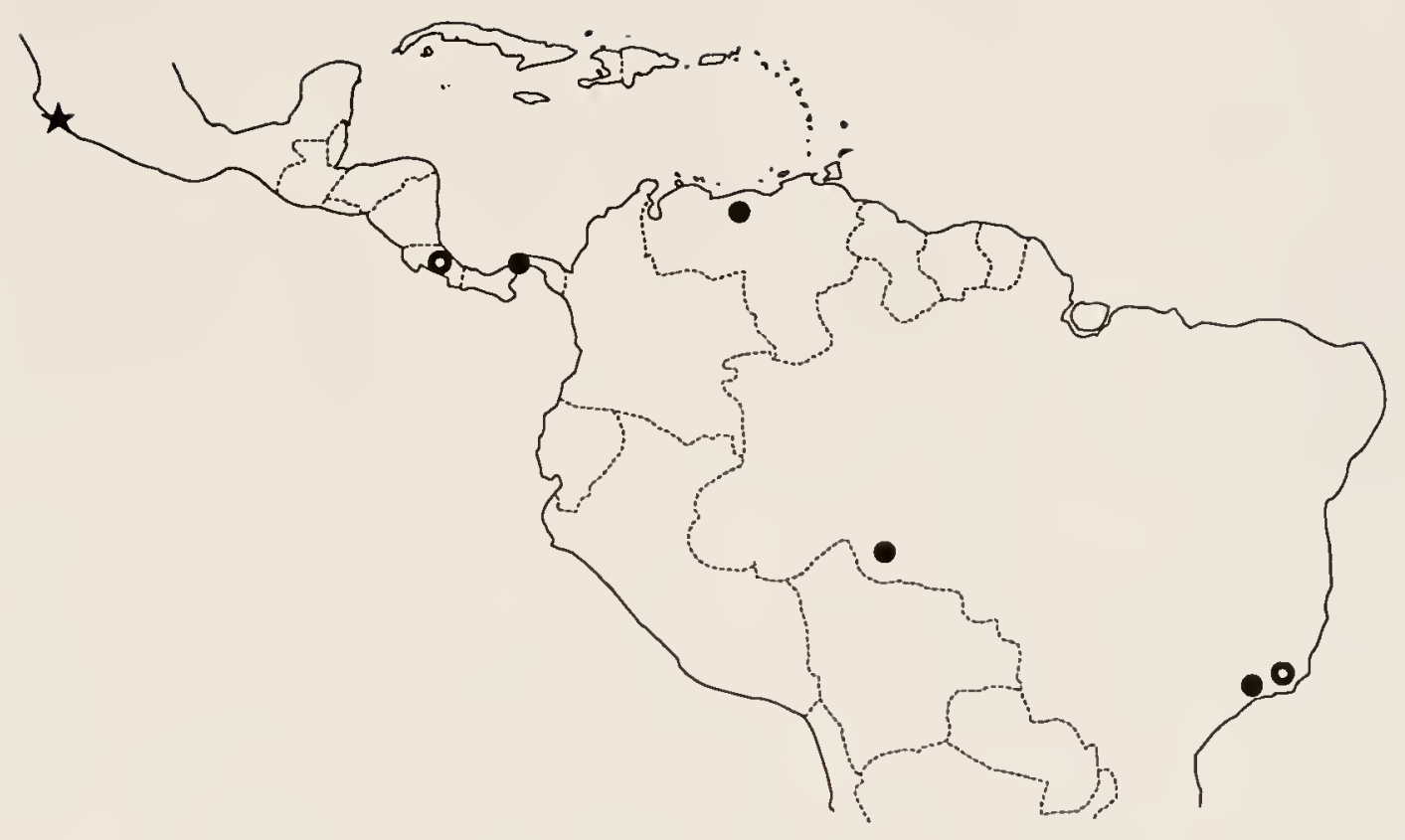

Figure 136. Ischyrus n. sp. 7 [circle] and I. n. sp. 8 [star] distribution map. 
Head orange-brown. Pronotum with thin black margins. Scutellum dark orange-black. Each elytron with black epipleural fold, small amount of orange at base; elytra finely margined in black; scutellar, central and lateral spots free, lateral spot anterior to central, central and lateral spot occasionally connected. Venter orange, margins of sclerites darker. Antennal club black, base orange; legs slightly darker than venter.

Head dorsal distance between eyes $=3 \mathrm{x}$ eye width; ocular striae reaching 0.75 distance to anterior angle of eye; vertex and epistome puncture size $=0.5$ to $0.75 \mathrm{x}$ facet, separated by 1 to 2 diameters. Antenna reaching basal 0.25 of pronotum; antennomere III as long as next 3 antennomere combined; antennomeres IX to XI symmetrical; antennomere XI oval, transverse (similar to Fig. 6i).

Maxillary palp terminal segment triangular, securiform, basally rounded, apical angles nearly $90^{\circ}$, length $=0.66 \mathrm{x}$ width. Labial palp terminal segment elongate, extended on medial side, rounded basally, length $=0.75 \times$ width. Labial palp width $=0.5 \times$ maxillary palp width (similar to Fig. 7a). Mentum with plate triangular, sides straight and equal in length, ridge medial extension short and projecting, acutely pointed (similar to Fig. 8i).

Pronotal disc puncture size $=1 \times$ facet, separated 2 to 3 diameters. Scutellum pentagonal, length $=0.6 \mathrm{x}$ width. Each elytron with 7 visible striae; strial puncture size at base $=1 \mathrm{x}$ facet, gradually becoming finer at apex; 
intervals finely punctate, hidden by strong microreticulations.

Prosternum convex and weakly pinched anterior; with foveate punctures in front of procoxa; coxal lines straight, length $=0.4 \times$ sternal length, lines not surpassing coxae, length $=0.75$ basal width; prosternal plate flat, apical width $=0.75 \times$ basal width; base shallowly concave.

Mesosternum basal width $=1.5 \times$ mesocoxal line length; coxal lines straight, anteriorly diverging; base sinuate. Metasternum coxal lines weakly recurved, not meeting at middle; coxal lines extend 0.25 to 0.33 distance to posterior lateral angle; sternum with medial punctures fine, few coarse lateral punctures weakly impressed.

First visible abdominal sternite coxal lines reaching 0.25 to 0.33 distance to posterior edge; rounded between metacoxae; coarse punctures laterally, fine punctures medially.

Male unknown.

Eemale genitalia with spermathecal head kidney-shaped, with strong top-knot; tail swollen, tightly curved like an inverted question mark, " $i$ " (Fig. 144) (3 dissected).

Presence of stridulatory files on occipital region of head unknown (heads retracted).

Variation. The central and lateral elytral spots are connected on one of the paratypes, forming a single wavy spot. Otherwise, no notable variation was observed. 
Specimens examined. Only 3 specimens were studied, representing 2 collection records. Label data: Mexico, Jalisco, UNAM Biol. Sta. Chamela, 9-VIII-1982, C. W. \& L. O'Brien, \& G. Wibmer, 200'elev., at night [2, PESC]; same data, at light [1, PESC $]$.

Distribution. Known only from Mexico (Fig. 136).

\section{Ischyrus n. sp. 2}

Diagnosis. Recognized by having the pronotum almost entirely black (except for anterior angles), elytral free basal spots forming a straight transverse line, and central elytral band not extended beyond apical third of elytra.

Description. Length: 4.2-5.7 mm; width: $2.6-3.4 \mathrm{~mm}$. Body elongate-ovoid, widest at basal quarter of elytra; weakly microreticulate dorsally, shining; strongly microreticulate ventrally, dull; black with paler markings; elytra yellow-orange with black markings (Eig. 59).

Head black, epistome often yellow. Pronotum black, often with orange anterior angles. Scutellum black. Each elytron with orange epipleural fold; free humeral spot; scutellar spot divided, free part size = humeral spot, other part broadly connected to base and suture; scutellar spots and humeral spots in a transverse line; suture margined in black; central band restricted to central third of elytra, not extending to apex, laterally narrowed and zig-zagged, not reaching lateral margin. Venter and legs black; tarsi and palpi tan. 
Head dorsal distance between eyes $=2 \mathrm{x}$ eye width; ocular striae reaching 0.75 distance to anterior angle of eye; vertex puncture size $=0.75 \mathrm{x}$ facet, separated by 1 to 3 diameters; epistome puncture size $=0.75 \mathrm{x}$ facet, coalescing. Antenna reaching basal 0.25 of pronotum; antennomere II as long as next 3 antennomere combined; antennomeres IX to XI symmetrical; antennomere X crescentshaped; antennomere XI subcircular, transverse narrower than antennomere X (Fig. 61).

Maxillary palp terminal segment triangular, sides rounded, lateral angle acute, medial angle nearly $90^{\circ}$, length $=0.5 \times$ width. Labial palp terminal segment triangular, extended medially, sides rounded, angles nearly $90^{\circ}$, length $=0.8 \mathrm{x}$ width. Labial palp width $=0.5 \mathrm{x}$ maxillary palp width (Fig. 70). Mentum with plate triangular, length $=$ width, sides concave, apical angle rounded; ridge medial extension lacking (similar to Fig. 8 )

Pronotal disc puncture size $=0.75$ to $1.0 \mathrm{x}$ facet, separated by 1 to 3 diameters. Scutellum pentagonal, sides short, length $=0.6 \mathrm{x}$ width. Each elytron with 7 complete striae, stria VII present at base and on apical half; strial puncture size at base = pronotal disc puncture, gradually becoming finer posteriorly; intervals finely punctate, impressed, distinct.

Prosternum strongly keeled and pinched anteriorly; with (female) or without (male) foveate punctures in front of 
procoxa; coxal lines arched or straight, length $=0.5 \mathrm{x}$ sternal length, lines not surpassing coxae, length $=0.6 \mathrm{x}$ basal width; prosternal plate flat, triangular to semicircular, apical width $=0.6 \times$ basal width; base shallowly concave.

Mesosternum basal width $=3 \times$ mesocoxal line length; coxal lines straight, parallel; base sinuate, medially lobed. Metasternum coxal lines meet at middle, often crenate; coxal lines extend 0.5 distance to posterior lateral angle; sternum shining, medial punctures fine; few coarse lateral punctures and strongly microreticulate laterally.

First visible abdominal sternite coxal lines continuous around coxa or weak and short, not surpassing coxa; broadly rounded between metacoxae; coarse punctures laterally, fine punctures medially.

Male genitalia with median lobe straight, apically truncate; internal sac without noticeable sclerotized structures; flagellum narrow, length $=1.6 \mathrm{x}$ median lobe length (Fig. 132a); base of flagellum straight, sclerite at base claw-shaped and thickened at connection with flagellum (Fig. $132 \mathrm{~b}-\mathrm{d}) \quad(5$ dissected)

Female genitalia with spermathecal head elongate kidney-shaped; tail narrow, coiled (Fig. 132e) (6 dissected).

Stridulatory files on occipital region of head not visible on males; presence of file unknown on females (heads 
retracted). Females with foveate punctures on prosternum in front of procoxae, obscured by microreticulation; males lack prosternal punctures.

Variation. The specimens from Panama have the anterior pronotal angle spot variable in size and distinctiveness, present or absent, and the humeral spot free. The female Brazilian specimen has the anterior pronotal angle spot distinct, sharply delineated from the rest of the pronotum, and the humeral spot connected to the elytral base.

When the elytra are together, the central mark varies from $W$ - to $V$-shaped, depending on the extent of the sutural connection.

specimens examined. A total of 18 specimens, representing 17 collection records, was studied (see Appendix C for specific data).

Distribution. Panama, Venezuela, Trinidad, and Brazil (Fig. 137)

Taxonomic notes. The Brazilian specimen may represent a separate taxon. Only additional material and study of male genitalia will solve this question.

Remarks. Ischyrus n. sp. 9 superficially resembles I. n. sp. 10 in color pattern and body shape. Ischyrus n. sp. 9 can be distinguished by the characters mentioned in the diagnosis and the genitalia.

$$
\text { Ischyrus n. sp. } 10
$$

Diagnosis. Recognized by having the pronotum almost entirely black (except for anterior angles), elytral free 


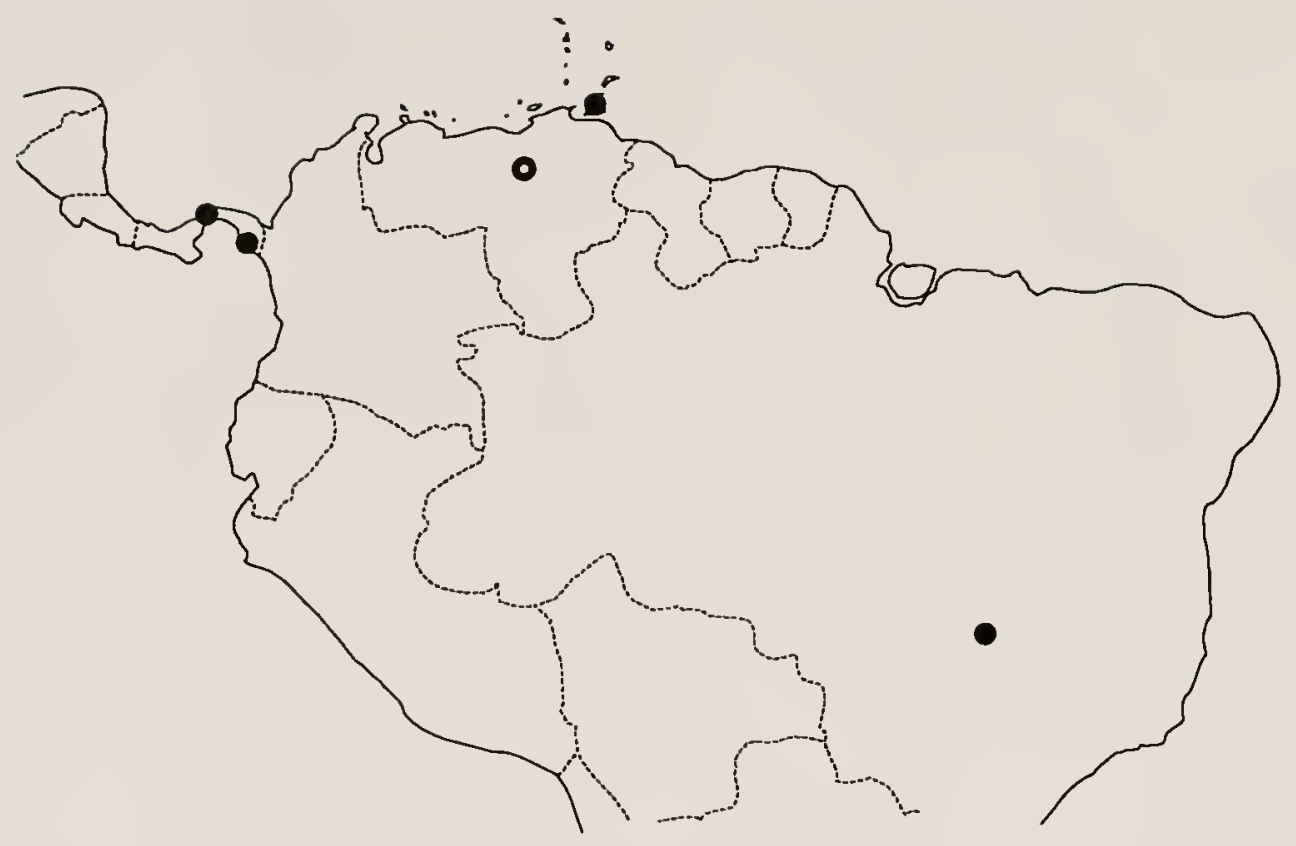

Figure 137. Ischyrus n. sp. 9 distribution map. 
basal spots forming an anteriorly convex arch, and central elytral band triangular, extending nearly to apex.

Description. Length: $5.1-5.8 \mathrm{~mm}$; width: $2.9-3.3 \mathrm{~mm}$. Body elongate-ovoid, widest at basal quarter of elytra; dorsum weakly microreticulate, shining, venter strongly microreticulate; body black with paler marking; elytra yellow with black markings (Fig. 60).

Head black with yellow epistome or entirely yellow. Pronotum black often with pale yellow spot on anterior angle. Scutellum black. Each elytron with yellow epipleural fold; small free subhumeral spot; scutellar spot divided, free part size = subhumeral spot, other part broadly connected to base and suture; scutellar spots and subhumeral spots in an anteriorly convex arch; suture with black margin, except at apex; central band triangular, widest anteriorly, narrowed posteriorly, often connected to lateral margin, nearly reaching apex, broadly connected to suture. Venter and appendages black; tarsi and palpi brown.

Head dorsal distance between eyes $=2 \mathrm{x}$ eye width; ocular striae reaching 0.5 to 0.75 distance to anterior angle of eye; vertex puncture size $=0.75 \mathrm{x}$ facet, separated by 1 to 2 diameters; epistome puncture size $=0.75 \mathrm{x}$ facet, coalescing. Antenna reaching basal 0.25 of pronotum; antennomere II as long as next 3 antennomere combined; antennomeres IX to XI symmetrical; antennomere X crescent shaped; antennomere XI subcircular, transversely elongate, narrower than antennomere $\mathrm{X}$ (similar to Fig. 61). 
Maxillary palp terminal segment triangular, sides rounded, Lateral angle acute, medial angle nearly $90^{\circ}$, width $=2 \times$ length. Labial palp terminal segment triangular, extended medially, sides rounded, angles nearly $90^{\circ}$, length $=0.8 \times$ width. Labial palp width $=0.5 \times$ maxillary palp width (similar to Fig. 70). Mentum with plate triangular, length $=$ width, sides concave, apical angle rounded; ridge medial extension lacking (similar to Fig. 8h).

Pronotal disc puncture size $=0.75 \times$ facet, separated by 1 to 2 diameters; sightly denser laterally. Scutellum pentagonal, sides short, length $=0.6 \mathrm{x}$ width. Each elytron with 7 complete striae; stria VIII present at base and apical half; strial puncture size at base = pronotal disc puncture, gradually becoming finer posteriorly; intervals finely punctate, impressed, distinct.

Prosternum strongly keeled and pinched anteriorly; with (female) or without (male) foveate punctures in front of procoxae; coxal lines slightly arched or straight, length = 0.5 x sternal length, lines barely surpassing coxae, length $=0.6$ to $0.75 \mathrm{x}$ basal width; prosternal plate flat, apical width $=0.6 \times$ basal width; base shallowly concave.

Mesosternum basal width $=3 \mathrm{x}$ mesocoxal line length; coxal lines straight, parallel; base sinuate. Metasternum coxal lines meeting at middle, often crenate, recurved; coxal lines extend 0.5 distance to posterior lateral angle; sternum weakly shining medially, medial punctures fine, few 
coarse lateral punctures obscured by strong microreticulation.

First visible abdominal sternite with coxal lines short, extending 0.25 to 0.5 distance to posterior margin; broadly rounded between metacoxae; coarse punctures laterally, fine punctures medially.

Male genitalia with median lobe weakly arched, apically rounded; internal sac with pair of darkened patches near median lobe; flagellum narrow, length $=1.8 \times$ median lobe length (Eig. 133a); base of flagellum straight, sclerite at base elongate, claw-shaped (Fig. 133b-d) (3 dissected).

Eemale genitalia with spermathecal head elongate kidney-shaped; tail narrow, looped (Fig. 133e) (5 dissected).

Presence of stridulatory files on occipital region of head unknown (heads retracted). Females with weakly impressed foveate punctures on prosternum in front of procoxae, obscured by strong microreticulations; males lack these punctures.

Variation. The Bolivian specimen has the head yellow, central band reaching lateral margin, and anterior pronotal angle spot distinct, delineated from the rest of pronotum. The other specimens have the head mostly black, central band not reaching the lateral margin, and the anterior pronotal angle spot gradually fading into the black.

specimens examined. A total of 10 specimens, representing 8 collection records, was studied. Label data: 
Bolivia, R. Japacani, e. Bolivia, J. Steinbach [1, ICCM]; British Guiana, Upper Courantyne R., IX-1935, G. A. Hudson [1, NHML]; Colombia, Rio Frio, II-1924, W. M. Mann [3, USNM]; Panama, Canal Zone, Barro Colorado Island, 1-9-V1964, W. D. \& S. S. Duckworth [1, USNM]; Canal Zone, Fort Clayton, V-1961, C. E. Yunker [1, CNCI]; Canal Zone, Fort Kobbe, 14-VI-1976, E. G. Riley [1, EGRC]; Trinidad, Simla, 5 mi.N.Arima, 18-VIII-1968, H. \& A. Howden [1, CMNC]; Simla, Arima-Blanchisseuse Rd., 22-VII-1975, J. Price, blacklight $[1$, ESCA $]$.

Distribution. Panama, British Guiana, Trinidad, Colombia, and Bolivia (Fig. 138).

Remarks. Ischyrus n. sp. 10 superficially resembles I. n. sp. 9 in color pattern and body shape. Ischyrus n. sp. 10 can be distinguish by the characters mentioned in the diagnosis and the genitalia.

\section{Ischyrus n. sp. 11}

Diagnosis. Recognized by having pronotal markings consisting of 2 free, 3 basal and hind angle spots, and with the subhumeral spot located at the basal third, far from the base.

Description. Length: $5.5-6.4 \mathrm{~mm}$; Width: $2.9-3.6 \mathrm{~mm}$. Body elongate-oval, widest at basal quarter of elytra; microreticulate, weakly shining; orange-red to yellow with black pattern (Fig. 61).

Head black with orange-red spot near the anterior angle of each eye. Pronotum with 2 free spots, one spot on each 


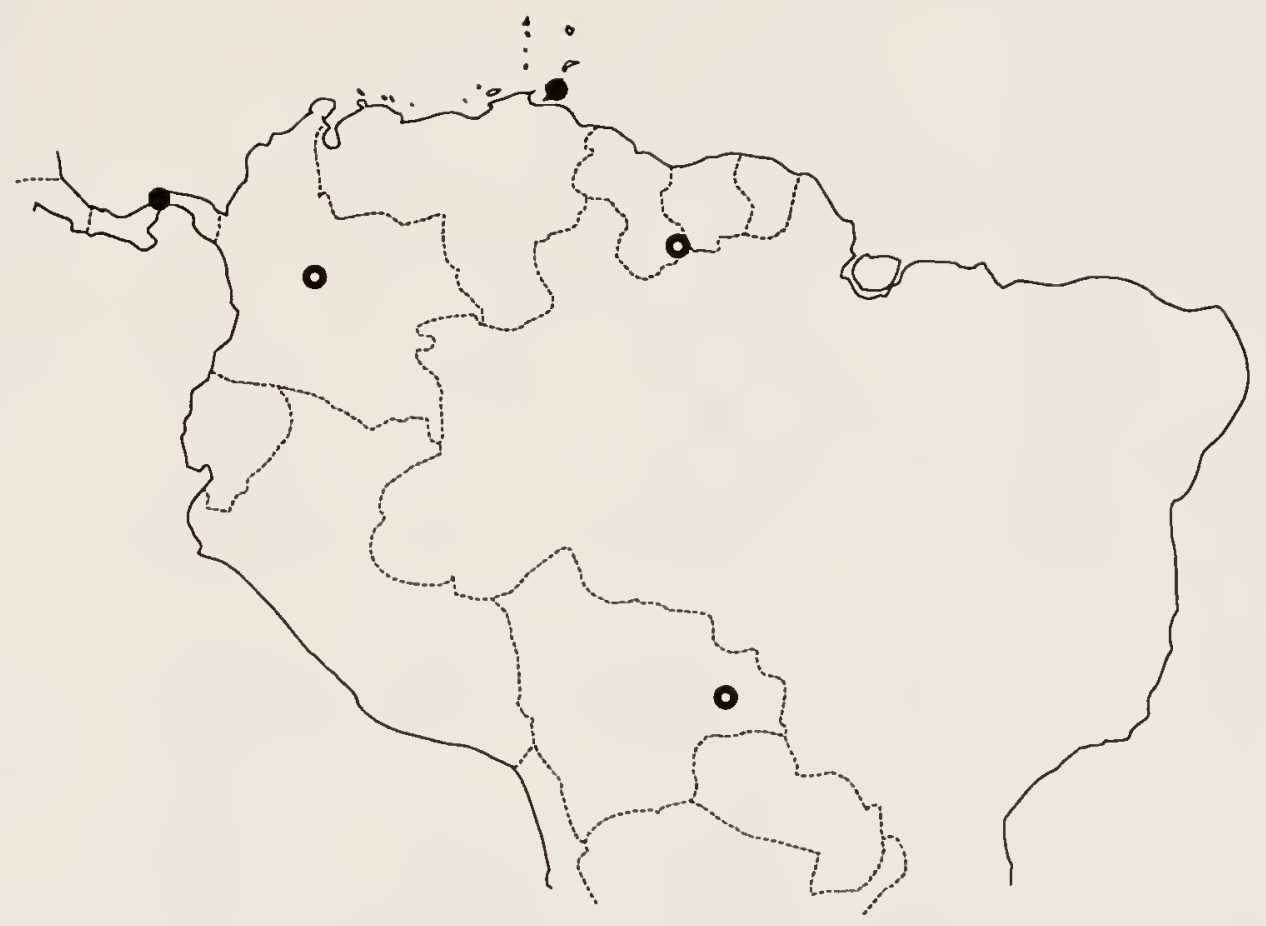

Eigure 138. Ischyrus n. sp. 10 distribution map. 
posterior angle, and 3 basal tooth-like spots. Scutellum black. Each elytron with orange-red epipleural fold; free subhumeral spot at basal third of elytra; scutellar spot narrowly connected to base at scutellum, broadly connected to suture; sutural margin black, complete almost to apex or consisting of 2 swellings (basal third of elytra and near apex); central and lateral spots free or connected to each other and suture; apical spot free. Appendages and venter black.

Head dorsal distance between eyes $=3 \mathrm{x}$ eye width; ocular striae reaching anterior angle of eye; vertex puncture size $=1$ x facet, separated by 1 to 2 diameters; epistome puncture size $=0.5 \mathrm{x}$ facet, nearly coalescing. Antenna reaching basal 0.25 of pronotum; antennomere II as long as next 3 antennomere combined; antennomeres IX to XI symmetrical; antennomere XI subcircular, = width of antennomere X (similar to Fig. 61).

Maxillary palp terminal segment triangular to semicircular, sides rounded, angles acute, width $=2 \mathrm{x}$ length. Labial palp terminal segment triangular, extended medially, sides rounded, angles nearly $90^{\circ}$, length $=0.5 \mathrm{x}$ width. Labial palp width $=0.75 \times$ maxillary palp width (similar to Fig. 7i). Mentum with plate broadly triangular, length $=0.5 \times$ width, sides concave (similar to Fig. 8e); ridge medial extension short, projecting, pointed but not acute. 
Pronotal disc puncture size = 1 x facet, medially separated by 1 to 2 diameters, laterally separated by 0.5 to 1.0 diameter. Scutellum pentagonal, length $=0.5 \mathrm{x}$ width. Each elytron with 7 complete striae; stria VIII present at base and apical half; strial puncture size at base $=1.0$ to $1.2 \times$ pronotal disc puncture, gradually becoming finer posteriorly; intervals finely punctate.

Prosternum strongly keeled and pinched anteriorly; with (female) or without (male) foveate punctures in front of procoxa; coxal lines slightly arched or straight, length = $0.5 \mathrm{x}$ sternal length, lines not surpassing coxae, length $=$ basal width; prosternal plate almost quadrate, weakly convex, apical width = basal width; base slightly concave.

Mesosternum basal width $=3 \mathrm{x}$ mesocoxal line length; coxal lines straight; base sinuate. Metasternum coxal lines meet at middle, line often crenate-punctate, weakly recurved; coxal lines extend 0.25 to 0.33 distance to posterior lateral angle; line behind mesocoxa deep, groovelike, almost pit-like medially; sternum medially shining, medial punctures fine, few coarse lateral punctures obscured by strong microreticulation.

First visible abdominal sternite with coxal lines short, extending 0.33 to 0.5 distance to posterior margin; rounded between metacoxae; coarse punctures laterally, fine punctures medially.

Male genitalia with median lobe moderately arched, apically rounded; internal sac without noticeable 
sclerotized structures; flagellum hair-like, length $=5.3 \mathrm{x}$ median lobe length (Fig. 134a); base of flagellum straight, sclerite at base claw-shaped (Fig. 134b-d) (2 dissected).

Female genitalia spermatheca not found (2 dissected). Presence of stridulatory files on occipital region of head unknown (heads retracted). Male with prosternumpronotal epipleural suture obscure in front of coxae; lacking prosternal punctures. Females with prosternumpronotal epipleural suture distinct; numerous foveate prosternal punctures in front of procoxae.

Variation. The Panama specimens have the sutural edge with a wide black margin, broadly connected to the central and scutellar spots (Fig. 61). The Colombian specimen has the black sutural marking reduced, thinly margined with 2 spot-like swellings; one at the basal third, the other at the apical quarter of the elytra.

specimens examined. A total of 4 specimens, representing 4 collection records, was studied. Label data: Colombia, Pueblo Bello, Sierra de Santa Marta, 14-15-IV1968, B. Malkin, at light [1, FMNH] ; Panama, Panama Prov., Cerro Campana, 11-15-V-1980, R. G. Riley [1, EGRC]; Panama Prov., Las Cumbres, 6-V-1974, H. Wolda [1, OSUC]; Tocuman, 6-I-1953, F. S. Blanton [1, USNM] .

Distribution. Panama and Colombia (Fig. 139). 
286

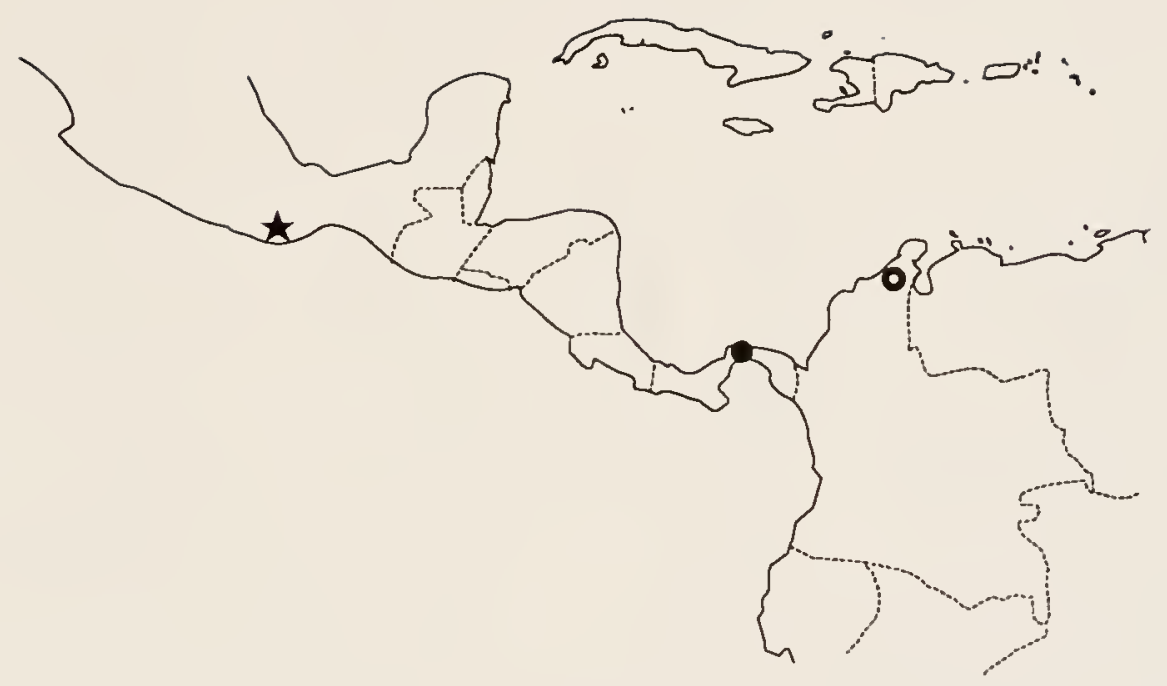

Figure 139. Ischyrus n. sp. 11 [circle] and I. n. sp. 12 [star] distribution map. 


\section{Ischyrus $n . \mathrm{sp} .12$}

Diagnesis. Recognized by having only 2 free pronotal spots, central and lateral elytral spots elongate, leaving an axe-shaped scutellar and sutural marking.

Description. Length $3.6 \mathrm{~mm}$; Width: $2.6 \mathrm{~mm}$. Body elongate-oval, widest at basal third of elytra; feebly microreticulate, shining; orange with black pattern (Fig. 72).

Head orange. Pronotum with 2 free spots, basally with narrow margin at medial half. Scutellum black. Each elytron with orange epipleural fold; free subhumeral spot; large scutellar spot broadly connected to base and suture; suture margined with black, swollen at basal third, gradually narrowing toward apex; central and lateral spots free, elongate, stripe-like. Venter black; except for orange anterior prothorax, lateral metasternum and posterior abdomen. Appendages black; tarsi, palpi, and base of antenna brown.

Head dorsal distance between eyes $=2.2 \mathrm{x}$ eye width; ocular striae reaching 0.5 distance to anterior angle of eye, continue forward as row of punctures; vertex puncture size = 1 x facet, separated by 1 diameter; epistome puncture size $=0.5 \times$ facet, nearly coalescing. Antenna reaching base of pronotum; antennomere II as long as next 3 antennomere combined; antennomeres IX to XI symmetrical; antennomere $X I$ transverse, narrower than antennomere $X$ (similar to Fig. 61). 
Maxillary palp terminal segment triangular, sides rounded, lateral angle acute, medial angle nearly $90^{\circ}$, length $=0.5 \mathrm{x}$ width. Labial palp terminal segment triangular, extended medially, sides rounded, angles nearly $90^{\circ}$, length $=0.8 \mathrm{x}$ width. Labial palp width $=0.5 \mathrm{x}$ maxillary palp width (similar to Eig. 7o). Mentum with plate triangular, length = width, all sides nearly equal in length, sides straight; ridge rounded anteriorly, with medial extension acute.

Pronotal disc puncture size = 1 x facet, separated by 1 to 2 diameters; laterally separated by 0.5 to 1.0 diameter. Scutellum pentagonal, length $=0.5 \mathrm{x}$ width. Each elytron with 7 complete striae; stria VIII present at base and apical half, often obscured by interval punctation; strial puncture size at base = pronotal disc puncture, gradually becoming finer posteriorly; intervals finely punctate, lateral punctures impressed and distinct.

Prosternum strongly keeled and pinched anteriorly; lacking foveate punctures in front of procoxa; coxal lines straight, length $=0.6 \mathrm{x}$ sternal length, lines surpassing coxae, length = basal width; prosternal plate flat, apical width $=0.75 \times$ basal width; base concave.

Mesosternum basal width $=2.5 \mathrm{x}$ mesocoxal line length; coxal lines straight; base sinuate. Metasternum coxal lines meeting at middle, punctate, recurved; coxal lines extend 0.5 distance to posterior lateral angle; sternum shining, 
medial punctures fine, few coarse lateral punctures obscured by strong microreticulation.

First visible abdominal sternite with coxal lines reaching 0.5 distance to posterior edge; broadly rounded between metacoxae; coarse punctures distributed across sternite.

Male genitalia with median lobe weakly arched, apically rounded; internal sac with pair of dark patches near median lobe; flagellum swollen on basal 0.5 , length $=1.6 \mathrm{x}$ median lobe length (Fig. 140a); base of flagellum straight, sclerite at base elongate, thickened at connection to flagellum (Eig. 140b-d) (1 dissected).

Eemale unknown.

Presence of stridulatory files on occipital region of head unknown (head retracted).

Specimens examined. Known only from one specimen, label data: Mexico, Oaxaca, $10 \mathrm{mi}$. N Matias Romaro, 3-VII1975, L. E. Watrous [1, CUIC].

Distribution. Known only from Mexico (Fig. 139).

Remarks. Ischyrus $n$. sp. 12 superficially resembles $I$. elegantulus, I. scutellaris, and I. chacojae. It can be distinguished from these by the elongate, stripe-like, lateral and central elytral spots.

\section{Ischyrus $n . s p, 13$}

Diagnosis. Recognized by having 4 free pronotal spots in transverse row, large free central elytral spot on each 

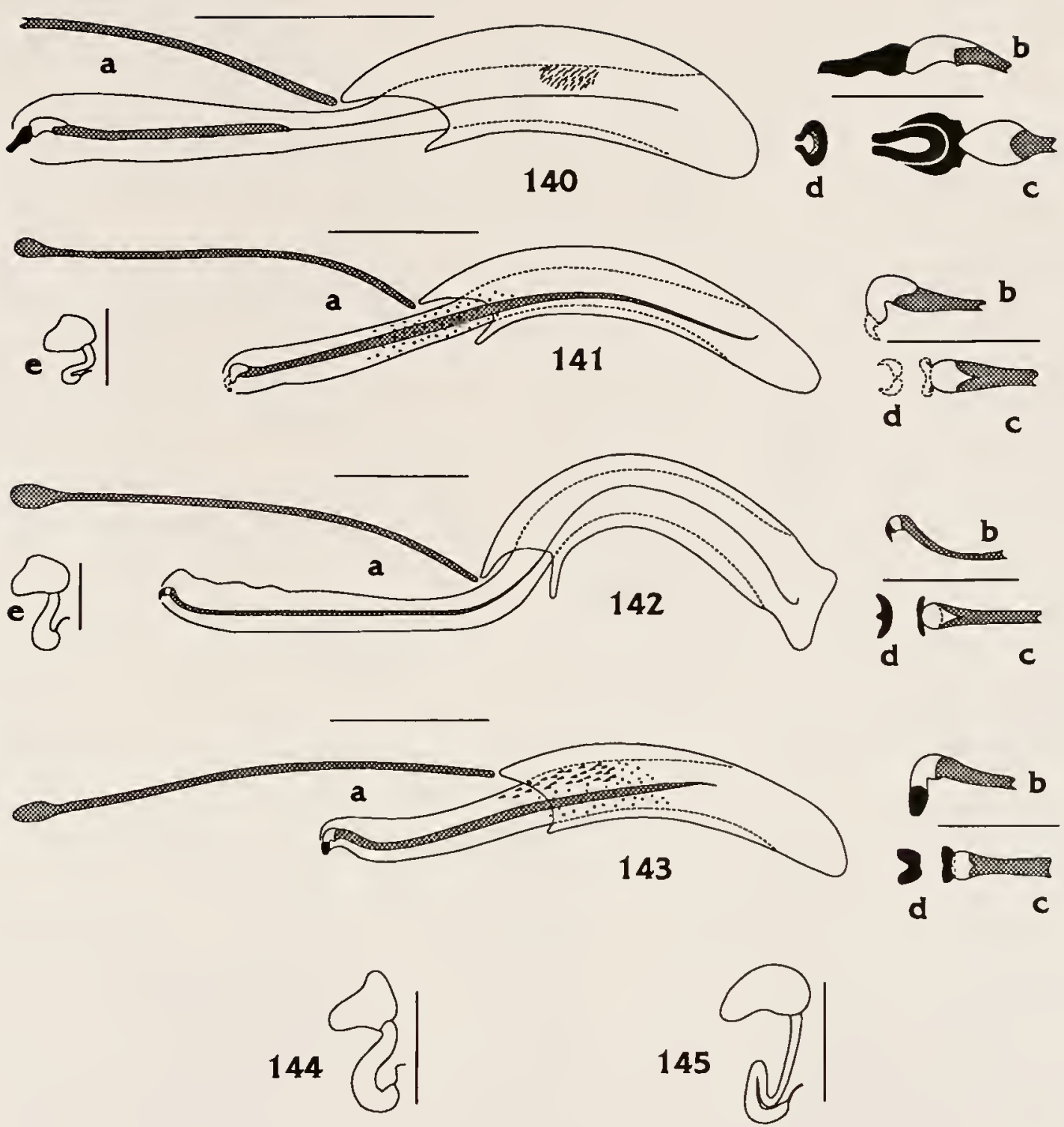

Figures 140-145. Genitalia: 140.) Ischyrus n. sp. 12 [male, Mexico, Oaxaca; female unknown]; 141.) I. n. sp. 14 [male, Mexico, Durango; female, Mexico, San Luis Potosi]; 142.) I. n. sp. 15 [male, Venezuela, Carabobo; female, Panama]; 143.) I. n. sp. 16 [male, Panama; female unknown]; 144.) I. n. sp. 8 [male unknown; female, Panama]; 145.) I. n. sp. 13 [male unknown; female, Panamal; a.) male genitalia, line $=0.66 \mathrm{~mm}$; b.) lateral view, c.) dorsal view, and d.) anterior view of the sclerotized muscle attachment at anterior end of male flagellum, line $=0.22 \mathrm{~mm}$; e.) female spermatheca, line $=0.33$ 
elytron, and basal elytral marking resembling an inverted bell.

Description. Length $5.5 \mathrm{~mm}$; Width: $2.8 \mathrm{~mm}$. Body elongate, widest at basal third of elytra; weakly microreticulate, shining; orange with black pattern (Fig. 73).

Head with apical half orange, bilobed black base. Pronotum with 4 free spots in transverse line. Scutellum dark orange. Each elytron with dark brown epipleural fold; free subhumeral spot; large scutellar spot broadly connected to suture, expanded at base to humeral angle; free, transverse central spot; apical spot broadly connected to suture, narrowly separated from apical edge. Venter dark brown. Legs black; tarsi and palpi pale; antenna brown, club black.

Head dorsal distance between eyes $=3.5 \times$ eye width; ocular striae reaching anterior angle of eye; vertex puncture size $=1 \mathrm{x}$ facet, separated by 2 to 3 diameters; epistome puncture size $=0.75$ to $1.0 \times$ facet, separated by 1 diameter. Antenna reaching basal 0.25 of pronotum; antennomere III as long as next 3 antennomere combined; antennomeres $\mathrm{X}$ to XI symmetrical; antennomere XI subcircular (similar to Fig. 6g).

Maxillary palp terminal segment triangular, securiform, base rounded, apical angles $90^{\circ}$ or more, length $=0.66 \mathrm{x}$ width, extended medially. Labial palp terminal segment triangular, extended on medial side, length $=0.66 \mathrm{x}$ width. 
Labial palp width $=0.8 \times$ maxillary palp width (similar to Fig. 7a). Mentum with plate broadly triangular, length = $0.5 \times$ width, sides inwardly curved, ridge medial extension small and acutely pointed (similar to Fig. 8e).

Pronotal disc puncture size $=1 \mathrm{x}$ facet, separated by 2 to 3 diameters; laterally separated by 1 to 2 diameters. Scutellum pentagonal, length $=0.5 \mathrm{x}$ width. Each elytron with 7 complete striae; stria VIII present apical half; strial puncture size at base $=2 \mathrm{x}$ pronotal disc punctures, gradually becoming finer posteriorly; intervals finely punctate, punctures obscure medially, weakly impressed laterally.

Prosternum keeled and pinched anteriorly; with few foveate punctures in front of procoxa; coxal lines straight, length $=0.5 \times$ sternal length, lines not surpassing coxae, length $=0.75 \times$ basal width; prosternal plate flat, apical width $=0.75 \times$ basal width; base concave.

Mesosternum basal width $=3 \mathrm{x}$ mesocoxal line length; coxal lines straight; base weakly sinuate. Metasternum coxal lines meet at middle, with 2 widely separated teeth (Fig. 15d), recurved; coxal lines extend 0.33 distance to posterior lateral angle; line behind mesocoxa deep groove, laterally pit-like; sternum shining, medial punctures fine, lacking coarse lateral punctures.

First visible abdominal sternite with coxal lines fine, reaching 0.25 distance to posterior edge; broadly rounded 
between metacoxae; coarse punctures laterally, fine punctures medially.

Male unknown.

Female genitalia with spermathecal head kidney-shaped; tail narrow, looped (Fig. 145) (1 dissected).

Presence of stridulatory files on occipital region of head unknown (head retracted).

specimens examined. The only known specimen has label data: Panama, Colon Prov., Porto Bello, 10-III-1911, E. A. Schwarz [1, USNM] .

Distribution. Known only from Panama (Fig. 146).

Taxonomic notes. This unique beetle differs from other species in color pattern and morphological features. I have no doubt that this female represents a new species.

\section{Ischyrus $n$. sp. 14}

Diagnosis. Recognized by having combination of 4 free pronotal spots in transverse row, 2 basal pronotal spots, scutellar and humeral elytral spots not touching, central elytral spot band-like, and free apical elytral spots.

Description. Length $6.9-8.3 \mathrm{~mm}$; Width: $3.5-4.2 \mathrm{~mm}$. Body elongate, widest at basal third of elytra; weakly microreticulate, shining; orange-yellow with black pattern (Eig. 75) .

Head black with orange spot on frons. Pronotum with 2 small anterior spots; 2 larger triangular basal spots, widely separated, connected by narrow basal margin on medial half; 4 free spots in anteriorly concave arch, lateral spots 


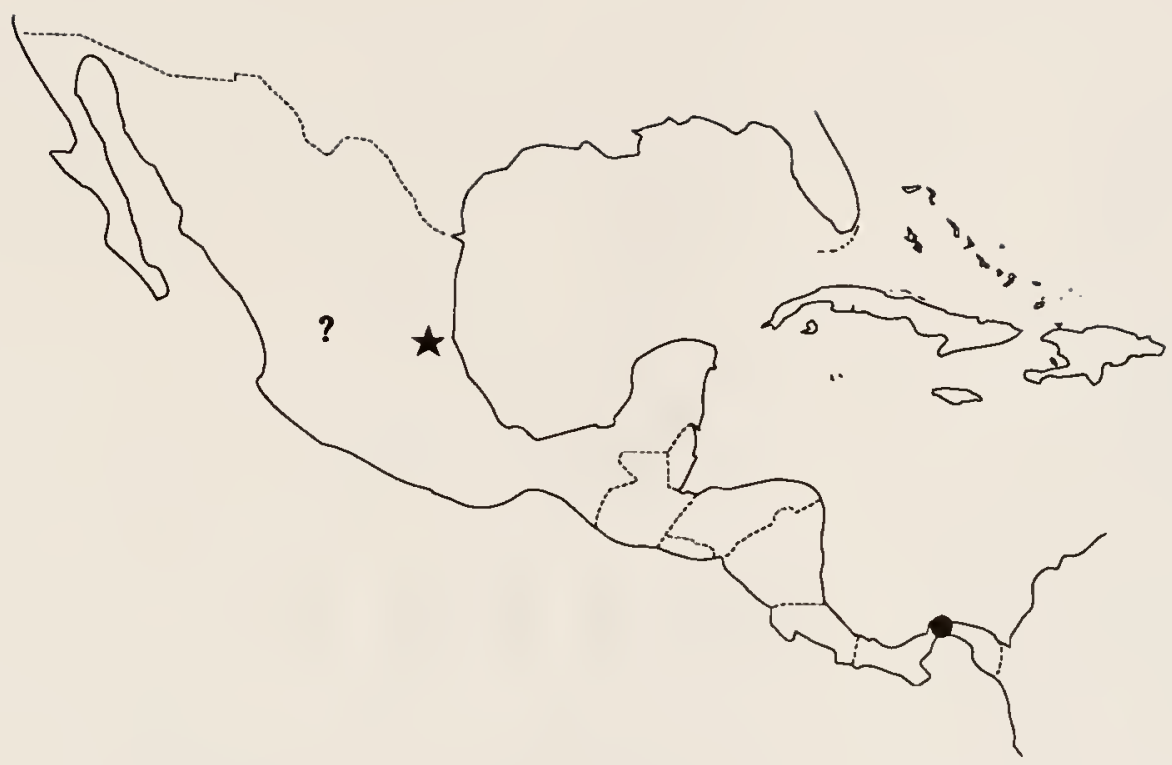

Eigure 146. Ischyrus n. sp. 13 [circle] and $I . n$. sp. 14 [star and "?"] distribution map. 
smaller than central spots. Scutellum dark orange to black. Each elytron laterally margined in black; black epipleural fold with brown base; subhumeral spot elongate, connected to base; scutellar spot large, rounded, broadly connected to base and suture; suture completely margined with black; central band not reaching lateral margin; apical spot free. Venter orange, sclerites with black margins. Appendages black; palpi and base of antennae brown; tarsi reddish. Head dorsal distance between eyes $=2.5 \times$ eye width; ocular striae reaching anterior angle of eye; vertex puncture size $=1$ x facet, separated by 1 to 2 diameters; epistome puncture size $=0.5 \mathrm{x}$ facet, nearly coalescing. Antenna reaching basal 0.25 of pronotum; antennomere III as long as next 3 antennomere combined; antennomeres IX to XI symmetrical; antennomere $\mathrm{X}$ wider than antennomere IX, slightly wider than antennomere XI; antennomere XI circular (Fig. 6m) .

Maxillary palp terminal segment triangular, securiform, basally rounded, apical angles nearly $90^{\circ}$, length $=0.66 \mathrm{x}$ width. Labial palp terminal segment elongate, extended on medial side, rounded basally, length $=0.75 \times$ width. Labial palp width $=0.5 \times$ maxillary palp width (similar to Fig. 7a). Mentum with plate triangular, length $=0.75 \times$ width, apical sides straight (similar to Fig. 8a), ridge medial extension acute, projecting.

Pronotal disc puncture size $=1 \mathrm{x}$ facet, separated 2 to 3 diameters; denser laterally, separated by 1 diameter. 
Scutellum pentagonal, length $=0.6 \mathrm{x}$ width. Each elytron with 7 complete striae; stria VIII present on apical half; strial punctures $=1.5 \times$ pronotal disc puncture, gradually becoming finer posteriorly; intervals finely punctate, distinct.

Prosternum keeled and pinched anteriorly; lacking distinct punctures in front of procoxa; coxal lines straight, length $=0.6 \times$ sternal length, lines barely surpassing coxae, length = basal width; prosternal plate slightly convex, apical width $=0.6 \times$ basal width; base concave.

Mesosternum basal width $=2 \mathrm{x}$ mesocoxal line length; coxal lines straight; base broadly sinuate. Metasternum coxal lines meet at middle, weakly undulate, recurved; coxal lines extend 0.33 to 0.5 distance to posterior lateral angle; sternum shining, medial punctures fine, few coarse lateral punctures weakly impressed.

First visible abdominal sternite with coxal lines reaching 0.5 distance to posterior edge; broadly rounded between metacoxae; coarse punctures laterally, fine punctures medially.

Male genitalia with median lobe moderately arched, narrowed and apically rounded; internal sac with speckled surface midway between median lobe and flagellar base; flagellum thick, gradually narrowing to apex, length $=1.2 \mathrm{x}$ median lobe length (Fig. 141a); base of flagellum thick, sclerite at base claw-shaped (Fig. 141b-d) (1 dissected). 
Female genitalia with spermathecal head kidney-shaped, with top-knot; tail weakly swollen, angled and curved onto itself (Fig. 14le) (1 dissected).

Presence of stridulatory files on occipital region of head unknown (heads retracted). Male prosternum smooth and without punctation. Female prosternum roughened-wrinkled; if punctures present, weakly impressed and obscure (difference possibly due to individual variation).

Variation. The only notable variation between the 2 specimens studied is the size of the orange mark on the frons. In the male specimen from "Sierra de Durango", Mexico, the orange spot occupies over half the face. The female from the state of San Luis Potosi, Mexico, has the spot smaller, covering less than a quarter of the face.

specimens examined. Only 2 specimens were studied, representing 2 collection records. Label data: Mexico, San Luis Potosi, $6.9 \mathrm{mi}$. W. El Naranjo, Rte. 80, 14-X-1965, G. E. Ball \& D. R. Whitehead [1, CuIC]; Sierra de Durango, Fry Coll. 1905-100 [1, NHML] .

Distribution. Known only from the state of San Luis Potosi and "Sierra de Durango", Mexico (Fig. 146). In the gazetteer to the Biologia Centrali-Americana, Selander and Vaurie (1962:57) stated that the locality "Sierra de Durango" is part of the Sierra Madre occidental and noted that "according to Champion (Coleoptera, vol.4, pt.4, p.210), specimens with this label obtained from Donckier are 
probably from Veracruz or Oaxaca rather than Durango." The exact origin of the "Sierra de Durango" specimen is unknown. Remarks. This species is similar in color pattern to I. grammicus Gorham and I. nigrolineatus Crotch. It can be separated by having the central elytral marking unbroken. Ischyrus grammicus and I. nigrolineatus have the central elytral marking broken into stripe-like spots.

\section{Ischyrus n. sp. 15}

Diagnosis. Recognized by large triangular central elytral marking, and heart-shaped central pronotal marking, bilobed posteriorly, pointed anteriorly.

Description. Length $6.2-7.9 \mathrm{~mm}$; Width: $3.2-4.2 \mathrm{~mm}$. Body elongate, widest at basal third of elytra; microreticulate, feebly shining; orange-red with black pattern (Fig. 76).

Head black, occasionally with orange-red epistome. Pronotum anteriorly with narrow black margin between eyes; base with black margin on medial half, each end of black margin with a spot; one free lateral spot on each side; disc with a pair of fused spots, connected with anterior margin, appearing like an inverted heart. Scutellum black. Each elytron with black epipleural fold; free subhumeral spot; large, trilobed scutellar spot connected broadly to base and suture; suture margined with black; large triangular central spot, from basal third nearly to apex, widest anteriorly, acute posteriorly at suture, sides undulate. Venter black, except for orange-red lateral prothorax and lateral 
abdominal sternites. Legs orange-red, base of tibia dark; palpi brown.

Head dorsal distance between eyes $=2 \times$ eye width; ocular striae reaching 0.75 to 1.0 distance to anterior angle of eye; vertex puncture size $=0.75 \times$ facets, separated by 2 to 3 diameters; epistome puncture size $=0.5$ x facet, separated by 1 diameter. Antenna reaching middle of pronotum; antennomere III as long as next 3 antennomere combined; antennomeres IX to XI symmetrical; antennomere X wider than antennomere IX, wider than antennomere XI (similar to Fig. 61).

Maxillary palp terminal segment triangular, securiform, basally rounded, medial angle nearly $90^{\circ}$, lateral angle acute, length $=0.4 \times$ width. Labial palp terminal segment elongate, almost triangular, extended on medial side, rounded base, length $=0.4 \mathrm{x}$ width. Labial palp width $=0.5$ $x$ maxillary palp width (similar to Fig. 7q). Mentum with plate triangular, length $=0.75 \times$ width, apical sides straight or outwardly curved, ridge medial extension acute, projecting (similar to Fig. 8a).

Pronotal disc puncture size $=0.75 \times$ facet, separated by 2 to 3 diameters; denser laterally, separated by 1 to 2 diameters. Scutellum pentagonal, length $=0.5 \mathrm{x}$ width. Each elytron with 7 complete striae; stria VIII present at base and apical half; strial punctures at base $=2 \mathrm{x}$ pronotal disc punctures, gradually becoming finer posteriorly; intervals finely punctate. 
Prosternum strongly keeled and pinched anteriorly; with (female) or without (male) foveate punctures in front of procoxa; coxal lines straight, length $=0.4$ to $0.5 \mathrm{x}$ sternal length, lines barely surpassing coxae, length $=0.75 \mathrm{x}$ basal width; prosternal plate slightly convex, apical width $=0.5$ $x$ basal width; base concave.

Mesosternum basal width $=2 \mathrm{x}$ mesocoxal line length; coxal lines straight; base sinuate. Metasternum coxal lines weakly meet at middle, if at all, recurved; coxal lines extend 0.25 to 0.33 distance to posterior lateral angle; sternum with medial punctures fine; few coarse lateral punctures weakly impressed, obscured by microreticulations.

First visible abdominal sternite with coxal lines reaching 0.25 to 0.33 distance to posterior edge; rounded between metacoxae; medially with fine punctures; coarse punctures laterally.

Male genitalia with median lobe strongly arched, apically truncate, slightly constricted just before the tip; internal sac without noticeable sclerotized structures; flagellum hair-like, length $=1.7 \mathrm{x}$ median lobe length (Fig. 142a); base of flagellum gradually curved, sclerite at base claw-shaped (Fig. 142b-d) (2 dissected).

Female genitalia with spermathecal head kidney-shaped, often with top-knot; tail swollen, weakly curved to tightly curved like an inverted question mark, " $i "$ (Eig. 142e) (9 dissected). 
Presence of stridulatory files on occipital region of head unknown (heads retracted). Males with prosternum slightly expanded onto pronotal epipleuron, reaching 0.33 distance from prosternal-pronotal epipleuron suture to lateral edge; females with suture in front of coxae obscured for half distance to anterior margin, not expanded. Females with a few foveate punctures on prosternum in front of procoxae, weakly impressed, obscure; males lack these punctures.

Variation. The Brazilian specimen has the prosternum swollen above the pinch, and a red epistome. All other specimens studied have the prosternum weakly developed and the head entirely black. Only the Venezuelan specimen has the subhumeral spot large and touching the scutellar spot. The subhumeral spot is free on the remaining specimens.

$$
\text { Specimens examined. A total of } 12 \text { specimens, }
$$
representing 11 collection records, was studied (see Appendix $C$ for specific data).

Distribution. Southern Central America and northern South America (Fig. 147).

Remarks. Ischyrus n. sp. 15 superficially resembles $I$. tripunctatus. Ischyrus tripunctatus lacks pronotal basal spots and has the central pronotal spot free; I. n. sp. 15 has pronotal basal spots and the central spot is narrowly connected to the anterior margin. 


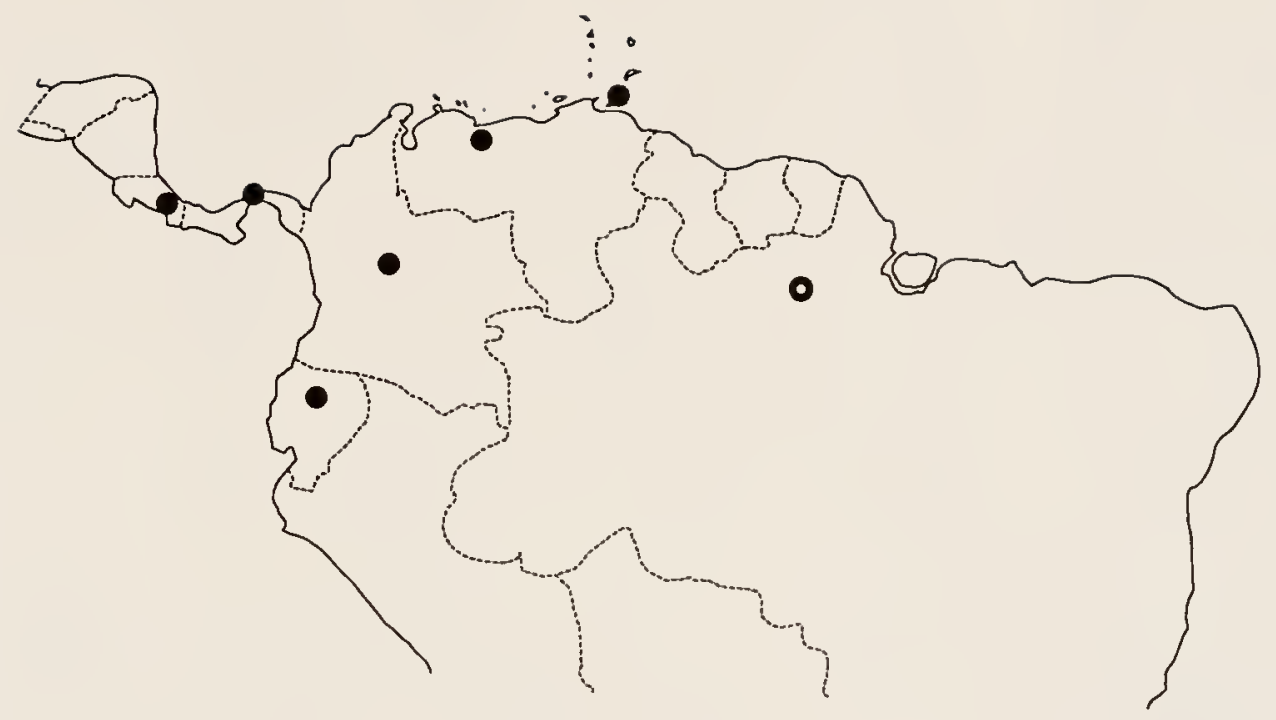

Eigure 147. Ischyrus n. sp. 15 distribution map. 


\section{Ischyrus $n$, sp. 16}

Diagnosis. Characterized by having 4 free pronotal spots in a transverse row, a spot at each pronotal hind angle, 2 basal pronotal spots separated by distance greater than 2 free central pronotal spots, central elytral band completely divided by a transverse orange mark, and its genitalic characters.

Description. Length $7.0 \mathrm{~mm}$; Width: $3.4 \mathrm{~mm}$. Body elongate, widest at basal third of elytra; microreticulate, dull; orange-red and pale yellow with black pattern (Fig. 78).

Head orange-red. Pronotum completely edged with black, widest on base; 2 triangular anterior spots; 2 triangular basal spots widely separated; one small spot on each posterior angle, appearing as a thickening in the black margin; 4 free pronotal spots in anteriorly concave arch, lateral spots smaller than central spots. Scutellum orangered with black margin. Each elytron with orange-red epipleural fold, edged in black; subhumeral spot free; free scutellar spot larger than subhumeral spot; suture finely edged in black; central band divided in middle by transverse orange-red band; apical spot connected to apical and sutural margin, separated from apical angle by orange-red spot. Venter orange-red. Legs orange-red, slightly darker than venter; tibia with black base; palpi pale brown.

Head dorsal distance between eyes $=2.5 \times$ eye width; ocular striae reaching anterior angle of eye; vertex 
puncture size $=0.5 \times$ facet, separated by 2 to 3 diameters; epistome puncture size $=0.25 \mathrm{x}$ facet, separated by 1 diameter. Antenna reaching basal 0.5 of pronotum; antennomere III as long as next 3 antennomere combined; antennomeres IX to XI symmetrical; antennomere $\mathrm{X}$ wider than antennomere IX \& XI; similar to Fig. 6m, except antennomere XI subcircular, wider than long.

Maxillary palp terminal segment triangular, securiform, basally rounded, apical angles nearly $90^{\circ}$, length $=0.66 \mathrm{x}$ width. Labial palp terminal segment elongate, extended on medial side, rounded basally, length $=0.75 \times$ width. Labial palp width $=0.5 \times$ maxillary palp width (similar to Fig. 7a). Mentum with plate triangular, length $=0.75 \mathrm{x}$ width, apical sides straight (similar to Fig. 8a), ridge medial extension acute, weakly projecting.

Pronotal disc puncture size $=0.75 \times$ facet, separated by 2 to 3 diameters. Scutellum pentagonal, length $=0.6 \mathrm{x}$ width. Each elytron with 7 complete striae; stria VIII present at base and apical half; strial puncture size at base $=1.5 \times$ pronotal disc punctures, gradually becoming finer posteriorly; intervals finely punctate, distinct.

Prosternum weakly keeled and pinched anteriorly; without foveate punctures in front of procoxa; coxal lines straight, arched inward at the ends, length $=0.6 \mathrm{x}$ sternal length, lines barely surpassing coxae, length = basal width; prosternal plate flat, apical width $=0.75 \times$ basal width; base concave. 
Mesosternum basal width $=2 \mathrm{x}$ mesocoxal line length; coxal Iines straight; base sinuate. Metasternum coxal lines not meeting at middle, recurved; coxal lines extend 0.5 distance to posterior lateral angle; sternum feebly shining, medial punctures fine; lacking coarse lateral punctures, strongly microreticulate.

First visible abdominal sternite with coxal lines reaching 0.5 distance to posterior edge; broadly rounded between metacoxae; medially with fine obscure punctures, if any; coarse punctures laterally.

Male genitalia with median lobe weakly arched, narrowed and apically rounded; internal sac speckled and with paired dark patch midway between the median lobe and flagellar base; flagellum thick, gradually narrowing toward apex, length = median lobe length (Fig. 143a); base of flagellum weakly curved, sclerite at base rounded, blunt (Fig. I43b-d) (1 dissected).

Femaie unknown.

Presence of stridulatory files on occipital region of head unknown (head retracted).

Specimens examined. Known only from a single specimen. Label data: Panama, Panama Prov., La Chorrera, 12-V-1912, Aug. Busck [1, USNM] .

Distribution. Known only from La Chorrera, Panama (Fig. 148).

Remarks. This specie's color pattern most closely resembles $I$. insolens crotch and $I$. fulmineus Kuhnt. 


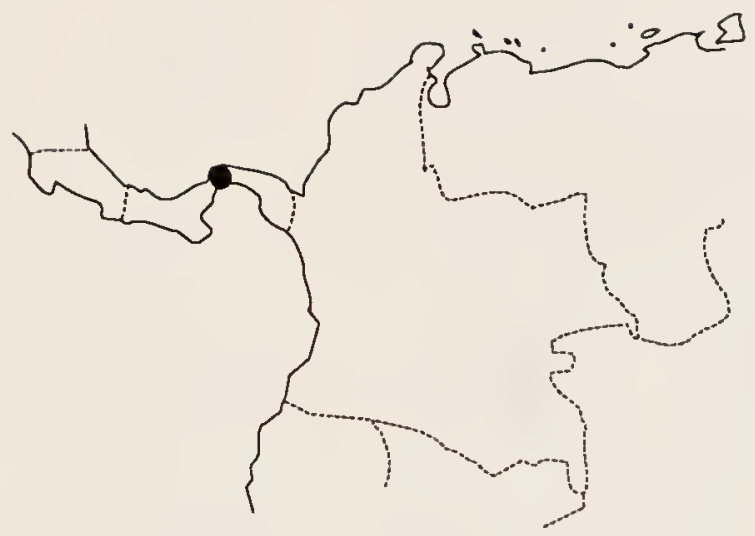

Figure 148. Ischyrus n. sp. 16 distribution map. 
Ischyrus insolens can be separated by the lack of 2 basal pronotal spots, which are present in I. n. sp. 16. Ischyrus fulmineus can be separated by the broad black connection of the central elytral marking between stria $V \& V I$; the central elytral marking is completely divided in I. n. sp. 16. 


\section{APPENDIX A \\ ISCHYRUS SPECIES NAMES}

This alphabetical list includes all specific names used in combination with the generic name Ischyrus; including valid names, names which have been moved to other genera, synonyms, homonyms, and nomina nuda. It is meant to serve as a guide in finding the current status of a name and help prevent the creation of name problems in future research.

Citations are presented in the format: name describer year:page. Original genus. Statements on current status and citations to the place where any changes were made.

Alvarenga (1965) changed many of the generic names listed in this Appendix. A proposal has been submitted to the International Commission of Zoological Nomenclature to conserve the generic names changed by Alvarenga (see Nomenclatural Status and Skelley \& Goodrich [1994]). Pending the ruling of the Commission, the species names are listed below in their current usage. This list does not reflect the generic changes made by Alvarenga.

affinis Duponchel 1825:47. Erotylus. Synonym of Ischyrus scriptus (Olivier) 1807:484, fide Lacordaire 1842:119.

agnatus Crotch 1876:426(50). Ischyrus. Variation of I. frontalis Lacordaire 1842:127, fide Gorham 1887:39.

alabamae Schaeffer 1931:175. Ischyrus. Described as a variety of I. quadripunctatus (Olivier) 1792:437. Synonym of I. q. quadripunctatus (Olivier), fide Mader $1938: 19$.

aleator Boyle 1954:46-48. Ischyrus. Valid.

amoenus Guérin-Méneville 1841:155. Lybas. Now

Callischyrus, fide Crotch 1876:(59)435. Ischyrus in

Gemminger \& Harold 1876:3690 and Lacordaire 1842:107108 .

angularis Lacordaire 1842:126. Ischyrus. Valid.

angustatus Lacordaire 1842:96-97. Ischyrus. Now Megischyrus, fide Crotch 1876:(47) 423 .

antedivisa Mader 1938:19. Ischyrus. Described as a variety of I. quadripunctatus (Olivier) 1792:437. Synonym of I. q. quadripunctatus (Olivier), fide Boyle 1954:39-41. 
auriculatus Lacordaire 1842:123. Ischyrus. Valid.

bahiae Crotch 1876:428(52). Ischyrus. Valid.

balteatus Duponchel 1825:164. Erotylus. Synonym of Megischyrus semipunctatus (Germar) 1824:612, fide Lacordaire 1842:99. Ischyrus in Dejean 1836:428.

basiguttiger Kuhnt [unpublished name]. Ischyrus. The "Type" specimen is in the Institut Royal sciences Naturelle Belgique.

bellicosus Lacordaire 1842:98. Ischyrus. Now Megischyrus, fide Crotch 1876:424(48).

bellopictus Kuhnt 1910:222. Episcaphula. Now Ischyrus, fide Delkeskamp 1957a:109. Synonym of I. auriculatus Lacordaire 1842:123, new synonymy.

bellus Guérin 1949:233-234, $231 \mathrm{fig. \# 6.} \mathrm{Ischyrus.} \mathrm{Valid.}$ blandus Erichson 1847:180. Ischyrus. Synonym of Callischyrus insignis (Laporte) 1840:250, fide Crotch $1876: 434(58)$.

bogotae Crotch 1876:430(54). Ischyrus. Valid.

boucardi Crotch 1876:429(53). Ischyrus. Valid.

brasiliensis Lacordaire 1842:91. Ischyrus. Now Megischyrus, fide Crotch 1876:422(46).

candezei Crotch 1876:58. Callischyrus. Ischyrus in Chapuis 1876:38 and Gemminger \& Harold 1876:3690.

catenulatus Lacordaire 1842:97-98. Ischyrus. Now Megischyrus, fide Crotch 1876:424(48).

chacojae Gorham 1887:43, t.3 f.5. Ischyrus. Valid.

chalcojae [sic] Gorham 1887:43. Ischyrus. Misspelling of I. chacojae Gorham 1887 in Kuhnt 1909:63.

chiasticus Boyle 1954:43-46. Ischyrus. Subspecies of I. quadripunctatus (Olivier) 1792:437, new status.

circumcinctus Delkeskamp 1957:98,108-109. Ischyrus. Valid. circumscriptus Duponchel 1825:165, t.3 f.83. Erotylus. Now Megischyrus, fide Crotch 1876:(49) 425. Ischyrus in Lacordaire 1842:102-103. 
coccineipennis Motschulsky 1858:117. Ischyrus. Now

Mycolybas, fide Crotch 1876:474(47).

collatinus Crotch 1876:57. Ischyrus. Valid.

columbianus Lacordaire 1842:95. Ischyrus. Now Megischyrus, fide Crotch 1876:(47) 423 .

conductus Kuhnt 1910:229-230. Ischyrus. Valid.

consanguineus Duponchel in litt., fide Lacordaire 1842:94.

Ischyrus. Variety of Megischyrus mexicanus

(Lacordaire) 1842:93-94, fide Gemminger \& Harold

$1876: 3689$.

consimilus Crotch 1876:53-54. Ischyrus. Valid.

cyanopterus Erichson 1847:180. Ischyrus. Now Callischyrus, fide Crotch 1876:434(58).

decempunctatus Guérin-Méneville 1841:154-155. Ischyrus. Now Megischyrus, fide Crotch 1876:(49) 425.

decorus Guérin 1949:234-235, 231 fig.\#7. Ischyrus. Valid.

dejeanii Chevrolat in Dejean 1836:428. Ischyrus. Synonym of Megischyrus discipennis (Lacordaire) 1842:101, fide Gemminger \& Harold 1876:3689.

dentiferus Chevrolat in Dejean 1836:428. Ischyrus. Synonym of Megischyrus brasiliensis (Lacordaire) 1842:91-92, fide Gemminger \& Harold 1876:3690.

discipennis Lacordaire 1842:101. Ischyrus. Now Megischyrus, fide Crotch 1873b:143.

disconiger Mader 1942 in Delkeskamp 1957:108-109. Ischyrus. Valid. A mandatory change in spelling for

"disconigrum" which does not agree in gender with the generic name Ischyrus.

disconigrum Mader 1942:195. Ischyrus. Now spelled disconiger, fide Delkeskamp 1957:108-109, a mandatory spelling change to agree in gender with the generic name Ischyrus.

distinguendus Lacordaire 1842:111. Ischyrus. Valid. dunedinensis Blatchley 1917:279. Ischyrus. Valid. duponti Lacordaire 1842:110-111. Ischyrus. Valid. elegantulus Lacordaire 1842:121-122. Ischyrus. Valid. 
ephippiatus Gorham 1887:43. Ischyrus. Valid.

episcaphulinus Gorham 1887:44, t.3 f.7. Ischyrus. Valid.

extricatus Crotch 1873a:354. Ischyrus. Now Pseudischyrus, fide Boyle 1956:130.

fasciato-dentatus Guérin MSS. Synonym of Megischyrus jurinei (Lacordaire) 1842:94-95, fide Crotch $1876: 422(46)$.

femoralis Chevrolat in Guérin-Méneville 1829-1838[1844]:63, t.18 f.10. Dacne. Now Ischyrus, fide Lacordaire 1842:114-115. Synonym of I. scriptus (Olivier) 1807:484-485, new synonymy.

flavitarsis Lacordaire 1842:130. Ischyrus. Now Oocyanus, fide Curran 1944:3.

flavus Motschulsky 1858:116. Ischyrus. Now Rhodotritoma, fide Chûjô \& Chûjô 1990:5.

Eraternus Lacordaire 1842:124. Ischyrus. Valid.

frontalis Lacordaire 1842:127. Ischyrus. Valid.

fulmineus Delkeskamp 1957:98,107-108. Ischyrus. Valid.

fulvitarsis Lacordaire 1842:129. Ischyrus. Now Oocyanus, fide Curran 1944:3.

grammicus Gorham 1883:86. Ischyrus. Valid.

grammistes Lacordaire 1842:105-106. Ischyrus. Synonym of Megischyrus Iineatus (Lacordaire) 1842:104-105, fide Crotch 1876:(49) 425 .

graphicus Lacordaire 1842:125-126. Ischyrus. Synonym of I. quadripunctatus (Olivier) 1792:437, new synonymy.

gratiosus Guérin-Meneville 1829-1838[1844]:310. Ischyrus. Synonym of $I$. incertus Lacordaire 1842:118-119, new synonymy.

gravis Chevrolat in Dejean 1836:428. Ischyrus. Synonym of Megischyrus mexicanus (Lacordaire) 1842:93-94, fide Gemminger \& Harold 1876:3689.

hamatus Kuhnt [unpublished name]. Ischyrus. The "Type" specimen is in the Institut Royal des sciences Naturelles de Belgique, labeled as a variety of $I$. auriculatus Lacordaire 1842:123. 
hieroglyphicus Duponchel 1825:46, t.1 f.24. Erotylus. Now Callischyrus, fide Crotch 1876:(59)435. Ischyrus in Gemminger \& Harold 1876:3690 and Lacordaire 1842:106107 .

humeralis Chevrolat in Dejean 1836:429. Mycotretus. Synonym of I. quadripunctatus (Olivier) 1792:437, fide Gemminger \& Harold 1876:3691.

impressopunctatus Crotch 1876:426(50). Ischyrus. Valid. incertus Lacordaire 1842:118-119. Ischyrus. Valid.

infernalis Chevrolat in Dejean 1836:428. Ischyrus. Synonym of Megischyrus scaphinotus (Lacordaire) 1842:96, fide Gemminger \& Harold 1876:3689.

insignis Laporte 1840:520. Erotylus. Now Callischyrus, fide Crotch 1876:434(58). Ischyrus in Gemminger \& Harold 1876:3690 and Lacordaire 1842:108-109. Author often cited as Castelnau.

insolens Crotch 1876:53. Ischyrus. Valid.

interruptus Duponche1 1825:48, t.1 f.27. Erotylus. Now Ischyrus, fide Lacordaire 1842:116-117. Valid.

intersectus Duponchel 1825:49, t.2 f.29. Erotylus. Now Brachysphaenus, fide Crotch 1876:512(136). In Lacordaire 1842:131, it is cited as Erotylus but is stated to be a member of Ischyrus.

jurinei Lacordaire 1842:94-95. Ischyrus. Now Megischyrus, fide Crotch 1876:422(46).

kempferi Alvarenga 1977:105. Micrischyrus. New name for Ischyrus nigripes Mader 1942:195, not I. nigripes Motschulsky 1858:116 (now Rhodotritoma). Valid.

knochi Lacordaire 1842:100. Ischyrus. Now Megischyrus, fide Crotch 1876:(49) 425 .

laetus Lacordaire 1842:122-123. Ischyrus. Valid.

lepidus Faldermann 1837:398, t.15 f.1. Ischyrus. Now Triplax, fide Chûjô \& Chûjô 1990:19.

lineatus Kuhnt 1910:228-229. Ischyrus. Valid species, but name change required; not $I$. lineatus Lacordaire $1842: 104-105$.

lineatus Lacordaire 1842:104-105. Ischyrus. Now Megischyrus, fide Crotch 1876:(49) 425. 
macularis Lacordaire 1842:128-129. Ischyrus. Valid.

maculiventris Lacordaire 1842:120-121. Ischyrus. Variety of I. scriptus (Olivier) 1807:484-485, fide Crotch

$1876:$ (55) 431 .

melanogaster Guérin-Méneville 1829-1838 [1844]:310.

Ischyrus. Now Callischyrus, fide Crotch 1876:433(58).

melanopus Guérin-Méneville 1841a:118. Morphoides. Now

Callischyrus, fide Crotch 1876:434(58). Ischyrus in

Gemminger \& Harold 1876:3691 and Lacordaire 1842:109110 .

mexicanus Lacordaire 1842:93-94. Ischyrus. Now Megischyrus, fide Crotch 1876:(47) 423.

modestus olivier 1807:483 t.3 f.35. Erotylus. Now Oocyanus, fide Curran 1944:2-3. Ischyrus in Gemminger \& Harold 1876:3691, Lacordaire 1842:130-131, and Crotch $1876: 432(56)$.

natalensis Guérin 1956:61-62 fig.24. Ischyrus. Valid.

nebulosus Guérin-Méneville 1841:155. Erotylus (Ischyrus). Now Brachysphaenus, fide Crotch 1876:504(128), (137) 512 .

nigrans Crotch 1873a:354. Ischyrus. Now Pseudischyrus, fide Casey 1916:156 and Boyle 1956:131.

nigripes Mader 1942:195. Ischyrus. Not I. nigripes Motschulsky 1858:116 (now Rhodotritoma), new name Micrischyrus kempferi Alvarenga 1977:105.

nigripes Motschulsky 1858:116. Ischyrus. Now Rhodotritoma, fide Arrow 1925:117 and Chûjô \& Chûjô 1990:6.

nigrolineatus Crotch 1876:56. Ischyrus. Valid.

nitidior Crotch 1876:54. Ischyrus. Valid.

nobilis Crotch 1876:53-54. Ischyrus. Valid.

oblongus Duponchel 1825:164-165, t.3 f.80. Erotylus.

Synonym of Megischyrus undatus olivier (1791:434), fide Gemminger \& Harold 1876:3689. Ischyrus in Dejean $1836: 428$.

oblongus Duponchel 1825:164, t.3 f.81. Erotylus. Variety of Megischyrus brasiliensis (Lacordaire) 1842:91-92, fide Gemminger \& Harold 1876:3690. Ischyrus in Dejean $1836: 428$. 
palliatus Lacordaire 1842:113-114. Ischyrus. Valid.

pallidior Crotch 1876:428(52). Ischyrus. Now Mycotretus, fide Gorham 1888:52.

pardalinus Guérin 1949:235, 231 f.8. Ischyrus. Valid.

patruelis Lacordaire 1842:124-125. Ischyrus. Valid.

perizonatus Lacordaire 1842:103-104. Ischyrus. Synonym of Megischyrus sicarius (Lacordaire) 1842:101-102, fide Crotch 1876:(49) 425 .

peruae Mader 1942:171,196. Ischyrus. Valid.

peruvianus Gorham 1883:85-86. Ischyrus. Synonym of I. boucardi Crotch 1876:429(53), new synonymy.

pictus Gorham 1887:42, t.3 f.4. Ischyrus. Valid.

planior Kirsch 1876:99. Ischyrus. Now Megischyrus, fide Gemminger \& Harold 1876:3689.

praeustus sturm 1826:139. Erotylus. Ischyrus in sturm $1843: 305$. Nomen nudum.

proximus Lacordaire 1842:113. Ischyrus. Valid.

puncticollis Gorham 1887:44-45. Ischyrus. Synonym of I. quadripunctatus (01ivier) 1792:437, new synonymy.

quadripunctatus Olivier 1792:437. Erotylus. Now Ischyrus, fide Lacordaire 1842:127-128. Valid. With 2

subspecies: I. q. quadripunctatus (Olivier) and I. quadripunctatus chisaticus Boyle 1954.

quadripunctatus Crotch 1873b:144. Ischyrus. Variety of I. graphicus Lacordaire 1842:125-126, fide Gemminger \& Harold 1876:3690. This is an incorrect interpretation of Crotch.

quinquepunctatus Gorham 1887:43-44, t.3 f.6. Ischyrus. Synonym of $I$. angularis Lacordaire 1842:126, new synonymy.

sanguinolentus Lacordaire 1842:97. Ischyrus. Now Megischyrus, fide Crotch 1873b:143.

sanguinosus Motschulsky 1858:116. Ischyrus. Now Mycolybas, fide Crotch 1876:474(98).

scaphinotus Lacordaire 1842:96. Ischyrus. Now Megischyrus, fide Crotch 1876:(47) 423. 
scriptus Olivier 1807:484-485, t.3 f.38. Erotylus. Now Ischyrus, fide Lacordaire 1842:119. Valid.

scutellaris Gorham 1887:41-42, t.3 f.2. Ischyrus. Valid. sedecimguttatus Guérin-Méneville 1829-1838[1844]:310.

Ischyrus. Now Mycotretus, fide Crotch 1876:(64)440.

semipunctatus Germar 1824:612. Erotylus. Now Megischyrus, fide Crotch 1876:(48) 424. Ischyrus in Lacordaire $1842: 99$.

semitinctus Erichson 1847:180. Ischyrus. Now Megishyrus, fide Crotch 1876:(49) 425 .

septemsignatus Gorham 1887:41, t.2 f.19. Ischyrus. Valid. sexpunctatus Chevrolat in Lacordaire 1842:113. Ischyrus. Synonym of $I$. proximus Lacordaire 1842:113, fide Gemminger \& Harold 1876:3691.

sheppardi Crotch 1876:428(52). Ischyrus. Valid.

sicarius Lacordaire 1842:101-102. Ischyrus. Now Megischyrus, fide Crotch 1876:(49) 425.

signaticollis Klug in Dejean 1836:429. Mycotretus. Synonym of Oocyanus flavitarsis (Lacordaire) 1842:130, fide Gemminger \& Harold 1876:3690.

similior Crotch 1876:432(56). Ischyrus. Valid.

similis Chevrolat in Dejean 1836:429. Mycotretus. Synonym of $I$. patruelis Lacordaire 1842:124-125, fide Gemminger \& Harold 1876:3691.

subcylindricus Lacordaire 1842:117-118. Ischyrus. Synonym of $I$. quadripunctatus (Olivier) 1792:437, new synonymy.

tarsalis Lacordaire 1842:106. Ischyrus. Now Oocyanus, fide Curran $1944: 4$.

tarsatus Lacordaire 1842:196-197. Oocyanus. Synonym of oocyanus tarsalis (Lacordaire) 1842:106, fide Curran $1944: 4$.

tetragrammus Kuhnt 1910:230-231, f.5. Ischyrus. Valid. tetraspilotus Guérin-Méneville 1829-1838[1844]:310. Ischyrus Valid.

tetrasticus Gorham 1887:41, t.3 f.1. Ischyrus. Valid. 
thoracica Dejean 1836:429. Mycotretus (Engis). Synonym of Oocyanus Elavitarsis (Lacordaire) 1842:130, fide Gemminger \& Harold 1876:3690.

tripunctatus Crotch 1873b:144. Ischyrus. Valid.

tripunctatus Blatchley 1917:238. Ischyrus. Not I.

tripunctatus Crotch 1873b:144, new name I. dunedinensis Blatchley 1917:279.

undatus Olivier 1791:434. Erotylus. Now Megischyrus, fide Crotch 18736:143. Ischyrus in Dejean 1836:428.

undulatus Gorham 1887:42, t.3 f.3. Ischyrus. Valid.

variabilis Duponchel 1825:46-47, t.1 f.25. Erotylus. Now Ischyrus, fide Lacordaire 1842:121. Valid.

variegata Dejean 1821:45. Engis. Synonym of $I$. subcylindrus Lacordaire 1842:117-118, fide Gemminger \& Harold 1876:3691.

velatus Lacordaire 1842:115-116. Ischyrus. Synonym of $I$. scriptus (Olivier) 1807:484-485, new synonymy.

venustus Lacordaire 1842:109. Ischyrus. Now Callischyrus, fide Crotch 1876:434(58).

vespertilio Lacordaire 1842:112. Ischyrus. Valid.

vittatus Crotch 1876:(51)427. Ischyrus. Valid

zonalis Lacordaire 1842:102. Ischyrus. Now Megischyrus, fide Crotch 1876:(49) 425 . 


\section{APPENDIX B \\ COLLECTIONS STUDIED AND CODENS}

This appendix is an alphabetical listing of the codens used in the text and the institution or personal collection for which they stand. Where possible, the codens follow those used by Arnett et al. (1993).

AAIC - A. Allen, Boise, ID, USA.

ABSC - Archbold Biological Station, Lake Placid, FL, USA.

AMNH - American Museum of Natural History, New York, NY, USA.

ANIC - Australian National Insect Collection, CSIRO, Canberra, Australia.

ANSP - Academy of Natural Sciences, Philadelphia, PA, USA.

ASUT - Arizona State University, Tempe, AZ, USA.

AUEM - Auburn University, Auburn, AL, USA

BYUC - Brigham Young University, Provo, UT, USA.

CASC - California Academy of Sciences, San Francisco, CA, USA.

CDAE - California Department of Food and Agriculture, California State Collection of Arthropods, Sacramento, CA, USA.

CEEF - Escuela Nacional de Ciencias Forestales, Siguatepeque, Honduras.

CMNC - Canadian Museum of Nature, Ottawa, Ontario, Canada.

CNCI - Canadian National Collection, Ottawa, Ontario, Canada.

CSCC - Chadron State College, Laboratory of Arthropod Diversity, Chadron, NE, USA.

CSUC - Colorado State University, Fort Collins, CO, USA.

CUCC - Clemson University, Clemson, SC, USA.

CUIC - Cornell University, Ithaca, NY, USA.

CUMZ - University of Cambridge Museum of Zoology, Cambridge, United Kingdom.

DAPC - D. A. Pollock, Edmonton, Alberta, Canada.

DEIC - Deutches Entomologisches Institut, Eberswalde Finow, Germany.

DENH - University of New Hampshire, Durham, NH, USA.

DEUN - University of Nebraska State Museum, Lincoln, NE, USA.

DHHC - D. H. Habeck, Gainesvilie, FL, USA.

DHKC - D. H. Kavanaugh, San Erancisco, CA, USA. 
EGRC - E. G. Riley, College Station, TX, USA.

EIUC - Eastern Illinois Univeristy, Charleston, IL, USA.

EJFC - E. J. Ford, Woodbury, TN, USA.

FAMU - Florida A. \& M. University, Tallahassee, EL, USA.

FIOC - Fundação Oswaldo Cruz, Rio de Janeiro, Rio de Janeiro, Brazil.

FMNH - Field Museum of Natural History, Chicago, IL, USA.

FSCA - Florida State Collection of Arthropods,

Gainesville, FL, USA.

GHNC - G. H. Nelson, Pomona, CA, USA.

HCCA - Hastings College, Hastings, NE, USA.

HNHM - Hungarian Natural History Museum, Budapest, Hungary.

ICCM - Carnegie Museum of Natural History, Pittsburg, $\mathrm{PA}$, USA.

IMLA - Fundacion Miguel Lillo, Tucuman, Argentina.

INHS - Illinois Natural History Survey, Urbana, IL, USA.

ISMS - Illinois State Museum, Springfield, IL, USA.

ISNB - Institut Royal des Sciences Naturalles de Belgique, Brussels, Belgium.

ISUI - Iowa State University, Ames, IA, USA.

JEWC - J. E. Wappes, Chadds Ford, PA, USA.

JLCC - J. L. Carr, Calgary, Alberta, Canada.

JMCC - J. M. Cicero, Gainesville, EL, USA.

JVMC - J. V. MCHugh, Ithaca, NY, USA.

JWIC - J. Watts, Gainesville, FL, USA.

KSUC - Kentucky State University, Erankfort, KY, USA.

LACM - Los Angeles County Museum, Los Angeles, CA, USA. MACN - Museo Argentino de Ciencias Naturales, Buenos Aires, Argentina.

MAIC - M. A. Ivie, Bozeman, MT, USA.

MCNZ - Museu de Ciencias Naturais, Porto Alegre, Rio Grande do Sul, Brazil.

MCTC - M. C. Thomas, Gainesville, FL, USA.

MCZC - Museum of Comparative Zoology, Cambridge, MA, USA.

MLPA - Universidad Nacional de La Plata, La Plata, Argentina.

MNHN - Museum National d'Histoire Naturelle, Paris, France.

MPEG - Museo Paraense Emílio Goeldi, Belem, Para, Brazil.

MSUC - Michigan State University, East Lansing, MI, USA.

MUIC - Mississippi State University, Mississippi, MS, USA.

NCSU - North Carolina State University, Raleigh, NC, USA.

NHMB - Naturhistorisches Museum, Basel, Switzerland. NHML - Natural History Museum, London, United Kingdom. 
OSUC - Ohio State Univeristy, Columbus, OH, USA.

PESC - P. E. Skelley, Gainesville, FL, USA.

PKLC - P. K. Lago, University, MS, USA.

PPCD - West Virginia Department of Agriculture,

Charlestown, WV, USA.

PURC - Purdue University, West Lafayette, IN, USA.

PWKC - P. W. Kovarik, Columbus, OH, USA.

QCAZ - Pontifica Universidad Católica de Ecuador, Quito, Ecuador.

RABL - R. A. B. Leschen, Lawrence, KS, USA.

RDCC - R. D. Cave, Tegucigalpa, Honduras.

RFMC - R. F. Morris, Lakeland, FL, USA.

RHTC - R. H. Turnbow, Jr., Fort Rucker, AL, USA.

RJBC - R. J. Barney, Erankfort, KY, USA.

RPIC - R. Prange, Gainesville, FL, USA.

RWFC - R. W. Flowers, Tallahassee, FL, USA.

RWLC - R. W. Lundgren, Archer, FL, USA.

SDSU - South Dakota State Univeristy, Brookings, SD, USA.

SEMC - Snow Entomological Museum, University of Kansas, Lawrence, KS, USA

SIUC - Southern Illinois University, Carbondale, IL, USA.

SMCC - S. MCCleve, Douglas, AZ, USA.

SMFC - S. M. Fullerton, Oviedo, FL, USA.

TAMU - Texas A. \& M. University, Tallahassee, FL, USA.

TKPC - T. K. Philips, Columbus, OH, USA.

UADE - University of Arkansas, Fayetteville, AR, USA.

UAIC - University of Arizona, Tucson, AZ, USA.

UASM - University of Alberta, Strickland Museum,

Edmonton, Alberta, Canada.

UGCA - University of Georgia, Athens, GA, USA.

ULIC - University of Louisville, Louisville, KY, USA.

UMIC - University of Mississippi, University, MS, USA.

UMMZ - Univerity of Michigan, Ann Arbor, MI, USA.

UMRM - University of Missouri, Columbus, MO, USA.

UNAM - Universidad Nacionál Autonoma de México, México, México.

USNM - United States National Museum, Washington, DC, USA.

UWEM - University of Wisconsin, Madison, WI, USA

VPIC - Virginia Polytechnic Institute and State

University, Blackburg, VA, USA.

WIUC - Western Illinois University, Macomb, IL, USA.

WMUC - Western Michigan University, Kalamazoo, MI, USA.

WSIC - W. Suter, Kenosha, WI, USA.

WSUC - Washington State University, Pullman, WA, USA.

ZMHB - Museum für Naturkunde der Humboldt-Universität zu Berlin, Berlin, Germany.

ZSMC - Zoologische Staatssammlung, München, Germany. 


\section{APPENDIX C \\ SPECIMEN LABEL DATA}

Specimens and their label data are the basis for any revisionary study. Label data from adult specimens studied for this revision are presented here as a voucher record; to aid in future research or reconfirm my findings. Species with less than 10 records are listed in the text. Species with 10 or more records are listed below. They are presented in tabular form to accommodate the voluminous data, and to provide an easily usable format.

The species are arranged in alphabetical order. Under each species, data are organized alphabetically by country and state, then alphabetically by county and specific locality. These data are presented in the following order: number of specimens studied, county, specific locality, daymonth-year of collection, collector, elevation, specific data (host or other important information), collection coden where specimen is deposited. See Appendix B for the codens full name.

Heading abbreviations are as follows: No. = number of specimens studied; Collr. = collector; El. = elevation; Data = additional information; Rep. = repository, collection of deposition.

No. County Locality Date Collr. El. Data Rep.

Guatemala

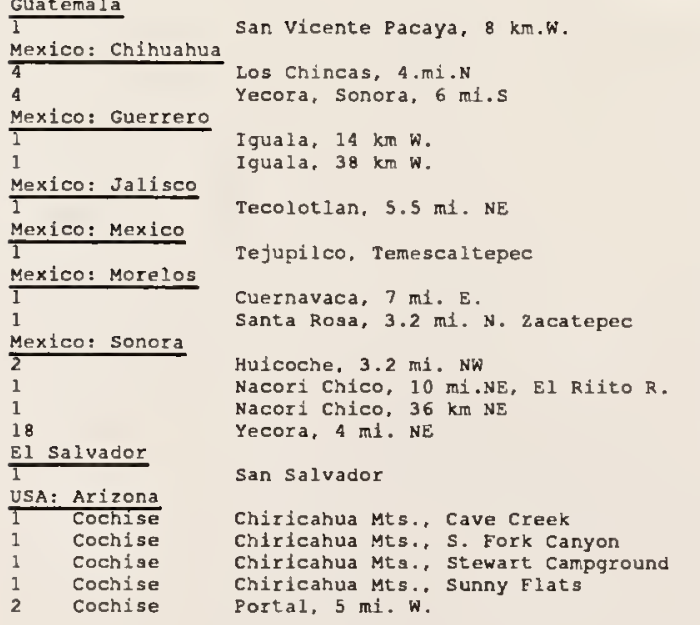

Ischyrus aleator Boyle

$14-V-1966$

9-10-VII-1989

2-3-VII-1990

25-VI I-1 987

25-VII-1987

$13-V I I-1982$

1932

15-VI I-196S

19-V-1968

$11-13-V I I-1989$

$14-V I I-1988$

8-VIII-1982

30-VI- 1990

$22-v-1953$

24-VI-1927

$14-V I I-1964$

$14-V I I-1964$
$19-V I I-1986$

28-29-VII-1989

31-VII-1987

Campbell J.M.
McCleve S.
McCleve S.
Turnbow R.H.
Turnbow R.H.
Andrews E.G.
Hinton H.E.
Campbell
McFadden
McCleve S.
Jump P.
McCleve S.
McCleve S.
Cartwright O.L.
Kusche J.A.
Arnett R.H.Jr.
Nelson G.H.
Bousquet Y.
Morris R.

4500

4910. UV light $5740^{\circ}$ UV light

RHTC

$3100^{\prime}$

$5170^{\circ}$ UV light

UV light

$1848 \mathrm{~m}$ at light

$5400^{\circ}$ UV l1ght

at light

7000' TYPE

blacklight

uV light

Hg light
RHTC
PESC

CDAE

NHML

CNCI

CUIC

CNC I

SMCC

SMCC

SMCC

SMCC

SMCC

USNM

CASC

FSCA

GHNC

CNCI
RFMC 


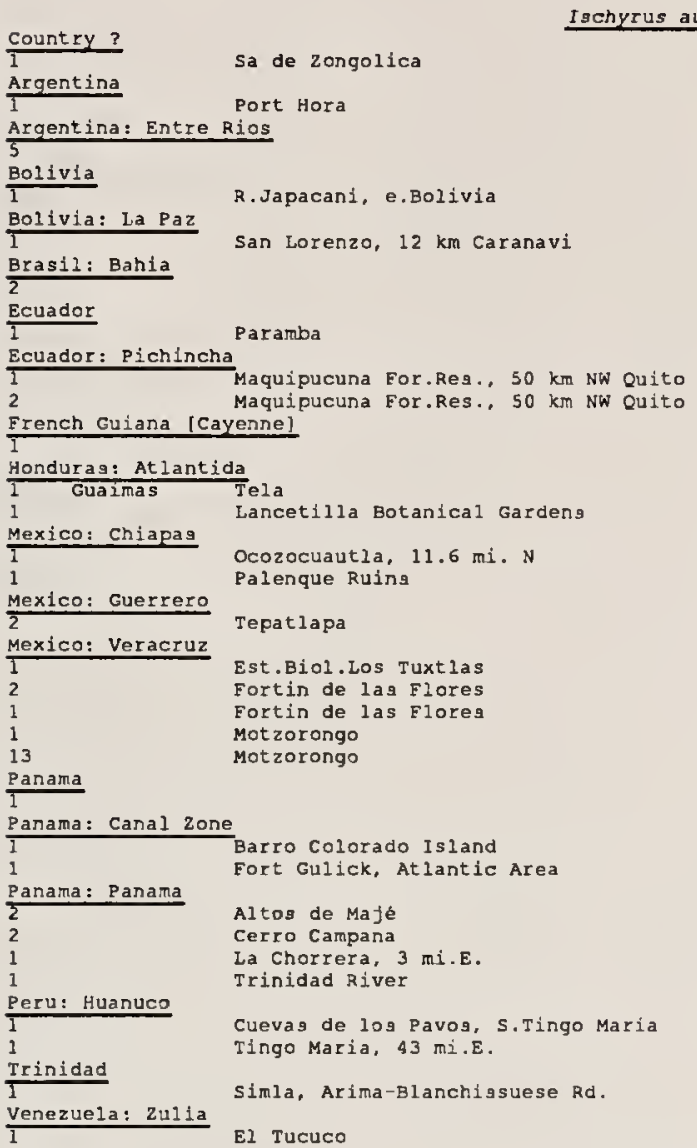

$\begin{array}{lc} & \\ \text { Camille Van Voixem } & \text { 2MHB } \\ \text { Camille Van Voixem } & \text { ISNB } \\ \text { Steinbach J. } & \text { ISNB }\end{array}$

1-2-I-1991 McHugh J.V.

JVM lot B91-24 JVMC

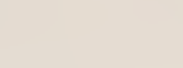

\section{Rosenburg}

21-XII-1991

23-XII-1991

carlton c.

Carlton $\mathrm{C}$.

$10-\mathrm{V}-1923$

29-V-1993

29-VIII -1967

$20-V=1972$

NHML

$7-\mathrm{X}-1989$

$7-\mathrm{X}-1989$
$26-30-\mathrm{VI}-1963$

7-I I-1966

$1300 \mathrm{~m}$
$1300 \mathrm{~m}$

NHML

SEMC

TYPE

14-VIII-1937

$10-17-v-1964$

$18-V-1965$

6-15-x-1975

$11-15-V-1980$

$8-I X-1952$

8-IX-1952

15-VII-1968

5-X-1954

27-VII-1975

20-23-IV-1981

Ischyrus bogotae frotch

\begin{tabular}{|c|c|}
\hline $\begin{array}{l} \\
\text { Costa Rica }\end{array}$ & Bogota \\
\hline 8 & Tarrazu \\
\hline Costa Rica: San J & José \\
\hline 1 & San Josè \\
\hline Costa Rica: Punta & arenas \\
\hline & Einca lag Cruces, S.San Vito de Java \\
\hline 1 & Monte Verde \\
\hline 1 & Monte Verde, Pens.Quetzal \\
\hline Ecuador: Pichinch & a \\
\hline & Tinlandia \\
\hline Guatemala & \\
\hline 3 & Moca, Sucha \\
\hline Guatemala: Escuis & te \\
\hline & $\overline{\text { Zapote }}$ \\
\hline Guatemala: San Ma & $\operatorname{rcos}$ \\
\hline $\begin{array}{l} \\
\text { Honduras }\end{array}$ & EI Tumbador \\
\hline Toxicos chianag & Lake Yojoa \\
\hline Mexico: Chiapag & \\
\hline$\overline{1}$ Mexico: Durango & Union Juarez, $5.3 \mathrm{mi}$. $\mathrm{s}$. \\
\hline & Canelas \\
\hline Mexico: Hidalgo & \\
\hline Mexico: Nayarit & Chapulhuacan, $3 \mathrm{mi}$. $\mathrm{N}$ on Hwy 65 \\
\hline Mexico: Veracruz & El Cora Tepic \\
\hline 3 & Cordoba \\
\hline 1 & Cordoba \\
\hline 3 & Est.Biol.zos Tuxtlas \\
\hline 1 & Est.Biol.Los Tuxtlag \\
\hline 1 & Est.Biol.Los Tuxtias \\
\hline 1 & Eat.Biol.Los Tuxtias \\
\hline 2 & Eat.Biol.Los Tuxtlas \\
\hline 2 & Est.Biol.Los Tuxtlas, Verda Darwin \\
\hline
\end{tabular}

29-VIII-1936

14-III-1911

28-30-IX-1986

$22-23-V-1974$

$18-\mathrm{V}-1988$

11-17-V-1986

25-VI-1947

9-VIII-1911

7-VII-1978

3-VIII-1972

$25-29-V-1984$

$22-\mathrm{X}-1963$

$3-V I I-1964$

13-30-XI-1988

3-15-XI I-1988

14-17-VI-1989

9-IX-1989

$7-x-1989$

$17-18-V I-1989$
Hubbel $1 \mathrm{H}$.

Thomas M.C.

Ball G.E.
Meyer P.A.

Meyer P.A.

Whitehead D.R.

Bal1 G.E.

Driver $\mathrm{E}$.

Duckworth W.D.

Chandler D.S.

Riley E.G.

Busck A.

O'Brien C.W. L L.B.

Schlinger E.I.

Price $\mathrm{J}$.

Townes H.

TYPE

CUM2

Marin E.

rotten trunk Inga sp. USNM

schmidt H.

Eger J.E.

Giesbert E.

Ratcliffe B.c.

$3200^{\circ}$ uv 2 ight

UMMZ

PESC

$300^{\circ}$ UV light

UASM

UASM

FMNH

2900 USNM

FMNH

2MHB

USNM

USNM

USNM

Eger J.E.

$1380 \mathrm{~m}$

$2500^{\circ}$

Johnson F.

$3000^{\circ}$

Champion G.C.

B.C.A., Col.

OSUC

EGRC

USNM

PESC

FMNH

osuc

Riedel S.G.

Manking J.V.

Heming B.S.

$3000^{\circ}$ UV light

ZMHB

ESCA

LACM

DEUN

ESCA

AMNH

NHML

ZMHB

CEEF

UASM

ZMHB

Thomas D.

DEUN

Lüdecke A.

ZMHB

Lau A.B.

Lau A.B.

Mcjorada E.

Mcjorada E.

Colin J.L.

Colin J.L.

Colin J.L.

colín J.L.

$\mathrm{HB}$

B

B

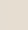


Ischyrus bogotae crotch (Cont.)

\section{country?}

$22-23-V-1965$
$1-X I-1989$
$15-X I I-1948$
$12-V I I-1989$
$24-25-V-1977$

Weems H.V.Jr. zargoza $S$.

Leech H.B.

2500-3000' blacklight FSCA

colin $\mathrm{J}$. pool in grove CASC

Howden H.S A.

$1300 \mathrm{~m}$

Ischyrus boucardi crotch

$\begin{array}{ll}\mathrm{X}-1945 & \text { Bade B.S W } \\ \text { Vigsa M.J. }\end{array}$

CNCI

Colombia

Colombia [Nova Granada)

Colombia: Cauca

Colombia: choco

I Camp. Sautat, Puerto Libre

MACN

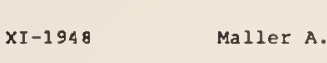

ZMHB

Guatemala

$28-V-1979$

TIdweI A.

CUMZ

16-17-V-1964 Duckworth W.D.

flight trap PESC

Schneider $F$.

USNM

Thamm

2MHB

NHML

2MHB

27-VIII-I992 Skelley P.E.

$4-19-X I-1984$

Kavanaugh D.

beating at night PESC

30-XII-1985 Kovarik P.W.

$12 \cdot 50 \cdot \mathrm{s}, 60 \cdot 20^{\prime} \mathrm{W} \mathrm{DHKC}$

TAMU

Nicaragua: Chontales

Panama

Panama Tocuman

Panama: Canal zone

2 Cano Saddle, Gatun Lake

Panama: Panama

Cano Saddle, Gatun Lake 12-V-1923

12-V-1923 Shannon R.C

Harlan H.J.

6-V-1974 Wolda H.

NHML

$\begin{array}{ll} & \text { ISNB } \\ & \text { 2MHB } \\ \text { TYPE } & \text { CUMZ }\end{array}$

1968

2MHB

Malaise trap osuc

NHML

B.C.A., Col., VII. NHML

USNM

Las Cumbres

blacklight $\quad$ USNM

osuc

\begin{tabular}{ll}
$\frac{\text { Country ? }}{\text { Mexico }}$ & \\
$\frac{1}{1}$ & \\
$\frac{\text { Mextco: Veracruz }}{2}$ & \\
1 & Cordoba \\
3 & Cordoba \\
1 & Cordoba \\
1 & Fortin de las Flores \\
1 & Fortin de las Flores \\
1 & Huatusco \\
1 & Orizaba \\
Monduras ? & Toxpam \\
\hline 1 & Copan, Vera Paz
\end{tabular}

Ischyrus distinguendus Lacordaire

\begin{tabular}{ll} 
USA: & Florida \\
\hline 1 & Alachua \\
2 & Broward \\
17 & Flagler \\
1 & Highlands \\
2 & Highlands \\
1 & Highlands \\
1 & Highlands \\
1 & Highlands \\
1 & Highlands \\
1 & Highlands \\
1 & Highlands \\
1 & Highlands
\end{tabular}

Ft.Lauderdale, Tamarac City
Palm Coast
Archbold Biological station
Archbold Biological station
Archbold Biological station
Archbold Biological station
Archbold Blological station
Archbold Blological station
Archbold Biological station
Archbold Blological station
Archbold Biological station

Ischyrus dunedinensis Blatchley

$12-22-V I-1965$
$4-V I I I-1965$
$30-V I I-1964$
$28-V I-1975$
$19-X-1964$

$28-V I-1975$
$19-X-1964$

LaL A.B.

Rabago

Wheeler Q.D

Lau A.B.
Coll. Chevr

CUMZ

TYPE

2MHB

CASC

USNM

USNM

blacklight PESC

CUIC

USNM

B.C.A., Col, sp.f1gured. NHML

Condradt B.C.A., Mycotretus ornatus var. NHML

$\begin{array}{ll}\text { V-1968 } & \text { Hetrick L.A. } \\ 20-V I I-1971 & \text { Ford E.J. } \\ 30-V-1993 & \text { Skelley P.E. L.H. } \\ 10-I X-1981 & \text { Lampert L.L.Jr. } \\ 27-I V-1981 & \text { Lampert L.L.Jr. } \\ 25-V-1982 & \text { Brattain R.M. } \\ 24-V I-1983 & \text { Deyrup M. } \\ 11-V I I-1983 & \text { Deyrup M. } \\ 24-V I I-1983 & \text { Deyrup M. } \\ 31-V I I-1983 & \text { Deyrup M. } \\ 12-V I I I-1983 & \text { Deyrup M. } \\ 22-I X-1983 & \text { Deyrup M. }\end{array}$

$\begin{array}{cc}\text { light trap } & \text { MCZC } \\ \text { light, beach scrub } & \text { PESC } \\ \text { UV light } & \text { FSCA } \\ \text { UV light } & \text { FSCA } \\ & \text { ABSC } \\ \text { Malaise trap } & \text { ABSC } \\ \text { Malaise trap } & \text { ABSC } \\ \text { Malalse trap } & \text { ABSC } \\ \text { Malalse trap } & \text { ABSC } \\ \text { Malaise trap } & \text { ABSC } \\ & \text { ABSC }\end{array}$




\section{Ischyrus dunedinensis Blatchley (Cont.)}

\begin{tabular}{|c|c|c|}
\hline 1 & Highiands & $\overline{\text { Arehbold Biological }}$ \\
\hline 1 & Highlands & Archbold Biological station \\
\hline 1 & Highlands & Archbold Biological station \\
\hline 1 & Highlands & Archbold Biological station \\
\hline 1 & Highlands & Archbold Biological station \\
\hline 1 & Highlands & Archbold Biological station \\
\hline 1 & Highlands & Archbold Biologlcal station \\
\hline 3 & Highlands & Archbold Biological station \\
\hline 6 & Highlands & Archbold Biological station \\
\hline 1 & Highlands & Archbold Blological station \\
\hline 1 & Highlands & Archbold Biological station \\
\hline 1 & Highlands & Archbold Biologlcal station \\
\hline 1 & Highlands & Archbold Blological station \\
\hline 1 & Hlghlands & Archbold Blological station \\
\hline 1 & Highlands & Archbold Biological station \\
\hline 2 & Highlands & Archbold Biological station \\
\hline 1 & Hillsborough & \\
\hline 1 & Hillsborough & Temple Terrace \\
\hline 1 & Indian River & F1.Med.Ent.Lab, SR-512 $0.5 \mathrm{ml} . \mathrm{W}$ I-95 \\
\hline 1 & Indian River & $5 R-5120.5 \mathrm{ml}$.W I-95 \\
\hline 1 & Indian River & F1.Med.Ent. Lab, SR-512 0.5mi.W I-95 \\
\hline 1 & Indian River & F1.Med.Ent.Lab, SR-512 $0.5 \mathrm{ml}$. W I-95 \\
\hline 1 & Indian River & F1.Med.Ent.Lab, SR-512 0.5mi.W I-95 \\
\hline 1 & Marion & Ocala Nat'1.Forest. Hopking Prairle \\
\hline 1 & Marion & Ocala Nat'1.Forest, T17s.R26E.Sec.22 \\
\hline 1 & Orange & Oviedo, Univ.Central El.campus \\
\hline 1 & Orange & oviedo, Univ.Central Fl.campus \\
\hline 1 & Orange & Oviedo, Univ.Central Fl.campus \\
\hline 1 & Orange & Oviedo, Univ.Central Fl.campus \\
\hline 2 & Orange & Oviedo, Undv.Central El.campus \\
\hline 1 & Pinellas & Dunedin \\
\hline 1 & Volugia & Daytona \\
\hline 1 & volusia & New Smyrna \\
\hline USA: & Georgia & \\
\hline & Chariton & Camp Cornelia \\
\hline
\end{tabular}

\begin{tabular}{|c|c|}
\hline $12-V I-1985$ & Deyrup $M$. \\
\hline $19-V I-1985$ & Deyrup M. \\
\hline $15-V I I-1985$ & Deyrup $M$. \\
\hline $10-11-V I-1986$ & Deyrup M. \\
\hline $17-18-V I-1986$ & Deyrup $M$. \\
\hline $21-23-V I-1986$ & Deyrup M. \\
\hline $15-V I-1987$ & Deyrup M. \\
\hline $22-26-V I-1987$ & Deyrup M. \\
\hline $1-3-v 1 I-1987$ & Deyrup M. \\
\hline $6-V I I-1987$ & Deyrup $\mathrm{M}$. \\
\hline $17-V I I-1987$ & Deyrup M. \\
\hline $8-V I I I-1987$ & Deyrup $M$. \\
\hline $5-1 X-1987$ & Deyrup M. \\
\hline $12-16-V I-1988$ & Deyrup $M$. \\
\hline $30-V I-1988$ & Skelley P.E. \\
\hline $7-V I I-1988$ & Skelley P.E. \\
\hline 7-VI-1968 & Woods \& Davidson \\
\hline $7-V I-1968$ & Wood F.E. \\
\hline $5-V I-1975$ & Thomas M.C. \\
\hline V-VI I - 1975 & Thomas M.C. \\
\hline 4-7-VI I - 1975 & Thomas M.C. \\
\hline $10-16-V I I-1975$ & Thomas M.C. \\
\hline $16-20-v-1976$ & Thomas M.C. \\
\hline $8-11-V-1979$ & Weems H.V.Jr. \\
\hline $25-V I I-1938$ & Hubbell \& Friaf \\
\hline $30-v-1991$ & Eullerton S.M. \\
\hline $23-V I-1991$ & Fullerton S.M. \\
\hline $2-x-1991$ & Fullerton S.M. \\
\hline 23-VIII-1992 & Fullerton S.M. \\
\hline $15-21-1 X-1992$ & Eullerton S.M. \\
\hline $2-v-1916$ & Blatchley w.s. \\
\hline 1951 & Rosenberg $\mathrm{N}$. \\
\hline 23-VII & Wright $M$. \\
\hline
\end{tabular}

\begin{tabular}{|c|c|c|}
\hline Malaige & trap & ABSC \\
\hline Malaige & trap & ABSC \\
\hline Malaige & trap & ABSC \\
\hline flight & trap & FSCA \\
\hline fllght & trap & ESCA \\
\hline flight & trap & ESCA \\
\hline Malalge & trap & ABSC \\
\hline Malaise & trap & ABSC \\
\hline Malaise & trap & ABSC \\
\hline window trap bu & ourn area & ABSC \\
\hline Malaige & trap & ABSC \\
\hline Malaise & trap & ABSC \\
\hline Malaige & trap & ABSC \\
\hline & & PESC \\
\hline blackli & ight & PESC \\
\hline blacklis & & PESC \\
\hline & & USNM \\
\hline & & USNM \\
\hline k-dawn suct & fion trap & MCTC \\
\hline 1sk-dawn guct & Ion trap & MCTC \\
\hline usk-dawn suct & fion trap & FSCA \\
\hline dugk-dawn guct & ion trap & FSCA \\
\hline usk-dawn suct: & tion trap & MCTC \\
\hline flight & trap & FSCA \\
\hline at $11 \mathrm{ght}$ & & GHNC \\
\hline Malaige tra & ap, scrub & SMFC \\
\hline Malaise $t r$ & ap, scrub & SMFC \\
\hline Malaise tra & ap, acrub & SMFC \\
\hline Malaise tr & ap, scrub & SMFC \\
\hline Malaige tra & cap, acrub & SMFC \\
\hline TYPE & & PURC \\
\hline & & USNM \\
\hline \{det. knu & 11119541 & osuc \\
\hline at light & & UGCA \\
\hline
\end{tabular}

Ischyrus elegantulus Lacordaire

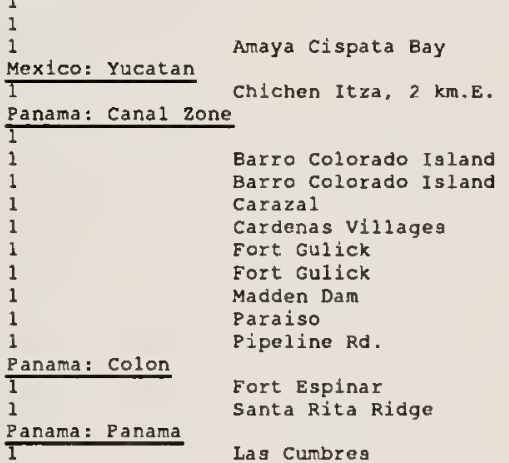

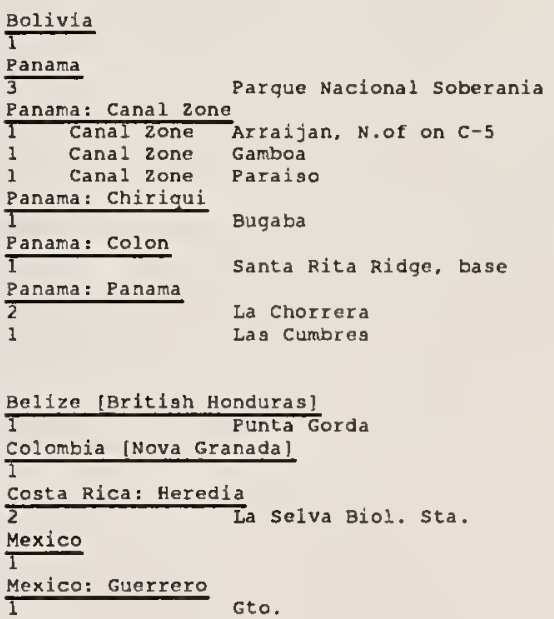

$\begin{array}{ll}19-V-1916 & \text { Martin B. } \\ 26-V-1981 & \text { Bellamy C.L. } \\ 26-I I I-1940 & \text { Wood G.C. } \\ \text { IV-X-1947 } & \text { Zetek } \\ 20-23-V-1964 & \text { Duckworth W.D. } \\ 27-I V-1911 & \text { Bugck A. } \\ 10-V-1980 & \text { Riley E.G. } \\ 19-I I I-1979 & \text { Harlan H.J. } \\ \text { II-1980 } & \text { Harlan H.J. } \\ 21-V-1978 & \text { O'Brien C.W. S L.B. } \\ 9-V-1911 & \text { Schwarz E.A. } \\ 12-V-1978 & \text { O'Brien C.W. S L.B. } \\ 14-V-1991 & \text { Turnbow R.H. } \\ 29-V-1980 & \text { Riley E.G. } \\ 14-V-1979 & \text { Wolda J. }\end{array}$

TYPE

Ischyrus ephippiatus Gorham

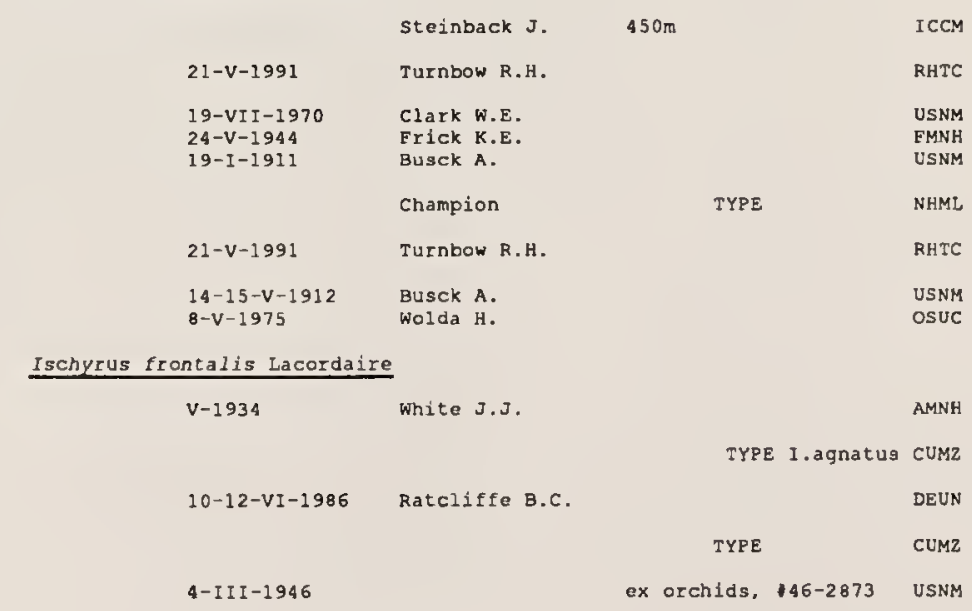




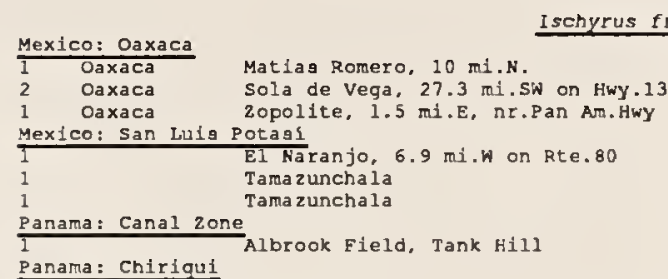

Panama: Chirigui

talis Lacordaire (Cont.)

$\begin{array}{ll}\text { 3-VII-1975 } & \text { Wheeler Q.D. } \\ \text { 18-VII-1986 } & \text { Mccleve S. } \\ \text { W-VII-1987 } & \text { Warner W.B. } \\ \begin{array}{l}\text { 14-X-1985 } \\ \text {-VIII-1946 }\end{array} & \text { Ball G.E. } \\ \text { 10-VIII-1946 } & \\ \text { 29-IV-1977 } & \text { R1ley E.G. } \\ & \text { Champion }\end{array}$

$3360^{\circ}$ UV light SUIC

SMCC

PESC ex orchids, $46-12972$ USNM ex orchids, \$6-14323 USNM

$1200^{\circ}$ B.C.A.CCOL NHML

\section{Ischyrus incertus Lacordaire}

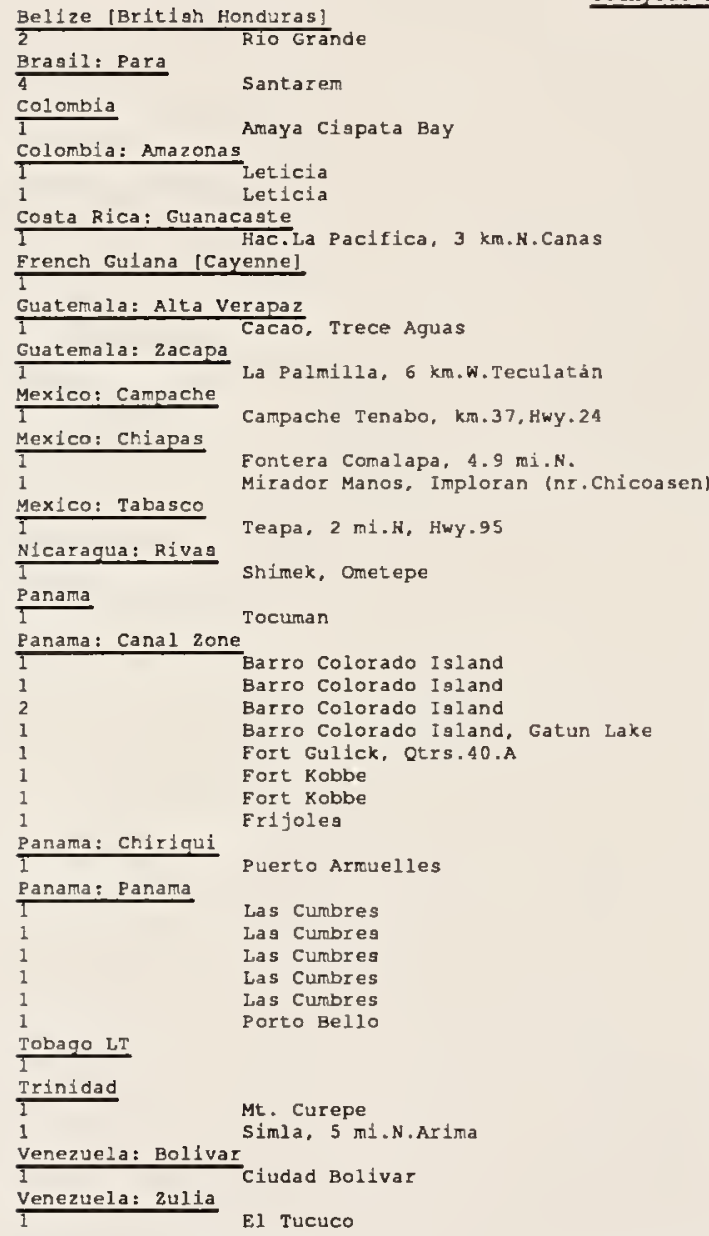

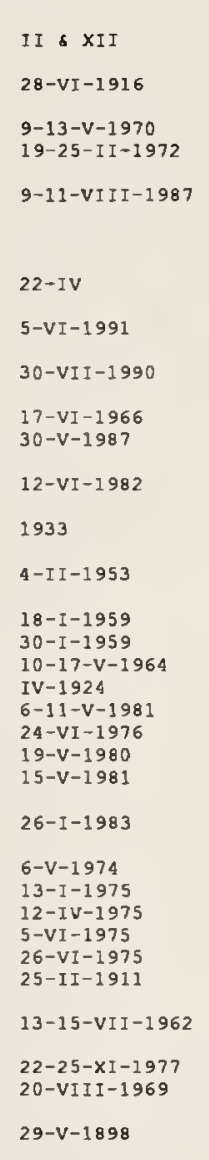

\section{Ischyrus pictus Gornam}

\begin{tabular}{|c|c|}
\hline Honduras & $\operatorname{san} J$ uan \\
\hline 1 & Lake Yojoa \\
\hline Mexico: Chiapas & \\
\hline$\overline{4}$ Mexico: Oaxaca & Palenque, $100 \mathrm{~km}$ SE on Bonampat Rd. \\
\hline 1 & Juchatengo, $4 \mathrm{mi} . \mathrm{N}$. \\
\hline $\begin{array}{l}\text { Mexico: Tabasco } \\
\text { Mexico: Veracruz }\end{array}$ & Villahermosa, $59.4 \mathrm{mi.SE}$. \\
\hline 1 & Est.Blol.Los Tuxtlas \\
\hline 1 & Est.Biol. Los Tuxtlas \\
\hline 1 & Fortin de las Flores \\
\hline 1 & $16 \mathrm{~km}$ N.Sonte Comapan \\
\hline 1 & Lake Catemaco \\
\hline 1 & Microonolas San Juan, S.Fortin \\
\hline 1 & Rio Quezalapan, $2 \mathrm{ml}$.E. Lago Catemaco \\
\hline Mexico: Yucatan & \\
\hline
\end{tabular}

ICCM

$\mathrm{ICCM}$

$\mathrm{ICCM}$

CAsC

Martin $\mathrm{B}$.

FMNH

Malkin B. $700^{\circ}$

Howden H.S A. $90 \mathrm{~m}$ CMNC

Coll. Reiche cumz

Barber \& Schwarz USNM

Howden H.S A.

o'Brien C.W.G L.B.

BaII G.E.

Warner W.B.

streit B.D.

blacklight at light

at light

Wickham

Blanton F.S.

Dybas H.S.

Dybas H.S.

Duckworth W.D.

Bradley J.C.

Harlan H.J.

Riley E.G.

Riley E.G.

Gill B.

Rodrlguez $R$.

wolda $H$

Wolda $\mathrm{H}$

Wolda $\mathrm{H}$

Wolda $H$

wolda $H$

USNM

USNM

at light

at $11 \mathrm{ght}$

blacklight

FMNH

FMNH

USNM

CUIC

FMNH

GRC

CHCI

blacklight PESC

osuc

osuc

UV light osuc

OSUC

USNM

CNCI

CMNC

CUIC

Howden H.G A.

Klages E.A.

$200 \mathrm{~m}$

Malalse trap

$\mathrm{CNCI}$

TYPE, B.C.A.,COL.,VII NHME

at 1 ight

I NHS

Peck S.

fleshy fungus

CNCI

Fischer E.

$3300^{\circ}$

LSCM

BalI G.E.

blacklight

CUIC

Colin $\mathrm{J}$

Colin $\mathrm{J}$.

Rabago D.

Bezark L.G.

Howden H.F.

Thomas M.C.

Meyer R.J.

blackl1ght

UNAM

UNAY

0-VII-1 964

2-9-VIII-1

7-VII- 1992

12-31-VII-1964 uv light OSUC

Dysart R.J
12-VIII-1952 Pallister J.

c 


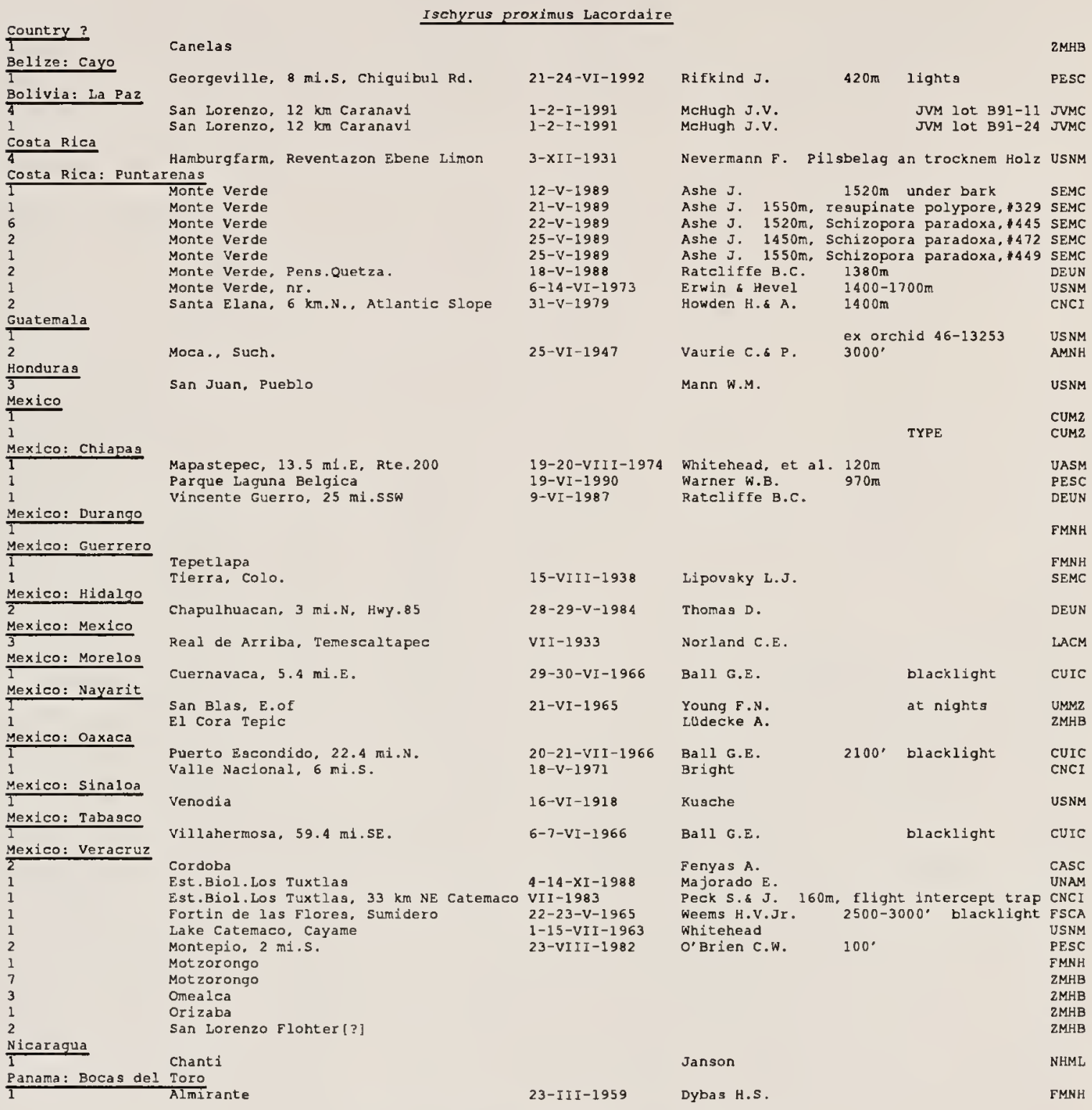

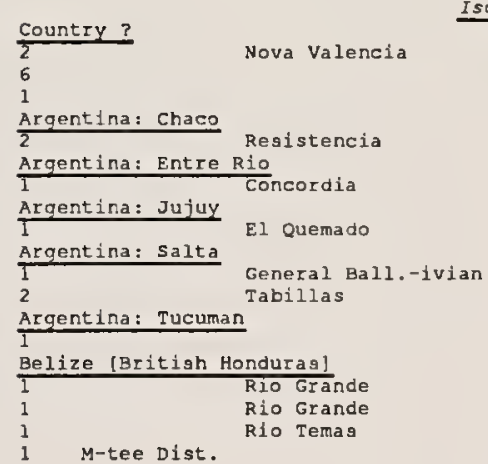

Ischyrus quadripunctatus guadripunctatus (011vier)

$\begin{array}{lll}2-X I I-1939 & \text { Biraben } & \text { MLPA } \\ & \text { Hayward } & \text { MLPA } \\ \text { III-V-1926 } & \text { Harrington G.L. } & \text { USNM } \\ 1927 & \text { Harrington G.L. } & \text { USNM } \\ \text { IX-1933 } & \text { Harrington G.L. } & \text { CASC } \\ \text { XI-1928 } & \text { Bruch C. } & \text { MACN } \\ & & \\ \text { VIII-1935 } & \text { Wh1te J.J. } & \text { ICCM } \\ \text { VIII-1937 } & \text { White A.J. } & \text { FMNH } \\ \text { VIII-1905 } & & \text { AMNH }\end{array}$




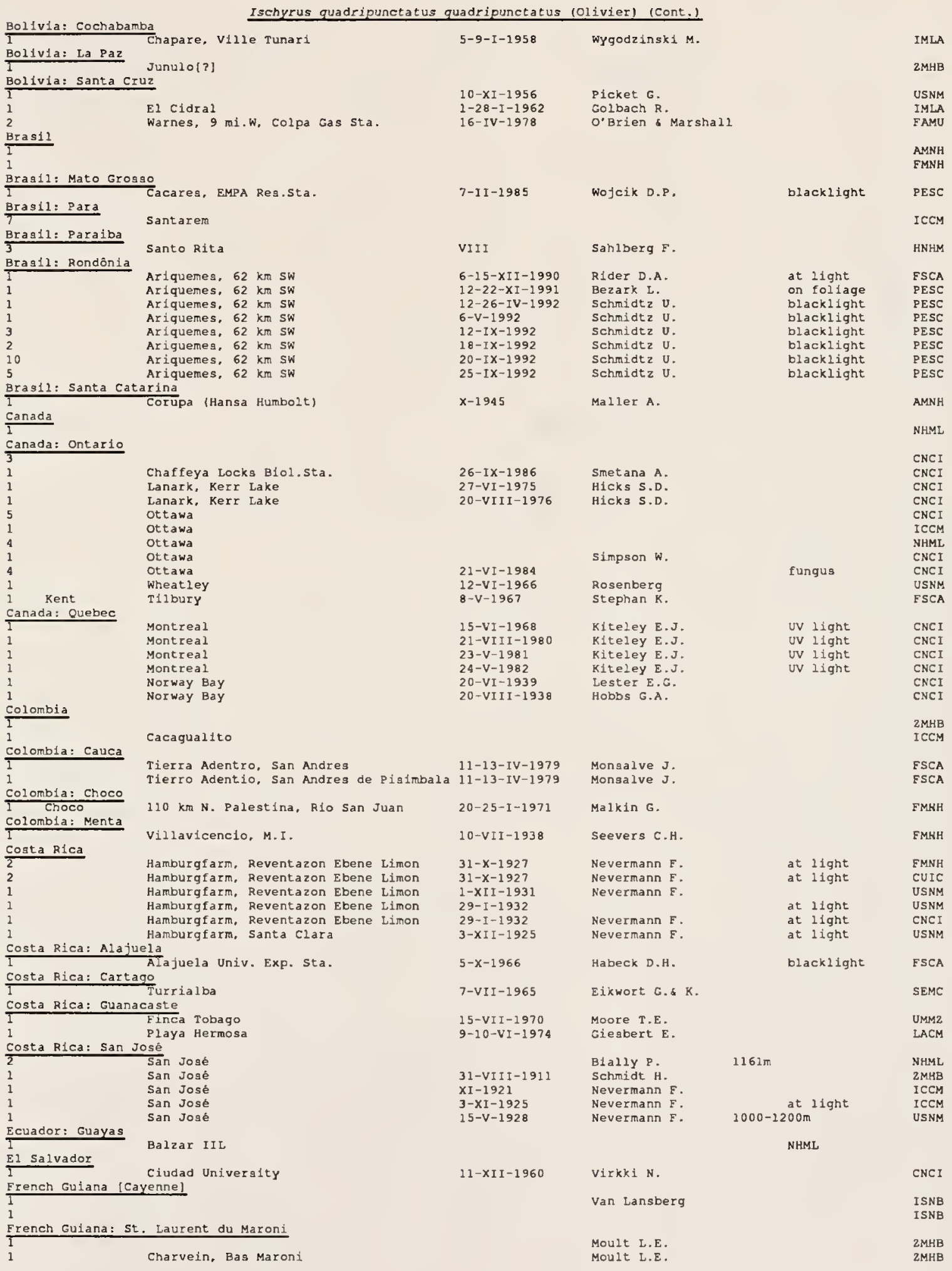




\section{Ischyrus quadripunctatus quadripunctatus (olivier) (Cont.)}

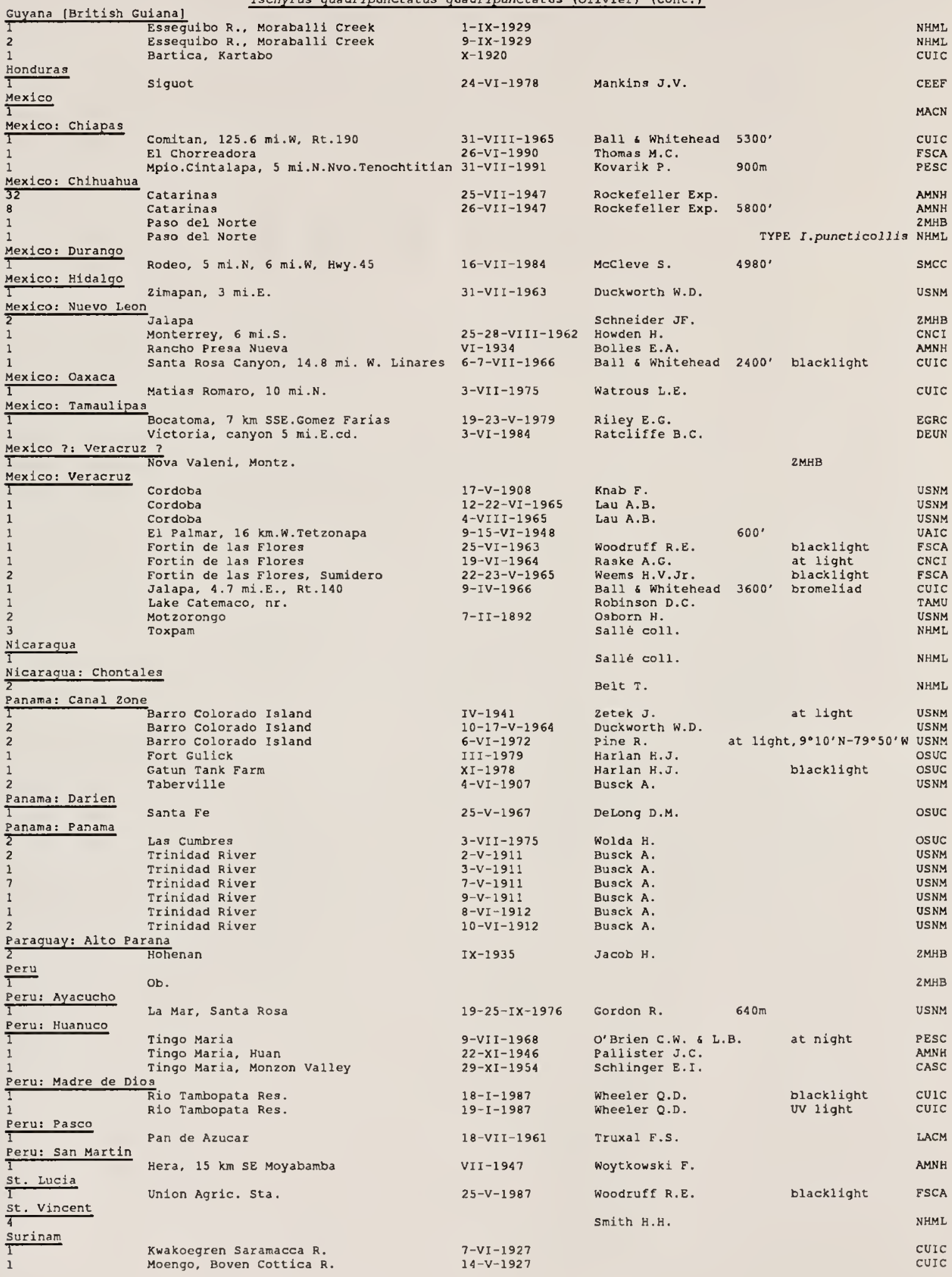




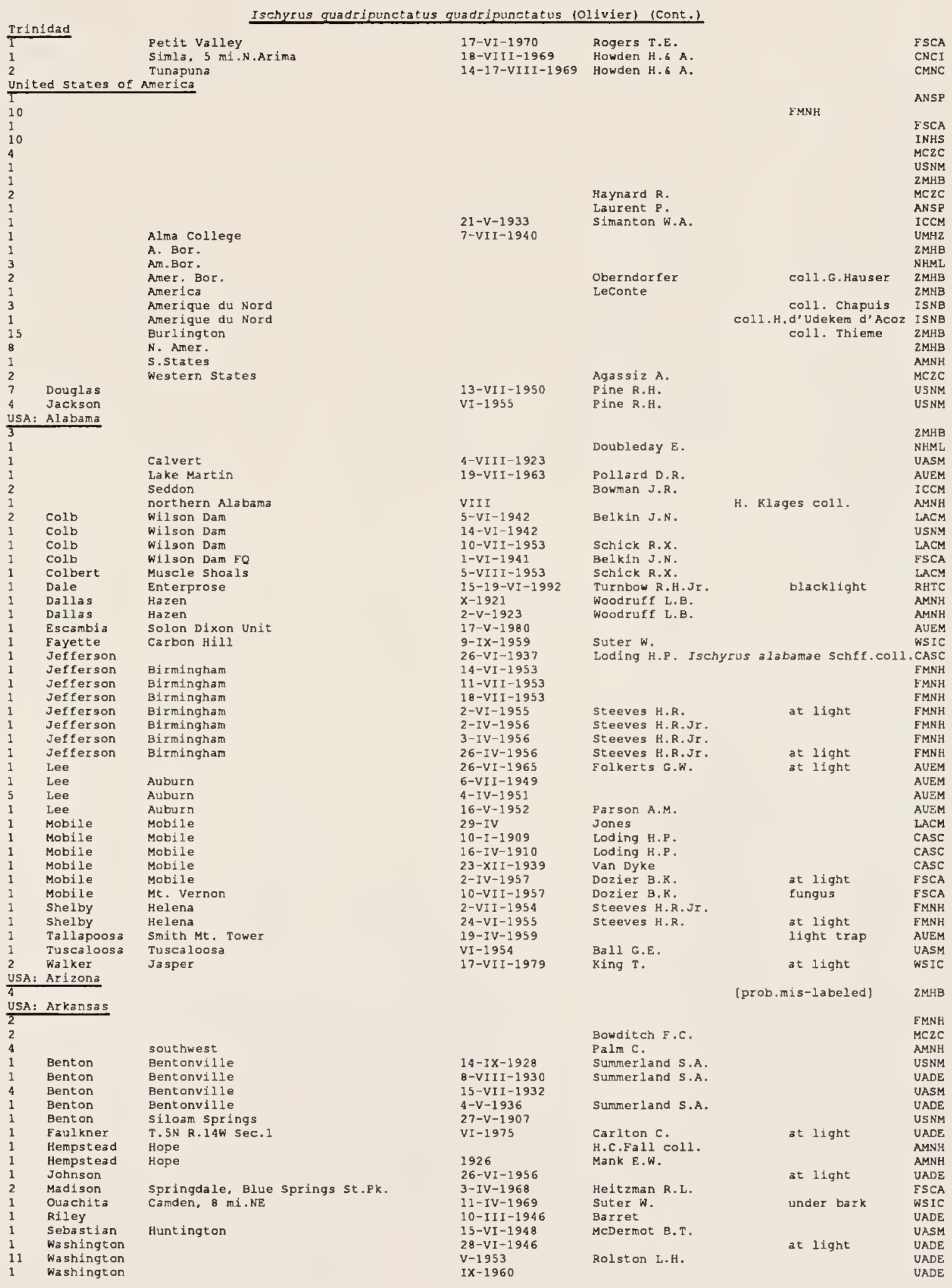




\begin{tabular}{|c|c|c|c|c|c|c|}
\hline 1 & $\frac{\text { Arkansas } 10}{\text { Washington }}$ & & & & & \\
\hline 1 & washington & & $\begin{array}{l}24-I V-1973 \\
13-V I-1974\end{array}$ & Wylie N.D. & llant trap & UADE \\
\hline 1 & Washington & & $27-V I-1975$ & Wyl ie W & light trap & UADE \\
\hline 1 & Waghingt on & Fayetteville & $13-v-1965$ & Wy $11 E$ W. & $\begin{array}{l}\text { light trap } \\
\text { light trap }\end{array}$ & $\begin{array}{l}\text { UADE } \\
\text { UADE }\end{array}$ \\
\hline 2 & Washington & Fayetteville, $12 \mathrm{mi} . \mathrm{W}$ on Hwy.16 & $14-V I I-1986$ & Leschen R.A.B. & Ipex lacteus & RABL \\
\hline 1 & Washington & Mt. Sequoyah & $19-V I-1938$ & Sanderson M.W. & at light & INHS \\
\hline $\begin{array}{l}\text { I } \\
\text { USA: }\end{array}$ & $\begin{array}{l}\text { Waghington } \\
\text { Connecticut }\end{array}$ & U. of Ark. Exp.Sta. & $30-v-1973$ & Haddox A.W. & blacklight & UADE \\
\hline USA: & District of & Columbia & & Bowditeh F.C. & & $\mathrm{MCzC}$ \\
\hline 1 & & Washington & $9-V I-1903$ & Burdon C.E. & & USNM \\
\hline 1 & & wa shington & $28-V I I-1923$ & Grealey J.R. & & AUEM \\
\hline 2 & & Washington, $2 \mathrm{mi} . \mathrm{NNW}$ & $28-V I-I 932$ & Barber H.S. & & USNM \\
\hline 1 & & Washington, Rock Creek & $24-V I-1905$ & & & USNM \\
\hline USA: & Florida & & & & & \\
\hline I & & & & & & NHML \\
\hline 1 & & & & & & 2MHB \\
\hline 2 & & & & Bowditch F.C. & & MCzC \\
\hline 1 & & & $6-V I-1903$ & Eddy F.A. & & MCZC \\
\hline 6 & & Crewsville & $2-I V-1941$ & Dekle G.W. & on Citrus $X$ paradisi & ESCA \\
\hline 15 & & Pablo Beach & $4-X I-1911$ & & & AMNH \\
\hline 1 & Alachua & & IV -1947 & & & FSCA \\
\hline 1 & Alachua & & $6-v-1969$ & May M.L. & & FSCA \\
\hline 1 & Alachua & Gainesville & $26-V-1947$ & Weems H.V.Jr. & at light & ESCA \\
\hline 1 & Alachua & Gainesville & $25-I V-1952$ & McGillis J.P. & & CNCI \\
\hline 1 & Alachua & Gainesville & $5-I V-1956$ & Denmark H.A. & & FSCA \\
\hline 1 & Alachua & Gainesville & IV-1965 & Hetrick L.A. & & FSCA \\
\hline 1 & Alachua & Gainesville & $I X-1966$ & Dickens T.H. & & VPIC \\
\hline 2 & Alachua & Gainesville & $9-I-1968$ & Watve C.M. & tree fungus & DHHC \\
\hline 6 & Alachua & Gainesville & $13-1-1968$ & Farngworth E.G. & tree fungus & DHHC \\
\hline 10 & Alachua & Gainesville & $13-1-1968$ & Habeck D.H. & fungus on $\log$ & DHHC \\
\hline 1 & Alachua & Gainesville & $12-I X-1972$ & Mead F.W. & blacklight trap & ESCA \\
\hline 2 & Alachua & Gainesville & $9-16-v-1976$ & Schuh $J$ & & AMNH \\
\hline 1 & Alachua & Galnesville & 2-VIII-1976 & Davia L.R.Jr. & & FSCA \\
\hline 1 & Alachua & Gainesville & $25-I I-1978$ & Rivera N. & rotten corn & RABL \\
\hline 1 & Alachua & Gainesville & $25-1 X-1978$ & Thomas M.C. & at light & MCTC \\
\hline 4 & Alachua & Gainesville & $1-3-V I I-1980$ & Stange L.A. & blacklighe trap & FSCA \\
\hline 1 & Al achua & Gainesville & $18-V I-1983$ & O'Conner B.M. & & UMMZ \\
\hline 1 & Alachua & Gainesville & $18-V I-1986$ & Mead F.W. & blacklight trap & FSCA \\
\hline 1 & Alachua & Gainesville & $7-I I I-1987$ & McCullogh & at light & PESC \\
\hline 1 & Alachua & Gainesville, Doyle Conner Building & $28-I I I-1970$ & Mead $\bar{F} . W$. & blacklight trap & FSCA \\
\hline 5 & Alachua & Gainesville, Hogtown Creek & $8-V I I-1987$ & Skelley P.E. & Poria ambigua & FSCA \\
\hline 27 & Alachua & Gainesville, Paynes Prairie & $23-V I I I-1987$ & Habeck D.H. & prostrate white fungus & PESC \\
\hline 2 & Alachua & Gaingeville, 2 mi.w. & $1-I V-1967$ & Bacheler J.S. & in fungus & FSCA \\
\hline 1 & Alachua & Newber ry & $11-V I I-1983$ & Vick K.W. & blacklight trap & ESCA \\
\hline 1 & Alachua & San Felasco Hammock & $22-X I-1975$ & Heppner J.B. & blacklight trap & FSCA \\
\hline 80 & Alachua & Santa Fe R. at Rt.441 & $14-V I I-1989$ & Skelley P.E. & log with fungus & PESC \\
\hline 1 & Broward & Andytown & $30-V I-1964$ & Dozler B.K. & at light & FSCA \\
\hline 4 & Calhoun & Chipola Park & $20-V I-1965$ & Lawrence J.F. & Poria ambigua & $\mathrm{MCZC}$ \\
\hline 1 & Columbla & Lake City & $6-v-1899$ & & & FSCA \\
\hline 1 & Columbia & O' Leno St.PX. & $22-V I I-198 I$ & Ford E.J. & light tIap & EJFC \\
\hline 3 & Columbia & O'Leno St.Pk. & $23-X I I-1987$ & Skelley P.E. & reared Poria ambigua & FSCA \\
\hline 1 & Columbia & O'Leno St.Pk. & $23-X I I-1987$ & Skelley P.E. & reared Poria ambigua & PESC \\
\hline 1 & Dade & Matheson Hammock & $11-I V-1951$ & Howden H.\& A. & & MCzC \\
\hline 1 & Dade & Matheson Hamnock & $17-x-1956$ & Paulson D.R. & & FSCA \\
\hline 1 & Dade & Miami & $1-V I-1960$ & Briggs P.E. & blacklight trap & FSCA \\
\hline 1 & Dixie & Suwannee River & $11-1-1940$ & Van Dyke & & CASC \\
\hline 1 & Gadsden & I-10 at Appalachicola $R$. & $11-V I-1988$ & Turnbow R.T. & at light & RHTC \\
\hline 2 & Gadsden & Quincy & $1-15-V I I I-1971$ & rreld $\mathrm{J}$. & & FSCA \\
\hline 5 & Gilchrist & Ginnie Springs & $27-v-1976$ & Perun P. & white fungus on $\mathrm{log}$ & DHHC \\
\hline 1 & Hernando & Withalacooche st.For. & 12-VIII-1992 & Skelley P.E. & & PESC \\
\hline 2 & Highlands & Archbold Biol.sta. & $13-I V-1983$ & Downie N.M. & & ESCA \\
\hline 1 & Highlands & Archbold Biol.sta., B mi.s Lake Placid & $2-V I I-1988$ & Skelley P.E. & blacklight trap & PESC \\
\hline 130 & Highlands & Hignlands Hammock st. PK. & $15-X I I-1957$ & Weems H.V.Jr. & under bark of Pinus & ESCA \\
\hline 1 & Highlands & Highlands Hammock St.Pk. & $14-111-1977$ & Platt E. & blackilght & UMRM \\
\hline 1 & Indian River & $\mathrm{SR}-512,0.5 \mathrm{mi} \cdot \mathrm{W} \mathrm{I}-95$ & $16-21-V I I-1975$ & Thomas M.C. & dugk-dawn suction trap & MCTC \\
\hline 1 & Indian River & SR-512,0.5 mi. $\mathrm{I}-95$ & $3-9-1 X-1975$ & Thomas M.C. & dugk-dawn guction trap & мстс \\
\hline 2 & Indian River & SR-512,0.5 mi.W I-95 & $16-20-V-1976$ & Thomas M.C. & & MCTC \\
\hline 1 & Indian River & SR-512,0.5 mi.W I-95 & $20-28-v-1976$ & Thomas M.C. & & MCTC \\
\hline 21 & La Fayette & Rt. 250 suwannee $R$. & $22-V I I-1977$ & Davis L.R.Jr. & & FSCA \\
\hline 1 & Leon & Tall Timbers Research Station & $1-8-V I I-1972$ & Jacques R.L. & & ESCA \\
\hline 6 & Leon & Tall Timbers Research station & $16-22-V I I-1972$ & Jacques R.L. & & FSCA \\
\hline 1 & Leon & Tall Timbers Regearch station & $29-30-I X-1989$ & Skelley P.E. & & PESC \\
\hline 1 & Liberty & & $11-I V-1967$ & Moore F.J. & & osve \\
\hline 2 & Liberty & Torreya St.Pk. & $1-V-1952$ & Peck 0 . & & CNCI \\
\hline 1 & Liberty & Torreya St.PK. & $17-V-1963$ & Weems H.V.Jr. & blacklight trap & ESCA \\
\hline 2 & Liberty & Torreya St.Pk. & $20-v-1966$ & Weems H.V.Jr. & blacklight trap & FSCA \\
\hline 1 & Liberty & Torreya St.Pk. & $8-1 X-1967$ & Moore E.J. & & osuc \\
\hline 1 & Liberty & Torreya St.Pk. & $18-1 X-1968$ & Weems H.V.Jr. & blacklight trap & ESCA \\
\hline 1 & Liberty & Torreya St.Pk. & $11-I V-1978$ & Stange L.A. & & ESCA \\
\hline 3 & Liberty & Torreya St.Pk. & $12-I V-1980$ & & & JWIC \\
\hline 1 & Liberty & Torreya St.Pk. & $21-I V-1984$ & Turnbow R.H. & blacklight trap & RHTC \\
\hline 3 & Liberty & Torreya st.Pk. & $25-I I I-1986$ & Hoebeke $\mathrm{E} . \mathrm{R}$. & flood plain & CUIC \\
\hline 1 & Liberty & Torreya St.Pk. & $25-$ III -1986 & Parkinson $\mathrm{J}$. & & CUIC \\
\hline 27 & Liberty & Torreya st.Pk. & $25-I I I-1986$ & Wheeler Q.D. & fung 1 under bark & JVMC \\
\hline 1 & Liberty & Torreya St.Pk. & $16-V I I-1987$ & Skelley P.E. & at light & PESC \\
\hline 3 & Liberty & Torreya st.Pk. & 27-III-I988 & Skelley P.E. & at light & PESC \\
\hline 1 & Madison & Madison, $12 \mathrm{mi} \cdot \mathrm{SE}$ & $28-29-V I I I-1949$ & Dybas H.S. & & FMNH \\
\hline
\end{tabular}




\section{Ischyrus guadripunctatus quadripunctatus (0livier) (Cont.)}

\begin{tabular}{|c|c|c|c|c|c|c|}
\hline I & Marion & Crtra, NW 24th Ave. & $15-V I-1991$ & Skillman F.w.Jr. & & PESC \\
\hline 2 & Marion & Ocala Forest & $4-I I-1978$ & Menezes $\mathrm{E} . \mathrm{B}$. & white fungus on $\log$ & DHHC \\
\hline 1 & Orange & oviedo, Univ. Central Fl.campus & $7-x I I-1979$ & Fullerton $\mathrm{s}$. & & SMFC \\
\hline 1 & Osceola & Kisaimmee & & Thaxter $R$. & & MC2C \\
\hline 1 & Polk & Lakeland & $16-$ I I I -1948 & Hussey R.F. & at light & UMHZ \\
\hline 1 & st.Johns & St. Augustine & $4-I I I-1940$ & Van Dyke & & CASC \\
\hline 3 & Suwannee & Suwannee R.St.Pk., $20 \mathrm{~km} \mathrm{NW}$ Live Oak & $10-I V-1987$ & Steiner W.E. & & USNM \\
\hline 2 & Volusia & Deland & III-1953 & Ramstadt H. & & FMNH \\
\hline 1 & Volusia & Enterprise & & & Schff.coll. & CASC \\
\hline 2 & Wakulla & Panacea & $24-31-V I I-1967$ & Hilfiker C. & & USNM \\
\hline USA : & Georgia & & & & & \\
\hline$\overline{1}$ & & & & Weyers & & ISNB \\
\hline 2 & & & & Bowditch F.C. & & $\mathrm{MC2C}$ \\
\hline 3 & & & & Morrison & & $2 \mathrm{MHB}$ \\
\hline 1 & & Bennington & & & & DENH \\
\hline 1 & & Dunwoody & & Menhinick E.F. & & osue \\
\hline 1 & Baker & Newton, Emory Univ.Field Stn. & $12-V I-1957$ & & & CMNC \\
\hline 1 & Chariton & Camp Cornelia, Suwanee Canal Rec.Area & $21-v-1988$ & Turnbow R.H. & MV o blacklight & RHTC \\
\hline 1 & Clarke & Athens & $27-V-1924$ & & & AMNH \\
\hline 2 & Clarke & Athens & $10-1 V-1964$ & Thewke S.E. & & UMRM \\
\hline 1 & clarke & Athens & $26-28-I V-1981$ & Brown S.N. & blacklight & UGCA \\
\hline 1 & clarke & Athens & $6-v-1986$ & McKinney $\mathrm{J}$. & & RFMC \\
\hline 1 & Deka1b & & $16-I V-1969$ & & & TAMU \\
\hline 1 & Dekalb & & $7-V I-1969$ & & & TAMU \\
\hline 1 & Deka lb & & $4-V I I-1970$ & & & TAMU \\
\hline 1 & Deka Ib & & $26-V I I-1970$ & & & TAMU \\
\hline 1 & Dekalb & & $1-V I I I-1971$ & Wappes J.E. & & TAMU \\
\hline 1 & Deka1b & & $8-V-1972$ & Wappes J.E. & uv light & TAMU \\
\hline 1 & Dekalb & Stone Mountain area & $16-I V-1969$ & Wappes J.E. & & JEWC \\
\hline 2 & Dekalb & Stone Moutain area & 15-IV-1972 & Wappes J.E. & & JEWC \\
\hline 2 & Effingham & & 21-VI I-1984 & Morris R.F. & & RFMC \\
\hline 1 & Lamar & & $29-I I I-1978$ & Morris R.F. & & RFMC \\
\hline 1 & Lamar & & 20-VI I I-1984 & Morris R.F. & & RFMC \\
\hline 1 & Lismon [?] & & $1-v-1983$ & Morris R.F. & & RFMC \\
\hline 1 & Pike & & $23-v-1983$ & Morris R.F. & & RFMC \\
\hline 1 & Upson & & $24-I V-1983$ & Morris R.F. & & RFMC \\
\hline 1 & Upson & Flint River & $5-I V-1986$ & Morria R.F. & & RFMC \\
\hline USA: & $\begin{array}{l}\text { Ware } \\
\text { Illinois }\end{array}$ & Okefenokee St.Pk. & $27-v-1990$ & Ford E.J. & light trap & EJFC \\
\hline 6 & & & & & & INHS \\
\hline 1 & & & & & & UMRM \\
\hline 3 & & & & & & $2 \mathrm{MHB}$ \\
\hline 1 & & & & & & USNM \\
\hline 3 & & & & Blanchard & & MC2C \\
\hline 1 & & & & Laurent $P$. & & ANSP \\
\hline 1 & & Maunie & 9-VIII-1937 & Dybas $H$. & & FMNH \\
\hline 2 & & northern & & & & INHS \\
\hline 1 & & northern & & Blanchard & & $\mathrm{MCZC}$ \\
\hline 1 & & southern & & Blanchard & & MC2C \\
\hline 3 & Adams & Quincy & & & & $\mathrm{MC2C}$ \\
\hline 1 & Adams & Quincy & $29-I I I-1885$ & & & INHS \\
\hline 3 & Alexander & Cairo & 21-VI-1939 & Burks \& Riegel & & INHS \\
\hline 2 & Alexander & Horseshoe Lake & $19-I V-1986$ & Skelley P.E. & & EIUC \\
\hline 1 & Calhoun & Kampsville & $25-V I-1931$ & Frison et al. & & INHS \\
\hline 1 & Champaign & & $23-I V-1960$ & Campbell J.M. & under bark & CNCI \\
\hline 1 & Champaign & & $1-V I I-1977$ & Barney R.J. & & RJBC \\
\hline 1 & Champaign & & $5-V I-1965$ & Lawaon H.R. & & $\operatorname{cscc}$ \\
\hline 1 & Champaign & Homer & $19-V I I-1924$ & & & INHS \\
\hline 1 & Champaign & Homer & $11-V I-1931$ & Mohr & & INHS \\
\hline 5 & Champaign & Urbana & & & & INHS \\
\hline 2 & Champaign & Urbana & & & H. Kahl coll. & AMNH \\
\hline 2 & Charpaign & Urbana & & & H. Kahl coll. & ICCM \\
\hline 1 & Champaign & Urbana & & Kahl H. & & AMNH \\
\hline 1 & Champaign & Urbana & 3-VI I I-1926 & Frankenfeld J.C. & & FSCA \\
\hline 1 & Clark & Clarkaville, N.of, Rocky Branch Creek & $4-V I I I-1988$ & Skelley P.E. & blacklight & PESC \\
\hline 1 & coles & & $21-I V-1967$ & DeHollander & & EIUC \\
\hline 1 & Coles & & $1-V I I I-1968$ & Mertz C.J. & student coll. & EIUC \\
\hline 1 & Coles & & $20-X I-1970$ & Corrigan $\mathrm{J}$. & student coll. & EIUC \\
\hline 1 & Coles & Charleston & $7-v$ & & & EIUC \\
\hline 1 & Coles & Charlestion & $2-V 11-1939$ & Lowrie D.C. & & FMNH \\
\hline 1 & Coles & Charleston & $v-1954$ & Hebert P. & & EIUC \\
\hline 1 & Coles & Charleston & $26-V I I-1989$ & Funk R.C. & at light & EIUC \\
\hline 1 & Coles & Charleston & 15-16-VIII-1990 & Goodrich M.A. & UV light trap & EIUE \\
\hline 1 & Coles & Embarras R. bluff & $12-V-1970$ & Decker & & EIUC \\
\hline 1 & Coles & Embarras R. bluff & $15-V I-1970$ & Decker & & EIUC \\
\hline 1 & Coles & Embarras R, floodplain & $28-I V-1970$ & Decker & & EIUC \\
\hline 1 & Coles & Embarras R. floodplain & $1-V I-1970$ & Decker & & EIUC \\
\hline 1 & coles & Enbarras R. floodplain & 10-VIII-1970 & Decker & & EIUC \\
\hline 1 & Cook & Chicago & & Dunicel J. & & FMNH \\
\hline 1 & Cook & Chicago & $6-X I I-1927$ & & & INHS \\
\hline 1 & Cook & Des Plaines, Carle woods & $11-V I I-1964$ & Suter W. & & WS IC \\
\hline 1 & Cook & Palog Hills & $31-v-1981$ & Watrous L.E. & drift at stream edge & FMNH \\
\hline 1 & Cook & Palos Park & $8-V I I-1911$ & Gerhard W.J. & at light & FMNH \\
\hline 1 & Cook & Thatcher woods, River Forest & $23-x-1980$ & & under loose bark & FMNH \\
\hline 1 & Douglas & & $28-V-1965$ & Lawson H.R. & & $\operatorname{cscc}$ \\
\hline 1 & Frank1in & zeigler & $12-V I-1932$ & Rarlovic J. & & USNM \\
\hline 1 & Gallatin & Pound's Hollow & $14-V I-1990$ & Goodrich M.A. & blacklight trap & EIUC \\
\hline 2 & Hancock & A.L.Kibbe Life Sci.sta. & $14-16-V I-1971$ & Sedman $Y$. & & WIUE \\
\hline 2 & Hancock & A.L.Kibbe Life Sci.sta. & $26-28-V I-1971$ & Sedman $Y$. & & WIUC \\
\hline
\end{tabular}




\section{Ischyrus guadripunctatus quadripunctatus (olivier) (Cont.)}

\begin{tabular}{|c|c|c|c|c|c|c|}
\hline 3 & Hancock & A.L.Kibbe Life sci.sta. & $16-V I I-1971$ & Sedman $Y$. & & WIUC \\
\hline 5 & Hancock & A.L.Kibbe L1fe Sci.sta. & $19-24-V I-1978$ & sedman $Y$. & & WIUC \\
\hline 3 & Hancock & A.L.Kibbe Life Sci.sta. & $30-V I-1978$ & Mattson $\mathrm{J}$. & & WIUC \\
\hline 4 & Hancock & A.I.Kibbe Life Sc1.Sta. & $1-V I I-1978$ & student coll. & & WIUC \\
\hline 2 & Hancock & A.L.Kibbe Life Sci.Sta. & $5-V I I-1978$ & student coll. & & WIUC \\
\hline 1 & Hancock & A.L.Kibbe life Sci.sta. & $7-V I I-1978$ & Mattson J. & & WIUC \\
\hline 2 & Hancock & A.L.Kibbe Life Sci.sta, & $11-V I I-1978$ & Sedman $Y$. & & WIUC \\
\hline 1 & Hancock & A.L.Kibbe Life Sci.Sta. & $26-V I I-1978$ & Sedman $Y$. & & WIUC \\
\hline 2 & Hancock & A.L.Kibbe Life Sci.sta. & $28-V I-1979$ & Sedman $Y$. & & WIUC \\
\hline 1 & Hancock & A.L.Klbbe Life sci.sta. & 5-VII-1979 & Sedman $Y$. & & WIUC \\
\hline 4 & Hancock & A.L.Kibbe life Sci.sta. & $9-13-V I I-1979$ & Sedman $Y$. & & WIUC \\
\hline 1 & Hancock & A.L.Kibbe Iife Sci.sta. & $21-v-1980$ & student coll. & & WIUC \\
\hline 3 & Hancock & A.l.Kibbe Life Sci.sta. & $27-28-v-1980$ & student coll. & & WIUC \\
\hline 1 & Hancock & A.L.Kibbe Life Sci.sta. & $4-V I-1980$ & student coll. & & wIUc \\
\hline 3 & Hardin & Elizabethtown & $22-V I-1922$ & T.E. \& R.D.G. & at light & INHS \\
\hline 1 & Jackson & & VIII-1971 & Adolphson P. & & SIUC \\
\hline 1 & Jackson & Carbondale & $23-I V-1957$ & Garrison J.D. & & SIUC \\
\hline 1 & Jackson & Carbondale & $29-I V-1957$ & Downer J.C. & & SIUC \\
\hline 1 & Jackson & Carbondale & $21-V-1957$ & Thomas D. & & SIUC \\
\hline 1 & Jackson & Carbondale & $1-v-1958$ & Yates R.W. & & SIUC \\
\hline 1 & Jackson & Carbondale & $9-V-1958$ & Holz B. & & SIUC \\
\hline 1 & Jackson & Carbondale & $16-I V-1960$ & Fulk B.R. & & SIUC \\
\hline 1 & Jackson & Carbondale & $22-I V-1960$ & Bender $M$. & & SIUC \\
\hline 1 & Jackson & Carbondale & $20-I V-1960$ & & & SIUC \\
\hline 1 & Jackson & Carbondale & $8-v-1960$ & Bender $M$. & & SIUC \\
\hline 1 & Jackson & Carbondale & $15-I I-1962$ & O'Dell D. & & SIUC \\
\hline 1 & Jackson & Carbondale & $14-V-1962$ & Helm F.E. & & SIUC \\
\hline 1 & Jackson & Carbondale & $11-V-1963$ & Cole V. & & SIUC \\
\hline 2 & Jackson & Carbondale & $21-V I-1963$ & Marek J.E. & & SIUC \\
\hline 1 & Jackson & Carbondale & $2-V-1964$ & ziech K. & & SIUC \\
\hline 1 & Jackson & Carbondale & $17-I V-1971$ & wortham $E$. & & SIUC \\
\hline 1 & Jackson & Glant City St.PK. & $5-V I I-1962$ & Campbell J.M. & & CNCI \\
\hline 1 & Jo Daviesa & Apple River Canyon St.Pk. & $14-16$-VIII-1946 & Dybas H.S. & & FMNH \\
\hline 1 & Johnson & Vienna & $16-v-1964$ & Montgmery R.A. & & SIUC \\
\hline 1 & Lasalle & Peru & $15-V I-1963$ & suter W. & old field sweep & WSIC \\
\hline 2 & Lasalle & Ottawa & $5-v-1946$ & Werner E.G. & & UAIC \\
\hline 1 & Lasalle & Starved Rock & $14-V I-1932$ & Doier 6 Pork & & INHS \\
\hline 1 & Macon & & $11-V-1980$ & Skelley P.E. & at light & PESC \\
\hline 1 & Macon & & $3-v-1982$ & Auten $\mathbf{R}$. & & PESC \\
\hline 1 & Macon & & $30-V I-1982$ & Auten $\mathrm{T}$. & & PESC \\
\hline 1 & Macon & & $9-V I I-1984$ & Skelley P.E. & at light & EIUC \\
\hline 1 & Marion & Kinmundy & $4-V-1962$ & Helm F.E. & & SIUC \\
\hline 1 & Marshall & Lacon & 13-VI-1929 & Barnes R.M. & & ISMS \\
\hline 2 & Marshall & Lacon & $4-V I I-1938$ & Barneg R.M. & & ISMS \\
\hline 1 & Marshall & Lacon & $9-V I I-1938$ & Barnes R.M. & & ISMS \\
\hline 1 & Marshall & Lacon & $10-V I I-1938$ & Barnes R.M. & & ISMS \\
\hline 1 & Marahall & Lacon & 4 -VI I I - 1938 & Barnes R.M. & & ISMS \\
\hline 2 & Marshall & Lacon & $4-V I I I-1938$ & Barnes R.M. & & ISMS \\
\hline 1 & Marahall & Lacon & $30-v-1939$ & Barnes R.M. & & ISMS \\
\hline 2 & Marshall & Lacon & $6-V I I-1939$ & Barnes R.M. & & ISMS \\
\hline 1 & Marshall & Lacon & $1-V I-1940$ & Barnes R.M. & & ISMS \\
\hline 1 & Marshall & Lacon & $29-I V-1941$ & Barnes R.M. & & ISMS \\
\hline 1 & Mason & Chautaugua Nat.Wldlf.Ref. & $28-V I-1978$ & Lundgren R.W. & sandy lake shore & RWLC \\
\hline 14 & Mason & Havana & 11-VIII & & under bark & INHS \\
\hline 1 & Mason & Havana & $3-V I-1905$ & & & INHS \\
\hline 12 & Mason & Havana & $11-$ VII I -1907 & & & INHS \\
\hline 2 & Mason & Havana & $11-V I I I-1907$ & & & USNM \\
\hline 2 & Massac & Ft.Massac St.Pk. & $3-v-1976$ & Lundgren R.W. & under bark of dead tree & RWLC \\
\hline 1 & McDonough & Macomb & 25-VII-1967 & gtudent coll. & & WIUC \\
\hline 1 & McDonough & Macomb & $7-V I-1970$ & Sedman $Y$ & & WIUC \\
\hline 1 & MCDonough & Mccomb & $11-V-1971$ & student coll. & & NCSU \\
\hline 4 & McDonough & Macomb & $5--1972$ & student coll. & & WrUC \\
\hline 1 & McDonough & Macomb & $24-V-1972$ & student coll. & & WIUC \\
\hline 6 & MeDonough & Macomb & $3-V I-1972$ & Sedman $X$ & & WIUC \\
\hline 1 & McDonough & Macomb & $9-I V-1975$ & Sedman $Y$. & & WIUC \\
\hline 1 & MCDonough & Macomb & $15-I V-1976$ & student coll. & & WIUC \\
\hline 1 & McDonough & Macomb & $15-V-1976$ & Sedman $Y$. & & WIUC \\
\hline 1 & McLean & Funks Grove & $17-x-1979$ & Lundgren R.W. & fungus covered $\log$ & RWLC \\
\hline 3 & Moultrie & & $16-v-1978$ & Quinn K.P. & student coll. & EIUC \\
\hline 1 & Peoria & Peoria, airport region & 3 -VIII-1941 & Hasbrouck F.F. & under bark & INHS \\
\hline 1 & Piatt & Monticello, Allertón Park & $25-I V-1964$ & Yamamoto $\mathrm{T}$. & & INHS \\
\hline 2 & Pope & & $1-3-V-1970$ & Funk R.C. & & EIUC \\
\hline 1 & Pope & Herod, $0.8 \mathrm{mi} . \mathrm{NW}$ & $3-V I-1986$ & Lisowsk1 E.A. & & INHS \\
\hline 1 & Putnam & & $23-I V-1933$ & Glenn M.O. & & INHS \\
\hline 2 & Putnam & & $29-V I-1931$ & Glenn M.O. & & INHS \\
\hline 3 & Rock I gland & Rock Island & $3-V I-1930$ & Frison Ross & & INHS \\
\hline 1 & Sangamon & springfield & $22-V-1974$ & suter w. & at light & WSIC \\
\hline 1 & Shelby & & $20-1 X-1985$ & Easlang $\mathrm{K}$. & gtudent coll. & EIUC \\
\hline 1 & Union & Giant city St.Pk. & $24-V I-1958$ & Dybas H. & at $11 \mathrm{ght}$ & INHS \\
\hline 1 & Union & Pine Hills & $6-v-1961$ & Landewe J.E. & & SIUC \\
\hline 1 & Union & Pine Hilla & 13-VII-1966 & Parsong D. & & SIUC \\
\hline 2 & Union & Pine Hills & $14-16$-VIII-1966 & Parsong $\mathrm{D}$. & & SIUC \\
\hline 1 & Union & Plne Hills & $26-V I I-1966$ & Parsons D. & & SIUC \\
\hline 2 & Union & Pine Hills & $5-v-1972$ & McPherson J.E. & & sive \\
\hline 1 & Union & Pine Hilla Rec.Area & 7 -VIII-1987 & skelley P.E. & at light & PESC \\
\hline 6 & Union & Holf Lake, $1.7 \mathrm{mi} . \mathrm{E}$. & $4-V I-1986$ & Lisowski E.A. & & INHS \\
\hline 5 & Union & Wolf Lake, Pine Hills & $22-v-1958$ & Dybas H.S. & Poria ambigua on beech & FMNH \\
\hline 3 & Union & wolf Lake, Pine Hills & $22-V I-1958$ & Dybas H.S. & Poria ambigua on beech & FMNH \\
\hline 14 & Union & Wolf Lake, Pine Hills & $26-V I-1958$ & Dybag H.S. & Poria ambigua on beech & EMNH \\
\hline
\end{tabular}




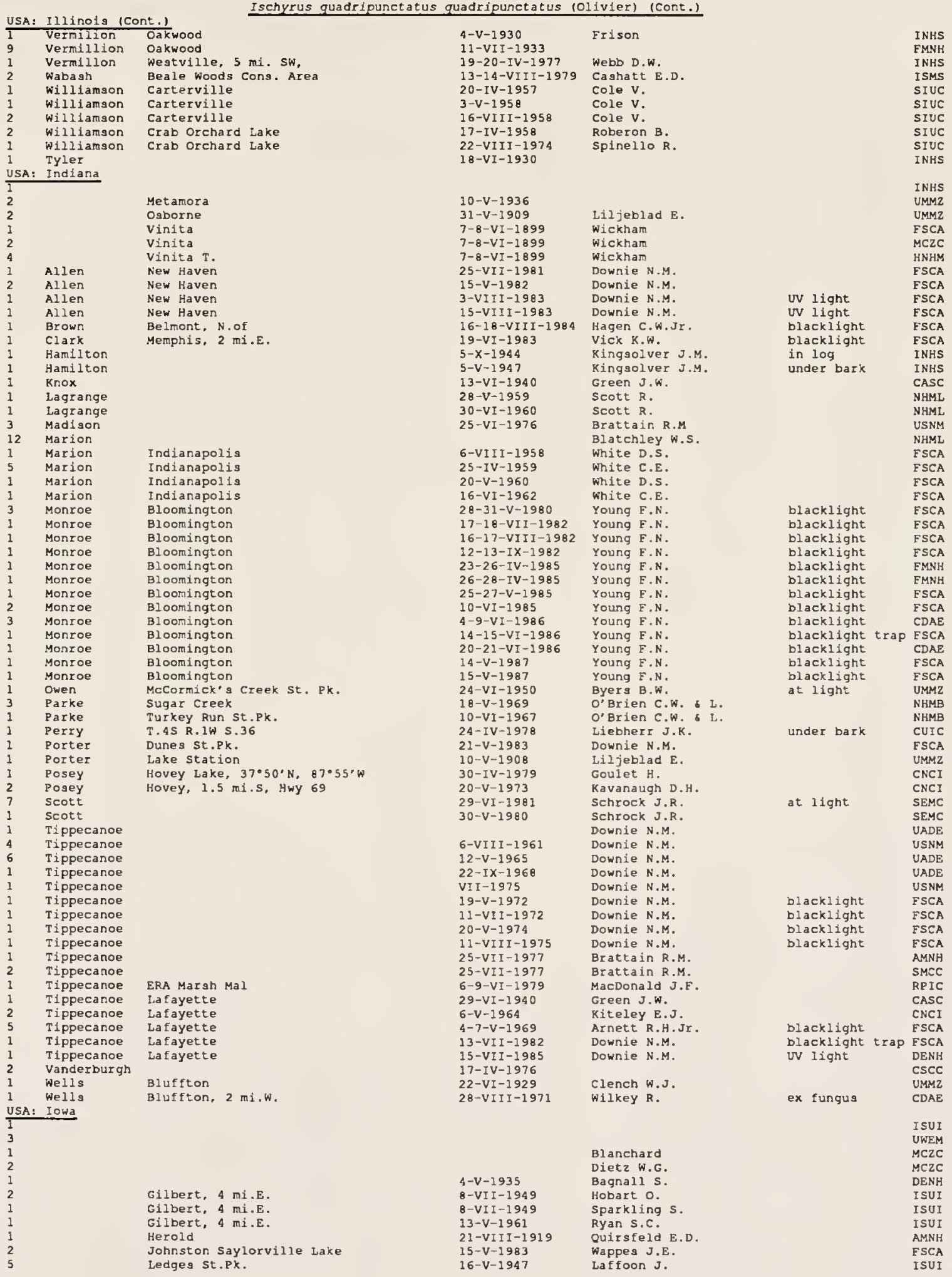




\begin{tabular}{|c|c|c|c|c|c|c|}
\hline USA: & Iowa icont. & & & & & \\
\hline $\begin{array}{l}1 \\
1\end{array}$ & $\begin{array}{l}\text { Boone } \\
\text { Clayton }\end{array}$ & Madrid & $19-V I I-1964$ & Baldwin $R$. & & ISUI \\
\hline 1 & Decatur & $\begin{array}{l}\text { Guttenberg } \\
\text { Leon }\end{array}$ & $8-V-1932$ & Soltau $\mathrm{H}$. & & FSCA \\
\hline 1 & Iowa & & $8-V-1932$ & Haa $\mathrm{a}$ L. & & $\begin{array}{l}\text { DENH } \\
\text { CSUC }\end{array}$ \\
\hline 1 & Iowa & Marengo, $3 \mathrm{mi} . \mathrm{S}$. & $11-x-1962$ & Olson L.G. & & ISUI \\
\hline 2 & Johnston & Saylor Lake & $15-v-1983$ & Wappes J.E. & & JEWC \\
\hline I & Johngton & Saylor Lake & $1-5-V I-1983$ & Schlefergtein R.H. & & JEWC \\
\hline 1 & Johngton & Saylor Lake & $16-30-V I-1983$ & Schlefergtein R.H. & & JEWC \\
\hline 1 & Johnston & Saylor Lake & $1-5-V I I-1983$ & Schieferstein R.H. & & JEWC \\
\hline 3 & Linn & Cedat Rapids & 4-VIII- 1926 & Harris H.M. & & ISUI \\
\hline 1 & Milla & Malvern & 12-VII-1971 & & light trap & ISUI \\
\hline 1 & Polk & Saylor Lake & $25-v-1985$ & Wappes Schieferatein & & JEWC \\
\hline 1 & Polk & Saylor Lake, west & $15-V I-1985$ & Wappes J.E. & & JEWC \\
\hline 2 & Story & Ames & & & & ISUI \\
\hline 1 & Story & Ames & & & & USNM \\
\hline 1 & Story & Ames & $7-I V-1924$ & & & ISUI \\
\hline 1 & Story & Ames & $20-I V-1925$ & & & ISUI \\
\hline 1 & Story & Ames & $15-V I-1925$ & G.W.M. & & ISUI \\
\hline 1 & Stary & Anes & $22-V-1927$ & & & ISUI \\
\hline 1 & Story & Ames & $20-I V-1928$ & T.A.R. & & IsUI \\
\hline 1 & story & Ames & $V-1930$ & Harria H.M. & & ISUI \\
\hline 1 & story & Ames & $11-v-1930$ & Ferguson F.P. & & ISUI \\
\hline 4 & story & Ames & 15-VII-1931 & Knight H.H. & & CNCI \\
\hline 5 & story & Ames & 15 -VII-1931 & knight H.H. & & ISUI \\
\hline 1 & story & Ames & 16-VII-1931 & & & ISUI \\
\hline 1 & Story & Ames & $11-I V-1932$ & Hixaon $\mathrm{H}$. & & ISUI \\
\hline 2 & story & Ames & $16-v-1932$ & Murphy $M$. & & ISUI \\
\hline 4 & story & Ames & $16-V-1932$ & Roudabush R.L. & & DEUN \\
\hline 1 & story & Ames & $5-v-1941$ & Smith L.F. & & ISUI \\
\hline 1 & story & Ames & $31-v-1947$ & Hicks E.A. & & ISUI \\
\hline 1 & story & Anea & $19-I V-1948$ & Tate W.H. & & ISUI \\
\hline 1 & story & Antes & $6-v-1948$ & Farrier & & ISUI \\
\hline 1 & story & Amea & $1-V I I-1948$ & Torgeson D. & & ISUI \\
\hline 2 & story & Ames & $7-v-1949$ & Ruhr C.E. & & ISUI \\
\hline 1 & story & Ames & $14-v-1950$ & Klonglan E. & & ISUI \\
\hline 1 & Story & Anes & $16-v-1950$ & Eckebreckt W.J. & & UASM \\
\hline 1 & Story & Ames & $12-V I-1950$ & Downes W.M.L. & & AMNH \\
\hline 1 & story & Ames & $14-v-1952$ & Madson J.B. & & ISUI \\
\hline 1 & Story & Anes & $19-I V-1955$ & Aburto S. & & ISUI \\
\hline 1 & story & Ames & $21-V-1955$ & Aborto $\mathrm{S}$. & & ISUI \\
\hline 1 & Story & Anes & $26-V-1958$ & King E. & & ISUI \\
\hline 3 & story & Ames & $6-v-1963$ & Hannah J. & & ISUI \\
\hline 1 & Story & Ames & $4-V I-1963$ & Richards L. & & ISUI \\
\hline 1 & Story & Ames & $15-V-1966$ & Bradley R. & & ISUI \\
\hline 1 & story & Amea & $22-v-1975$ & stewart A. & at light & ISUI \\
\hline 1 & story & Ames & $13-V I-1975$ & stewart A. & at light & ISUI \\
\hline 1 & story & Ames, Osborn & & & & ISUI \\
\hline USA: & Kansas & & & & & \\
\hline 1 & & & & & & FHNH \\
\hline 2 & & & & & & ICCM \\
\hline 1 & & & & Ashton & & PURC \\
\hline 2 & & & & Hauser $G$. & & 2MHB \\
\hline 1 & & Needsha & $16-v-1959$ & willis $\mathrm{H}$. & & FSCA \\
\hline 3 & & Osaga & $19-v-1923$ & Crevecoeur & & CASC \\
\hline 1 & Atchinson & Atchinson & $17-V I-1956$ & McReynolds J.W. & at light & FSCA \\
\hline 1 & Atchinson & Atchingon & $28-V I-1957$ & MCReynolds J.W. & & FSCA \\
\hline 4 & Cherakee & Columbus, $12 \mathrm{mi}$.W, $5 \mathrm{mi} . \mathrm{s}$ & $8-9-V I-1976$ & Hevel G.F. & & USNM \\
\hline 3 & Douglas & & & Dyche L.L. & & csuc \\
\hline 1 & Douglas & & $13-V I I-1950$ & Pine R.H. & & TAMU \\
\hline 1 & Douglas & Lawrence & $7-v-1961$ & Funk R.C. & & EIUC \\
\hline 1 & Douglas & Lawrence & $30-v-1961$ & Funk R.C. & & EIUC \\
\hline 1 & Douglas & Lawrence & $18-v-1967$ & & & FSCA \\
\hline 1 & Douglas & Lawrence, $6 \mathrm{mi} . \mathrm{NE}$ & $24-v-1959$ & McF arI and $\mathrm{N}$. & & LACM \\
\hline 1 & Labette & Oswego & 2-VII-196I & Hevel G.F. & at light & USNM \\
\hline 1 & Labette & Oswego & 29-I I I-1963 & Hevel G.F. & at light & USNM \\
\hline 3 & Labette & Parsons & $20-I V-1962$ & Hevel G.F. & & USNM \\
\hline 1 & Pottawatomie & & $18-I V-1955$ & MCReynolds J.W. & & FSCA \\
\hline 1 & Shawnee & Topeka & & & & $2 \mathrm{MHB}$ \\
\hline 2 & Shawnee & Topeka & & Hayward $R$. & & MC2C \\
\hline USA: & Kentucky & & & & & \\
\hline 1 & & & & Bowditch F,C. & & $\mathrm{MC2C}$ \\
\hline 1 & & & & Malkin & & FMNH \\
\hline 1 & & wycliffe & $11-V I-1907$ & & & USNM \\
\hline 2 & Chriatian & & $25-v-1960$ & Campbe11 J.M. & & AMNH \\
\hline 2 & Chrigtian & & $15-V I-1960$ & Campbel1 J.M. & & CNCI \\
\hline 1 & Green & Crailhope & $7-1 V-1947$ & cook C. & & MSUC \\
\hline 1 & Henderson & Henderson & $3-I V-1923$ & Marshall W.V. & & CUIC \\
\hline 3 & Henderson & Henderson & $8-I V-1923$ & Marshall M.Y. & & $\mathrm{CNCI}$ \\
\hline 1 & Jefferson & Valley station & $15-V-1987$ & Nichola B.C. & at $11 \mathrm{ght}$ & ULIC \\
\hline 12 & Laurel & Bald Rock & $11-V I-1978$ & Fischer R.L. & & MSUC \\
\hline 1 & Marshall & Aurora & $23-V I-1982$ & Goddara $G$. & & UMIC \\
\hline 1 & Meade & Otter Creek Park & $8-V-1987$ & Nichola B.C. & at light & ULIC \\
\hline 1 & Rowan & Morehead & 21-VI-1962 & Freeman \& Lewia & & $\mathrm{CNCI}$ \\
\hline 1 & Fayette & & $29-I V-1970$ & & & Ksuc \\
\hline 1 & Fayette & & $13-V I-1970$ & & & KSUC \\
\hline 2 & Pulaski & & $5-v-1970$ & & & ksuc \\
\hline 1 & Trigg & Land between the Lakes, Devils Elbow & $6-v-1986$ & Pollock D.A. & & DAPC \\
\hline
\end{tabular}




$26-V I-1983$
$26-V I I I-1971$
$7-V-1954$
$19-V I I-1944$
$V I-1930$
$14-V I-1930$
$16-V I-1930$
$19-V I-1930$
$27-V I-1930$
$10-V I I-1930$
$8-V I I I-1930$

6-VI-1971

24-III

17-VI-1981

5-V-1910

$25-\mathrm{v}-1982$

19-20-IV-1985

22-23-IV-1985

$27-V-1966$

23-VI II -1967

22-VI-1967

$7-\mathrm{V}$

1-VIII-1902

24-IX-1902

20-V-1903

28-IV-1905

2-VIII-1914

VI -1919

2-VI-1919

11-VII-1922

6-8-VII-1969

$18-V-1972$

$30-V I-1950$

$14-V I-1949$

25-VII-1947

28-XI I - 198

20-V-1982

12-II-1950

21-IV-1982

17-VI-1985

12-IV-1970

21-VII-1951

21-VII-1951

21-VII-1951

21-VI I I-195

21-VII-1952

21-VII-195?

$21-V-1983$

4-VII-1982

$23-\mathrm{v}-1907$

4-VIII-1938

$21-V I-1910$

$9-\mathrm{VI}-1973$

$21-24-V I-1977$

$1-V I I-1919$

$23-V-1985$

$30-I V-1948$

$20-v-1959$

$28-I V-1970$

19-VI-1955

21-VI-1966

27-VI-1966

22-VIII-1968

$14-V I I I-1969$

$30-V I I-1980$

$19-v-1975$

$12-1 X-1936$

$26-V-1921$

8-VI-1939

1-VIII-1942

7-VIII-1947

$10-V-1953$

27-VII-1909

7-IV-1947

2-IX-1947

25-VII-1948
Cars B.F.\& J.L.

obin

Dybas H.S.

Werner F.G

Glick P.A.

Frost C.A.

Gilck P.A.

Gilck P.A.

Glick P.A.

Hevel G.F.

Ford E.J.

Barber H.S

Staines C.L.Jr.

Staines C.L.JI.

staines C.L.Jr.

Ford E.J.

Gordon R.

Ford E.J.

McAtee M.L.

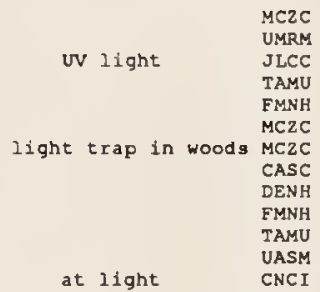

Schwarz Barber

Spangler P.J.

Hevel G.S. E.

Nelson G.H.

Chermock $F$

Dieke

Guarnieri $F$.

Hardy H.R.

Dozier B.K.

Steiner W.E.

Ford E.J.

Druckenbrod $M$.

NeIson G.H.

Nelson G.H.

Nelson G.H

Nelson G.H.

Nelson G.H.

Nelaon H.G.

Ford E.J.

steiner $W . E$.

light trap

blacklight

blacklight

blacklight

light trap

light trap

USNM

USNM

EJFC

FSCA
CNCI
CNCI

$\mathrm{CNC} 1$

EJFC

USNM

EJFC

USNM

USNM

at light USNM

USNM

USNM

USNM

USNM

USNM

powdery fungus on $\log$ GHNC

ICCM

at light USNM

under loose bark CUIC

under oak bark CDAE

USNM

light trap EJFC

AMNH

CNC I

powder fungi,black oak GHNC black oak fungus JMCC

powder fung1, black oak CNCI

light trap EJFC

C.F.B.

Hubbard Schwarz

USNM

Steyskal G.

Andrews A.W.

Giesbert E.

Liebherr J.K.

Hubbell T.H.

Giesbert $\mathrm{E}$.

Fischer R.L.

Donahue J.P.

Dawson A.D.

Evans E.D.

Fischer R.L.

Fischer R.L.

Fischer R.L.

Cowen C.P.

wolcott R.H.

Wol scott R.H.

Ruesink L.

Moore $S$.

Andrews A.W.

Andrews A.W.

Moore $S$.

INHS

USNM

UMMZ

UMM2

LACM

ov light CUIC

UMMZ

FSCA

MSUC

MSUC

MSUC

MSUC

AMNH

MSUC

MSUC

MSUC

DEUN

DEUN

blacklight CUIC

UMM2

UMM2

UMM2

UMM Z

UMM Z

UMM 2

CNCI

Liljeblad E.

steyskal $G$.

steyskal G

steyskal G.

LACM

LACM 
Ischyrus quadripunctatus guadripunctatus (0livier) (Cont.)

\begin{tabular}{|c|c|c|c|c|c|c|}
\hline I & & & & & & FMNH \\
\hline 8 & & Minneapolis & $30-v-1951$ & Kiteley E.J. & & CNCI \\
\hline 2 & & St. Paul & & & & INHS \\
\hline $\begin{array}{l}2 \\
\text { USA: }\end{array}$ & Houston & New Albin, IA, 3-6 mi.s & $30-v-1960$ & Raske A. & under bark & CNCI \\
\hline 1 & & Agr. Col. & $9-V-1921$ & Ware B.F. & & MUIC \\
\hline i & & Agr. Col. & $24-I I I-1922$ & Hull F.M. & & CUIC \\
\hline 1 & & state college & $31-I V-1951$ & Howell H.D. & & MUIC \\
\hline 1 & & State College & $23-I V-1973$ & Hepner L.W. & & MUIC \\
\hline 1 & & State college & $11-I V-1975$ & Snodgraga G. & & MUIC \\
\hline 1 & & state Line & $17-I I I-1931$ & Dietrich H. & & CUIC \\
\hline 1 & Adams & Natchez & $15-v-1977$ & Zuccaro A.E. & & UMIC \\
\hline 1 & Adams & Natchez & $22-V-1977$ & 2uccaro A.E. & & UMIC \\
\hline 2 & Adams & Natchez & $27-V-1977$ & Zuccaro A.E. & & UMIC \\
\hline 1 & Adams & Natchez & $30-v-1977$ & Zuccaro A.E. & & UMIC \\
\hline 1 & Amite & Mt.Nebo, $2.3 \mathrm{mi}$.NE Rosetta & $29-v-1988$ & Lago P.K. & & UMIC \\
\hline 1 & Baldwin & & $21-v-1965$ & McCoy J.R. & & MUIC \\
\hline 1 & Baldwin & Adaton & $15-$ I I I 1982 & Cross W.H. & blacklight trap & MUIC \\
\hline 1 & Baldwin & Gulf shores st.PK. & $18-V I-1984$ & Brown R.L. 6 B.B. & & MUIC \\
\hline 1 & Baldwin & starkvilie & $2-V I-1979$ & Snodgrasa G.L. & Incandegcent light & MUIC \\
\hline 1 & Baldwin & Tensaw, 1 mi.s & $11-V-1984$ & Harris s.c. & & UMIC \\
\hline 1 & Barry & Eagle Rock & $11-V I I I-1966$ & Eikwort G.s K. & & SEME \\
\hline 1 & Bolivar & Rosedale, 2 mi.w & $20-V I-1980$ & Lago P.K. & & UMIC \\
\hline 1 & Chicksaw & Van vleet, $11 \mathrm{mi} . \mathrm{Sw}$ & $22-v-1989$ & Lago P.K. & & UMIC \\
\hline 1 & Forregt & Hattiesburg. Camp Shelby & $5-1 I-1944$ & Michener C.D. & & AMNH \\
\hline 1 & George & Lucedale & 8-VIII-1929 & Dietrich H. & & $2 \mathrm{MHB}$ \\
\hline 1 & George & Lucedale & $30-x I I-1929$ & Dietrich H. & & CUIC \\
\hline 1 & George & Lucedale & 27 - I I I- 1930 & Dietrich $\mathrm{H}$. & & cuIc \\
\hline 1 & George & Lucedale & $18-I V-1930$ & Dietrich $\mathrm{H}$. & & cuIc \\
\hline 2 & George & Lucedale & $26-I-1931$ & Dietrich $\mathrm{H}$. & & curc \\
\hline 2 & George & Lucedale & $26-I-1931$ & Dietrich $\mathrm{H}$. & & $2 \mathrm{MHB}$ \\
\hline 1 & George & Lucedale & $28-I-1931$ & Dietrich $\mathrm{H.}$ & & $2 \mathrm{MHB}$ \\
\hline 1 & George & Lucedale & $5-V-1931$ & Dietrich H. & & CUIC \\
\hline 9 & George & Lucedale & $7-1 V-1932$ & Dietrich $\mathrm{H}$. & & curc \\
\hline 1 & George & Lucedale & $7-I V-1932$ & Dietrich $\mathrm{H}$. & & 2МHB \\
\hline 3 & George & Lucedale, $12 \mathrm{mi} . \mathrm{sW}$ & $23-I X-1983$ & Lago P.K. & & UMIC \\
\hline 1 & George & Lucedale, $12 \mathrm{ml}$.SW & $19-V-1987$ & Lago P.K. & & UMIC \\
\hline 1 & Hancock & Gainesville & $2-v-1966$ & Hepburn H.R. & & SEME \\
\hline 2 & Hinds & Jackson & $24-27-1 I I-1959$ & A.E.L. & & LACM \\
\hline 1 & Jackson & Gulf Isl.Nat.Sea. & $3-6-V I-1984$ & Brown R. & & MUIC \\
\hline 1 & Lafayette & & & Hull F.M. & & CNCI \\
\hline 1 & Lafayette & & $V-V I-1945$ & Hull F.M. & & CNCI \\
\hline 1 & Lafayette & oxford & 29 -I II-1971 & Mecraine $T$. & & UMIC \\
\hline 1 & Lafayette & Oxford & $14-V-1974$ & Dargt P.H. & & UMIC \\
\hline 1 & Lafayette & Oxford & $12-v-1975$ & Lago P.K. & & UMIC \\
\hline 1 & Lafayette & Oxford & $30-I I I=1977$ & Elliott S.C. & & UMIC \\
\hline 1 & Laf ayette & Oxford & $29-v-1977$ & Lago P. & & PKLC \\
\hline 1 & Lafayette & Oxford & $15-V I-1977$ & Lago P.K. & & UMIC \\
\hline 1 & Lafayette & Oxford & $12-V I I-1977$ & Lago P. & & PKLC \\
\hline 1 & Lafayette & oxford & $3-1 V-1978$ & Lago P.K. & & UMIC \\
\hline 1 & Lafayette & Oxford & $8-1 V-1978$ & Sanford D.F. & & UMIC \\
\hline 3 & Lafayette & oxford & $18-I V-1978$ & Lago P.K. & & UMIC \\
\hline 1 & Lafayette & Oxford & $30-I V-1978$ & Mann M.O. & & UMIC \\
\hline 1 & Lafayette & Oxford & $20-V I-1979$ & Lago P.K. & & UMIC \\
\hline 1 & Lafayette & Oxford & $7-I V-1980$ & Lago P.K. & & UMIC \\
\hline 1 & Lafayette & Oxford & 28 -I I I-1981 & Lago P.K. & & UMIC \\
\hline 1 & Lafayette & Oxford & $18-I V-1981$ & Lago P.K. & & UMIC \\
\hline 1 & Lafayette & oxford & $17-$ I I I-1982 & Lago P.K. & & UMIC \\
\hline 1 & Lafayette & Oxford & $6-V-1983$ & Lago P.K. & & UMIC \\
\hline 1 & La fayette & Oxford & 18 - I I I - 1984 & Lago P.K. & & UMIC \\
\hline 1 & Laf ayette & Oxford & S-IV-1986 & P.G.G. & & UMIC \\
\hline 1 & Lafayette & Oxford & $26-v-1986$ & Lago P.K. & & UMIC \\
\hline 1 & Lafayette & OxEord & $28-V I I-1987$ & Lago P.K. & & UMIC \\
\hline 2 & Laf ayette & Oxford & $18-I V-1989$ & Lago P.K. & & UMIC \\
\hline 1 & Lafayette & Oxford & $25-I V-1989$ & Lago P.K. & & UMIC \\
\hline 1 & Lafayette & oxford & $29-I V-1989$ & Lago P.K. & & UMIC \\
\hline 1 & Lafayette & Oxford & $3-v-1991$ & Weems H.V.Jr. & at light & FSCA \\
\hline 3 & Laf ayet te & Oxford, $5 \mathrm{mi} . \mathrm{E}$ & $18-V I-1977$ & Sanford D.F. & & UMIC \\
\hline 1 & Lafayette & Oxford, $5 \mathrm{mi} . \mathrm{E}$ & $7-1 V-1978$ & Sanford D.F. & & UMIC \\
\hline 2 & Lafayette & Oxford, $7 \mathrm{mi} . \mathrm{NW}$ & $19-V I I-1984$ & Lago P.K. & & UMIC \\
\hline 1 & Laf ayette & Oxford, $9 \mathrm{mi} . \mathrm{s}$ & 29 - I I I-1977 & Nolan R.L. & & UMIC \\
\hline 78 & Lafayette & Oxford, $11 \mathrm{mi}$.NW & $4-I V-1978$ & Hurdle S. \& D.F.Sanford & & UMIC \\
\hline 1 & Lafayette & Oxford, $11 \mathrm{mi} . \mathrm{NW}$ & $21-I V-1978$ & Lago $P$. & & PKLC \\
\hline 5 & Lafayette & Oxford, $11 \mathrm{mi} . \mathrm{NW}$ & $21-I V-1978$ & Lago P.K. & & UMIC \\
\hline 3 & Laf ayette & Oxford, $11 \mathrm{mi} . \mathrm{NW}$ & $25-V I I-1978$ & Lago P.K. & & UMIC \\
\hline 2 & Lamar & Baxterville, $12 \mathrm{mi} \cdot \mathrm{N}$ & $9-I V-1981$ & Lago P.K. & & UMIC \\
\hline 1 & Lauderdale & Meridian & $17-I V-1987$ & Davis L.R. & & FSCA \\
\hline 1 & Lefore & Greenwood & $8-I V$ & & at light & USNM \\
\hline 1 & Neshoba & Dixon, $1.5 \mathrm{mi} . \mathrm{N}$ & $9-V-1979$ & Lago P.K. & & UMIC \\
\hline 1 & Oktibbeha & Dorman Lake & 8 -III-1983 & Porter P. & & MUIC \\
\hline 2 & Perty & New Augusta & $12-I I-1931$ & Dietrich $\mathrm{H}$. & & CUIC \\
\hline 1 & Pontotoc & Pontotoc, I mi.N. & $21-V I-1977$ & Head R.B. & & UMIC \\
\hline 1 & Rankin & & $15-V-1963$ & Cambre L.A. & & osve \\
\hline 1 & Smith & L. Marathon $2 \mathrm{mi} . \mathrm{w}$. & $7-v-1980$ & Lago P.K. & & UMIC \\
\hline 1 & Tippah & Ripley & $1-v-1939$ & Stanford T.L. & & MUIC \\
\hline 1 & Tishomingo & Tishomingo st.Pk. & $17-V I-1977$ & Lago $P$. & & PKLC \\
\hline 1 & Үazoo & & III-1962 & Herrin C.C. & & BYUC \\
\hline
\end{tabular}




\begin{tabular}{|c|c|c|c|c|c|c|c|}
\hline 1 & & Bunker & 6-VIT-1972 & & & & \\
\hline 1 & & Lk. Ponme De Terr St.PK. (?] & $29-\mathrm{y}-1972$ & Thewke s.A. & & & UMRM \\
\hline 2 & & Mun...? & & & & & AMNH \\
\hline 1 & & Shpp [?] & $23-X I-1954$ & Davis P.D. & & & UMRM \\
\hline 1 & & Willard & $26-V I-1927$ & Brower A.E. & & & AMNH \\
\hline 1 & Bollinger & Duck Creek Wldlf. Area & $11-V I-1975$ & swadener S.O., & et al. & & UMRM \\
\hline 1 & Bollinger & Duck creek wldlf.Area & 10-VII-1975 & Swadener s.o.. & et al. & & UMRM \\
\hline 1 & Bollinger & Marble Hill & $12-X I I-1934$ & Swackhammer & & & UMRY \\
\hline 1 & Boone & & $19-x-1940$ & Robertg I. & & & UMRM \\
\hline 1 & Boone & & $6-I V-1975$ & Gillespie & & & WIUC \\
\hline 2. & Boone & Ashland & $28-V I I-1968$ & & & light trap & UMRM \\
\hline 1 & Boone & Aahland & $29-V I I-1968$ & & & light trap & UMRM \\
\hline 1 & Boone & Ashland & $4-V I I I-1968$ & & & light trap & UMRM \\
\hline 1 & Boone & Ashland & 17-VIII-1968 & & & light trap & UMRM \\
\hline 5 & Boone & Columbia & & & & & 2MHB \\
\hline 1 & Boone & Columbia & $8-V-1938$ & & & & UMRM \\
\hline 1 & Boone & Columbia & $15-V-1938$ & & & & UMRM \\
\hline 1 & Boone & Columbia & 20-VI I-1951 & Haseman L. & & & UMRM \\
\hline 1 & Boone & Columbia & $11-v-1953$ & Ross R.D. & & & UMRM \\
\hline 1 & Boone & Columbia & $24-I V-1954$ & Enns W.R. & & at $1 \mathrm{ight}$ & UMRM \\
\hline 1 & Boone & Columbia & $11-V I I-1954$ & Enns W.R. & & at light & UMRM \\
\hline 1 & Boone & Columbia & $6-V-1959$ & Woodson A.M. & & & UMRM \\
\hline 3 & Boone & Columbia & $10-V I I-1963$ & Wood F.E. & & & USNM \\
\hline 1 & Boone & Columbia & $v-1964$ & Wiobley R. & & under bark & UMRM \\
\hline 1 & Boone & Columbia & $2-V-1964$ & Wood F.E. & & & USNM \\
\hline 1 & Boone & Columbia & $20-v-1964$ & Truelsen $\mathrm{K}$. & & grass & UMRM \\
\hline 1 & Boone & Columbia & $1-I X-1964$ & Chandler J. & & & UMRM \\
\hline 1 & Boone & Columbia & 12-VIII-1965 & stryker R.G. & & & UMRM \\
\hline 1 & Boone & Columbia & $9-1 X-1965$ & Parshall A.E. & & fungus & UMRM \\
\hline 1 & Boone & Columbia & $10-1 X-1965$ & Schridt G.T. & & & UMRM \\
\hline 1 & Boone & Columbia & $21-1 X-1965$ & Ereeman M.E. & & & UMRM \\
\hline 1 & Boone & Columbia & 10-VII-1966 & Riddle D.D. & & & UMRM \\
\hline 1 & Boone & Columbia & $27-X I I-1967$ & & & light trap & UMRM \\
\hline 1 & Boone & Columbia & $28-X I I-1967$ & & & light trap & UMRM \\
\hline 1 & Boone & Columbia & $24-I V-1972$ & Riley T.J. & & & EGRC \\
\hline 3 & Boone & Columbia & $21-V-1974$ & Thewke S.E. & & light trap & UMRM \\
\hline 1 & Boone & Columbia & $20-V I-1977$ & Thewke S.E. & & blacklight trap & UMRM \\
\hline 1 & Boone & Columbia & $28-V I-1977$ & Thewke S.E. & & blacklight trap & UMRM \\
\hline 2 & Boone & Columbia & $10-I V-1978$ & Thewke S.E. & & & UMRM \\
\hline 1 & Boone & Columbia, $5 \mathrm{mi} . \mathrm{w}$ on Perche Creek & $11-V-1964$ & Wood F.E. & & & UMRM \\
\hline 2 & Boone & Columbla, 5 mi.w on Perche Creek & $16-V-1964$ & Wood F.E. & & & UMRM \\
\hline 1 & Boone & Columbla, nr.Rick Bridge on Rt.K. & $22-V-1978$ & Rice M.E. & & & UMRM \\
\hline 1 & Callaway & Fulton & $10-V I-1947$ & Thomas G.E. & over & ripe strawberry & UMRM \\
\hline 2. & Callaway & Fulton & $29-v-1949$ & Thomas G.W. & & & UMRM \\
\hline 1 & Cape Girard. & Cape Girardeau & $1-v-1938$ & Wingo $c$. & & & UMRM \\
\hline 1 & Charles & Dardeen slough & $30-X I-1954$ & charles B. & & & UMRM \\
\hline 1 & Clay & Coolie Lake & $2-V-1968$ & Heitzman $R$. & & & FSCA \\
\hline 1 & Cole & Jefferson City & $19-1 V-1968$ & Allen R.P. & & & CDAE \\
\hline 1 & Cooper & Boonville & $26-X I I I-1957$ & Wood F.E. & & light trap & UMRM \\
\hline 1 & Cooper & Boonville, Bell's Orchard & $24-X I I-1957$ & Wood F.E. & & & UMRM \\
\hline 2 & Cooper & Boonville, Bell Orchard & $18-V I I I-1959$ & Enns W.R. & & light trap & UMRM \\
\hline 1 & Jackson & & VI -1955 & Pine R.H. & & & TAMU \\
\hline 1 & Jackson & Independence & 12-VII-1969 & Heitzman $R$. & & & FSCA \\
\hline 1 & Jackgon & Independence & $21-V-1970$ & Heitzman R.L. & & & FSCA \\
\hline 1 & Jackson & Independence, Adair PK. & $3-V-1968$ & Heitzman J.R. & & & FSCA \\
\hline 2 & Jackson & Rayton & $15-v-1972$ & Nelgon G.H. & & at light & GHNC \\
\hline 1 & Jackson & Rayton & 13-VIII-1974 & Nelson G.H. & & uv light & GHNC \\
\hline 12 & Johnson & warrensburg & $19-V-1946$ & Malkin $\mathrm{B}$. & & & FMNH \\
\hline 1 & Newton & Neosho & & & intercepte & ed at Yermo, CA & CDAE \\
\hline 4 & Nodaway & Maryville & $21-V I-1933$ & & & & FMNH \\
\hline 1 & Phelps & Rolla, SW of, Mill Creek & $26-V-1979$ & Peck S.S J. & & UV light & $\mathrm{CNCI}$ \\
\hline 2 & Polk & & VII-1915 & & & & VPIC \\
\hline 1 & Randolph & Moberly, 1 mi.E. & $22-V I-1972$ & Riley R.G. & & & EGRC \\
\hline 2 & Randolph & Moberly, 1 mi.e. & 29-VII-1972 & Riley T.J. & & & EGRC \\
\hline 1 & Randolph & Moberly, 1 mi.E. & $23-V I I-1973$ & Riley R.G. & & & EGRC \\
\hline 3 & Randolph & Moberly, 1 ri.e. & $24-V I I-1973$ & Riley R.G. & & & EGRC \\
\hline 2 & Randolph & Moberly, 1 mi.E. & 25-VI I I-1973 & Riley R.G. & & & EGRC \\
\hline 2 & Randolph & Moberly, I mi.E. & 29-VI-1975 & Riley E.G. & & blacklight & UMPM \\
\hline 1 & Ripley & Doniphon & $17-V I-1972$ & Hardy H.R. & & white light & CDAE \\
\hline 1 & $s \cot t$ & Chaffee & 21-VI-1919 & Painter H.R. & & & USNM \\
\hline 1 & scott & Chaffee & 21-VI-1919 & Painter H.R. & fungus & covered stump & CNCI \\
\hline 1 & st. Louis & Howard Bend & $22-V I-1937$ & Gordon W.M. & & & CUIC \\
\hline 10 & St. Louls & Ranken & $23-V I-1935$ & Meiner E.P. & & & UMRM \\
\hline 3 & St. Loulg & St. Louis & & & & & ICCM \\
\hline 2 & St. Louls & St. Louis & $24-V I-1936$ & & & USDA trapa & UMRM \\
\hline 4 & St. Louis & Jefferson Barracks & $14-1 V-1919$ & Roelofs P.J. & & & I SNB \\
\hline 1 & stoddard & Puxico, $4 \mathrm{mi} . \mathrm{w}$, Mingo Wldlf.Ref. & $15-I V-1982$ & Heitzman R.L. & & blacklight & FSCA \\
\hline 2 & Wayne & Williamsville & $24-I V-1947$ & Becker E.C. & & under bark & UMRM \\
\hline USA: & Nebraska & & & & & & \\
\hline 1 & & Malcolm & $12-V I I-1909$ & Oertal C.R. & & & $\mathrm{MCZC}$ \\
\hline 2 & Ad ams & & $14-V I I-1986$ & springer C.A. & & vV $11 \mathrm{ght}$ & EIUE \\
\hline 1 & Adams & & $5-V I I-1985$ & Milligan $w$. & & & EIUC \\
\hline 1 & Adams & & $4-V I I-1987$ & springer C.A. & & UV light & EIUC \\
\hline 8 & Call & Louisville, Camp Kitaki & $4-V-1987$ & & & & DEUN \\
\hline 3 & Colfax & Schuyler, $4 \mathrm{mi} . \mathrm{w}$ & 8-VII-1992 & Schmidt D.A. & under bar & ck of rotten log & DEUN \\
\hline 13 & Dawson & & 5-VI I I-1989 & Springer C.A. & & & HCCA \\
\hline 7 & Dawson & Gothenburg & $11-V I I I-1988$ & springer C.A. & & uv light & HCCA \\
\hline 3 & Dawson & Lexington & $28-I V-1968$ & Ratcliffe B.C. & & under bark & VAIC \\
\hline 7 & Dawson & Lexington & $28-V I-1968$ & Ratcliffe B.C. & & & LACM \\
\hline
\end{tabular}




\begin{tabular}{|c|c|c|c|c|c|c|}
\hline 5 & Fillmore & Fairmont & 4-VTIT-1912 & Demong $\&$. & & \\
\hline 5 & Fillore & Fairmont & $4-\mathrm{VIT}-1912$ & Deming G.W. & & DEUN \\
\hline 2 & Jefferson & & $11-13-V I=1989$ & Soringer $\mathrm{c}$. & & DEUN \\
\hline 4 & Lancaster & Hickman & $19-V I-1969$ & Ratcliffe B.C. & & LACM \\
\hline 1 & Lancaster & Lincoln & & & & DEUN \\
\hline 1 & Lancaster & Lincoln & XII 1911 & & & DEUN \\
\hline 1 & Lincoln & North Platte & $3-1 X-1966$ & Ratcliffe B.C. & & LACM \\
\hline 4 & Nemaha & Peru & $v-1907$ & & & DEUN \\
\hline 4 & Nemaha & Peru & $v-1967$ & & & DEUN \\
\hline 4 & Nuckolla & Superior, 4 mi.E. & 26 -VII-1990 & springer C.A. & under bark of bur oak & HCCA \\
\hline 2 & Sarpy & Fontenelle Foreat & 11-VII-1969 & Ratcliffe B.C. & & LACM \\
\hline USA: & New Jersey & & & & & \\
\hline 1 & & springfield & VII -1910 & & & AMNH \\
\hline 1 & & Springfield & $I X-1913$ & We1sa H.B. & & AMNH \\
\hline 1 & & Westville & IV -1924 & Liebeck & & MCZC \\
\hline 1 & Bergen & & $2-V I I-1968$ & & & TAMU \\
\hline 1 & Cape May & Avalon & & Kamp & & ANSP \\
\hline 1 & Mercer & Princeton & $7-I X$ & Doolittle & & USNM \\
\hline USA: & New Mexico & & & & & \\
\hline 1 & Midalgo & Animas Mts., Godfrey Place & $8-V I I-1981$ & Dobrott s. & $1706 \mathrm{~m}$ & SMCC \\
\hline 3 & Hidalgo & Guadaloupe Canyon & $7-V I I I-1967$ & Smith J.W. & & TAMU \\
\hline 10 & Hidalgo & Guadalupe Canyon & 19-VIII-1967 & Andrews F.G. & & CDAE \\
\hline USA: & New York & & & & & \\
\hline 1 & & & & & & AMNM \\
\hline 5 & & & & & & HNHM \\
\hline 16 & & & & & & LACM \\
\hline 1 & & Bridgeport & $13-V I I-1915$ & & & USNM \\
\hline 1 & & Chaffee & $17-V I I-1939$ & Franclemont J.G. & & FSCA \\
\hline 1 & Cayuga & Fair Haven Beach St.Pk. & $8-V I-1968$ & Eickwort G. $6 \mathrm{~K}$. & & CUIC \\
\hline 1 & Jefferson & Picton Ialand, Clayton & $15-V I I-1958$ & Heineman $B$. & & AMNH \\
\hline 4 & Tompkins & Mchean Boga Reserve & $18-V I-1953$ & Spilman T.J. & & CUIC \\
\hline 2 & Tompkins & Mclean Boga Reaerve & $20-V I-1953$ & Spilman T.J. & & CUIC \\
\hline 1 & Tompkins & Mclean Bogs Reserve & $21-V I-1953$ & spilman T.J. & & CUIC \\
\hline 4 & Wayne & Newark & 1962 & Lenczy & & USNM \\
\hline 2 & Wayne & Newark & 1963 & Lenczy & & HNHM \\
\hline USA: & North Caroli & & & & & \\
\hline 1 & & $\bar{F}$ letcher & $13-v-1970$ & Lampert L.L. & light & JMCC \\
\hline 1 & & Southern Knotlis Igland & $12-V I I-1959$ & Morria J.P.E. & grass clumps on boarda & USNM \\
\hline 1 & Dare & Kill Devil Hilla & $23-26-v-1952$ & Arnett R.H.Jr. & woods at light & FSCA \\
\hline 1 & Durham & Durham & $V I-1971$ & Hughes $\mathrm{S}$. & blacklight & CDAE \\
\hline 6 & Edgecombe & Tarboro $10 \mathrm{~km} \mathrm{NNE}$ & $7-V I I-1983$ & Steiner $\mathbf{E}$. & & USNM \\
\hline 1 & Haywood & Lake Junalagka & 6 -VII -1983 & Weems H.V.Jr. & & FSCA \\
\hline 6 & Moore & Southern Pines & & & & INHS \\
\hline 1 & Moore & Southern Pines & $17-X I-1928$ & Manee & & INHS \\
\hline 1 & Wake & & $20-I V-1955$ & Mabeck D.M. & & FSCA \\
\hline USA: & North Dakota & & & & & \\
\hline 1 & Cass & & $3-v-1962$ & Gordon R. & & USNM \\
\hline 7 & Casa & & $16-1 X-1962$ & Gordon R. & & USNM \\
\hline USA: & Onio & & & & & \\
\hline 1 & & & & Pool G.J. & & NHML \\
\hline 1 & & John Bryan St.Pk. & $24-V I I I-1969$ & O'Brien L.6 C.W. & & USNM \\
\hline 1 & & St. Marys & & & & EMNH \\
\hline 3 & Athens & Athens & $25-I I I-1936$ & H.B. & & osuc \\
\hline 2 & clermont & & 23 -VII - 1937 & Wright J. & & UMM2 \\
\hline 1 & Delaware & & VI-1921 & Knull D.J. \& J.N. & & osuc \\
\hline 1 & Fairfleld & Lancaster, $10 \mathrm{mi} . \mathrm{s} .$, clear creek & $10-v-1974$ & Janus C.A. & & osuc \\
\hline 2 & Franklin & Canal Winchester & 23-VII-1985 & Clark S.M. & & PWKC \\
\hline 1 & Franklin & Columbus & $5-v-1924$ & Everly R.T. & & UAIC \\
\hline 1 & Franklin & Columbus & $2-V I-1937$ & Markos B.G. & & DENH \\
\hline 1 & Franklin & Columbus & $14-$ I I I-1961 & & & LACM \\
\hline 1 & Franklin & Columbus & $21-V I I-1986$ & Clark S.M. & & PWKC \\
\hline 1 & Franklin & Westerville & $4-V-1949$ & Sleeper E.L. & & osuc \\
\hline 1 & Guernsey & & $6-I X-1963$ & & & osuc \\
\hline 3 & Наmilton & & $3-V I-1935$ & Everly R.T. & & osuc \\
\hline 1 & Hamilton & Cincinatti & & & Schfi. coll. & CASC \\
\hline 4 & Hamilton & Cincinnati & & & Holland coll. & ICCM \\
\hline 4 & Hamilton & cincinnati & & Braun & & ANSP \\
\hline 1 & Mamilton & Cincinnati & $29-1 V-1901$ & Braun & & ANSP \\
\hline 2 & Hamilton & Cincinnati & 22 -VIII-1901 & Braun & & ANSP \\
\hline 1 & Hamilton & Cincinnati & IV -1934 & & & UMMZ \\
\hline 1 & Hamilton & Cincinnati & VII-1935 & & & UMMZ \\
\hline 1 & Hocking & & $6-I I-1961$ & Robertson $\mathrm{J}$. & & LACM \\
\hline 1 & knox & & $5-V I-1942$ & Strohecker H.F. & & ESCA \\
\hline 1 & Knox & Gambier & 17-VII - 1940 & & & CNCI \\
\hline 4 & Knox & Gambier & 17 -VII- 1940 & & & FSCA \\
\hline 1 & Knox & Gambier & $17-V I I-1940$ & & & LACM \\
\hline 1 & Licking & Reynoldaburg & $16-19-V I-1983$ & Miller R.S. & blacklight & TKPC \\
\hline 1 & Licking & Reynoldaburg & $14-15-V I-1989$ & Milier R.S. & blacklight & TKPC \\
\hline 1 & Muskingum & & & & & osuc \\
\hline 1 & Mugkingum & & $15-v-1935$ & & & osuc \\
\hline 6 & Ottawa & S.Basa Island, Put-in-Bay & $5-V I I-1983$ & Nichols S.W. & reared ex fungus & CUIC \\
\hline 1 & Paulding & Paulding Twp.Sec.28, Flat Rock Creek & $21-v-1934$ & Everly R.T. & & osuc \\
\hline 1 & Richland & & $6-V I I I-1968$ & & & osuc \\
\hline 1 & Ross & & $23-v-1967$ & Moore F.J. & & osuc \\
\hline 1 & Seneca & & $7-I V-1964$ & & & osuc \\
\hline 1 & Tugcasawas & & $11-V I-1974$ & Wheeler Q.D. & & CuIc \\
\hline 1 & Wayne & Wooster & $27-V-1899$ & & & osuc \\
\hline
\end{tabular}




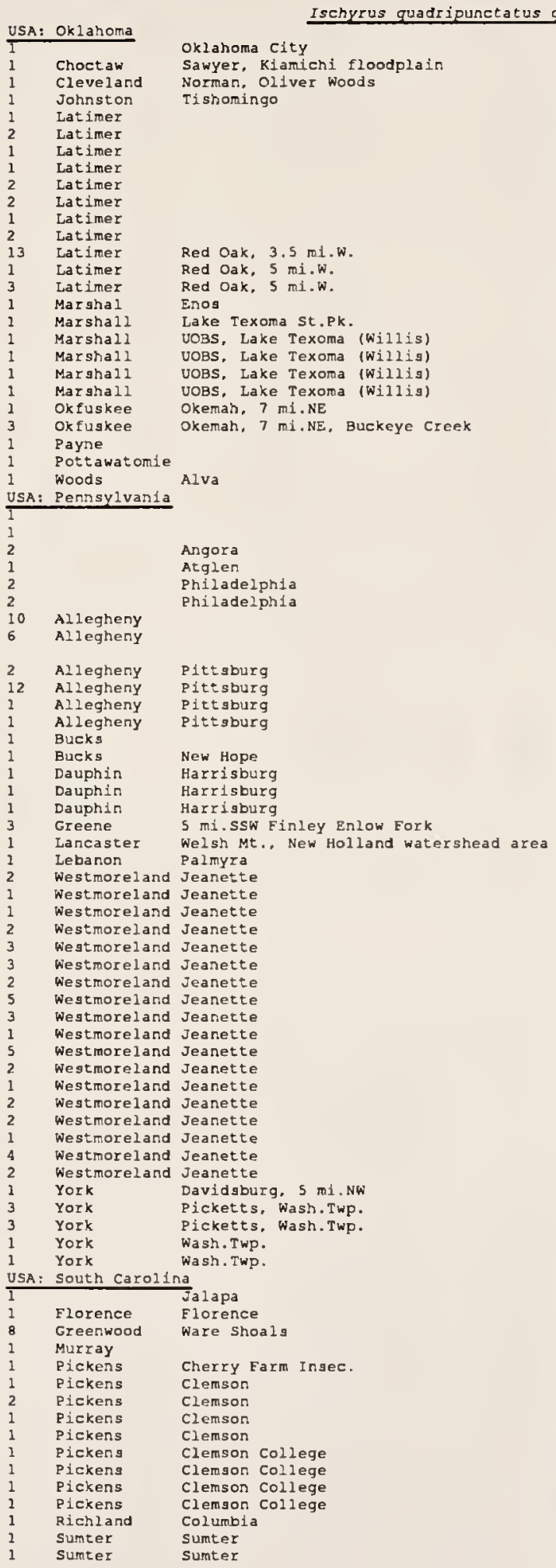

$\begin{array}{ll}\text { IO-VIII-1953 } & \text { Deonier C.E. } \\ \text { 17-VI-1968 } & \text { Suter W. } \\ 30-V I-1969 & \text { Suter W. } \\ 26-I V-1975 & \text { Shepard W.D. } \\ \text { VIII-1982 } & \text { Stephan K. } \\ \text { IV-1983 } & \text { Stephan K. } \\ \text { VI-1983 } & \text { Stephan K. } \\ \text { VII-1983 } & \text { Stephan K. } \\ \text { X-1983 } & \text { Stephan K. } \\ \text { IV-1985 } & \text { Stephan K. } \\ \text { IV-1986 } & \text { Stephan K. } \\ \text { V-1986 } & \text { Stephan K. } \\ 19-21-V-1989 & \text { Kovarik Stephen } \\ 2-I V-1978 & \text { Stephan K. } \\ 27-I V-1978 & \text { Stephan K. } \\ 26-V I I I & \text { Miller G.A. } \\ 18-20-V I-1989 & \text { Morris R.F. } \\ 18-I V-1968 & \text { Suter W. } \\ 16-V I-1968 & \text { Suter W. } \\ 11-V I-1969 & \text { Arnett R.H.Jr. } \\ 30-V I-1969 & \text { Suter W. } \\ 5-V I I-1972 & \text { Johnson J. } \\ 7-I X-1972 & \text { Johngon J. } \\ 1962 & \text { Reinert J. } \\ 2-V I-1974 & \\ 7-V-1965 & \text { Cochran J. }\end{array}$

$\begin{array}{ll}\text { subeortical log } & \text { AMNH } \\ \text { under bark } & \text { WSIC } \\ \text { bracket fungus } & \text { JLCC } \\ & \text { FSCA } \\ \text { mushroom on log FSCA } & \text { FSCA } \\ \text { blacklight } & \text { FSCA } \\ \text { under oak bark } & \text { FSCA } \\ \text { mushroom on log } & \text { FSCA } \\ & \text { FSCA } \\ & \text { FSCA } \\ & \text { PESC } \\ & \text { FSCA } \\ & \text { FSCA } \\ & \text { UMRM } \\ \text { REMC } \\ \text { at light } & \text { WSIC } \\ \text { at light } & \text { WSIC } \\ \text { at light } & \text { WSIC } \\ \text { at light } & \text { WSIC } \\ & \text { AMNH } \\ & \text { AMNH } \\ & \text { USNM } \\ & \text { ICCM } \\ \text { on dead tree } & \text { ASUT }\end{array}$

20-VI

Green J.W.

XI-1928 Weaver J.S.

23-VI-1980 Taylor P.

$9-V I-1989$

VIII

IX

$\mathrm{VI}-1902$

22-IX

14-V-1949

14-VIII- 1910

14-VIII-1910

$14-V I I I-1916$

$18-V-1989$

20-VI-1978

$28-V-1988$

$10-V_{I}$

20-VI

$6-V I I$

10-VII

21-VII

28-VII

2-IX

$4-I X$

$6-1 x$

$7-I X$

$2-1 x$

$10-I X$

$11-I X$

$14-I X$

$21-I X$

$10-X$

IX-1921

23-VII-1971

22-VII-195I

26-VII-195I

23-VI-1951

24-VI-195I

$12-V-1968$

24-VII-1930

$12-V I-1943$

$2-I X$

27-VI-1984

$30-I V-1956$

$30-V-1958$

$24-V I I-1960$

$30-I V-1975$

$21-V-192$

VI-1931

14-VI-1933

25-VII-1933

18 -III-1946

$20-x-1926$

20-IV-1973
$\mathrm{Kl}$ age $\mathrm{E}$. A .

Bowman J.R

Cazier M.H.

Kirk H.B.

Kirk H.B.

Rawling J.E.

Weaver J.S

Yackley W.H

Klages H.G.

Klageg H.C.

Klages H.C.

Klages H.G.

Klages H.G

Klages H.G

Klageg H.G.

Klages H.G.

Klages H.G.

Klages H.G.

Spangler P.J.

Spangler P.J.

spangler P.J.

spangler P.J.

spangler $P . J$.

Lampert L.L.

Cartwright 0.L.

Nicolay A.

Bowman J.R.

Hof fman $K$.

Donavan D.

Fox R.C.

Ableg J.R.

Berly J.A.

Dunavan D.

Cartwright O.L.

Cartwright C.L.

Choate P.M.
CASC

MCZC

DENH

OSUC

blacklight CUIC

ICCM

Klages coll. ICCM

Klages Col1. ICCM

Klages coll. ICCM

Klageg COL1. ICCM

ICCM

FMNH

FMN

CUIC

ICCM

DENH

ICCM

Klages col2. ICCM

KLages coll. ICCM

Klages Coll. ICCM

Klages coll. ICCM

Klages Coll. ICCM

Klages coll. ICCM

Klages coll. ICCM

Klages coll. ICCM

Klages coll. ICCM

Klageg coll. ICCM

Klages Col1. ICCM

Klages Coll. ICCM

Kla

Klages coll. ICCM

Klages coll. ICCM

$\mathrm{Klages}$ coll. ICCM

at light USNM

USNM

USNM

USNM

light JMCC

CUCC

USNM

blacklight trap CUCC

light trap eucc

ov light CUCC

TAMU

CUCC

cucc

USNM

CUCC

CUIC at light USNM

light trap MSUC 
Ischyrus quadripunctatus guadripunctatus (Olivier) (Cont.)

\begin{tabular}{|c|c|c|c|c|c|c|}
\hline \multirow{2}{*}{$\begin{array}{l} \\
3 \\
\text { USA: }\end{array}$} & & springfield & $18-V_{T}-1930$ & Severin H.L. & & SDSU \\
\hline & Tenne g gee & & & & & \\
\hline$I$ & Andergon & Oak Ridge & $4-V-1962$ & Lindsley D. & & CDAE \\
\hline 1 & Cannon & Weedbury & $27-I V-1990$ & Ford E.J. & light trap & EJFC \\
\hline 1 & DekaIb & & $1-V I 1 I-1975$ & Kondratieff $\mathrm{B}$. & & VPIC \\
\hline 1 & Greene & Greeneville & $20-I V-1955$ & Dozier B.K. & light trap & FSCA \\
\hline 1 & Henderson & Natchez Trace St.For. & $12-v-1968$ & Baker N.T. & & MSUC \\
\hline 1 & Lake & Reelfoot Lake & $2-V I-1954$ & Knull D.J. S J.N. & & osuc \\
\hline 2 & Lake & Tiptonville & $20-1 V-1935$ & & & FSCA \\
\hline 6 & Monroe & Jackson & $7-V I-1970$ & Wharton $B$. & & TAMU \\
\hline 1 & Montgomery & Clarksville & 13-VII-1915 & & & osuc \\
\hline 1 & Rutherford & Murphreesboro, Todd Lake & $20-v-1945$ & Wright $M$. & & NHML \\
\hline 1 & Shelby & Shelby For.st.Pk. & $7-V I-1971$ & Wildie $B$ & & MSUC \\
\hline 1 & Warren & Morrison & $9-I V-1921$ & Bottimer L.J. & & CNCI \\
\hline USA: & Texag & & & & & \\
\hline 2 & & & & & & ANSP \\
\hline 1 & & & & & & CUIC \\
\hline 1 & & & & & & FMNH \\
\hline 2 & & & & & & LACM \\
\hline 8 & & & & & & $\mathrm{MCZC}$ \\
\hline 1 & & Armatrong Ranch & $16-1 X-1960$ & & & CNCI \\
\hline 2 & & Camp Bullis & $19-V I-1963$ & Reinert J.F. & & USKM \\
\hline 3 & Anderson & & $27-X I-1059$ & Burke H.R. & & TAMU \\
\hline 1 & Andergon & Tennessee Colorys & $4-5-1 I I-1967$ & Blanchard A. & & USNM \\
\hline 1 & Anderson & Tennessee Colony & $12-v-1969$ & Blanchard A.\& M.E. & & USNM \\
\hline 1 & Bastrop & Smithfield, $5 \mathrm{~km} \mathrm{~N}$. & $31-$ I I I-1983 & Rawlings J.E. & & ICCM \\
\hline 2 & Bexar & San Antonio & $22-$ I I I-1958 & Lawrence J.F. & & MC2C \\
\hline 1 & Bexar & San Antonio & $22-I I I-1958$ & Lawrence J.F. & & TAMU \\
\hline 1 & Bexar & San Antonio & $31-$ II I-1979 & Hoebeke Carter & & CUIC \\
\hline 2 & Bexar & San Antonio & $22-v-1981$ & Thomas R.R. & & TAMU \\
\hline 1 & Bosque & clifton & $31-v-1907$ & & & UASM \\
\hline 2 & Brazos & & $20-$ I I I -1957 & & & TAMU \\
\hline 1 & Brazos & & 8-VII-1959 & Burke H.R. & light trap & TAMU \\
\hline 1 & Brazos & & $22-V I I-1960$ & & & TAMU \\
\hline 1 & Brazos & & $9-I X-1960$ & Welso S.G. & & MSUC \\
\hline 2 & Brazos & Bryan & $8-I V-1968$ & schaf fner J.R. & at light & TAMU \\
\hline 1 & Brazos & Bryan & $25-V-1974$ & Schaffner J.C. & at $11 \mathrm{ght}$ & TAMU \\
\hline 4 & Brazos & Bryan, $1.5 \mathrm{mi} . \mathrm{w}$. & $28-31-$ I I I-1980 & Turnbow R.H. & blacklight trap & RHTC \\
\hline 4 & Brazos & college station & $11-I V-1928$ & & & TAMU \\
\hline 1 & Brazos & College station & $9-v-1930$ & Joneg S.E. & light trap & TAMU \\
\hline 1 & Brazog & College station & $19-V-1933$ & Rienhard H.J. & light trap & TAMU \\
\hline 1 & Brazos & College station & $12-I V-1960$ & Welso S.G. & & MSUC \\
\hline 1 & Brazos & College station & $21-X I-1962$ & Sterling W.L. & & TAMU \\
\hline 1 & Brazos & College station & $26-x-1963$ & Schaffner J.C. & blacklight & TAMU \\
\hline 2 & Brazos & College station & $1-V I-1970$ & Board V.v. & blackllght & TAMU \\
\hline 1 & Brazos & College station & $10-v-1970$ & Murray R.R. & & TAMU \\
\hline 1 & Brazos & College station & 16-I I I-1974 & Ashe J.S. & & TAMU \\
\hline 1 & Brazos & College station & $12-18-I V-1975$ & Jackman J.A. & at $1 \mathrm{ight}$ & TAMU \\
\hline 2 & Brazos & College station & $15-I I I-1977$ & Jackman J.A. & & TAMU \\
\hline 1 & Brazos & College station & $3-1 X-1978$ & Peigler R.S. & at light & TAMU \\
\hline 1 & Brazos & College station & $18-I I I-1979$ & Agrew C.W. & & TAMU \\
\hline 1 & Brazos & College station & $31-I I I-1979$ & Agnew C.W. & & TAMU \\
\hline 1 & Brazos & College station & $2-12-$ I I I-1982 & Wharton $R$. & Malaise trap & TAMU \\
\hline 1 & Brazos & college station & $16-I V-1982$ & Kovarık P.W. & incandescent Iight & TAMU \\
\hline 1 & Brazos & Edge & $27-x-1974$ & Brooks G.W. & & P WKC \\
\hline 1 & Brazog & Edge & $16-I V-1978$ & Bagar D.S. & & TAMU \\
\hline 2 & Caldwell & Luling, Palmetto swamp st.Pk. & $15-I X-1942$ & Ross E.S. & & CASC \\
\hline 1 & Cameroon & & $19-x-1961$ & Eads R.B. & & csuc \\
\hline 1 & Cameroon & Brownsville & $15-v-1935$ & KnUII J.N. & & osuc \\
\hline 1 & Cameroon & Browngville & $12-V I-1968$ & Board v.v. & & TAMU \\
\hline 3 & Cameroon & Browngville & $15-$ I I I-1972 & Graham H.M. & light trap & MSUE \\
\hline 1 & Cameroon & Los Fresnos & 15-III-1972 & Graham H.M. & light trap & MSUC \\
\hline 1 & Cameroon & Sabal Palm Grove Sanct., nr.s most & $19-20-V I-1981$ & Turnbow R.H. & blacklight & TAMU \\
\hline 1 & Cass & Atlanta & $26-V-1964$ & stephan $\mathrm{K}$. & & FSCA \\
\hline 3 & Colorado & & $14-I V-1922$ & wiley $B$. & & SEMC \\
\hline 1 & Coma 1 & Honey Creek Nat. Concervancy & 18 - III-1984 & Cicero J.M. & & JMCC \\
\hline 1 & Coma 1 & New Braunfels & & & Schff.coll. & CASC \\
\hline 1 & Crosby & & $29-30-I V-1963$ & Beamer R.B. \& L.O. & & SEMC \\
\hline 2 & Dallas & & $12-I I I-1939$ & Maxwell R.E. & & INHS \\
\hline 1 & Dallas & & 12 - III-1939 & Maxwell R.E. & & UASM \\
\hline 10 & Dallag & Dallas & & & & $\mathrm{MCzC}$ \\
\hline 1 & Dallas & Dallas & & & & $2 \mathrm{MHB}$ \\
\hline 6 & Fannin & & $10-I V-1938$ & Strandtmann R.W. & & osuc \\
\hline 1 & Gonzales & Gonzales & $4-I V-1920$ & D.B. & & ISUI \\
\hline 1 & Gonzales & Palmetto St.Pk. & $14-v-1985$ & Rawling J.E. & & ICCM \\
\hline 2 & Gonzolas & Gonzales, Palmetto st.Pk. & $1-I V-1979$ & Hoebeke \& Carter & & CUIC \\
\hline 1 & Hardin & Beech Creek & $19-11 I-1978$ & Hagen $\$$ Andow & & cuIC \\
\hline $\bar{I}$ & Hardin & Beech Creek & $23-I I I-1978$ & Hagen \& Andow & & CUIC \\
\hline 10 & Harris & Houston & $22-v-1905$ & Shoemaker F.H. & & DEUH \\
\hline 1 & Harris & Katy & II -1971 & stephan $K$. & & FSCA \\
\hline 1 & Hidalgo & Bentsen Rio Grande St.Pk. & $17-V-1972$ & Giesbert E. & & LACM \\
\hline 2 & Hidalgo & Bentsen Rio Grande St.Pk. & $18-24-V I I-1972$ & & & FMNH \\
\hline 1 & Hidalgo & Bentsen Rio Grande St.Pk. & $26-28-V I-1973$ & & & NCSU \\
\hline 2 & Hidalgo & Bentsen Rio Grande St.Pk. & VII-1975 & & & USHM \\
\hline 2 & Hidalgo & Bentsen Rio Grande St.Pk. & $16-V I I-1975$ & Wheeler Q.D. & & CUIC \\
\hline 1 & Hidalgo & Bentgen Rio Grand St.Pk. & $17-I V-1984$ & Nelson G.H. & Uv light & GHNC \\
\hline 1 & Hidalgo & Mercedes & $22-23-I-1974$ & Moody $\mathrm{s}$ & leaf litter & TAMU \\
\hline 1 & Jasper & B.A.Stenhagen Lake & $28-v-1977$ & Riley R.G. & blacklight & EGRC \\
\hline
\end{tabular}


Ischyrus quadripunctatus quadripunctatus lolivier) (Cont.)

\begin{tabular}{|c|c|c|c|c|c|c|}
\hline 1 & Jasper & Town Bluff (Dam B) & $6-V I-1967$ & Blanchard A.\& M.E. & & USNM \\
\hline 1 & Jeff Davia & Davig Mt.St.Pk. & $18-21-V I I-1973$ & Hovore E.T. & & ESCA \\
\hline 2 & Jeff Davis & Ft. Davis & $4-V I-1950$ & Johnston E.C. & & CNCI \\
\hline 2 & Jeff Davis & Et. Davis & $30-v-1959$ & Howden Becker & & $\mathrm{CNCI}$ \\
\hline 1 & Jeff Davis & Et. Davis, Limpia Canyon St.Pk. & 16-VII-1969 & suter w. & at $1 \mathrm{ight}$ & WSIC \\
\hline 1 & Jeff Davis & Et. Davis, Limpia Canyon & 26-VII-1979 & Wappes J.E. & & JEWC \\
\hline 1 & Jeff Davis & Prude Ranch & $16-V I-1988$ & Morrig R.F. & & RFMC \\
\hline 1 & Kerr & Kerrville, Guadeloupe River & $25-v-1983$ & Olson $\mathrm{C}$. & & UAIC \\
\hline 1 & Kimble & Junction & $24-V I I I-1958$ & Weems H.V.Jr. & at light & ESCA \\
\hline 1 & Limestone & Mexia & $2-V I I-1937$ & & light trap & TAMU \\
\hline 1 & Litaestone & Mexia, St.Pk. Sur. [?] & $15-x-1937$ & & light trap & TAMU \\
\hline 3 & Lubbock & Lubbock & $3-1 X-1975$ & Bush $E$. & & PESC \\
\hline 1 & Montgomery & The Woodlands & $18-V I-1977$ & Wappes J.E. & & JEWC \\
\hline 1 & Mont gomery & The Woodlands & $1-8-V I I-1977$ & Wappes J.E. & & ESCA \\
\hline 1 & Montgomery & The Woodlands & $1-6-V I I-1977$ & Wappes J.E. & & JEWC \\
\hline 1 & Montgomery & The Woodlands & $20-26-V I I-1977$ & Wappes J.E. & & ESCA \\
\hline 1 & Montgomery & The Woodlands & $4-7-1 X-1977$ & Wappes J.E. & & JEWC \\
\hline 1 & Montgomery & The Woodlands & $19-111-1978$ & Wappes J.E. & & TAMU \\
\hline 1 & Mont gomery & The woodl ands & $20-23-I V-1978$ & Wappes J.E. & & TAMU \\
\hline 1 & Montgomery & The Woodlands & $12-X I-1978$ & Wappes J.E. & & JEWC \\
\hline 1 & Montgomery & The woodlands & 31 -III- 1979 & Wappes J.E. & & JEWC \\
\hline 1 & Montgomery & The woodlands & 31-III- 1979 & Wappes J.E. & & TAMU \\
\hline 1 & Montgomery & The Woodlands & $19-v-1979$ & Wappes J.E. & & ESCA \\
\hline 1 & Montgomery & The woodlands & $1-1 V-1980$ & Wappes J.E. & & JEWC \\
\hline 1 & Morrig & Daingerfield & $13-V I I-1937$ & & & TAMU \\
\hline 1 & Morris & Daingerfield & $14-V I I-1937$ & & & TAMU \\
\hline 1 & Morris & Daingerfield & $18-V I I-1937$ & & & TAMU \\
\hline 6 & Nacogdoches & Lufkin, $15.4 \mathrm{mi}, \mathrm{E}$, Etoile Pk. & $28-V I I-1975$ & Ashe J.S. & & TAMU \\
\hline 1 & Panola & Carthage & $8-v-1952$ & Cazier M. & & AMNH \\
\hline 2 & Real & Leakey, 6 mi.se & $1-V I I-1971$ & NeIson G.H. & at light & GHNC \\
\hline 1 & San Patricio & sinton, Welder Refuge & $18-v-1976$ & Gordon R. & ov $11 \mathrm{ght}$ & USNM \\
\hline 1 & Smfth & Tyler St.Pk. & $9-V I I-1968$ & Heitzman $R$. & & ESCA \\
\hline 1 & sterling & Water City, 8 mi.w. & $14-V I-1987$ & Morris R.F. & & RFMC \\
\hline 2 & Travis & Austin & & & & USNM \\
\hline 1 & Travis & Austin & $x-1900$ & & & USNM \\
\hline 1 & Travis & Austin & $11-16-x-1985$ & Rawling Davidson & $140 \mathrm{~m}$ & ICCM \\
\hline 1 & Tyler & Town Bluff (Dan B) & $11-I I I-1966$ & & & LACM \\
\hline 3 & Tyler & Town Bluff (Dam B) & 3-III-1967 & Blanchard $\mathrm{A}$. & blacklight & USNM \\
\hline 20 & Tyler & Warren & $17-I V-1971$ & Blanchard A.\& M.E. & & USNM \\
\hline 2 & Uvalde & Concan & 6-VII-1936 & Beamer J.D. & & UASM \\
\hline 4 & victoria & Victorla & $29-I V-1916$ & Mitchel J.D. & rotten $\log$ & USNM \\
\hline 1 & walker & stubblefield Lake & $3-1 V-1977$ & Peigler R.S. & & TAMU \\
\hline 2 & Walker & Stubblefleld Lake St.Rec Area & $10-X I I-1980$ & Kovarik P.W. & & TAMU \\
\hline 1 & Williamson & Georgetown & $17-I V-1937$ & Milne L.J. & & DENH \\
\hline 1 & williamson & Georgetown & $28-I V-1937$ & Milne L.J. & & DENH \\
\hline 1 & Wflliamson & Taylor & $25-I I I-1963$ & Hafernik J.E. & & TAMU \\
\hline 1 & willtamson & Taylor & $12-v-1965$ & Hafernik J.E. & & TAMU \\
\hline 1 & williamson & Taylor & $18-v-1968$ & Hafernik J.E. & & TAMU \\
\hline USA: & virginia & & & & & \\
\hline 4 & & & & & & MCZC \\
\hline 4 & & Glencarlyn & $14-V I-1910$ & & & USNM \\
\hline 1 & Falyfax & Alexandria & $14-V I-1910$ & & & CUIC \\
\hline 2 & Ea土rfax & Alexandria & $14-V I-1910$ & Shoemaker $\mathrm{E}$. & & AMNH \\
\hline 3 & Eairfax & Alexandria & $18-V I-1910$ & & & AMNH \\
\hline 3 & Fairfax & Alexandria & $18-V I-1910$ & & & cUIC \\
\hline 4 & Fatefax & Mt. Vernon & $23-V I-1916$ & & & UASM \\
\hline 1 & Fa 1 rfax & Mt. Vernon & $26-V I-1916$ & & & eUIC \\
\hline 1 & Fairfax & Mt. Vernon & $15-V I-1917$ & Nicolay A. & & USNM \\
\hline 1 & Eairfax & Mt. Vernon & 11-VII-1942 & Nicolay A. & & USNM \\
\hline 1 & Isle wright & Holland & 2-VIII-1924 & Burt J.G. & blacklight trap & VPIC \\
\hline 1 & Is le wright & Holland & 25-VII-1955 & & & VPIC \\
\hline 11 & James Clty & Norge & 9-VIII-1942 & Schwab E.M. & & USNM \\
\hline 1 & Montgomery & Longshop & $29-V-1962$ & Vockeroth J.R. & & CNCI \\
\hline 1 & Nansemond & Lake Drummond, Dismal Swamp & $7-8-V I I-1962$ & Gurney A.B. & & USNM \\
\hline 4 & Nelson & & $27-V I-1919$ & Robingon $w$. & & USNM \\
\hline USA: & West virginia & & & & & \\
\hline$\overline{2}$ & Kanawha & Charleston & $23-V-1987$ & Thomas M.C. & at light & PPCD \\
\hline 1 & Kanawha & Charleston & $29-v-1987$ & Thomas M.C. & at light & PFCD \\
\hline 3 & Kanawha & Guthrie & $15-v-1990$ & clark S.M. & & PPCD \\
\hline 1 & Kanawha & Kanawha & $22-v-1992$ & clark S.M. & & PFCD \\
\hline 2 & Kanawha & Saint Albans & $15-v-1970$ & Cole A.E. & blacklight & PPCD \\
\hline 1 & Logan & Chlef Logan St.Pk. & $14-I X-1990$ & Clark S.M. & & PFCD \\
\hline 2 & Mason & Lakin & $19-v-1989$ & Hagenbuch B.E. & blacklight & PPCD \\
\hline 1 & Mason & Mcclintic wldlf.sta. & $6-V I I I-1980$ & Coffman C.C. & malaise trap & PFCD \\
\hline 1 & Ohio & Valley Grove & $29-v-1989$ & Hagenbuck B.E. & & PPCD \\
\hline 1 & Preston & & $16-v-1974$ & Milier A.R. & blacklight & PPCD \\
\hline USA: & Wisconsin & & & & & \\
\hline I & $\overline{\mathrm{DOO}}$ & & $23-V I-1933$ & & & UWEM \\
\hline 1 & Rock & & 1896 & Chope E.B. & & FMNH \\
\hline 1 & Wood & Griffith St. Nurgery & $28-V I-1947$ & Shenefelt R.D. & & UWEM \\
\hline 1 & Wood & Griffith St. Nursery & $11-V I I-1947$ & sherefelt R.D. & & UWEM \\
\hline \multirow{2}{*}{\multicolumn{7}{|c|}{ Venezuela }} \\
\hline & & & & & & \\
\hline$\overline{1}$ & & & & & & NHMB \\
\hline 1 & & & & & & NHML \\
\hline 1 & & & & & & $\mathrm{ZMHB}$ \\
\hline
\end{tabular}


Ischyrus guadripunctatus guadripunctatus (0livier) (Cont.)

\begin{tabular}{|c|c|c|c|c|c|c|c|}
\hline \multicolumn{2}{|c|}{$\begin{array}{l}4 \\
\text { Venezuela: Portugu }\end{array}$} & $\begin{array}{l}\text { suapure, Caura R. } \\
\text { uesa }\end{array}$ & $13-21-V I-1899$ & Klages E.A. & & & CUIC \\
\hline \multicolumn{2}{|c|}{ Veneruela: zulia } & Guanare & $12-1 X-1957$ & Malking $\mathrm{B}$. & & at light & CAsC \\
\hline \multicolumn{2}{|c|}{1} & Embalse Cachiri & $18-V I-1976$ & Menke A.s. & & & USNM \\
\hline \multicolumn{8}{|c|}{ Ischyrus quadripunctatus chiasticus Boyle } \\
\hline \multirow{2}{*}{\multicolumn{2}{|c|}{$\begin{array}{l}\text { Mexico: Cninuanua } \\
23 \\
\text { Mexico: Morelos }\end{array}$}} & Los Chinacas, 4 mi.N., & $9-10-V I I-1989$ & Mccleve s. & $4910^{\prime}$ & ov light & PESC \\
\hline & & Yecora, Sonora, $6 \mathrm{mi} . \mathrm{s}$ & $2-3-V I I-1990$ & Mccleve s. & $5740^{\prime}$ & ov light & PESC \\
\hline \multicolumn{2}{|c|}{$\begin{array}{l}\text { Mexico: Nayarit } \\
\end{array}$} & Cuernavaca, $4.4 \mathrm{mi} . \mathrm{E}$ & $27-29-V I I-1976$ & Pelgler et al. & & at light & TAMU \\
\hline & co: Sinaloa & Compostela & $27-V I I-1954$ & Cazier M. & & & AMNH \\
\hline 1 & & Venedio & $17-V I-1918$ & Van Dyke & & & CASC \\
\hline Mes & co: Sonora & Venodio & $17-V I-1918$ & & & & USNM \\
\hline$\overline{2}$ & & Coyote, $7 \mathrm{~km} \cdot \mathrm{N}$ & $26-V I-1981$ & Mecleve s. & $1200 \mathrm{~m}$ & at light & SMCC \\
\hline 1 & & Huicoche, $3.2 \mathrm{mi}$. NW & $11-13-V I I-1989$ & Mccleve S. & $5170^{\circ}$ & uV light & SMCC \\
\hline 1 & & Imuris, 9 mi.NNE & $7-11-V I I-1958$ & Alcorn J.D. & & & SEMC \\
\hline 3 & & Moctezuma, $17 \mathrm{~km} . \mathrm{sw}$ & $21-28-V I I-1980$ & Mccleve s. & $944 \mathrm{~m}$ & at light & SMCC \\
\hline 2 & & Moctezuma, $17 \mathrm{~km} . \mathrm{sw}$ & $27-V I-1981$ & Mccleve s. & $944 \pi$ & at 1 ight & SMCC \\
\hline 1 & & Palm Canyon, $17 \mathrm{mi}$. E.Magdalena & 4-VIII-1981 & Thomas D. & & & UAIC \\
\hline 2 & & Sierra los Ajon, N.end, Canyon de Evans & $28-V I I I-1970$ & Roth V. & & & AMNH \\
\hline $\begin{array}{l}4 \\
\text { US }\end{array}$ & Arizona & Yecora, $4 \mathrm{~mL}$. NE & $30-V I-1990$ & Mccleve S. & $5400^{\circ}$ & UV light & SMCC \\
\hline 1 & & Huachuca Mts. & $1-V I I I-1927$ & Readio P.A. & & & $\mathrm{CNCI}$ \\
\hline 1 & & Huachuca Mts. & $19-V I I I-1950$ & KnuIl D.J. & & & OSUC \\
\hline 2 & & Huachuca Mts.., Sunnyside Canyon & $1-I X-1970$ & Stephan K. & & & FSCA \\
\hline 1 & & Santa Catalina Mts.. Molino Canyon & $20-I X-1969$ & Stephan K. & & & FSCA \\
\hline 1 & & Santa Catalina Mts..Pepper Sauce Canyon & $17-V I I I-1924$ & Martin J.o. & & & CNCI \\
\hline 4 & Cochise & Aravaipa Canyon & 16-19-VII-1973 & Goodrich M.A. & & & EIUC \\
\hline 1 & Cochise & Chiricahua Mts, Portal & 13-VIII-1971 & Knu11 D.J. & & & osuc \\
\hline 1 & Cochise & Chiricahua Mts, nr. Portal & $9-V I I I-1966$ & Beard R.G. & & UV light & CUIC \\
\hline 1 & Cochise & Chiricahua Mta., Paradise & 22-VIII -1927 & Kusche J.A. & $5000-6$ & $000^{\circ}$ & CASC \\
\hline 1 & Cochise & Chiricahua Mts., stewart Campground & 6-VII-1977 & Nelson G.H. & & UV light & GMNC \\
\hline 1 & Cochise & Chiricahua Mts.. Stewart Campground & 19-VII-1986 & Nesion G.H. & & ov light & GMNC \\
\hline 1 & Cochise & Chiricahua Mts., Sunnyflat & $28-29-V I I-1989$ & Bousquet $Y$. & & & CNCI \\
\hline 1 & Cochise & Douglas & 30-VIII-1959 & Russell J.H. & & at light & USNM \\
\hline 1 & Cochise & Guadaloupe Mts., Guadalupe Canyon & $24-V I I I-1978$ & Olson $\mathrm{C}$. & & blacklight & UAIC \\
\hline 1 & Cochise & Guadalupe Canyon & VIII -1972 & & & & USNM \\
\hline 14 & Cochise & Guadelupe Canyon & 1 -VII-1976 & Junp $P$. & $4300^{\prime}$ & & LACM \\
\hline 1 & Cochise & Guadalupe Canyon & 1-VII-1976 & Mccleve s. & & at light & VAIC \\
\hline 1 & Cochige & Guadalupe Canyon & 8-VII-1976 & Mccleve s. & & at light & AMNH \\
\hline 1 & Cochise & Guadalupe Canyon & 15-VII-1976 & Mccleve s. & & at light & AMNH \\
\hline 1 & Cochtse & Guadalupe Canyon & $30-V I-1977$ & Mccleve s. & & at $11 \mathrm{ght}$ & AMNM \\
\hline 1 & Cochise & Guadalupe Canyon & 1-VII-1977 & McCleve S. & & at light & AMNH \\
\hline 1 & Cochise & Guadalupe Canyon & 2-VIII-1977 & Mccleve s. & & at light & AMNH \\
\hline 3 & Cochise & Guadalupe Canyon & 2-VIII-1977 & Mccleve S. & & at $11 \mathrm{ght}$ & SMCC \\
\hline 1 & Cochise & Guadalupe Canyon & 8-VIII-1983 & Olson $\mathrm{C}$. & & & UAIC \\
\hline 4 & Cochise & Guadalupe Canyon, $30 \mathrm{mi}$.E.Douglas & $25-V I I-1985$ & Lago P. & & & PKLC \\
\hline 3 & Cochise & Guadalupe Canyon, $32 \mathrm{mi}$.E.Douglas & 14 -VIII-1 967 & Beard R.G. & & UV light & CUIC \\
\hline 1 & Cochise & Guadalupe Canyon, $1.3 \mathrm{mi} . \mathrm{NE}$ of entry & $12-V I I-1966$ & Beard R.G. & $4200^{\circ}$ & uv light & CUIC \\
\hline 8 & Cochise & Huachuca Mts.. Bear Canyon & $8-I X-1958$ & Menke s stange & & & LACM \\
\hline 1 & Cochise & Huachuca Mts.. Ash Canyon & 7-VIII - 1991 & Valentine B.D. & & & CDAE \\
\hline 1 & Cochise & Huachuca Mts.. Ash Canyon & 10-VIII-1991 & Valentine B.D. & $5100^{\circ}$ & & CDAE \\
\hline 1 & Cochise & Huachuca Mts.. Agh Canyon Rd. & 2-5-VI I I - 1989 & Bousquet $\mathrm{Y}$. & & & CNCI \\
\hline 1 & Cochise & Peloncilla Mts. & 31-VII-1975 & Mccleve s. & & at light & SMCC \\
\hline 10 & Cochise & Peloncilla mts. & $1-V I I-1976$ & McCleve S. & & at light & SMCC \\
\hline 1 & Cochise & Peloncilla Mts. & $26-V I-1977$ & Mccleve S. & & at light & SMCC \\
\hline 1 & Cochise & Peloncilla Mts. & 15-VII 1978 & Mccleve s. & $1300 \mathrm{~m}$ & at light & SMCC \\
\hline 1 & Cochise & Peloncilla Mts. & $6-V I I I-1981$ & McCleve S. & $1300 \mathrm{~m}$ & at light & SMCC \\
\hline 2 & Cochise & Peloncilla mts. & $17-V I I I-1981$ & Mccleve s. & $1300 \mathrm{~m}$ & at light & SMCC \\
\hline 6 & Cochise & Portal & 3-VIII I-1964 & Puckle J. & $4700^{\circ}$ & at light & ASUT \\
\hline 1 & Cochise & Portal & 20-VII-1965 & Rosenberg & & & USNM \\
\hline 1 & Cochiae & Portal & VI I -1968 & Lenczy & & & USNM \\
\hline 1 & Cochise & Portal, $5 \mathrm{mi} . \mathrm{w}$. & 25-VII 1969 & Kosztarab M. & $5400^{\circ}$ & blacklight & VPIC \\
\hline 1 & Cochise & Sierra viata & $29-V I I-1963$ & Sternitzky R.F. & & & CNCI \\
\hline 1 & Coconino & Sedona & $26-V I-1957$ & Butler G. & & & UAIC \\
\hline 1 & Gila & Globe & $8-V I I I-1949$ & Werner F.G. & & & UAIC \\
\hline 1 & Gila & Globe & 12-VIII-1952 & Parker F.M. & & at light & UAIC \\
\hline 1 & Gila & Globe & 14-VIII-1952 & Parker F.H. & & at light & UAIC \\
\hline 3 & Gila & Globe & 17-VIII-1952 & Parker F.M. & & at light & UAIC \\
\hline 1 & Gila & Globe & 23-VIII-1952 & Parker F.H. & & at light & UAIC \\
\hline 1 & Gila & Globe & $24-V I I-1955$ & Parker F.S. & & & UAIC \\
\hline 1 & Gila & Globe & 23-VIII-1957 & Parker F.M. & & at light & UAIC \\
\hline 1 & Gila & Globe & $31-V I I-1983$ & Parker F.S. & & & UAIC \\
\hline 1 & Gila & Roosevelt, $12 \mathrm{mi}$.NE, Tonto Nat. For. & VII -1972 & Rosenburg & & & USNM \\
\hline 1 & Gila & San Carlos & $11-V I I-1936$ & Parker & & & UAIC \\
\hline 1 & Graham & Aravaipa Canyon & 8-12-VIII-1975 & McCleve $s$. & & at light & AAIC \\
\hline 2 & Graham & Aravaipa Canyon & 12-VIII 1975 & Mccleve S. & & at light & SMCC \\
\hline 3 & Graham & Aravaipa Canyon & $24-V I I-1976$ & Campbell J.M. & $900 \mathrm{~m}$ & & CNCI \\
\hline 3 & Graham & Aravaipa Canyon & $24-V I I I-1976$ & Chandler D.S. & $3050^{\circ}$ & uv ilght & UAIC \\
\hline 1 & Graham & Aravaipa Canyon, $17.7 \mathrm{~km}$-N.Klondyke & 24-VII-1976 & Ball G.E. & & uv light & UASM \\
\hline 10 & Graham & Aravaipa Canyon, Turkey Creek & $24-27-V I I-1989$ & Bousquet $Y$. & & & CNCI \\
\hline 2 & Graham & Turkey Creek I mi. s. Arav.ck. & 11-VIII-1975 & Mccleve S. & & at light & SMCC \\
\hline
\end{tabular}


Ischyrus quadripunctatus chiasticus Boyle (Cont.)

\begin{tabular}{|c|c|c|c|c|c|c|c|c|}
\hline 1 & Green & Iee & Eagle Creek, Honeymoon Cpqd. & $27-V I I T-1979$ & 01 gon $\mathrm{C}$. & & & \\
\hline 2 & Maricc & opa & sunflower, sycamore creek & 18 -VII-1985 & Lago $P$. & & & PKLC \\
\hline 3 & Pima & & Arivaca, $4 \mathrm{mi} . \mathrm{S}$. . Fragulta Wash & $10-V I I-1977$ & Mccleve s. & & at light & SMCC \\
\hline 1 & Pima & & Arivaca, 5 mi.w. & $4-1 X-1965$ & Jump P.M. & & & LACM \\
\hline 6 & PIma & & Baboquivari Mts. & & Snow F.H. & & & SEMC \\
\hline 3 & Pina & & Baboquivar1 Mts. & 1924 & Poling o.c. & & & CUIC \\
\hline 1 & P1ma & & Baboquivari Mts.. Brown's Canyon & $8-V I-1952$ & Cazier M. & & & AMNH \\
\hline 1 & Pima & & Baboquivari Mts.. Brown's Canyon & $28-V I I-2952$ & Leech H.B. & & & CASC \\
\hline 1 & Pima & & Baboquivar1 Mts.. Brown's Canyon & $29-V I I-1952$ & Leech H.B. & & & CASC \\
\hline 1 & Fima & & Babogulvar1 Mts.. Brown's Canyon & $30-V I I-1952$ & Leach H.B. & & & UASM \\
\hline 1 & Pima & & Baboqulvari Mts., Brown's Canyon & $30-V I I-1952$ & Leech H.B. & & & AMNH \\
\hline 1 & Pima & & Baboquivari Mts., Brown's Canyon & $30-V I I-1952$ & Leech H.B. & & & CASE \\
\hline 1 & Pima & & Baboguivari Mts.. Brown's Canyon & $4-V I I I-1962$ & Werner F.G. & & ov light & UAIC \\
\hline 1 & Plma & & Baboquivari Mta.. Sabino Canyon & $31-V I I-1979$ & Mccleve s. & $1243 \pi$ & at 1 ight & SMCC \\
\hline 2 & Pima & & Madera Canyon & $1-2-I X-1954$ & Menke s stange & & & LACM \\
\hline 1 & Pina & & Madera Canyon & $7-11-V I I-1973$ & Wappes J.E. & & & JEWC \\
\hline 8 & P1ma & & Madera Canyon & VII-1975 & Lenczy & & & USNM \\
\hline 1 & Pima & & Madera Canyon & VII-1979 & Lenczy & & & USNM \\
\hline 1 & Pima & & Madera Canyon & VII-1982 & Lenczy & & & USNM \\
\hline 1 & Pima & & Santa Rita Mts. & $24-V I I-1927$ & Beamer R.H. & & & SEMC \\
\hline 1 & Plma & & Santa Rita Mto., Box Canyon & $25-\operatorname{VIII}-1949$ & Martin L.M. & & & LACM \\
\hline 1 & Pima & & Santa Rita Mta., Madera Canyon & $1-5=1 X-1957$ & Martin L.M. & & & LACM \\
\hline 1 & Pima & & Santa Rita Mts.. Madera Canyon & $9-V 1 I I-1961$ & Nelson G.H. & & at light & GHNC \\
\hline 1 & Pinal & & Devila Canyon Us -60 & $26-V I I-1989$ & Warner w.B. & & at light & PESC \\
\hline 1 & Santa & cruz & Atasco Mts. & 6 -VIII-1961 & Andrew $9 . G$. & & & CDAE \\
\hline 2 & Santa & Cruz & Atascosa Mts.., Sycamore Canyon & 12-VII-1977 & Mccleve S. & & at light & SMCE \\
\hline 1 & Santa & Crur & Canelo & $23-V I I I-1956$ & Morley & & at $1 \mathrm{ight}$ & UAIC \\
\hline 1 & Santa & Cruz & Lochiel, $2 \mathrm{mi.E}$ & $8-I X-1958$ & Menke stange & & & LACM \\
\hline 5 & Santa & cruz & Madera Canyon & 2-VIII-1960 & Wood K.L. & & blacklight & BYUC \\
\hline 1 & Santa & Cruz & Madera Canyon & $4-V I I-1975$ & Cicero J. & & & JMCE \\
\hline 1 & Santa & cruz & Madera Canyon & $9-V I I-1975$ & cicero J. & & & JMCC \\
\hline 1 & Santa & Cruz & Madera Canyon & $11-V I I-1975$ & Cicero J. & & & JEWC \\
\hline 1 & Santa & cruz & Madera Canyon & $18-V I I-1978$ & Gllbert A.J. & & blacklight & CDAE \\
\hline 2 & Santa & Cruz & Nogales & 12 VIII-1906 & Nunenmacher E.W. & & & FMNH \\
\hline 1 & Santa & cruz & Nogales & 22-VIII-1906 & Nunenmacher $F . W$. & & & FMNH \\
\hline 2 & Santa & cruz & Nogalea & 29-VIII-1959 & & & & UAIC \\
\hline 2 & Santa & Cruz & Nogalea & 30-VIII-1906 & Nunenmacher $\mathrm{F} . \mathrm{W}$. & & & EMNH \\
\hline 2 & Santa & Cruz & Nogales & $1-1 X-1906$ & Nunenmacher $\mathrm{E} . \mathrm{W}$. & & & EMNH \\
\hline 1 & Santa & Cruz & Nogales & $5-1 X-1906$ & Koebele & & & $\mathrm{ICCM}$ \\
\hline 1 & Santa & crur & Nogales & $6-I X-1906$ & Nunenmacher $F . W$. & & & FMNH \\
\hline 1 & Santa & Crui & Nogales & $8-1 X-1906$ & & & & INHS \\
\hline 2 & Santa & Cruz & Nogales & $9-I X-1906$ & Nunenmacher $\mathrm{E} . \mathrm{W}$. & & & FMNH \\
\hline 1 & Santa & Cruz & Pajarlto Mts., Pena Blanca Canyon & $19-V I I-1959$ & Arnett R.H.Jr. & & at $21 \mathrm{ght}$ & ESCA \\
\hline 2 & Santa & cruz & Pajarito Mts.. Pena Blanca Canyon & $21-22-V I I-2959$ & Arnett R.H.JI. & & at light & ESCA \\
\hline 5 & Santa & Cruz & Pajarito Mts.. Pena Blanca Canyon & 8 -VIII-1959 & Arnett R.H.Jr. & & at light & ESCA \\
\hline 5 & Santa & cruz & Pajarito Mts.. Pena Blanca Canyon & $22-26-V I I-1961$ & Arnett R.H.Jr. & & at $l i g h t$ & FSCA \\
\hline 1 & Santa & cruz & Pajarito Mts.. Pena Blanca Canyon & $31-V I I-1961$ & Arnett R.H.Jr. & & at light & ESCA \\
\hline 3 & Santa & crur & Pajarito Mt9.. Pena Blanca Canyon & 5-9-VIII-1961 & Arnett R.H.Jr. & & at light & ESCA \\
\hline 1 & Santa & Cruz & Pajarito Mts., Pena Blanca Canyon & 14-VIII-1961 & Asnett R.H.Jr. & & at light & FSCA \\
\hline 3 & Santa & cruz & Pajarito Mts.. Pena Blanca Canyon & $28-V I-1962$ & Arnett R.H.Jr. & & at light & FSCA \\
\hline 2 & Santa & cruz & Pajarito Mts., Pena Blanca Canyon & 3-VII-1962 & Arnett R.H.Jr. & & at light & FSCA \\
\hline 2 & Santa & cruz & Pajarito Mts.. Pena Blanca Canyon & 1-5-VIII-1962 & Arnett R.H.Jr. & & at light & FSCA \\
\hline 3 & Santa & cruz & Pajarito Mts... Pena Blanca Canyon & $28-V I I-1970$ & stephan $\mathrm{K}$. & & & FSCA \\
\hline 1 & Santa & Cruz & Pajarito Mta.. Pena Blanca Canyon & $27-V I I-1978$ & Mecleve s. & $1191 \mathrm{~m}$ & at $11 \mathrm{ght}$ & SMCC \\
\hline 1 & Santa & Cruz & Pajarito Mta., Pena Blanca Canyon & 2-VII-1980 & Mccleve S. & $1191 \mathrm{~m}$ & at $2 i \mathrm{ght}$ & SMCC \\
\hline 9 & Santa & Cruz & Pajarito Mts., sycamore Canyon & 24 -VIII-1968 & stephan $K$. & & & FSCA \\
\hline 2 & Santa & cruz & Pajarito Mts.. Sycamore Canyon & $24-V I I I-1968$ & stephan $\mathrm{K}$. & & & GHNC \\
\hline 2 & Santa & cruz & Pajarito Mts.., Walker Canyon & $28-V I I-1978$ & Mecleve $\mathrm{s}$. & $1191 \mathrm{~m}$ & at light & AMNH \\
\hline 2 & Santa & cruz & Pajarito Mts.. Walker Canyon & $28-V I I-1978$ & Mccleve s. & $1191 \mathrm{~m}$ & at light & SMCC \\
\hline 1 & Santa & cruz & Patagonia & $2-V I I I-1924$ & Van Duzee E.P. & & & CASC \\
\hline 4 & Santa & Cruz & Patagonia & VII-1936 & Rog9 E.S. & & & CASC \\
\hline 2 & Santa & cruz & Patagonia & $18-V I I-1948$ & Vaurie C.d P. & & & AMNH \\
\hline 1 & Santa & Cruz & Patagonia & $9-V I I-1954$ & Schmitt R. & & NJ light trap & UAIC \\
\hline 1 & Santa & Cruz & Patagonia & 8-VIII-1954 & Schmitt R. & & NJ 11 ght trap & UAIC \\
\hline 2 & Santa & cruz & Patagonia & $25-V I I I-1954$ & Schmitt $R$. & & NJ 11ght trap & UAIC \\
\hline 1 & Santa & Cruz & Patagonia & $14-1 x-1954$ & Schmitt R. & & NJ light trap & UAIC \\
\hline 3 & Santa & Cruz & Patagonia & 15 -VII-1955 & Werner F.G. & & at light & UAIC \\
\hline 2 & Santa & cruz & Patagonla & 6-VII-1976 & Cazier $M$. & & & AMNH \\
\hline 30 & Santa & Cruz & Patagonia, 1 mi.s. & $29-30-V I I-1964$ & Davis D.R. & & & USNM \\
\hline 3 & Santa & Cruz & Patagonia, $2 \mathrm{ml} . \mathrm{sw}$ & $30-V I I-1948$ & & $4050^{\circ}$ & & UAIC \\
\hline 10 & Santa & Cruz & Patagonia, $2 \mathrm{mi} . \mathrm{sw}$ & $6-V I I-1958$ & Alcorn J.R. & & & SEMC \\
\hline 1 & Santa & crur & Patagonia, $4.3 \mathrm{mi} . \mathrm{Sw}$ & $3-I X-1969$ & Noonan B.R. & & blacklight & CDAE \\
\hline 1 & Santa & Cruz & Patagonia, 5 mi.sw & $25-V I I I-1950$ & Cohn T. & $3500^{\circ}$ & & ASUT \\
\hline 1 & Santa & Cruz & Patagonia, 5 mi.sw & $25-V I I I-1950$ & Cohn $I$. & $3700^{\circ}$ & & AMNH \\
\hline 1 & Santa & Cruz & Patagonla, Senoita River & $18-V I I-1948$ & Vaurle C.\& P. & & & AMNH \\
\hline 5 & Santa & cruz & Pena Blanca & $11-V I I I-1960$ & Ball G.E. & $4000^{\circ}$ & at $11 \mathrm{ght}$ & USNM \\
\hline 1 & Santa & Cruz & Pena Blanca & $27-V I I I-1960$ & Ball G.E. & $4000^{\circ}$ & at light & USNM \\
\hline 4 & Santa & crur & Pena Blanca & $31-V I I I-1966$ & Andrews F.G. & & & CDAE \\
\hline 1 & Santa & Cruz & Pena Blanca & VII -1970 & & & & USNM \\
\hline 1 & Santa & Cruz & Pena Blanca & $1-V I I-1970$ & Triplehorn C.A. & & & osuc \\
\hline 2 & Santa & Cruz & Pena Blanca & $26-V I I I-1971$ & Petty J.L. & & & BYUC \\
\hline 1 & Santa & Cruz & Pena Blanca & $12-V I I I-1972$ & Gordon $\mathrm{R}$. & & ov light & USNM \\
\hline 1 & Santa & Cruz & Pena Blanca & 27-VII-1979 & Cicero J. & & & JMCC \\
\hline 1 & Santa & Cruz & Pena Blanca Canyon & $27-28-V I I-1964$ & Davis D.R. & & & USNM \\
\hline 1 & Santa & Cruz & Pena Blanca Lake & $20-V I I-1985$ & Lago $P$. & & & PKLC \\
\hline 2 & Santa & CruI & Pena Blanca Lake, $0.5 \mathrm{mi}$.NE.Castle Rock & $23-V I I I-1971$ & Kolner M.A. & $4000^{\circ}$ & at light & AsUT \\
\hline 2 & Santa & Cruz & Pena Blanca Lake, $3.2 \mathrm{~km} \mathrm{~s}$ & $28-V I I-1989$ & Andergon R.S. & & Uv light & TAMU \\
\hline 1 & Santa & Cruz & Pena Blanca, $10 \mathrm{mi}$.W.Nogales & $1-V I I I-1961$ & Werner F.G. & & ov light & UAIC \\
\hline 1 & Santa & Cruz & Santa Rita Mts.. Madera Canyon & $8-V I I-1959$ & Franclemont J.G. & & & TAMU \\
\hline
\end{tabular}


Ischyrus guadripunctatus chiasticus Boyle (Cont.)

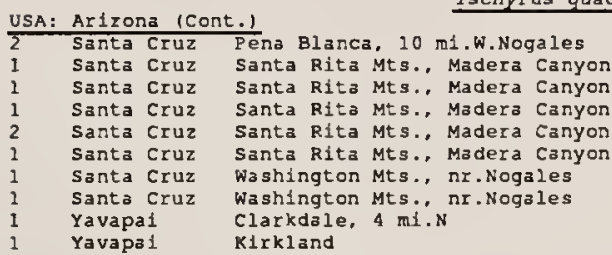

$3-V I I I-1959$
$5-V I I I-1919$
$24-V I I I-1946$
$11-V I I I-1959$
$10-26-V I I-1964$
$14-V I I I-1989$
$7-I X-1927$
$7-I X-1927$
$16-V I I-1985$
$31-V I I-1970$

Roever $\mathrm{K}$.

Arnett R.H.Jr.

Nicolay S.S.

Eranclemont J.G.

Davis D.R.

Pollock D.A.

Kusche J.A.

Yavapoi

$$
\begin{aligned}
& 6 \\
& 1 \\
& 1 \\
& \text { AI } \\
& 1
\end{aligned}
$$$$
1
$$
Argentina: Jutuy$$
\begin{aligned}
& 1 \\
& 1 \\
& 1
\end{aligned}
$$

\section{Argentina: Misiones}

$$
\begin{aligned}
& \text { Ar } \\
& 1 \\
& 1 \\
& 1 \\
& 1 \\
& 2 \\
& \text { Ar }
\end{aligned}
$$

$$
\begin{aligned}
& 1 \\
& 1 \\
& \text { Ar }
\end{aligned}
$$

\section{Ar}$$
\begin{aligned}
& 1 \\
& 1 \\
& 2 \\
& 3
\end{aligned}
$$$$
\begin{aligned}
& 1 \\
& 2 \\
& 3 \\
& 1 \\
& \text { Argentina: Tucuman }
\end{aligned}
$$$$
\text { Argentina: Tucuman }
$$$$
\begin{aligned}
& 1 \\
& 1 \\
& 1 \\
& 2 \\
& 2 \\
& 1 \\
& 10 \\
& 1 \\
& \text { Bolivia }
\end{aligned}
$$$$
\text { Bolivia: Chuguisaca Tiguipa }
$$$$
\frac{801 i v 1 a: \text { Chuquisaca }}{2} \text { Chuquis area, Monteaguado }
$$$$
\text { Bolivia: Cochabamba? }
$$$$
\text { I Tunari chapare }
$$$$
\text { Bolivia: La Paz }
$$$$
\begin{array}{ll}
3 & \text { San Lorenzo, } 12 \mathrm{~km} \text { Caranavi } \\
7 & \text { San Lorenzo, } 12 \mathrm{~km} \text { Caranavi } \\
1 & \text { San Lorenzo, } 12 \mathrm{~km} \text { Caranavi } \\
1 & \text { Yungas La Paz, Puenta Mururrat }
\end{array}
$$$$
\text { Brasil }
$$$$
\text { Bras }
$$$$
\begin{aligned}
& 1 \\
& 2 \\
& 1
\end{aligned}
$$$$
1
$$

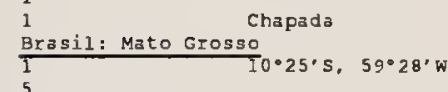$$
5
$$$$
\text { Brasil: Para }
$$$$
3 \text { Santarem }
$$$$
\text { Bras11: Paraná }
$$$$
\begin{aligned}
& \text { Foz do Iquazu } \\
& \text { Bras11: Rio de Janeiro } \\
& \hline \text { J }
\end{aligned}
$$$$
\begin{array}{ll}
\text { Brasil: Rio de Janeiro } \\
1 & \text { Petropolis } \\
1 & \text { Petropolis } \\
1 & \text { Rio de Janelro }
\end{array}
$$$$
\text { Brasil: Santa Catarina }
$$

$$
\begin{aligned}
& \text { Colombia [Nova Granada] } \\
& 1 \\
& 1 \\
& 1 \\
& 1
\end{aligned}
$$

$\begin{array}{ll}\text { Colombia: Boyaca } & \\ 1 & \text { Muzo } \\ \text { Muzo }\end{array}$

Kushe J.A. Kirkland

Ischyrus scriptus (01ivier)

$$
\text { San Lorenzo }
$$

$12-V I-1930$

Cerro San xavier

Cludad Universitaria

Falloa Blanca, Dpto.Burruyato

Horco Molle

Parque Aconquija

Nat.Park, El Cortaderal km.6 18-28-XII-1987

IX-1921

I-1961

IV -1931

IV -1981

$x-1947$

15-XII-I987

10-xII-1987

10-XII-1987

$2 I-I I I-I 957$
$X-X I-1933$
$I-I I I-1967$
$I-I X-I 933$
$I-1934$
$I-I 956$
$11-I I-1951$
$1 I-I I-195 I$
$18-I I-1959$
$X I I-1946$
$7-8-I I-1961$
$I-27-V I I I-1965$
$X I I-I 946$
$2-X I-1963$
$I I I-1922$
XII-I984

XII-I 984

$X I-1992$

1-2-I-199I

$1-2-I-1991$

$1-2-1-1991$

Uuccaro H.E.Jr.

MaY J.E.

Bruch C.

Harrington

Peck S.6 J.

Harrington G.L.

Foerster J.

Bruch C.

Viana $M$.

Monros

Harrington W.C.

Golbach R.

Harrington G.L.

Harrington G.L.

Bruch C.

Golbach $R$.

Ross \& Michelbacher

Ross Michelbacher

Clark J.F.

Golbach R.

Golbach R.

Porter $C$.

Golbach $R$.

weyruch

Pena L.E.

Pena L.

McHugh J.V.

MeHugh J.V.

McHugh J.V.

$\begin{array}{ll}\text { blacklight } & \text { UAIC } \\ \text { ot light } & \text { FSCA } \\ & \text { FMNH } \\ & \text { TAMU } \\ & \text { USNM } \\ & \text { DAPC } \\ & \text { ICCM } \\ & \text { CASC } \\ & \text { PKLC } \\ \text { UV light } & \text { UAIC }\end{array}$

UAIC

(SCA

TAMU

USNM

ICCM

PKLC

UAIC

ZMHB

2MHB

F IOC

ZMHB

MACN

$800 \mathrm{~m}$ Malaise FIT

MLPA

$300 \mathrm{~m}$

CMNC

IMLA

MACN

MLPA

MLPA

MLPA

MLPA

Peck S.6 J. $890 \mathrm{~m}$, WV light, thorn forest CMNC Peck S.s J. $900 \mathrm{~m}$, UV light, thorn forest cMNC Peck S.6 J. $1200 \mathrm{~m}$ fungi on log CMNC

$1100 \mathrm{~m}$

IMLA

CASC

IMLA

CASC

MACN

CUIC

CASC

FMNH

USNM

IMLA

IMLA

IMLA

IMLA

IMLA

USNM

$1300 \mathrm{~m}$

HNHM

PESC

Pena L.E.

$1200-1600 \mathrm{~m}$ lot B91-42 JVMC

JVM 10 B $891-11$ JVMC JVM lot B91-24 JVMC JVM lot B91-42 JVMC

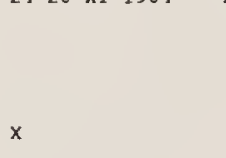

17-22-I I I-1977

Engleman D

LECTOTYPE I.maculiventris $\begin{array}{r}\text { CMHB } \\ \text { ICCM }\end{array}$

NHMB

NHML

Rohde $S$.

$300 \mathrm{~m}$

EGRC

2MHB

ICCM

Ross C.E.S E.S.

NHML

25-IV-1964

Sahlburg $T$.

Sahlburg $T$.

II

Sahlburg $T$.

1-X-1944 Plauman F.

HNHM

HNHM

NHML

AMNH

ZMHB

ISNB

NHMB

LECTOTYPE I. velatus MNHN

2MHB 
Ischyrus scriptus (011vier) (Cont.)

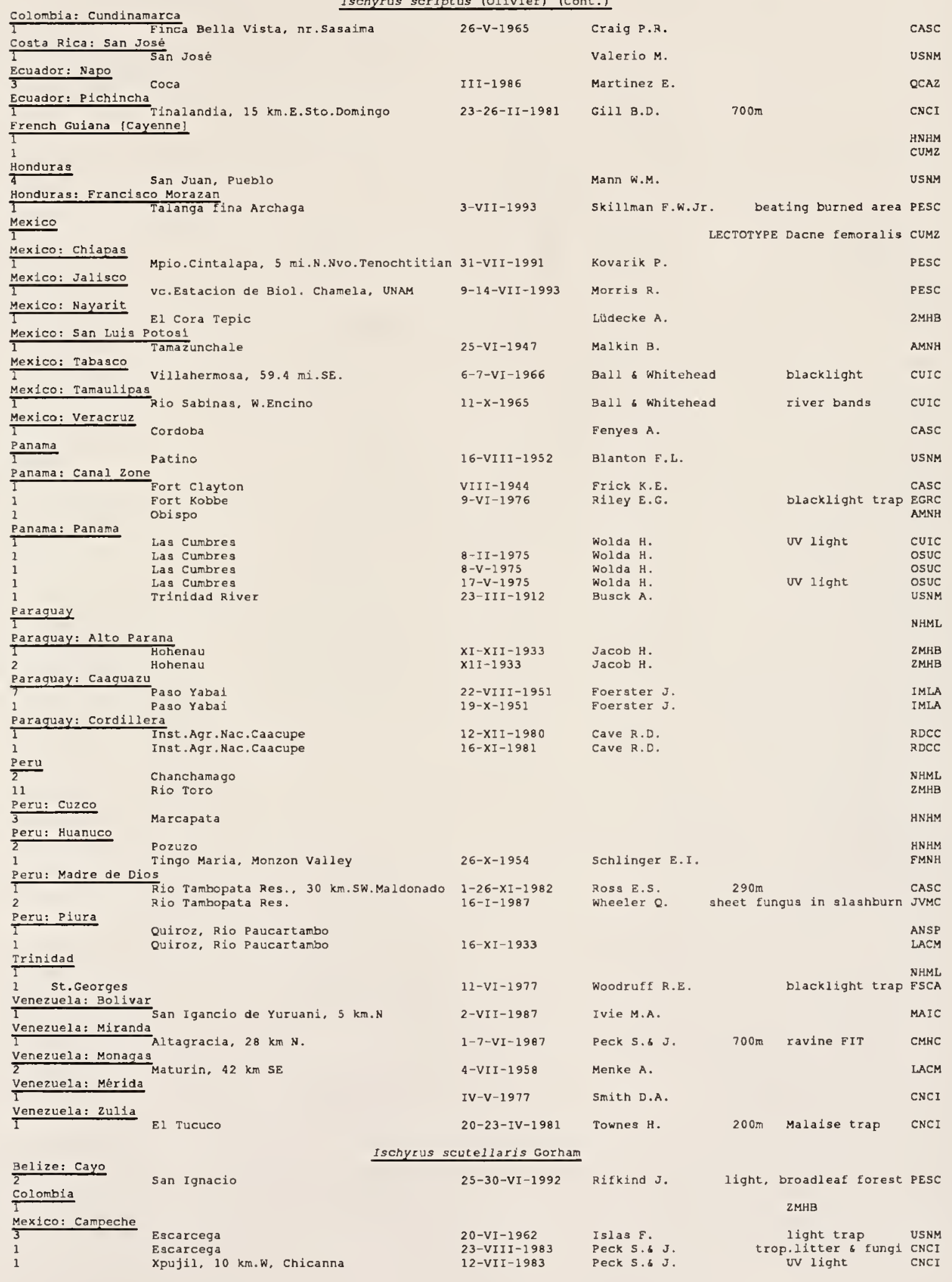




\section{Ischyrus scutellaris Corham (Cont.)}

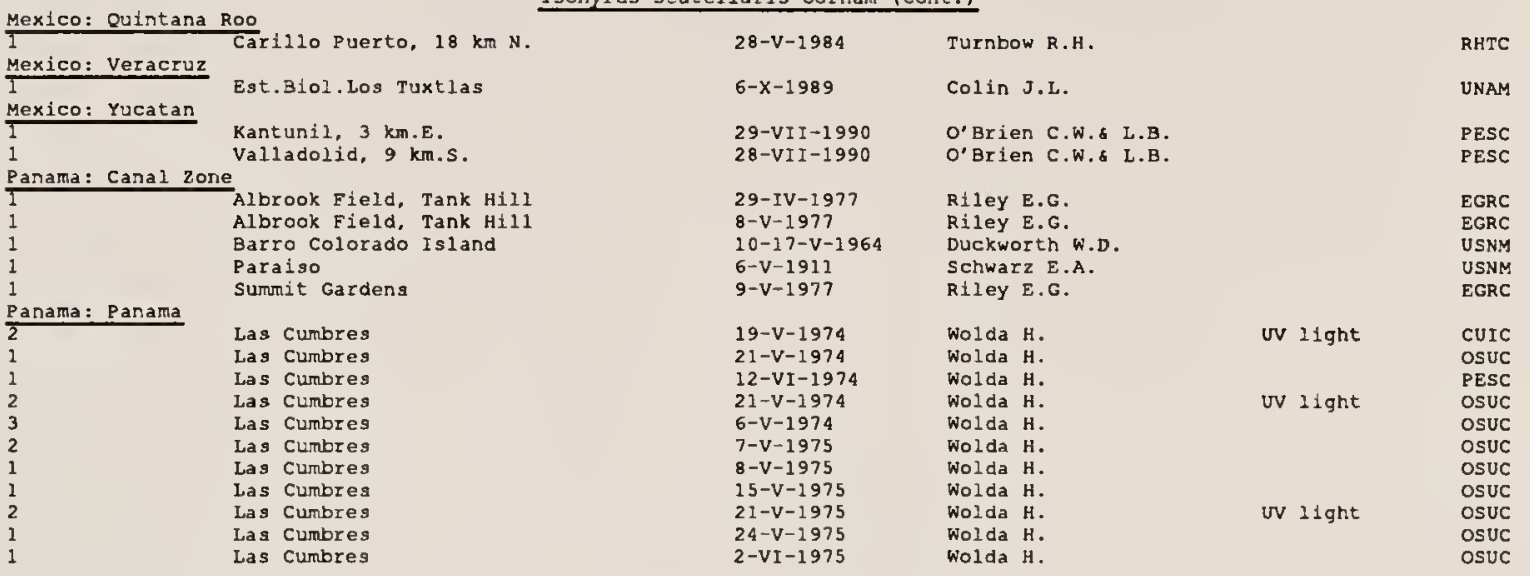

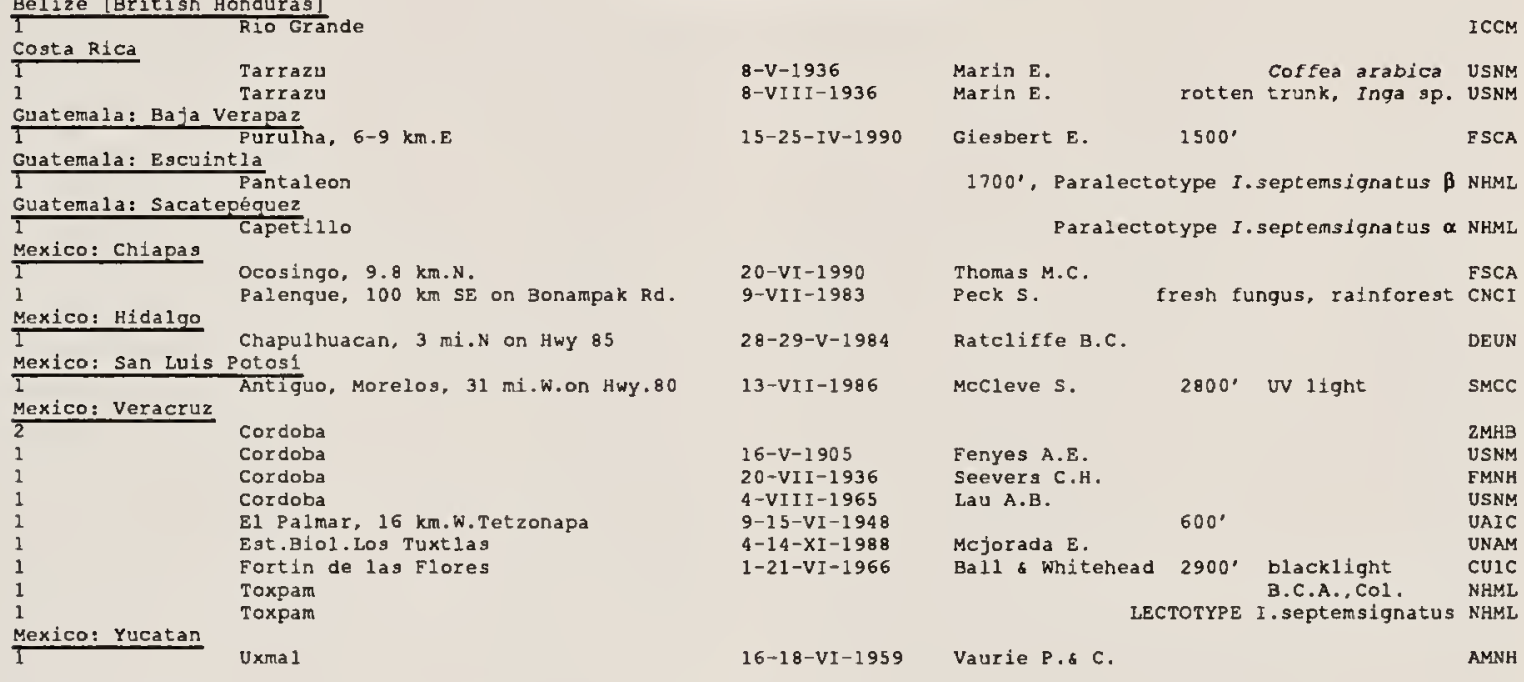

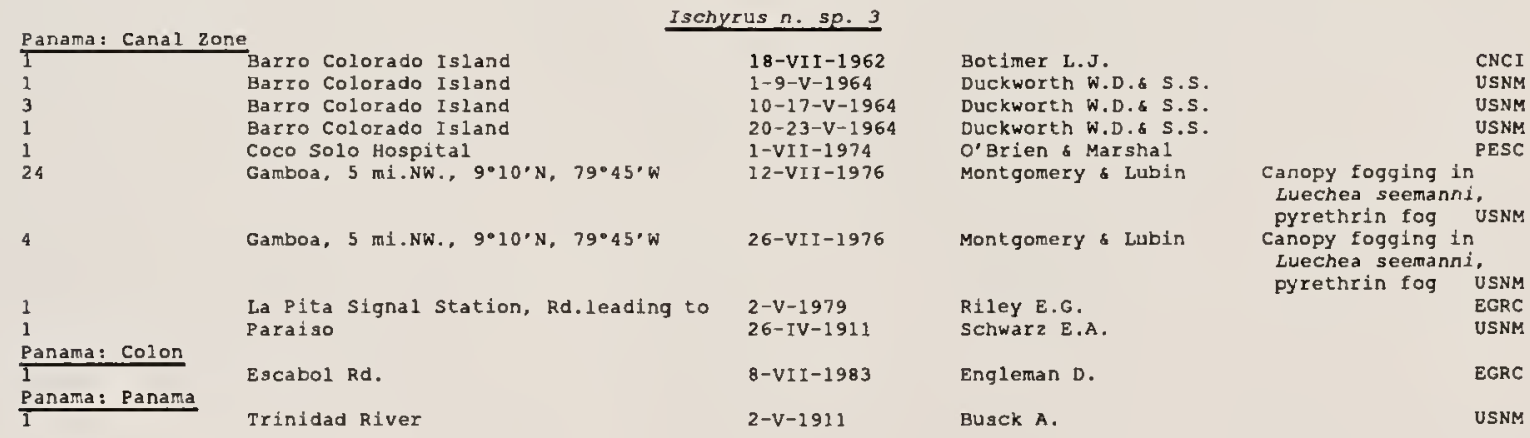




$\begin{array}{ll}\frac{\text { Cuba } ?}{1} & \text { Cejanal P.del Rio } \\ \frac{\text { Cuba }}{1} & \text { Baragua } \\ 1 & \text { Camaguey Baragua } \\ 1 & \text { Camaguey Baragua } \\ 1 & \text { Camaguey Baragua } \\ 1 & \text { Soledad (Cienfuegos) } \\ 1 & \text { Soledad (Cienfuegos) } \\ 3 & \text { Soledad (Cienfuegos) } \\ 1 & \text { Soledad (Cienfuegos) } \\ 2 & \text { Soledad (Cienfuegos) } \\ 1 & \text { Soledad (Cienfuegos) }\end{array}$

Bolivia: Sara

Brasil

Bras11: Alagoas

Bras1l: Rio de Janeiro Miguel dog Campos

1 Rio de Janeiro

Costa Rica: Alajuela

Costa Rica: Cartago

Costa Rica: Heredia

Costa Rica: Puntazenas

El Salvador Monteverde

El Salvador San salvador

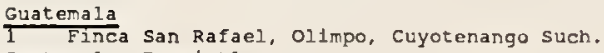

Guatemala: Escuintla

Honduras: Santa Barbara

Panama: Bocas del Toro

Panama: Bocas del Toro

Panama: Canal zone

$\begin{array}{ll}\text { Panama: Canal 2one } & \text { Barro Colorado Island } \\ 1 & \text { Barro Colorado Island } \\ 1 & \text { Barro Colorado Island } \\ 1 & \text { Barro Colorado Island } \\ 1 & \text { Barro Colorado Island } \\ 1 & \text { Barro Colorado Island, } 90^{\circ} 10^{\circ} \mathrm{N}, 790^{\circ} \\ 1 & \text { Fifoles } \\ \text { Panama: Panama } & \text { Trinidad River }\end{array}$

Iscryeus n. sp. 6

Ischyrus n. sp. 4

$10-\mathrm{X}-1993$

Ischyrus n. sp. 7

Brasil: Rondônia

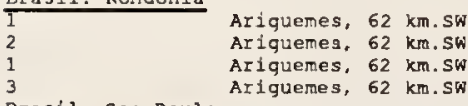

Brasil: Sao Paulo

I Faz. Campininas, Mogi Guacu.

17 Piracicaba

1 Ubatuba

Costa Rica

Panama: Canal zone

\section{Ubatuba}

10 Cardenas Village

8 Cardenas village

Panama: Colon

Venezuela: Aragua

1 Cagua

Choroni, nr.$$
\begin{aligned}
& \frac{B r}{1} \\
& \frac{P a}{1} \\
& 1 \\
& 1 \\
& 1 \\
& 1 \\
& 1 \\
& 2 \\
& 1
\end{aligned}
$$

Brasil: Mato Grosso

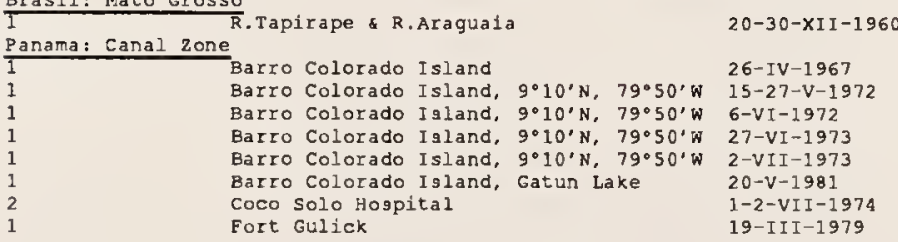

XII-1928

22-VII-1929

$11-V I-1932$

26-V -1932

$31-v-1932$

$24-\mathrm{x}-1925$

$31-x-1926$

$8-X I-192$

VI -1929

2-12-VI I I-1934

VIII-1936

VIII

IV-1984

I-1947

9-V-1987

$19-v-1979$

30-I-1992

1-3-VI-1984

1-5-V-1958

10-IV-1965

8-9-VIII

30-III-1959

28-VII-1938

III-IV-1949

19-I-1959

19-I-1959

$26-I-1959$
$10-17-V-1964$

$28-V I-1973$

28-IV-1981

VII-1911

27-IV-1992

8-IX-1992

20-IX-1992

5-17-x-1993

23-31-VI I-1969

$11-V I-1965$

14-VI-1965

$22-x-1964$

2-VII-1967

$10-v-1980$

$17-18-V-1980$

$22-v-1980$

26-V-1980

14-v-1991

28-VI-1961

6-VIII-1984

steinbach $\mathrm{J}$.

$450 \mathrm{~m}$

at $11 \mathrm{ght}$

FMNH

Scaramuzza L.C.

at $11 \mathrm{ght}$

at light

at light

Christenson

Christenson

Darlington P.J.

Darlington P.J.

Darlington P.J.

Darlington P.J.

Darlington P.J.

ICCM

ICCM

Oliveira F.M.

ICCM

USNM

CMNC

Cruz E.

Howden H.\& A.

$600 \mathrm{~m}$

at night

CNCI

Bell W.

$100 \mathrm{~m}$

SEMC

Riley E.G.

EGRC

Cartwright O.L.

at light

USNM

Campiell J.M.

$1700^{\circ}$

CNCI

Knab F.

USNM

Turnbow $R$.

RHTC

Dybas H.S.

FMNH

Williamson E.C.Jr.

Zetek

Dybas H.S.

Dybas H.S.

Duckworth W.D.\& S.S.

Erwin $\mathrm{T}$

Gill B.

Busck A.

FMNH

USNM

FMNH

FMNH

USNM

USNM

CNCI

USNM

Schmitz $U$.

Schmitz $U$.

schnitz $U$.

Eger J.E.

Campbell J.M.\& B.A.

Triplehorn C.A.

Triplehorn C.A.

Moses

Spangler P.J.

blacklight trap OSUC

blacklight trap PESC blacklight trap PESC blacklight trap PESC

RIley E.G.

RIley E.G.

Riley E.G.

Riley E.G.

Turnbow R.H.

US NM

EGRC

EGRC

EGRC

Bordon

Watts $\mathrm{J}$.

at light

RHTC

MAIC

PESC

Malkin B. night sweeping along trail FMNH

Akre R.D.

Pine R.

Erwin $T$.

Erwin T.L. \& L.J.

Gill B.

O'Brien C.W.\& L.O

Harlan H.J.

light

USNM

USNM

USNM

19-I I I-1979 at light
Erwin T.L. \& L.J. light USNM 


Panama: Colon
1
1
Panama: Darlen
Panama: Panama
$\frac{1}{1}$
Trinidad
$\frac{1}{1}$ St.Georges
Venezuela
I

Colon

Porto Bello

Santa Fe

Altos de Maje (Isle), $9^{\circ} 8^{\prime} \mathrm{N}, 78^{\circ} 49^{\prime} \mathrm{W}$ Cerro Campana

Tunapuna

Curepe

Santa Lucio
Ischyrus n. sp. 9 (Cont.)

16-V-1991 Turnbow R.H.

17-II-1911 Schwarz E.A.

IV-V-1967 Delong G Triplehorn

Ratcliffe B.C.

Riley E.G.

Howden H.S A.

Mason W.R.M.

Reynolds L.R.

$28-30-X I-1977$

v-1922

Ischyrus n. sp. 15

Brasil: Pará

Serra Norte, Est.do Faloca [?]

Colombla: Meta villavicencio

Costa Rica: Cartago

Turrialba 23-17-III-1965

Ecuador: Pichincha St.Domingo, $16 \mathrm{~km} . \mathrm{E}$. . d.1.Colorados

Panama: Canal Zone

I Barro Colorado Island

Barro Colorado Island, $9^{\circ} 10^{\prime} \mathrm{N}, 79^{\circ} 50^{\circ} \mathrm{W} \quad 15-27-\mathrm{V}-1972$

Cardenas village

Panama: Panama Las Cumbres

lo tas cumbres

Trinidad

26-V-1975

Simla, Arima-Blanchisseuse Rd.

Venezuela: Carabobo
$1-V I I-1938$
$15-27-V-1972$

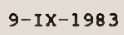

14-VII-1938

29-21-XII-1987

$17-18-V-1980$

$7-v-1975$

$26-V-1975$

22-VII-1975

$30-X I-1939$
Ramon F.F.

Dybas H.S.

Duckworth S.S.\& W.D. 21ght

Valentine B.D.

$685 \mathrm{~m}$

Williams E.C.Jr.

Erwin $T$...et al.

Riley E.G.

Wolda $H$.

Wolda $\mathrm{H}$.

Price J.

Anduze P.J.
MV \& blacklight RHTC

USNM

osuc

DEUN

EGRC

CMNC

CNCI

FMNH

MPEG

FMNH

USNM

PESC

FMNH

USNM

lacklight osuc

blacklight trap FSCA

FMNH 


\section{LITERATURE CITED}

Alexander, R. D., T. E. Moore, \& R. E. Woodruff. 1963. The evolutionary differentiation of stridulatory signals in beetles (Insects: Coleoptera). Animal Behavior $11(1): 111-115,19 \mathrm{fig}$.

Alvarenga, M. 1965. Espécies tipo dos gēneros e subgêneros neotropicais da familia Erotylidae (Coleoptera). Bol. Univ. Fed. Paraná Zool. 2(6):75-92.

Alvarenga, M. 1977. Notas taxônomicas sobre a familia Erotylidae (Coleoptera). Dusenia 10(2):103-107.

Arnett, R. H., Jr. 1963. The beetles of the United States. The Catholic University of America Press, Washington, DC. $1112 \mathrm{pp}$.

Arnett, R. H., Jr. 1985. American insects, a handbook of the insects of America north of Mexico. Van Nostrand Reinhold Company, New York. 850 pp.

Arnett, R. H., Jr., G. A. Samuelson, \& G. M. Nishida. 1993. The insect and spider collections of the world. Second edition. Sandhill Crane Press, Inc., Gainesville, FL. $310 \mathrm{pp}$.

Arrow, G. J. 1924. Vocal organs in the coleopterous families Dytiscidae, Erotylidae, and Endomychidae. Trans. Royal Entomol. Soc. London 2-3:134-143.

Arrow, G. J. 1925. The fauna of British India, including Ceylon and Burma. Coleoptera. Clavicornia. Erotylidae, Languriidae, and Endomychidae. Taylor and Francis, London. pp. i-xvi, 1-416, 1 pl., 1 map.

Arrow, G. J. 1942. The origin of stridulation in beetles. Royal Entomol. Soc. London Proc. (Ser. A.) 17(7-9):8386 .

Barber, H. S., \& J. C. Bidwell. 1940. Dejean catalogue names (Coleoptera). Bull. Brooklyn Entomol. Soc. $35(1): 1-12$.

Beutenmüller, W. 1891. Bibliographic catalogue of the described transformations of $\mathrm{N}$. American Coleoptera. J. New York Microscopical Soc. $7(1): 1-52$. 
Blackwelder, R. E. 1939. Fourth supplement 1933 to 1938

(inclusive) to the Leng Catalogue of the Coleoptera of America north of Mexico. John D. Sherman, Mt. Vernon, New York. $146 \mathrm{pp}$.

Blackwelder, R. E. 1941. The gender of scientific names in zoology. J. Washington Acad. Sci. 31:135-140.

Blackwelder, R. E. 1945. Checklist of the coleopterous insects of Mexico, Central America, the West Indies, and South America. Bull. United States Nat. Mus. $185(3): 343-550$.

Blackwelder, R. E. 1949. Studies on dates of books on Coleoptera I. Coleopt. Bull. 3(3):42-46; II, Coleopt. Bull. 3(5):76; III, Coleopt. Bull. 3(6):92-94.

Blackwelder, R. E. 1957. Checklist of the coleopterous insects of Mexico, Central America, the West Indies, and South America. Bull. United States Nat. Mus. $185(6): i-v i+927-1492$.

Blatchley, W. S. 1910. An illustrated descriptive catalogue of the Coleoptera or beetles (exclusive of the Rhynchophora) known to occur in Indiana. The Nature Publishing Co., Indianapolis. 1385 pp.

Blatchley, W. S. 1917. On some new or noteworthy Coleoptera from the west coast of Florida. Canadian Entomol. 49:137-143, 236-240, 272-279.

Borror, D. J., \& R. E. White. 1970. A field guide to the insects of America north of Mexico. Houghton Mifflin Company, Boston. 404 pp., 16 pls.

Boyle, W. W. 1954. Concerning the status of Ischyrus graphicus Lacordaire, with descriptions of four new erotylid species from western North America

(Coleoptera: Erotylidae). J. New York Entomol. Soc. $62: 39-53$.

Boyle, W. W. 1956. A revision of the Erotylidae of America north of Mexico (Coleoptera). Bull. American Mus. Nat. Hist. $110(2): 61-172$.

Brimley, C. S. 1938. The insects of North Carolina. North Carolina Department of Agriculture, Division of Entomology, Raleigh. $560 \mathrm{pp}$.

Brown, R. W. 1985. Composition of scientific words. Smithsonian Institution Press, Washington, D.C. 882 $\mathrm{pP}$. 
Candeze, E. C. A. 1861. Histoire des métamorphoses de quelques Coléoptères exotiques. Mem. Soc. Roy. Sci. Liege 16:235-410, 6 pls.

Casey, T. L. 1916. Some random studies among the Clavicornia. Erotylidae. Memoirs on the Coleoptera 7:146-172. Lancaster, PA.

Castelnau, 1840. See Laporte, 1840.

Chagnon, G. 1917. A preliminary list of the insects of the province of Quebec. Part III. Coleoptera. Supplement to Report of the Quebec Society for the Protection of Plants, Quebec. $277 \mathrm{pp}$.

Chagnon, G., \& A. Robert. 1962. Principaux Coléoptères de la Province de Québec. Les Presses de L'Université de Montréal, Montréal. $440 \mathrm{pp}$.

Champion, G. C. 1902-1906. Insecta. Coleoptera. Vol.IV part 4. Rhynchophora. Curculionidae. Curculioninae (part). In Godman, F. Du Cane, \& O. Salvin (eds.). Biologia Centrali-Americana. R. H. Porter, London. 750 pp., 35 pls.

Chantal, C. 1979. Les Erotylidae (Coleoptera) du Quebec. Eabreries 5(1):15-20.

Chapuis, F. 1876. Tome Douzième. Famille des Érotliens, des Endomychides et des Coccinellides. $424 \mathrm{pp}$. In Th. Lacordaire \& F. Chapuis. Histoire naturelle des

Insectes. Genera des Coléoptères ou exposé méthodique et critique de tous les genres proposés jusqu'ici dans cet ordre d'Insectes. Librairie Encyclopédique de Roret, Paris. [often cited as Lacordaire 1876]

Chapuis, M. F., \& M. E. Candeze. 1853 [1855]. Catalogue des larves des Coléoptères connues jusqu'a ce jour avec la descriptions de plusiers espèces. Memoires Soc. R. Sci. du Liege 8:347-615, 22pls.

Chûjô, M., \& M. Chûjô. 1988. A catalog of the Erotylidae (Insecta, Coleoptera) from the old World (excl. the Ethiopian Region). Esakia 26:139-185. [Subfamily Dacninae]

Chûjô, M., \& M. Chûjô. 1989. A catalog of the Erotylidae (Insecta, Coleoptera) from the old world (excl. the Ethiopian Region). Esakia 28:75-96. [Subfamily Encaustinae ]

Chûjô, M., \& M. Chûjô. 1990. A catalog of the Erotylidae (Insecta; Coleoptera) from the old World (excl. the Ethiopian Region) III. Esakia 29:1-67. [Subfamily Triplacinae] 
Costa, C., S. A. Vanin, \& S. A. Casari-Chen. 1988. Larvas de Coleoptera do Brasil. Museu de Zoologia, Universidade de São Paulo. 282 pp., 165 pls.

Crotch, G. R. 1873a. Synopsis of the Erotylidae of boreal America. Trans. American Entomol. Soc. 4:349-358.

Crotch, G. R. 1873b. A list of Erotylidae collected by Edward M. Janson, in the vicinity of Santo Domingo, Chontales, Nicaragua, with descriptions of new genera and species. Cistula Entomol. 1:141-150.

Crotch, G. R. 1873c. Checklist of the coleoptera of America, north of Mexico. Naturalist's Agency, Salem, MA. $136 \mathrm{pp}$.

Crotch, G. R. 1876. A revision of the coleopterous family Erotylidae. Cistula Entomo1. 1:377-572(1-196). [In the text the page numbers for both the journal and the paper appear on each page. Numbers in parentheses are for the revision. The other numbers are in sequence for the journal.]

Crowson, R. A. 1981. The biology of the coleoptera. Academic Press, London. $802 \mathrm{pp}$.

Curran, C. H. 1944. Notes and descriptions of some American Erotylidae. American Mus. Novitat. 1256:1-14.

Deelder, C. L. 1942. Revision of the Erotylidae (Coleoptera) of the Leiden Museum. Zool. Meded. 24(12) : 49-115, 5 figs.

Dejean, P. F. M. A. 1821. Catalogue de la collection de Coléoptères de M. le Baron Dejean. [First Edition]. Chez Chevot, Paris. viii + 136p.

Dejean, P. F. M. A. 1833-1836. Catalogue des Coléoptères de la collection de $M$. le comte Dejean. [Second Edition]. Chez Méquignon-Marvis Pere et Fils, Paris. [1833]1+2:1-176, [1834]3:177-256, [1835]4:257-360, [1836] $5: 361-443$.

Dejean, P. F. M. A. 1836-1837. Catalogue des Coléoptères de la collection de $M$. le comte Dejean. Troisième Édition, Revue, Corregee et Augmentée. Chez MéquignonMarvis Pere et Fils, Paris. [1836]1-4:1-384, [1837] 5:385-503p.

Delkeskamp, K. 1943. Aus Afrikas Erotyliden-Fauna (Col.) 9. Beitrag zur kenntnis der Erotyliden. Deutsche Entomol. Zeit. 1-2:28-55. 
Delkeskamp, K. 1957. Beiträge zur Kenntnis der

insektenfauna Boliviens. Teil III. Coleoptera II,

Erotylidae. (22. Beitrag zur kenntnis der Erotylidae

(Col.)). Veröffentlichungen der Zoologischen

Staatssammlung München 5:93-116.

Delkeskamp, K. 1959. Sekundäre Geschlechtsmerkmale bei Erotyliden. 27. Beitrag zur kenntnis der Erotylidae (Col.). Wissenschaftliche Zeitschrift der MartinLuther Universität Halle-Wittenberg 8(6) S:1089-1098.

Delkeskamp, K. 1981. Erotylidae von Africa und Madagascar. Coleopterorum Catalogus Supplementa 34:1-65.

Dillon, E. S., \& L. S. Dillon. 1961. A manual of common beetles of Eastern North America. Row, Peterson and Company, Evanston, IL. 884 pp.

Duponchel, P. A. J. 1825. Monographie du genre Erotyle (1). Mem. Mus. Hist. Nat., Paris. 12:30-61, 156-176, pl.1-2,7. [Often cited as Duponchel 1824, with different page numbers, the remainder of the citation is the same. I follow the date, fide Blackwelder 1957, and page numbers on the copy I studied in the library at Cambridge Univeristy, U.K.]

Edwards, J. G. 1949. Coleoptera or beetles east of the Great Plains. Edwards Brothers, Inc., Ann Arbor, MI. 181 pp., 23 pls.

Erichson, W. F. 1847. Conspectus Insectorum Coleopterorum quae in Republica Peruana observata sunt. Archiv. für Naturg. $13(1): 67-185$.

Fabricius, J. C. 1775. Systema entomologiae, sistens insectorum classes, ordines, genera, species.

Flensburg and Leipzig. $832 \mathrm{pp}$.

Falderman, F. 1837. Fauna Entomologica Trans-Caucasica. Coleoptera Pars II. 400 pp., 15 col.taf.

Fattig, P. W. 1937. The Coleoptera or beetles of Georgia (V). Entomol. News 48(9):250-255.

Fleutiaux, E. 1886. Supplément au catalogue des Coléoptères de M.M.Gemminger et de Harold (Languriides et Erotylides). Ann. Soc. Entomol. Belgique 30:216-224.

Eroeschner, R. C., \& E. P. Meiners. 1953. The Languriidae and Erotylidae (Coleoptera) of Missouri with notes and keys. J. Kansas. Entomol. Soc. 26(1):18-25. 
Frost, S. W. 1964. Insects taken in light traps at the Archbold Biological Station, Highlands County, Florida. Florida Entomol. 47 (2) 129-161.

Gemminger, M., \& B. von Harold. 1876. Catalogus Coleopterorum, Huacusque descriptorum, synonymicus et systematicus. Tom 12. Chrysomelidae (Pars 2), Languriidae, Erotylidae, Endomychidae, Coccinellidae, Corylphidae, Platypsillidae. Monachii, London. pp. 3479-3822, i-lxxiii.

Germar, E. F. 1824. Insectorum species novae aut minus cognitae, descriptionibus illustratae. Coleoptera. Halaae, Hendel. 624 pp., 2taf.

Germar, E. F. 1843. Lacordaire's Eintheilung der Erotyliden. Entomol. Zeit. Stett. 4(1):131-139.

Girard, M. 1873. Traité élémentaire d'entomologie, comprenant l'histoire des espéces utiles et de leurs produits des espéces nuisibles et des moyens de les détruire l'étude des métamorphoses et des moeurs les procédés de chasse et de conservation. IntroductionColeopteres. Librairie J.B. Bailliève et Fils, Paris. $840 \mathrm{pp}$.

Gorham, H. S. 1883. Descriptions of new species of beetles belonging to the family Erotylidae. Proc. Zool. Soc. London $6: 75-87$.

Gorham, H. S. 1887-1899. Insecta. Coleoptera. Vol. VII. Erotylidae, Endomychidae, and Coccinellidae. In Godman, F. Du Cane, \& O. Salvin (eds.). Biologia CentraliAmericana. R. H. Porter, London. 276 pp., 13 pls.

Gorham, H. S. 1898. On the Coleoptera of the families Erotylidae, Endomychidae, and Coccinellidae collected by Mr. H.H. Smith in St. Vincent, Grenada, and the Grenadines, with descriptions of new species. Proc. Zool. Soc. London 22:334-343, pl.27 figs.6, 11-12.

Guérin, J. 1948. Catalogo dos Erotylidae (Col.) das coleções do Instituto de Ecologia e Experimentação Agricolas do Ministerio da Agricultura, com a descrição de algumas especies novas. Boletim do Instituto de Ecologia e Experimentação Agricolas. Sociedade Brasileira de Entomologia, São Paulo. 8:1-26. [Bibliografia with many errors.]

Guérin, J. 1949. Descrição de novas espécies Neotropicais das familias Clytridae, Megalopodidae e Erotylidae (Col.). Rev. Entomol. 20(1-3):229-236. 
Guérin, J. 1953. Coleoptera do Brasil. Departmentos de Zoologia e de Eisiologia Geral e Animal, São Paulo, Brasil. 356p., $41 \mathrm{pls}$.

Guérin, J. 1956. Descrição de novas espécies e variedades de Erotylidae (Coleoptera) neotropicais. Dusenia $7(1): 45-$ 64, Est.II, III.

Guérin-Méneville, M. F. E. 1841. Description de quelques espèces nouvelles d'Erotylides. Extraite du manuscrit du texte explicatif de l'Iconographie du Régne Animal. Revue Zoologique par la Société Cuvierienne 1841:153161 .

Guérin-Méneville, M. F. E. 1829-1838 [1844]. Iconographie du Régne animal de G. Cuvier, ou représentation d'après nature de l'une des espèces les plus remarquables, et souvent non encore figurées, de chaque genre d'animaux. Insectes. J. B. Bailliere, Paris. 7 bd. 576 pp. 450 taf. 104 taf. [1829-1838 appears on the volume, actual publication date 1844 fide Horn \& Schenkling 1928-1929 and Blackwelder 1957.]

Haldeman, S. S., \& J. L. LeConte. 1853. Catalogue of the described Coleoptera of the United States by Friedrich Ernst Melsheimer. Revised by S. S. Haldeman \& J. L. Leconte. Smithsonian Institution, Washington, DC. 174 $\mathrm{pp}$.

Harold, E. von. 1875. Literatur. Coleopterologische Hefte $14: 146-208$.

Hatch, M. H. 1928. A geographical index to the catalogues and local lists of Nearctic Coleoptera. J. New York Entomol. Soc. 36(4):335-354.

Hatch, M. H. 1929. A supplement to the indices to the keys to and local lists of Nearctic Coleoptera. J. New York Entomol. Soc. $37(2): 135-143$.

Hatch, M. H. 1941. A second supplement to the indices to the keys to and local lists of Nearctic Coleoptera. J. New York Entomol. Soc. 49(1):21-42.

Henshaw, S. 1885. List of the Coleoptera of America, north of Mexico. American Entomological Society, Philadelphia. $161 \mathrm{pp}$.

Herbst, J.F.W. 1793. Natursystem aller bekannten in und ausländischen Insecten, als eine Fortsetzung der von Buffonschen Naturgeschichte. Der Käfer, vol. 5., 392 pp., 6 taf. Berlin. 
Horn, G. H. 1886. A review to the species described by olivier in the "Entomologie." Trans. American Entomol. Soc. 13 (Apr.) : 135-144.

Horn, G. H. 1887. A monograph of the Aphodiini inhabiting the United States. Trans. American Entomol. Soc. 14:1110 .

Horn, W., \& I. Kahle. 1935-1937. Über entomologische Sammlungen. (Ein Beitrag zur Geschichte der EntomoMuseologie). Entomologische Beihefte aus Berlin-Dahlem. Band 2-4. Teil 1[1935]:1-160, pls.1-16; Teil 2[1936]:162-296, pl.17-26; Teil 3[1937]:297-536, pls. 27-35.

Horn, W., \& S. Schenkling. 1928-1929. Index literaturae entomologicae. Serie I. Die Welt-Literatur uber die gesamte Entomologie bis inklusive 1863. (1928) 1:352, 1 pl.; 2:353-704, 1 pl.; 3:705-1056, 1 pl.; (1929) 4:i$\mathrm{xxi}+1057-1426,1 \mathrm{pl}$.

Hubbard, H. G., \& E. A. Schwarz. 1878. 3. Contribution to a list of the Coleoptera of the lower peninsula of Michigan. pp. 643-666. In Hubbard, H. G., \& E. A. Schwarz (eds.). The Coleoptera of Michigan. Proc. American Philos. Soc. 17:593-666.

Khalaf, K. T. 1980. Micromorphology of beetle elytra, using some simple replicas. Florida Entomol. $63(3): 307-340$.

Kirk, V. M. 1969. A list of beetles of South Carolina, Part I - northern coastal plain. South Carolina Agr. Exp. Sta. Tech. Bull. 1033:1-124.

Kirk, V. M. 1970. A list of the beetles of South Carolina, Part II - mountain, piedmont, and southern costal plain. South Carolina Agr. Exp. Sta. Tech. Bull. 1038:1-117.

Kirk, V. M., \& E. U. Balsbaugh, Jr. 1975. A list of the beetles of South Dakota. South Dakota St. Univ. Agr. Exp. Sta. Tech. Bull. 42:1-139.

Kirsch, T. 1876. Beiträge zur kenntniss der Peruanischen käferfauna aus Dr. Adendroth's sammlungen basirt. Deutsche Entomol. Zeit. 20(1):81-133 (sechstes stück).

Kuhnt, P. 1909. Coleoptera, fam. Erotylidae, subfam. Erotylinae. In P. Wytsman (ed.), Genera insectorum. V. Verteneuil \& L. Desmet, Brussels. Fasc. 88, 139 pp., 4 pls. 
Kuhnt, P. 1910. Neue Erotylidae (Col.). Deutsche Entomol. zeit. 3:219-270.

Kuhnt, P. 1911. Family Erotylidae. In W. Junk, Coleopterorum catalogus, Pars 34. 15:1-103. W. Junk, Berlin.

Lacordaire, J. T. 1842. Monographie des Erotyliens, Famille de l'Ordre des Coléoptères. Roret, Paris. xiv + 543 pp.

Laporte, F. L. N. de Caumont. (Comte de Castelnau) . 1840. Histoire naturelle des Insectes coléoptères, avec une introduction renfermant l'anatomie et la physiologie des animaux articulés par M. Brullé. Histoire naturelle des Animaux Articulés: Annelides, Crustaces, Arachnides, Myriapodes et Insectes. P. Dumenil, Paris. $2: 1-563$.

Lawrence, J. F. 1991. Erotylidae (Cucujoidea) (Including Dacnidae). pp. 473-475. In F. W. Stehr (ed.).

Immature Insects, Volume 2. Kendall Hunt Publishing Co., Dubuque, IA. xvi + 975 pp.

Leconte, J. L. 1854. Synopsis of the Erotylidae of the United States. Proc. Acad. Nat. Sci. Philadelphia $7: 158-163$.

Leconte, J. L. [ed.]. 1859. The complete writings of Thomas Say on the entomology of North America. Baillière Brothers, New York. Vol.1:xxiv + 385 pp., 53 pls.; Vol.2:814 pp. [See Say 1835]

Leconte, J. L., \& G. H. Horn. 1883. Classification of the Coleoptera of North America. (second edition). Smithsonian Misc. Coll. 26(4): i-xxxviii, 1-567.

Leng, C. W. 1920. Catalogue of the Coleoptera of America, north of Mexico. Mt. Vernon, New York. 470 pp.

Leng, C. W. 1928. Coleoptera. In Leonard, M. D. [ed.]. A list of the insects of New York, with a list of spiders and certain other allied groups. Cornell University Agr. Exp. Sta. Mem. 101:1-1121.

Leng, C. W., \& A. J. Mutchler. 1914. Article 30. A preliminary list of the Coleoptera of the West Indies as recorded to Jan. 1, 1914. Bull. American Mus. Nat. Hist. $33(30): 391-493$.

Leng, C. W., \& A. J. Mutchler. 1933. Second and third supplements 1925 to 1932 (inclusive) to the catalogue of the Coleoptera of America, north of Mexico. J. D. Sherman, Mt. Vernon, New York. $112 \mathrm{pp}$. 
Leschen, R. A. B. 1991. Ecological and behavioral correlates among mycophagous Coleoptera. pp. 171-192. In J. L. Navarrete-Heredia \& G. A. Quiros-Rocha [eds]. I Simposio Nacional Sobre la Interacción Insecto-Hongo Memorias. Veracruz, Veracruz, México. 192 pp.

Lindroth, C. H. 1957. The principle terms used for male and female genitalia in Coleoptera. Opuscula Entomol. $22(2-3): 241-156$.

Loding, H. P. 1933. Alabama Coleoptera not generally listed from the Gulf Coast states east of the Mississippi River, Fla., Ga., Ala., and Miss. Bull. Brooklyn Entomol. Soc. 28(4):139-151.

Loding, H. P. 1945. Catalogue of the beetles of Alabama. Geol. Surv. Alabama Monogr. 11:1-172.

Mader, L. 1938. Über neue und bekannte Erotyliden. Entomol. Blätter 34(1):14-19.

Mader, L. 1942. Erotylidae (Coleoptera). pp. 149-201. In E. Titschack. Beiträge zur fauna Perus. Nach der Ausbeute der Hamburger Südperu-Expedition 1936, anderer sammlungen, wie auch auf grund von literaturangaben. Band II. Wissenschaftliche Bearbeitungen. Verlag von Gustav Fischer, Jena. 287 pp., 4 pls.

Mader, L. 1951. Die Erotyliden von Peru (Col.) [cont.]. Entomol. Arbeiten aus dem Museum G. Frey 2:197-225.

Mader, L. 1952. Erotylidae (Coleoptera) pp. 138-188. In E. Titschack. Beiträge zur fauna Perus. Nach der Ausbeute der Hamburger Südperu-Expedition 1936, anderer sammlungen, wie auch auf grund von literaturangaben. Second Edition. Band III. Wissenschaftliche Bearbeitungen. Verlag von Gustav Fischer, Jena. 266 pp., 4 taf.

Madge, R. B. 1988. The publication dates of Dejean's catalogues. Archiv. Nat. Hist. $15(3): 317-321$.

Montgomery, B. E., \& J. M. Amos. 1941. Contributions to the list of Coleoptera of Clark County State Forest. Proc. Indiana Acad. Sci. 50:251-258.

Motschulsky, V. von. 1858. II. Entomologie spéciale. Insectes des Indes Orientales. Etudes Entomol. Helsingfors $7: 20-122$.

Neave, S. A. 1939-1940. Nomenclator zoologicus. A list of names of genera and subgenera in zoology from the tenth edition of Linnaeus 1758 to the end of 1935 . The Zoological Society of London, London. 1-4:1-3805. 
Nichols, S. W., \& R. T. Schuh. 1989. The Torre-Bueno glossary of entomology. Revised edition of a glossary of entomology by J.R. de la Torre-Bueno, including Supplement A by G.S. Tulloch. New York Entomol. Soc., NY. $\quad$ xvii + $840 \mathrm{pp}$.

Olivier, A. G. 1792. Encyclopédie méthodique. Histoire naturelle insectes. Paris. 6(2):369-704, pl. 236-237.

Olivier, A. G. 1807. Entomologie, ou histoire naturelle des insectes, avec leur caractères génériques et spécifiques, leur descriptions, leur synonymie et leur figure eluminée. Coléoptères. Baudonin, Paris. 5:1612,59 Taf.

Pallister, J. C. 1955a. The pleasing fungus beetles of North Central Mexico collected on the David Rockefeller Mexican expediton of 1947 (Coleoptera: Erotylidae). American Mus. Novitat. 1703:1-6.

Pallister, J. C. 1955b. The pleasing fungus beetles collected on the Explorers Club-American Museum of Natural History entomological expedition to Yucatan, Mexico, in 1952 (Coleoptera: Erotylidae). American Mus. Novitat. 1745:1-8.

Pittier, H., \& P. Biolley. 1895. Invertebrados de Costa Rica. I. Coleópteros. Instituto fisico-geográfico nacional, San José. 42 pp.

Popenoe, E. A. 1877. A list of Kansas Coleoptera. Trans. Kansas Acad. Sci. 5:21-40.

Roberts, A. W. Rymer. 1958. On the taxonomy of the Erotylidae (Coleoptera), with special reference to the morphological characters of the larvae. II. Trans. R. Entomol. Soc. London $110(8): 245-285$.

Ruette, R. de. 1970. A catalogue of types of Coleoptera in the Canadian National Collection of insects. Mem. Entomol. Soc. Canada 72:1-134.

Sachtleben, H. 1961. Nachträge zu "Walter Horn \& Isle Kahle: Über entomologische sammlungen." Beit. zur Entomol. $11(95 / 6): 481-540$.

Say, T. 1835. Descriptions of new North American coleopterous insects, and observation on some already described. Boston J. Nat. Hist. 1:151-203. [See Leconte 1859]

Schaeffer, C. 1931. On a few new and known Coleoptera. Bull. Brooklyn Entomol. Soc. 26:174-176. 
Schwarz, E. A. 1878. The Coleoptera of Florida. Proc. American Philos. Soc. $17(101)$ :353-472.

Seidlitz, G. 1891. Fauna Transsylvanica. Die kaefer (Coleoptera) Siebenbürgens. Königsberg, Hartungsche Verlagsdruckerei. lvi, 192, 914 pp., 1 taf.

Selander, R. B., \& P. Vaurie. 1962. A gazetteer to accompany the "Insecta" volumes of the "Biologia Centrali-Americana." American Mus. Novitat. 2099:1-70.

Sharp, D., \& F. Muir. 1912. The comparative anatomy of the male genital tube in Coleoptera. Trans. Entomol. Soc. London 1912:477-642.

Skelley, P. E. 1988a. Pleasing fungus beetles (Coleoptera: Erotylidae). Entomol. Circ. 313. Florida Dept. Agric. \& Consumer Services, Div. Plant Ind., Gainesville, FL. $2 \mathrm{pp}$.

Skelley, P. E. 1988b. The pleasing fungus beetles of Florida (Coleoptera: Erotylidae). M.S. Thesis. University of Florida, Central Science Library, Gainesville, FL. 172 pp. [unpublished]

Skelley, P. E. 1990. [Cover illustration; Ischyrus dunedinensis Blatchley]. Coleopt. Bull. $44(2)$.

Skelley, P. E. 1993. A method of genitalia preparation and dry preservation for Coleoptera. Proc. Entomol. Soc. Washington $95(2): 131-138$.

Skelley, P. E., \& M. A. Goodrich. 1989. A redescription of Ischyrus dunedinensis Blatchley (Coleoptera:

Erotylidae) with a key to the species of Ischyrus for America, north of Mexico. Coleopt. Bull. 43(4):349354 .

Skelley, P. E., \& M. A. Goodrich. [1994]. Ischyrus Lacordaire, 1842, Mycotretus Lacordaire, 1842, Lybas Lacordaire, 1842, and Megischyrus Crotch, 1873 (Insecta: Coleoptera): proposed conservation. Bull. zool. Nomenclature [in press].

Skelley, P. E., M. A. Goodrich, \& R. A. B. Leschen. 1991. Fungal host records for the Erotylidae (Coleoptera: Cucujoidea) of America north of Mexico. Entomol. News $102(2): 57-72$.

Smith, J. B. 1899. Insects of New Jersey. A list of species occurring in New Jersey, with notes on those of economic importance. Supplement to the 27 th Annual Report to the state Board of Agriculture, New Jersey. MacCrellish \& Quigley, state Printers, Trenton, NJ. 755 $\mathrm{pP}$. 
Smith, J. B. 1910. Insects of New Jersey. Ann. Rept. New Jersey St. Mus. (1909). MacCrellish and Quigley, Trenton, NJ. $888 \mathrm{pp}$.

Snodgrass, R. E. 1957. A revised interpretation of the external reproductive organs of male insects. Smithsonian Misc. Coll. 135(6):1-60, 15 pls.

Sturm, J. 1826. Catalog meiner insecten-sammlung. Nünberg, Verfasser. Erster Theil. Käfer. viii +207 pp., 4 col. taf.

Sturm, J. 1843. Catalog der kaefer-sammlung. Nürnberg, Verfasser. xil + $386 \mathrm{pp} ., 6 \mathrm{col}$. taf.

Summers, S. V. 1874. Catalogue of the Coleoptera from the region of Lake Pontchartrain, La. Bull. Buffalo Soc. Natur. Sci. 2:78-99.

Tanner, V. M. 1927. A preliminary study of the genitalia of female Coleoptera. Trans. American Entomol. Soc. 53 (Mar.) :5-50, 15pls.

Tuxen, S. I. (ed.). 1970. Taxonomist's glossary of genitalia in insects. Second revised and enlarged edition. Munksgaard, Copenhagen. 359 pp.

Ulke, H. 1902. A list of the beetles of the District of Columbia. Proc. United States Nat. Mus. 25:1-57.

Verhoeff, C. 1895. Vergleichend-morphologische untersuchengen über das abdomen der Endomychiden, Erotyliden, und Languriiden (im alten sinne) und über die muskulatur des copulationsapparates von Triplax. Archiv für Natur. 61 (1):213-287. pls.12-13

Wade, J.S. 1935. A contribution to a bibliography of the described immature stages of North American Coleoptera. United States Department of Agriculture, Bur. Entomol. Plant Quar. E-358:1-114 pp.

Weiss, H. B. 1920. Notes on Ischyrus quadripunctatus oliv., bred from fungus. Canadian Entomol. 52:14-15.

Weiss, H. B., \& E. West. 1920. Fungous insects and their hosts. Proc. Biol. Soc. Washington 33:1-20.

Wickham, H. F. 1894. The Coleoptera of Canada. VI. The Endomychidae and Erotylidae of Ontario and Quebec. Canadian Entomol. 26:337-342.

Williams, J. L. 1945. The anatomy of the internal genitalia of some Coleoptera. Proc. Entomol. Soc. Washington $47: 73-91$. 
Wood, S. I. 1952. Observations on the homologies of the 361 copulatory apparatus in male coleoptera. Ann. Entomol. Soc. America 45:613-617, 14 figs, 1 table.

Zesch, F., \& O. Reinecke. 1881. List of the Coleoptera observed and collected in the vicinity of Buffalo. Bul1. Buffalo Soc. Natur. Sci. 4:2-15. 
BIOGRAPHICAL SKETCH

Paul Edward Skelley was born 15 June 1964 to Mr. and Mrs. Paul F. Skelley of Decatur, Illinois. He attended grades one through 12 at Warrensburg-Latham, a small rural school. He became interested in insects while working on a Boy scout project in 1977. Throughout high school, Paul's interests in nature compelled him to take advanced science classes and sell insect collections to support his entomological interests. In May 1982, he graduated from Warrensburg-Latham High School, 3 rd in a class of 86 . That fall he attended Eastern Illinois University, enrolled in the engineering program. A year later, he changed his major to zoology. Dr. M. A. Goodrich, his advisor, saw his interest in insects and put him to work curating the Coleoptera in the Spooner-Riegel Insect Collection. Paul graduated summa cum laude in May 1986 from Eastern Illinois University. Paul applied to the University of Florida and received a Master of Science degree in August 1988 under the guidance of $\mathrm{Dr}$. R. E. Woodruff, whom he assisted in curating Coleoptera in the Florida State Collection of Arthropods. In November 1992 Paul married Lucile Heyer. He currently works at the Florida State Collection of Arthropods as a technician assisting in the curation of several taxa. 
I certify that I have read this study and that in my opinion it conforms to acceptable standards of scholarly presentation and is fully adequate, in scope and quality, as a dissertation for the degree of Doctor of Philosophy.

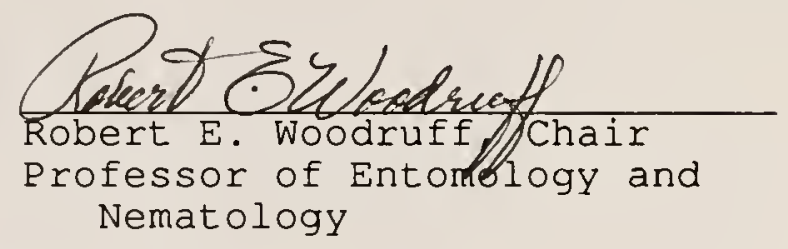

I certify that I have read this study and that in my opinion it conforms to acceptable standards of scholarly presentation and is fully adequate, in scope and quality, as a dissertation for the degree of Doctor of Philosophy.

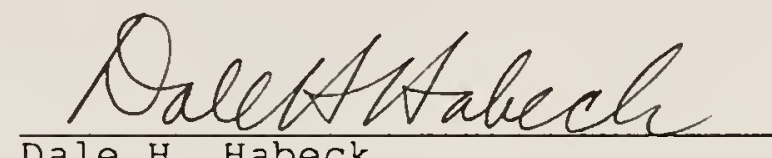

\section{Dale H. Habeck \\ Professor of Entomology and Nematology}

I certify that I have read this study and that in my opinion it conforms to acceptable standards of scholarly presentation and is fully adequate, in scope and quality, as a dissertation for the degree of Doctor of Philosophy.

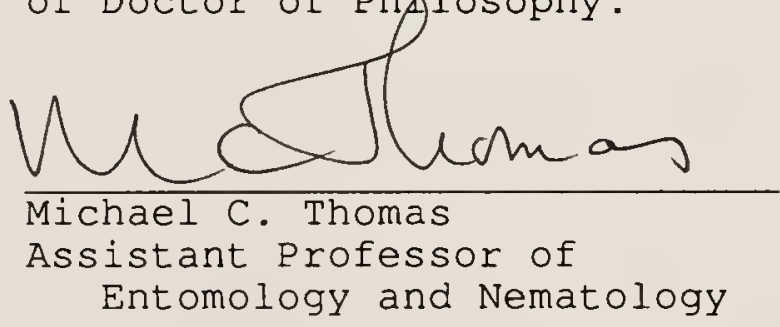

I certify that I have read this study and that in my opinion it conforms to acceptable standards of scholarly presentation and is fully adequate, in scope and quality, as a dissertation for the degree of Doctor of Philosophy.

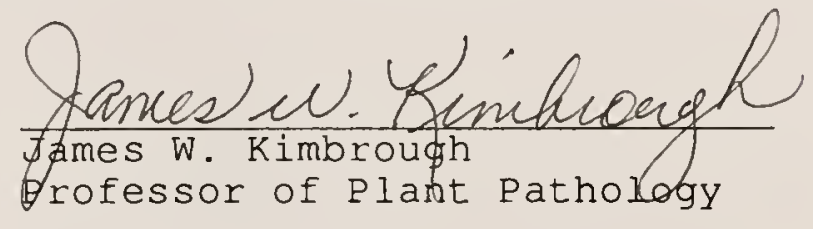


This dissertation was submitted to the Graduate Faculty of the College of Agriculture and to the Graduate School and was accepted as partial fulfillment of the requirements for the degree of Doctor of Philosophy.

April 1994

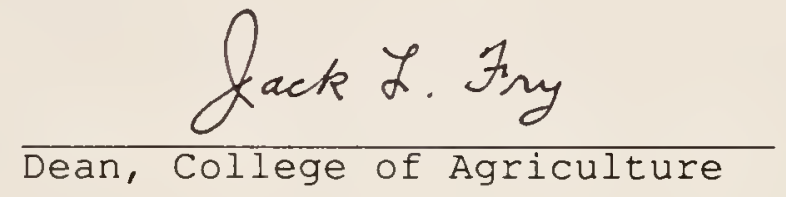

Dean, Graduate School 


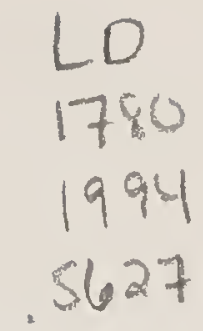

UNIVERSITY OF FLORIDA

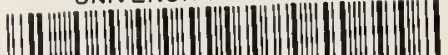

31262085570827 